Portland State University

PDXScholar

Fall 12-11-2014

\title{
New 4-Aminoquinoline Compounds to Reverse Drug Resistance in P. falciparum Malaria, and a Survey of Early European Antimalarial Treatments
}

Katherine May Liebman

Portland State University

Follow this and additional works at: https://pdxscholar.library.pdx.edu/open_access_etds

Part of the Medicinal-Pharmaceutical Chemistry Commons Let us know how access to this document benefits you.

\section{Recommended Citation}

Liebman, Katherine May, "New 4-Aminoquinoline Compounds to Reverse Drug Resistance in P. falciparum Malaria, and a Survey of Early European Antimalarial Treatments" (2014). Dissertations and Theses. Paper 2114.

https://doi.org/10.15760/etd.2112

This Dissertation is brought to you for free and open access. It has been accepted for inclusion in Dissertations and Theses by an authorized administrator of PDXScholar. Please contact us if we can make this document more accessible: pdxscholar@pdx.edu. 
New 4-Aminoquinoline Compounds to Reverse

Drug Resistance in P. falciparum Malaria, and a Survey of Early European Antimalarial Treatments

by

Katherine May Liebman

A dissertation submitted in partial fulfillment of the requirements for the degree of

Doctor of Philosophy

in

Chemistry

Dissertation Committee:

David H. Peyton, Chair

Michael Riscoe

Kenneth Stedman

Robert Strongin

Mark Woods

Portland State University

2014 
(C) 2014 Katherine May Liebman 


\begin{abstract}
Intermittent fevers caused by Plasmodium parasites have been known for millennia, and have caused untold human suffering. Today, millions of people are afflicted by malaria each year, and hundreds of thousands die. Historically, the most successful synthetic antimalarial drug was chloroquine, as it was safe, inexpensive, and highly efficacious. However, plasmodial resistance to chloroquine now greatly limits its utility. Previously in our laboratories it has been shown that attachment of a "reversal agent moiety" to the side chain of chloroquine can result in the restoration of activity against chloroquine-resistant strains of $P$. falciparum malaria. In the first part of the work presented here, a study has been made of the importance of the quinoline ring substitution pattern to the activity of such reversed chloroquines. The compounds presented here include those bearing a substituent in the 2-, 5, 6-, 7-, and/or 8- position, and include those with chloro, bromo, iodo, fluoro, nitro, trifluoromethyl, methyl, and methoxy substituents. For reversed chloroquines, 2-, 5-, and 8- substituents have been found to decrease in vitro antiplasmodial activity against $P$. falciparum relative to 7chloro substitution, whereas 6- and 7- substituted compunds with various substituents have in many cases similar activity to that of 7-chloro substituted compounds. Little difference has been observed between 6- and 7- substitution, or between chlorine and a methyl group in position 6 . In most cases these effects on activity are directionally similar to those observed for chloroquine analogs without an attached reversal agent, but the magnitude of the effect is generally smaller, suggesting that the activities of reversed
\end{abstract}


chloroquines are less affected by modifications to the quinoline ring system than is true for chloroquine analogs without an attached reversal agent.

The second portion of this work presents an asymmetrical bis-quinoline (PL241) that is highly active against $P$. falciparum malaria, with an $\mathrm{IC}_{50}$ of less than $0.1 \mathrm{nM}$ for all strains tested. Mechanistic studies have been performed in which the substitution patterns of the two quinoline rings of PL241 are modified in ways that indicate that either ring system is equally capable of participating in the antimalarial activity of these compounds. The excellent in vitro antiplasmodial activity of PL241 makes this a compound of great interest for further development as a potential antimalarial drug.

In the third part of this work, a survey has been made of antimalarial treatments recommended in the European medical literature from the time of Pliny the Elder (active in the first century A.D.) through the advent of modern malaria chemotherapy in the early twentieth century. In the fifteen primary sources utilized in this study, 251 distinct substances - primarily plants - were identified as having likely been used in the treatment of malaria. Of the 38 substances that were described in three or more sources, at least fifteen have been examined by other workers for antiplasmodial activity; in many cases, they were found to have antiplasmodial activity in vitro or in vivo. However, the majority of the phytotherapies for malaria identified in this project have not yet been tested against Plasmodium species, and may provide valuable leads in the search for new compounds active against drug-resistant malaria. 


\section{Dedication}

For Mom, Dad, Michael, and Rolf.

Let the fields and the gliding streams in the valleys delight me.
Inglorious, let me court the rivers and forests.

${ }^{1}$ Virgil: ... rura mihi et rigui placeant in vallibus amnes, flumina amem silvasque
inglorius. (Georgics, Book II, Line 485) 


\section{ACKNOWLEDGEMENTS}

I would like to thank my advisor, Dr. David Peyton, for being invested in my education, for improving my thinking about science, for allowing me to explore, and for always making time to help me no matter how busy he was. I am grateful to my committee members, Dr. Michael Riscoe, Dr. Kenneth Stedman, Dr. Robert Strongin, and Dr. Mark Woods, for all that they have put into this project, and for their help and advice over the years. I would like to thank Dr. Jane Xu Kelly and Dr. Yuexin Li at the Veterans Administration Medical Center, who performed the tests of in vitro antiplasmodial activity of the compounds described here, sometimes at very short notice. The members of the Peyton lab group, past and present, have been wonderful coworkers and friends. Special thanks go to two undergraduate volunteers, Alvin Annen and Michael Liebman, for their work on the 5,7-dichloroquinolines and methylquinolines found in these pages, and to my mentors, Steven Burgess and Cheryl Hodson, from whom I have learned so much. Cheryl, thank you for encouraging me to seek a career in science - I wouldn't have been here if it weren't for you. I would like to thank my teachers for all that I have learned from them. I am very grateful also to the numerous library staff members that helped with this project, in particular Interlibrary Loan for locating references that I feared would prove impossible to find. Last but not least, I would like to thank my friends and family for their advice and encouragement. Rolf Winter must especially be thanked for technical training and advice, for improving my German, for providing difficult-to-find references out of his personal collection, for 
endless careful reading of this document, and for keeping me calm during the difficult final weeks of dissertation writing. In addition to being an invaluable assistant in the laboratory, my brother Michael is the best imaginable brother and friend. Mom and Dad, thanks for instilling into me a love of reading and learning, and for being supportive of me as I found my path. I could never have done this without you. 


\section{TABLE OF CONTENTS}

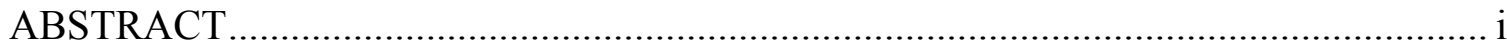

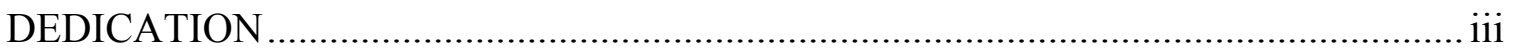

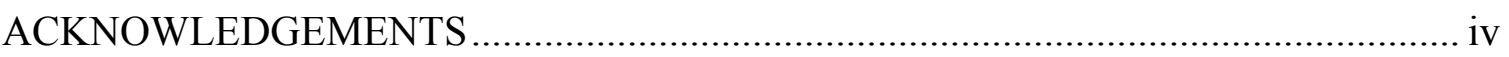

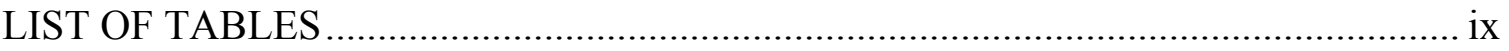

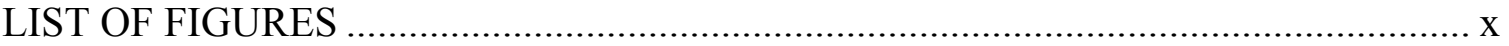

CHAPTER 1:

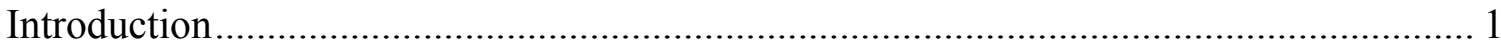

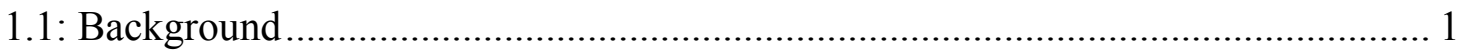

1.2: The early history of quinoline antimalarials: How chloroquine came to be........... 3

1.3: Chloroquine resistance..................................................................................... 17

1.4: A strategy to overcome chloroquine resistance ……........................................... 22

1.5: The effect of the quinoline ring system substitution patterns on the antimalarial

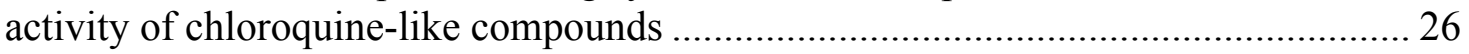

\section{CHAPTER 2:}

Quinoline Ring-Modified Analogues of Reversed Chloroquine-type Compounds.......... 31

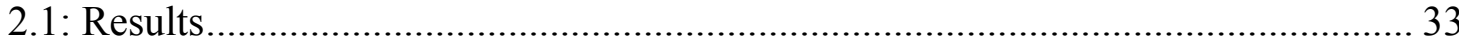

2.1.1: Effect of a substituent in the 2-, 5-, or 8- position.......................................... 33

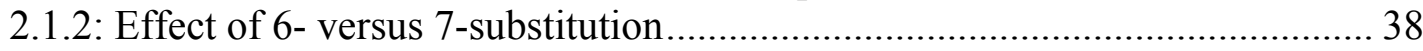

2.1.3: Effect of halogen substituents ........................................................................ 41

2.1.4: Effect of strongly electron-withdrawing groups in position 6 or 7: nitro and trifluoromethyl substituents ................................................................................ 44

2.1.5: Unsubstituted compounds and those with an electron-donating group in

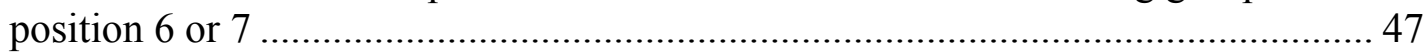

2.2: Significance of the findings ................................................................................. 49

2.2.1 Effect of the quinoline ring system substitution on accumulation of chloroquine-like drugs in the digestive vacuole by $\mathrm{pH}$ trapping .............................50 2.2.2. Effect of quinoline ring system substitution on heme binding and $\beta$-hematin

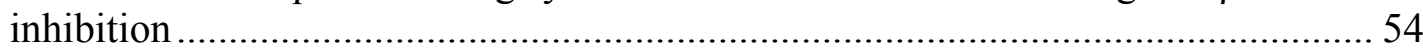

2.2.3 Effect of the side chain on activity: beyond $\mathrm{pH}$ trapping?............................. 55

2.2.4: The relationship between accumulation and inhibition of hemozoin formation

2.2.5. Modulation of resistance

2.3: Summary of the present work, and future directions............................................ 66

CHAPTER 3:

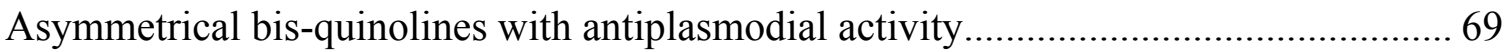

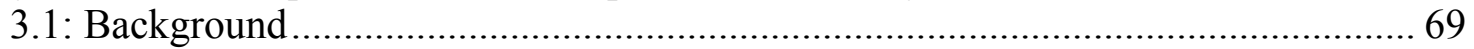

3.2: A novel, asymmetrical bis-quinoline: PL241 …………………………........... 73 
3.3: A short mechanistic study: The effect of inactivating groups upon the activity of PL241

3.4: A second short mechanistic study: The effect of exchanging chlorine for hydrogen

3.5 The future of PL 241: A potential antimalarial drug?

CHAPTER 4:

A survey of historical therapies used in Europe to treat intermittent fevers..................... 89

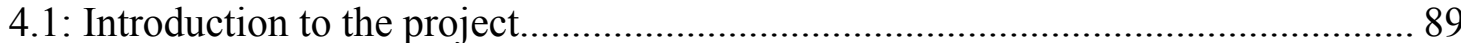

4.2: Tables of the historical remedies found in this survey ........................................ 103

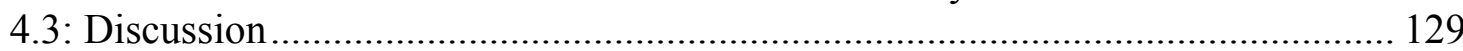

4.4: Further notes on historical remedies, and a word of caution for medicinal chemists

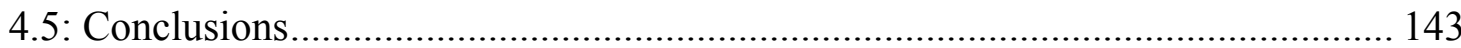

\section{CHAPTER 5:}

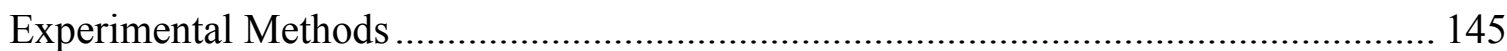

5.1.: General synthetic methods.......................................................................... 145

5.1.1.: Synthesis of drug candidates and intermediates: Quinoline-ring modified reversed chloroquine-type compounds ............................................................. 145

5.1.2: Synthesis of asymmetrical bis-quinoline type compounds ............................ 149

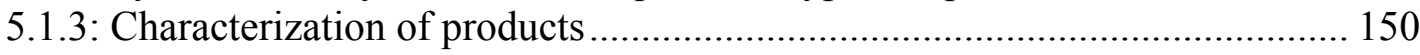

5.2: In vitro studies on inhibition of $\mathrm{P}$. falciparum parasite growth .......................... 151

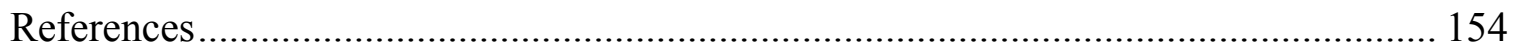

APPENDIX A: Specific synthetic methods and characterization data........................... 177

Table A1: Compounds listed by code number (PL number) ................................... 177

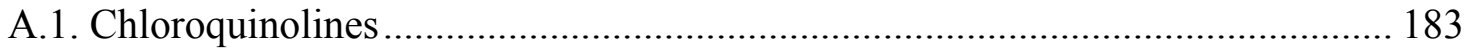

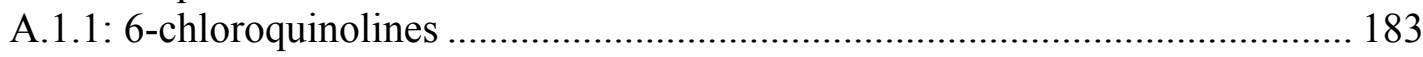

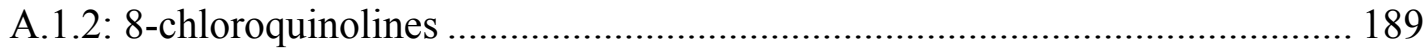

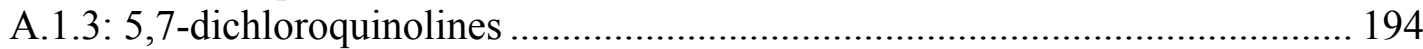

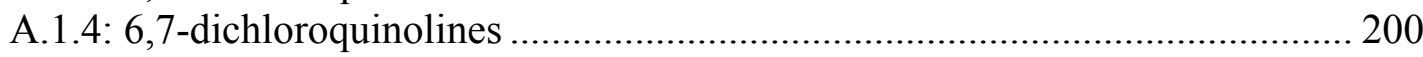

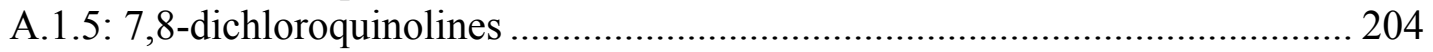

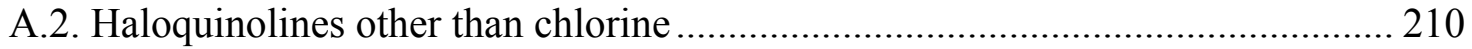

A.2.1: 6-fluoroquinolines.......................................................................... 210

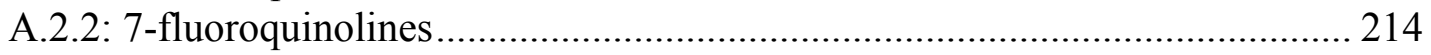

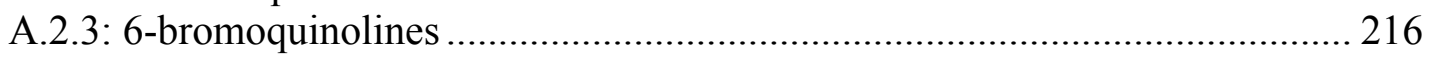

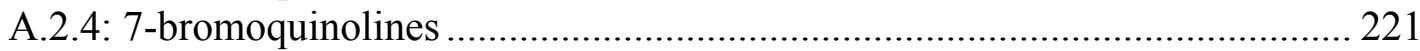

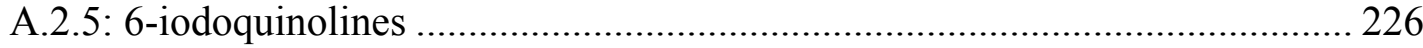

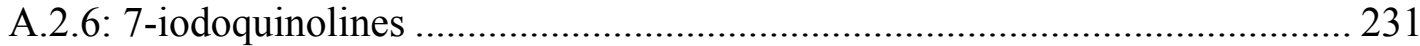

A.3.: Nitroquinolines, trifluoromethyl quinolines, and 7-chloro-2-methylquinolines 235

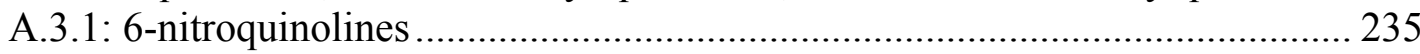

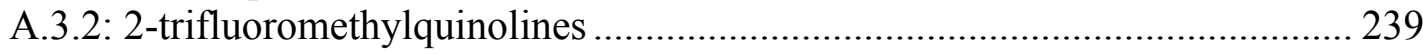

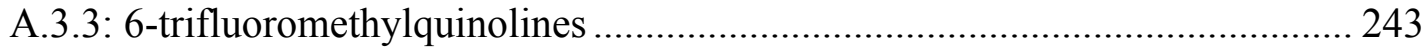

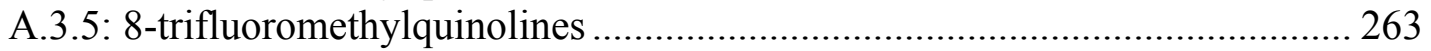




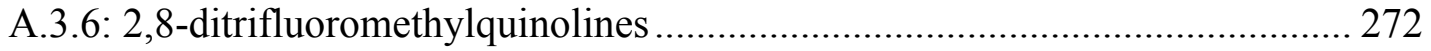

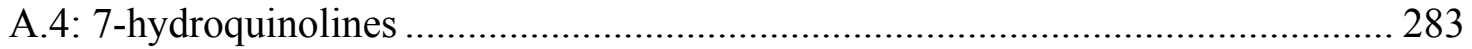

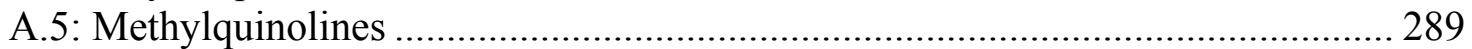

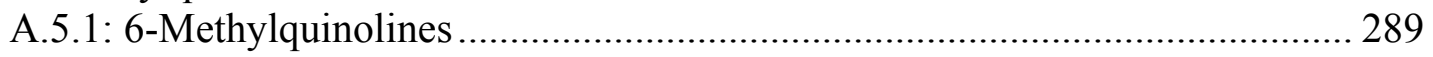

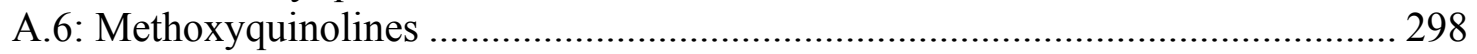

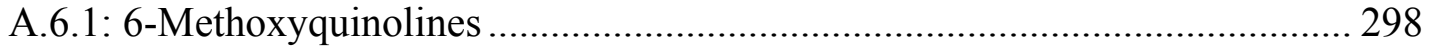

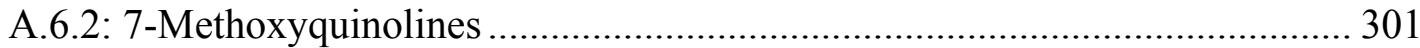

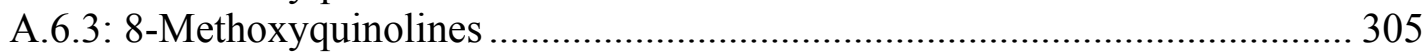

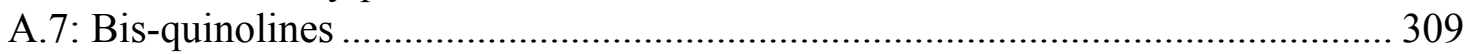

A.7.1: Bis-quinoline starting materials not described above ............................... 309

A.7.2: Bis-quinoline final products.................................................................. 316

A.7.3: Original method used to synthesize PL241 (for primary method, see page

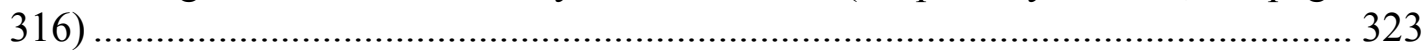

APPENDIX B: Tables of antiplasmodial activity and cytotoxicity .............................. 325

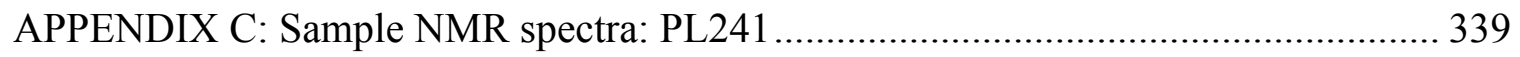




\section{LIST OF TABLES}

Table 4.1: Historical remedies used to treat malaria..................................................... 108

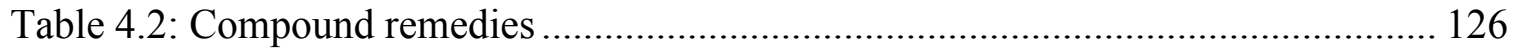

Table 4.3: Remedies listed in three or more historical sources ...................................... 133 


\section{LIST OF FIGURES}

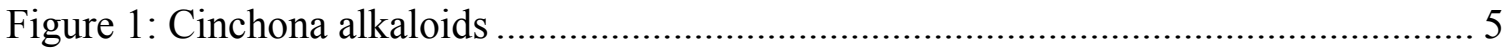

Figure 2: Elucidation of quinine's structure (adapted from Schulemann, 1932) ............... 6

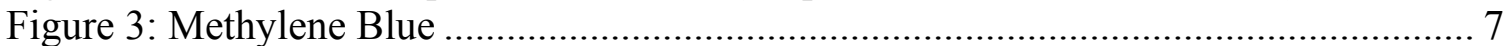

Figure 4: Synthetic antimalarials from the Bayer research team at Elberfeld.................. 9

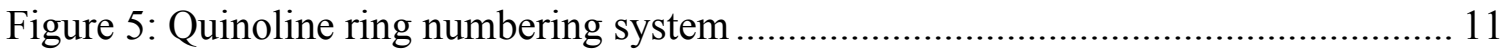

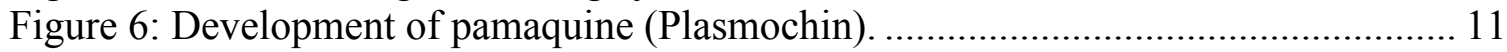

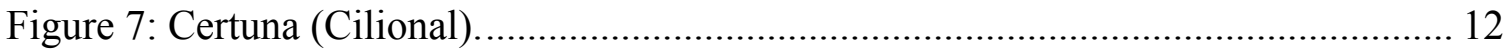

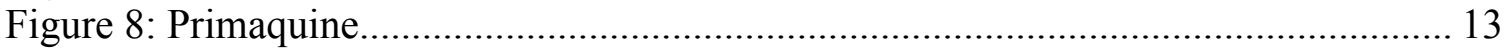

Figure 9: Quinacrine (Atebrin, Atabrine, Mepacrine) ................................................ 13

Figure 10: Development of chloroquine (Resochin) from quinacrine (Atebrin)............. 15

Figure 11: Hans Andersag's synthetic route to 2-unsubstituted 4-aminoquinolines......... 16

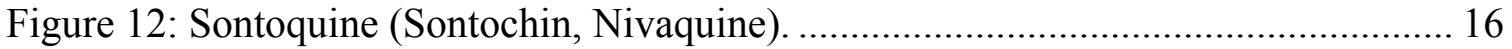

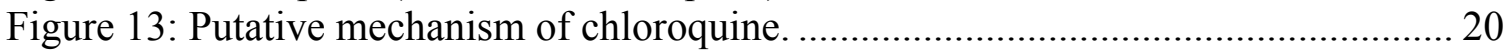

Figure 14: Proguanil. ............................................................................................... 21

Figure 15: Two known reversal agents for chloroquine resistance in P. falciparum

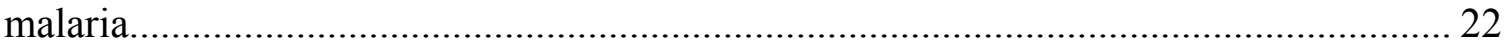

Figure 16: The reversed chloroquine-type compound PL01 combined features of chloroquine and imipramine. In vitro antiplasmodial activity is shown as $\mathrm{IC}_{50}$, the

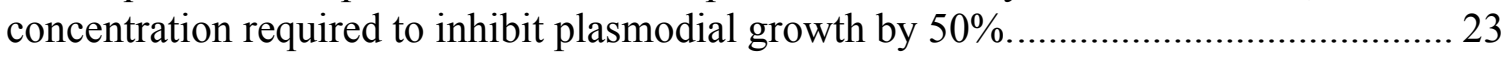

Figure 17: Representative compounds from the initial structure-activity relationship study

during which reversed chloroquine-type compounds were developed.......................... 24

Figure 18: PL06, chloroquine, and their des-chloro analogues ..................................... 25

Figure 19: Some substituents of 4-aminoquinolines used by the Bayer research team at

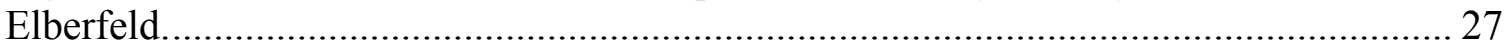

Figure 20: Effect of quinoline ring substitution pattern on chloroquine analogs ............ 28

Figure 21: In vitro antiplasmodial activities of a selection of the compounds in the present work against chloroquine sensitive and chloroquine resistant strains of Plasmodium

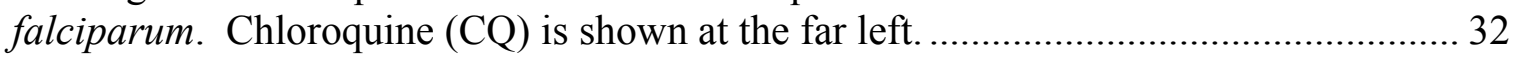

Figure 22: Effect of 2- or 8- substitution compared to 7-substitution and 7,8, or 2,7-

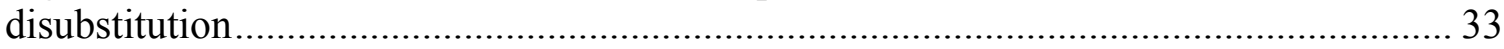

Figure 23: Effect of 8- substitution with a methyl or methoxy substituent, compared with

7- or 8-chloro- substitution.

Figure 24: In a series of 7-chloro substituted compounds, an added 2-methyl substituent decreased activity, but to a smaller extent than an added 2-trifluoromethyl substituent.. 35 Figure 25: The cyclization step of the Gould Jacobs reaction, a representative quinoline

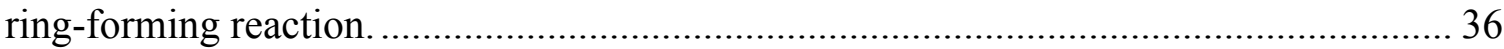
Figure 26: Example of the effect of 5,7-disubstitution compared to 7-substitution and 7,8-

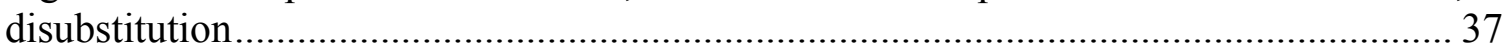

Figure 27: Activity of 5-chloro-2-trifluoromethyl and 2-trifluoromethyl compounds..... 37 
Figure 28: Two previously uncharacterized quinolines were made during the course of

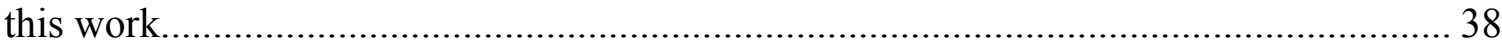

Figure 29: 6- versus 7-substituted chloroquine analogs with and without an attached

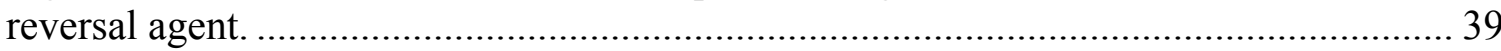

Figure 30: The effect of 6,7-disubstitution compared to 6- and 7-monosubstitution....... 40 Figure 31: The effect of 6-versus 7- substitution for chloro, bromo, and iodo-substituted

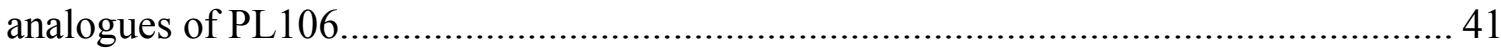

Figure 32: Representative bromo- and iodo- substituted compounds ............................ 42

Figure 33: The effect of 6-chloro versus 6-fluoro substitution....................................... 43

Figure 34: The effect of nitro substitution on chloroquine analogues with and without an

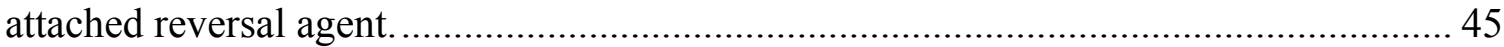

Figure 35: The effect of trifluoromethyl substitution on chloroquine analogs with and

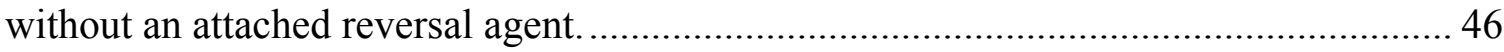

Figure 36: Des-chloro analogues of PL06 and PL69.................................................... 47

Figure 37: A 6-methyl substituted compound compared to 7-chloro and 7-hydro

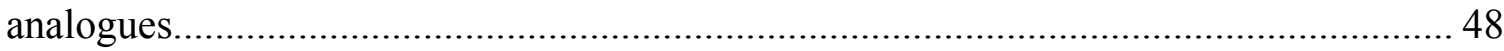

Figure 38: The effect of 7-methoxy substitution on chloroquine analogs with and without

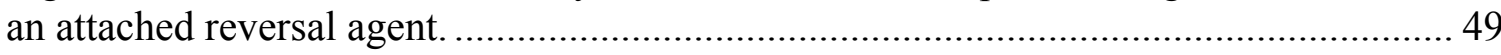

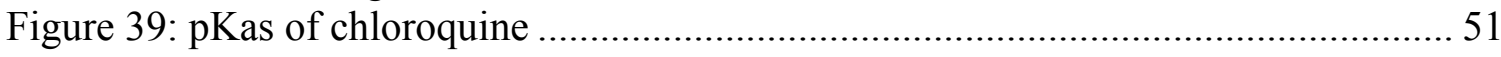

Figure 40: Variability of the reversal agent moeity of reversed chloroquine-type

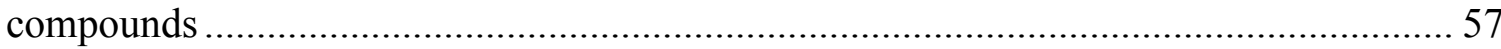

Figure 41: A chloroquine analogue closely related to the above reversed chloroquine-type compounds, also with high activity against chloroquine resistant parasites......................58 Figure 42: Altering side chain length of chloroquine analogues restores activity against

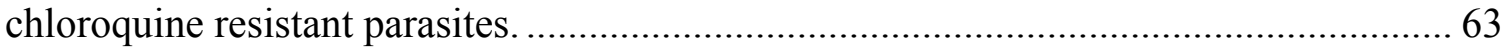

Figure 43: Apparent cross-resistance with chloroquine was observed for some ringmodified reversed chloroquine-type compounds ................................................................6 65

Figure 44: Piperaquine, a bis-quinoline antimalarial....................................................... 69

Figure 45: Some bis-quinolines used as examples in the original patents for piperaquine

by Rhône-Poulenc. ………………………………….......................................... 70

Figure 46: A range of bis-(4-amino)quinoline compounds with antiplasmodial activity. 72 Figure 47: PL69, a reversed chloroquine-type antimalarial synthesized by Steven J.

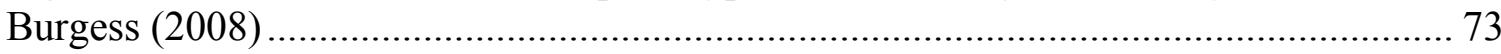

Figure 48: PL67, an intermediate originally used to produce PL69 ............................... 73

Figure 49: In this work, PL67 was used to produce the novel bis-quinoline, PL241....... 74

Figure 50: In vitro antiplasmodial activity of PL241 compared to that of piperaquine ... 74 Figure 51: (4-Piperidyl)-4-aminoquinolines previously shown to have antiplasmodial

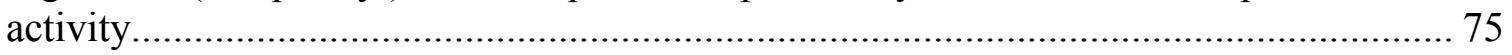

Figure 52: A tertiary nitrogen in position 4 of the quinoline ring system lowers

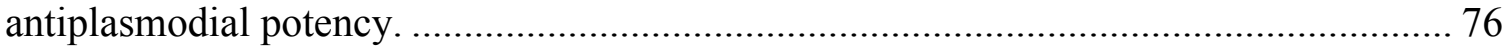
Figure 53: Atebrine and its N,N,N-trisubstituted analogue (Schönhöfer, 1942)............. 76 Figure 54: Tautomerization of atebrine predicted by Schönhöfer to have significance for

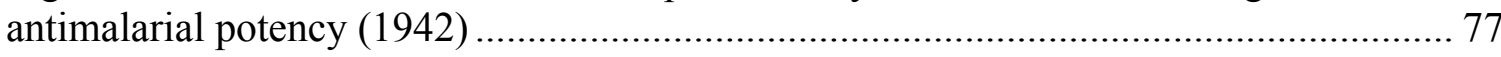


Figure 55: Resonance stabilization of the positive charge on the protonated ring nitrogen

of chloroquine

Figure 56: PL69, a reversed chloroquine type compound, compared to the structures of piperaquine and PL241

Figure 57: 8-trifluoromethyl-substituted PL241 analogues, shown with PL241, PL69, and

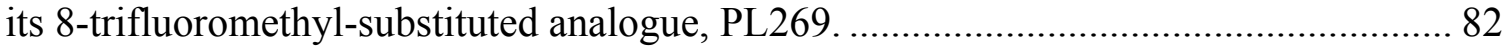

Figure 58: A PL241 analog with two 8-trifluoromethyl-substituted quinoline ring systems.

Figure 59: Piperaquine analogues made during previous work, in which chlorine has been exchanged for hydrogen (Gunsaru, 2010). Also shown is chloroquine with its 7-hydro

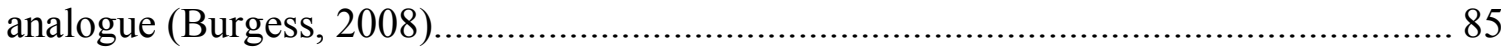

Figure 60: Analogues of PL241 in which chlorine has been exchanged for hydrogen. ... 86 Figure 61: Artemisinin and two flavones believed to potentiate its antimalarial activity: artemetin and casticin.

Figure 62: Synthesis of 4-chloroquinolines by the Gould-Jacobs reaction, followed by chlorination with phosphorus oxychloride.

Figure 63: Synthesis of 2-trifluoromethyl-4-chloroquinolines by the Conrad-Limpach reaction, followed by phosphorus oxychloride chlorination.

Figure 64: Reaction of 4-chloroquinolines with 3-amino-1-propanol, followed by activation of the resulting alcohol by methanesulfonyl chloride.

Figure 65: Reaction of mesyl alcohols with secondary amines to produce the final products.

Figure 66: Synthesis of one starting material for asymmetrical bis-quinoline compounds.

Figure 67: Synthesis of asymmetrical bis-quinoline compounds. 


\section{CHAPTER 1}

\section{Introduction}

But who could revere enough the diligent research of the ancients?

(Pliny, Natural History, Vol. XXVII, II.) ${ }^{2}$

\section{1: Background}

Intermittent fevers caused by Plasmodium parasites have been known for millennia. Examination of Egyptian mummies dating from periods as early as the 1400s B.C. has revealed Plasmodium parasites (Hawass, 2010; Lalremruata, 2013), and infection by Plasmodium is believed that to have afflicted mankind for far longer (Hoeppli, 1959; Hay, 2004; Tanabe, 2010; Prugnolle, 2011). Although the causative agents and underlying physiological basis of malaria's effects were only discovered in the 19th and early 20th century (Gilles, 2002), the Ebers Papyrus (ca. 1550 B.C.) refers to fever with swollen spleen, and malaria symptoms are described in detail in The Yellow Emperor's Classic of Internal Medicine (China, age unknown but certainly prior to 400 B.C.; Veith, 1972), in the Atharvaveda (India, ca. 450 B.C.), and by the Greek and Latin authors (Hippocrates, ca. 400 B.C.; Celsus, 25 B.C. - 50 A.D.; Jones, 1909). Today it is

\footnotetext{
${ }^{2}$ Sed antiquorum curam diligentiamque quis possit satis venerari? (Translation by W.H.S. Jones, 1956.)
} 
known that protozoa of the genus Plasmodium cause intermittent fevers, and the resulting disease is called malaria. At least six Plasmodium species parasitize human beings, including P. falciparum, P. vivax, P. ovale, P. malariae, P. knowlesi (Strydom, 2014); recently, an infection by P. cynomologi has also been reported (Ta, 2014). Most malaria cases are caused by $P$. falciparum and $P$. vivax. Although $P$. falciparum causes the most fatalities, P. vivax is also a severe problem (Baird, 2014; Quispe, 2014; Price, 2014). In addition to loss of life, the impact of malaria upon the economic and social welfare of malaria-endemic nations can scarcely be underestimated (Jones, 1909; WHO, 2013). Malaria infection is spread between human hosts by the bite of infected female mosquitoes of the genus Anopheles. In the human host, the parasite initially resides in the liver, followed by a blood stage. The classical symptom of untreated malaria is the febrile paroxysm, a dramatic series of chills followed by fever followed by afebrile periods, although not all victims experience this. The length of time between paroxysms varies with the species and strain of malaria. In the case of P. falciparum, vivax, and ovale, the cycle typically lasts 48 hours, while for $P$. malariae it typically lasts 72 hours (Warrell, 2002; Schlitzer, 2007; WHO Malaria Report 2013). These are often referred to in the older literature as tertian and quartan fevers, with fits occurring on the first and third day (tertian) and on the first and fourth day (quartan; Hoeppli, 1959). Comparison of genetic analysis of historical materials with historical medical records has provided additional confirmation that the terms tertian and quartan fever do indeed refer to malaria (Fornaciari, 2010). If parasitemia is not completely cleared by drug therapy, recrudescence may occur. In the case of $P$. vivax and ovale, the liver stage parasites may 
persist in dormant form so that relapses continue to occur at intervals of months or years (Warrell, 2002; Schlitzer, 2007).

Malaria today is most prevalent in Africa, Southeast Asia, and South America, but was formerly common over an even larger range, including much of Europe, Russia, and North America (Taylor, 1945; Nuttall, Cobbet, and Strangeways-Pigg, 1901; Gilles, 2002). In 2012, the World Health Organization (WHO) estimates that there were 207 million cases, of which an estimated 627,000 were fatal (WHO, 2013). However, the number of cases and deaths may be higher than estimated by the WHO (Cibulskis, 2011).

Our primary defenses against malaria include control of its vector, the Anopheles mosquito, and chemotherapy that targets the parasite directly. Work is also underway on malaria vaccines (Thera, 2012). Antimalarial drugs are used not only to treat cases of malaria (chemotherapy) but also to prevent them (chemoprophylaxis). Drug resistance is a severe problem, and there currently exists no class of antimalarial drugs for which resistance has not been reported. For this reason, the only drug therapies currently recommended by the WHO in most malaria-endemic regions are combinations of two drugs from different classes (WHO, 2013).

\section{2: The early history of quinoline antimalarials: How chloroquine came to be}

In China, treatment of intermittent fevers with quinghao (sweet wormwood,

Artemisia annua L.) has been known at least since the third century A.D. (O’Neill, 2004), 
but it is often stated that prior to the discovery of cinchona bark in the 16th century, the West had no really effective cure. Cinchona bark comes from a group of species of evergreen tree of the genus Cinchona. The trees are native to the western side of South America and grow there at high altitudes, 5,000-8,000 feet above sea level on average (Flückiger and Hanbury, 1874; Geerlings, 1999). Different species and varieties contain widely varying amounts of alkaloids. The most valued species was formerly Cinchona ledgeriana, also known as Cinchona officinalis 'Ledgeriana', which contains up to $15 \%$ quinine in its bark (Taylor, 1945, Geerlings, 1999). Although the native people may not have used cinchona bark to treat malaria (and in fact it is generally thought that malaria did not exist in the New World before the arrival of the Spaniards, although this has been debated (Guerra, 1977; Yalcindag 2012; de Calda, 2005)), it is said that they were aware that the bark of the cinchona tree had medicinal properties (Greenwood, 1992). Gaspar Caldera de Heredia wrote in 1663 that the Spanish Jesuit priests had observed miners in the province of Quito using an infusion of the bark in water to treat chills resulting from low temperatures (Guerra, 1977; Jarcho, 1993). The Jesuits are said to have discovered the antimalarial efficacy of cinchona bark after using it to relieve the chills of intermittent fevers. The bark was soon imported to Europe. Although the new treatment did not meet at once with universal acceptance, it gradually became the accepted remedy for intermittent fevers (Guerra, 1977; Jarcho, 1993). For this and other purposes, huge quantities were exported to Europe from the South American colonies and later from the independent South American countries, to the extent that the trees were almost eliminated in some regions. By the late nineteenth century, cinchona trees were also being 
cultivated successfully outside of their native habitat on a large scale by the British in India and by the Dutch in the East Indies. By the early twentieth century, the Dutch plantations in Java produced the bulk of the world's cinchona bark (Flückiger and Hanbury, 1874; Taylor, 1945; Greenwood, 1992).

Of the constituents found in cinchona bark, those to which antimalarial activity is usually ascribed are the crystallizable alkaloids occurring in the largest quantity - quinine, quinidine, cinchonine, and cinchonidine (Figure 1):

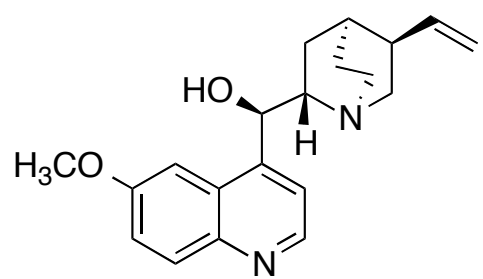

Quinine

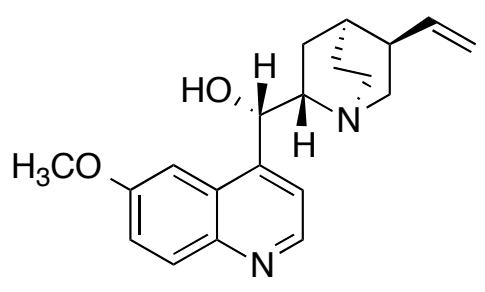

Quinidine

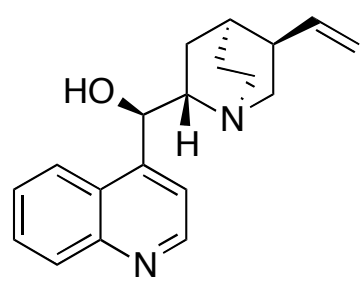

Cinchonidine

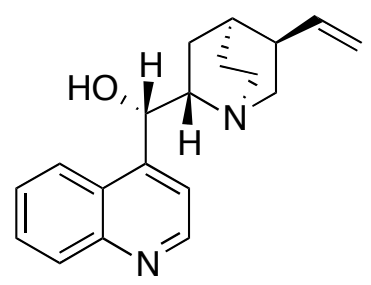

Cinchonine

Figure 1: Cinchona alkaloids

Of these very closely related compounds, quinine has the best ratio of antimalarial activity to toxicity (quinidine is more active than quinine but may also be more dangerous to administer; Chopra, 1938; Wesche, 1990; Warhurst, 2003; White, 2007). Evidence has also been found that the four alkaloids above act synergistically, and that there may be other components of cinchona bark that add to this synergistic action (Baranger, 1948; 
Druilhe,1988; Merkus, 1988; Wesche, 1990; Rasoanaivo, 2011). Quinine was isolated from cinchona bark in 1820 by Pierre-Joseph Pelletier and Joseph Bienaimé Caventou (although possibly also earlier), and its chemical formula was determined by Adolph Strecker in 1854 (Pelletier and Caventou, 1820; Strecker, 1854; Kaufman, 2005). The structure was elucidated piecewise by Zdenko Hans Skraup (1879), W. Königs (1894), and Heinrich Hörlein and Paul Rabe (1907) (see Figure 2; Schulemann, 1932):

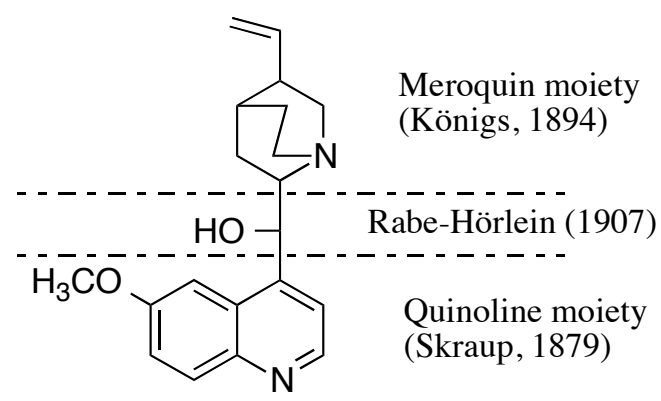

Figure 2: Elucidation of quinine's structure (adapted from Schulemann, 1932)

Administration of purified quinine allowed for better dosage control (since amounts of alkaloids vary in crude bark) and also may have reduced side effects (nausea, blurred vision, and depression of the heart were reportedly caused to a greater extent by cinchonine and quinidine than by quinine (Chopra, 1938)). The bark of C. ledgeriana contains mostly quinine, while another species, C. succirubra, contains relatively more quinidine, cinchonin, and cinchonidine, and for a long time continued to be grown in order to provide supplies of these compounds (Taylor, 1945). Although total synthesis of quinine has been achieved (Rabe and Kindler, 1918, Woodward and Doering, 1944 and 1945 (see also Smith and Williams, 2008); stereoselective synthesis by Stork, 2001), a commercially viable synthesis of this complex natural product with four chiral centers 
has never been found.

Despite quinine's value, it had disadvantages. Firstly, the supply of a natural product - especially one that could grow only under a fairly narrow range of conditions might be threatened (as was feared with the over harvesting of cinchona trees in South America, and as was experienced by the Germans during World War I and by the Allies during World War II). Secondly, because of the Dutch monopoly, it was desirable for other powers to find a replacement for quinine for economic reasons (Greenwood, 1992 and 1995; Slater, 2009). Thirdly, to be really effective, quinine needed be taken several times per day, and was not without side effects (nausea, tinnitus, reduction in hearing ability, vertigo, and vision disturbances; Goodman and Gilman, 1985; Mühlens, 1937). The development of synthetic organic chemistry led to hope of a synthetic substitute for natural quinine. Synthetic medicaments effective in lowering fevers had already been discovered by the end of the 19th century - notably, the analgesics and antipyretics, including Antifebrin (1886) and Phenacetin (1887; Hückel, 1962). However, these were not effective treatments for malaria (Guttmann and Ehrlich, 1891).

The first encouraging result came in 1891 with the histological stain methylene blue (Figure 3):

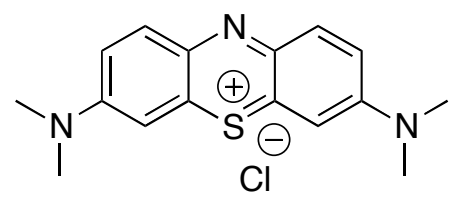

Methylene Blue

Figure 3: Methylene Blue 
Histological stains were of interest as possible medicines both because of their known bacteriocidal activity and because of their selective and specific affinity to certain cell groups and parts of cells (Guttmann and Ehrlich, 1891; Mietzsch, 1951). Methylene blue was known to have an affinity for the cells of Plasmodium and was already used in malaria diagnosis. Paul Ehrlich and Paul Guttmann used methylene blue to treat two malaria patients with apparent success and no serious side effects (Guttmann and Ehrlich, 1891). In subsequent trials by other researchers, the administration of methylene blue often failed to give the same encouraging results and in at least one study was invariably attended by unpleasant side effects (severe stomach pain and vomiting); meanwhile other researchers confirmed Guttmann and Ehrlich's findings and found no serious side effects (Lava, 1891; Mya, 1892; and Thayer, 1892, results summarized in Supplement to the British Medical Journal, 1891 and 1892). The difference in side effects observed possibly could have been due to the purity of the dye used, in light of the fact that Guttmann and Ehrlich specify the use of chemically pure methylene blue, whereas historically the dye has often been used for staining applications at relatively low purity. Methylene blue was sometimes recommended for treatment of malaria during the early 20th century (Potter's Therapeutics, Materia Medica, and Pharmacy, 1917, contains the following recommendation: "Methylene blue, next to quinine, has been considered as the most valuable drug. It is given in 2-grain doses every 4 hours"). More recently, the clinical efficacy of methylene blue against malaria has been reëxamined (Akoachere, 2005; Meissner, 2006).

The first useful synthetic antimalarials, pamaquine (Plasmochin, Plasmoquine, 
1924/5), quinacrine (Atebrin, Atabrine, Mepacrine, 1932), chloroquine (Resochin, 1934), and sontoquine (Sontochin, Nivaquine, 1936), were all developed between the World Wars by researchers at Farbenfabrik Bayer, Elberfeld (then part of I.G. Farbenindustrie). All except for quinacrine were quinoline compounds (Figure 4):

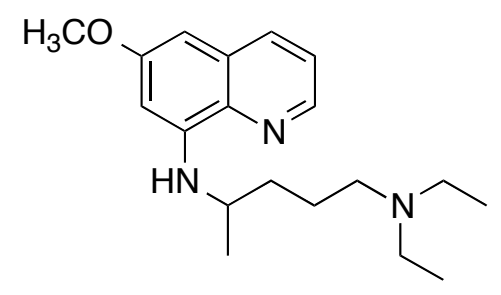

Pamaquine (Plasmochin, Plasmoquine)

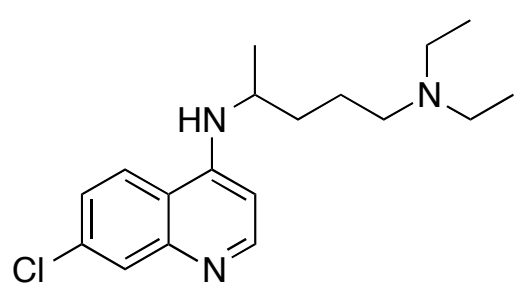

Chloroquine (Resochin)

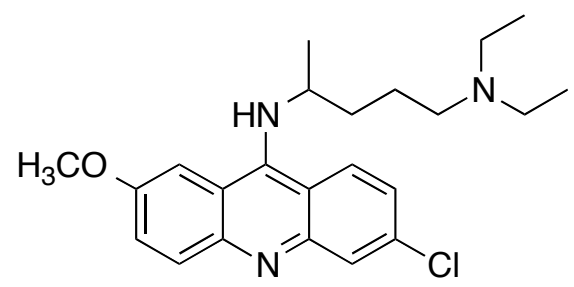

Quinacrine (Atebrin, Atabrine, Mepacrine)

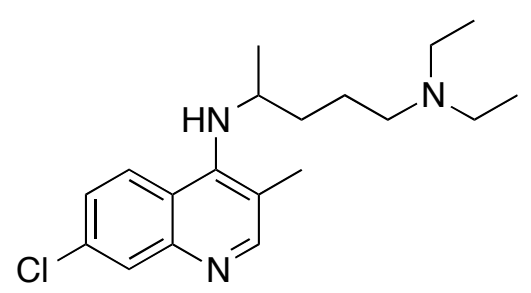

Sontoquine (Sontochin, Nivaquine)

Figure 4: Synthetic antimalarials from the Bayer research team at Elberfeld.

The research team at Elberfeld embarked on structure activity relationship studies having first quinine and then methylene blue as starting points, with the goal of finding a synthetic antimalarial with an improved ratio of activity to toxicity. Advances in techniques of animal testing by Elberfeld's Wilhelm Roehl - a former student of Paul Ehrlich - allowed the reliable screening of thousands of candidate compounds, and techniques developed by his successor, Walter Kikuth, together with Lilly MudrowReichenow, allowed even the differentiation between activity against the sexual and 
asexual stages of the parasite (Kikuth, 1942; Andersag, 1948; Slater, 2009). Compounds successful in animal models (the Plasmodium relictum infection of canaries) were then tested against human infection. Germany had no colonies at that time and no body of soldiers and staff in malaria endemic regions, and domestic cases of malaria were by then rare. Bayer's human testing was therefore contracted to Franz Sioli at the DüsseldorfGrafenberg psychiatric hospital, who was able to administer the drug candidates to neurosyphilis patients during the normal course of malaria therapy (Slater, 2009). ${ }^{3}$

The first of the successes to emerge from the Elberfeld malaria project was pamaquine (Figure 4), synthesized in 1924 (Schulemann, 1932, Andersag, 1948). The drug was the first successful application of a principle called by its developers "basic alkylation" (basische Alkylierung; Mauss and Mietzsch, 1933; Schönhöfer, 1965), that would then be applied successfully in quinacrine, chloroquine, and sontoquine. Extension of the dimethylamino substituent of methylene blue into a basic side chain - synthesized by Fritz Schönhöfer and August Wingler - had led to improved activity, but had also increased toxicity. Attachment of a basic side chain to the quinoline nucleus of quinine was next attempted by Fritz Schönhöfer. It was initially planned to put the aminoalkyl

\footnotetext{
${ }^{3}$ Malaria therapy, developed by the Austrian doctor Julius Wagner Ritter von Jauregg, was the only known method of curing late stage syphilis at the time. The patient was infected with malaria and the high fever was allowed to kill the trypanosomes (although this mechanism of action has been disputed); the patient was then cured of their malaria with quinine. This treatment for syphilis was widely practiced in Europe and the United States, and Wagner Ritter von Jauregg won the 1927 Nobel Prize for his discovery. In addition to saving thousands of lives, malaria therapy provided scientists in many countries with an invaluable opportunity to test new medicines for malaria (Covell \& Nicol, 1951; Chernin, 1984; Freitas, 2014). Interestingly, the induction of a high body temperature for the treatment for syphilis, together with guaiacum therapy, was used at least as early as 1519 (Forrester, 2005), and the disappearance of late stage syphilis after incidental infection with quartan fever was noted by Jean Fernel in his great work of philosophical medicine, De Abditis Rerum Causis (On the hidden causes of things; 1542).
} 
group at the 6-position (replacing the methoxy group of quinine; see Figure 5 for the numbering system of quinoline compounds); however, when this compound proved too difficult to purify, Schönhöfer synthesized the 8-amino derivative instead (which could be steam distilled).

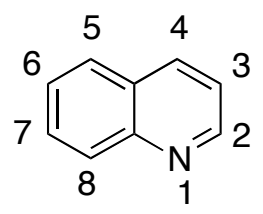

Figure 5: Quinoline ring numbering system.

The resulting compound had an activity far superior to quinine in bird malaria. A 6methoxy substituent was then introduced by the project leader, Werner Schulemann, by analogy to quinine; this, too led to a jump in activity, yet the results against human malaria were disappointing (Schönhöfer, 1965). Further variation of the basic side chain - to that which would later be used in chloroquine - led at last to Pamaquine (then called Plasmochin or Plasmoquine) in 1924, the first successful synthetic antimalarial (Figure 6; Slater, 2009):

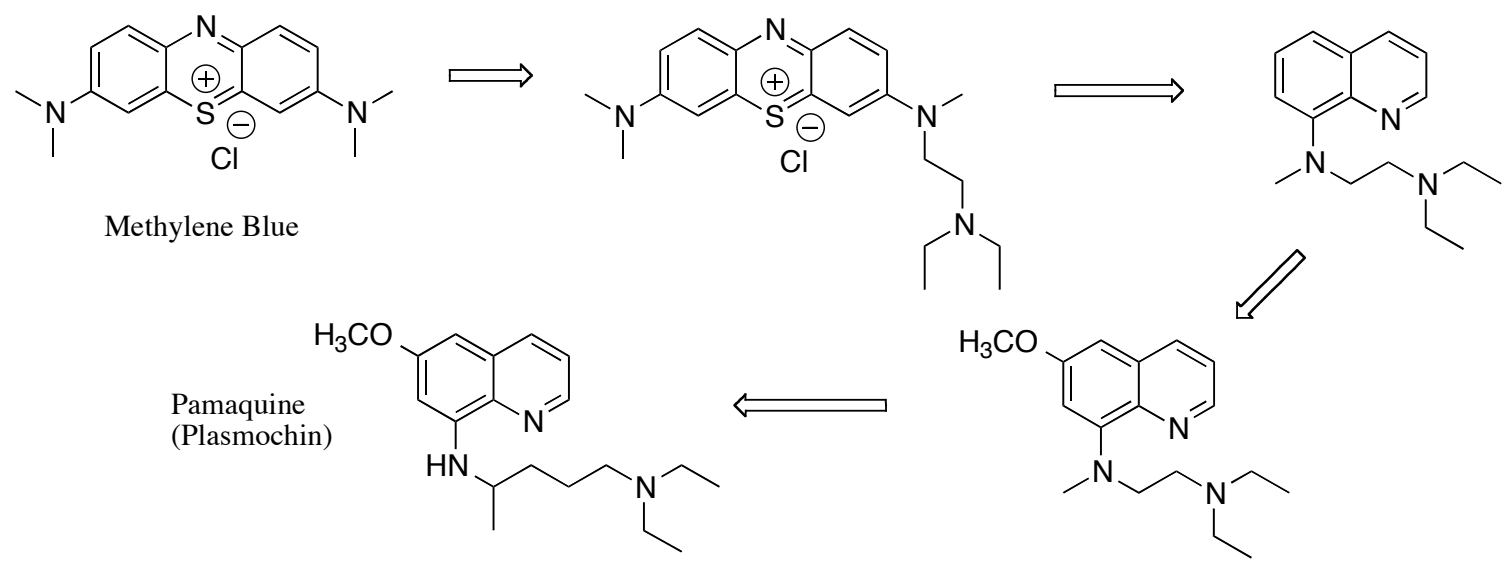

Figure 6: Development of pamaquine (Plasmochin). 
It was moreover reported that the drug was active against the gametocyte stage of Plasmodium (unlike other known antimalarials), and therefore offered hope that perhaps malaria could not only be treated, but eradicated by blocking transmission (Schulemann, 1932; Kikuth, 1942). The new compound was also active against the liver stage of $P$. vivax malaria and therefore offered a permanent cure to sufferers from relapsing malaria (Schulemann, 1932; Burrows, 2011). Unfortunately, it had significant toxic side effects, rendering it less than ideal for long-term administration as a prophylactic. Although it is often implied today that pamaquine never came into common use due to its toxicity, this is not entirely true; for instance, in 1942 the drug was manufactured by ICI in Great Britain in amounts "sufficient for 32 million tablets" (Greenwood, 1995, Slater, 2009). Researchers at Bayer appreciated that the toxicity of pamaquine was a drawback and later launched Certuna (also known as Cilional), a related compound discovered by Schönhofer (Figure 7):

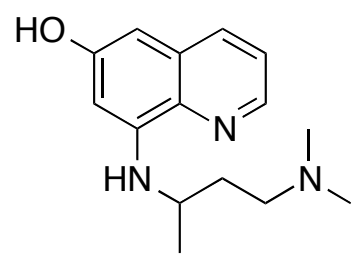

Figure 7: Certuna (Cilional).

Certuna was less toxic, but also less effective than Plasmochin (Chopra, 1938; Slater, 2009), and was never a great success. Plasmochin and Certuna remained the only drugs active against the gametocyte stage of Plasmodium until being supplanted by the less 
toxic des-diethyl pamaquine derivative, Primaquine, following World War II (Figure 8; Slater, 2009, Burrows, 2011). Primaquine was synthesized by Robert C. Elderfield and coworkers at the University of Michigan (Elderfield, 1946).

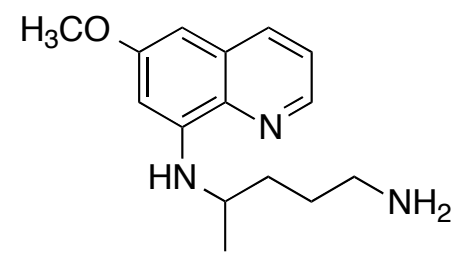

Figure 8: Primaquine.

In addition to quinolines, acridines - their close chemical relatives - were also of interest as potential antimalarials. Their development would ultimately lead to the development of chloroquine, a drug that would save more lives than any other synthetic antimalarial. Acridine compounds with antibacterial properties were already known. At Elberfeld, Fritz Mietzsch and Hans Mauss carried over the principle of basic alkylation to the acridine nucleus (along with a variety of other heterocycles), and discovered quinacrine (then called Atebrin or Atabrine, also called mepacrine or Italchina). Quinacrine shared with quinine the point of attachment of its alkylamine residue, and shared with pamaquine a methoxy group para to the ring nitrogen (Mauss and Mietzsch, 1933) as well as the identical aminoalkylamino side chain. In the third fused ring, meta to the nitrogen of the middle ring, a chlorine atom was introduced (Figure 9):

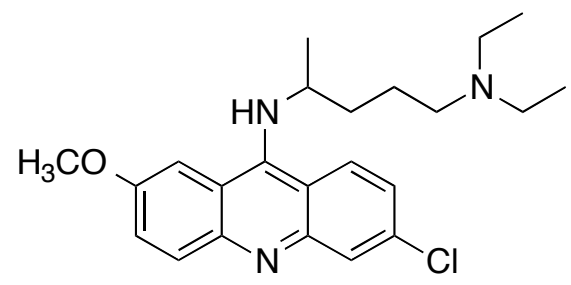

Figure 9: Quinacrine (Atebrin, Atabrine, Mepacrine). 
That introduction of a chlorine atom might lead to active compounds was discovered accidentally. During synthetic work on 8-aminoquinolines, Schönhöfer had used tin (II) hydrochloride reduction to reduce a 6-alkyl-8-nitroquinoline, unaware that this had sometimes been found to introduce a chlorine atom into the quinoline ring system. The resulting compound had excellent activity, but turned out to contain chlorine. This inspired Mauss and Mietzsch to introduce halogens into their acridine compounds (Schönhöfer, 1965).

Quinacrine was highly successful as an antimalarial, being more active than quinine and having fewer side effects. Its tolerability made it suitable for prophylactic use, and it was used extensively for this purpose, although long term use tended to turn the skin yellow (Mietzsch, 1933, Kikuth, 1942, Greenwood, 1995, Slater, 2009). It was manufactured in the United States as well as Germany (having been jointly licensed to Bayer and to its American partner, the Winthrop Chemical Company), although in the United States there were reports of quinacrine-related psychosis, similar to that later observed for mefloquine (Slater, 2009). During the Second World War, it was manufactured by both sides on a large scale (Greenwood, 1995).

During quinacrine's development, it was observed that the presence or absence of a 7-chloro substituent had greater influence upon antimalarial activity than did that of the methoxy group (Andersag, 1948). If one imagines removing the 6-methoxy containing ring from the structure of quinacrine, one obtains a quinoline compound with the structure of chloroquine (Figure 10): 


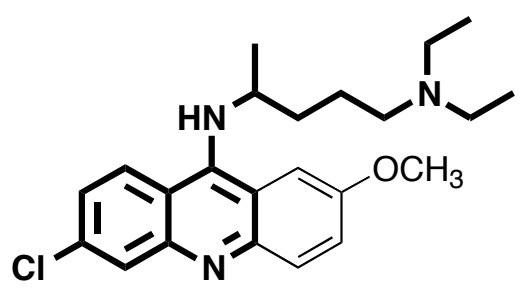

Quinacrine (Atebrin)

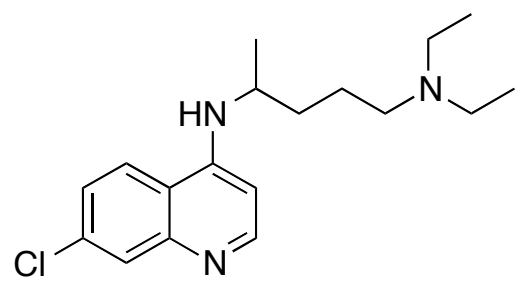

Chloroquine (Resochin)

Figure 10: Development of chloroquine (Resochin) from quinacrine (Atebrin).

Thus, by analogy to quinacrine, quinoline compounds with the aminoalkyl substituent opposite the ring nitrogen were made (Andersag and Breitner, 1956). Initially however, these 4-aminoquinoline compounds could not be made without a substituent in the 2position, and such compounds were inactive against malaria. However, the clever adaptation of a newly patented synthetic route to kynurenic acid (2-carboxy-4-quinoline, see Figure 11 below) allowed Hans Andersag to make 4-aminoquinolines with the 2position unsubstituted (Figure 11; Wislicenus, 1889; Hoffmann-LaRoche, 1933; Andersag, 1948): 


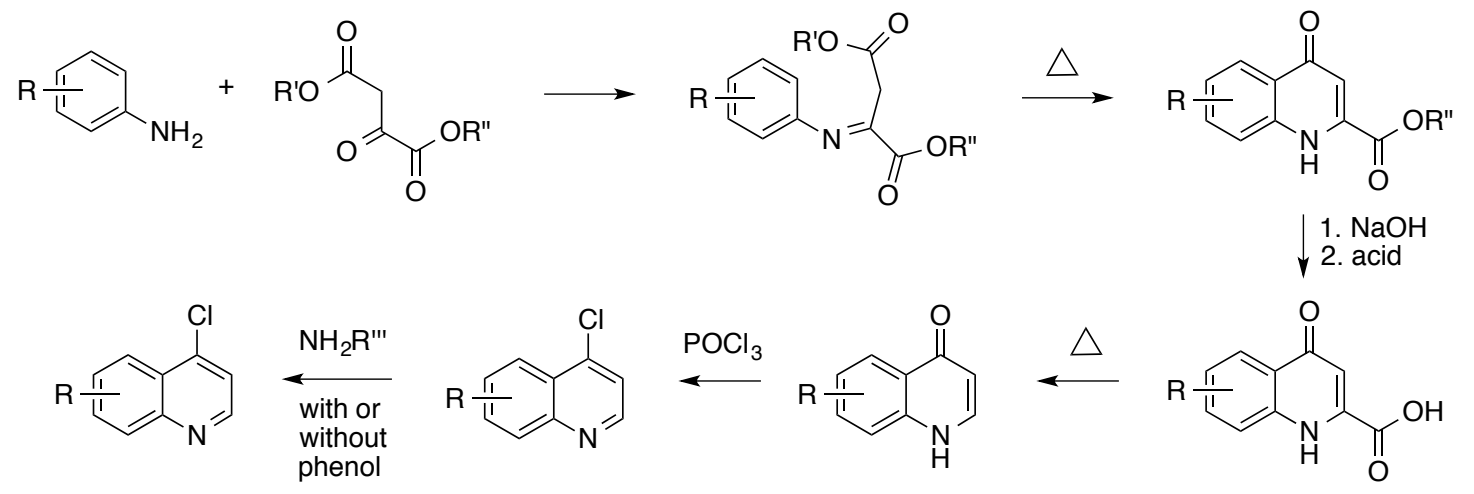

Figure 11: Hans Andersag's synthetic route to 2-unsubstituted 4-aminoquinolines.

Among these he made the 7-chloro-substituted chloroquine (then called Resochin), and together with Stefan Breitner and Heinrich Jung he made sontoquine shortly thereafter (Sontochin in German, later also called Nivaquine, Figure 12; Andersag, 1948, Mietzsch, 1951; Andersag, 1956).

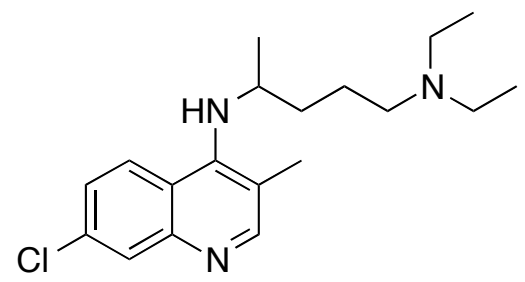

Figure 12: Sontoquine (Sontochin, Nivaquine).

Yet chloroquine was abandoned by Bayer in favor of sontoquine, either because Roehl's tests found toxicity in animal subjects, or because human toxicity was observed by Sioli (Slater, 2009; it has been suggested that since the human test subjects were in the late stages of syphilis, it is possible that unusual physical symptoms would occur that might be attributed erroneously to the test compound (Riscoe, personal communication)). 
However, chloroquine would soon be rediscovered.

In 1939, the National Research Council of the United States launched an antimalarial research initiative that by the end of the Second World War had grown into a massive screening and development program involving industry, government, and academic research labs alike. The program collaborated with researchers in Britain and Australia, and screened over 14,000 compounds against malaria, initially identifying quinacrine as the best compound but later fixing upon chloroquine (Wiselogle, 1946; Coatney, 1952; Greenwood, 1992; Slater, 2004 and 2009). Both chloroquine and sontoquine had been patented in the United States by Winthrop, but they were not included in the screening program until sontoquine was found in the possession of troops captured at Tunis in 1943. Field trials, conducted by the Australian medical officer Neil Hamilton Fairley, demonstrated that chloroquine was even more effective than sontoquine (Greenwood, 1995; Slater, 2009). Chloroquine entered clinical use in 1947. Because of its efficacy and lack of toxicity - even when administered to pregnant women and children - chloroquine was the standard antimalarial therapy for decades (Schlitzer, 2007; Slater, 2009).

\section{3: Chloroquine resistance}

There is substantial evidence that chloroquine acts by interference with the heme detoxification mechanism of Plasmodium species (Sullivan, 1996; Egan, 2005; Martin, 2009). When in the red blood corpuscle, Plasmodium species obtain nutrients by 
digestion of hemoglobin (Kirk, 2014). During the blood stage of $P$. falciparum malaria, the concentration of parasites in the blood has been estimated to be as high as millions of organisms per milliliter of blood (Dondorp, 2005, Pisciotta, 2007), which can consume $60-80 \%$ of the body's hemoglobin (Francis, 1997). Although the parasite utilizes the amino acid portion of hemoglobin as a food source, it does not utilize the central oxygenbinding porphyrin of hemoglobin, heme (Slater, 1991). In the acidic, aqueous environment of the food vacuole, pairs of heme molecules link together into heme dimers in which the propionate side chain of one molecule coördinates to the iron atom of the other (Slater, 1991, Egan, 2008). Both free heme and heme dimers are toxic to the parasite and if allowed to accumulate, would lead to its death by oxidative or osmotic stress (Francis, 1997, Pisciotta, 2007). To avoid this, the parasite is able to initiate the crystallization of the heme dimers into an aggregated structure, hemozoin, which is insoluble in the digestive vacuole and is thus rendered non-toxic (Fitch, 1987, Slater, 1991). The structure of hemozoin is thought to be a large crystal in which the heme dimers associate by hydrogen bonding (Hänscheid, 2007, Egan, 2008). The process by which hemozoin formation is initiated, as well as the exact location of its formation, are a matter of debate, but the process may occur at the surface of lipid droplets within the acidic, aqueous environment of the digestive vacuole (Jackson, 2004, Oliveira, 2005 (for other protozoal diseases), 2007, Egan, 2007; Pisciotta, 2007). Once heme has crystallized, it remains within the digestive vacuole, where it may be stored within lipid droplets (Pisciotta, 2007). Microscopy of malaria parasites reveals large, dark masses of crystallized hemozoin, referred to as malaria pigment; observation of malaria pigment in 
the blood of patients with fever has been used since the nineteenth century to diagnose malaria (Sullivan, 2002). Malaria pigment accumulates in the brain, spleen, and blood vessels of malaria victims and can be observed upon autopsy without a microscope - the earliest existing written description of malaria pigment dates to 1771, although its presence was not connected with malaria until 1849 (Sullivan, 2002, Hänscheid, 2007).

When chloroquine is present in the bloodstream, it passively diffuses into the red blood corpuscle, into the parasite, and thence into the parasite's digestive vacuole (Kirk, 2013). Chloroquine's accumulation in the digestive vacuole has been estimated as one thousand to several thousand times greater than the concentration in uninfected erythrocytes (Foley, 1997, Kelly, 2002, Sullivan, 2002). Once inside the vacuole, the quinoline ring system of chloroquine is thought to bind to the heme dimer, preventing the formation of hemozoin (Dorn, 1998; Roepe, 2002). The continued presence and accumulation of drug-bound heme dimers then leads to the parasite's death, possibly by oxidative and osmotic stress (Sullivan, 1996; Lakshmanan, 2005; Egan, 2005; Martin, 2009) (Figure 13). 


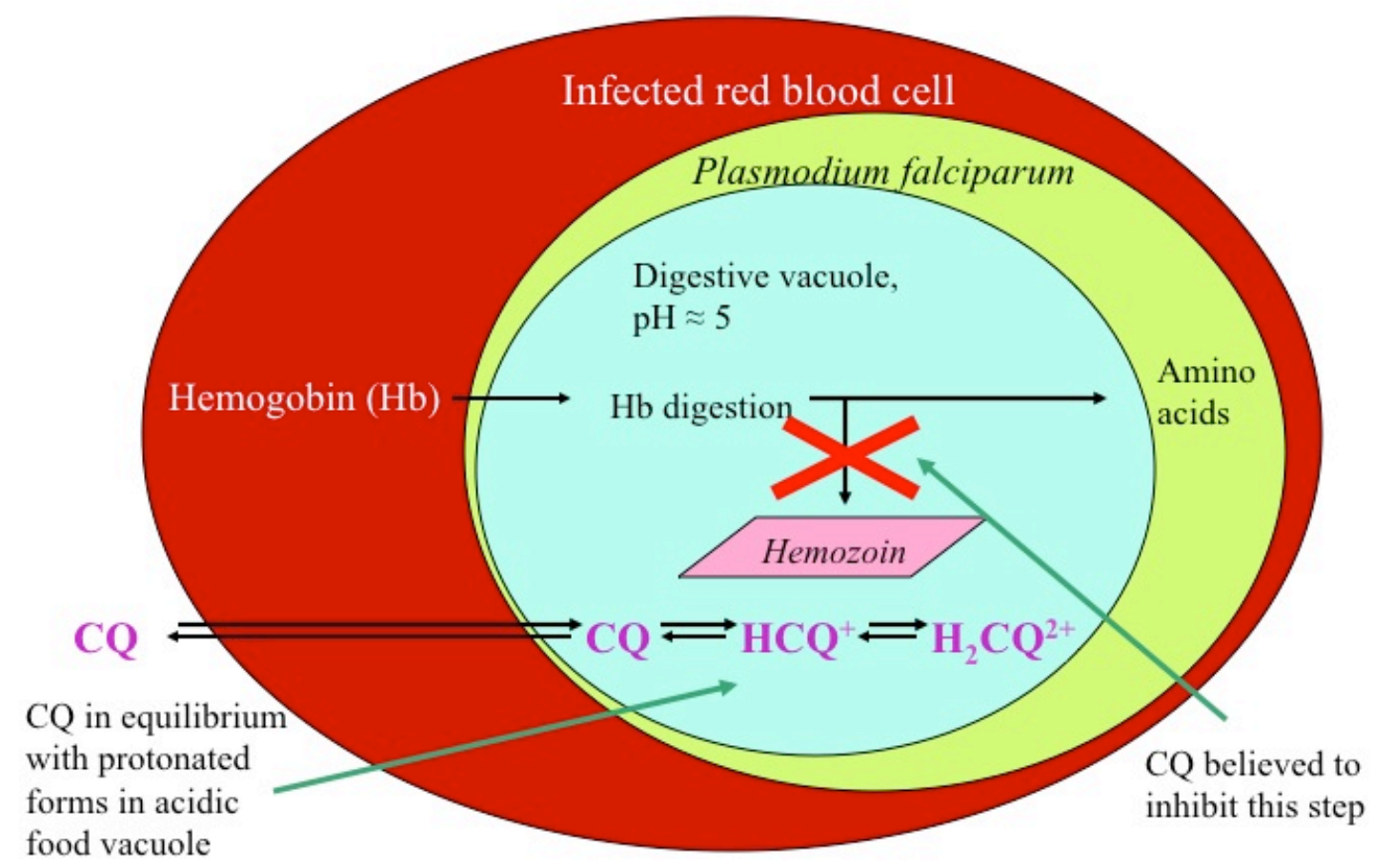

Figure 13: Putative mechanism of chloroquine.

Inhibition of hemozoin formation is not the only possible mechanism of action for chloroquine, but it is the mechanism for which there is the most evidence. Other possibilities that have been explored include DNA intercalation, interference with polyamine biosynthesis, or interference with enzyme activity due to a change in the $\mathrm{pH}$ of the digestive vacuole (Hahn, 1966, Bolte, 1979, Yayon, 1985, Krogstad, 1987, Schlesinger, 1988). It is quite possible that chloroquine may act by more than one pathway. In this work, however, it has been assumed that chloroquine's primary mode of action is inhibition of hemozoin formation within the digestive vacuole. 
The heavy and widespread use of chloroquine and other antimalarials, as well as the increased size, density, and mobility of the world's population, gave rise to concern early on that drug resistant strains of malaria would emerge. By the end of the 1940s, resistance to the antimalarial proguanil (Figure 14), pamaquine, and even quinine had been artificially induced in the laboratory, and proguanil resistance had been observed in the field in Indonesia and Malaysia (Bishop, 1951).

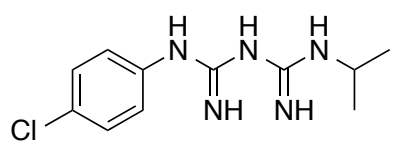

Figure 14: Proguanil.

In the 1950s, chloroquine resistant strains of P. falciparum were reported in Southeast Asia and South America (Young, 1961; Rathore, 2005; Packard, 2014). Since that time, resistance has become widespread (WHO, 2013). Chloroquine resistant parasites exhibit reduced accumulation of chloroquine within the digestive vacuole (Krogstad, 1987). Chloroquine resistance in P. falciparum has been linked to one or more mutations (importantly, K76T) in the transporter PfCRT (Plasmodium falciparum chloroquine resistance transporter), present in the membrane of the parasite's digestive vacuole. It is thought that this mutated transporter is able to export chloroquine out of the vacuole, thus allowing the heme detoxification process to proceed normally (Fidock, 1996; Lakshmanan, 2005; Martin, 2009; Roepe, 2011). Additional mutations in other transporters, such as PfMDR1 (Plasmodium falciparum Multidrug Resistance Transporter 1) and PfMRP1 (Plasmodium falciparum Multidrug Resistance Protein 1), 
have been linked with chloroquine resistance in some strains of chloroquine resistant parasites (Kirk, 2013).

\section{4: A strategy to overcome chloroquine resistance}

An attractive strategy to find new antimalarial compounds is the modification of existing drugs to which resistance exists in a way that restores their activity against drug resistant strains. Among other approaches, this can be done by the attachment of a reversal agent. Reversal agents are drugs that are able to restore the activity of a drug to which resistance exists, when co-administered. When given together with chloroquine, the calcium channel blocker Verapamil (normally used to treat high blood pressure, angina, and cardiac arrhythmia) and the tricyclic antidepressant Desipramine (among others) have been observed to have this effect (Figure 15; Martin, 1987; Krogstad, 1987; Bitonti, 1988):
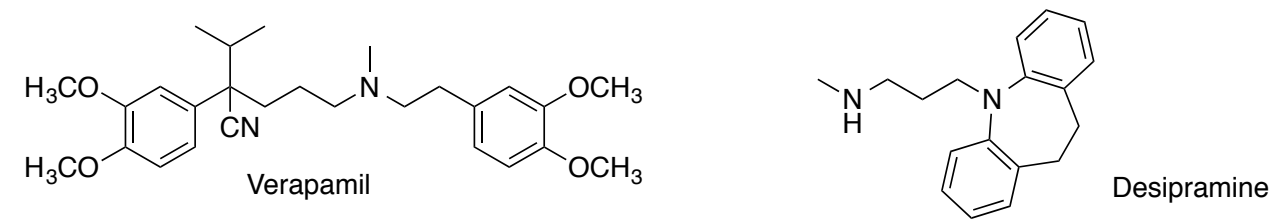

Figure 15: Two known reversal agents for chloroquine resistance in P. falciparum malaria.

Reversal agents appear to work by reducing efflux of chloroquine from the food vacuole in some manner, perhaps by blocking the chloroquine resistance transporter, PfCRT (Bray, 2005; Martin, 2009). However, if such a reversal agent were to be coadministered with chloroquine therapeutically, it is possible that the reversal agent drug, 
which has therapeutic activity of its own, might have undesirable effects at the concentration needed for it to accumulate in the parasite's digestive vacuole. In Dr. Peyton's laboratory, it has previously been shown that the combination of a chloroquinelike moiety with a reversal agent-like moiety in a single molecule - which was named a "reversed chloroquine" (RCQ) compound - may be an effective approach through the initial compound PL01 (Figure 16), which links a chloroquine-like structure with that of the anti-depressant Imipramine (Burgess, 2006; Peyton, 2012):
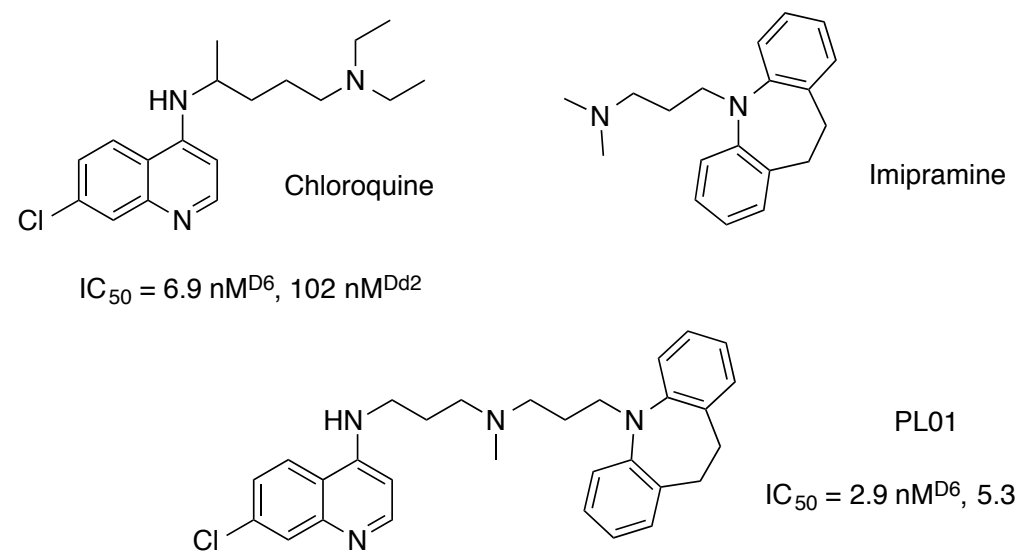

PL01
$\mathrm{IC}_{50}=2.9 \mathrm{nM}^{\mathrm{D} 6}, 5.3 \mathrm{nM} \mathrm{Dd}^{\mathrm{D} 2}$

Figure 16: The reversed chloroquine-type compound PL01 combined features of chloroquine and imipramine. In vitro antiplasmodial activity is shown as $\mathrm{IC}_{50}$, the concentration required to inhibit plasmodial growth by $50 \%$.

The hybrid compound had roughly equal activity in vitro against both chloroquine sensitive and chloroquine resistant strains of $P$. falciparum,${ }^{4}$ and its activity was not at all

\footnotetext{
${ }^{4}$ Antiplasmodial activity is given herein as $\mathrm{IC}_{50}$, the concentration required to inhibit plasmodial growth by $50 \%$. The strains of $P$. falciparum used in this work for in vitro testing were D6, a chloroquine sensitive strain, and $\mathrm{Dd} 2$ and 7G8, two chloroquine resistant strains originally isolated in southeast Asia and Brazil, respectively. In quoting results from other research groups, when $\mathrm{IC}_{50}$ values are given for compound activity against other $P$. falciparum strains, it is noted whether these are chloroquine sensitive (CQS) or chloroquine resistant (CQR) strains.
} 
diminished relative to that of chloroquine (Burgess, 2006). A structure-activity relationship study was then performed in which the reversal agent moiety attached to the 4-amino side chain of the 7-chloroquinoline nucleus was varied (see Figure 17 for representative compounds; Andrews, 2006, Burgess, 2008, Burgess, 2010, Andrews, 2010, Gunsaru, 2010, Peyton, 2012):
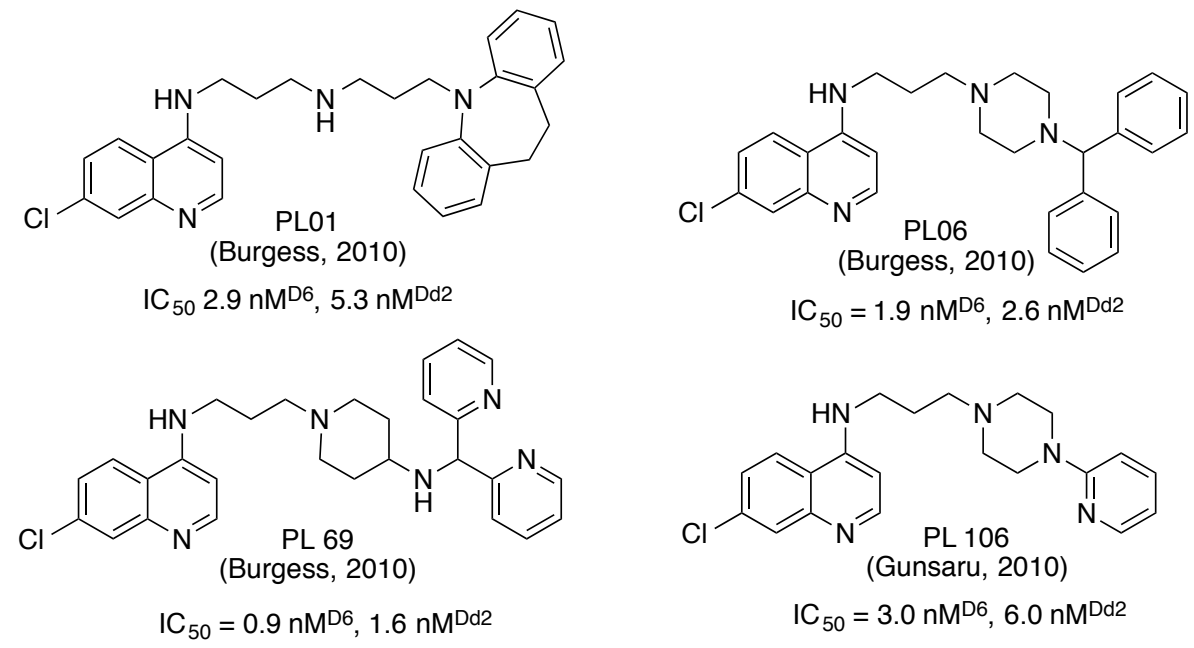

Figure 17: Representative compounds from the initial structure-activity relationship study during which reversed chloroquine-type compounds were developed.

We believe that reversed chloroquine-type compounds act against $P$. falciparum by the same mechanism as chloroquine (i.e. by inhibition of the detoxification of heme by conversion to hemozoin). This is supported by in vitro studies in which it has been shown that 7-substituted reversed-chloroquines are able to bind heme, to inhibit the formation of $\beta$-hematin, and to inhibit the formation of hemozoin in P. falciparum 
parasites in vitro (Burgess, 2010). However, it is possible that this may not be the correct or only mechanism of these compounds.

During this work it was assumed initially that changes in substitution pattern of the quinoline ring moiety of the reversed chloroquines would only lead to a decrease in activity relative to the 4-amino-7-chloro substitution pattern seen in chloroquine, since it has previously been shown for other 4-aminoquinoline antimalarials that the 7-chloro substitution pattern confers optimal activity (see below). However, as part of a mechanistic investigation of the reversed chloroquine analogue PL06, the des-chloro analogue PL64 was synthesized (Figure 18; Burgess, 2008; Burgess, 2010):
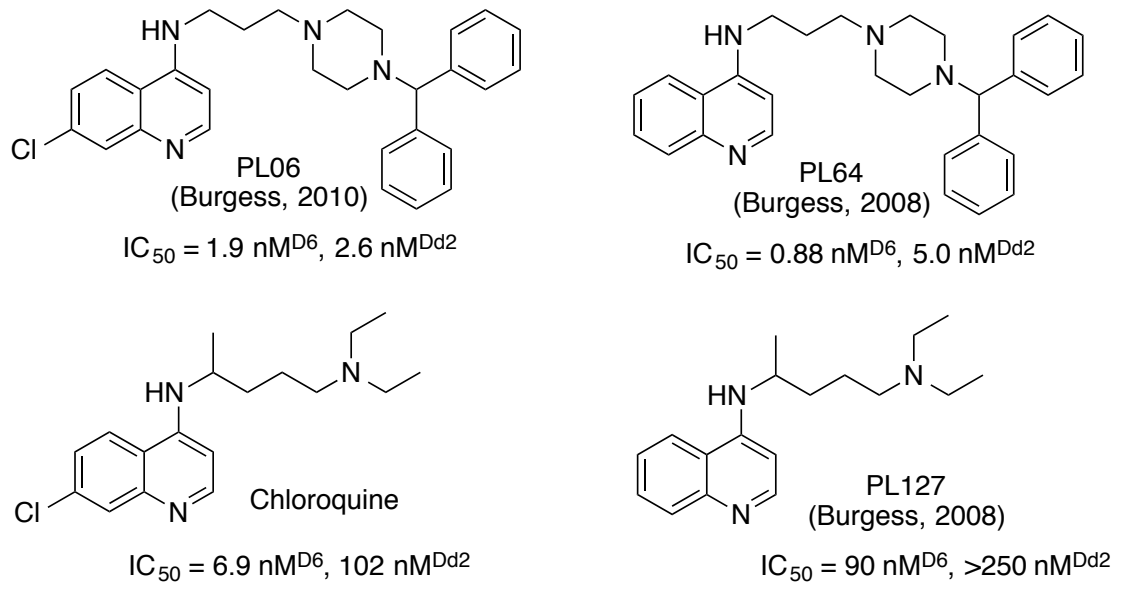

Figure 18: PL06, chloroquine, and their des-chloro analogues

Contrary to what was expected based on the known low activity of des-chloro chloroquine (PL127, Figure 18), this compound had excellent antiplasmodial activity against both chloroquine sensitive and chloroquine resistant $P$. falciparum malaria 
parasites. This indicated that modification of the quinoline ring substitution pattern of reversed chloroquine-type compounds might, in fact, be a useful line of inquiry (Burgess, 2010).

\section{5: The effect of the quinoline ring system substitution patterns on the antimalarial activity of chloroquine-like compounds}

During the original development of chloroquine and sontoquine during the 1930s and 1940s by researchers at Farbenfabrik Bayer, Elberfeld, 4-aminoquinolines with a large number of different quinoline ring substitution patterns were tested, but much of the data on the relative antimalarial efficacy of these compounds was never made public. The following information may be gleaned from the patent literature and various publications:

1) From the patent literature, 4-aminoquinolines may have been made and tested with at least the following substitution patterns (see also Figure 19):

- 2-methyl-6-methoxy (Schulemann, 1929; and Schulemann, 1930)

- 2-methyl (Ibid)

- 7-halo, alkyl, hydroxyl, thiol, alkoxy, alkylmercapto, cyano, thiocyano, amino, alkylamino, and trifluoromethyl (Andersag, 1939)

- In the 3 position of the above 7 -substituted quinolines, alkyl, aryl, aralkyl (Ibid)

- In the 2 position of the above 7- substituted quinolines, an unknown alkyl substituent, probably methyl (Ibid)

- 7-chloroquinolines with additional substituents from the above in one or more additional positions (3,5-, 6-, or 5,6-) (Ibid) 


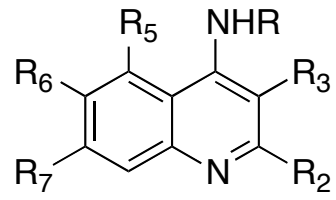

$\mathrm{R}_{2}: \mathrm{H}$ or $\mathrm{CH}_{3}$

$\mathrm{R}_{3}$ : $\mathrm{H}$ or alkyl, aryl or aralkyl

$\mathrm{R}_{5}$ : $\mathrm{H}$ or $\mathrm{Cl}, \mathrm{Br}, \mathrm{I}$, alkyl, $\mathrm{OH}, \mathrm{SH}, \mathrm{OR}, \mathrm{SR}, \mathrm{CN}, \mathrm{SCN}, \mathrm{NH}_{2}, \mathrm{NHR}$ or $\mathrm{NR}_{2}, \mathrm{CF}_{3}$ $\mathrm{R}_{6}: \mathrm{H}$ or $\mathrm{Cl}, \mathrm{Br}, \mathrm{I}, \mathrm{OR}$

$\mathrm{R}_{7}: \mathrm{H}$ or $\mathrm{Cl}, \mathrm{Br}$, I, alkyl, $\mathrm{OH}, \mathrm{SH}, \mathrm{OR}, \mathrm{SR}, \mathrm{CN}, \mathrm{SCN}, \mathrm{NH}_{2}, \mathrm{NHR}$ or $\mathrm{NR}_{2}, \mathrm{CF}_{3}$, benzyl

Figure 19: Some substituents of 4-aminoquinolines used by the Bayer research team at Elberfeld.

2) Of these, the most effective compounds contained a halogen atom in the 7position. The halogens used included fluorine, chlorine, bromine, and iodine. Amongst chlorine, bromine, and iodine, roughly equal antimalarial activity was observed, whereas substitution with fluorine decreased activity. Many other 7substituted compounds were also active.

3) The presence of a methyl group in the 3-position of 7-haloquinolines apparently did not reduce the efficacy of these compounds. Larger 3-alkyl groups resulted in reduced efficacy. For other 7-substituted compounds, 3-substitution did not always result in reduced efficacy and sometimes increased efficacy.

4) An alkyl group in the 2-position resulted in a compound with lowered activity regardless of any other substituents.

In monographs published by Frederick Y. Wiselogle (1946) and G. Robert Coatney (1952) on the results of the American-British-Australian wartime screening project, it is further observed that a substituent in the 8-position also reduces activity. 
Coatney also states that the activity of compounds with a relatively short aminoalkylamino chain is more susceptible to variation upon modification of the quinoline ring system substituents than is the activity of compounds with a longer chain.

The advent of chloroquine resistance has inspired research on the effect of varying quinoline ring substitution of 4-aminoquinolines upon activity against chloroquine resistant strains (De, 1996; De, 1998; Vippagunta, 1999; Bhattacharjee, 2001; Stocks, 2002; Kaschula, 2002; Madrid, 2005; Hocart, 2011; Pou, 2012; Nsumiwa, 2013). The results of this research can be summarized as follows (see also Figure 20, below).

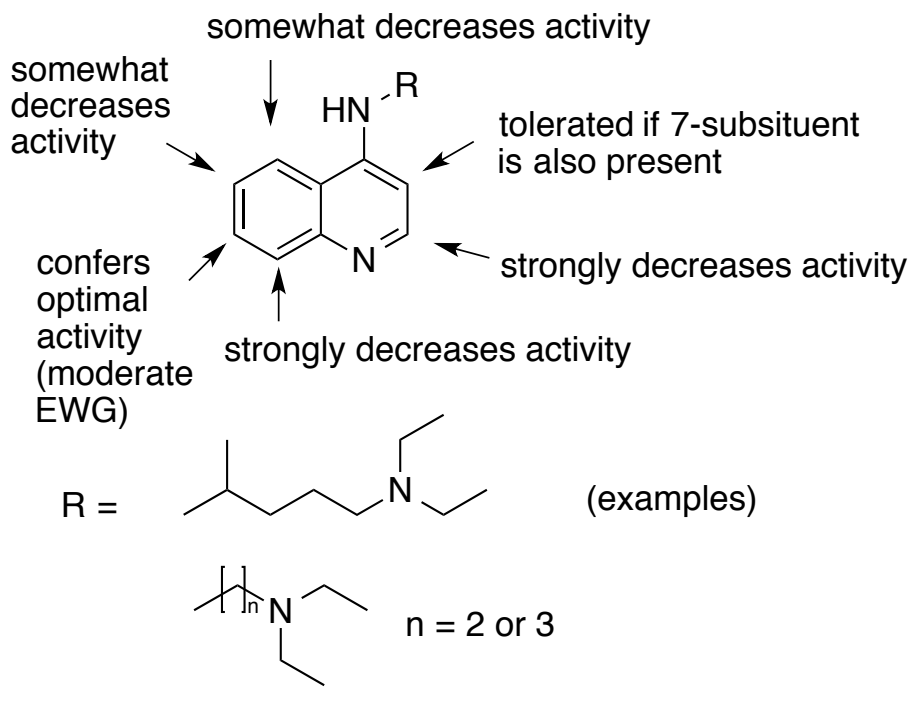

Figure 20: Effect of quinoline ring substitution pattern on chloroquine analogs without an attached reversal agent

As for the position of substituents, 7-substitution is optimal whereas moving the substituent to position 6 results in either diminished or poor efficacy (De, 1996; 
Vippagunta, 1999; Hocart, 2011; Pou, 2012). Substitution in the 2- or 8-position invariably gives poor efficacy (De, 1996; Madrid, 2005; Hocart, 2011). This is also true for 5- substitution, but to a lesser extent (Madrid, 2005). With only hydrogen, very poor efficacy is observed (De, 1996; Vippagunta, 1999; Hocart, 2011). As to the nature of the substituent, among the halogens some workers have found that chlorine is optimal, while other workers have found that there is little difference between iodine, bromine, and chlorine (De, 1998; Vippagunta, 1999; Kaschula, 2002; Hocart, 2011). Fluorine gives lowered efficacy (De, 1998; Kaschula, 2002; Pou, 2012). Electron-donating groups (amino, hydroxy, methoxy) in the 7-position generally reduce efficacy, often dramatically, and a strong electron-withdrawing group (nitro or trifluoromethyl) frequently reduces efficacy as well. In the case of the 7-trifluoromethyl group, the effect is not as dramatic and there are notable exceptions (De, 1998; Vippagunta, 1999; Stocks, 2002; Kaschula, 2002; Madrid, 2005; Hocart, 2011; Pou, 2012). Finally, there is some evidence for resistance reversal relative to chloroquine in the case of 7-iodo substitution, 7-trifluoromethyl substitution, 7-nitro substitution, or simultaneous 3-methyl and 7chloro substitution (the substitution pattern of sontoquine, see Figure 12; De, 1998; Vippagunta, 1999; Stocks, 2002; Pou, 2012). Additionally, there is evidence that a bulky substituent in position 7 (phenoxy, Madrid, 2005) or in position 3 (trifluoromethoxy phenyl, Pou, 2012) may enhance activity against resistant parasites.

The research described above concerns chloroquine analogues without an attached reversal agent. As discussed in section 1.4, the activity of chloroquine analogs 
with reversal agent attached may be affected differently by changes to the quinoline ring system substitution pattern. Particularly in light of the results described above for resistant parasites, a study of the effects of quinoline ring substitution pattern on the antiplasmodial activity of reversed chloroquine-type compounds seems well warranted. 


\section{CHAPTER 2:}

\section{Quinoline Ring-Modified Analogues of Reversed Chloroquine-type Compounds}

In the present work, a study has been made of the effect of the quinoline ring substititution pattern upon the activity of chloroquine analogs with a reversal agent attached. The 53 compounds synthesized in this work include those bearing a substituent in the 2-, 5-, 6-, 7-, or 8- position, as well as some disubstituted compounds, and include those with chloro, bromo, iodo, fluoro, nitro-, trifluoromethyl, methyl, and methoxy substituents, in addition to unsubstituted compounds (see Appendix B, Table B1 for structures).

In vitro testing of the new compounds has revealed a wide range of activity against $P$. falciparum malaria. The bar graph in Figure 21, below, shows the in vitro antiplasmodial activities of a selection of the compounds tested against two strains of $P$. falciparum (D6, a chloroquine sensitive strain, and Dd2, a chloroquine resistant strain). As above, antiplasmodial activity is given as $\mathrm{IC}_{50}$, the concentration required to inhibit plasmodial growth by 50\%. For comparison, chloroquine (CQ, far left) is also included. For methods used to obtain these results, see Experimental Methods, Chapter 5. For antiplasmodial activities of all ring-modified reversed chloroquine compounds made in the present work, see Table B1, Appendix B. 


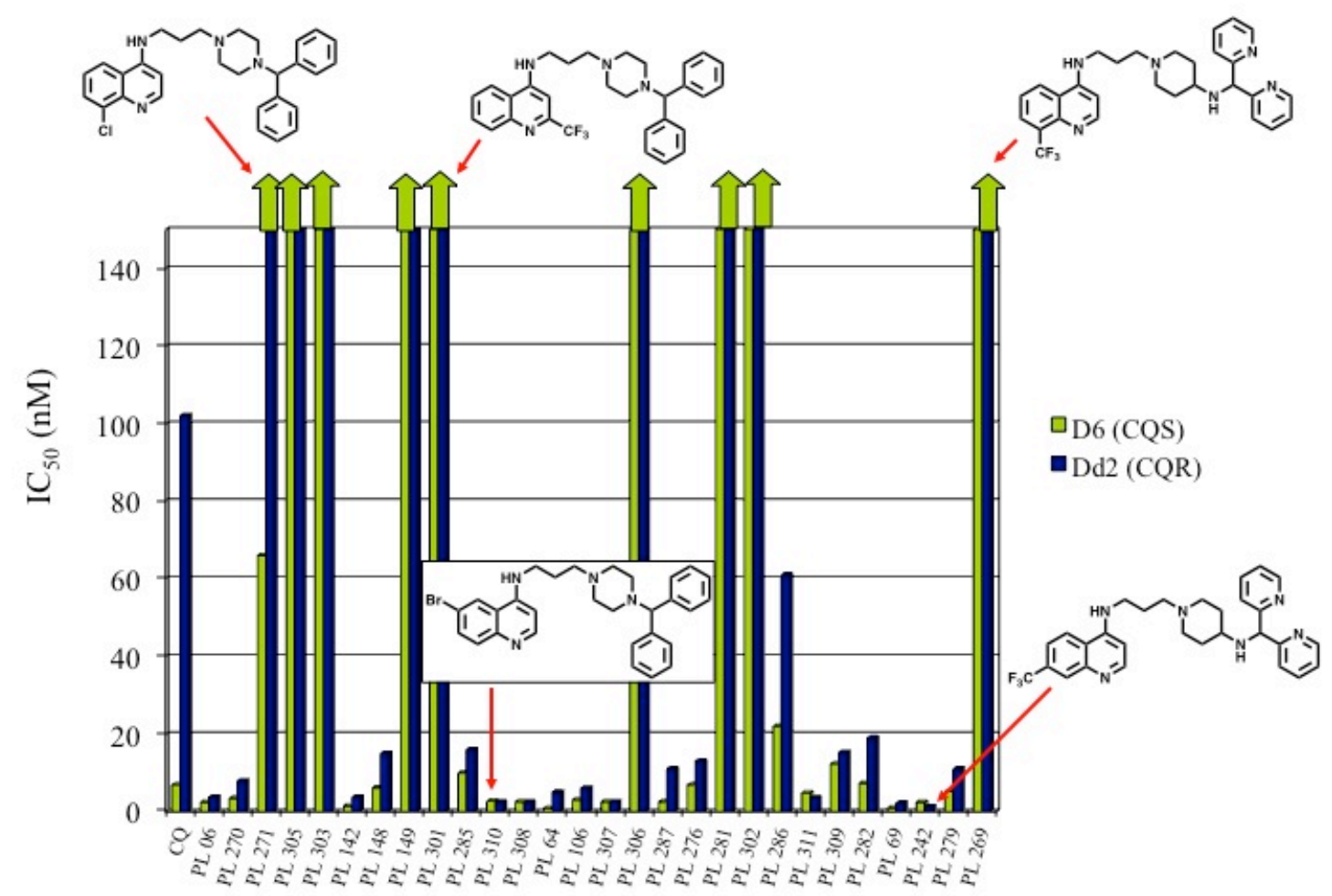

Figure 21: In vitro antiplasmodial activities of a selection of the compounds in the present work against chloroquine sensitive and chloroquine resistant strains of Plasmodium falciparum. Chloroquine (CQ) is shown at the far left.

Some of the study compounds performed at least as well as chloroquine, and as well as the original 7-chloro reversed chloroquine-type compounds, while others had greatly diminished activity (see Figure 21, and Figure 22, below). The following is a summary of the results obtained, and a discussion thereof. 


\section{1: Results}

\subsection{1: Effect of a substituent in the 2-, 5-, or 8- position}

Compounds with a predominantly electron-withdrawing substituent in the 2- or 8position (either chlorine or a trifluoromethyl group, see PL302 and PL149, figure 22, below, and others in Table B1, Appendix B) had little activity in the $\mathrm{IC}_{50}$ range tested, in accord with the findings described above for chloroquine analogues without an attached reversal agent (Chapter 1, section 1.5). It was not clear however whether this was due to the lack of a substituent in the 7-position, or to the presence of a substituent in the 2- or 8- position as such. Therefore, compounds were synthesized with 2,7- and 7,8disubstitution (PL398 and PL305). These were also found to have little activity, and so it seems that it might be the presence of the substituent in these positions that is responsible for the decrease in activity for 2- and 8- substituted compounds relative to those substituted with a 7- chloro substituent alone (Figure 22 and Table B1, Appendix B):

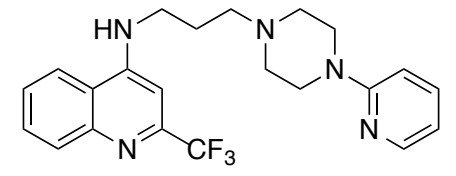

PL302

$\mathrm{IC}_{50}>2500^{\mathrm{D} 6}, 1294 \mathrm{nM} \mathrm{Dd} 2$

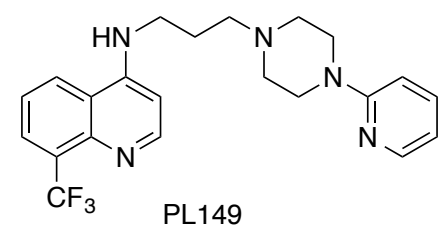

$\mathrm{IC}_{50}>250 \mathrm{nM}{ }^{\mathrm{D} 6},>250 \mathrm{nM} \mathrm{Dd}^{\mathrm{D}}$

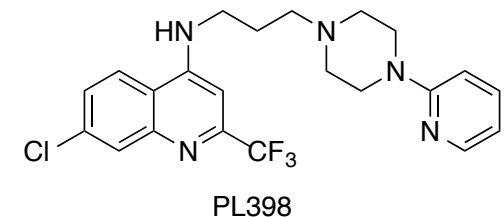

$\mathrm{IC}_{50} 660 \mathrm{nM}{ }^{\mathrm{D} 6}, 540 \mathrm{nM} \mathrm{Dd}^{\mathrm{D}}$

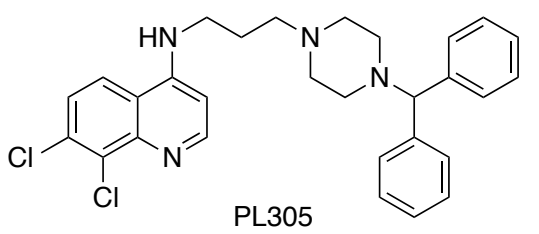

$\mathrm{IC}_{50} 108 \mathrm{nM} \mathrm{D}^{\mathrm{D}}, 491 \mathrm{nM} \mathrm{Dd}^{\mathrm{D}}$

Figure 22: Effect of 2- or 8- substitution compared to 7-substitution and 7,8, or 2,7-disubstitution 
Since only electron-withdrawing substituents were tested initially, it was not known whether the trend of reduced activity for 2- and 8- substituted compounds would also be observed for compounds with an electron-donating group in the 2- or 8-position. Therefore, an 8-methoxy substituted compound (PL390) and two 8-methyl substituted compounds (PL393 and PL394) were synthesized and tested. Two of these (PL390 and 393) proved to have equally low activity when compared to their analogue containing an electron-withdrawing group (PL284), while a third molecule with a larger reversal agent moiety (PL394) had somewhat improved activity, although still far lower than its 7chloro analogue, PL271 (see Figure 23, below and Table B1, Appendix B). Thus, based on this limited sample, the reduction of activity observed with electron-withdrawing 2and 8- groups seems to extend to electron-donating groups as well, but perhaps to a lesser extent for compounds with a larger reversal agent moiety.

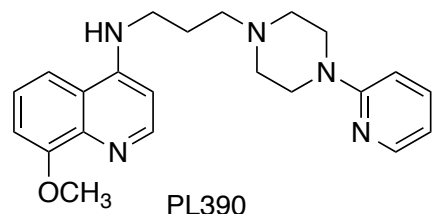

$\mathrm{IC}_{50} 240 \mathrm{nM}{ }^{\mathrm{D} 6}, 930 \mathrm{nM} \mathrm{Md}^{\mathrm{d} 2}$

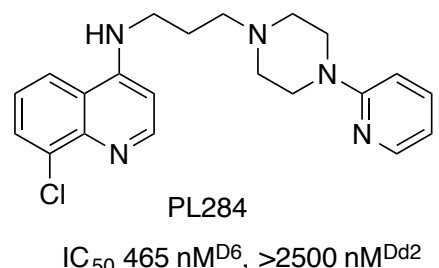

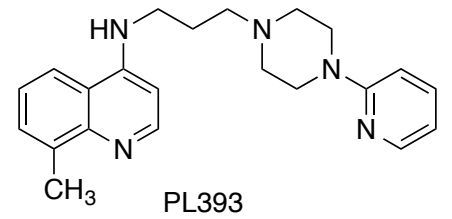

$\mathrm{IC}_{50} 350 \mathrm{nM}{ }^{\mathrm{D} 6}, 1830 \mathrm{nM} \mathrm{Dd}^{\mathrm{d} 2}$

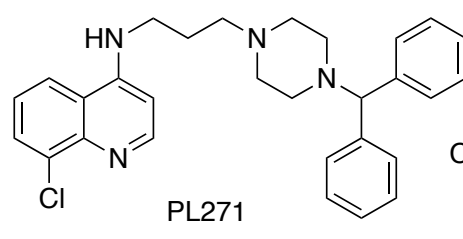

$\mathrm{IC}_{50} 66 \mathrm{nM}^{\mathrm{D} 6},>250 \mathrm{nM} \mathrm{Dd} 2$

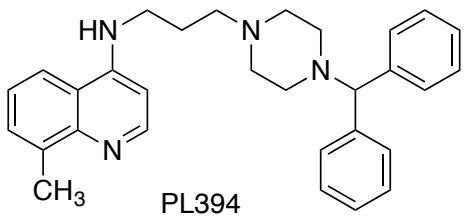

$\mathrm{IC}_{50} 14 \mathrm{nM}^{\mathrm{D} 6}, 74 \mathrm{nM}$ Dd2

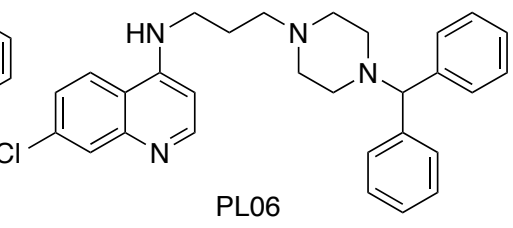

$\mathrm{IC}_{50} 1.9 \mathrm{nM} \mathrm{D}^{\mathrm{D}}, 2.6 \mathrm{nM} \mathrm{Dd}^{\mathrm{d}}$

Figure 23: Effect of 8- substitution with a methyl or methoxy substituent, compared with 7- or 8-chlorosubstitution. 
A 7-chloro-2-methyl substituted compound was also tested (PL399). It proved to have much lower activity than that of its 7-chloro-substituted analogue (PL106), but its activity was much increased relative to that of the 7-chloro-2-trifluoromethyl- substituted analogue, PL398 (Figure 24, below, and Table B1, Appendix B). For chloroquine analogues without an attached reversal agent, a 2-methyl substituent in addition to a 7chloro substituent is also known to lower activity (Andersag, 1948; Wiselogle, 1948; Vippagunta, 1999; Pou, 2012).

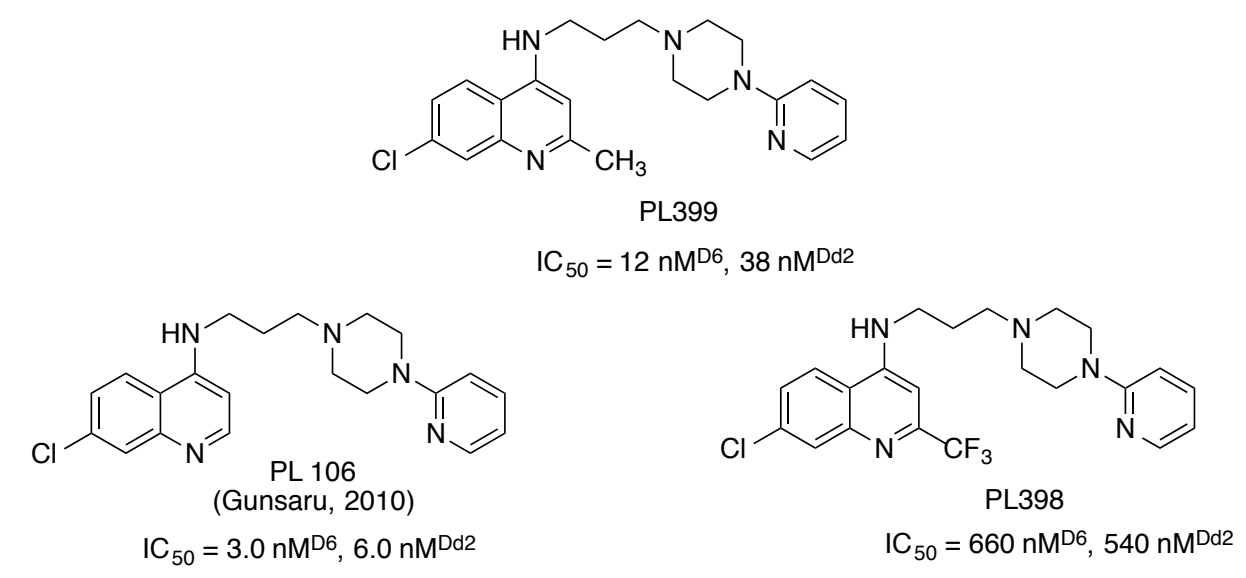

Figure 24: In a series of 7-chloro substituted compounds, an added 2-methyl substituent decreased activity, but to a smaller extent than an added 2-trifluoromethyl substituent.

It also was thought desirable to produce 5-substituted compounds for study. However, a synthetic challenge was presented by the production of a 4-aminoquinoline compound with a substituent in position 5 alone. In the course of synthesis of the 7substituted 4-chloroquinolines needed to produce the compounds under study, a small quantity of the 5-substituted regioisomer was usually (but not always) produced during the initial cyclization step (Figure 25): 

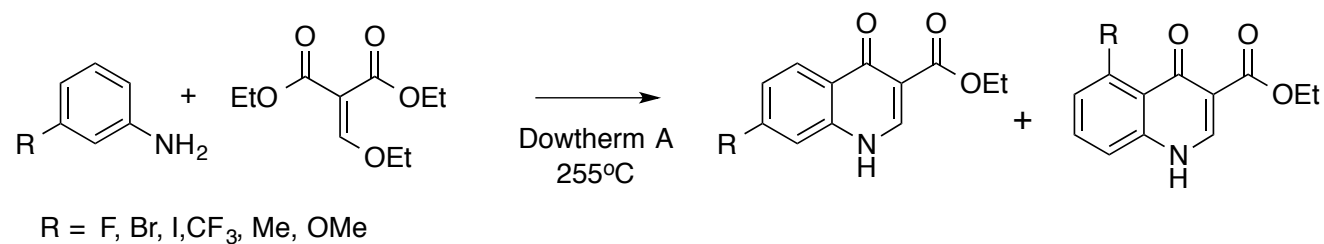

Figure 25: The cyclization step of the Gould Jacobs reaction, a representative quinoline ring-forming reaction.

However, the isolation of a sufficient quantity of pure 5-regioisomer - which was nearly always produced in a much smaller quantity than the 7-regioisomer - proved difficult upon being attempted with several compounds, such as 5- and 7-bromo-4chloroquinoline and 5- and 7-fluoro-4-chloroquinoline, since neither crystallization nor chromatography provided the 5-regioisomer in pure form (although both methods were effective in producing the pure 7-regioisomer; see Appendix A). Two 5,7-dichloro substituted compounds (PL367 and 379, see Table B1, Appendix B, and Figure 26, below) were therefore produced under the presumption that the results obtained would give some indication of the impact on activity of the 5- substituent when compared to the compound with the 7-chloro substituent alone. When tested in vitro, these compounds proved to have somewhat diminished activity compared to their 7-chloro analogues. However, the reduction in activity was not nearly as strong as was observed for the 7,8disubstituted analogue, PL306 (Figure 26, below and Table B1, Appendix B): 


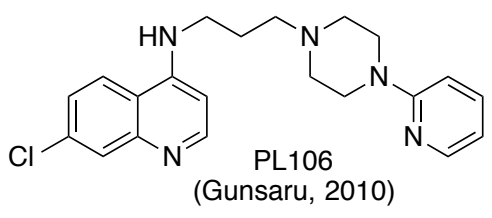

$\mathrm{IC}_{50}=2.7 \mathrm{nM}{ }^{\mathrm{D} 6}, 1.8 \mathrm{nM} \mathrm{Dd}^{2}$

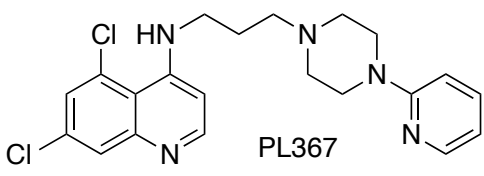

$\mathrm{IC}_{50}=33 \mathrm{nM} \mathrm{D}^{\mathrm{D}}, 67 \mathrm{nM} \mathrm{Dd}^{\mathrm{D} 2}$

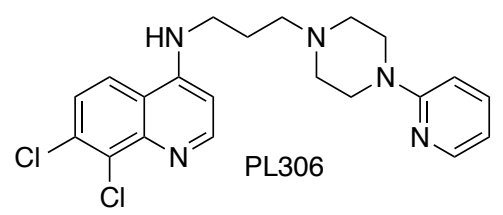

$\mathrm{IC}_{50}=217 \mathrm{nM} \mathrm{M}^{\mathrm{D}}, 990 \mathrm{nM} \mathrm{Md}^{\mathrm{D}}$

Figure 26: Example of the effect of 5,7-disubstitution compared to 7-substitution and 7,8-disubstitution

These results are in agreement with results obtained by Madrid et al. for 5-substituted chloroquine analogues with no attached reversal agent and with and without an additional substituent in position 6 or 7 (Madrid, 2005).

A 2,5-disubstituted compound (PL303) was inadvertantly made during the attempted synthesis of PL398 (Figure 24 and Table B1, Appendix B). In vitro testing of this compound revealed that its activity was extremely low, even lower than that of its 2trifluoromethyl substituted analogue (Figure 27, below and Table B1, Appendix B):
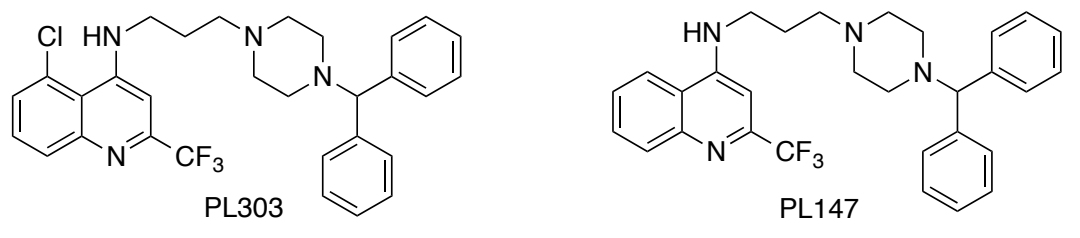

$\mathrm{IC}_{50}=690 \mathrm{nM}{ }^{\mathrm{D} 6}, 1250 \mathrm{nM} \mathrm{Dd}^{2}$

$\mathrm{IC}_{50}=402 \mathrm{nM}{ }^{\mathrm{D} 6}, 639 \mathrm{nM}{ }^{\mathrm{Dd} 2}$

Figure 27: Activity of 5-chloro-2-trifluoromethyl and 2-trifluoromethyl compounds. 
Interestingly, the 4-chloroquinoline intermediate to this compound, 4,5-dichloro-2(trifluoromethyl)quinoline, was the only 5-regioisomer more readily isolated (by recrystallization) than its 7- substituted analogue (4,7-dichloro-2(trifuoromethyl)quinoline). These two quinolines proved to be the only 4chloroquinoline intermediates synthesized in the course of this study that had not been reported and characterized previously in the literature (Figure 28):
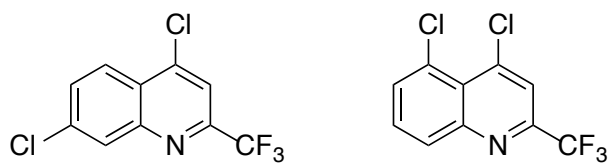

Figure 28: Two previously uncharacterized quinolines were made during the course of this work.

\subsection{2: Effect of 6- versus 7-substitution}

Compounds with a substituent in the 6- position had good activity, in some cases equal to that of their 7- substituted analogues and in others somewhat diminished (see Figure 29, below, and Table B2, Appendix B). The former is in contrast to most of the previous work for compounds without an attached reversal agent. 


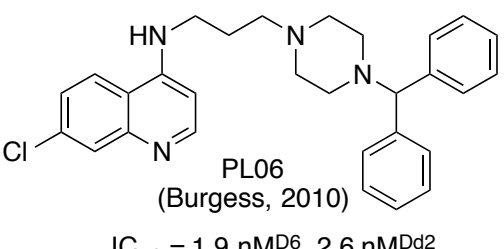

$\mathrm{IC}_{50}=1.9 \mathrm{nM}^{\mathrm{D} 6}, 2.6 \mathrm{nM} \mathrm{Dd}^{\mathrm{D}}$

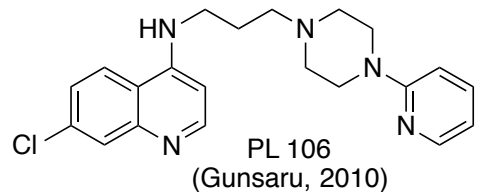

$\mathrm{IC}_{50}=2.7 \mathrm{nM}^{\mathrm{D} 6}, 1.8 \mathrm{nM} \mathrm{Dd}^{\mathrm{D} 2}$

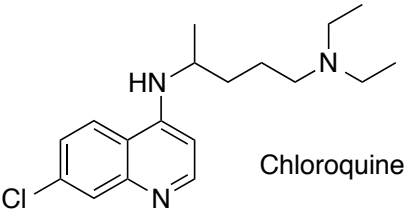

$\mathrm{IC}_{50}=6.9 \mathrm{nM}^{\mathrm{D} 6}, 102 \mathrm{nM} \mathrm{Dd}^{\mathrm{D} 2}$ (Burgess, 2010)

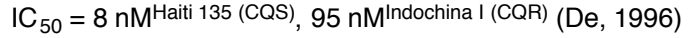

$\mathrm{IC}_{50}=13 \mathrm{nM}^{\mathrm{NF54}(\mathrm{CQS})}, 350 \mathrm{nM}^{\mathrm{K} 1(\mathrm{CQR})}$ (Vippagunta, 1999)

Figure 29: 6- versus 7-substituted chloroquine analogs with and without an attached reversal agent.

Additionally, a 6,7- dichloro substituted compound (PL307) showed no diminuition of activity relative to its 7 -substituted analogue (PL106), but had improved activity relative to its 6-substituted analogue, PL283 (Figure 30 and Table B1, Appendix B): 


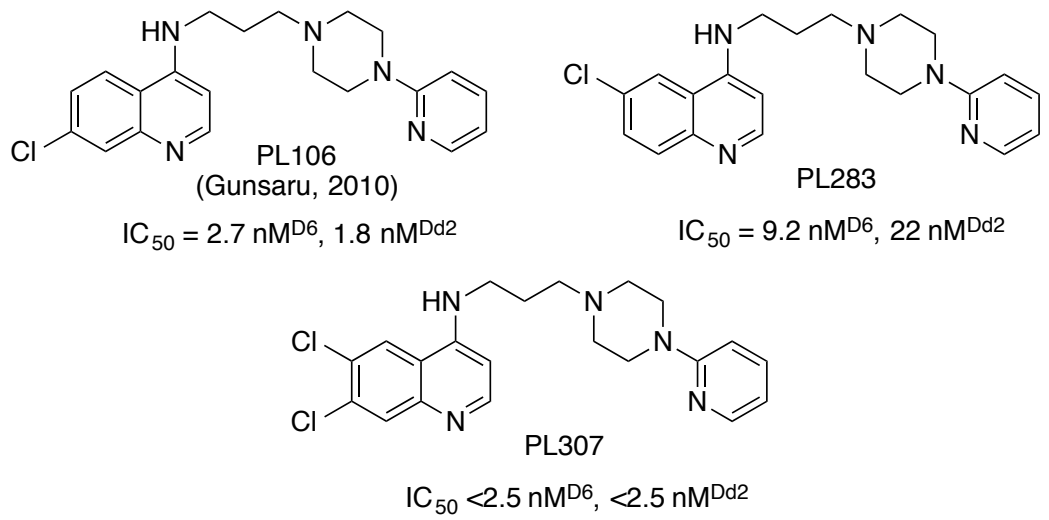

Figure 30: The effect of 6,7-disubstitution compared to 6- and 7-monosubstitution.

An interesting feature of the results is that for halogen-substituted analogues of PL106 (bearing a single pyridyl ring in their reversal agent moiety), a change in substituent position from 7 to 6 resulted in a noticeable decrease in activity in the case of chloro- and bromo-substituted compounds, but this was much less marked in the case of iodosubstituted compounds (Figure 31 and Table B2, Appendix B). This effect was observed only in the case of PL106 analogues, and not in the case of the PL06 analogues (bearing the larger diphenylmethyl group in their reversal agent moiety). The latter showed virtually no diminuition of activity when the position of the halogen was changed from 7to 6-. 

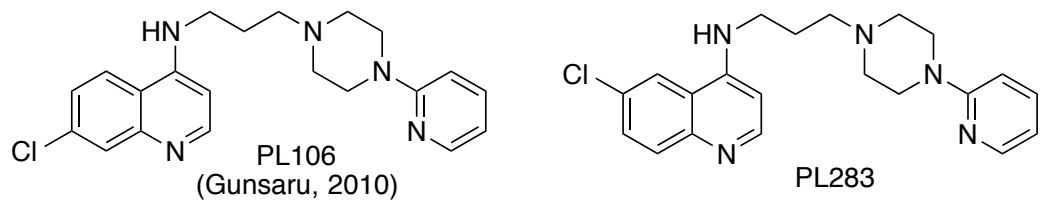

$\mathrm{IC}_{50}=2.7 \mathrm{nM}^{\mathrm{D} 6}, 1.8 \mathrm{nM}^{\mathrm{Dd} 2}$

$\mathrm{IC}_{50}=9.2 \mathrm{nM}^{\mathrm{D} 6}, 22 \mathrm{nM}{ }^{\mathrm{Dd} 2}$
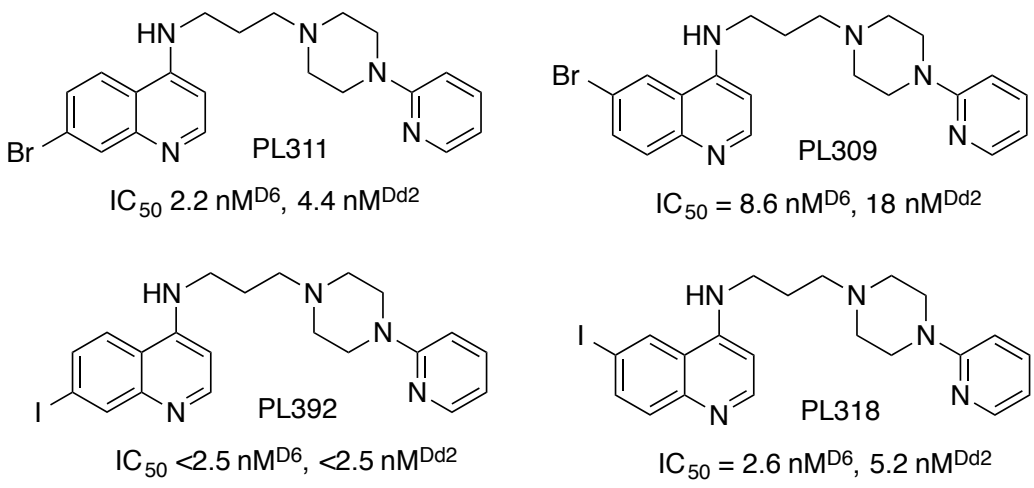

Figure 31: The effect of 6-versus 7- substitution for chloro, bromo, and iodo-substituted analogues of PL106.

\subsection{3: Effect of halogen substituents}

With regard to the halogen series (Table B3, Appendix B), substitution of bromine or iodine for chlorine in a given position (6- or 7-) did not appear to result in any significant change in in vitro activity within the limits of the assay, although some bromo- and iodo-substituted compounds had activity too high for the range in which they were tested (Figure 32 and Table B3, Appendix B): 

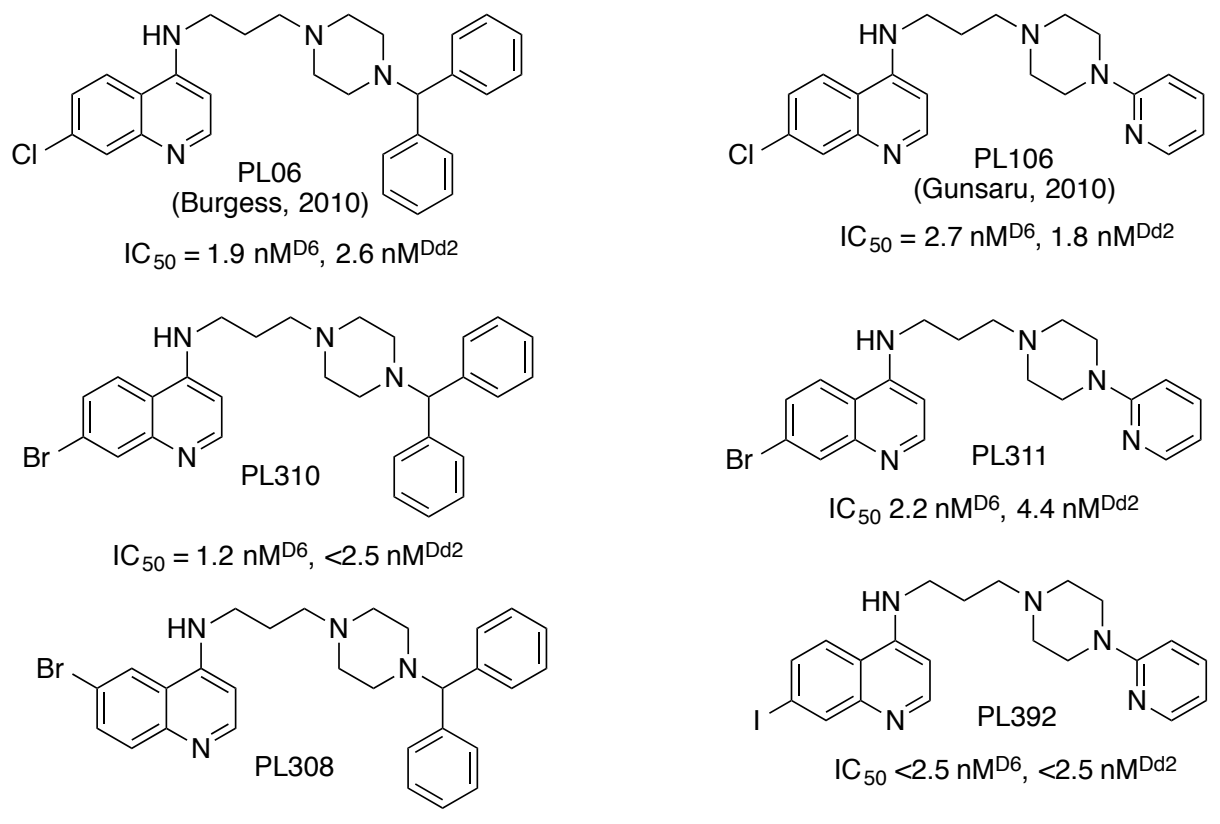

$\mathrm{IC}_{50}<2.5 \mathrm{nM}^{\mathrm{D} 6},<2.5 \mathrm{nM}^{\mathrm{Dd} 2}$

Figure 32: Representative bromo- and iodo- substituted compounds

These results are similar to those obtained from much of the previous work on compounds without an attached reversal agent (Vippagunta, 1999, Kaschula, 2002, Hocart, 2011, Nsumiwa, 2013). As mentioned previously, substitution with iodine is of particular interest because there is some evidence for resistance reversal in 7-iodo analogues of chloroquine (De, 1998).

Compounds with 6-fluoro substitution had somewhat diminished activity relative to their 6-chloro analogues (Figure 33 and Table B3, Appendix B): 


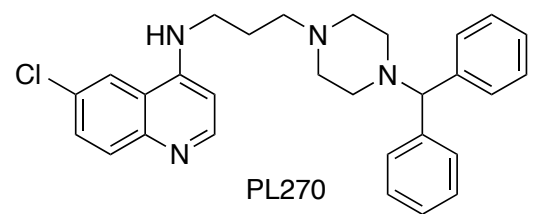

$\mathrm{IC}_{50}=3.4 \mathrm{nM}^{\mathrm{D} 6}, 7.9 \mathrm{nM} \mathrm{Dd}^{\mathrm{D}}$

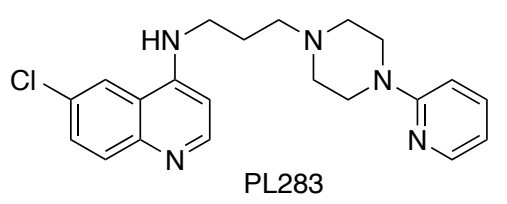

$\mathrm{IC}_{50}=9.2 \mathrm{nM}{ }^{\mathrm{D} 6}, 22 \mathrm{nM}{ }^{\mathrm{Dd} 2}$

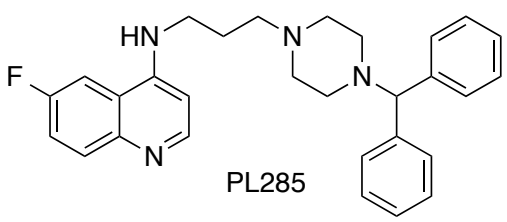

$\mathrm{IC}_{50}=10 \mathrm{nM}^{\mathrm{D} 6}, 16 \mathrm{nM}^{\mathrm{Dd} 2}$

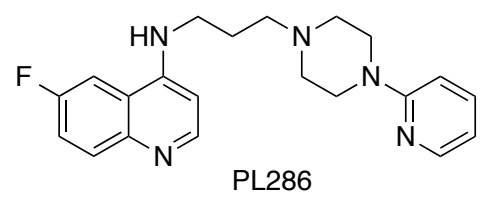

$\mathrm{IC}_{50}=13 \mathrm{nM}^{\mathrm{D} 6}, 37 \mathrm{nM} \mathrm{Md}^{\mathrm{D}}$

Figure 33: The effect of 6-chloro versus 6-fluoro substitution

The above results are in agreement with those obtained from work on chloroquine-like compounds (De, 1998, Hocart, 2011, Nsumiwa, 2013), in which the effects of 7-chloroversus 7-fluoro-substitution are compared. In this work, the synthesis of compounds with 7-fluoro substitution proved more challenging than expected, since the 7-fluoroquinolines appear to undergo nucleophilic aromatic substitution easily in the presence of amines (this has been observed previously by Snyder, Freier, Kovacic, and Van Heyningen, 1947). On the basis of the results obtained by other researchers for 7 -fluoro substituted chloroquine analogues without an attached reversal agent, and on the basis of the results obtained in this study for 6-fluoro substituted compounds, it appeared likely that the activity of a 7-fluoro-substituted compound would be lower than that observed for the 7chloro-substituted analogue. Therefore, these compounds have not been pursued further. 


\subsection{4: Effect of strongly electron-withdrawing groups in position 6 or 7: nitro and trifluoromethyl substituents}

Compounds with strongly electron-withdrawing groups in positions 6 or 7 were also made and tested (Table B4, Appendix B). Only one nitro-substituted compound was made (PL282). This compound did not have significantly diminished activity relative to its 6-chloro analog, PL283. The activity of this compound was also far higher than has been observed for short-chain 7-nitro-substituted chloroquine analogs without an attached reversal agent, but similar to that observed for 7-nitro substituted chloroquine analogs with the side chain of chloroquine (Figure 34 and Table B4, Appendix B). These compounds cannot be compared directly, since the chloroquine analogues without an attached reversal agent attached are substituted in the 7-position. On the basis of other results described herein for 6- and 7-substituted compounds of this type, it seems probable that a 7-nitro-substituted chloroquine analog with an attached reversal agent would possess slightly higher activity than the 6-nitro compound. 


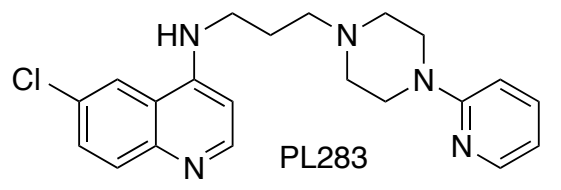

$\mathrm{IC}_{50}=9.2 \mathrm{nM}{ }^{\mathrm{D} 6}, 22 \mathrm{nM} \mathrm{Dd}^{\mathrm{d}}$

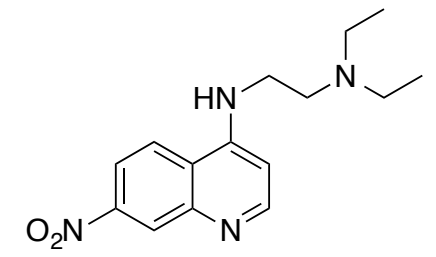

$\mathrm{IC}_{50}=325$ nMNF54 (CQS) (Kaschula, 2002)

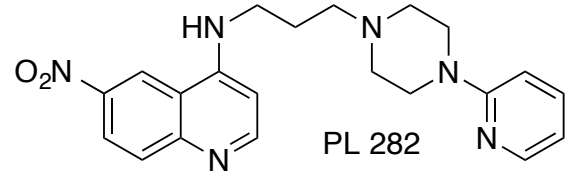

$\mathrm{IC}_{50}=10.7 \mathrm{nM} \mathrm{M}^{\mathrm{D}}, 15 \mathrm{nM} \mathrm{Md}^{\mathrm{D}}$

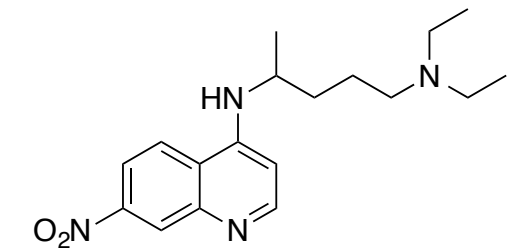

$\mathrm{IC}_{50}=15 \mathrm{nM}^{\mathrm{NF54}(\mathrm{CQS})}, 68 \mathrm{nM}^{\mathrm{K} 1(\mathrm{CQR})}$ (Vippagunta, 1999)

Figure 34: The effect of nitro substitution on chloroquine analogues with and without an attached reversal agent.

Of the trifluoromethyl-substituted compounds, in most cases the activity was not significantly different from that of the chloro-substituted analogues (although in a few cases the activity was somewhat lower). This is in contrast to many of the findings for chloroquine analogues without an attached reversal agent (De, 1996, Kaschula, 2002), but in agreement with others (Stocks, 2002) (Figure 35, below and Table B4, Appendix B). 


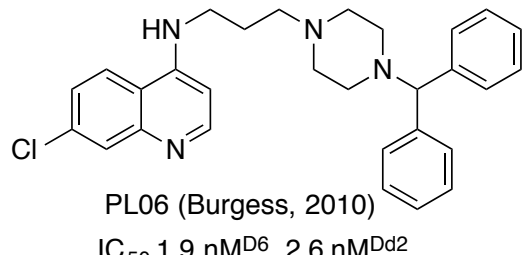

$\mathrm{IC}_{50} 1.9 \mathrm{nM} \mathrm{n}^{\mathrm{D}}, 2.6 \mathrm{nM} \mathrm{nd}^{\mathrm{D} 2}$<smiles>Clc1ccc2c(NCCCN3CCN(c4ccccn4)CC3)ccnc2c1</smiles>

$$
\mathrm{IC}_{50}=3.0 \mathrm{nM} \mathrm{D}^{\mathrm{D}}, 6.0 \mathrm{nM} \mathrm{nd}^{\mathrm{D} 2}
$$<smiles>CCN(CC)CCCC(C)Nc1ccnc2cc(Cl)ccc12</smiles>

$\mathrm{IC}_{50}=6.9 \mathrm{nM}{ }^{\mathrm{D} 6}, 102 \mathrm{nM} \mathrm{Dd}^{\mathrm{D} 2}$ (Burgess, 2010)

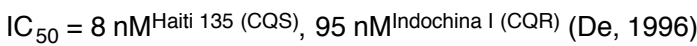<smiles>CCN(CC)CCNc1ccnc2cc(Cl)ccc12</smiles>

$\mathrm{IC}_{50}=37 \mathrm{nM}^{\mathrm{NF54}}$ (CQS) $($ Kaschula, 2002)<smiles>CC(C)(C)NCCNc1ccnc2cc(Cl)ccc12</smiles>

$\mathrm{IC}_{50}=4.3 \mathrm{nM}^{\mathrm{HB} 3}$ (CQS), $15.3 \mathrm{nM}^{\mathrm{K} 1 \text { (CQR) }}$ (Stocks, 2002)<smiles>FC(F)(F)c1ccc2c(NCCCN3CCN(C(c4ccccc4)c4ccccc4)CC3)ccnc2c1</smiles>

$\mathrm{IC}_{50} 1.5 \mathrm{nM}^{\mathrm{D} 6}, 3.9 \mathrm{nM} \mathrm{Dd}^{\mathrm{Dd}}$<smiles>FC(F)(F)c1ccc2c(NCCCN3CCN(c4ccccn4)CC3)ccnc2c1</smiles>$$
50=2.5 \mathrm{nM}^{\mathrm{D} 6}, 11 \mathrm{nM}^{\mathrm{Dd} 2}
$$

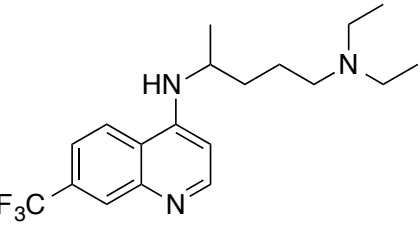

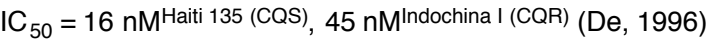<smiles>CCN(CC)CCNc1ccnc2cc(C(F)(F)F)ccc12</smiles>

$\mathrm{IC}_{50}=99 \mathrm{nM}^{\mathrm{NF} 54}$ (CQS) $($ Kaschula, 2002)<smiles>CC(C)(C)NCCNc1ccnc2cc(C(F)(F)F)ccc12</smiles>

$\mathrm{IC}_{50}=5.5 \mathrm{nM}^{\mathrm{HB} 3}$ (CQS), $9.8 \mathrm{nM}^{\mathrm{K} 1(\mathrm{CQR})}$ (Stocks, 2002)

Figure 35: The effect of trifluoromethyl substitution on chloroquine analogs with and without an attached reversal agent. 


\subsection{5: Unsubstituted compounds and those with an electron-donating group in position 6 or 7}

As mentioned in the introduction, a des-chloro analogue of PL06 (PL64) had been made previously by Steven Burgess and was the catalyst for this study. During the course of this study, a des-chloro analog of another compound made by Steven Burgess, PL69, was also made (PL375). This proved to have unexpectedly low in vitro activity against $P$. falciparum compared to that observed for PL64, particularly against the chloroquine resistant strains, Dd2 and 7G8 (Figure 36, below and Table B5, Appendix B). HPLC revealed that this compound may have been less pure than had been believed when this compound was tested in vitro, but this alone seems insufficient to account for the difference in activity observed, particularly against the chloroquine resistant strains. However, this compound would need to be re-synthesized, further purified, and re-tested before any firm conclusions could be made.
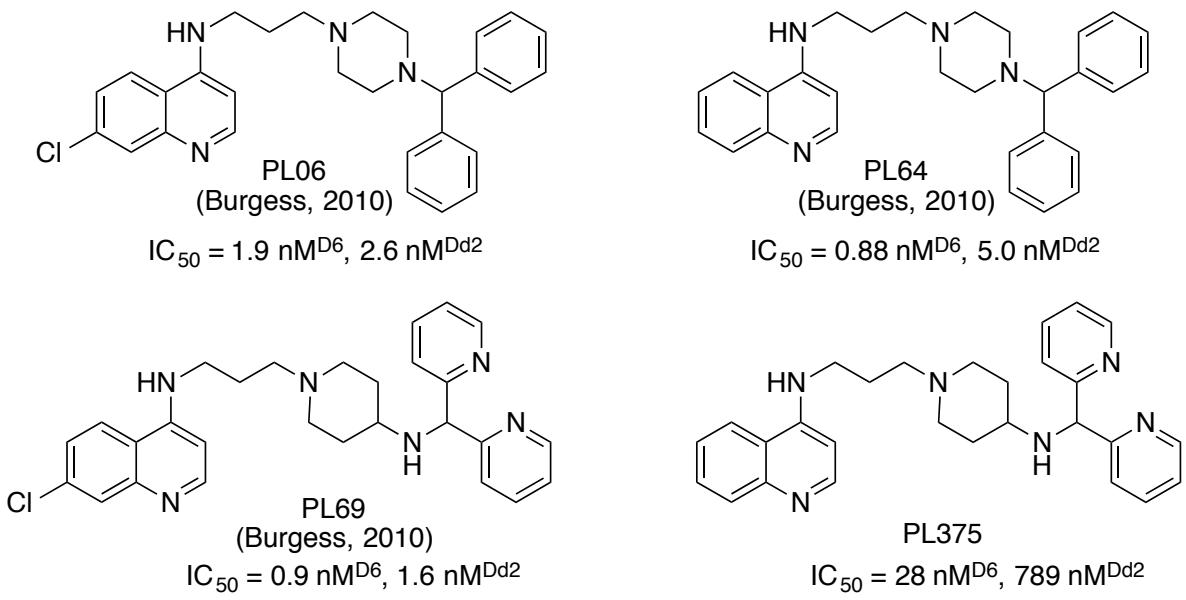

Figure 36: Des-chloro analogues of PL06 and PL69. 
A 6-methyl substituted compound (PL383) proved to have similar activity to that of the 6-chloro analog, PL270, and to that of the des-chloro analog, PL64 (Figure 37, below; see also Figure 31, above and Table B5, Appendix B). This is in contrast to reported activity for chloroquine analogues with a 7-methyl group and without an attached reversal agent.

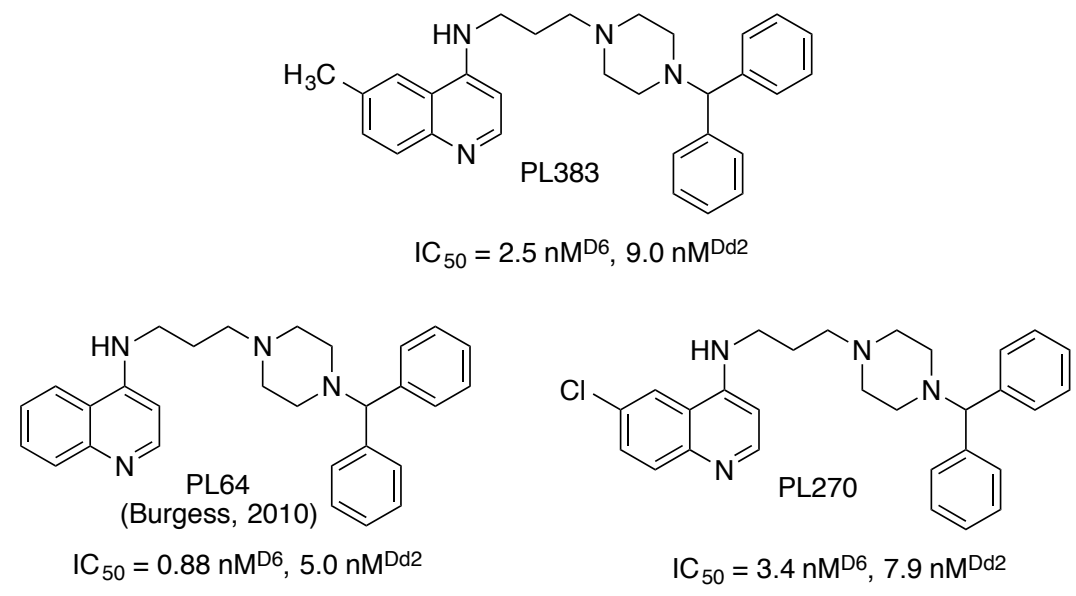

Figure 37: A 6-methyl substituted compound compared to 7-chloro and 7-hydro analogues.

A compound with an electron-donating 7-methoxy substituent (PL391) had diminished activity relative to that of its 7-choro analog (PL106). However, the decrease in activity was not so great as has been reported in the literature for chloroquine analogues without an attached reversal agent (Figure 38): 


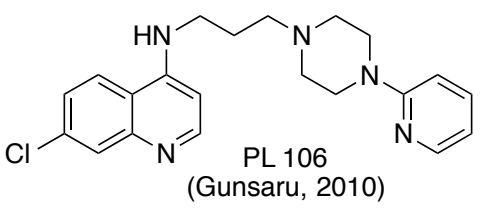

$\mathrm{IC}_{50}=2.7 \mathrm{nM}^{\mathrm{D} 6}, 1.8 \mathrm{nM} \mathrm{Md}^{\mathrm{D} 2}$

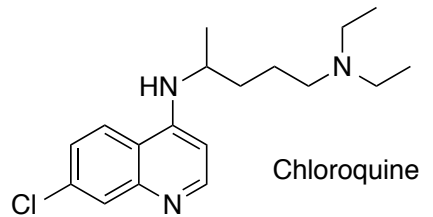

$\mathrm{IC}_{50}=8 \mathrm{nM}^{\text {Haiti } 135 \text { (CQS) }} 95 \mathrm{nM}$ Indochina I (CQR) $(\mathrm{De}, 1996)$

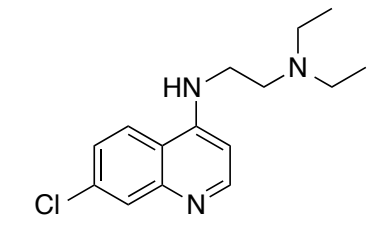

$\mathrm{IC}_{50}=37$ nMNF54 (CQS) (Kaschula, 2002)

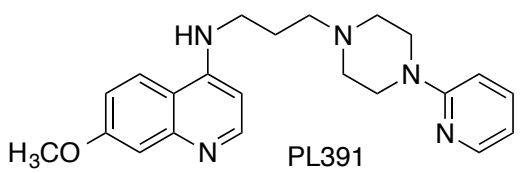

$\mathrm{IC}_{50}=21 \mathrm{nM}{ }^{\mathrm{D} 6}, 53 \mathrm{nM} \mathrm{Dd}^{\mathrm{D}}$

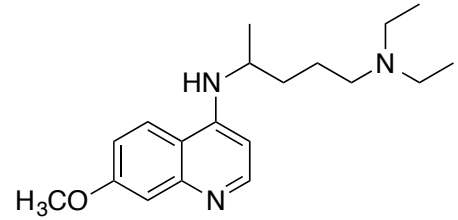

$\mathrm{IC}_{50}=55 \mathrm{nM}^{\text {Haiti } 135 \text { (CQS) }} 3000 \mathrm{nM}^{\text {Indochina I (CQR) }}$ (De, 1996)

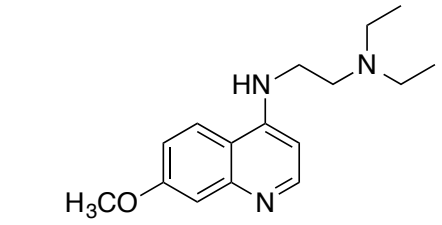

$\mathrm{IC}_{50}=448 \mathrm{nM}^{\mathrm{NF} 54}$ (CQS) (Kaschula, 2002)

Figure 38: The effect of 7-methoxy substitution on chloroquine analogs with and without an attached reversal agent.

\section{2: Significance of the findings}

The above results show that the antiplasmodial activity of reversed chloroquinetype compounds is significantly affected by the substitution pattern of the quinoline ring system. These effects upon activity are directionally similar to those observed for chloroquine analogs without an attached reversal agent, but are generally smaller, except in the case of 2- and 8- substituted compounds. In an attempt to understand why the substitution pattern of the quinoline ring system should affect the antiplasmodial activity of chloroquine analogues, and to understand why the effect on reversed chloroquine-type compounds should differ from the effect on chloroquine analogues without an attached 
reversal agent, several possibilities should be considered. Firstly, the quinoline ring system substitution may affect accumulation of the drug at its site of action, and this effect may be smaller for compounds with an attached reversal agent. Secondly, the quinoline ring system substitution may affect the activity of the drug, and this effect may be smaller for compounds with an attached reversal agent. Thirdly, in the case of chloroquine resistant parasites, the substitution pattern of the quinoline ring system may have an impact on drug efflux from the digestive vacuole. Each of these possibilities will be discussed in turn.

\subsubsection{Effect of the quinoline ring system substitution on accumulation of chloroquine-like drugs in the digestive vacuole by $\mathrm{pH}$ trapping}

As mentioned previously, the concentration of chloroquine at its site of action, the parasite's digestive vacuole, has been estimated to be one thousand to several thousand times greater than the concentration in uninfected erythrocytes, based on uptake experiments (Kelly, 2002; Sullivan, 2002). This extraordinary degree of accumulation has been postulated to occur primarily for two reasons: firstly, because the lower $\mathrm{pH}$ of the digestive vacuole compared to that of the cytosol favors the accumulation of the weakly basic chloroquine within the digestive vacuole, and secondly, because chloroquine binds to heme dimers that are present within the vacuole (Yayon, 1985; Schlesinger, 1988; Bray, 1998; Bray, 1999; Kaschula, 2002). Additionally, although chloroquine's entry into the vacuole is generally thought to occur primarily by passive diffusion of the uncharged drug across the membrane, membrane traversal by charged 
drug is not inconceivable (Kaschula, 2002). It is further possible that there may be active transport of some kind, which would constitute a third mechanism of accumulation. However, if such a mechanism exists, it has not been identified with certainty (Kirk, 2013).

Chloroquine is considered to have two protonatable nitrogens. One is in the quinoline ring system itself $(\mathrm{pKa}=8.1)$, and the other is the tertiary nitrogen of the side chain $(\mathrm{pKa}=10.2$; Figure 39; Martin, 2009):

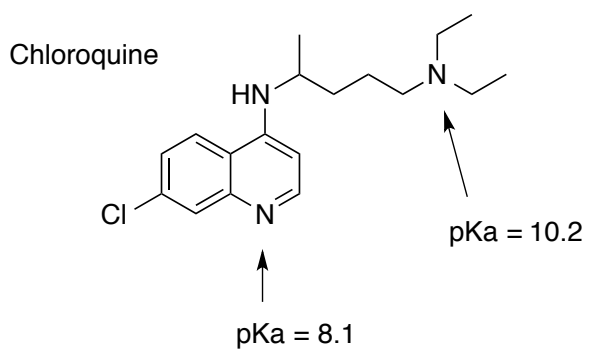

Figure 39: pKas of chloroquine

The nitrogen in position 4 of the quinoline ring system is thought to be less basic for reasons that will be explored during the discussion of bis-quinolines. Neutral chloroquine is able to diffuse freely through the vacuolar membrane, but it is generally assumed that little diffusion of diprotonated chloroquine through the membrane occurs (Kaschula, 2002; Warhurst, 2007; Kirk, 2013). The relatively lower pH of the digestive vacuole as compared to the cytosol therefore favors the accumulation of diprotonated chloroquine within the vacuole (a mechanism referred to as $\mathrm{pH}$ trapping). Prediction of the extent of accumulation by $\mathrm{pH}$ trapping depends upon the $\mathrm{pKa}$ values that are used for chloroquine's protonatable nitrogens, and upon the difference between the values used for the vacuolar and cytosolic $\mathrm{pH}$. The precise values used vary within the literature. 
The $\mathrm{pH}$ outside of the vacuole is often given as approximately 7.4, whereas the interior of the vacuole has been estimated to be between pH 4.5 and 5.9 (Martin, 2009; Kirk, 2013). Based on a vacuolar $\mathrm{pH}$ of $\sim 5$ and a cytosolic $\mathrm{pH}$ of 7.4 , Martin et al. calculate that approximately $83 \%$ of the drug outside the vacuole should be present in the diprotonated form, with approximately $17 \%$ monoprotonated, in contrast to approximately $100 \%$ diprotonoated inside of the vacuole (Martin, 2009). On the basis of these values, the drug would be predicted to accumulate within the digestive vacuole to a small extent by the mechanism of $\mathrm{pH}$ trapping; however, $\mathrm{pH}$ trapping alone is insufficient to account for chloroquine's remarkable accumulation in the digestive vacuole (Krogstad, 1987; Sullivan, 2002; Martin, 2009).

The primary cause of chloroquine's accumulation is thought to be binding to heme dimers (Krogstad, 1987; Bray, 1998; Bray, 1999). This mechanism of accumulation is intimately associated with the drug's mode of action, which is thought to begin with reversible binding to heme (Dorn, 1998).

The quinoline ring system substitution pattern is postulated to have an impact on drug accumulation both through $\mathrm{pH}$ trapping and through binding to heme (the effect on heme binding will be discussed together with antiplasmodial activity, below; Egan, 2000; Kaschula, 2002). As stated above, accumulation of chloroquine by $\mathrm{pH}$ trapping would be significantly affected by the pKas of chloroquine's protonatable nitrogens. It has been shown that the substitution pattern of the quinoline ring system strongly affects the $\mathrm{pKa}$ of the ring nitrogen (pKa1), as well as the nitrogen of the alkylamino side chain (pKa 2; Kaschula, 2002). Values of pKa1 and pKa2 for variously substituted chloroquine-like 
compounds have been determined experimentally by Kaschula et al. (2002), and vary by as much as two $\mathrm{pKa}$ units from molecule to molecule, depending on the ring substituent. It is interesting that the quinoline ring substituent should have an effect not only upon the pKa of the quinoline ring nitrogen, but upon the side chain nitrogen as well. The effect on the side chain nitrogen evidently occurs through space rather than through bonds. Kaschula et al. (2002) have speculated that for shorter-chain chloroquine analogues, this effect would be more pronounced than for chloroquine analogues with longer and bulkier chains. Longer side chains may spend more time away from the quinoline ring system and may even be sterically prevented from approaching the ring system or its substituent. It has been pointed out by Kaschula et al. (2002) that this may account for the observation that the antiplasmodial activity of 4-aminoquinolines with a shorter alkyl chain is more vulnerable to modification of the quinoline ring system than that of 4aminoquinolines with a longer chain (Coatney, 1953, Kaschula, 2002, Nsumiwa, 2013). By extension, this may be the explanation for the observation in this work that for chloroquine analogs with an attached reversal agent, many modifications of the quinoline ring system substitution pattern have relatively little impact on activity as compared to that observed for chloroquine analogues without an attached reversal agent. The long and bulky reversal agent side chain may hold the protonatable nitrogen of the side chain far enough away from the quinoline ring system to negate an effect of the latter upon side chain nitrogen $\mathrm{pKa}$. However, because the impact of $\mathrm{pH}$ trapping on accumulation is believed to be relatively small, the importance of quinoline ring system substitution to antiplasmodial activity cannot be explained by $\mathrm{pH}$ trapping alone. Moreover, it is 
probable that the differences in $\mathrm{pKa}$ between compounds with certain substitution patterns in the present study are less than would be predicted on the basis of their activity, if differences in accumulation due to $\mathrm{pH}$ trapping were the only cause of the variations in activity observed. For the compounds under study, however, pKa values have not been determined.

\subsubsection{Effect of quinoline ring system substitution on heme binding and $\beta$-hematin inhibition}

For chloroquine and chloroquine-like drugs, the binding site of the heme dimer is believed to be the quinoline ring system itself (Egan, 2000). The structure of the bound drug-heme complex in vivo is not known, but it is often envisioned as a $\pi-\pi$ stacking interaction between the aromatic ring systems of the porphyrin and the quinoline (Leed, 2002; Stocks, 2002; Crespo, 2010). The side chain is thought to have little involvement in this binding, for reasons that will be discussed later. Binding of the drug to heme is thought to be an important step in inhibition of the formation of hemozoin and hence, the antimalarial activity of quinoline drugs (Dorn, 1998). In vitro models have been extensively studied both for heme binding (either as the heme monomer or as the heme dimer) and for inhibition of the formation of hemozoin (as inhibition of the formation of $\beta$-hematin, the chemically identical in vitro analogue of the biomineral hemozoin; Fitch, 1987; Slater, 1991; Dorn, 1998; Egan, 2000). In the course of these studies it has been found that heme binding strength does not always correlate to $\beta$-hematin inhibition compounds capable of inhibiting the formation of $\beta$-hematin exhibit strong heme binding 
ability, but heme binding ability alone does not predict whether a compound will inhibit the formation of $\beta$-hematin (Egan, 2000; Kaschula, 2002). Quinoline compounds with a wide variety of substitution patterns have been shown to bind to heme in aqueous solution (Vippagunta, 1999; Egan, 2000; Kaschula, 2002), but there is a much greater variation in ability to inhibit the formation of $\beta$-hematin (Egan, 2000; Kaschula, 2002). Thus, it has been proposed by Egan (2000) that while the quinoline ring system itself is responsible for binding to heme, the inhibition of formation of hemozoin is modulated by the substitution pattern of the ring system. If the quinoline ring system always binds to the heme dimer in a similar position, regardless of its substituents, this effect could be due to the ability of the substituent to block the site at which the association between dimers occurs, preventing hemozoin from forming. The large effects on antiplasmodial activity observed upon variation of the nature of the quinoline ring substituent (electronegativity, lipophilicity, steric bulk) or variation of its position on the quinoline ring would make sense if such a substituent-specific blocking were occurring. Another explanation might be that the positioning of the quinoline ring system with respect to heme is changed by altering the position and nature of the substituent. Perhaps the 7choro substituent is correctly placed and has the right stereoelectronic character to stop the biomineralization from occurring (Vippagunta, 1999; Kaschula, 2002).

\subsubsection{Effect of the side chain on activity: beyond pH trapping?}

It would at first seem likely that the side chain would also exert an effect on heme 
binding and inhibition of hemozoin formation. In the case of chloroquine it has been suggested previously that the side chain is involved in binding to the heme dimer by association of the protonated side chain nitrogen of chloroquine with the propionate moieties of heme (O’Neill, 1997). In the case of quinoline methanols (quinine and mefloquine), which are thought to work similarly to 4-aminoquinolines (at least in part), portions of the side chain are thought to be important for heme binding (Alumasa, 2011). Additionally, it has been observed that chloroquine associates more strongly with heme in vitro as compared to chloroquine analogs with the same quinoline ring substitution pattern, but a shorter side chain (Egan, 2000). In the context of the observation that the antiplasmodial activity of chloroquine-like compounds with longer side chains is less vulnerable to modification of the quinoline ring system substitution pattern, and in the context of the present work in which it is shown that chloroquine analogues with an attached reversal agent are even less vulnerable to side chain modification, it is worth considering that a longer side chain may have a relatively larger impact on heme binding and perhaps on inhibition of hemozoin formation. Conceivably, the larger side chain might alter the binding geometry of the quinoline ring system to heme, affecting inhibition of hemozoin formation, or the chain itself might block the site of hemozoin formation. However, because of the extreme variations in side chain structure that are possible without affecting antiplasmodial activity, it is thought that the side chain is not directly involved in these compounds' mechanism of action. This is true both for the alkylamine side chain of chloroquine analogues and for the reversal agent moeity of chloroquine analogues with an attached reversal agent. In the course of work performed 
by others in our group (Burgess, 2008; Andrews, 2010; Burgess, 2010; Gunsaru, 2010) it has been observed that the reversal agent moiety of reversed chloroquine-type compounds can be widely varied without affecting in vitro antiplasmodial activity (Figure 40):
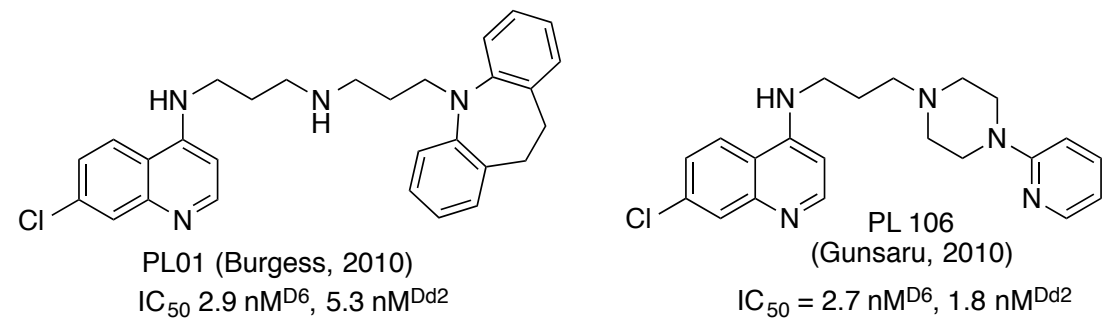<smiles>Clc1ccc2c(NCCCN3CCC(NC(c4ccccn4)c4ccccn4)CC3)ccnc2c1</smiles>

PL 69 (Burgess, 2010) $\mathrm{IC}_{50}=0.9 \mathrm{nM} \mathrm{M}^{\mathrm{D}}, 1.6 \mathrm{nM} \mathrm{Dd} 2$<smiles>Clc1ccc2c(NCCCN3CCN(CC4CCCCC4)CC3)ccnc2c1</smiles><smiles>Clc1ccc2c(NCCN(CCN(Cc3ccccc3)Cc3ccccc3)Cc3ccccc3)ccnc2c1</smiles><smiles>Clc1ccc2c(NCCCN3CCN(C4C5CC6CC(C5)CC4C6)CC3)ccnc2c1</smiles>

PL37 (Andrews, 2010)

$\mathrm{IC}_{50}=2.4 \mathrm{nM}^{\mathrm{D} 6}, 5.1 \mathrm{nM} \mathrm{Md}^{\mathrm{D} 2}$

Figure 40: Variability of the reversal agent moeity of reversed chloroquine-type compounds

A structurally-related molecule with similarly high in vitro potency against chloroquine resistant Plasmodium falciparum was published by Ryckebush and coworkers in 2003 (Figure 41): 


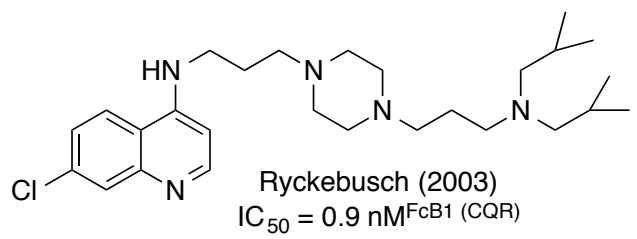

Figure 41: A chloroquine analogue closely related to the above reversed chloroquine-type compounds, also with high activity against chloroquine resistant parasites.

On the other hand, the above reversed chloroquine-type compounds all bear a lipophilic group on their alkylamino side chain, whether aromatic or saturated. As there is substantial evidence that hemozoin formation occurs at the interface of lipid droplets within the digestive vacuole (Jackson, 2004; Oliveira, 2005 (for other protozoal diseases); Pisciotta, 2007; Egan, 2007), it is possible that in addition to any reversal agent activity that these groups may have, they also favor the presence of the reversed chloroquine compound at the lipid droplet interface. Conceivably, the protonated side chain might stand outside of the lipid droplet, while the lipophilic group might stand inside. Alternatively, deprotonated molecules might accumulate inside of the lipid droplet, constituting an additional mechanism of accumulation (this may be true for chloroquine analogues without an attached reversal agent as well; Warhurst, 2007). In any case, whether or not the side chain is involved in the mechanism of action of aminoquinolines, it is an important modulator of resistance, as will be discussed below (section 2.2.5). 


\subsection{4: The relationship between accumulation and inhibition of hemozoin formation}

It has been observed repeatedly in the literature that the ability of a 4aminoquinoline compound to inhibit the formation of $\beta$-hematin formation in vitro does not unequivocally predict in vitro antiplasmodial activity (Vippagunta, 1999; Egan, 2000; Kaschula, 2002). Chloroquine analogues with high in vitro antiplasmodial activity have a high ability to inhibit the formation of $\beta$-hematin, but not all compounds that inhibit the formation of $\beta$-hematin have high in vitro antiplasmodial activity. This lack of correlation has been explained by invoking the variation in accumulation by $\mathrm{pH}$ trapping of the various compounds involved. In a study by Kaschula et al. (2002), $\beta$-hematin inhibitory activity, and in vitro antiplasmodial activity were determined for a series of variously substituted short-chain chloroquine analogs. Among others, the series of compounds in that study included those in which the quinoline ring system was substituted in the 7-position with a halogen, with a nitro group, with hydrogen, and with a methoxy group. It was observed that compounds with a halogen substituent (chlorine, bromine, or iodine) had good $\beta$-hematin inhibitory activity and good in vivo activity. Compounds bearing a strong electron-withdrawing group (nitro or trifluoromethyl) had excellent $\beta$-hematin inhibitory activity, but poor in vitro antiplasmodial activity. Compounds with an electron-donating methoxy group, as well as those without an attached substituent, had much lower $\beta$-hematin inhibitory activity, and their in vitro antiplasmodial activity was low as well. However, their antiplasmodial activity was not as low as might be predicted from their $\beta$-hematin inhibitory activity alone, if $\beta$-hematin 
inhibition and antiplasmodial activity were directly correlated. Side chain and quinoline ring nitrogen $\mathrm{pKa}$ for the study compounds were determined experimentally, and were used to estimate accumulation due to $\mathrm{pH}$ trapping relative to that of chloroquine (as described above in the discussion of $\mathrm{pH}$ trapping, section 4.3.1). Upon adjusting the in vitro $\beta$-hematin inhibitory activity of the study compounds for accumulation, a good correlation was obtained between accumulation-corrected $\beta$-hematin inhibitory activity and in vitro antiplasmodial activity. It therefore appeared to the authors of that study that the halogen-substituted compounds presented the best compromise between accumulation and $\beta$-hematin inhibitory properties, leading to their superior activity relative to compounds with other substituents. As mentioned above (section 4.3.1), accumulation of chloroquine at its site of action may occur largely due to heme binding, with accumulation due to $\mathrm{pH}$ trapping playing a relatively minor role. Yet in contrast to $\beta$ hematin inhibitory activity, heme binding ability (as determined in vitro) varies comparatively little amongst variously substituted chloroquine analogues. If the conclusions of Kaschula and coworkers are correct, and the differences in in vitro antiplasmodial activity are partly explained by differences in accumulation due to $\mathrm{pH}$ trapping, then it is interesting that the latter should play such a comparatively important role, though constituting a relatively small proportion of total accumulation (Kaschula, 2002). Another explanation might be that accumulation is related not only to heme binding but to hemozoin inhibition as well, such that for some reason compounds that inhibit hemozoin formation accumulate more strongly; however, if so, this has not been elucidated. 
The compounds in the study described above were substituted only in the 7position of the 4-aminoquinoline ring system, so it was not clear from that study whether the results would be the same for other substitution patterns. Additionally, as observed by Kaschula and coworkers, the impact of the quinoline ring system substitution upon the pKa of the 4-aminoquinoline side chain nitrogen may partially depend on side chain length, and this may help explain why the antiplasmodial activity of compounds with a longer side chain is relatively less impacted by quinoline ring system substitution than shorter chain compounds. It is therefore of interest that in many cases, compounds substituted in the 2- and 8- position seem to have the same strong, negative effect on activity regardless of side chain length and type, including the reversed chloroquine-type antiplasmodials in the present study. If the deleterious effect of this substitution pattern on activity were due to a change in the pKa of the side chain nitrogen, leading to reduced accumulation by $\mathrm{pH}$ trapping, then it would be anticipated that 2- and 8- substituted compounds with a longer side chain would be more active relative to those with a shorter side chain. If one assumes that the conclusions made by Kaschula and coworkers are correct, a possible explanation might be that 2-and 8- substituted compounds are so poor at inhibiting the formation of hemozoin that accumulation is irrelevant. If this is true, it would be interesting to learn whether the effect of the 2 - or 8 -substituent is primarily a steric or an electronic one. Based on the results in the present work, it appears that in position 8 the effect is at least partially a steric one, as the 8-methoxy and one of the 8methyl substituted compounds performed as poorly as 8-trifluoromethyl substituted compounds; however, an 8-methyl-substituted compound with a larger reversal agent 
moiety did not perform as poorly (see Figure 23). Comparing the two compounds in the present study with a 2-methyl versus a 2-trifluoromethyl group (Figure 24), it was seen that the 7-chloro-2-methyl substituted compound synthesized in the present study had weak but improved activity relative to its 2-trifluoromethyl analogue. However, this does not necessarily mean that the effect of the substituent in position 2 is an electronic one, since the trifluoromethyl group is also more sterically demanding than the methyl group (Bégué, 2008). Synthesis and testing of a compound with a smaller electron-withdrawing group or a larger electron-donating group in position 2 might help to decide this question.

It seems probable that neither an effect on accumulation nor an effect on the ability to inhibit the formation of hemozoin can be the sole reason for the importance of the quinoline ring system substitution pattern. Rather, it appears that both accumulation and hemozoin inhibitory activity are likely to be involved.

\subsubsection{Modulation of resistance}

In the literature it has often been observed that modification of the chloroquine side chain has a powerful effect on the resistance profile of chloroquine analogues (De, 1996; Stocks, 2002). Changes in chain length and bulk generally confer improved activity against chloroquine resistant parasites relative to activity against chloroquine sensitive parasites (referred to as resistance index). ${ }^{5}$ The chloroquine resistance

\footnotetext{
${ }^{5}$ Effect on resistant parasites, or cross resistance, is often discussed in terms of the resistance index, the ratio of activity against chloroquine resistant (CQR) and chloroquine sensitive (CQS)
} 
transporter or transporters seem to have evolved in such a way that they are able to specifically recognize the side chain of chloroquine. This has been exploited in the development of AQ-13 (De, 1996), F2Bu (Stocks, 2002), and ferroquine (Brocard, 1995; Dive, 2008), amongst others (Figure 42):
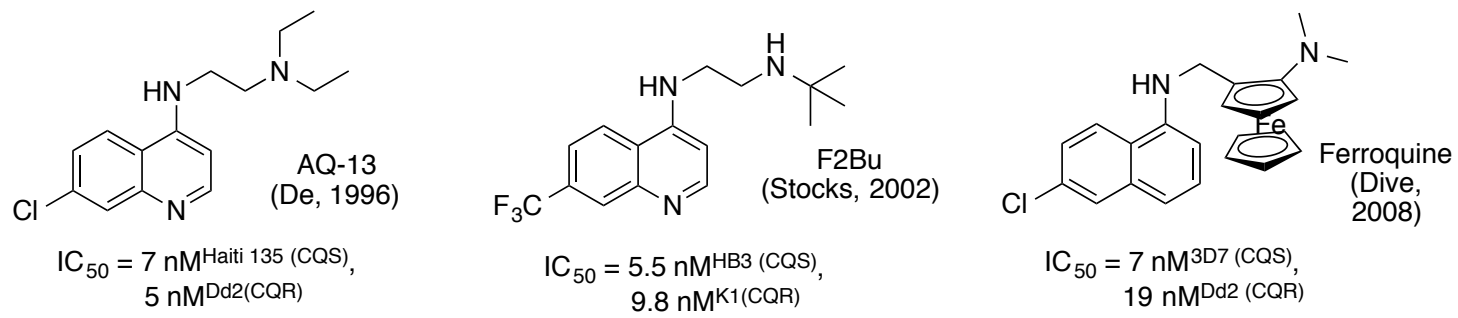

Figure 42: Altering side chain length of chloroquine analogues restores activity against chloroquine resistant parasites.

In contrast, it has generally been observed in the literature that modifications of the quinoline ring system itself have a negative impact on activity without enhancing the resistance index. As stated above in the review of previous work, exceptions to this are known. For the substitution pattern of sontoquine (Vippagunta, 1999; Pou, 2012), and for compounds with a larger quinoline ring substituent such as an iodo, phenoxy, or trifluoromethoxyphenyl group (De, 1998; Madrid, 2005; Pou, 2012), an improved resistance index has been observed. Additionally, for some smaller substituents (nitro, cyano) some improvement in the resistance index has been observed also (Nsumiwa, 2013). Therefore it appears that the assumption that the quinoline ring system has no impact on resistance is not entirely correct - the chloroquine resistance transporter may have some ability to recognize the 7-chloroquinoline moiety of chloroquine as well as its

strains. Thus, a drug with lower overall activity than chloroquine may still show an improved resistance profile in terms of its ratio of activity against CQS and CQR parasites. 
side chain. For the bulkier ring substituents at least, it is also possible that the compound simply does not fit the transporter - perhaps the compound is pushed into a less favorable conformation for binding (Pou, 2012).

For the compounds in the present study, it was not possible to observe the impact of the quinoline ring system substitution pattern on the resistance index, since a resistance-reversing side-chain was already in place. Enhancement of activity against resistant parasites relative to sensitive parasites was not observed upon modification of the quinoline ring system. However, it occasionally appeared that modification of the quinoline ring system decreased activity against chloroquine resistant parasites relative to activity against chloroquine sensitive parasites (Figure 43): 


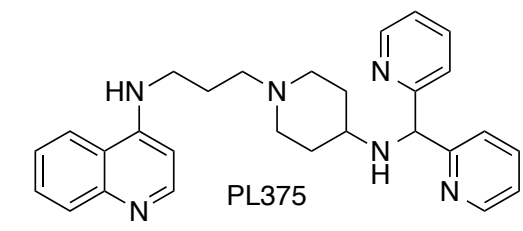

$\mathrm{IC}_{50}=28 \mathrm{nM}{ }^{\mathrm{D} 6}, 789 \mathrm{nM}^{\mathrm{Dd} 2}$<smiles>FC(F)(F)c1ccc2nccc(NCCCN3CCC(NC(c4ccccn4)c4ccccn4)CC3)c2c1</smiles>

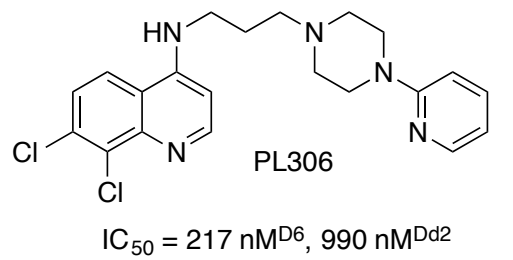

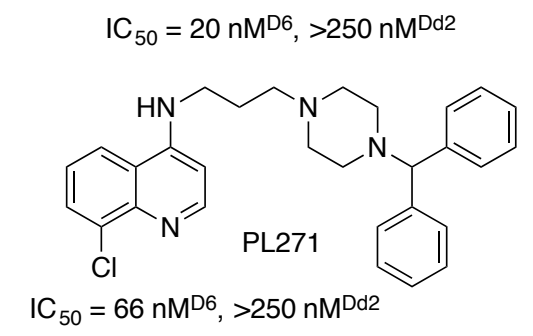<smiles>COc1cccc2c(NCCCN3CCN(c4ccccn4)CC3)ccnc12</smiles>

Figure 43: Apparent cross-resistance with chloroquine was observed for some ring-modified reversed chloroquine-type compounds

Significantly lower activity against chloroquine resistant parasites than against chloroquine sensitive parasites was most commonly observed in the case of 8 -substituted compounds. The causes of this phenomenon are unclear at the present time. It is possible that this modification to the quinoline ring system somehow negates the effect of the reversal agent in preventing efflux (although this seems far fetched), or perhaps it is related to non-resistance-related mutations in the resistant parasites which somehow affect the hemozoin inhibition properties of these particular compounds. It might be 
informative to determine whether this apparent cross-resistance is reversed by a reversal agent, such as verapamil.

Nevertheless, it appears that in many cases the 7-chloro substituent of reversed chloroquine-type compounds can be altered without adversely affecting either activity or resistance profile. If reversed chloroquine-type compounds were to be used as drugs, it is possible that modification of the quinoline ring system might serve as an additional protection against the development of resistance.

\section{3: Summary of the present work, and future directions}

Fifty three reversed chloroquine-type compounds have been synthesized in which the 7-chloro substituent is changed to another electron-withdrawing substituent in the 2-, 5-, 6-, 7-, and 8- positions of the quinoline ring system, to a methyl substituent in position 2-, 6- or 8-, or to a methoxy substituent in position 7- or 8- (see Table B1, Appendix B). For this class of compounds, 2-, 5-, and 8- substituents appear to decrease in vitro antiplasmodial activity against $P$. falciparum relative to 7-chloro substitution, whereas 6and 7- substituted compounds have similar activity to that of 7-chloro substituted compounds except in the case of nitro-, fluoro-, and methoxy-substituted compounds. These effects on activity are directionally similar to those observed for chloroquine analogues without an attached reversal agent, but the magnitude of the effect is smaller. The results of this study support and extend the conclusions of Coatney and others that the importance of the quinoline ring system substitution pattern to antiplasmodial activity 
may be smaller for chloroquine analogues with a longer side chain. Furthermore, the results obtained for 2-and 8- substituted compounds may indicate that the deleterious effect of these substituent positions on the antiplasmodial activity of 4-aminoquinoline compounds may be primarily a steric rather than an electronic one.

To complete this series, 7-fluoro, 7-nitro, 7-methyl and 6-methoxy substituted compounds should be made. The 3-position is of particular interest by analogy to sontoquine, which Andersag reported as having similar activity to chloroquine, and for which Vippagunta (1999) and Pou (2012) have found evidence of resistance reversal relative to chloroquine. Additionally, bulky electron-donating substituents would be of interest (such as phenoxy, tert-butoxy, trifluoromethoxy, or pentafluorosulfanyloxy ($\mathrm{OSF}_{5}$ ), as would the bulky, lipophilic, electron-withdrawing pentafluorosulfanyl group ($\mathrm{SF}_{5}$ ). As far as is known, the pentafluorosulfanyl group is of a metabolic stability comparable to the trifluoromethyl group, and is analogous in its electron-withdrawing effect, but its larger size and increased lipophilicity should offer intriguing differences in biological activity (Welch, 2007 and 2009; Kirsch, 2007). ${ }^{6}$ Additionally, compounds substituted with a bulkier substituent in position 2 or 8 would be of interest in order to determine whether this would decrease activity still further than has been observed with the study compounds. This might indicate whether the observed effect is due to steric or other factors. Finally, it would be of interest to determine pKa values for a selection of

\footnotetext{
${ }^{6}$ In recent years the pentafluorosulfanyl group has met with increasing interest as a new substituent for bioactive molecules (Stump, 2009; Welch, 2007; Micheli, 2010; Wipf, 2009), especially since the methods used to incorporate it into organic molecules have improved (although regrettably few $\mathrm{SF}_{5}$-containing organic building blocks and reagents used to introduce it are commercially available). This substituent has been incorporated into the quinoline ring system of mefloquine analogues synthesized at the Walter Reed Army Institute (Wipf, 2009; Mo, 2010).
} 
the study compounds in order to determine whether, in fact, the side chain $\mathrm{pKa}$ is indeed less strongly effected by the quinoline ring system substitution pattern than has been observed for chloroquine analogues without an attached reversal agent, and in order to determine the effect of substituents in various positions upon $\mathrm{pKa}$. If indeed the $\mathrm{pKa}$ of the side chain nitrogen is less strongly affected in these molecules than in shorter chain chloroquine analogues, it would also be of interest to determine the conformation adopted by some of these molecules as salts in acidic aqueous solution, which might be possible by two-dimensional NMR spectroscopy (NOESY).

The results of this study show that the substitution pattern of the quinoline ring system of reversed chloroquine type antiplasmodials is much more flexible than that observed for chloroquine analogs without an attached reversal agent. In the light of findings by other workers that some quinoline ring system substitution patterns offer an improved resistance index relative to the 7-chloro substitution pattern of chloroquine, it is possible that modification of the quinoline ring system substitution pattern of reversed chloroquine-type compounds would provide enhanced protection against the emergence of resistance. At present, however, it is not known whether these compounds are equally active in vivo. 


\section{CHAPTER 3}

\section{Asymmetrical bis-quinolines with antiplasmodial activity}

In the second portion of this work, a novel type of asymmetrical bis-quinoline has been developed that has unusually high antiplasmodial potency. In this chapter, the subject of bis-quinolines as antimalarials will first be introduced (Section 3.1, Background). This will be followed by a description of the asymmetrical bis-quinolines made in this work, followed by a discussion of their in vitro antiplasmodial activity and potential for further development (Sections 3.2-3.5).

\section{1: Background}

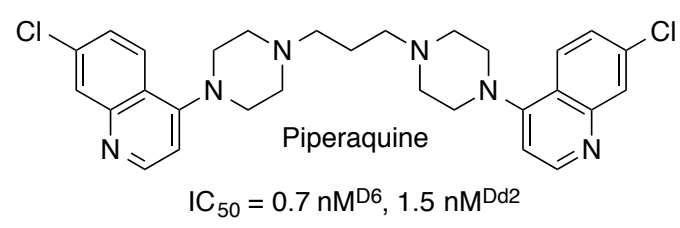

Figure 44: Piperaquine, a bis-quinoline antimalarial

Like the mono-(4-amino)quinoline compounds discussed in the previous chapters, the class of bis-(4-amino)quinolines includes many compounds with antiplasmodial activity. The bis-quinoline antimalarial piperaquine (above, Figure 44), is a long-acting component of dihydroartemisinin-piperaquine, one of the five artemisinin combination 
therapies recommended by the World Health Organization to treat $P$. falciparum malaria (WHO Report, 2013). Piperaquine was originally synthesized at the French chemical firm, Rhône-Poulenc. In the original patents for this compound, submitted by RhônePoulenc in 1962 (France, granted in 1965) and subsequently in Belgium (granted in 1963), examples are given not only for the synthesis of piperaquine but also a variety of analogues (Figure 45):<smiles>Clc1ccc2c(N3CCN(CC4CCC(CN5CCN(c6ccnc7cc(Cl)ccc67)CC5)CC4)CC3)ccnc2c1</smiles><smiles>Clc1ccc2c(N3CCN(Cc4ccc(CN5CCN(c6ccnc7cc(Cl)ccc67)CC5)cc4)CC3)ccnc2c1</smiles><smiles>CN(CCN1CCN(c2ccnc3cc(Cl)ccc23)CC1)CCN1CCN(c2ccnc3cc(Cl)ccc23)CC1</smiles><smiles>Clc1ccc2c(N3CCN(CCCN4CCN(c5ccnc6ccc(Cl)cc56)CC4)CC3)ccnc2c1</smiles><smiles>CC1CN(CCCN2CC(C)N(c3ccnc4cc(Cl)ccc34)[C@H](C)C2)[C@@H](C)CN1c1ccnc2cc(Cl)ccc12</smiles><smiles>COc1ccc2c(N3CCN(CCCN4CCN(c5ccnc6cc(Cl)ccc56)CC4)CC3)ccnc2c1</smiles>

Figure 45: Some bis-quinolines used as examples in the original patents for piperaquine by Rhône-Poulenc.

Piperaquine attracted the interest of Chinese researchers, who synthesized it in $1965 .^{7}$ Following successful clinical trials performed during the early 1970s it was widely used in China both as a treatment and as prophylaxis for P. falciparum and vivax malaria (Davis, 2005; Schlitzer, 2007; Warhurst, 2007; Chen, 2014).

\footnotetext{
${ }^{7}$ It has sometimes been stated that piperaquine was synthesized independently in China (Davis, 2005, and citing authors); however, in the reference given for this information by Davis and coauthors, I could not find a statement to this effect. In the above I have followed Chen (2014) and Warhurst (2007).
} 
Piperaquine is believed to work by a mechanism similar to that of chloroquine and other 4-aminoquinolines (Warhurst, 2007); however, it retains activity against many chloroquine-resistant strains, perhaps because its large size prevents its being exported by the chloroquine resistance transporter (Vennerstrom, 1992; Basco, 2003; Davis, 2005; Naudé, 2005; Pascual, 2012). However, piperaquine resistance is now common in some parts of Asia, particularly the areas of China in which piperaquine was heavily used following its introduction (Schlitzer, 2007; Chen, 2014). The mechanism of piperaquine resistance is not known, and attempts to associate resistance to piperaquine with mutations known to confer resistance to other quinoline antimalarials have produced conflicting results (Muangnoicharoen, 2009; Briolant, 2010; Eastman, 2011; Hao, 2013; Pasual, 2013). Disturbingly, the development of resistance to the combination dihydroartemisinin-piperaquine has been reported in southeast Asia (Saunders, 2014).

In addition to piperaquine itself, a diverse range of other bis-4-aminoquinoline compounds have been shown to have antiplasmodial activity (Figure 46, following page). Like piperaquine, these compounds tend to be active against chloroquine-resistant strains (Rhône-Poulenc, 1962; Elslager, 1969; Makler, 1990; Vennerstrom, 1992; Raynes, 1995; Vennerstrom, 1998; Ayad, 2001; Ryckebusch, 2003; Khan, 2009; Ribeiro, 2013; Tomar, 2013). 


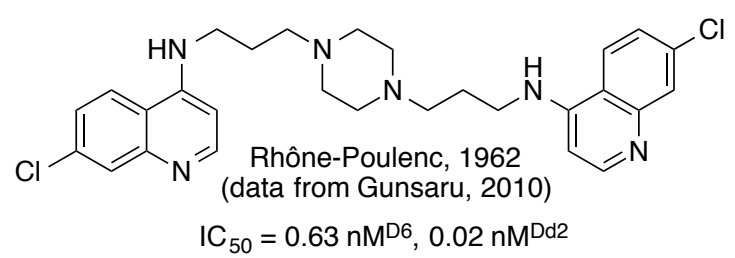<smiles></smiles>

Dequalinium Makler, 1990

$\mathrm{Cl}$<smiles>NC1CCCCC1Nc1ccnc2cc(Cl)ccc12</smiles>
WR 268,668 (Ro 48-6910) (Vennerstrom, 1992) $\mathrm{IC}_{50}=1.0 \mathrm{nM}^{\mathrm{D} 6}, 1.4 \mathrm{nM}$ W2 (CQR)

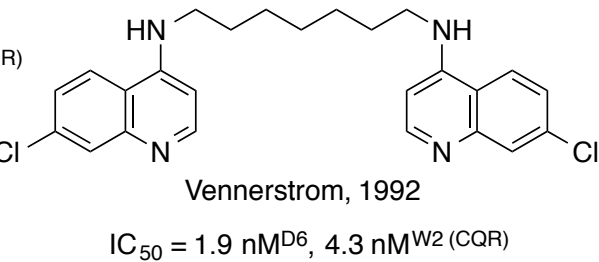<smiles>CCN(CC)CCCC(C)Nc1ccnc2c(NC(C)=O)cccc12</smiles>

Raynes, 1996

$\mathrm{IC}_{50}=130 \mathrm{nM}^{\mathrm{D} 10}$ (CQS), $120 \mathrm{nM}^{\mathrm{FAC8}}$ (CQR)<smiles>CCN(CC)CCCC(C)Nc1cc(C(C)C)nc2cc(Cl)ccc12</smiles>

Ayad, 2001

$\mathrm{IC}_{50}=43 \mathrm{nM}^{\mathrm{D} 10}$ (CQS), $17 \mathrm{nM}^{\mathrm{K} 1}$ (CQR)<smiles>Clc1ccc2c(NN3CCN(Nc4ccnc5cc(Cl)ccc45)CC3)ccnc2c1</smiles>

Elslager, 1969

Mouse study: $2.8 \mathrm{mg} / \mathrm{kg} / \mathrm{day}$ suppressed parasitemia by $90 \%(P$. berghei); 2.5 times as potent as chloroquine in the same study.<smiles>Clc1ccc2c(NCCN3CCN(c4ccnc5cc(Cl)ccc45)CC3)ccnc2c1</smiles>

Vennerstrom, 1998

$\mathrm{IC}_{50}=1.2 \mathrm{nM}^{\mathrm{D} 6}, 9.0 \mathrm{nM}^{\mathrm{W} 2}$ (CQR)

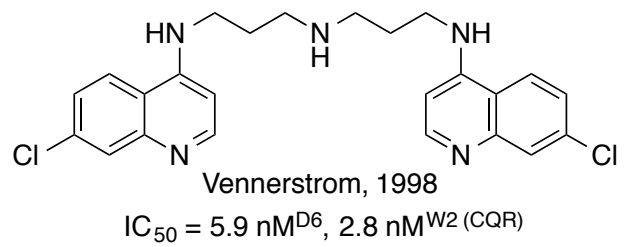<smiles>CCNCCN(CCNCC)c1ccnc2cc(Cl)ccc12</smiles>

Khan, 2009

$\mathrm{IC}_{50}=7.5 \mathrm{nM}^{\mathrm{D} 6}$, $19.2 \mathrm{nMW}^{\mathrm{W}}$ (CQR)<smiles>CC(CNC(=O)CNc1ccnc2cc(Cl)ccc12)Nc1ccnc2cc(Cl)ccc12</smiles>

$\mathrm{IC}_{50}=5.9 \mathrm{nM}^{\mathrm{D} 6}, 2.8 \mathrm{nM}$ 2(CQR)<smiles>CCCC(C)Nc1cccc2cc(Cl)ccc12</smiles>

Figure 46: A range of bis-(4-amino)quinoline compounds with antiplasmodial activity 


\section{2: A novel, asymmetrical bis-quinoline: PL241}

During the initial structure-activity relationship study in which reversed choroquine-type compounds were developed (Burgess, 2008; Burgess, 2010), the compound PL69 was produced (Figure 47):

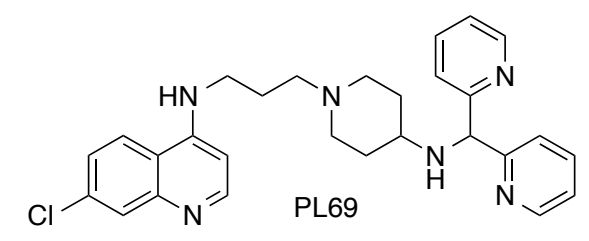

Figure 47: PL69, a reversed chloroquine-type antimalarial synthesized by Steven J. Burgess (2008)

The original synthetic method for PL69 required the use of the following compound (PL67) as an intermediate (Figure 48):

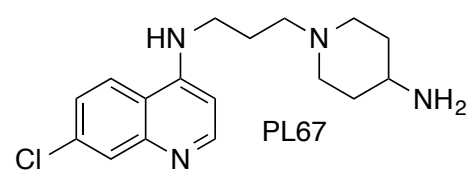

Figure 48: PL67, an intermediate originally used to produce PL69

In the present work, at the suggestion of Steven Burgess, PL67 was used to synthesize a bis-quinoline compound, as follows (Figure 49): 


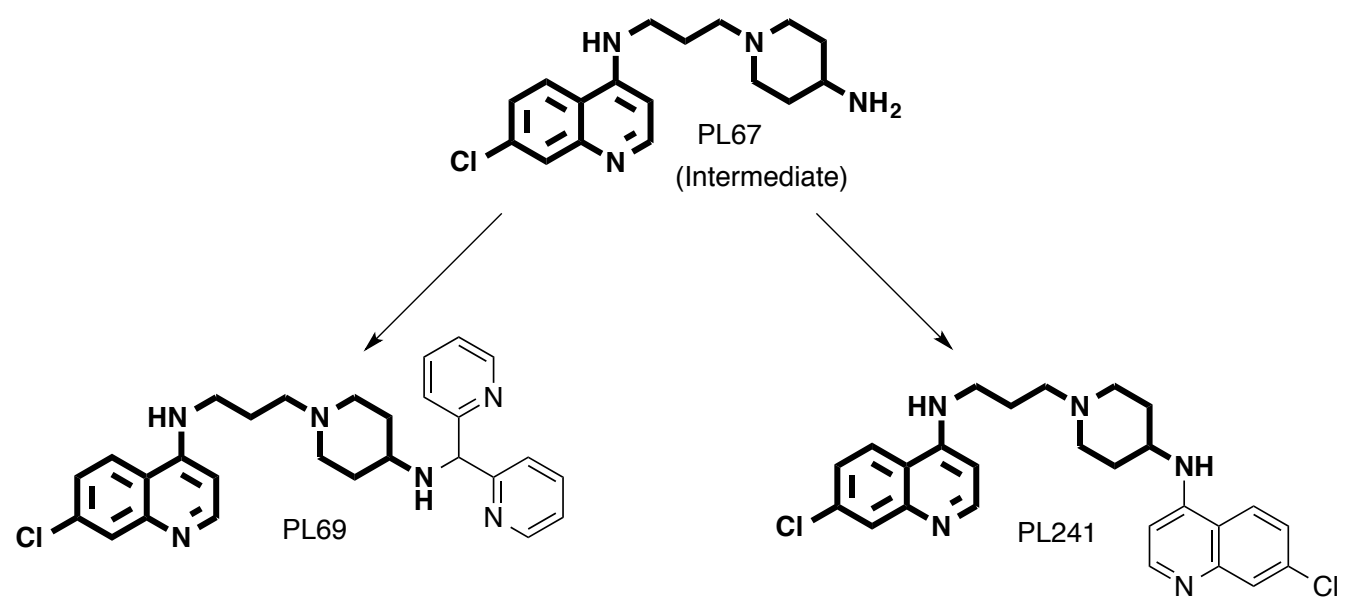

Figure 49: In this work, PL67 was used to produce the novel bis-quinoline, PL241.

The new compound had extremely high in vitro activity against chloroquine sensitive and chloroquine resistant strains of $P$. falciparum. With an $\mathrm{IC}_{50}$ of less than $0.1 \mathrm{nM}$ for all strains tested, its activity was superior to any compound previously synthesized in our laboratory, as well as to that of piperaquine (Figure 50):
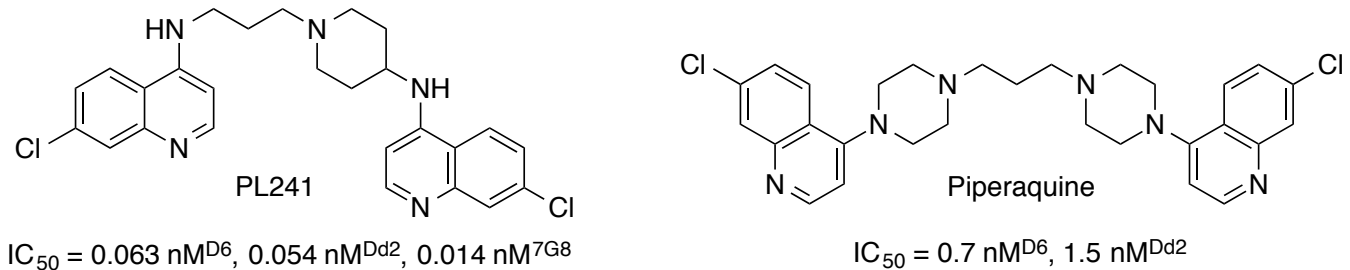

Figure 50: In vitro antiplasmodial activity of PL241 compared to that of piperaquine

PL241 is noticably different from piperaquine. Firstly, it is asymmetrical. Secondly, in contrast to piperaquine's piperazine ring system, PL241 contains a 4- 
aminopiperidine moiety directly attached to one of its quinoline rings. This structural motif has previously been incorporated into other quinoline compounds with antiplasmodial activity, including a recently published bis-quinoline conjugated with squaric acid (Wiselogle, 1948; Madrid, 2006; Hocart, 2011; Ribeiro, 2013; Figure 51):

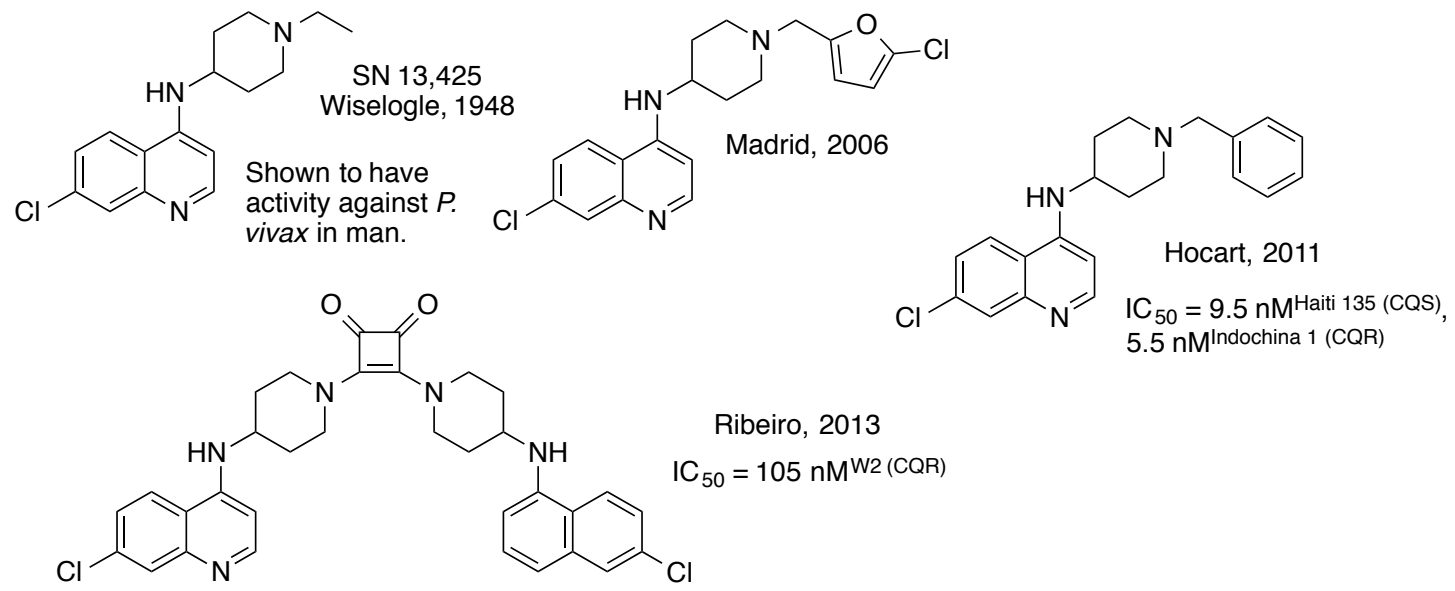

Figure 51: (4-Piperidyl)-4-aminoquinolines previously shown to have antiplasmodial activity.

The third important difference between piperaquine and PL241 is that the nitrogen in position 4 of each of the quinoline ring systems of PL241 is secondary rather than tertiary. This is significant in view of the frequent observation that for mono-(4amino)quinolines and related antiplasmodials, the presence of a tertiary rather than a secondary nitrogen in position 4 of the quinoline ring system lowers antiplasmodial potency. This is true not only for chloroquine analogues without an attached reversal agent (Wiselogle, 1948; Warhurst, 2007), but for reversed chloroquine-type compounds as well (Figure 52; Burgess, 2008): 

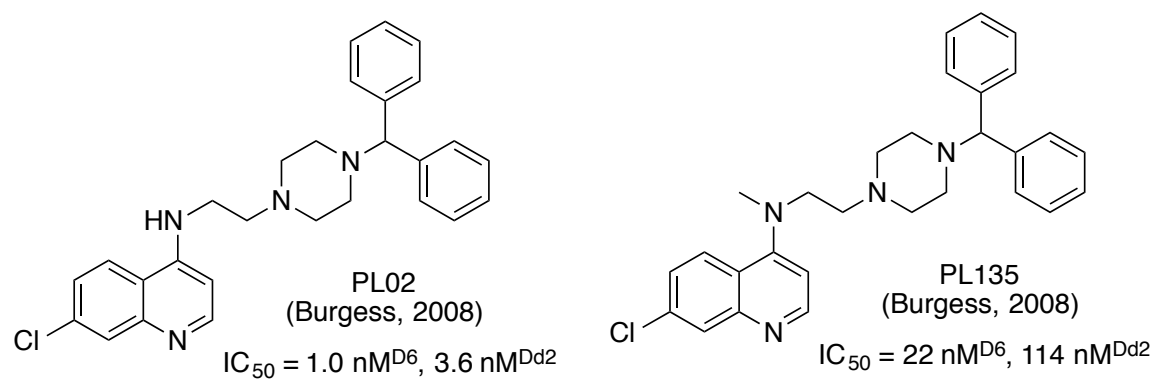

Figure 52: A tertiary nitrogen in position 4 of the quinoline ring system lowers antiplasmodial potency.

This phenomenon was originally observed in the case of 8-aminoquinoline antimalarials and acridines. In the course of a mechanistic study upon the quinoline and acridine antimalarials atebrine (quinacrine), plasmochin (pamaquine), and certuna (cilional), Schönhöfer and coworkers synthesized an N,N,N-trisubstituted derivative of the active antimalarial, atebrine (Schönhöfer, 1942). The N,N,N-trisubstituted compound was devoid of antimalarial activity (Figure 53):
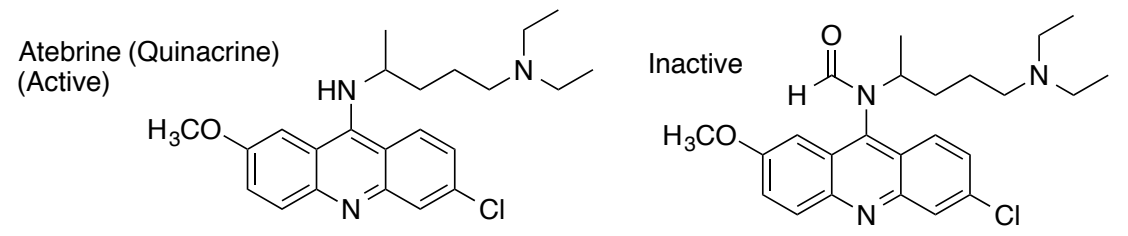

Figure 53: Atebrine and its N,N,N-trisubstituted analogue (Schönhöfer, 1942).

It was remarked by Schönhöfer that the introduction of a second substituent on the amino group para to the acridine ring nitrogen would prevent the following tautomerization from occurring (Figure 54): 


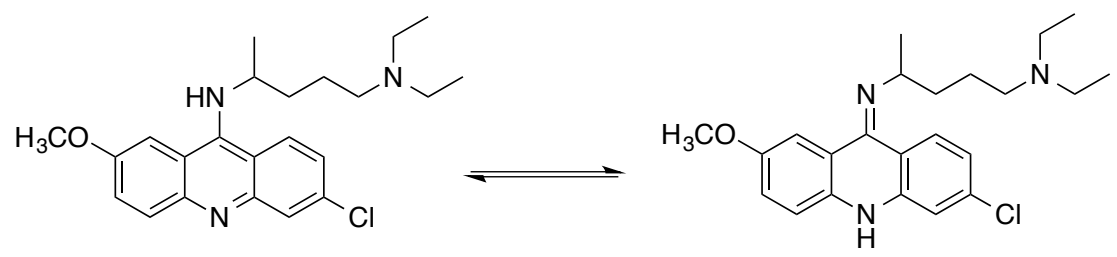

Figure 54: Tautomerization of atebrine predicted by Schönhöfer to have significance for antimalarial potency (1942)

In the context of this and other observations, Schönhöfer speculated that the form of the drug active in vivo might be that in which it has transiently rearranged to the above structure.

In the case of 4-aminoquinolines, which are closely related to acridines, disubstitution of the amino group para to the ring nitrogen would also block tautomerization. It is now believed that the site of action of quinoline (and acridine) antimalarials is the parasite's acidic digestive vacuole, where the quinoline ring is expected to be protonated. The tautomerization shown above has been revisited as resonance stabilization of positive charge on the ring nitrogen resulting from protonation (Egan, 2000; Figure 55):
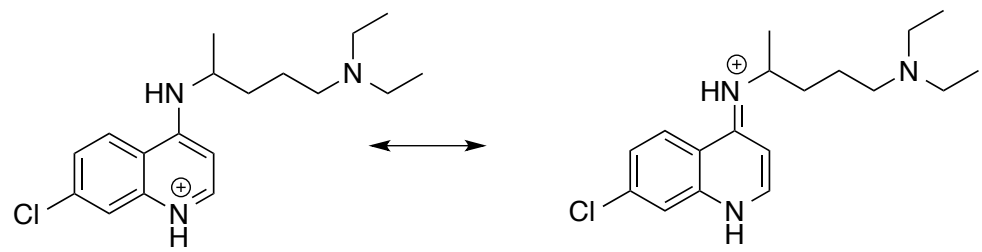

Figure 55: Resonance stabilization of the positive charge on the protonated ring nitrogen of chloroquine 
It has also been found by Egan (2000) that within the series including 2-, 3-, 4-, 5, 6-, and 8-aminoquinoline, the only quinolines able to bind strongly to heme are those for which the above resonance stabilization is possible, to wit, the 2- and 4-aminoquinolines. The ability to stabilize a positive charge on the ring nitrogen leads to increased basicity in the 2- and 4-aminoquinolines, and therefore presumably to increased accumulation in the digestive vacuole. It is also possible that the altered electronic properties of the protonated, resonance-stabilized structure lead to improved heme binding ability (Egan, 2000).

It would at first appear that the resonance stabilization shown above would be equally effective for tertiary 4-aminoquinolines. However, it has been suggested by Warhurst (2007) in the case of piperaquine that steric hindrance between the proton in position 5 of the quinoline ring system and the piperazine methylene results in twisting of the substituted 4-amino group out of the plane of the ring, so that resonance stabilization is decreased. This would result in reduced basicity of the ring nitrogen for tertiary compounds, leading to reduced accumulation in the digestive vacuole. Experimental determination of the pKas of piperaquine has shown that it is indeed less basic than chloroquine (Warhurst, 2007).

In view of the observation for the general class of 4-aminoquinolines that the presence of a tertiary quinoline-4-amino group leads to reduced antiplasmodial activity, it is curious that piperaquine, with its two tertiary quinoline-4-amino groups, should have high activity. The reason for this is unknown. Assuming that piperaquine's mode of action is the same as that of chloroquine, Warhurst (2007) has predicted that while 
piperaquine's accumulation in the aqueous acidic vacuole should be somewhat less than that of chloroquine, its accumulation in the lipid portions of the vacuole is expected to be much greater (based on the empirically determined pKas and cLogP of both compounds; Warhurst, 2007). This may be significant in view of the evidence that hemozoin may form at the surface of or inside of lipid droplets within the digestive vacuole (Warhurst, 2007; Pisciotta, 2007; Egan, 2007). It is also conceivable that the availability of two heme binding sites in piperaquine compensates in part for lower accumulation relative to that of chloroquine, with its single heme binding site. Finally, if the importance of the mesomerism described above lies in its effect upon the electronic nature - and therefore binding ability - of the quinoline ring system of 4-aminoquinolines in general, then it is conceivable that piperaquine may be a special case in which the presence of the specific combination of the bulky aminoalkyl motif and second quinoline ring system results in a binding geometry altered in such a way that it is different from that of other 4aminoquinolines but provides equally strong heme binding and inhibition of hemozoin formation.

Whatever the reasons behind piperaquine's high activity, the fact that PL241 has improved activity over that of piperaquine may indicate that the presence of a tertiary amine is indeed detrimental to 4-aminoquinoline antimalarials and that piperaquine's activity represents a compromise between the detriment of the tertiary 4-amino group and other more favorable properties. PL241 may possess the positive features of piperaquine with the additional advantage of the secondary quinoline-4-amino group.

An interesting feature of bis-quinoline compounds is that they retain activity 
against many chloroquine-resistant strains of $P$. falciparum malaria. To explain piperaquine's activity against chloroquine resistant strains, it has been suggested that due to the increased bulk and lipophilicity of piperaquine relative to that of chloroquine, the bis-quinoline is unable to be exported through the Plasmodium falciparum chloroquine resistance transporter, PfCRT (Warhurst, 2007). This is similar to the explanation that has been advanced for the activity of reversed chloroquine-type antimalarials, and it has been remarked that piperaquine might be thought of as a reversed chloroquine-type antimalarial (Burgess, 2008). This also applies to PL241, which is structurally similar to the reversed chloroquine PL69 (Figure 56):

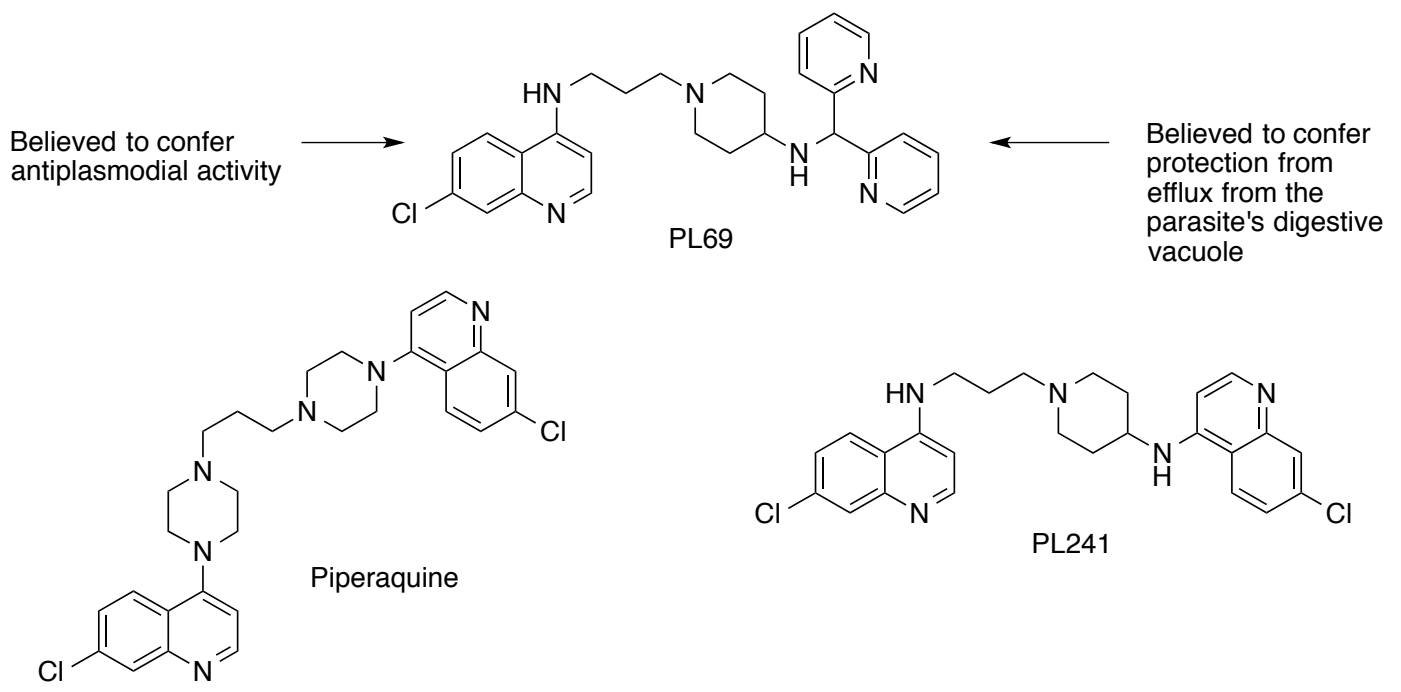

Figure 56: PL69, a reversed chloroquine type compound, compared to the structures of piperaquine and PL241

Piperaquine is a symmetrical molecule, but PL241 is not. In view of this, it is 
uncertain whether the quinoline rings of PL241 are equally important to the antimalarial activity or whether one ring has weaker antimalarial activity and is perhaps acting primarily as a reversal agent (as we believe occurs with the $\mathrm{N}$-(dipyridin-2ylmethylene)piperidin-4-amine group in the case of PL69, above). To help determine this, a short mechanistic study was performed.

\section{3: A short mechanistic study: The effect of inactivating groups upon the activity of PL241}

To determine whether the two quinoline ring systems of PL241 are equally important to its antimalarial activity, several PL241 analogues were made and tested in vitro against Plasmodium falciparum. In the first two analogues, the 7-chloro substituent of one quinoline ring system was changed to an 8-trifluoromethyl group, a substitution pattern that was expected to be inactivating based on the work described in Chapter 2 for quinoline ring-modified reversed chloroquine-type compounds. It was anticipated that if one of the ring systems is more important to antimalarial activity than the other, then substitution of this ring with an 8-trifluoromethyl group would result in a diminuition of in vitro activity. The results obtained are shown below (Figure 57; see also Appendix B, Table B6). For comparison, PL69 is also shown, together with its 8-trifluoromethylsubstituted analogue, PL269, as well as PL241: ${ }^{8}$

\footnotetext{
${ }^{8}$ With the exception of PL241, the bis-quinolines in this project were not tested against the chloroquine resistant strain Dd2, but only against $7 \mathrm{G} 8$, another chloroquine resistant strain of $\mathrm{P}$. falciparum malaria.
} 


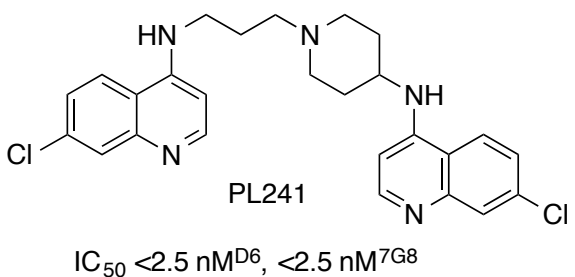

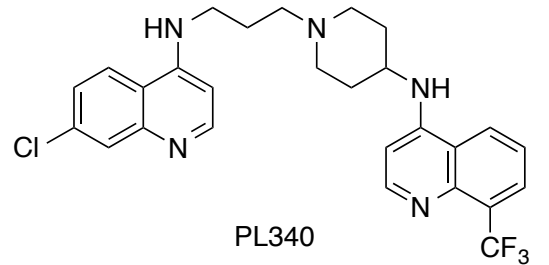

$\mathrm{IC}_{50}<2.5 \mathrm{nM}^{\mathrm{D} 6},<2.5 \mathrm{nM}^{7 \mathrm{G} 8}$

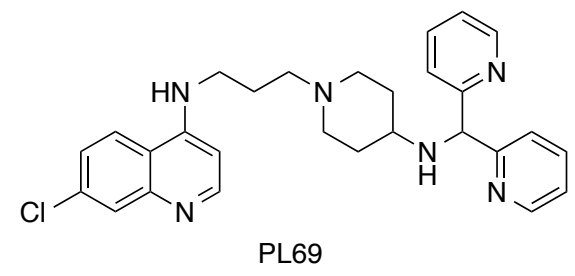

$\mathrm{IC}_{50}=0.9 \mathrm{nM}^{\mathrm{D} 6}, 1.8 \mathrm{nM}^{7 \mathrm{G} 8}$

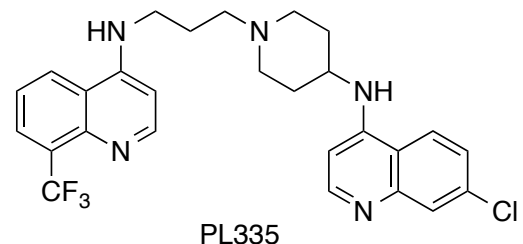

$\mathrm{IC}_{50}<2.5 \mathrm{nM}^{\mathrm{D} 6},<2.5 \mathrm{nM}^{7 \mathrm{G} 8}$

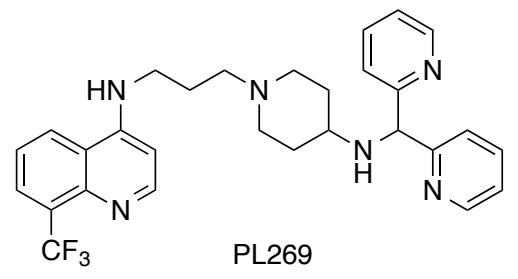

$\mathrm{IC}_{50}>250 \mathrm{nM}^{\mathrm{D} 6},>250 \mathrm{nM}^{7 \mathrm{G} 8}$

Figure 57: 8-trifluoromethyl-substituted PL241 analogues, shown with PL241, PL69, and its 8trifluoromethyl-substituted analogue, PL269.

Within the range of the test, the activities of both 8-trifluoromethyl-substituted PL241 analogues were equivalent to that of the parent drug. These results may be interpreted to mean that neither quinoline ring system is of primary importance to the antimalarial activity of PL241. However, whether the 8-trifluoromethyl group would in fact be inactivating in the context of these compounds was unknown. Therefore, an additional PL241 analogue was synthesized in which both rings were substituted with an 8trifluoromethyl group (Figure 58): 


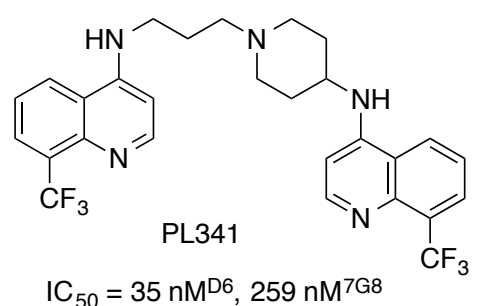

Figure 58: A PL241 analog with two 8-trifluoromethyl-substituted quinoline ring systems.

The activity of the bis-8-trifluoromethyl PL241 analogue was substantially decreased relative to that of PL241. Therefore it seems probable that the 8-trifluoromethyl substitution is indeed an inactivating substitution pattern for compounds of this type, as with reversed chloroquine-type compounds. Taken together with the results above for PL241 analogues with a single 8-trifluoromethyl substitution, these results suggest that either quinoline ring system is equally capable of participating in the antimalarial action of PL241.

It is notable that for the bis-8-trifluoromethyl substituted PL241 analogue, PL341, the decrease in activity observed for the chloroquine sensitive parasites was not as great as that observed for other 8-substituted reversed chloroquine-type antimalarials when compared to their 7-substituted analogues (see PL69 and PL269, Figure 57, above). Possibly, this might be attributable to a slightly different binding pattern induced by the larger side chain of these compounds (including the second quinoline ring system).

For the chloroquine resistant parasites, the activity of the bis-8-trifluoromethyl analogue of PL241 was much lower. Regrettably, the magnitude of this effect cannot be compared to the effect on the activity of 8-trifluoromethyl substituted reversed chloroquine-type compounds tested against resistant parasites, since the assays used to 
test the latter did not test in the same range (all had $\mathrm{IC}_{50}>250 \mathrm{nM}$ ).

Finally, it is of interest that the same phenomenon of apparent cross resistance is observed here as for most of the 8-substituted reversed chloroquine-type antimalarials (see Figure 43). Again, it would be informative to determine whether this apparent crossresistance is reversible by verapamil (and thus whether it relates to increased efflux of the 8-substituted compounds from the digestive vacuole, or to another, unknown mechanism).

\section{4: A second short mechanistic study: The effect of exchanging chlorine for hydrogen}

In Chapter 1, it was noted that the activity of chloroquine analogues without an attached reversal agent is detrimentally affected by removal of the 7-chloro substituent, but that this is not always true for reversed chloroquine-type compounds (see Figure 18). Previous work in Dr. Peyton's laboratory has examined the importance of the 7-chloro substituent to the class of bis-quinolines. Analogues of piperaquine and a related bisquinoline, PL192, have been made in which chlorine has been exchanged for hydrogen (Figure 59; Gunsaru, 2010): 

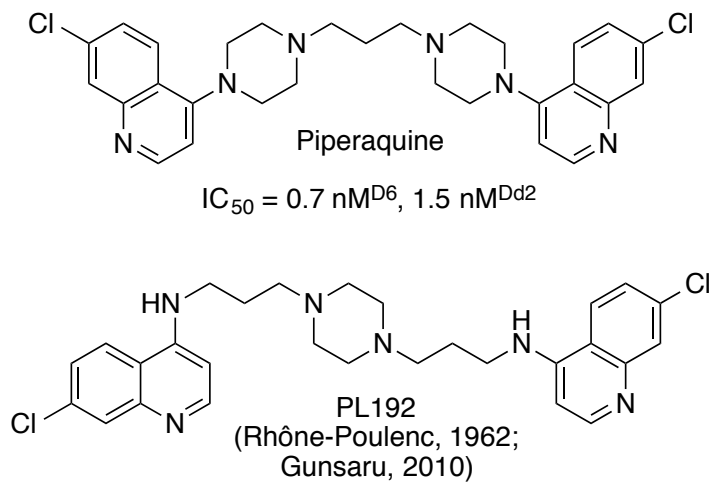

$\mathrm{IC}_{50}=0.63 \mathrm{nM} \mathrm{D}^{\mathrm{D}}, 0.02 \mathrm{nM} \mathrm{nd}^{\mathrm{D} 2}$

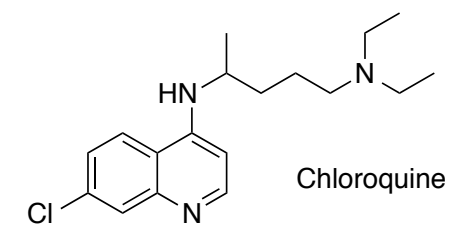

$\mathrm{IC}_{50}=6.9 \mathrm{nM} \mathrm{D}^{\mathrm{D}}, 102 \mathrm{nM} \mathrm{Dd}^{\mathrm{D} 2}$ (Burgess, 2008)
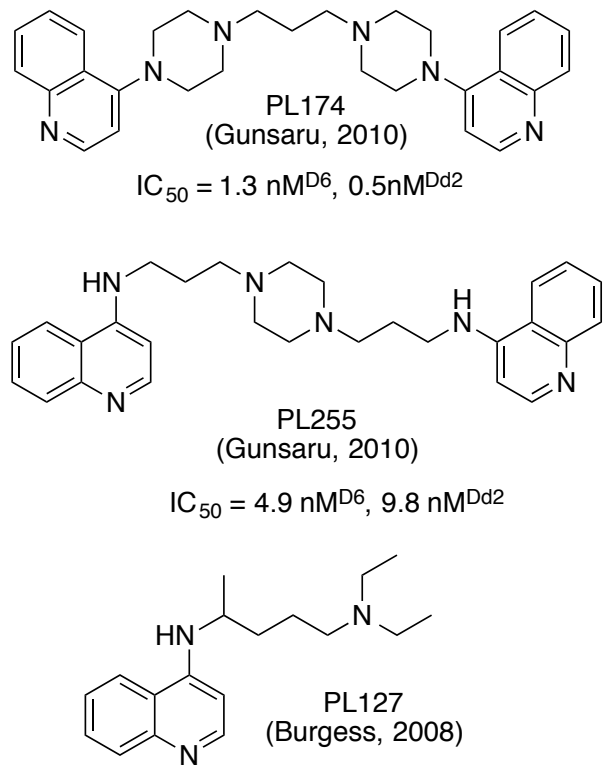

$\mathrm{IC}_{50}=90 \mathrm{nM}^{\mathrm{D} 6},>250 \mathrm{nM}{ }^{\mathrm{Dd} 2}$

Figure 59: Piperaquine analogues made during previous work, in which chlorine has been exchanged for hydrogen (Gunsaru, 2010). Also shown is chloroquine with its 7-hydro analogue (Burgess, 2008).

Similarly to the case of reversed chloroquine-type compounds, no significant difference in activity was observed between piperaquine and its bis-7-hydro analogue, PL174 (Figure 59, above). PL192 differs from piperaquine in the arrangement of its aminoalkyl motif, such that both quinoline ring systems have a secondary rather than tertiary 4-amino group. In contrast to what was observed for piperaquine, and in contrast to what has been observed for some reversed chloroquine-type compounds, PL255 (the des-chloro analogue of PL192; Figure 59, above) showed a diminuition in activity compared to PL192 (Gunsaru, 2010). However, it was not known whether this effect would generalize to other bis-quinolines containing secondary quinoline-4-amino groups.

To help determine this, analogues of PL241 were made in which either or both quinoline ring systems were substituted with hydrogen in position 7 (Figure 60; see also 
Appendix B, Table B6):

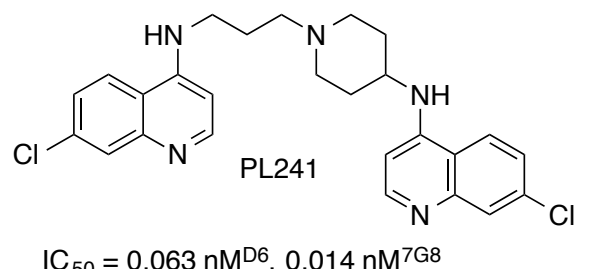

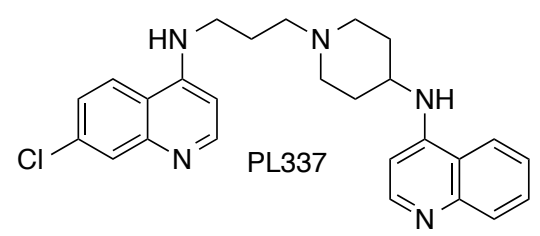

$\mathrm{IC}_{50}<2.5 \mathrm{nM}^{\mathrm{D} 6},<2.5 \mathrm{nM}^{7 \mathrm{G} 8}$

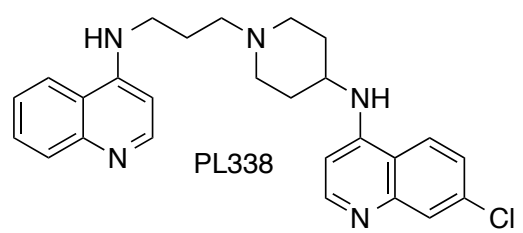

$\mathrm{IC}_{50}<2.5 \mathrm{nM}^{\mathrm{D} 6},<2.5 \mathrm{nM}^{7 \mathrm{G} 8}$

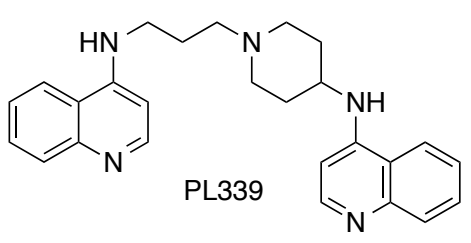

$\mathrm{IC}_{50}=17 \mathrm{nM}^{\mathrm{D} 6}, 28 \mathrm{nM}^{7 \mathrm{G} 8}$

Figure 60: Analogues of PL241 in which chlorine has been exchanged for hydrogen.

As was observed in the case of the 8-trifluoromethyl substituted PL241 analogues, substitution of a single 7-chloroquinoline ring system with 7-hydroquinoline did not result in any reduction in activity within the range of the assay. However, exchange of both rings for 7-hydroquinolines resulted in a reduction of activity similar to that seen for the bis-8-trifluoromethyl PL241 analogue, indicating that in the case of PL241, removal of the 7-chloro substituent is detrimental to antiplasmodial activity. This limited study provides further support to the tentative conclusion from Gunsaru's work (2010) that the activity of bis-quinoline compounds with secondary quinoline-4-amino groups is more sensitive to the removal of chlorine than is that of compounds more similar to 
piperaquine, with tertiary quinoline-4-amino groups. The reasons for this remain unclear. It would be of interest to know whether the weak activity of other tertiary 4aminoquinoline antiplasmodials is insensitive to the removal of the 7-chloro group, or whether the effect is specific to piperaquine. It would also be of interest to determine the effect of removing chlorine from only one quinoline ring system of PL192 (see Figure $59)$.

\subsection{The future of PL241: A potential antimalarial drug?}

The excellent in vitro antiplasmodial activity of PL241 makes this a compound of great interest for further development as a potential antimalarial drug, particularly if it were to be found that it is active against piperaquine-resistant strains of Plasmodium. However, for bis-quinolines as well as for other classes of compounds, high in vitro activity does not always predict high activity in vivo (Vennerstrom, 1998), and even a compound with high activity in vivo may not be a suitable drug. Considered as a potential drug, PL241 has some features that are cause for concern. Firstly, toxicity may be an issue. In the course of this work, an initial in vitro test to determine the possible toxicity of PL241 was performed using mouse spleen lymphocytes (see Appendix B, Table B7). Toxicity is given as $\mathrm{LC}_{50}$, the concentration required to kill $50 \%$ of the cells. PL241 was found to be substantially more toxic $\left(\mathrm{LC}_{50}=190\right)$ than chloroquine $\left(\mathrm{LC}_{50}=\right.$ 12400), and also more toxic than the reversed chloroquine-type compounds tested (representative $\mathrm{LC}_{50}=6500$ for PL69). However, the antiplasmodial activity of PL241 is 
substantially better than that of chloroquine - at least in vitro - so it is possible that could be administered at a much lower dose, below the threshold of toxicity. The therapeutic index (ratio of activity to toxicity) of PL241 using the mouse spleen lymphocyte assay compares favorably to that of chloroquine (3500 versus 122). A second concern is the known low water solubility of PL241, even as the phosphate salt. Low aqueous solubility could present a problem in terms of biological absorption. The use of a solubilizing counterion, such as mesylate or lactate (Stahl, 2003a), or a special formulation (Stahl, 2003b) might alleviate this problem, but the former might not do enough to improve solubility while the latter would unacceptably increase cost. It is possible that PL241 might turn out to be is more absorbable in vivo than might be predicted (it may be worth noting that the predicted cLogP (octanol-water partition coefficient, a predictor of water solubility) of PL241 is 7.0 (ChemBioDraw), compared to 6.5 predicted for piperaquine). However, at this early stage, the best approach might be to modify the structure of PL241 such that the drug properties would be improved without excessively compromising activity. For example, in view of the easy synthetic variability of the quinoline ring system, together with the results shown above for ring-modified reversed chloroquinetype compounds, it may be possible to add solubilizing substituents to the quinoline ring system without unacceptably compromising activity (Wermuth, 2003). 


\section{CHAPTER 4}

\section{A survey of historical therapies used in Europe to treat intermittent fevers}

The mere treatment of this subject undoubtedly increases the admiration that I at least feel for the men of old; the greater the number of plants waiting to be described, the more one is led to revere the careful research of the ancients and their kindness in passing on the results.

$$
\text { (Pliny, Natural History, Vol. VII, 1.) }{ }^{9}
$$

\section{1: Introduction to the project}

Malaria has been with us for many centuries, perhaps for all of human history (Hoeppli, 1959; Hay, 2004; Hawass, 2010; Fornaciari, 2010). Its former range was much larger than it is today, including much of Europe (Nuttall, 1901; Russell, 1955; Hay, 2004). The following chapter will survey selected therapies used in Europe to treat malaria prior to and along with cinchona bark, from the time of Pliny the Elder (active in the first century A.D.) through the advent of modern malaria chemotherapy in the early twentieth century. The substances utilized for treatment were primarily plant remedies (phytotherapies). The remedies include what may be considered traditional or folk medicine, as well as official or scientific medicine. These two categories are not distinct, and for the purposes of this survey they have been considered together.

There has been much interest in the traditional phytotherapies used to treat

\footnotetext{
${ }^{9}$ Crescit profecto apud me certe tractatu ipso admiratio antiquitatis, quantoque maior copia herbarum dicenda restat, tanto magis adorare priscorum in invendiendo curam, in tradendo benignitatem subit. (Translation by W.H.S. Jones., 1956.)
} 
malaria in the parts of the world where malaria is currently endemic. Thousands of articles and books have been published on this subject (see for example Dharani, 2010; Zhu, 2012; Singh, 2011; Soejarto, 2012; Koch, 2005). However, with the exception of cinchona, the historical malaria therapies used in Europe prior to the development of modern antimalarial chemotherapy have attracted relatively little interest. The reasons for this may be fourfold. Firstly, malaria has not been considered endemic to most of Europe for nearly a century (Hay, 2004). In many formerly malaria endemic regions, malaria has been absent for far longer, as has been discused by Nuttall, Cobbett, and Strangeways-Pigg (1901). Naturally enough, the possibility that native European antimalarial phytotherapies might have existed is not often considered. Secondly, historical phytotherapies are often dismissed as folk medicine. Scientists, medical practitioners, and even historians within the European tradition have typically considered modern medicine to be contradictory and incompatible with folk medicine, which is often regarded with amusement and scorn (Cameron, 2006; De Vos, 2010). It is no longer considered acceptable in scholarship to ridicule and dismiss traditional remedies used in other parts of the world, but this attitude is more rarely applied to the traditional medicine of one's own culture. Thirdly, in part because of the historical attitude of dismissal towards traditional remedies, and partly also because of the lapse in time since malaria has been prevalent in Europe, much of the European traditional medicine that was formerly used to treat malaria has been forgotten. It is no longer part of the daily lives of most of the population. Fourthly, there is a notion extremely prevalent in the literature that no antimalarial remedy worthy of the name existed in Europe until the appearance of 
cinchona bark in the $17^{\text {th }}$ century. Cinchona bark is generally thought of as having taken over relatively quickly as the malaria treatment of choice, as if in a vacuum. In reality, this was far from true (Jarcho, 1993; Adams, 2011). The prevalence of this belief has helped to obscure a large number of antimalarial remedies that existed in the past.

The examination of early treatments for malaria and other diseases is not only of historical interest. Both quinine and the artemisinins were originally discovered by isolation of active constituents from plants used to treat malaria. Especially now that there is so much interest in finding novel scaffolds that are not yet subject to drug resistance, it is likely that phytochemical sources of interest could surface from a serious examination of the old literature. Recently, Adams, Zimmerman and coworkers have screened 61 plants used in the European materia medica for in vitro antiplasmodial activity (Adams, 2011; Zimmerman, 2013). Thirty-four of the plants were discovered by inspection of eight German language herbals from the $16^{\text {th }}$ and $17^{\text {th }}$ century, while the remainder were plants with known medicinal activity. Of the plants mentioned in the Renaissance herbals, Adams, Zimmerman and coworkers found that many had some degree of antiplasmodial activity. In view of this, it can no longer be assumed that cinchona bark was the only malaria remedy used in Europe that had antimalarial efficacy. Moreover, it appears likely that a search of the historical medical literature may yield useful leads for the treatment of drug-resistant malaria.

In the present project, fifteen European primary sources have been searched for malaria remedies. The remedies that were found are presented in tabular form, followed 
by a brief discussion. The sources used begin with Pliny the Elder, whose Natural History was written in the first century A.D., and end with Mrs. M. Grieve, whose Modern Herbal was published in 1931. When possible, these sources were read in their native language, but due to the inability of the author to read ancient Greek, Latin, Middle Welsh, or Anglo Saxon, translations were sometimes used. The fifteen sources used in this project are described briefly below. In the course of the project, several additional sources were examined without finding reference to any disease that could clearly be identified as malaria; the names of these sources are also briefly noted below.

Pliny the Elder: Plinii Naturalis Historiae $\left(1^{\text {st }}\right.$ century A.D.)

Pliny the Elder, born in 23 A.D, was a Roman official and encyclopedist known for his love of reading and interest in the natural sciences. In 79 A.D. he was killed by toxic fumes from the eruption of Vesuvius, having sailed to the nearby Stabiae to observe the results of the eruption (Rackham, 1938). His best-known work, Plinii Naturalis Historiae (Natural History by Pliny), includes sections on the treatment of various ailments and on the medical uses of plants. The edition used in this project is that translated into English by H. Rackham, W.B.S. Jones, and D.E. Eichholz, divided into ten volumes originally published during the years 1938 through 1957. 
Dioscorides: Herbal $\left(1^{\text {st }}\right.$ century A.D. $)$

Dioscorides' herbal describes the medical uses of herbs, animals, and minerals. It was written in Greek by Pedanius Dioscorides, a Greek physician active in Rome during the reign of Nero, 54-68 A.D. (Gunther, 1934; Major; 1954; Grant, 1970; Cameron, 2006); he was roughly contemporary with Pliny the Elder. Dioscorides' Herbal remained a standard medical work through the 1700 s, having been translated into Latin early in its history (as Materia Medica). Although its large size made it unavailable to many physicians due to the expense of producing a copy, excerpts and epitomes were widely available and it is frequently referred to in the older medical literature (Cameron, 2006). The English botanist John Goodyer translated the Herbal into English during the years 1652-1655, and this translation was finally published in 1934, with amended translations of species names, by Robert T. Gunther. A reprint of the 1934 edition has been used as a reference here.

Alexander of Tralles: A work on fevers (525-605 A.D.)

Alexander of Tralles (525-605) was a Byzantine physician who died in Rome. He wrote several medical works in Greek, including a treatise on fevers. In the latter he often gives scathing critiques of the methods of treatment used by other physicians, including Galen (whom, however, he greatly admired). An augmented edition of his works, translated into Latin, was widely used during the Middle Ages (Cameron, 2006). 
The edition used in this work is a reprint of the 1878 translation from Greek into German by T. Puschmann.

The Herbarium of Pseudo Apuleius (Anglo Saxon version, $10^{\text {th }}$ century or earlier)

In its Latin original, the Herbarium of Pseudo Apuleius (Herbarium) was a widely used health handbook on the European continent. It is a collection of three works. The first of these is a short work on the uses of the herb betony (probably Stachys officinalis (L.) Trevis.) by a Roman physician, Antonius Musa. The second book is a series of herbal remedies, organized by ailment and ascribed to Apuleius Platonicus (this portion of the text is thought to have originated in the $6^{\text {th }}$ or $7^{\text {th }}$ century A.D.; Anderson, 1977). The final book is a Latin epitome of Dioscorides. The Herbarium was translated into Anglo-Saxon from Latin at an unknown date, no later than the $10^{\text {th }}$ century (Cameron, 2006). Together with other works, the Herbarium was translated from Anglo Saxon into English by the Reverend Thomas Oswald Cockayne, and published as a three volume set entitled Leechdoms, Wortcunning, and Starcraft of Early England (1864-1866). ${ }^{10}$ Of the included works, only the three books of the Herbarium include remedies for a disease that can be identified with relative certainty as malaria, despite the fact that malaria may have existed in Britain at that time (Nuttall, 1901). Although the Herbarium is a translation of a work that survives in Latin and (in the case of Dioscorides) in ancient Greek, it is nevertheless valuable to examine the Anglo Saxon text. Firstly, the

\footnotetext{
${ }^{10}$ The same author also published a series entitled The Shrine: A Collection of Occasional Papers on Dry Subjects.
} 
translation into Anglo Saxon may reflect usage by a wider number of physicians in the British Isles (viz, literate physicians without knowledge of Latin or Greek; as pointed out by Cameron, it is significant that no fewer than four Anglo Saxon copies of the Herbarium of Pseudo Apuleius survive today). Secondly, as noted above, its inclusion of remedies for a disease that can be identified as malaria may be unique among the surviving Anglo Saxon texts. Finally, the Anglo Saxon translator or translators often rendered Latin plant names that he did not recognize as the names of local plants. The plants selected may reflect to some extent existing local usage (Cameron, 2006).

Hildegard of Bingen: Causae et Curae $\left(12^{\text {th }}\right.$ century $)$

Causaue et Curae is a health handbook written in Latin by Hildegard of Bingen (1098-1179), a Benedictine abbess at Disibodenberg and later, Rupertsberg in RheinlandPfalz. She personally attended and treated the sick, including not only members of her religious community but of the community at large; she also supervised the abbey's herb garden. Much of her writing and music survives today. Although most of her writings are on subjects theological and mystical, Hildegard of Bingen was greatly interested in natural history, particularly the medicinal uses of plants (Anderson, 1977; Pawlik, 1989). Causae et Curae is partly based on historical medicine, partly on observation, and partly on Christian theology. It was transcribed many times during the centuries after its composition, and influenced the writings of future German botanists (Anderson, 1977). The edition used here was translated into English by Patrick Madigan (1994). 
The Physicians of Myddfai (Prior to 1234)

The text of the Physicians of Myddfai (Meddygon Myddfai) is a compilation of prescriptions collected and written down in Middle Welsh by Rhiwallon of Myddfai, court physician to the South Welsh prince, Rhys Gryg (died 1234). The collection is presumed to include much older material. A transcription of the text was included in the Red Book of Hergest (Llyfr Coch Hergest), collected in 1382, and has survived in this form up to the present day (Henderson, 1994; Breverton, 2012). The classic 1861 English translation by John Pughe unfortunately could not be obtained, and therefore a more recent translation by Terry Breverton was used.

Bartholomæus Anglicus: De proprietatibus rerum (Prior to 1283)

Bartholomæus Anglicus (Bartholomew the Englishman) was a Franciscan teacher active in Paris and Saxony during the $13^{\text {th }}$ century. He may possibly have been the protégé of Albertus Magnus (Anderson, 1977). His De proprietatibus rerum (On the properties of things) was written in Latin prior to 1283 . It is an early encyclopedia that includes a section on the medicinal uses of plants. The work originally may have been intended as an educational text for evangelical friars; however, it gained wide popularity in the ensuing centuries and was translated into French, English, Dutch, Spanish, and possibly Bavarian (Anderson, 1977; Keen, 2007). The edition used in this project is a reprint of the 1398 translation into English by John Trevisa. 
Otto Brunfels: Contrafayt Kreüterbioch (1532) and Ander Teyl des Teütschen Contrafayten Kreüterbuchs (1537) ${ }^{11}$

The Contrafayt Kreüterbich (1532, Straßburg) is an early example of a new type of herbal that would become common in the ensuing centuries. Unlike many contemporary medical texts, it is written in German rather than Latin (it is a translation of the Latin Herbarium Vivae Eicones, 1530, by the same author); in the ensuing years, many more herbals would be written in the native language of their country (Arber, 1912). The Kreüterbuich is renowned especially for its naturalistic woodcuts by Hans Weiditz, who based his woodcuts on drawings directly from plant specimens. Illustrations in earlier books were primarily copies of earlier illustrations, and tended to be conceptual or decorative rather than naturalistic (Arber, 1912; Collins, 2000). Herbals of the years following the Contrafayt Kreüterbich began to include illustrations based on observation of plant specimens (Arber, 1912). In its text, the Kreüterbuich draws substantially on earlier authors, including Dioscorides and Pliny, and provides information about the astrological character of the plants, followed by information on how to find and use them. Much effort is spent in trying to identify local plants as those spoken of by Dioscorides (Anderson, 1977). The author, Otto Brunfels (circa 14891534), was a former monk who subsequently converted to Protestantism; after working as a preacher and a schoolmaster, he studied to become a physician (Isely, 1994). A

\footnotetext{
${ }^{11}$ Here, as elsewhere, historical spelling has been preserved whenever possible.
} 
facsimile reprint of the 1532 edition of the Contrafayt Kreüterbuich, including the posthumously published Ander Teyl des Teütschen Contrafayten Kreüterbůchs (1537), was used in this project.

Hieronymus Bock: Kreutterbi̊ch (1572)

In contrast to many earlier and contemporary medical works, the 1539 Kreutterbich of Heironymus Bock (also known as Tragus; 1498-1554) focuses on the empirical identification and uses of local plants, rather than on the identification of local plants as those described by ancient physicians (Anderson, 1977). The book was originally written in German, not Latin, and the style is colloquial (Arber, 1912). The author seems to take delight in relating superstitions about plants, only to disprove or reject them. Hieronymus Bock studied medicine, and later supervised the gardens of the Count Palatine Ludwig; subsequently he became a Lutheran pastor (Anderson, 1977). A facsimile of the 1572 edition of the Kreuterbuch was used in this project.

John Gerard, Dr. Priest, and Thomas Johnson: The Herball or Generall Historie of Plantes (1597 and 1633)

The Herball or Generall History of Plantes, one of the best loved of all English botanical works, originated as a translation of Pemptades by the Belgian botanist Rembert Dodoens (1517-1585). The original translator, a certain Dr. Priest, died before 
being able to ready his translation for publication. The publisher, John Norton, enlisted the assistant of the botanist John Gerard (1545-1612), a surgeon and well known horticulturist (Jackson, 1950). It is possible that Gerard merely rearranged the work before publication (Arber, 1912; Anderson, 1977), but it is also possible that he substantially revised and augmented it with his own work (Isely, 1994; Jackson, 1950); in any case, The Herball was published in 1597 without crediting Dr. Priest. An enlarged and improved edition was published in 1633 by Thomas Johnson (Arber, 1912; Anderson, 1977). Facsimile versions of both editions were used in this project.

Nicolas Culpepper, Peter Cole, and Joseph Blagrave: The English Physician (1677)

The London physician and astrologer Nicolas Culpepper (1616-1654) was a noted proponent of astrological botany, wherein ailments and remedies are related to various planetary influences; in various forms, this doctrine was both controversial and popular throughout the Middle Ages and ensuing centuries, up to the present day (Anderson, 1977). Culpepper was also known for giving medical advice to the poor without fee (Lee, 1950). In 1649, Culpepper caused dismay and outrage among the London College of Physicians by publishing an unauthorized English translation of their Pharmacopeia (as The London Physical Directory; Anderson, 1977; Arber, 1912). Although described by Culpepper's opponents as "very filthily done", this book was terrifically popular and appeared in numerous editions. In 1653, together with Peter Cole, Culpepper published The English Physician, a book of remedies from 369 English herbs. This book too had 
enormous popularity and continued to appear in various editions in the decades after Culpepper's death from consumption in 1654 (Lee, 1950). The version used in this project is a facsimile of an enlarged 1677 edition published by Joseph Blagrave.

William Coles: Adam in Eden, or, Nature's Paradise: The History of Plants, Fruits, Herbs, and Flowers. (1657)

The English botanist William Coles (sometimes spelled Cole; 1626-1662) published his great botanical work, Adam in Eden, or, Nature's Paradise, in 1657. Many of the remedies given relate to the doctrine of signatures, the theory that the shapes of plants indicate their medical uses (e.g. the walnut for disorders of the brain). Giambattista Porta is credited with much of the formal development of this theory as it existed in early modern Europe (in his Phytognomonica, 1588), but the doctrine of signatures has existed in various forms for far longer and in many parts of the world (Arber, 1912; Bennet, 2007). Coles is credited with further development of the doctrine of signatures in his work. He was also the author of another work, The Art of Simpling (1656). In this project, a fascimile of the 1657 edition of Adam in Eden was used.

William Salmon: A Family Dictionary (1696)

William Salmon (1644-1713) practiced medicine in London, sold prescriptions, including his own patent medicines, and practiced astrology and alchemy. He published 
many medical works, including a translation of Sydenham's Practice of Physic (sometimes referred to today for its descriptions of malaria), as well as works on other subjects including theology and travel; he had at one time traveled to New England (Moore, 1950). His Family Dictionary is a domestic handbook, including medical advice, recipes, and instructions for making alcoholic beverages, perfumes, and various medicines. Many of the prescriptions are intended for home manufacture, but others describe patent medicines obtainable at William Salmon's practice. The Family Dictionary is of special interest because it is avowedly directed not at medical practitioners but at the literate layman. The edition used in this project was a facsimile of the expanded second edition, originally published in 1696.

Robert John Thornton: A New Family Herbal (1814)

Robert John Thornton (1783-1837) was a physician, botanist, and lecturer on medical botany. He published two botanical works, including both the New Family Herbal and another work called A New Illustration of the Sexual System of Linnaeus; the beautiful and expensive plates in the latter book unfortunately led to the financial ruin of the author (University of Cambridge Alumni Database, 2009-2011). Despite its name, the New Family Herbal appears to be intended not only for lay people but for physicians as well. Its entries generally include a botanical description, a history of medical use (often including use by country people), a discussion of current usage, and detailed 
advice on dosage and administration. A facsimile of the expanded second edition (1814) was used in this project.

Mrs. M. Grieve: A Modern Herbal (1931)

The herbalist and historian Maude Grieve (1858-1941) published her A Modern Herbal in 1931. Part primary source and part work of history, the book contains the following types of information on hundreds of herbs: firstly, information on historical usage gathered from dozens of primary sources, secondly, folklore and information on use by country people, and thirdly, information on current production and use by herbalists, including cultivation, dosage, method of administration, and chemical constituents when available. A useful feature of the book is its list of many common or country names of plants, without which this project would have been much more difficult. A service index of Latin names of plants was added in 1940, but the book lacks an index by usage, and does not contain a list of the works consulted (although names of sources are given within the text). Neverthelesss, the Modern Herbal is frequently referred to by historians and herbalists, and has been reprinted many times. In this project, a reprint from 1996 was used.

The following is a list of works consulted in which malaria remedies were not found, or in which malaria could not be identified with relative certainty:

Theophrastes: On the Nature of Plants (370-285 B.C.) 
Marcellus: De Medicamentus Liber (On medicaments; $4^{\text {th }}-5^{\text {th }}$ century)

Isidore of Seville: The medical writings (d. 636; Sharpe, 1964)

Bald's Leechbook (circa 950 A.D.)

Leechbook III (perhaps circa 950 A.D.)

Lacnunga (Later than 950 A.D.; Cockayne, 1864-6; Cameron, 2006)

Jean Fernel: De Abditis Rerum Causis (On the hidden causes of things; 1542)

\section{2: Tables of the historical remedies found in this survey}

Following are the remedies for malaria that were discovered in this survey, in the form of two tables. Table 4.1 provides the plants and other substances encountered, organized when possible by Latin name. Plant names used are those currently recommended by the Royal Botanic Garden at Kew (The Plant List, 2013). Some of the substances listed in Table 4.1 were part of more complex remedies; when this is true, the reader is referred to Table 4.2, in which complex remedies are given, organized by the source in which they were found.

A significant difficulty encountered in the course of the project was the accurate identification of malaria in the sources. The variety of the terminology used to describe different diseases and symptoms, as well as the different understanding of the causes of disease, often makes it difficult to determine whether the illness that is being described is malaria or not. The word "malaria" was not commonly used to describe the disease itself until the beginning of the twentieth century, although it was associated with the disease-causing agent during the nineteenth century, and had been used to describe 
unhealthful marsh air for centuries earlier (Russell, 1955; Jarcho, 1993) ${ }^{12}$. For the purpose of this survey the following terms have been regarded as likely to refer to malaria: ague or cold ague, intermittent fever or intermittent, remitting fever, periodic fever, quartan or quartan fever, tertian or tertian fever, aestivoautumnal fever, Dreitägiges Fieber (three-day fever), and Viertägiges Fieber (four-day fever). The terms fever or chills when taken alone were not considered likely to refer to malaria, nor was swelling of the spleen (although a recognized symptom of chronic malaria; Jones, 1909) ${ }^{13}$, as these symptoms are common to multiple ailments. The term quotidian fever was also rejected, although it may also describe malaria (Jones, 1909). Unless a hot ague was specified, ague was accepted as likely to refer to malaria despite the fact that the term "ague" is known to have been used for any acute fever during some periods (Nuttall, 1901; MacArthur, 1954). The vocabularly used in a given source is provided in the table, so that the reader may make his own distinctions. Naturally, there is substantial possibility for error in the identification of disease, particularly when dealing with translated materials. Due to time and language limitations, it had to be assumed that the translator in many cases a medical historian - had made his best effort to translate medical terminology correctly. It is quite possible that not every remedy listed here was in fact used to treat malaria, and it is very likely that some remedies were rejected inappropriately.

\footnotetext{
${ }^{12}$ Russell (1955) and Jarcho (1993) provide a useful discussion of the origins of the term, malaria; these authors and others have shown that it does not originate with the physician Francesco Torti, as is sometimes stated.

${ }^{13}$ According to the Oxford English Dictionary (1971), the term "ague cake" was formerly used to describe enlargement and hardening of the spleen.
} 
The second primary difficulty encountered was the identification of the substances used. Plants in particular are often difficult to identify with certainty, as they have changed their names and classifications many times over the course of millennia (Singer, 1961; De Vriend, 1984). Some plants that are described in ancient texts may not exist today (Vehling, 1977). In many cases, especially in the older texts, the identification provided can only be an informed suggestion. A more complex situation arises when using texts that are themselves historical translations of earlier documents, intended for contemporary use as medical texts. In these cases, it is extremely probable that many of the plants that were unknown to the translator were identified as local or imported plants that were not, in fact, those intended by the original author (De Vriend, 1984; Cameron, 2006). Nevertheless, as these mistranslated plants were presumably then used to treat malaria, they were considered valuable for this project in themselves; no attempt was made to correct false identifications made in historical translations that were used as medical books in their own right. This category includes the following: the translation of Dioscorides by John Goodyer (1655), the De Proprietatibus Rerum of Bartholomæus Anglicus, translated by John Trevisa (1283), and the Herbarium of Pseudo Apuleius, translated into Anglo Saxon during the tenth century or earlier. Several of the other sources, such as Otto Brunfels' Contrafayt Kreüterbůch, also contain translations of remedies from other texts, such as Dioscorides and Pliny.

Not all of the plants in the sources were European natives, or cultivated in the region of the source describing them. Imported plants were nevertheless included here. Some of these plants, such as ginger (Zingiber officinale Roscoe) and black pepper (Piper 
nigrum L.), are used to treat malaria on other continents, and in some cases their antimalarial activity has been studied (Willcox, 2004; Kamaraj 2012). The plants in Table 4.1 were roughly categorized as being either imported or available somewhere in Europe (whether native or cultivated, and not necessarily in the region of the source). In the older literature, a distinction was made between tertian and quartan fevers, and this distinction has been preserved in the table. The distinction may be that between malaria caused by Plasmodium falciparum, vivax, and ovale, leading to the occurrence of the fit on every other day, and malaria caused by Plasmodium malariae, leading to the occurrence of the fit on every third day (Hoeppli, 1959; Adams, 2011). It is recognized today as in the past that not every remedy is appropriate for every form of malaria. The manner in which remedies are prepared and administered is also given in Table 4.1. The possible importance of this will be addressed below.

\section{KEY TO THE TABLES}

Abbreviations used for sources:

Pl - Pliny the Elder: Plinii Naturalis Historiae ( $1^{\text {st }}$ century A.D.)

D - Dioscorides: Herbal ( $1^{\text {st }}$ century A.D.)

AvT - Alexander of Tralles: A work on fevers (525-605 A.D.)

HAP - The Herbarium of Pseudo Apuleius (Anglo Saxon version, $10^{\text {th }}$ century or earlier)

HvB - Hildegard of Bingen: Causae et Curae $\left(12^{\text {th }}\right.$ century)

Myd - The Physicians of Myddfai (Prior to 1234)

BA - Bartholomæus Anglicus: De proprietatibus rerum (Prior to 1283)

OB - Otto Brunfels: Contrafayt Kreüterbuch (1532) and Ander Teyl des Teütschen Contrafayten Kreüterbi̊chs (1537) 
HB - Hieronymus Bock: Kreutterbůch (1572)

Co - William Coles: Adam in Eden, or, Nature's Paradise: The History of Plants, Fruits, Herbs, and Flowers. (1657)

JG - John Gerard, Dr. Priest, and Thomas Johnson: The Herball or Generall Historie of Plantes (1597) and (1633)

$\mathrm{Cu}$ - Nicolas Culpepper, Peter Cole, and Joseph Blagrave: The English Physician (1677)

Sa - William Salmon: A Family Dictionary (1696)

Th - Robert John Thornton: A New Family Herbal (1814)

Gr - Mrs. M. Grieve: A Modern Herbal (1931)

A small $\mathrm{h}$ in parentheses after a source, e.g. $\mathrm{Gr}(\mathrm{h})$, indicates that source is not referring to a treatment contemporary with itself, but to a historical treatment.

Further abbreviations:
Afr. - Africa
Aust. - Australia
Boi. - Boiled
Dec. - Decoction
Dist. - Distillate or distilled
Eur. - Europe (cultivated or native)
Ext. - External or topical
Extr. - Extract
Inf. - Infusion
Ingred. - Ingredients
Int. - Internal
Med. - Mediterranean
Mid. E. - Middle East
N. Afr. - North Africa
New W. - New World
Powd. - Powder or powdered
Purg. - Purgative
Tincture - tinct.
Unsp. - unspecified
With - w/ 
Table 1: Historical remedies used to treat malaria

\begin{tabular}{|c|c|c|c|c|c|}
\hline Scientific name & $\begin{array}{l}\text { Common } \\
\text { name }\end{array}$ & bility & Source & Specificity & $\begin{array}{l}\text { Method/part of } \\
\text { plant }\end{array}$ \\
\hline $\begin{array}{l}\text { Achillea millefolium } \\
\text { L. }\end{array}$ & Yarrow & Eur. & $\begin{array}{l}\text { Gr (h), } \\
\text { HvB }\end{array}$ & $\begin{array}{l}\text { Ague (Gr), Three- } \\
\text { day fever (HvB) }\end{array}$ & $\begin{array}{l}\text { Int., dec. herb } \\
\text { (Gr (h)); Int., } \\
\text { HvB 1 }\end{array}$ \\
\hline Aconitum napellus L. & Wolfbane, Monkshood & Eur. & Th & Intermittent fevers & $\begin{array}{l}\text { Int., w/ caution } \\
\text { (dried leaves } \\
\text { or inspissated } \\
\text { juice) }\end{array}$ \\
\hline Acorus calamus L.? & Bitter flag & Eur. & Gr (h) & Intermittent fevers & Root, Gr 1 \\
\hline $\begin{array}{l}\text { Adiantum capillus- } \\
\text { veneris L. }\end{array}$ & Maidenhair & Eur. & AvT & & Int., AvT 13 \\
\hline $\begin{array}{l}\text { Aegopodium } \\
\text { podagraria } \mathrm{L} .\end{array}$ & Herb Gerard & Eur. & JG & Quartan agues (JG) & $\begin{array}{l}\text { Int., root } \\
\text { powd. in wine } \\
\text { before fit, to } \\
\text { cure (JG) }\end{array}$ \\
\hline $\begin{array}{l}\text { Aesculus } \\
\text { hippocastanum } \mathrm{L} .\end{array}$ & Horse chestnut & Eur. & Gr & Intermittent fevers & Int., inf. Bark \\
\hline $\begin{array}{l}\text { Agrimonia eupatoria } \\
\text { L. }\end{array}$ & Agrimony & Eur. & $\begin{array}{l}\mathrm{Gr}(\mathrm{h}), \\
\mathrm{Cu}\end{array}$ & $\begin{array}{l}\text { Agues, tertian, } \\
\text { quartan }\end{array}$ & $\begin{array}{l}\text { Int., dec. or } \\
\text { juice of herb }\end{array}$ \\
\hline $\begin{array}{l}\text { Ailanthus altissima } \\
\text { (Mill.) Swingle }\end{array}$ & Tree of heaven & $\begin{array}{l}\text { Eur., } \\
\text { Asia }\end{array}$ & $\mathrm{Gr}$ & $\begin{array}{l}\text { Malaria ("the } \\
\text { action of the trees } \\
\text { in malarial districts } \\
\text { is considered to } \\
\text { resemble that of } \\
\text { Eucalyptus" } \\
\text { (elsewhere } \\
\text { recommended to } \\
\text { treat intermittent } \\
\text { fevers) }\end{array}$ & Int., inf. Bark \\
\hline $\begin{array}{l}\text { Ajuga chamaepitys } \\
\text { (L.) Schreb. }\end{array}$ & Yellow bugle & Eur. & $\mathrm{Gr}$ & Agues & $\begin{array}{l}\text { Int., powd. or } \\
\text { inf. Leaves }\end{array}$ \\
\hline $\begin{array}{l}\text { Allium } \\
\text { ampeloprasum } \mathrm{L} .\end{array}$ & Leek & Eur. & AvT & Tertians & Int., AvT 14 \\
\hline Allium sativum L. & Garlic & Eur. & $\mathrm{Pl}, \mathrm{Th}$ & Quartans & $\begin{array}{l}\text { Int., one head, } \\
\text { Pl } 3\end{array}$ \\
\hline $\begin{array}{l}\text { Alnus glutinosa (L.) } \\
\text { Gaertn. }\end{array}$ & Alder & Eur. & $\mathrm{Gr}$ & Agues & Int., dec. bark \\
\hline $\begin{array}{l}\text { Aloe vera }(\mathrm{L} .) \\
\text { Burm.f. }\end{array}$ & Aloe & Afr. & $\mathrm{Sa}$ & Agues & $\begin{array}{l}\text { Int., Sa } 3 \text { or } \\
\text { Sa } 4\end{array}$ \\
\hline $\begin{array}{l}\text { Alpinia galanga (L.) } \\
\text { Willd., A. } \\
\text { officinarum Hance }\end{array}$ & $\begin{array}{l}\text { China root (galangal, } \\
\text { galingale) }\end{array}$ & $\begin{array}{l}\text { Eur., } \\
\text { Asia }\end{array}$ & $\begin{array}{l}\mathrm{Cu}, \\
\mathrm{HvB}\end{array}$ & $\begin{array}{l}\text { Agues, quotidian or } \\
\text { intermittent }(\mathrm{Cu}) \text {, } \\
\text { Three-day fever } \\
(\mathrm{HvB})\end{array}$ & $\begin{array}{l}\text { Int., boi. in } \\
\text { wine, water, or } \\
\text { broth }(\mathrm{Cu}) \text {, Int. } \\
\text { HvB } 2\end{array}$ \\
\hline $\begin{array}{l}\text { Alstonia constricta } \\
\text { F. Muell. }\end{array}$ & Alstonia bark & Aust & $\mathrm{Gr}$ & Agues & $\begin{array}{l}\text { Int., powd. } \\
\text { Bark }\end{array}$ \\
\hline $\begin{array}{l}\text { Alstonia scholaris } \\
\text { (L.) R. Br. }\end{array}$ & Dita bark & Asia & $\mathrm{Gr}$ & Malarial fever & $\begin{array}{l}\text { Int., inf. of } \\
\text { bark }\end{array}$ \\
\hline $\begin{array}{l}\text { Anacyclus pyrethrum } \\
\text { (L.) Lag. }\end{array}$ & $\begin{array}{l}\text { Pellitory of Spain, } \\
\text { Spanish chamomile }\end{array}$ & Eur. & JG & $\begin{array}{l}\text { Agues of long } \\
\text { standing }\end{array}$ & $\begin{array}{l}\text { Int., root, } \\
\text { against }\end{array}$ \\
\hline
\end{tabular}




\begin{tabular}{|c|c|c|c|c|c|}
\hline & & & & & shivering \\
\hline $\begin{array}{l}\text { Anacyclus pyrethrum } \\
\text { (L.) Lag. }\end{array}$ & Bertram & Eur. & OB & $\begin{array}{l}\text { Longstanding } \\
\text { fevers w/ shivering } \\
\text { and cold } \\
\text { ("langwyrigen } \\
\text { feberen so mit } \\
\text { shauderen/ zytteren } \\
\text { und kelte angond"). }\end{array}$ & Int. \\
\hline Anagallis arvensis L. & Scarlet pimpernel & Eur. & $\begin{array}{l}\text { HAP } \\
(?), \\
\text { Mdf }\end{array}$ & $\begin{array}{l}\text { Agues (cold fever) } \\
\text { (HAP), Intermittent } \\
\text { fevers (Mdf) }\end{array}$ & $\begin{array}{l}\text { Ext., boi.. in } \\
\text { oil, before fit } \\
\text { (HAP), Ext. } \\
\text { Mdf 1, Int. } \\
\text { Mdf 2 }\end{array}$ \\
\hline $\begin{array}{l}\text { Anchusa officinalis } \\
\text { L., Alkanna } \\
\text { tinctoria (L.) } \\
\text { Tausch, Anchusa } \\
\text { azurea Mill. }\end{array}$ & $\begin{array}{l}\text { Alkanet, bugloss, or } \\
\text { wild bugloss }\end{array}$ & Eur. & $\begin{array}{l}\text { JG, D, } \\
\text { Pl (h) }\end{array}$ & $\begin{array}{l}\text { Agues and diseases } \\
\text { of spleen }(\mathrm{JG}) \text {, } \\
\text { Tertians, quartans } \\
(\mathrm{D}, \mathrm{P1})\end{array}$ & $\begin{array}{l}\text { Int. dec. root, } \\
\text { w/ mead or } \\
\text { honeyed water } \\
\text { (JG), Herb boi. } \\
\text { in wine (D), } \\
\text { pith, amulet } \\
\text { (Pl). }\end{array}$ \\
\hline $\begin{array}{l}\text { Anemone nemorosa } \\
\text { L. }\end{array}$ & Wood anemone & Eur. & $\begin{array}{l}\text { Gr (h), } \\
\text { Pl (h) }\end{array}$ & $\begin{array}{l}\text { Agues (tertian) } \\
\text { (Gr), Tertian and } \\
\text { quartan (Pl) }\end{array}$ & $\begin{array}{l}\text { Int. root, } \\
\text { leaves, juice } \\
(\mathrm{Gr}), \text { Amulet } \\
(\mathrm{Pl})\end{array}$ \\
\hline $\begin{array}{l}\text { Anethum gravelans } \\
\text { L. }\end{array}$ & Dill & Eur. & AvT & & Int., dec. herb \\
\hline $\begin{array}{l}\text { Angelica } \\
\text { archangelica } \mathrm{L} .\end{array}$ & Angelica & Eur. & $\mathrm{Sa}$ & $\begin{array}{l}\text { Agues, prevent and } \\
\text { cure }(\mathrm{Sa})\end{array}$ & $\begin{array}{l}\text { Int., root } \\
\text { powd. Sa } 5\end{array}$ \\
\hline $\begin{array}{l}\text { Angostura trifoliata } \\
\text { (Willd.) T.S.Elias }\end{array}$ & Angostura & $\begin{array}{l}\text { New } \\
\text { W. }\end{array}$ & $\mathrm{Gr}$ & $\begin{array}{l}\text { "Some doctors } \\
\text { prefer Angostura } \\
\text { Bark to Cinchona } \\
\text { for use in fever } \\
\text { cases" }\end{array}$ & $\begin{array}{l}\text { inf. of powd. } \\
\text { bark }\end{array}$ \\
\hline $\begin{array}{l}\text { Anthemis chia L., } A \text {. } \\
\text { rosea } \mathrm{Sm} .\end{array}$ & Anthemis & $\begin{array}{l}\text { Mid. } \\
\text { E. }\end{array}$ & $\mathrm{D}$ & $\begin{array}{l}\text { Recurring fevers } \\
\text { (D) }\end{array}$ & \\
\hline Apium graveolans $\mathrm{L}$. & Celery & Eur. & $\begin{array}{l}\text { AvT, } \\
\text { JG }\end{array}$ & $\begin{array}{l}\text { Agues (lingering), } \\
\text { tertians (JG) }\end{array}$ & $\begin{array}{l}\text { Int., Juice in } \\
\text { syrup (JG), } \\
\text { Int., AvT } 13\end{array}$ \\
\hline $\begin{array}{l}\text { Aristolochia rotunda } \\
\text { L. }\end{array}$ & Birthwort, Smearwort & Eur. & $\begin{array}{l}\text { JG, } \\
\text { HAP }\end{array}$ & $\begin{array}{l}\text { Agues (shaking } \\
\text { and shivering of), } \\
\text { hardness of spleen } \\
\text { (JG), Fevers (not } \\
\text { specific) (HAP) }\end{array}$ & $\begin{array}{l}\text { Int., Dried and } \\
\text { burnt (the } \\
\text { smoke is } \\
\text { inhaled) }\end{array}$ \\
\hline $\begin{array}{l}\text { Aristolochia } \\
\text { serpentaria } \mathrm{L} .\end{array}$ & Snakeroot & $\begin{array}{l}\text { New } \\
\text { W. }\end{array}$ & $\mathrm{Gr}, \mathrm{Th}$ & $\begin{array}{l}\text { Intermittent fevers } \\
(\mathrm{Gr}, \mathrm{Th})\end{array}$ & $\begin{array}{l}\text { Int., dried } \\
\text { roots }(\mathrm{Gr}), \mathrm{Th} \\
3\end{array}$ \\
\hline $\begin{array}{l}\text { Armoracia rusticana } \\
\text { P.Gaertn., B.Mey. \& } \\
\text { Scherb. }\end{array}$ & $\begin{array}{l}\text { Horse radish, Dittander } \\
\text { or Pepperwort }\end{array}$ & & JG & $\begin{array}{l}\text { Quartan Agues } \\
\text { (purgative) }\end{array}$ & $\begin{array}{l}\text { Int., syrup } \\
\text { made from } \\
\text { rinds in vinega } \\
\text { r\& honey, as } \\
\text { purgative } \\
\text { (vomiting) }\end{array}$ \\
\hline
\end{tabular}




\begin{tabular}{|c|c|c|c|c|c|}
\hline & & & & & (JG) \\
\hline Arnica montana L. & Mountain arnica & Eur. & Th & Intermittent fevers & Int., flowers \\
\hline $\begin{array}{l}\text { Artemisia abrotanum } \\
\text { L. }\end{array}$ & Southernwood & Eur. & $\begin{array}{l}\text { JG, Gr } \\
\text { (h) }\end{array}$ & Agues & $\begin{array}{l}\text { Ext.?, with oil } \\
\text { to remove } \\
\text { shivering of } \\
\text { fits (JG), Ext., } \\
\text { annoint } \\
\text { backbone to } \\
\text { prevent fit (Gr, } \\
\text { h) }\end{array}$ \\
\hline $\begin{array}{l}\text { Artemisia absinthium } \\
\text { L. }\end{array}$ & Wormwood & Eur. & $\begin{array}{l}\text { AvT, } \\
\text { AvT } \\
\text { (h), } \\
\text { Mdf, } \\
\text { Gr, Th, } \\
\text { Co }\end{array}$ & $\begin{array}{l}\text { Quartans (AvT), } \\
\text { Tertians (AvT), } \\
\text { Intermittent fevers } \\
\text { (Mdf, Th), Agues } \\
\text { (Gr (h)), } \\
\text { Intermittent agues } \\
\text { (Co) }\end{array}$ & $\begin{array}{l}\text { Dec. herb } \\
\text { (AvT (h)), Ext. } \\
\text { (AvT), Int. } \\
\text { Mdf 3, Int. } \\
\text { powd. dried } \\
\text { flowers (Gr } \\
\text { (h)), dec. herb } \\
\text { (Th), Int. dec. } \\
\text { powd.,or } \\
\text { juice, or inf. in } \\
\text { wine (Co) }\end{array}$ \\
\hline $\begin{array}{l}\text { Artemisia maritima } \\
\text { L. }\end{array}$ & Sea wormwood & Eur. & JG & $\begin{array}{l}\text { Intermittent fevers } \\
\text { (Gr) }\end{array}$ & $\begin{array}{l}\text { Young } \\
\text { flowering tops, } \\
\text { shoots }\end{array}$ \\
\hline Artemisia pontica L. & $\begin{array}{l}\text { Pontic wormwood, } \\
\text { Roman wormwood }\end{array}$ & Eur. & JG & $\begin{array}{l}\text { Agues (lingering), } \\
\text { Tertians }\end{array}$ & \\
\hline Artemisia vulgaris L. & Mugwort & Eur. & $\begin{array}{l}\text { Gr, } \\
\text { Mdf, } \\
\text { Th }\end{array}$ & $\begin{array}{l}\text { Intermittent fevers } \\
\text { (Gr, Mdf), Ague } \\
\text { (Th) }\end{array}$ & $\begin{array}{l}\text { Int., juice and } \\
\text { inf. of herb } \\
\text { (Gr, Th), Ext., } \\
\text { Mdf } 2\end{array}$ \\
\hline Arum maculatum L. & $\begin{array}{l}\text { Arum, Cuckoo's Pint, } \\
\text { Wake Robin }\end{array}$ & Eur. & Th & Intermittent fevers & \\
\hline $\begin{array}{l}\text { Asarum europaeum } \\
\text { L. }\end{array}$ & $\begin{array}{l}\text { European wild ginger } \\
\text { (Asarabacca, } \\
\text { Haselwurz, Hazelwort) }\end{array}$ & Eur. & $\begin{array}{l}\text { OB, } \\
\text { JG, } \\
\text { Co, Gr } \\
\text { (h) }\end{array}$ & $\begin{array}{l}\text { Lingering and } \\
\text { quartan fevers } \\
\text { (OB), Quartans, } \\
\text { agues of long } \\
\text { continuance (JG), } \\
\text { Agues (Gr from } \\
\mathrm{Cu}, \mathrm{Co} \text { ) }\end{array}$ & $\begin{array}{l}\text { Roots, inf. or } \\
\text { boi. (purgative } \\
\text { by vomiting) } \\
\text { (JG), Int., Gr. } \\
\text { 4; Ext., Co 6; } \\
\text { Int., inf. leaves } \\
\& \text { roots in } \\
\text { wine (Co) }\end{array}$ \\
\hline $\begin{array}{l}\text { Asplenium } \\
\text { scolopendrium L. }\end{array}$ & $\begin{array}{l}\text { Hart's tongue } \\
\text { (Hirzzung, Wald } \\
\text { Asplenon) }\end{array}$ & Eur. & HB & Quartans (HB) & $\begin{array}{l}\text { Int., whole } \\
\text { plant stewed in } \\
\text { wine }\end{array}$ \\
\hline $\begin{array}{l}\text { Athamanta cretensis } \\
\text { L. }\end{array}$ & Candy carrot & Eur. & AvT & Quartans & Int., AvT 15 \\
\hline $\begin{array}{l}\text { Athamanta } \\
\text { macedonia (L.) } \\
\text { Spreng. }\end{array}$ & Macedonian parsely & Eur. & AvT & Quartans & Int., AvT 11 \\
\hline Avena sativa $\mathrm{L}$. & Oats & Eur. & AvT & $\begin{array}{l}\text { Tertians, possibly } \\
\text { quartans }\end{array}$ & Int., gruel \\
\hline Bellis perennis L. & $\begin{array}{l}\text { Field daisy, common } \\
\text { daisy, English daisy }\end{array}$ & Eur. & JG & Agues & $\begin{array}{l}\text { Int., dec. in } \\
\text { water (JG) }\end{array}$ \\
\hline
\end{tabular}




\begin{tabular}{|c|c|c|c|c|c|}
\hline Berberis vulgaris L. & Barberry & Eur. & $\begin{array}{l}\mathrm{Sa}, \mathrm{Gr}, \\
\mathrm{JG}\end{array}$ & $\begin{array}{l}\text { Agues (Sa), } \\
\text { intermittent fevers } \\
(\mathrm{Gr})\end{array}$ & $\begin{array}{l}\text { Int., inner bark } \\
\text { boi. in wine } \\
\text { (Sa), Int., } \\
\text { powd. bark } \\
\text { (Gr) }\end{array}$ \\
\hline $\begin{array}{l}\text { Betula pubescens } \\
\text { Ehrh. }\end{array}$ & Birch & Eur. & $\mathrm{Gr}$ & Intermittent fevers & Inner bark \\
\hline Bidens tripartita L. & Water agrimony & Eur. & $\begin{array}{l}\mathrm{Gr}(\mathrm{h}), \\
\mathrm{Cu}\end{array}$ & Agues (tertian) & Herb \\
\hline $\begin{array}{l}\text { Bituminaria } \\
\text { bituminosa (L.) } \\
\text { C.H.Stirt. }\end{array}$ & $\begin{array}{l}\text { Trifolium, trefoil, pitch } \\
\text { trefoil }\end{array}$ & Med. & $\mathrm{D}$ & Tertians, Quartans & $\begin{array}{l}\text { Int., leaves or } \\
\text { seeds in wine } \\
\text { (D) }\end{array}$ \\
\hline Blechnum sp. & Blechnum & Eur. & HvB & Three-day fever & Int. HvB 1 \\
\hline Borago officinalis L. & Borage & Eur. & $\begin{array}{l}\mathrm{HB}, \\
\mathrm{Mdf}\end{array}$ & $\begin{array}{l}\text { Tertians, Quartans } \\
\text { (HB), Intermittent } \\
\text { fevers (Mdf) }\end{array}$ & $\begin{array}{l}\text { Int., whole } \\
\text { plant stewed in } \\
\text { wine (HB), Int. } \\
\text { Mdf 2 }\end{array}$ \\
\hline $\begin{array}{l}\text { Calendula officinalis } \\
\text { L. and others }\end{array}$ & Marigold & Eur. & $\mathrm{JG}, \mathrm{Gr}$ & $\begin{array}{l}\text { Pestilential agues } \\
\text { (JG), Ague (Gr) }\end{array}$ & Any $(\mathrm{JG})$ \\
\hline Capparis spinosa L. & Capers & Eur. & JG, D & Quartans (JG) & $\begin{array}{l}\text { Int., w/ food } \\
\text { (JG) }\end{array}$ \\
\hline $\begin{array}{l}\text { Capsella bursa- } \\
\text { pastoris (L.) Medik. }\end{array}$ & Shepherd's Purse & Eur. & Co & $\begin{array}{l}\text { Ague (to prevent } \\
\text { the fits) }\end{array}$ & $\begin{array}{l}\text { Int., juice of } \\
\text { the herb w/ } \\
\text { wine }\end{array}$ \\
\hline Capsicum annuum L. & $\begin{array}{l}\text { Capsicum, Guinea } \\
\text { pepper, Chilli pepper }\end{array}$ & & Th & Intermittent fevers & Int., seeds \\
\hline Carum carvi $\mathrm{L}$ & Caraway & Eur. & Mdf & Intermittent fevers & Int., Mdf 2 \\
\hline $\begin{array}{l}\text { Castanea vesca } \\
\text { Gaertn. }\end{array}$ & Sweet chestnut & Eur. & $\mathrm{Gr}$ & Agues & $\begin{array}{l}\text { Int., dec. } \\
\text { leaves }\end{array}$ \\
\hline $\begin{array}{l}\text { Centaurea benedicta } \\
\text { (L.) L. }\end{array}$ & $\begin{array}{l}\text { Blessed thistle (Cardo } \\
\text { Benedict, Holy thistle) }\end{array}$ & Eur. & $\begin{array}{l}\text { JG, } \\
\mathrm{HB}, \\
\mathrm{Gr}, \\
\mathrm{OB}, \\
\mathrm{Co}\end{array}$ & $\begin{array}{l}\text { Quartan (JG, HB, } \\
\text { OB, Co), Ague } \\
\text { (Co), Intermittent } \\
\text { fevers (Gr) }\end{array}$ & $\begin{array}{l}\text { Int., hot, boi. } \\
\text { in wine, extr. } \\
\text { of leaves (JG), } \\
\text { powd. in wine } \\
\text { (HB), inf. of } \\
\text { herb as } \\
\text { diaphoretic } \\
\text { (Gr) Int., } \\
\text { powd. or dec. } \\
\text { of the herb in } \\
\text { posset for any } \\
\text { ague; extr. for } \\
\text { quartan ague } \\
\text { (Co) }\end{array}$ \\
\hline $\begin{array}{l}\text { Centurium erythraea } \\
\text { Rafn }\end{array}$ & Centaury & Eur. & $\begin{array}{l}\text { JG, Sa, } \\
\text { Gr (h) }\end{array}$ & $\begin{array}{l}\text { Lingering agues } \\
\text { (JG), Tertians (Sa), } \\
\text { Intermittent fevers } \\
\text { (Gr) }\end{array}$ & $\begin{array}{l}\text { Int., dec. (JG, } \\
\text { Sa), Herb and } \\
\text { leaves (Gr) }\end{array}$ \\
\hline $\begin{array}{l}\text { Chamaemelum } \\
\text { nobile (L.) All. }\end{array}$ & $\begin{array}{l}\text { Chamomile, Roman } \\
\text { chamomile }\end{array}$ & Eur. & $\begin{array}{l}\text { JG, } \\
\text { AvT, } \\
\text { Gr, Th, } \\
\text { Co }\end{array}$ & $\begin{array}{l}\text { Agues (Co), Agues } \\
\text { in children, cold } \\
\text { Agues (JG), } \\
\text { Quartans (AvT), } \\
\text { Intermittent fevers }\end{array}$ & $\begin{array}{l}\text { Int. boi. in } \\
\text { posset ale } \\
\text { (JG), Ext. } \\
\text { (AvT), Int., } \\
\text { inf. of flowers }\end{array}$ \\
\hline
\end{tabular}




\begin{tabular}{|c|c|c|c|c|c|}
\hline & & & & (Gr, Th) & $\begin{array}{l}\text { (Gr, Th), Th } 1 \\
\text { (Th), dec. } \\
\text { flowers (Co) }\end{array}$ \\
\hline $\begin{array}{l}\text { Chelidonium majus } \\
\text { L. }\end{array}$ & Greater celandine & Eur. & Th (h) & Intermittent fevers & Int., herb juice \\
\hline $\begin{array}{l}\text { Chionanthus } \\
\text { virginicus L. }\end{array}$ & $\begin{array}{l}\text { Fringe tree (Old Man's } \\
\text { Beard) }\end{array}$ & $\begin{array}{l}\text { New } \\
\text { W. }\end{array}$ & $\mathrm{Gr}$ & Intermittent fevers & $\begin{array}{l}\text { Int., extr. of } \\
\text { dried root bark }\end{array}$ \\
\hline $\begin{array}{l}\text { Cichorium endiva } \\
\text { L.? }\end{array}$ & Endive & Eur. & AvT & Tertians, quartans & Stalks \\
\hline Cicorium intybus L. & Chicory & Eur. & Gr (h) & Agues & Int., Gr 2 \\
\hline Cinchona sp. & $\begin{array}{l}\text { Peruvian bark, } \\
\text { cinchona }\end{array}$ & $\begin{array}{l}\text { New } \\
\text { W. }\end{array}$ & $\begin{array}{l}\text { Sa, } \\
\text { Gr?, } \\
\text { Th }\end{array}$ & $\begin{array}{l}\text { Agues (Sa), } \\
\text { Febrifuge (Gr), } \\
\text { Intermittent fevers } \\
\text { (Th) }\end{array}$ & $\begin{array}{l}\text { Int., bark in } \\
\text { wine, } \\
\text { sweetened } \\
\text { (Sa), Int., dec. } \\
\text { of bark (Gr, } \\
\text { Th) }\end{array}$ \\
\hline $\begin{array}{l}\text { Cinnamomum verum } \\
\text { J.Presl and C. cassia } \\
\text { (L.) J.Presl }\end{array}$ & Cinnamon & Asia & $\mathrm{Sa}$ & Agues & $\begin{array}{l}\text { Int., Sa } 2 \text { or } \\
\text { Sa } 3\end{array}$ \\
\hline Cistus creticus L.? & Ladanum (Labdanum) & Med. & $\mathrm{Pl}$ & Tertians & \\
\hline $\begin{array}{l}\text { Citrullus colocynthis } \\
\text { (L.) Schrad. }\end{array}$ & Colocynth & $\begin{array}{l}\text { Mid. } \\
\text { E. }\end{array}$ & $\begin{array}{l}\text { AvT, } \\
\text { HB } \\
\text { (h), Pl, } \\
\text { BA }\end{array}$ & $\begin{array}{l}\text { Quartans (HB, } \\
\text { AvT, Pl, BA), } \\
\text { Tertians (HB, Pl) }\end{array}$ & $\begin{array}{l}\text { Int., fruit AvT } \\
\text { 7, Int., seeds } \\
\text { (HB), Ext., } \\
\text { seeds, amulet } \\
\text { (Pliny) }\end{array}$ \\
\hline $\begin{array}{l}\text { Citrus limon (L.) } \\
\text { Osbeck }\end{array}$ & Lemon & Eur. & $\begin{array}{l}\text { JG, Gr, } \\
\text { Th }\end{array}$ & $\begin{array}{l}\text { Agues (JG), } \\
\text { Antiperiodic (Gr), } \\
\text { Remittent fever } \\
\text { (Th) }\end{array}$ & $\begin{array}{l}\text { Int., fruit juice } \\
\text { w/ aqua vitae } \\
\text { at approach of } \\
\text { fit; Int., dist. } \\
\text { Fruit; Int., dec. } \\
\text { fruit (Gr), Int., } \\
\text { juice, saturated } \\
\text { w/ salt (Th) }\end{array}$ \\
\hline Citrus medica L. & Citron & Eur. & AvT & & Peels \\
\hline $\begin{array}{l}\text { Clinopodium nepeta } \\
\text { (L.) Kuntze } \\
\text { subsp.glandululosum }\end{array}$ & $\begin{array}{l}\text { Mountain mint, lesser } \\
\text { calamint }\end{array}$ & Eur. & $\begin{array}{l}\text { JG, Gr } \\
\text { (h), Cu }\end{array}$ & Agues & $\begin{array}{l}\text { Int., alone or } \\
\text { w/ mead or } \\
\text { honeyed water } \\
\text { to remove } \\
\text { shivering, Ext. } \\
\text { boi. in salad } \\
\text { oil to remove } \\
\text { shivering (JG) }\end{array}$ \\
\hline $\begin{array}{l}\text { Commiphora myrrha } \\
\text { (Nees.) Engl. and } \\
\text { others }\end{array}$ & Myrrh & $\begin{array}{l}\text { Mid. } \\
\text { E., } \\
\text { N. } \\
\text { Afr. }\end{array}$ & $\begin{array}{l}\mathrm{D}, \mathrm{Sa} \\
\mathrm{Cu}\end{array}$ & $\begin{array}{l}\text { Agues, esp. } \\
\text { Quartans }(\mathrm{D}, \mathrm{Cu}) \text {, } \\
\text { Ague or quartan } \\
\text { ague }(\mathrm{Sa})\end{array}$ & $\begin{array}{l}\text { Int. w/ pepper } \\
\text { and water (D), } \\
\text { Int. Sa 3, in } \\
\text { wine for } \\
\text { quartan (Sa), } \\
\text { Int. two hours } \\
\text { before the fit } \\
\text { to prevent } \\
\text { shaking; For } \\
\text { quartans, in }\end{array}$ \\
\hline
\end{tabular}




\begin{tabular}{|c|c|c|c|c|c|}
\hline & & & & & $\begin{array}{l}\text { muscadine } \\
\text { before the fit, } \\
\text { to provoke } \\
\text { sweating }(\mathrm{Cu})\end{array}$ \\
\hline $\begin{array}{l}\text { Conium maculatum } \\
\text { L. }\end{array}$ & Hemlock & Eur. & AvT & $\begin{array}{l}\text { Quartans (provoke } \\
\text { sleep to reduce } \\
\text { severity of fit) }\end{array}$ & Int., AvT 16 \\
\hline $\begin{array}{l}\text { Consolida regalis } \\
\text { Gray? }\end{array}$ & Larkspur & Eur. & HAP & Quartans & $\begin{array}{l}\text { Int., juice } \mathrm{w} / \\
\text { pepper, for } \\
\text { three days. }\end{array}$ \\
\hline $\begin{array}{l}\text { Convolvulus arvensis } \\
\text { L. }\end{array}$ & Field bindweed & Eur. & $\mathrm{D}$ & Intermittent fevers & Ext. w/ oil \\
\hline $\begin{array}{l}\text { Convolvulus } \\
\text { Scammonia L. }\end{array}$ & $\begin{array}{l}\text { Scammony or purging } \\
\text { bindweed }\end{array}$ & Eur. & $\begin{array}{l}\text { Sa, JG, } \\
\text { AvT }\end{array}$ & $\begin{array}{l}\text { Tertians (JG, AvT), } \\
\text { quartans (AvT) }\end{array}$ & $\begin{array}{l}\text { JG } 3(\mathrm{JG}) \text {, } \\
\text { Int., Sa } 3 \text { and } \\
\text { Sa } 4 \text { (Sa), Int., } \\
\text { juice as a mild } \\
\text { purgative; or } \\
\text { AvT } 9\end{array}$ \\
\hline $\begin{array}{l}\text { Coriandrum sativum } \\
\text { L. }\end{array}$ & Coriander & Eur. & $\mathrm{Pl}, \mathrm{OB}$ & Tertians & $\begin{array}{l}\text { Int., grains, or } \\
\text { Ext. in } \\
\text { ointment to } \\
\text { forehead }(\mathrm{Pl})\end{array}$ \\
\hline Cornus florida $\mathrm{L}$. & American boxwood & $\begin{array}{l}\text { New } \\
\text { W. }\end{array}$ & $\mathrm{Gr}$ & Intermittent fevers & Int., root bark \\
\hline Cornus sericea L. & Red American osier & $\begin{array}{l}\text { New } \\
\text { W. }\end{array}$ & $\mathrm{Gr}$ & $\begin{array}{l}\text { "Active properties } \\
\text { similar to those } \\
\text { found in Peruvian } \\
\text { bark" }\end{array}$ & \\
\hline Crocus sativus L. & Saffron & Eur. & $\mathrm{Sa}$ & $\begin{array}{l}\text { Agues (tertian) } \\
(\mathrm{Sa})\end{array}$ & Int., $\mathrm{Sa} 4$ \\
\hline $\begin{array}{l}\text { Croton eluteria (L.) } \\
\text { W.Wright }\end{array}$ & $\begin{array}{l}\text { Cascarilla, Willow- } \\
\text { leaved croton }\end{array}$ & $\begin{array}{l}\text { New } \\
\text { W. }\end{array}$ & $\mathrm{Th}$ & $\begin{array}{l}\text { Agues/Remitting } \\
\text { fevers }\end{array}$ & Int., bark \\
\hline Cucumis melo L. & Melon & Eur. & AvT & Quartans (some) & $\begin{array}{l}\text { Int., as part of } \\
\text { cooling diet }\end{array}$ \\
\hline $\begin{array}{l}\text { Cucurbitae sp. } \\
\text { (various) }\end{array}$ & Gourd or cucumber & Eur. & $\begin{array}{l}\text { BA, } \\
\text { JG (h) }\end{array}$ & Agues (BA, JG) & $\begin{array}{l}\text { Int., roasted or } \\
\text { fried (BA); } \\
\text { Placed in bed } \\
\text { w/ a sleeping } \\
\text { infant sick w/ } \\
\text { ague, to cure } \\
\text { (JG) }\end{array}$ \\
\hline Curcuma longa $\mathrm{L}$. & Turmeric & Asia & Thr & Intermittent fevers & Int., powd. \\
\hline $\begin{array}{l}\text { Curcuma zedoaria } \\
\text { (Christm.) Roscoe }\end{array}$ & Zedoary & Asia & $\mathrm{Gr}$ & Antiperiodic & $\begin{array}{l}\text { Int., alone or } \\
\text { w/ aloe }\end{array}$ \\
\hline $\begin{array}{l}\text { Cuscuta epithymum } \\
\text { L. and others }\end{array}$ & Dodder, Hell weed & Eur. & $\begin{array}{l}\text { JG, Sa, } \\
\text { AvT, } \\
\text { Gr (h) }\end{array}$ & $\begin{array}{l}\text { Long tertians (JG), } \\
\text { Quartans (JG, } \\
\text { AvT), agues in } \\
\text { children (JG, Sa, } \\
\text { Gr) }\end{array}$ & $\begin{array}{l}\text { Int., that } \\
\text { growing upon } \\
\text { brambles (JG), } \\
\text { that growing } \\
\text { on thyme, AvT } \\
7 \text { and }(\mathrm{Sa})\end{array}$ \\
\hline $\begin{array}{l}\text { Cydonia oblonga } \\
\text { Mill. }\end{array}$ & Quince & Eur. & $\mathrm{AvT}$ & $\begin{array}{l}\text { Tertians, quartans } \\
(\text { AvT) }\end{array}$ & Int. \\
\hline
\end{tabular}




\begin{tabular}{|c|c|c|c|c|c|}
\hline $\begin{array}{l}\text { Cynoglossum } \\
\text { officinale L. }\end{array}$ & Hound's tongue & Eur. & $\begin{array}{l}\text { HAP, } \\
\text { Pl }\end{array}$ & $\begin{array}{l}\text { Tertians, Quartans } \\
\text { (HAP, Pl) }\end{array}$ & $\begin{array}{l}\text { Int., root boi.in } \\
\text { water (HAP), } \\
\text { Int. (Pl) }\end{array}$ \\
\hline $\begin{array}{l}\text { Drosera anglica } \\
\text { Huds. }\end{array}$ & English sundew & Eur. & $\mathrm{Sa}$ & Quartans & $\begin{array}{l}\text { Ext., dist. } \\
\text { water of plant } \\
\text { applied to the } \\
\text { pulse for } 6 \\
\text { hours }\end{array}$ \\
\hline $\begin{array}{l}\text { Dysphania } \\
\text { ambrosioides (L.) } \\
\text { Mosyakin \& } \\
\text { Clemants }\end{array}$ & American wormseed & $\begin{array}{l}\text { New } \\
\text { W. }\end{array}$ & $\mathrm{Gr}$ & Malaria & $\begin{array}{l}\text { Int., the } \\
\text { volatile oil }\end{array}$ \\
\hline $\begin{array}{l}\text { Eucalyptus globulus } \\
\text { Labill. }\end{array}$ & Eucalyptus & Aust & $\mathrm{Gr}$ & Intermittent fever & Int., extr. \\
\hline $\begin{array}{l}\text { Eupatorium } \\
\text { perfoliatum } \mathrm{L} .\end{array}$ & Boneset/Thoroughwort & $\begin{array}{l}\text { New } \\
\text { W. }\end{array}$ & $\mathrm{Gr}$ & Intermittent fevers & Herb \\
\hline Euphorbia esula L. & $\begin{array}{l}\text { Leafy spurge, } \\
\text { Wolffsmilch }\end{array}$ & Eur. & $\mathrm{OB}$ & Quartans & $\begin{array}{l}\text { Int., powd., } \\
\text { OB } 2\end{array}$ \\
\hline $\begin{array}{l}\text { Ferula assa-foetida } \\
\text { L. }\end{array}$ & $\begin{array}{l}\text { Asafoetida (Asafetida), } \\
\text { Devil's dung }\end{array}$ & $\begin{array}{l}\text { Mid. } \\
\text { E. }\end{array}$ & $\mathrm{Cu}$ & $\begin{array}{l}\text { Agues (the shaking } \\
\text { fit), Quartans (Cul) }\end{array}$ & $\begin{array}{l}\text { Int., } \mathrm{Cu} 1 \text { and } \\
\mathrm{Cu} 2\end{array}$ \\
\hline
\end{tabular}

\begin{tabular}{|c|c|c|c|c|c|}
\hline $\begin{array}{l}\text { Ferula gummosa } \\
\text { Bois., F. galbanifera } \\
\text { (Mill.) W.D.J.Koch? }\end{array}$ & Galbanum & $\begin{array}{l}\text { Mid. } \\
\text { E. }\end{array}$ & $\begin{array}{l}\mathrm{Sa}, \\
\mathrm{AvT}\end{array}$ & Agues & $\begin{array}{l}\text { Int., Sa 3, Int. } \\
\text { AvT } 1\end{array}$ \\
\hline $\begin{array}{l}\text { Ferula persica } \\
\text { Willd. }\end{array}$ & Ferula of Media & $\begin{array}{l}\text { Mid. } \\
\text { E. }\end{array}$ & $\mathrm{D}$ & Intermittent fevers & Int., the liquor \\
\hline $\begin{array}{l}\text { Filipendula ulmaria } \\
\text { (L.) Maxim. }\end{array}$ & $\begin{array}{l}\text { Meadowsweet, Queen } \\
\text { of the meadow }\end{array}$ & Eur. & $\mathrm{JG}, \mathrm{Gr}$ & Quartans (JG, Gr) & $\begin{array}{l}\text { Int., flowers } \\
\text { boi. in wine } \\
\text { (JG) }\end{array}$ \\
\hline $\begin{array}{l}\text { Foeniculum vulgare } \\
\text { Mill. }\end{array}$ & Fennel & Eur. & $\begin{array}{l}\text { Mdf, } \\
\text { Pl }\end{array}$ & $\begin{array}{l}\text { Intermittent fevers } \\
\text { (Mdf), Quartans } \\
\text { (Pl) }\end{array}$ & $\begin{array}{l}\text { Int., Mdf } 2 \\
\text { (Mdf), Int., Pl } \\
2\end{array}$ \\
\hline Fraxinus excelsior L. & Ash & Eur. & $\mathrm{Gr}$ & Intermittent fevers & $\begin{array}{l}\text { Int., dec. of } \\
\text { bark }\end{array}$ \\
\hline $\begin{array}{l}\text { Fumaria officinalis } \\
\text { L. }\end{array}$ & Fumitory & Eur. & $\begin{array}{l}\text { JG, } \\
\text { Mdf }\end{array}$ & $\begin{array}{l}\text { Quartans (JG), } \\
\text { Intermittent fevers } \\
\text { (Mdf) }\end{array}$ & $\begin{array}{l}\text { Int., dec. herb, } \\
\text { syrup of juice, } \\
\text { dist. water of } \\
\text { herb (JG), Int., } \\
\text { Mdf } 3\end{array}$ \\
\hline $\begin{array}{l}\text { Garrya fremontii } \\
\text { Torr. }\end{array}$ & Californian Fever Bush & $\begin{array}{l}\text { New } \\
\text { W. }\end{array}$ & $\mathrm{Gr}$ & Antiperiodic & Int., leaves \\
\hline $\begin{array}{l}\text { Gelsemium } \\
\text { sempervirens (L.) } \\
\text { J.St.-Hil. }\end{array}$ & $\begin{array}{l}\text { Gelsemium (yellow } \\
\text { jasmine) }\end{array}$ & $\begin{array}{l}\text { New } \\
\text { W. }\end{array}$ & $\mathrm{Gr}$ & Intermittent fevers & $\begin{array}{l}\text { Int., inf. of } \\
\text { root }\end{array}$ \\
\hline $\begin{array}{l}\text { Gentiana lutea } \mathrm{L} ., \\
\text { Gentiana purpurea } \\
\text { L. }\end{array}$ & $\begin{array}{l}\text { Yellow gentian, purple } \\
\text { gentian }\end{array}$ & Eur. & $\begin{array}{l}\text { Gr, Th, } \\
\text { Co }\end{array}$ & $\begin{array}{l}\text { Intermittent fevers } \\
\text { (Gr, Th), Agues } \\
\text { (Co) }\end{array}$ & $\begin{array}{l}\text { Int., root Gr } 3 \\
\text { or Thr } 4 \text {, Int., } \\
\text { inf. herb in } \\
\text { wine }(\mathrm{Co})\end{array}$ \\
\hline $\begin{array}{l}\text { Gentiana } \\
\text { quinquefolia Hill. }\end{array}$ & Five-flowered gentian & Eur. & $\mathrm{Gr}$ & Intermittent fevers & $\begin{array}{l}\text { Int., tinct. of } \\
\text { root }\end{array}$ \\
\hline $\begin{array}{l}\text { Gentianella amarella } \\
\text { (L.) Harry Sm. }\end{array}$ & Autumn gentian & Eur. & $\mathrm{Cu}$ & Agues & $\begin{array}{l}\text { Int. dist. water } \\
\text { of herb, or root }\end{array}$ \\
\hline
\end{tabular}




\begin{tabular}{|c|c|c|c|c|c|}
\hline & & & & & in liquid $(\mathrm{Cu})$ \\
\hline Geum urbanum L. & Avens & Eur. & $\begin{array}{l}\text { Gr, Sa, } \\
\text { Th }\end{array}$ & $\begin{array}{l}\text { Intermittent fevers } \\
\text { (Gr, Th), Agues, } \\
\text { esp. tertians (Sa) }\end{array}$ & $\begin{array}{l}\text { Int., dec. or } \\
\text { inf. of powd. } \\
\text { root or herb } \\
\text { (Gr), Int., root } \\
\text { or herb boi. in } \\
\text { water or posset } \\
\text { before fit (Sa), } \\
\text { Root powd. } \\
\text { (Th) }\end{array}$ \\
\hline $\begin{array}{l}\text { Glechoma hederacea } \\
\text { L. }\end{array}$ & $\begin{array}{l}\text { Ground ivy (Gill-over- } \\
\text { the-ground) }\end{array}$ & Eur. & Mdf & Intermittent fevers & Int., Mdf 2 \\
\hline $\begin{array}{l}\text { Gratiola officinalis } \\
\text { L. }\end{array}$ & Hedge hyssop & Eur. & Thr & Autumnal fevers & Int., Thr 5 \\
\hline $\begin{array}{l}\text { Helianthus annuus } \\
\text { L. }\end{array}$ & Sunflower & Eur. & $\mathrm{Gr}$ & Intermittent fevers & $\begin{array}{l}\text { Int., tinct. of } \\
\text { the seed in } \\
\text { ethanol }\end{array}$ \\
\hline $\begin{array}{l}\text { Heliotropum } \\
\text { europaeum L. ? }\end{array}$ & Heliotrope & Eur. & $\mathrm{P} 1$ & $\begin{array}{l}\text { Tertians, Quartans } \\
(\mathrm{Pl})\end{array}$ & $\begin{array}{l}3 \text { or } 4 \text { grains of } \\
\text { seed in wine } \\
\text { for tertians and } \\
\text { quartans } \\
\text { respectively } \\
\text { (Pl) }\end{array}$ \\
\hline Helleborus niger L. & $\begin{array}{l}\text { Black hellebore, wild } \\
\text { black hellebore, Great } \\
\text { oxheel, Setterwort or } \\
\text { bearfoot, "Christwurz } \\
\text { or Nieswurz" (OB) }\end{array}$ & Eur. & $\begin{array}{l}\mathrm{JG}, \\
\mathrm{OB}, \\
\mathrm{Pl}, \mathrm{Co}, \\
\mathrm{BA}\end{array}$ & $\begin{array}{l}\text { Quartans (as } \\
\text { purgative) (JG, } \\
\text { OB, Pl, Co, BA) }\end{array}$ & $\begin{array}{l}\text { Strong } \\
\text { purgative, only } \\
\text { for strong } \\
\text { bodies (JG), } \\
\text { As purgative, } \\
\text { w/ caution } \\
\text { (OB, } \mathrm{Pl}, \mathrm{Co} \text { - } \\
\text { root) }\end{array}$ \\
\hline $\begin{array}{l}\text { Hieracium murorum } \\
\text { L. }\end{array}$ & Hawkweed & Eur. & Gr (h) & Agues & Herb \\
\hline Hippurus vulgaris L. & Horsetail & Eur. & $\mathrm{D}$ & Intermittent fevers & $\begin{array}{l}\text { Drunk w/ wine } \\
\text { one hour } \\
\text { before the fit }\end{array}$ \\
\hline $\begin{array}{l}\text { Hordeum distichon } \\
\text { L. }\end{array}$ & Barley & Eur. & AvT & $\begin{array}{l}\text { Tertians and } \\
\text { possibly quartans }\end{array}$ & $\begin{array}{l}\text { Int. (barley } \\
\text { water or gruel } \\
\text { [Gerstenschlei } \\
\text { msaft]) }\end{array}$ \\
\hline Humulus lupulus L. & Hops, Wild hops & Eur. & $\begin{array}{l}\mathrm{JG} \\
\mathrm{OB}\end{array}$ & $\begin{array}{l}\text { Agues (lingering), } \\
\text { spleen stoppages } \\
\text { (JG), Quartans } \\
\text { (OB) }\end{array}$ & $\begin{array}{l}\text { Leaves, tender } \\
\text { stalks, \& } \\
\text { flowers, boi. in } \\
\text { whey (JG), } \\
\text { OB } 1 \text { (OB) }\end{array}$ \\
\hline $\begin{array}{l}\text { Hybanthus } \\
\text { calceolaria (L.) } \\
\text { Oken }\end{array}$ & Ipecacuanha & $\begin{array}{l}\text { New } \\
\text { W. }\end{array}$ & Th & Intermittent fevers & $\begin{array}{l}\text { Int., a small } \\
\text { amount before } \\
\text { the fit OR to } \\
\text { cause vomiting } \\
\text { at the end of } \\
\text { the cold stage. }\end{array}$ \\
\hline Hyoscyamus niger & Henbane and other & Eur. & AvT & Quartans & Int., AvT 5; \\
\hline
\end{tabular}




\begin{tabular}{|l|l|l|l|l|l|}
\hline L., H. albus L. & hyoscyamus sp. & & & & AvT 16 \\
\hline $\begin{array}{l}\text { Hypericum } \\
\text { androsaemum L. }\end{array}$ & Tutsan & Eur. & Mdf & Intermittent fevers & Ext., Mdf 1 \\
\hline
\end{tabular}

\begin{tabular}{|c|c|c|c|c|c|}
\hline Hypericum coris L. & $\begin{array}{l}\text { Heath-leaved St. John's } \\
\text { Wort, Aaron's beard }\end{array}$ & Eur. & HAP & Quartans & $\begin{array}{l}\text { Pounded, and } \\
\text { drunk in wine. }\end{array}$ \\
\hline $\begin{array}{l}\text { Hypericum } \\
\text { perforatum } \mathrm{L} .\end{array}$ & St. John's wort & Eur. & $\mathrm{Sa}, \mathrm{HB}$ & $\begin{array}{l}\text { Agues (quartan or } \\
\text { tertian) (Sa), } \\
\text { Tertians, Quartans } \\
\text { (HB) }\end{array}$ & $\begin{array}{l}\text { Int., warm dec. } \\
\text { of leaves and } \\
\text { seeds before } \\
\text { the fit (Sa), } \\
\text { Int. (HB) }\end{array}$ \\
\hline $\begin{array}{l}\text { Hypericum } \\
\text { tomentosum } \mathrm{L} .\end{array}$ & Woolly St. John's Wort & Eur. & JG & $\begin{array}{l}\text { Tertians and } \\
\text { quartans }\end{array}$ & $\begin{array}{l}\text { Drink w/ wine } \\
\text { (JG from D) }\end{array}$ \\
\hline $\begin{array}{l}\text { Hypericum } \\
\text { triquetrifolium } \\
\text { Turra, Hypericum } \\
\text { barbatum Jacq. }\end{array}$ & Hypericum sp. & Eur. & $\mathrm{D}, \mathrm{Pl}$ & $\begin{array}{l}\text { Tertians, Quartans } \\
\text { (D), Quartans (Pl) }\end{array}$ & $\begin{array}{l}\text { Int., w/ wine } \\
\text { (D), Int. as a } \\
\text { component of } \\
\text { P1 } 1\end{array}$ \\
\hline $\begin{array}{l}\text { Hyssopus officinalis } \\
\text { L. }\end{array}$ & Hyssop & Eur. & $\begin{array}{l}\text { AvT } \\
\text { (h) }\end{array}$ & & Int., AvT 10 \\
\hline Ilex aquifolium $\mathrm{L}$. & Holly & Eur. & $\mathrm{Gr}$ & Intermittent fevers & $\begin{array}{l}\text { Int., inf. or } \\
\text { dec. of powd. } \\
\text { Leaves }\end{array}$ \\
\hline $\begin{array}{l}\text { Ilex verticillata (L.) } \\
\text { A.Gray }\end{array}$ & Black American alder & $\begin{array}{l}\text { New } \\
\text { W. }\end{array}$ & $\mathrm{Gr}$ & Intermittent fevers & $\begin{array}{l}\text { Int., dec. of } \\
\text { bark }\end{array}$ \\
\hline $\begin{array}{l}\text { Inula conyza } \\
\text { (Griess.) DC. }\end{array}$ & $\begin{array}{l}\text { Fleabane (HAP, } \\
\text { identification } \\
\text { uncertain), Spikenard } \\
(\text { AvT) }\end{array}$ & Eur. & $\begin{array}{l}\text { HAP?, } \\
\text { AvT }\end{array}$ & $\begin{array}{l}\text { Agues (cold fever) } \\
\text { (HAP), Quartans } \\
\text { (AvT) }\end{array}$ & $\begin{array}{l}\text { boi. in oil and } \\
\text { applied Ext. } \\
\text { (HAP), Int., } \\
\text { AvT } 8\end{array}$ \\
\hline $\begin{array}{l}\text { Ipomoea jalapa (L.) } \\
\text { Pursh and } I . \\
\text { pandurata (L.) G. } \\
\text { Mey }\end{array}$ & Jalap bindweed & $\begin{array}{l}\text { New } \\
\text { W. }\end{array}$ & $\mathrm{Sa}$ & Agues & Int., Sa 3 \\
\hline $\begin{array}{l}\text { Iris } \mathrm{x} \text { germanica } \mathrm{L} \text {., } \\
\text { I. pallida Lam. and } \\
\text { others }\end{array}$ & $\begin{array}{l}\text { Iris (Flower de Luce, } \\
\text { Orris) }\end{array}$ & Eur. & $\begin{array}{l}\text { AvT, } \\
\text { Co }\end{array}$ & $\begin{array}{l}\text { Quartans (AvT), } \\
\text { Shaking fits of } \\
\text { ague (Co) }\end{array}$ & $\begin{array}{l}\text { Int., AvT 1, } \\
\text { Int., dec. of } \\
\text { roots w/ honey } \\
(\mathrm{Co})\end{array}$ \\
\hline Juglans nigra L. & Walnut & Eur. & $\mathrm{Co}, \mathrm{Gr}$ & Agues $(\mathrm{Co}, \mathrm{Gr})$ & $\begin{array}{l}\text { Int., root bark } \\
\text { powd. and } \\
\text { infused into } \\
\text { vinegar (Co), } \\
\text { Juice of green } \\
\text { walnut husks } \\
\text { (Gr) }\end{array}$ \\
\hline $\begin{array}{l}\text { Juniperus communis } \\
\text { L. }\end{array}$ & Juniper & Eur. & $\mathrm{Sa}, \mathrm{BA}$ & $\begin{array}{l}\text { Agues (Sa), } \\
\text { Quartans (BA) }\end{array}$ & $\begin{array}{l}\text { Int., the extr. } \\
\text { Sa 3, Taken } \\
\text { every day } \\
\text { (BA) }\end{array}$ \\
\hline Justicia adhatoda L. & Malabar nut & India & $\mathrm{Gr}$ & Intermittent fevers & $\begin{array}{l}\text { Int. leaves, } \\
\text { flowers, fruit, } \\
\text { root }\end{array}$ \\
\hline Lactuca sativa $\mathrm{L}$. & Lettuce & Eur. & AvT & Tertians, quartans & Stalks \\
\hline Lamium purpureum & Lamium (Dead nettle) & Eur. & Gr (h), & Quartans (Gr, Co), & Int.? (Gr), As \\
\hline
\end{tabular}




\begin{tabular}{|c|c|c|c|c|c|}
\hline L. & & & $\mathrm{Pl}, \mathrm{Co}$ & $\begin{array}{l}\text { Tertians, quartans } \\
\text { (Pl) }\end{array}$ & $\begin{array}{l}\text { an amulet }(\mathrm{Pl}) \text {, } \\
\text { Int., the } \\
\text { flowers }(\mathrm{Co})\end{array}$ \\
\hline $\begin{array}{l}\text { Laserpitum } \\
\text { (identification } \\
\text { uncertain, possibly } \\
\text { Thapsia garganica } \\
\text { or silphion, or } \\
\text { Narthex silphium, } \\
\text { but probably extinct) }\end{array}$ & $\begin{array}{l}\text { Magydare, Laser, } \\
\text { Laserwort, Silphium }\end{array}$ & $\begin{array}{l}\text { Eur., } \\
\text { Mid. } \\
\text { E. }\end{array}$ & $\mathrm{JG}, \mathrm{Pl}$ & $\begin{array}{l}\text { Agues (shaking } \\
\text { and shivering of) } \\
\text { (JG), Quartans (JG, } \\
\text { Pl) }\end{array}$ & $\begin{array}{l}\text { Int., JG 2, Pl } \\
3\end{array}$ \\
\hline Laurus nobilis L. & Bay & Eur. & Gr (h) & Agues & $\begin{array}{l}\text { Int., inf. of } \\
\text { berries }\end{array}$ \\
\hline $\begin{array}{l}\text { Levisticum officinale } \\
\text { W.D.J.Koch }\end{array}$ & Lovage & Eur. & Gr (h) & Agues & $\begin{array}{l}\text { Int., dec. of } \\
\text { herb (Gr from } \\
\mathrm{Cu})\end{array}$ \\
\hline $\begin{array}{l}\text { Liquidambar } \\
\text { orientalis Mill. }\end{array}$ & Storax (Liquidambar) & $\begin{array}{l}\text { Mid. } \\
\text { E. }\end{array}$ & AvT & Quartans & Int., AvT 1 \\
\hline $\begin{array}{l}\text { Magnolia acuminata } \\
\text { (L.) L. and } M \text {. } \\
\text { virginiana L. }\end{array}$ & Magnolia & $\begin{array}{l}\text { New } \\
\text { W. }\end{array}$ & $\mathrm{Gr}$ & Malaria & $\begin{array}{l}\text { Int., bark of } \\
\text { stem and root }\end{array}$ \\
\hline $\begin{array}{l}\text { Malva sylvestris L. } \\
\text { or Althaea officinalis } \\
\text { L. }\end{array}$ & Mallow & Eur. & Mdf & Intermittent fevers & $\begin{array}{l}\text { Ext., Mdf 1, } \\
\text { Int., Mdf } 2\end{array}$ \\
\hline $\begin{array}{l}\text { Mandragora } \\
\text { officinarum L. }\end{array}$ & Mandrake & Eur. & AvT & Quartans & $\begin{array}{l}\text { Int., the bark } \\
\text { AvT } 6\end{array}$ \\
\hline Many sp. & Balsam & $\begin{array}{l}\text { Mid. } \\
\text { E. }\end{array}$ & BA & Quartans & Sap or resin \\
\hline
\end{tabular}

\begin{tabular}{|c|c|c|c|c|c|}
\hline $\begin{array}{l}\text { Marchantiophyta sp., } \\
\text { unidentified (possiby } \\
\text { various) }\end{array}$ & Stone liverwort & Eur. & JG & Tertians & \\
\hline Melissa officinalis L. & $\begin{array}{l}\text { Melissa, Lemon balm, } \\
\text { "Muterkraut, } \\
\text { Pfaffenkraut" }\end{array}$ & Eur. & $\mathrm{OB}$ & Quartans & Int., the herb \\
\hline $\begin{array}{l}\text { Mentha spicata } \mathrm{L} ., \\
\text { Mentha } \text { x piperita } \mathrm{L} .\end{array}$ & Mint & Eur. & $\mathrm{Sa}$ & $\begin{array}{l}\text { Agues (quartan) } \\
\text { (Sa) }\end{array}$ & Int., Sa 2 \\
\hline Mentha pulegium $\mathrm{L}$. & $\begin{array}{l}\text { Pennyroyal (Dwarf } \\
\text { dwostle) }\end{array}$ & Eur. & $\begin{array}{l}\text { HAP, } \\
\text { AvT } \\
\text { (h), Pl, } \\
\text { Co }\end{array}$ & Tertians & $\begin{array}{l}\text { Ext., twigs in } \\
\text { wool, wound } \\
\text { about the head, } \\
\text { for headache } \\
\text { caused by fit } \\
\text { (HAP), Ext., } \\
\text { or smell, } \\
\text { wrapped in } \\
\text { wool, before } \\
\text { fit, or place } \\
\text { under } \\
\text { bedclothes } \\
\text { (Pl); AvT 10, } \\
\text { Co } 3\end{array}$ \\
\hline $\begin{array}{l}\text { Menyanthes } \\
\text { trifoliata } \mathrm{L} .\end{array}$ & $\begin{array}{l}\text { Bogbean (Buckbean, } \\
\text { Water trefoil) }\end{array}$ & Eur. & $\begin{array}{l}\text { Gr, } \\
\text { Thr }\end{array}$ & $\begin{array}{l}\text { Agues }(\mathrm{Gr}), \\
\text { Tertians and }\end{array}$ & $\begin{array}{l}\text { Leaves, finely } \\
\text { powd. (Gr), }\end{array}$ \\
\hline
\end{tabular}




\begin{tabular}{|c|c|c|c|c|c|}
\hline & & & & quartans (Thr) & $\begin{array}{l}\text { Leaves, finely } \\
\text { powd., inf. or } \\
\text { extr. (Thr) }\end{array}$ \\
\hline $\begin{array}{l}\text { Mercurialis perrenis } \\
\text { L. }\end{array}$ & Dog's mercury & Eur. & $\operatorname{Gr}(\mathrm{h})$ & Ague & $\begin{array}{l}\text { Int., dec. in } \\
\text { rooster broth }\end{array}$ \\
\hline $\begin{array}{l}\text { Myristica fragrans } \\
\text { Houtt. }\end{array}$ & Nutmeg, Mace & Asia & $\mathrm{Sa}, \mathrm{Gr}$ & $\begin{array}{l}\text { Agues (Sa), } \\
\text { Intermittent fevers } \\
\text { (Gr) }\end{array}$ & $\begin{array}{l}\text { Int., Sa 3,w/ } \\
\text { other unsp. } \\
\text { ingred. (Gr) }\end{array}$ \\
\hline $\begin{array}{l}\text { Myrrhis odorata (L.) } \\
\text { Scop. }\end{array}$ & $\begin{array}{l}\text { Hartswort or Seseli } \\
\text { (Cicely?) }\end{array}$ & Eur. & JG & Agues & $\begin{array}{l}\text { Int., seed, w/ } \\
\text { wine }\end{array}$ \\
\hline $\begin{array}{l}\text { Narcissus } \\
\text { pseudonarcissus L. }\end{array}$ & Daffodil & Eur. & $\begin{array}{l}\mathrm{Cu}, \mathrm{Gr} \\
\text { (h) }\end{array}$ & $\begin{array}{l}\text { Agues, esp. } \\
\text { Tertians }(\mathrm{Cu})\end{array}$ & $\begin{array}{l}\text { Root, boi. in } \\
\text { posset, to } \\
\text { cause vomiting } \\
\text { (at beginning } \\
\text { of disease) }\end{array}$ \\
\hline Nepeta cataria L. & Catnip (Katzenkraut) & Eur. & $\begin{array}{l}\mathrm{HB} \\
\mathrm{OB}\end{array}$ & $\begin{array}{l}\text { Tertians (HB), } \\
\text { Quartans (OB) }\end{array}$ & Int., juice (HB) \\
\hline $\begin{array}{l}\text { Nicotiana tabacum } \\
\text { L. }\end{array}$ & Tobacco & $\begin{array}{l}\text { New } \\
\text { W. }\end{array}$ & $\mathrm{Sa}, \mathrm{Co}$ & $\begin{array}{l}\text { Agues (Co), Agues } \\
\text { (especially tertian) } \\
\text { (Sa) }\end{array}$ & $\begin{array}{l}\text { Int., dist. water } \\
\text { of herb w/ } \\
\text { sugar before fit } \\
\text { (Co), Ext. Sa } \\
1\end{array}$ \\
\hline $\begin{array}{l}\text { Nigella sativa } \mathrm{L}, \\
\text { Nigella damascena } \\
\text { L., and others }\end{array}$ & Nigella, Fennel flower & Eur. & Co & Tertians, quartans & $\begin{array}{l}\text { Int., seeds in } \\
\text { wine before fit }\end{array}$ \\
\hline $\begin{array}{l}\text { Oenanthe aquatica } \\
\text { (L.) Poir. }\end{array}$ & Water dropwort & Eur. & $\mathrm{Gr}$ & Intermittent fevers & $\begin{array}{l}\text { Int., powd. } \\
\text { Fruits }\end{array}$ \\
\hline $\begin{array}{l}\text { Opopanax chironium } \\
\text { Koch }\end{array}$ & Opoponax & $\begin{array}{l}\text { Eur., } \\
\text { Mid. } \\
\text { E. }\end{array}$ & AvT & Quartans & Int., AvT 1 \\
\hline Origanum vulgare L. & Oregano & Eur. & $\begin{array}{l}\text { AvT } \\
\text { (h) }\end{array}$ & & Int., AvT 10 \\
\hline $\begin{array}{l}\text { Paeonia officinalis } \\
\text { L. }\end{array}$ & Peony & Eur. & $\begin{array}{l}\text { D, } \\
\text { HAP }\end{array}$ & $\begin{array}{l}\text { Quartans, and } \\
\text { fevers that come w/ } \\
\text { shivering (D), } \\
\text { Tertians and } \\
\text { quartans (HAP) }\end{array}$ & $\begin{array}{l}\text { Herb, amulet } \\
\text { (D); Ext., juice } \\
\text { w/ rose oil } \\
\text { (HAP) }\end{array}$ \\
\hline $\begin{array}{l}\text { Papaver somniferum } \\
\text { L. }\end{array}$ & Opium & $\begin{array}{l}\text { Eur., } \\
\text { Asia }\end{array}$ & AvT & $\begin{array}{l}\text { Quartans (internal } \\
\text { pains of); Provoke } \\
\text { sleep to reduce } \\
\text { severity of fit }\end{array}$ & $\begin{array}{l}\text { Int., AvT 12; } \\
\text { AvT } 16 \text { (to } \\
\text { provoke sleep, } \\
\text { thus reducing } \\
\text { severity of fit) }\end{array}$ \\
\hline $\begin{array}{l}\text { Passiflora } \\
\text { maliformis } \mathrm{L} . \& \text { P. } \\
\text { suberosa L. }\end{array}$ & Granadilla & $\begin{array}{l}\text { New } \\
\text { W. }\end{array}$ & $\mathrm{Gr}$ & Intermittent fevers & Int., leaf juice \\
\hline Pastinaca sativa L. & Parsnip & Eur. & $\mathrm{Gr}$ & Intermittent fevers & Int., seeds \\
\hline $\begin{array}{l}\text { Persicaria amphibia } \\
\text { (L.) Delarbre }\end{array}$ & Amphibious persicaria & Eur. & Mdf & Intermittent fevers & Ext., Mdf 1 \\
\hline $\begin{array}{l}\text { Persicaria bistorta } \\
\text { (L.) Samp. }\end{array}$ & Bistort & Eur. & $\mathrm{Gr}(\mathrm{h})$ & Intermittent fevers & Root, Gr 1 \\
\hline $\begin{array}{l}\text { Petroselinum } \\
\text { crispum (Mill.) Fuss }\end{array}$ & Parsely & Eur. & $\mathrm{Gr}$ & Intermittent fevers & Int., dec. seeds \\
\hline
\end{tabular}




\begin{tabular}{|c|c|c|c|c|c|}
\hline $\begin{array}{l}\text { Peucedanum } \\
\text { ostruthium (L.) } \\
\text { W.D.J. Koch }\end{array}$ & Masterwort & Eur. & $\begin{array}{l}\mathrm{OB}, \\
\mathrm{Co} \\
\mathrm{HB}\end{array}$ & $\begin{array}{l}\text { Quartan agues } \\
\text { (Co), Quotidians } \\
\text { (OB) }\end{array}$ & $\begin{array}{l}\text { Int., root inf. } \\
\text { (OB), Root } \\
\text { (Co) }\end{array}$ \\
\hline $\begin{array}{l}\text { Phoenix dactylifera } \\
\text { L. }\end{array}$ & Dates & $\begin{array}{l}\text { Mid. } \\
\text { E. }\end{array}$ & $\mathrm{Co}$ & $\begin{array}{l}\text { Agues, compound } \\
\text { and long }\end{array}$ & Int., in wine \\
\hline $\begin{array}{l}\text { Pimpinella anisum } \\
\text { L. }\end{array}$ & Anise & Eur. & $\begin{array}{l}\text { AvT, } \\
\text { Pl }\end{array}$ & Quartans (Pl) & $\begin{array}{l}\text { Int., AvT 14, } \\
\text { Int., P1 } 2\end{array}$ \\
\hline Piper nigrum L. & Pepper & Asia & $\begin{array}{l}\text { D, } \\
\text { AvT } \\
\text { (h), } \\
\text { Thr }\end{array}$ & $\begin{array}{l}\text { Intermittent fevers } \\
(\mathrm{D}, \mathrm{Thr})\end{array}$ & $\begin{array}{l}\text { Int. or Ext. } \\
\text { (D), Int. AvT } \\
1 \text { or AvT 9, } \\
\text { Int., large dose } \\
\text { to cure (Thr) }\end{array}$ \\
\hline Pistacia lentiscus L. & Mastic & $\begin{array}{l}\text { Mid. } \\
\text { E. }\end{array}$ & AvT & Quartans & $\begin{array}{l}\text { Int., gum, AvT } \\
\text { 7; Int., } \\
\text { flowers, AvT } 8\end{array}$ \\
\hline $\begin{array}{l}\text { Pisum sativum L., } \\
\text { Cicer arietinum L., } \\
\text { or Lathyrus odoratus } \\
\text { L. (unlikely) }\end{array}$ & $\begin{array}{l}\text { Zyßeren erbsen (Pea, } \\
\text { chick pea, or sweet } \\
\text { pea?) }\end{array}$ & Eur. & OB & Quartans, Tertians & $\begin{array}{l}\text { Int., legumes } \\
\text { boi. in water }\end{array}$ \\
\hline $\begin{array}{l}\text { Plantago major } \mathrm{L} . \\
\text { and P. lanceolata } \mathrm{L} .\end{array}$ & $\begin{array}{l}\text { Plantain, waybread } \\
\text { (Wegerich, } \\
\text { Spitzwegerich) }\end{array}$ & Eur. & $\begin{array}{l}\text { D, } \\
\text { HAP, } \\
\text { OB, } \\
\text { HB, } \\
\text { Thr, } \\
\text { Pl, Gr, } \\
\text { AvT }\end{array}$ & $\begin{array}{l}\text { Tertians (HAP, D, } \\
\text { OB, HB, Thr, P1), } \\
\text { Quartans (D, OB, } \\
\text { HB), Intermittent } \\
\text { fevers (Gr) }\end{array}$ & $\begin{array}{l}\text { Int. roots in } \\
\text { wine (D), Int. } \\
\text { sprouts in } \\
\text { water or wine, } \\
\text { fasting, before } \\
\text { fit (HAP), Int. } \\
\text { roots in wine } \\
\text { and water; Int. } \\
\text { dist.; Int. herb } \\
\text { juice (OB), } \\
\text { Int., roots boi. } \\
\text { in wine; Int. } \\
\text { root dist. (HB) } \\
\text { Reported by } \\
\text { others (Thr), } \\
\text { Int. root juice } \\
\text { or the pounded } \\
\text { root in water } \\
\text { or honey water } \\
\text { before fit (Pl), } \\
\text { Int., fluid extr. } \\
\text { of leaves, root, } \\
\text { flower spikes } \\
\text { (Gr) }\end{array}$ \\
\hline $\begin{array}{l}\text { Polygonum aviculare } \\
\text { L. }\end{array}$ & Knotgrass & Eur. & $\begin{array}{l}\mathrm{D}, \mathrm{Gr} \\
(\mathrm{h}), \mathrm{Pl}\end{array}$ & $\begin{array}{l}\text { Intermittent fevers } \\
\text { (D, Gr), Tertians } \\
\text { (Pl) }\end{array}$ & $\begin{array}{l}\text { Int. w/ wine } \\
\text { before fit (D), } \\
\text { Int., juice (Gr), } \\
\text { Amulet against } \\
\text { tertians (Pl) }\end{array}$ \\
\hline $\begin{array}{l}\text { Polypodium vulgare } \\
\text { L. }\end{array}$ & $\begin{array}{l}\text { Common polypody } \\
\text { (oak fern, Engelfuß, } \\
\text { Steinfarn) }\end{array}$ & Eur. & $\begin{array}{l}\mathrm{Gr}, \\
\mathrm{HB}, \\
\mathrm{Co}\end{array}$ & $\begin{array}{l}\text { Agues (Gr), } \\
\text { Quartans (HB, Co) }\end{array}$ & $\begin{array}{l}\text { Int., dist. water } \\
\text { of roots \& } \\
\text { leaves (Gr, } \\
\text { HB), Int., herb } \\
\text { dec. or inf. }\end{array}$ \\
\hline
\end{tabular}




\begin{tabular}{|c|c|c|c|c|c|}
\hline & & & & & $(\mathrm{Co}) ; \mathrm{Co} 4$ \\
\hline $\begin{array}{l}\text { Potentilla anserina } \\
\text { L. }\end{array}$ & Silverweed & Eur. & $\mathrm{Gr}$ & Ague & $\begin{array}{l}\text { Int., dried } \\
\text { powd. leaves, } \\
\text { roots }\end{array}$ \\
\hline $\begin{array}{l}\text { Potentilla erecta (L.) } \\
\text { Raeusch. }\end{array}$ & Tormentil & & $\begin{array}{l}\text { Co, } \\
\text { Gr, Th }\end{array}$ & $\begin{array}{l}\text { Agues (Co), } \\
\text { Intermittent fevers } \\
\text { (Gr, Th) }\end{array}$ & $\begin{array}{l}\text { Int., herb } \\
\text { steeped } \\
\text { overnight in } \\
\text { wine and dist. } \\
\text { (Co), Gr 3; } \\
\text { large dose } \\
\text { (Thr); Thr } 4\end{array}$ \\
\hline Potentilla reptans $\mathrm{L}$. & Cinquefoil & Eur. & $\begin{array}{l}\text { JG, D, } \\
\text { Gr, Pl, } \\
\text { Co }\end{array}$ & $\begin{array}{l}\text { Tertians, quartans } \\
(\mathrm{JG}, \mathrm{D}, \mathrm{Pl}) \\
\text { Intermittent fevers } \\
(\mathrm{Gr}[\mathrm{h}]), \text { Ague }(\mathrm{Co})\end{array}$ & $\begin{array}{l}\text { Int., root juice, } \\
\text { JG } 4 \text {; int., } \\
\text { herb, D } 1 \text {; Int., } \\
\text { herb in wine or } \\
\text { vinegar }(\mathrm{Co}) \text {, } \\
\text { Int., leaves, } \\
\text { either as D or } \\
\text { in honey water } \\
\text { w/ pepper }(\mathrm{Pl})\end{array}$ \\
\hline $\begin{array}{l}\text { Prunus laurocerasus } \\
\text { L. }\end{array}$ & Cherry laurel & Eur. & Th & Agues & $\begin{array}{l}\text { Int., dist. water } \\
\text { of leaves }\end{array}$ \\
\hline $\begin{array}{l}\text { Prunus sp., } \\
\text { unidentified }\end{array}$ & $\begin{array}{l}\text { Flanders or Kentish } \\
\text { cherries }\end{array}$ & Eur. & JG & Agues & Int., fruit \\
\hline Prunus spinosa $\mathrm{L}$. & Sloe tree & Eur. & Th & Agues & $\begin{array}{l}\text { Int., bark } \\
\text { powd. }\end{array}$ \\
\hline $\begin{array}{l}\text { Pulicaria } \\
\text { dysenterica (L.) } \\
\text { Bernh. }\end{array}$ & $\begin{array}{l}\text { Fleawort and Never } \\
\text { dying fleawort }\end{array}$ & Eur. & $\mathrm{JG}, \mathrm{Cu}$ & Tertians (JG) & $\begin{array}{l}\text { Int., JG 3; } \\
\text { Seed boi. in } \\
\text { water or } \\
\text { infused, dec. } \\
\text { or inf. } \\
\text { (purgative and } \\
\text { cooling) (JG) }\end{array}$ \\
\hline Punica granatum L. & Pomegranate & Eur. & $\mathrm{JG}, \mathrm{Gr}$ & $\begin{array}{l}\text { Agues (JG), } \\
\text { Intermittent fevers } \\
\text { (Gr) }\end{array}$ & $\begin{array}{l}\text { Int., sour seeds } \\
\text { (JG), Int., } \\
\text { powd. rind of } \\
\text { fruit }(\mathrm{Gr})\end{array}$ \\
\hline $\begin{array}{l}\text { Quercus robur } \mathrm{L} . \\
\text { and others }\end{array}$ & Common oak, Oak & Eur. & $\mathrm{Th}, \mathrm{Gr}$ & $\begin{array}{l}\text { Intermittent fevers } \\
(\mathrm{Th}, \mathrm{Gr})\end{array}$ & $\begin{array}{l}\text { Int., bark (Th), } \\
\text { Int., bark extr. } \\
(\mathrm{Gr})\end{array}$ \\
\hline $\begin{array}{l}\text { Raphanus } \\
\text { raphanistrum subsp. } \\
\text { sativus (L.) Domin }\end{array}$ & Radish & Eur. & $\mathrm{HvB}$ & Three-day fever & Int. HvB 2 \\
\hline $\begin{array}{l}\text { Rheum rabarbarum } \\
\text { L. }\end{array}$ & Rhubarb & Eur. & $\begin{array}{l}\mathrm{D}, \mathrm{Sa}, \\
\mathrm{JG}\end{array}$ & $\begin{array}{l}\text { Intermittent fevers } \\
\text { (D), Agues (Sa), } \\
\text { Lingering agues } \\
\text { (JG) }\end{array}$ & $\begin{array}{l}\text { Int. w/ wine } \\
\text { (D); Int., root } \\
\text { boi. in posset } \\
\text { before fit (Sa), } \\
\text { Int., leaves inf. } \\
\text { in ale (strong } \\
\text { purgative) } \\
\text { (JG); Int., } \\
\text { Roots JG 1 }\end{array}$ \\
\hline
\end{tabular}




\begin{tabular}{|c|c|c|c|c|c|}
\hline & & & & & $(\mathrm{JG})$ \\
\hline Ricinus communis L. & $\begin{array}{l}\text { Satyrion royall, Palma } \\
\text { christi, Castor bean }\end{array}$ & Eur. & JG & Quartan & $\begin{array}{l}\text { Int., roots, } \\
\text { crushed w/ } \\
\text { wine before fit } \\
\text { (as purgative) }\end{array}$ \\
\hline Rosa sp. & Rose & Eur. & $\begin{array}{l}\mathrm{Cu}, \mathrm{Sa}, \\
\mathrm{Gr}(\mathrm{h})\end{array}$ & $\begin{array}{l}\text { Agues (Cu, Sa, Gr } \\
\text { (h), BA) }\end{array}$ & $\begin{array}{l}\text { Int., syrup of } \\
\text { dried red roses } \\
(\mathrm{Cu}, \mathrm{Gr}) ; \text { Int. } \\
\mathrm{Sa} 2 \text {; Ext., oil } \\
\text { (BA) }\end{array}$ \\
\hline Rubia tinctorum L. & Madder & Eur. & $\mathrm{HvB}$ & Four-day fever & Int. HvB 3 \\
\hline Rubus sp. & Brier & Eur. & $\mathrm{HvB}$ & Four-day fever & Int. HvB 3 \\
\hline Rumex acetosa $\mathrm{L}$. & $\begin{array}{l}\text { Garden sorrel, Sheep } \\
\text { sorrel }\end{array}$ & Eur. & $\begin{array}{l}\text { Gr (h), } \\
\text { JG }\end{array}$ & $\begin{array}{l}\text { Agues }(\mathrm{JG}) \text {, fiery } \\
\text { fits of ague }(\mathrm{Gr})\end{array}$ & $\begin{array}{l}\text { Int., dec. } \\
\text { leaves w/ } \\
\text { unsp. Ingred. } \\
\text { (JG) }\end{array}$ \\
\hline Rumex acetosella $\mathrm{L}$. & $\begin{array}{l}\text { Sorrel, Knobbed sorrel, } \\
\text { Sheep sorrel and others }\end{array}$ & Eur. & JG & Agues & $\begin{array}{l}\text { Int., dec. } \\
\text { leaves w/ } \\
\text { unsp. Ingred. } \\
\text { (JG) }\end{array}$ \\
\hline Ruscus aculeatus L. & Butcher's broom & Eur. & Mdf & Intermittent fevers & $\begin{array}{l}\text { Ext., Mdf 1; } \\
\text { Int., Mdf } 2\end{array}$ \\
\hline Ruta graveolans L. & Rue, Herb Grace & Eur. & $\begin{array}{l}\text { JG, D, } \\
\text { AvT, } \\
\text { Sa, Co, } \\
\text { Gr (h) }\end{array}$ & $\begin{array}{l}\text { Agues (JG), } \\
\text { Intermittent fevers } \\
\text { (D), Agues, } \\
\text { especially tertian } \\
\text { (Sa, Co), Shaking } \\
\text { of ague (Sa, Gr, } \\
\text { Co) }\end{array}$ & $\begin{array}{l}\text { Int., possibly } \\
\text { seed in wine } \\
\text { (D); Int. AvT } \\
\text { 3; dec. (Sa, Gr } \\
\text { (h)); Int., dec., } \\
\text { to relieve } \\
\text { shaking of } \\
\text { ague (Sa), } \\
\text { Ext., Sa 6; } \\
\text { Int., Co 5; } \\
\text { dec. of } \\
\text { leaves/flowers } \\
\text { (Co) }\end{array}$ \\
\hline S. paniculata Mill. & English saxifrage & Eur. & JG & Agues & $\begin{array}{l}\text { Int., dec. in } \\
\text { wine }\end{array}$ \\
\hline Salix alba $\mathrm{L}$. & White willow & Eur. & Gr, Th & $\begin{array}{l}\text { Antiperiodic (Gr), } \\
\text { Intermittent fevers } \\
\text { (Th) }\end{array}$ & $\begin{array}{l}\text { Int., dec. bark } \\
\text { or powd. Root }\end{array}$ \\
\hline Salix caprea L. & $\begin{array}{l}\text { Great round-leaved } \\
\text { willow }\end{array}$ & Eur. & Th & Intermittent fevers & Int., bark \\
\hline Salix $\mathrm{x}$ fragilis $\mathrm{L}$. & Crack willow & Eur. & $\mathrm{Th}$ & Intermittent fevers & Int., bark \\
\hline Salvia officinalis L. & Sage & Eur. & $\mathrm{Sa}, \mathrm{Gr}$ & $\begin{array}{l}\text { Agues (especially } \\
\text { tertian) (Sa), Ague } \\
\text { (Gr) }\end{array}$ & Ext., Sa 6 \\
\hline Sambucus ebulus L. & Dwarf elder & Eur. & $\begin{array}{l}\mathrm{Cu} \\
\mathrm{Mdf} \\
\mathrm{OB}\end{array}$ & $\begin{array}{l}\text { Agues }(\mathrm{Cu}) \text {, } \\
\text { Intermittent fevers } \\
\text { (Mdf), Quartans } \\
\text { (OB) }\end{array}$ & $\begin{array}{l}\text { Int., flowers in } \\
\text { water, spirit, or } \\
\text { vinegar, \& } \\
\text { cover up to } \\
\text { sweat }(\mathrm{Cu}) \text {; } \\
\text { Int., seed or }\end{array}$ \\
\hline
\end{tabular}




\begin{tabular}{|c|c|c|c|c|c|}
\hline & & & & & $\begin{array}{l}\text { flower \& bark } \\
\text { oil, to vomit } \\
(\mathrm{Cu}) \text {; syrup of } \\
\text { the berries, } \\
\text { buds, or bark } \\
\text { (for children; } \\
\mathrm{Cu}) \text {; dec. in } \\
\text { honey and } \\
\text { vinegar, on } \\
\text { intermitting } \\
\text { days (Cu); } \\
\text { crystallized } \\
\text { salt of elder } \\
(\mathrm{Cu}) \text {; Cu } 4 \text {; } \\
\text { Ext. Mdf } 1 \text {; } \\
\text { Int. juice OB } \\
2\end{array}$ \\
\hline Sambucus nigra L. & Elder & Eur. & Mdf & $\begin{array}{l}\text { Intermittent fevers } \\
(\mathrm{Mdf})\end{array}$ & $\begin{array}{l}\text { Int., root bark } \\
\text { Mdf } 2\end{array}$ \\
\hline Santalum album L. & $\begin{array}{l}\text { Sandalwood (white and } \\
\text { yellow) }\end{array}$ & India & $\mathrm{Cu}$ & Agues, hot fits of & $\begin{array}{l}\text { Ext., applied } \\
\text { w/ rosewater } \\
\text { to the temples }\end{array}$ \\
\hline $\begin{array}{l}\text { Sassafras albidum } \\
\text { (Nutt.) Nees }\end{array}$ & Sassafras or Ague tree & $\begin{array}{l}\text { New } \\
\text { W. }\end{array}$ & $\mathrm{JG}, \mathrm{Cu}$ & Tertians (JG) & $\begin{array}{l}\text { Int. wood inf., } \\
\text { for days } \\
\text { together }(\mathrm{JG}) \text {; } \\
\text { dec. of wood? } \\
(\mathrm{Cu})\end{array}$ \\
\hline $\begin{array}{l}\text { Saussurea costus } \\
\text { (Falc.) Lipsch. }\end{array}$ & Costus & India & $\begin{array}{l}\mathrm{D} \\
\mathrm{AvT} \\
\mathrm{Cu}\end{array}$ & $\begin{array}{l}\text { Agues, Quartans } \\
(\text { AvT }), \text { Cold fits of } \\
\text { ague }(\mathrm{Cu})\end{array}$ & $\begin{array}{l}\text { Ext. w/ oil, } \\
\text { before fit (D), } \\
\text { Int., AvT } 2 \text {, } \\
\text { Ext., w/ oil to } \\
\text { warm during } \\
\text { cold fit }(\mathrm{Cu})\end{array}$ \\
\hline $\begin{array}{l}\text { Scutellaria } \\
\text { galericulata L. }\end{array}$ & Common scullcap & Eur. & $\mathrm{Gr}$ & Tertians & $\begin{array}{l}\text { Int., juice or } \\
\text { herb inf. }\end{array}$ \\
\hline
\end{tabular}

\begin{tabular}{|c|c|c|c|c|c|}
\hline Sedum acre L. & Wall pepper & Eur. & JG & $\begin{array}{l}\text { Quartans and other } \\
\text { agues of long } \\
\text { standing }\end{array}$ & $\begin{array}{l}\text { Int., extr. juice } \\
\text { w/ vinegar or } \\
\text { other liquor, as } \\
\text { purgative } \\
\text { (vomiting) } \\
\text { (JG) }\end{array}$ \\
\hline $\begin{array}{l}\text { Sedum roseum (L.) } \\
\text { Scop. ? }\end{array}$ & Aaron & Eur. & $\mathrm{Sa}$ & $\begin{array}{l}\text { Agues (quartan) } \\
(\mathrm{Sa})\end{array}$ & Int., Sa 2 \\
\hline $\begin{array}{l}\text { Sempervivum } \\
\text { tectorum L. }\end{array}$ & Houseleek & Eur. & $\mathrm{Co}$ & $\begin{array}{l}\text { Quartans, lingering } \\
\text { agues }(\mathrm{Co}, \mathrm{Th})\end{array}$ & $\begin{array}{l}\text { Int., juice w/ } \\
\text { vinegar or } \\
\text { posset }(\mathrm{Co})\end{array}$ \\
\hline $\begin{array}{l}\text { Senna alexandrina } \\
\text { Mill. }\end{array}$ & $\begin{array}{l}\text { Senna, Alexandrian } \\
\text { senna }\end{array}$ & $\begin{array}{l}\text { N. } \\
\text { Afr. }\end{array}$ & $\mathrm{Co}$ & Quartans (Co) & $\begin{array}{l}\text { Int., dec. or } \\
\text { inf. of leaves } \\
(\mathrm{Co})\end{array}$ \\
\hline Sideritis sp. & $\begin{array}{l}\text { Sideritis, Ironwort, } \\
\text { Greek mountain tea }\end{array}$ & Eur. & $\mathrm{Pl}$ & Tertians & Int., w/ oil? \\
\hline
\end{tabular}




\begin{tabular}{|c|c|c|c|c|c|}
\hline $\begin{array}{l}\text { Silphium laciniatum } \\
\text { L. }\end{array}$ & Rosin-weed & $\begin{array}{l}\text { New } \\
\text { W. }\end{array}$ & $\mathrm{Gr}$ & Intermittent fevers & \\
\hline $\begin{array}{l}\text { Silybum marianum } \\
\text { (L.) Gaertn. }\end{array}$ & Milk thistle & Eur. & $\mathrm{Gr}, \mathrm{Co}$ & Ague (Gr (h), Co) & $\begin{array}{l}\text { Int., dec. or } \\
\text { powd. (Co), } \\
\text { inf. (Gr) }\end{array}$ \\
\hline $\begin{array}{l}\text { Simaba cedron } \\
\text { Planch. }\end{array}$ & Cedron & $\begin{array}{l}\text { New } \\
\text { W. }\end{array}$ & $\mathrm{Gr}$ & $\begin{array}{l}\text { Intermittent } \\
\text { fevers/Antiperiodic }\end{array}$ & $\begin{array}{l}\text { Int., inf. of } \\
\text { powd. seeds }\end{array}$ \\
\hline Sinapis alba $\mathrm{L}$. & White mustard & Eur. & $\mathrm{D}$ & Intermittent fevers & $\begin{array}{l}\text { Int., dried, in } \\
\text { beverage (D) }\end{array}$ \\
\hline Sison aтотит L. & Bastard stone parsely & Eur. & AvT & Quartans & Int., AvT 8 \\
\hline $\begin{array}{l}\text { Solidago virgaurea } \\
\text { L. }\end{array}$ & $\begin{array}{l}\text { Saracen's Confound } \\
\text { (Heidnisch Wundkraut) }\end{array}$ & Eur. & $\mathrm{Cu}$ & Agues, continual & $\begin{array}{l}\text { Int., herb boi. } \\
\text { in wine }\end{array}$ \\
\hline $\begin{array}{l}\text { Stachys officinalis } \\
\text { (L.) Trevis. }\end{array}$ & Betony & Eur. & $\begin{array}{l}\text { JG, Sa, } \\
\mathrm{OB}, \\
\mathrm{Co}, \mathrm{Pl}\end{array}$ & $\begin{array}{l}\text { Agues (JG, Sa), } \\
\text { Quotidians, } \\
\text { tertians, quartans } \\
\text { (OB), Quartans } \\
\text { (Co) Tertians and } \\
\text { quartans (Pl) }\end{array}$ & $\begin{array}{l}\text { Dried leaves } \\
\text { (JG), Int. Sa } 2 \\
\text { (Sa), Int., Co } \\
3(\mathrm{Co}) \text {, Int., in } \\
\text { hydromel, or } \\
\text { specifically for } \\
\text { quartans, Pl } 1 \\
\text { (Pl) }\end{array}$ \\
\hline $\begin{array}{l}\text { Symphytum } \\
\text { officinale L. }\end{array}$ & Comfrey & Eur. & JG & $\begin{array}{l}\text { Agues (to temper } \\
\text { the heat) }\end{array}$ & Int. JG 1 (JG) \\
\hline Syringa vulgaris L. & Lilac & Eur. & $\mathrm{Gr}$ & $\begin{array}{l}\text { Antiperiodic/Malar } \\
\text { ia }\end{array}$ & Leaves, fruit \\
\hline $\begin{array}{l}\text { Syzygium } \\
\text { aromaticum (L.) } \\
\text { Merr. \& L.M. Perry }\end{array}$ & Cloves & Asia & $\begin{array}{l}\mathrm{Sa}, \mathrm{Co}, \\
\mathrm{HvB}\end{array}$ & $\begin{array}{l}\text { Agues (Co, Sa), } \\
\text { Three-day fever } \\
\text { (HvB) }\end{array}$ & $\begin{array}{l}\text { Int., the oil } \\
\text { (Co), Int., Sa } \\
3 \text {, Int., as a } \\
\text { component of } \\
\text { HvB } 2 \\
\end{array}$ \\
\hline $\begin{array}{l}\text { Tanacetum } \\
\text { balsamita L.? }\end{array}$ & Balsam herb & Eur. & HvB & Three-day fever & Int., HvB 2 \\
\hline $\begin{array}{l}\text { Tanacetum } \\
\text { parthenium (L.) } \\
\text { Sch.Bip. }\end{array}$ & Feverfew & Eur. & $\begin{array}{l}\text { JG, Gr } \\
\text { (h), Pl } \\
\text { (?) }\end{array}$ & $\begin{array}{l}\text { Agues (JG, Gr), } \\
\text { Tertians }(\mathrm{Pl})\end{array}$ & $\begin{array}{l}\text { Int., in } \\
\text { beverage (JG); } \\
\text { Ext., w/ bay } \\
\text { salt and powd. } \\
\text { glass, wrist } \\
\text { plaster (JG), } \\
\text { Bound to the } \\
\text { wrists (Gr), } \\
\text { Int., a leaf in } \\
\text { water (Pl, but } \\
\text { ident. of plant } \\
\text { uncertain) }\end{array}$ \\
\hline $\begin{array}{l}\text { Tanacetum vulgare } \\
\text { L. }\end{array}$ & Tansy & Eur. & Gr, Co & Agues & $\begin{array}{l}\text { Int., herb extr. } \\
\text { (Gr), Ext., } \\
\text { juice applied } \\
\text { to wrists and } \\
\text { soles of feet } \\
\text { during hot fit } \\
\text { (Co) }\end{array}$ \\
\hline $\begin{array}{l}\text { Taraxacum } \\
\text { campylodes G.E. }\end{array}$ & Dandelion & Eur. & Mdf & Intermittent fevers & Int., Mdf 3 \\
\hline
\end{tabular}




\begin{tabular}{|c|c|c|c|c|c|}
\hline Haglund & & & & & \\
\hline $\begin{array}{l}\text { Terminalia bellerica } \\
\text { (Gaertn.) Roxb., } T \text {. } \\
\text { chebula Retz., } T \text {. } \\
\text { citrina Roxb. ex } \\
\text { Fleming, and others }\end{array}$ & $\begin{array}{l}\text { Myrobalans or } \\
\text { Mirobalans }\end{array}$ & Asia & Co & $\begin{array}{l}\text { Tertians, quartans, } \\
\text { long continued } \\
\text { agues }(\mathrm{Co})\end{array}$ & Int., fruits \\
\hline $\begin{array}{l}\text { Teucrium } \\
\text { chamcedrys L. }\end{array}$ & Wall germander & Eur. & $\mathrm{Gr}$ & Intermittent fevers & Int., herb \\
\hline $\begin{array}{l}\text { Teucrium scordium } \\
\text { L. }\end{array}$ & Water germander & Eur. & $\begin{array}{l}\text { HAP, } \\
\text { Gr }\end{array}$ & $\begin{array}{l}\text { Tertians, } \\
\text { Quotidians (HAP), } \\
\text { Intermittent fevers } \\
\text { (Gr) }\end{array}$ & $\begin{array}{l}\text { Ext., tied about } \\
\text { the body } \\
\text { (HAP), Int., } \\
\text { dried herb inf. } \\
\text { (Gr) }\end{array}$ \\
\hline Thuja occidentalis $\mathrm{L}$. & $\begin{array}{l}\text { Yellow cedar (arbor } \\
\text { vitae) }\end{array}$ & Eur. & $\mathrm{Gr}$ & Intermittent fevers & $\begin{array}{l}\text { Int., dec. } \\
\text { recently dried } \\
\text { leafy twigs }\end{array}$ \\
\hline
\end{tabular}

\begin{tabular}{|c|c|c|c|c|c|}
\hline Thymus serpillum L. & $\begin{array}{l}\text { Wild thyme, Thyme } \\
\text { marjorum }\end{array}$ & Eur. & JG & Agues & $\begin{array}{l}\text { Int., boi. in } \\
\text { wine }\end{array}$ \\
\hline Thymus vulgaris L. & Garden thyme & Eur. & $\begin{array}{l}\mathrm{JG}, \\
\mathrm{BA}\end{array}$ & Quartans (JG, BA) & $\begin{array}{l}\text { Int.?, flower } \\
\text { (BA) }\end{array}$ \\
\hline $\begin{array}{l}\text { Trifolium } \\
\text { bituminosum } \\
\text { Garsault, Trifolium } \\
\text { odoratum, or } \\
\text { Trigonella caerulea } \\
\text { (L.) Ser. }\end{array}$ & $\begin{array}{l}\text { Stinking trefoil or } \\
\text { Treacle Cleaver, } \\
\text { Siebengezeit }\end{array}$ & Eur. & $\begin{array}{l}\mathrm{JG}, \\
\mathrm{HB}\end{array}$ & $\begin{array}{l}\text { Tertians, Quartans } \\
\text { (JG, HB) }\end{array}$ & $\begin{array}{l}\text { Int., leaves w/ } \\
\text { wine or seeds } \\
(\mathrm{JG}), \text { Int., dec. } \\
\text { herb (HB) }\end{array}$ \\
\hline $\begin{array}{l}\text { Trigonella caerulea } \\
\text { (L.) Ser.? }\end{array}$ & Sweet trefoil or balsam & Eur. & $\mathrm{Co}$ & Tertians, Quartans & Int., dec. herb \\
\hline $\begin{array}{l}\text { Trigonella caerulea } \\
\text { (L.) Ser.? }\end{array}$ & Sweet trefoil or balsam & Eur. & Co & Tertians, Quartans & Int., dec. herb \\
\hline $\begin{array}{l}\text { Trigonella fonum- } \\
\text { grcecum L. }\end{array}$ & Fenugreek & $\begin{array}{l}\text { Eur., } \\
\text { Asia, } \\
\text { Mid. } \\
\text { E. }\end{array}$ & $\mathrm{Gr}$ & $\begin{array}{l}\text { "Said to be equal to } \\
\text { quinine in } \\
\text { preventing fevers" }\end{array}$ & Int., seeds \\
\hline $\begin{array}{l}\text { Tussilago farfara } L \text {. } \\
?\end{array}$ & Coltsfoot? & Eur. & $\mathrm{HvB}$ & Three-day fever & Int. HvB 2 \\
\hline Urtica dioica $\mathrm{L}$. & Stinging nettle & Eur. & $\mathrm{Gr}$ & Ague & $\begin{array}{l}\text { Int., seeds and } \\
\text { flowers in } \\
\text { wine (Gr) }\end{array}$ \\
\hline $\begin{array}{l}\text { Verbena officinalis } \\
\text { L. }\end{array}$ & $\begin{array}{l}\text { Vervain, verbena } \\
\text { (Eisenkraut) }\end{array}$ & Eur. & $\begin{array}{l}\mathrm{D}, \mathrm{Sa}, \\
\mathrm{OB}, \\
\mathrm{Co}, \mathrm{Pl}, \\
\mathrm{Gr}\end{array}$ & $\begin{array}{l}\text { Agues (D), Tertian } \\
(\mathrm{Sa}, \mathrm{OB}, \mathrm{Co}, \mathrm{Pl}), \\
\text { Quartans }(\mathrm{Co}, \mathrm{Pl}) \text {, } \\
\text { Intermittent fevers } \\
(\mathrm{Gr})\end{array}$ & $\begin{array}{l}\text { Stand before } \\
\text { the patient w/ } \\
\text { the branches } \\
\text { during the } \\
\text { shivering fit } \\
\text { (D), Int. (?), } \\
\text { the herb (Sa, } \\
\text { Co), Int., water } \\
\text { of the leaves } \\
\text { (OB); dec. } \\
\text { leaves or roots } \\
\text { (OB); Int., }\end{array}$ \\
\hline
\end{tabular}




\begin{tabular}{|c|c|c|c|c|c|}
\hline & & & & & $\begin{array}{l}\text { herb in wine } \\
\text { (Pl), Int., } \\
\text { leaves and } \\
\text { flowering } \\
\text { heads (Gr) }\end{array}$ \\
\hline Verbena supina L. & Supine vervain & Eur. & $\mathrm{D}$ & Tertians, Quartans & $\begin{array}{l}\text { Int., herb in } \\
\text { beverage }\end{array}$ \\
\hline Viola lutea Huds. & $\begin{array}{l}\text { Wall flower, mountain } \\
\text { pansy }\end{array}$ & Eur. & JG & Agues & $\begin{array}{l}\text { Ext., crushed } \\
\text { leaves w/ bay } \\
\text { salt bound } \\
\text { about the } \\
\text { wrists (JG) }\end{array}$ \\
\hline Viola odorata $\mathrm{L}$. & Violet & Eur. & Gr, JG & Ague (Gr (h)) & $\begin{array}{l}\text { Int., syrup of } \\
\text { flowers ( } \mathrm{Gr} \\
\text { (h)) }\end{array}$ \\
\hline Viola tricolor L. & Heart's ease, or Pansies & Eur. & $\begin{array}{l}\text { JG, Gr } \\
\text { (h) }\end{array}$ & $\begin{array}{l}\text { Agues (especially } \\
\text { in infants \& } \\
\text { children) }\end{array}$ & Int. \\
\hline Vitis vinifera $\mathrm{L}$. & Grape & Eur. & AvT & Quartans (some) & $\begin{array}{l}\text { Int., as part of } \\
\text { cooling diet }\end{array}$ \\
\hline $\begin{array}{l}\text { Zanthoxylum } \\
\text { americanum Mill. }\end{array}$ & Prickly ash & $\begin{array}{l}\text { New } \\
\text { W. }\end{array}$ & $\mathrm{Gr}$ & Agues & Int., dec. bark \\
\hline $\begin{array}{l}\text { Zingiber officinale } \\
\text { Roscoe }\end{array}$ & Ginger & Asia & $\mathrm{HvB}$ & Three-day fever & $\begin{array}{l}\text { Int. } \mathrm{HvB} 2 ; \\
\text { Int., } \mathrm{Cu} 3\end{array}$ \\
\hline Ziziphus jujuba Mill. & Beade Tree, Jujube tree & $\begin{array}{l}\text { Eur., } \\
\text { Asia }\end{array}$ & JG & Agues (JG) & $\begin{array}{l}\text { Int., dec. bark } \\
\text { JG } 5\end{array}$ \\
\hline \multicolumn{6}{|l|}{$\begin{array}{l}\text { Non-plant remedies } \\
\text { and ingredients: }\end{array}$} \\
\hline $\begin{array}{l}\text { Agaricus or Boletus } \\
\text { sp. (various) }\end{array}$ & $\begin{array}{l}\text { Agarics or boletes } \\
\text { (unsp.) }\end{array}$ & Eur. & $\mathrm{D}, \mathrm{Cu}$ & Agues & $\begin{array}{l}\text { Int. in wine } \\
\text { before fit (D), } \\
\text { Int., Cu } 3\end{array}$ \\
\hline Amber & Amber & Eur. & $\mathrm{Sa}$ & Agues & Int., Sa 3 \\
\hline Annelida sp. & Earthworms & Eur. & $\mathrm{D}$ & Tertians & Ext., ground \\
\hline Antimony & Antimony & Eur. & $\mathrm{Sa}$ & Agues & $\begin{array}{l}\text { Int., dist. w/ } \\
\text { sugar, give in } \\
\text { wine before } \\
\text { fit, } 2-3 \text { times } \\
\text { to cure (Sa); } \\
\text { Sa } 5\end{array}$ \\
\hline Araneae sp. & Spiders & Eur. & $\mathrm{D}$ & Tertians, Quartans & $\begin{array}{l}\text { Ext., paste, for } \\
\text { tertian; amulet } \\
\text { for quartan (D) }\end{array}$ \\
\hline Brachyura sp. & $\mathrm{Crab}$ & Eur. & $\mathrm{Sa}$ & $\begin{array}{l}\text { Agues (quartan) } \\
\text { (Sa) }\end{array}$ & $\begin{array}{l}\text { Int., the eye } \\
\text { Sa 2; Int., } \\
\text { powd. black } \\
\text { tips of claws in } \\
\text { any liquid (Sa) }\end{array}$ \\
\hline Castor fiber & $\begin{array}{l}\text { Beaver (source of } \\
\text { castoreum) }\end{array}$ & Eur. & AvT & Quartans & $\begin{array}{l}\text { Int., AvT 4, } \\
\text { AvT } 5\end{array}$ \\
\hline Cimex lectularius? & Bed bugs & Eur. & $\mathrm{D}$ & Quartans & $\begin{array}{l}\text { Seven of them } \\
\text { w/ beans, }\end{array}$ \\
\hline
\end{tabular}




\begin{tabular}{|c|c|c|c|c|c|}
\hline & & & & & before the fit \\
\hline Gallus gallus & Rooster & Eur. & D & Agues (lingering) & $\begin{array}{l}\text { Int., broth, D } \\
2\end{array}$ \\
\hline $\begin{array}{l}\text { Polypores growing } \\
\text { on Larix sp. }\end{array}$ & $\begin{array}{l}\text { Shelf fungi growing on } \\
\text { larch }\end{array}$ & Eur. & $\begin{array}{l}\mathrm{JG}, \mathrm{Sa}, \\
\mathrm{AvT}, \\
\mathrm{Gr}, \\
\mathrm{Co}, \mathrm{Pl}\end{array}$ & $\begin{array}{l}\text { Agues (JG, Sa), } \\
\text { agues (lingering) } \\
\text { (JG), tertians (AvT, } \\
\text { Co, Pl), } \\
\text { Antiperiodic (Gr), } \\
\text { Quartans (Pl) }\end{array}$ & $\begin{array}{l}\text { Mixed w/ } \\
\text { unsp. ingred. } \\
\text { (JG), Int., Sa } \\
\text { 3, w/ } \\
\text { rosewater, } \\
\text { honey \& } \\
\text { vinegar (AvT), } \\
\text { Int.,to check } \\
\text { sweating (Gr), } \\
\text { w/ oxymel or } \\
\text { as Co 1, Co ) } \\
\end{array}$ \\
\hline Sulfur & Spirit of sulfur & Eur. & $\mathrm{Sa}$ & $\begin{array}{l}\text { Agues (tertian) } \\
(\mathrm{Sa})\end{array}$ & Int., $\mathrm{Sa} 4$ \\
\hline $\begin{array}{l}\text { Worms (unidentified } \\
\text { sp.) in Dipsacus } \\
\text { fullonum L. }\end{array}$ & $\begin{array}{l}\text { Worms in the heads of } \\
\text { teasel (also teazle) }\end{array}$ & Eur. & $\begin{array}{l}\mathrm{D}, \mathrm{HB} \\
\text { (h), Gr } \\
\text { (h), } \\
\text { OB (h) }\end{array}$ & $\begin{array}{l}\text { Quartans (D, HB, } \\
\text { OB) }\end{array}$ & $\begin{array}{l}\text { Amulet, the } \\
\text { worms bound } \\
\text { up in a purse, } \\
\text { hung at the } \\
\text { neck or arm } \\
\text { (D, OB, Gr, } \\
\text { HB) }\end{array}$ \\
\hline
\end{tabular}

Table 2: Compound remedies

\begin{tabular}{|c|c|c|}
\hline $\begin{array}{l}\text { Name of } \\
\text { compound }\end{array}$ & Specificity & Components \\
\hline AvT 1 & Quartans & Storax, myrrh, opoponax, iris, pepper, galbanum, poppy juice. \\
\hline AvT 2 & Quartans & $\begin{array}{l}\text { Saffron, opium, galbanum, cassia-cinnamon, storax, myrrh, } \\
\text { castoreum, costus, pepper, spikenard, honey. }\end{array}$ \\
\hline AvT 3 & Quartans & $\begin{array}{l}\text { Kyrenaischer saft (Cyrenian liquid, identity uncertain), pepper, } \\
\text { myrrh, rue. }\end{array}$ \\
\hline AvT 4 & Quartans & $\begin{array}{l}\text { Castoreum, poppy, myrrh, white pepper, Kyrenaischer saft } \\
\text { (Cyrenian liquid, identity uncertain). }\end{array}$ \\
\hline AvT 5 & Quartans & Opoponax, opium, castoreum, henbane seeds. \\
\hline AvT 6 & Quartans & $\begin{array}{l}\text { Poppy seeds and juice, white henbane, liquorice juice, storax, } \\
\text { anise, saffron, castoreum, mandrake bark. }\end{array}$ \\
\hline AvT 7 & Quartans & $\begin{array}{l}\text { Wormwood, colocynth, aloe, gum mastic, dodder growing on } \\
\text { thyme. }\end{array}$ \\
\hline AvT 8 & Quartans & $\begin{array}{l}\text { Myrrh, spikenard, saffron, castoreum, opium, amomum (exact } \\
\text { species unknown), anise, Macedonian parsely, celery seed, mastic } \\
\text { flowers, cassia, white pepper, black pepper, storax, Sison } \\
\text { amomum, Sesel (unidentified), sage, honey. }\end{array}$ \\
\hline AvT 9 & $\begin{array}{l}\text { Tertians, } \\
\text { quartans }\end{array}$ & Scammony, larch agaric, rosewater, honey, pepper. \\
\hline AvT 10 & Quartans & Pennyroyal, oregano, hyssop, and barley water \\
\hline AvT 11 & Quartans & Macedonian parsely, scammony, larch agaric, and white pepper \\
\hline
\end{tabular}




\begin{tabular}{|c|c|c|}
\hline AvT 12 & $\begin{array}{l}\text { Quartans } \\
\text { (Internal } \\
\text { pains) }\end{array}$ & $\begin{array}{l}\text { Opium with saffron, opium, cassia, storax, myrrh, and galbanum } \\
\text { resin }\end{array}$ \\
\hline AvT 13 & $\begin{array}{l}\text { Tertians, } \\
\text { quartans }\end{array}$ & Roots of celery and maidenhair, cooked until soft \\
\hline AvT 14 & $\begin{array}{l}\text { Tertians, } \\
\text { quartans }\end{array}$ & Anise, celeriac, leek leaves, honey, and vinegar \\
\hline AvT 15 & Quartans & Candy carrot seeds, with pepper, in hot water \\
\hline AvT 16 & Quartans & Opium, henbane, and hemlock. \\
\hline Co 1 & $\begin{array}{l}\text { Ague and } \\
\text { cold shaking }\end{array}$ & $\begin{array}{l}\text { Sliced larch agaric, ginger, rock salt, polypodium, damask rose } \\
\text { infusion, sugar }\end{array}$ \\
\hline Co 2 & $\begin{array}{l}\text { Ague and } \\
\text { cold shaking }\end{array}$ & $\begin{array}{l}\text { Hiera Picta (aloe juice, boiled down and powdered, with the bark } \\
\text { of white cinnamon, Canella alba), larch agaric, aloe, honey, roses }\end{array}$ \\
\hline Co 3 & Quartans & Betony and pennyroyal in decoction, with mead \\
\hline $\mathrm{Co} 4$ & Quartans & $\begin{array}{l}\text { Common polypody with whey, honeyed water, barley water, or } \\
\text { chicken broth with thyme, beet, and mallows }\end{array}$ \\
\hline $\mathrm{Co} 4$ & Agues & European wild ginger, let sit in sun with laudanum \\
\hline Co 5 & $\begin{array}{l}\text { Shaking fit } \\
\text { of ague }\end{array}$ & Decoction of rue with dried dill herb and flowers \\
\hline $\mathrm{Cu} 1$ & $\begin{array}{l}\text { Shaking fit } \\
\text { of ague }\end{array}$ & Asfoetida, myrrh, pepper and frankincense \\
\hline $\mathrm{Cu} 2$ & Quartan & Asfoetida, pepper, ginger, and rue \\
\hline $\mathrm{Cu} 3$ & Ague & Agaricus or boletus sp. with ginger, honey, and vinegar \\
\hline $\mathrm{Cu} 4$ & Ague & Rob of elder with blessed thistle, followed by vinegar \\
\hline D1 & $\begin{array}{l}\text { Quartans, } \\
\text { tertians, } \\
\text { quotidians }\end{array}$ & $\begin{array}{l}\text { Cinquefoil drunk with hydromel or diluted wine, and a little } \\
\text { pepper; three leaves for tertian, four for quartan, and one for } \\
\text { quotidian }\end{array}$ \\
\hline D2 & $\begin{array}{l}\text { Agues, } \\
\text { lingering }\end{array}$ & $\begin{array}{l}\text { Broth of an old rooster with sea colewort, mercury, cnicum } \\
\text { (Carthamus tinctorius), or polypodium (Polypodium vulgare) }\end{array}$ \\
\hline JG 1 & $\begin{array}{l}\text { Agues (to } \\
\text { temper the } \\
\text { heat) }\end{array}$ & $\begin{array}{l}\text { Syrup made from comfrey, liquorice, poleroot, pinenuts, jujubes, } \\
\text { mallow seed, poppies, sugar, and honey }\end{array}$ \\
\hline JG 2 & $\begin{array}{l}\text { Agues } \\
\text { (shaking and } \\
\text { shivering of), } \\
\text { Quartans } \\
\end{array}$ & Laserpitum, wine, pepper, and white frankincense \\
\hline JG 3 & Tertians & Scammony with apple and fleawort or prunes \\
\hline JG 4 & $\begin{array}{l}\text { Tertians, } \\
\text { quartans }\end{array}$ & $\begin{array}{l}\text { Cinquefoil root juice drunk in mead or honeyed water, or wine } \\
\text { with pepper }\end{array}$ \\
\hline JG 5 & Agues & Beade tree bark with fumitory and mirobalans \\
\hline JG 6 & Agues & Wrist plaster with wall flower or with feverfew and ground glass \\
\hline JG 7 & $\begin{array}{l}\text { Agues of } \\
\text { long } \\
\text { standing (as } \\
\text { strong } \\
\text { purgative) }\end{array}$ & $\begin{array}{l}\text { Bastard rhubarb roots boiled in water of blessed thistle, with } \\
\text { honey, taken before the fit on two or three separate occasions }\end{array}$ \\
\hline Gr 1 & $\begin{array}{l}\text { Intermittent } \\
\text { fevers }\end{array}$ & Bistort root and calamus root \\
\hline Gr 2 & Agues & Chicory and endive (historic) \\
\hline Gr 3 & $\begin{array}{l}\text { Intermittent } \\
\text { fevers }\end{array}$ & Gentian with astringents such as tormentil or galls \\
\hline Gr 4 & Agues & European wild ginger, let sit in sun with laudanum \\
\hline
\end{tabular}




\begin{tabular}{|c|c|c|}
\hline HvB 1 & $\begin{array}{l}\text { Three-day } \\
\text { fever }\end{array}$ & Blechnum and yarrow, boiled in wine and strained \\
\hline HvB 2 & $\begin{array}{l}\text { Three-day } \\
\text { fever }\end{array}$ & $\begin{array}{l}\text { Balsam herb, small coltsfoot, cloves, galangal, ginger, radish, and } \\
\text { wine }\end{array}$ \\
\hline HvB 3 & $\begin{array}{l}\text { Four-day } \\
\text { fever }\end{array}$ & $\begin{array}{l}\text { Madder, brier bush, fallow root (unidentified), and wine, heated } \\
\text { with red-hot steel }\end{array}$ \\
\hline Mdf 1 & $\begin{array}{l}\text { Intermittent } \\
\text { fevers }\end{array}$ & $\begin{array}{l}\text { Mugwort, dwarf elder, tutsan, amphibious persicaria, pimpernel, } \\
\text { butcher's broom, elder bark, mallow boiled together and added to } \\
\text { the patient's bath }\end{array}$ \\
\hline Mdf 2 & $\begin{array}{l}\text { Intermittent } \\
\text { fevers }\end{array}$ & $\begin{array}{l}\text { Moss, ground ivy, elder or caraway, mallow, fennel, pimpernel, } \\
\text { butcher's broom, borage, and young leaves of the earth nut, boiled } \\
\text { together and mixed with the juice of elder root bark and fermented } \\
\text { with goat's or cow's whey. After taking, consume apple, honey, or } \\
\text { wood sorrel to remove the taste. }\end{array}$ \\
\hline Mdf 3 & $\begin{array}{l}\text { Intermittent } \\
\text { fevers }\end{array}$ & $\begin{array}{l}\text { Fumitory, infusion with dandelion in the morning, then } \\
\text { wormwood infusion at noon }\end{array}$ \\
\hline OB 1 & Quartans & Hops seethed in wine, "mit hirtzzung und senet bletter" \\
\hline OB 2 & Quartans & The juice of dwarf elder with powdered leafy spurge \\
\hline Pl 1 & Quartans & $\begin{array}{l}\text { Betony powdered with hypericum seed and panaces (an } \\
\text { unidentified herb) }\end{array}$ \\
\hline P1 2 & Quartans & Fennel and anise in vinegar and honey \\
\hline Pl 3 & Quartans & Garlic, one head with silphium (see laserpitum) in dry wine \\
\hline Sa 1 & $\begin{array}{l}\text { Agues, esp. } \\
\text { tertians }\end{array}$ & Tobacco, rue, sage, bay salt, and vinegar (wrist plaster) \\
\hline Sa 2 & Agues & Betony, aaron roots, crabs' eyes, cinnamon, sugar of roses, mint \\
\hline Sa 3 & Agues & $\begin{array}{l}\text { Scammony, myrrh, aloe, galbanum, jallop, white agaric, nutmeg, } \\
\text { amber, cinnamon, cloves, and juniper }\end{array}$ \\
\hline Sa 4 & Agues & Scammony, saffron, aloe, spirit of wine, and spirit of sulfur \\
\hline Sa 5 & Agues & Antimony, angelica, and canary wine (as vomitory) \\
\hline Sa 6 & Agues & Wrist plaster of rue, sage, tobacco, bay salt, and vinegar \\
\hline Thr 1 & $\begin{array}{l}\text { Intermittent } \\
\text { fevers }\end{array}$ & $\begin{array}{l}\text { Powdered chamomile flowers, salt of wormwood, and antimony } \\
\text { (given as diaphoretic) }\end{array}$ \\
\hline Thr 2 & $\begin{array}{l}\text { Intermittent } \\
\text { fevers }\end{array}$ & Dried arum root, rhubarb, and tartarus vitriolatus \\
\hline Thr 3 & $\begin{array}{l}\text { Intermittent } \\
\text { fevers }\end{array}$ & Cinchona with snake root added to increase the efficacy \\
\hline Thr 4 & $\begin{array}{l}\text { Intermittent } \\
\text { fevers }\end{array}$ & Gentian with astringents such as tormentil or galls \\
\hline Thr 5 & $\begin{array}{l}\text { Autumnal } \\
\text { fevers }\end{array}$ & Gentian with hedge hyssop \\
\hline
\end{tabular}




\section{3: Discussion}

In the fifteen sources used, 251 substances were identified as having likely been used in the treatment of malaria. Of these, 239 are plants; the remaining twelve include sulfur, antimony, unidentified fungi, and animal ingredients. Not all of the remedies in the table were intended to remove disease; many were intended to palliate symptoms, while others may have been added to compound remedies in order to improve their taste, appearance, or perceived value. It was often impossible to determine whether a given remedy or ingredient was intended to cure the disease or for one of these other purposes. Nevertheless, it is probable that a large portion of the substances in the table were intended to cure malaria. Some substances appear repeatedly and may be of special interest from a medicinal chemistry standpoint; these will be discussed in more detail below.

From the table, it will be seen that some of the remedies are what would today be considered as food rather than medicine. As in the Chinese and Ayurvedic medical traditions, the Greek and Roman physicians considered diet to be of paramount importance to the maintenance of health and prevention of disease. It was believed that one of the causes of disease was an immoderate or imbalanced diet, sometimes to the extent that a disorder might be caused or cured by the consumption of particular food items (Celsus, 1960; Phillips, 1973). The medieval physicians also held strongly to this belief (Major, 1954; Gottfried, 1986), and specific dietary recommendations are not always extricable from medicament. As an example, in his section on medicinal plants, 
Bartholomæus Anglicus (writing before 1283) gives the following information about the cucurbit:

And it is to hem that hauen the feuer agu bothe mete an medicyne yrostid other fryed; for he purgeth the matiere by vryne and laxeth, and abateth the hetes and comforteth the sike. ${ }^{14}$ (Bartholomæus Anglicus, translated by John Trevisa, 1398.)

It is certainly possible that some of the foods given in the dietary prescriptions may have contained compounds active against malaria, or may perhaps have contributed to the efficacy of other remedies; however, this portion of the table is perhaps of more historical than medicinal chemistry interest.

Several of the remedies listed in the table are meant to be carried or worn as amulets against malaria. It is not commonly believed today that amulets could have had other than a psychological effect in treatment or prevention of disease (Cameron, 2006). Indeed, the sources used in this project often describe amulets with some degree of skepticism. The colorful nature of some of these remedies may have led to their perpetuation in the literature. For example, the following use of the worms found in the heads of teasel (Dipsacum fullonum L.) appears in four of the sources examined:

But ye worms of ye heads being bound up in a purse, $\&$ hanged about the neck or the arme, are sayd to cure such as have quartanes. (Dioscorides, Book III, 13.; Goodyer.)

\footnotetext{
${ }^{14}$ In the above quotation, as well as others by Bartholomæus Anglicus, the runic letter for the sound "th" has been rendered as th.
} 
From Goodyer's translation, Dioscorides appears to be relating this superstition at a slight distance. In fact, each of the sources including this remedy evinces some degree of scepticism. For example, Hieronymus Bock mentions it thus:

Dioscorides writes that the worms that are sometimes found in the interior of this thistle are good for quartan fever, wrapped up and carried about the neck. I have not tried it - I have certainly found the worms. ${ }^{15}$

(Hieronymus Bock, Kreutterbůch, 1572 edition)

Aside from those remedies overtly intended for use as amulets, there are ritual components in many of the other prescriptions found in the sources. A frequent example is the instruction that for a tertian fever, one should use a plant with three stems, or take three leaves or roots, or cut at the third joint, and that for a quartan fever, one should use a plant with four stems, or take four leaves or roots, or cut at the fourth joint. This appears at least four times in Pliny's Natural History, including the following descriptions of the use of cinquefoil (possibly Potentilla reptans L.) and vervain (Verbena officinalis L.):

Some have prescribed doses of three cinquefoil leaves for tertians, of four for quartans, and of more for the other fevers; others prescribe for all three oboli with pepper in hydromel. Vervain in wine indeed is a remedy for fever even of beasts of burden, but for tertians the plant must be cut at the third joint, and for quartans at the fourth. (Pliny, Book XXVI, Chapter LXXI., translated by W.H.S. Jones.) ${ }^{16}$

\footnotetext{
${ }^{15}$ Dioscorides schreibet/das die würmlin so etwann im marck diser distel funden werden/seien güt für das feber quartana eingewickelt unnd am halß getragen/ich habs nicht erfaren/ die würmlin hab ich wol funden. (Translation mine.)

${ }^{16}$ Quinquefolii folia quidam terna tertianis dedere, quaterna quartanis, plura ceteris, alii omnibus tres obolos cum pipere ex aqua mulsa. Verbenaca quidem et iumentorum febribus in vino medetur, sed in tertianis a tertio geniculo incisa, quartanis a quarto.
} 
In addition to their possible magical purpose and psychological value, apparent ritual elements in a remedy may have contributed to the activity of the remedies in other ways. As an example, the following is Hildegard of Bingen's prescription for a four-day fever:

A person who suffers from a four-day fever should take madder, the same weight of brier bush, and three times this combined amount of fallow root and boil them in wine. Then pour clear, very good wine into a basin and plunge a heated, glowing-hot piece of steel into it; plunge the heated steel into the wine in this basin a second time. Do it ten times with the same wine and the same steel. After that, take the wine in which you boiled the plants, pour it into the heated wine into which you have plunged the hot steel bar, cause the whole thing to boil up one more time, and when the fever begins again, drink it immediately, and keep it up until you are healthy. (Hildegard of Bingen, Translation by P. Madigan, 1994)

The manner of heating is of interest. Although at first it seems ritualistic, it would likely result in the presence of iron salts in the resulting liquid. As malaria is known to cause anemia (Greenwood, 2005), it is possible that this method of heating might have helped the patient to recover more quickly.

However, the majority of the remedies listed are plants or combinations of plants intended to be of primarily medicinal rather than dietary or magical use against malaria. Of these, most (approximately $65 \%$ ) are referred to in only a single source. From the sheer number of different substances that were recommended at various times, it is hard to escape a conclusion that most of the remedies were not very effective (Cameron, 2006). However, approximately $35 \%$ of the remedies are referred to repeatedly. A scientific examination of these plants for antimalarial activity might be of particular value. Only a portion of the plants listed here have been examined previously for antimalarial activity. 
Of the 251 entries in Table 4.1, 38 substances were referred to in three or more sources (Table 4.3, below). Of these, at least fifteen have previously been examined for antiplasmodial activity; in many cases, they were found to have antiplasmodial activity in vitro or in vivo. A small selection of the plants in Table 4.3 will be discussed in more detail below.

\section{Table 4.3: Remedies listed in three or more historical sources}

\begin{tabular}{|c|c|c|c|c|}
\hline Scientific name & Common name & $\begin{array}{l}\text { Number of } \\
\text { references in } \\
\text { survey }\end{array}$ & Tested for malaria? & $\begin{array}{l}\text { Activity } \\
\text { observed } \\
\text { (Yes/No) }\end{array}$ \\
\hline $\begin{array}{l}\text { Anchusa officinalis L., Alkanna } \\
\text { tinctoria (L.) Tausch, Anchusa } \\
\text { azurea Mill. }\end{array}$ & Alkanet, bugloss & 3 & $\begin{array}{l}\text { Ozbilgin (2014) } \\
\text { (Alkanna tinctoria) }\end{array}$ & No \\
\hline Artemisia absinthium L. & Wormwood & 6 & Zimmerman (2012) & Yes \\
\hline Artemisia vulgaris $\mathrm{L}$. & Mugwort & 3 & $\begin{array}{l}\text { Milhau (1997) } \\
\text { Zimmerman (2012) } \\
\text { Bamunuarachchi } \\
(2013)\end{array}$ & Yes \\
\hline Asarum europaeum L. & European wild ginger & 4 & Not found & \\
\hline Berberis vulgaris L. & Barberry & 3 & Not found & \\
\hline Centaurea benedicta $(\mathrm{L}.) \mathrm{L}$. & Blessed thistle & 5 & Not found & \\
\hline Centurium erythraea Rafn & Centaury & 3 & Danzel (1948) & \\
\hline $\begin{array}{l}\text { Chamaemelum nobile (L.) All., } \\
\text { Matricaria chamomilla L. }\end{array}$ & Chamomile & 5 & Fujisaki (2012) & No \\
\hline Cinchona sp. & $\begin{array}{l}\text { Peruvian bark, } \\
\text { cinchona }\end{array}$ & 3 & $\begin{array}{l}\text { Saunders (1783) } \\
\text { Vaughan (1795) } \\
\text { (and many others) }\end{array}$ & Yes \\
\hline $\begin{array}{l}\text { Citrullus colocynthis (L.) } \\
\text { Schrad. }\end{array}$ & Colocynth & 4 & Not found & \\
\hline Citrus limon (L.) Osbeck & Lemon & 3 & Not found & \\
\hline Clinopodium nepeta (L.) & Mountain mint, lesser & 3 & Not found & \\
\hline
\end{tabular}




\begin{tabular}{|c|c|c|c|c|}
\hline Kuntze subsp.glandululosum & calamint & & & \\
\hline Commiphora myrrha (Nees.) & & & & \\
\hline Engl. and others & Myrrh & 3 & Not found & \\
\hline Convolvulus scammonia $\mathrm{L}$. & Scammony & 3 & Not found & \\
\hline $\begin{array}{l}\text { Cuscuta epithymum L. and } \\
\text { others }\end{array}$ & Dodder, Hell weed & 4 & Not found & \\
\hline $\begin{array}{l}\text { Gentiana lutea L., Gentiana } \\
\text { purpurea L. }\end{array}$ & $\begin{array}{l}\text { Yellow gentian, } \\
\text { purple gentian }\end{array}$ & 3 & $\begin{array}{l}\text { Zimmerman (2012) } \\
\text { See also Riscoe } \\
(2005)\end{array}$ & Yes \\
\hline Geum urbanum L. & Avens & 3 & Zimmerman (2012) & Yes \\
\hline Helleborus niger L. & Black hellebore & 5 & Not found & \\
\hline Lamium purpureum $\mathrm{L}$. & $\begin{array}{l}\text { Lamium (Dead } \\
\text { nettle) }\end{array}$ & 3 & Not found & \\
\hline Mentha pulegium L. & Pennyroyal & 4 & Not found & \\
\hline $\begin{array}{l}\text { Peucedanum ostruthium (L.) } \\
\text { W.D.J. Koch }\end{array}$ & Masterwort & 3 & Zimmerman (2012) & Yes \\
\hline Piper nigrum $\mathrm{L}$. & Pepper & 3 & Kamaraj (2012) & \\
\hline $\begin{array}{l}\text { Plantago major L. and } P \text {. } \\
\text { lanceolata } \mathrm{L} \text {. }\end{array}$ & $\begin{array}{l}\text { Plantain, waybread } \\
\text { (Wegerich, } \\
\text { Spitzwegerich) }\end{array}$ & 7 & $\begin{array}{l}\text { Sangian }(2013)(P . \\
\text { lanceolata })\end{array}$ & Yes \\
\hline Polygonum aviculare L. & Knotgrass & 3 & Not found & \\
\hline Polypodium vulgare $\mathrm{L}$. & $\begin{array}{l}\text { Common polypody } \\
\text { (oak fern, Engelfuß, } \\
\text { Steinfarn) }\end{array}$ & 3 & Not found & \\
\hline Potentilla erecta (L.) Raeusch. & Tormentil & 3 & Zimmerman (2012) & Yes \\
\hline Potentilla reptans $\mathrm{L}$. & Cinquefoil & 5 & Not found & \\
\hline Rheum rabarbarum $\mathrm{L}$. & Rhubarb & 3 & Not found & \\
\hline Rosa sp. & Rose & 3 & Not found & \\
\hline Ruta graveolans L. & Rue, Herb Grace & 6 & Not found & \\
\hline Sambucus ebulus L. & Dwarf elder & 3 & Zimmerman (2012) & Yes \\
\hline $\begin{array}{l}\text { Saussurea costus (Falc.) } \\
\text { Lipsch. }\end{array}$ & Costus & 3 & Not found & \\
\hline Stachys officinalis (L.) Trevis. & Betony & 5 & Not found & \\
\hline Syzygium aromaticum (L.) & Cloves & 3 & Fujisaki (2012) & Yes \\
\hline
\end{tabular}




\begin{tabular}{|l|l|l|l|l|}
\hline Merr. \& L.M. Perry & & & & \\
\hline $\begin{array}{l}\text { Tanacetum parthenium (L.) } \\
\text { Sch.Bip. }\end{array}$ & Feverfew & 3 & Zimmerman (2012) & Yes \\
\hline Verbena officinalis L. & $\begin{array}{l}\text { Vervain, verbena, } \\
\text { Eisenkraut }\end{array}$ & 6 & Zimmerman (2012) & Yes \\
\hline Polypores growing on Larix sp. & Shelf fungi on larch & 6 & Not found & \\
\hline $\begin{array}{l}\text { Worms (unidentified sp.) in } \\
\text { Dipsacus fullonum L. }\end{array}$ & $\begin{array}{l}\text { Worms in teasel } \\
\text { heads }\end{array}$ & 4 & Not found & \\
\hline
\end{tabular}

Artemisia absinthium L. and Artemisia vulgaris L.

In this survey, wormwood (Artemisia absinthium L.) and mugwort (Artemisia vulgaris L.) were recommended to treat intermittent fevers by six and three sources respectively. These plants are widely naturalized throughout various continents, including the United States. Their use to treat malaria is intriguing, since they are relatives of Artemisia annua (qinghao), the source of the antimalarial artemisinin (qinghaosu); the additional Artemisia species $A$. abrotanum L. (southernwood), $A$. ponticum L. (Roman wormwood), and A. maritima L. (sea wormwood) are also mentioned in the sources as having antimalarial acitivity. Both $A$. absinthium and $A$. vulgaris have been tested for antimalarial properties, and activity has been found both in vitro and in vivo (Plasmodium berghei in a mouse model; Milhau, 1997; Zimmerman, 2012; Bamunuarachchi, 2013 and others). There has, however, been a report that a traveler to West Africa attempted to use Artemisia vulgaris L. as antimalarial prophylaxis, and contracted malaria (Kurtzhals, 2005). 


\section{Berberis vulgaris $\mathrm{L}$.}

Barberry (probably Berberis vulgaris L.), a Eurasian shrub producing edible berries, is recommended to treat intermittent fevers in three of the sources surveyed. Although it appears that this species of barberry may not have been screened as an antimalarial, the roots of this plant are known to produce berberine, a compound with antiplasmodial activity. Both this and other barberries are used in natural medicine in many parts of the world (Duke, 1985; Hutchens, 1991; Bahar, 2014).

\section{Citrus limon (L.) Osbeck}

The rind or juice of lemon (perhaps Citrus limon (L.) Osbeck) was recommended to treat intermittent fevers by three of the sources in the survey. Although the lemon does not appear to have been assayed for activity against Plasmodium, the peel and juice of other species of citrus have been found to have antiplasmodial activity. In a mouse study, the juice of grapefruit was found to confer some degree of protection against infection by rodent malaria (P. berghei; Oreagba, 2008), and acridones with antimalarial activity have been isolated from the peel of Citrus grandis (Fujioka, 1989). Ascorbic acid (present in lemon juice) has also been found to potentiate the antimalarial activity of the oxidant drug, exifone (Winter, 1997). 
Helleborus niger $\mathrm{L}$. and others:

Hellebore (including Helleborus niger L., Christmas Rose) was described in nearly all of the sources in this survey, and is one of the few medicaments recommended by Hippocrates (460-370 B.C., translated by Jones, 1957) and Celsus (25 B.C. - 50 A.D., translated by Spencer, 1960). Although an Old World plant, it is grown in the United States as an ornamental. It was formerly used in herbal medicine as a drastic purgative, but at the time of Celsus it was already considered quite dangerous and not appropriate for all patients - its use causes nausea and diarrhea, and larger doses cause vomiting, narcosis and coronary arrest (Gerard, 1597; Duke, 1985; Frohne, 2005). Five of the sources in this survey recommended the use of hellebore in intermittent fevers. However, each author urges caution in its use. Bartholomæus Anglicus gives the following warning:

Dias and othre auctors meneth that it is a ful violent herbe and schal be ytake redily and warly, for he greueth and son[e]st ageins many yueles if it is vnredily ytake to ony person... he destroyeth the feuere quarteyn... (Bartholomæus Anglicus, translated by John Trevisa.)

Gerard has the following:

Blacke Hellebor purgeth downwards flegme, choler, and also blacke choler especially, and all melancholike humors, yet not without trouble and difficultie. Therefore it is not to be giuen but to robustious and strong bodies, as Mesues teacheth. A purgation of blacke Hellebor is good for mad and furious men, for melancholike, dull, and heauie persons, for those that are troubled with the falling sicknesse, for lepers, for them that are sicke of a quartaine ague, and briefly for all those that are troubled with 
blacke choler, and molested with melancholie. (John Gerard and Dr. Priest, 1597)

Although hellebore was intended to purge disease-causing humors, it is possible that this plant may contain compounds that are active against Plasmodium species. As this plant apparently has not been assayed for antimalarial activity, it may be another phytochemical source of interest.

Plantago major L. and Plantago lanceolata L.

The plantains (waybread, or Wegerich, and ribwort, or Spitzwegerich) are recommended to treat intermittent fevers in seven of the sources surveyed, more frequently than any other plant. These edible plants are present on several continents, and both species are common in the Pacific Northwest as an introduced species. The plantains are used in traditional medicine in many parts of the world (Duke, 1985). Sangian and coworkers (2013) have recently reported that an ethanolic extract of $P$. major had mild antiplasmodial activity in vitro $\left(\mathrm{IC}_{50}=40 \mu \mathrm{g} / \mathrm{mL}\right)$. Therefore, further examination of both $P$. lanceolata $\mathrm{L}$. and $P$. major $\mathrm{L}$. appears promising, particularly as these plants are readily available. 


\section{Potentilla reptans $\mathrm{L}$.}

Cinquefoil, tentatively identified as Potentilla reptans L., was recommended to treat intermittent fevers by five of the sources in this survey. However, it does not appear to have been assayed for antimalarial activity. A related species, Potentilla discolor, is used in Chinese medicine to treat malaria (Yang, 2010).

\section{4: Further notes on historical remedies, and a word of caution for medicinal chemists}

While the approach of looking for active compounds in medicinal plants is intriguing from the perspective of medicinal chemistry, it is attended by certain dangers from an anthropological or historical point of view. There is a large difference between an herbal remedy administered in the recommended form within in its cultural context, and a purified compound given as a pharmaceutical drug. It must not be concluded that because a plant extract does not have in vitro antiplasmodial activity that the remedy was useless. In vitro and even in vivo testing of plant extracts may provide misleading results for several reasons. Firstly, the importance of psychological factors in determining the efficacy of medical treatment must not be underestimated. Secondly, whole plants may contain active constituents that are degraded under the conditions of the techniques used to extract them. In view of this it is important to consider the recommended method of administration of the remedy. Thirdly, more than a single constituent may be important to the antimalarial activity of a plant remedy. Multiple active constituents may be present 
that act either separately or synergistically, or it may be that compounds are present that have little antimalarial activity of their own, but potentiate the activity of the active constituents. The latter may be true in the case of qinghao (sweet wormwood, Artemisia annua L.), the source of the antimalarial compound artemisinin (qinghaosu). Mice fed whole plant Artemisia annua have been observed to have far higher levels of artemisinin in their blood than those fed an equivalent amount of purified artemisinin (Weathers, 2011), and in a mouse model of malaria it has also been observed that whole-plant Artemisia annua has higher antimalarial activity than would be expected on the basis of its content of artemisinin (Elfawal, 2012). It has therefore been suggested that other compounds are present in the whole plant that act synergistically with artemisinin; these compounds may be removed when artemisinin is purified. Flavones isolated from Artemisia annua, such as artemetin and casticin (Figure 61, below), have been observed to potentiate the in vitro antiplasmodial activity of artemisinin (Elford, 1987; Liu, 1992; Rasoanaivo, 2011).
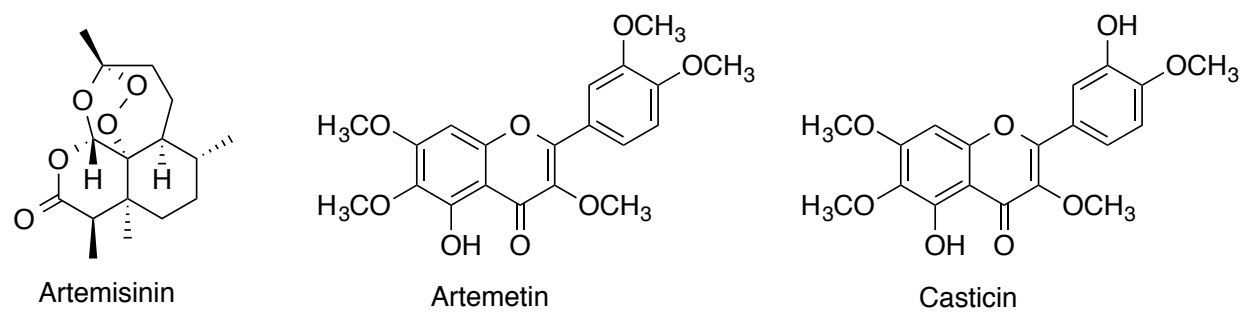

Figure 61: Artemisinin and two flavones believed to potentiate its antimalarial activity: artemetin and casticin. 
Synergistic activity has also been observed in the case of cinchona alkaloids (Baranger, 1948; Druilhe, 1988; Rasonaivo, 2011). For the same reason, it is also important to remember that many of the remedies in the table were not intended to be given alone. Some of the compound remedies identified in the course of this project may have had antimalarial activity due to the synergistic action of constituents in several different ingredients.

The sources used in this project generally provide the method in which a remedy should be prepared and administered, often in great detail. As with modern pharmaceutical preparations, this may have had a significant effect on efficacy. Some plants were recommended for fresh use, while others were recommended for use in a dried state; the state of the plant certainly would affect the constituents, but the determination of active constituents in fresh plant matter presents great challenges. Remedies intended for internal use are most often administered in liquid form. The most common liquids used are water, wine (usually white wine is specified), vinegar, ale, and milk. The prescriptions were sometimes heated - at times using sunlight - and other times not. Heating in wine or vinegar would have a high likelihood of extracting active principles; it is conceivable that the prescriptions that are not meant to be heated may contain active constituents that would be destroyed by heat. Honey is a frequent component of remedies. It is easy to assume that this was simply added to improve the taste of an otherwise less palatable remedy, but the possibility that its presence increased the efficacy of the remedy cannot be neglected. Writing in 1951, W.H.S. Jones has observed the following: 
There is at least one ingredient of the Plinian remedies that must have been of great value. Honey appears again and again in both potions and external applications, full use being made of its healing powers. The superseding of honey by sugar has been by no means an unmixed blessing.

(W.H.S. Jones, introduction to Pliny, volume VI, 1951.)

More recently, honey has attracted considerable interest for its possible activity as an antibacterial, antiinflammatory, antidiabetic, and anticancer agent (Alvarez-Suarez, 2013; Carina, 2014; Erujawa, 2014).

Finally, as mentioned above, some remedies are not single herbs (simples), but combinations of two or more herbs. Compound medicines, sometimes including more than ten different substances, are often encountered. William Coles, the author of The Art of Simpling, makes the following remark about compound remedies in the introduction to his Adam in Eden:

And now let me tell the ingenious Reader, and by him others, that if those of these times would but be, by a joynt Concurrence, as industrious to search into the Secrets of the Nature of Herbs, as some of the former, and make tryall of them as they did, they should no doubt find the force of Simples many times no leße effectual, then that of the Compounds, to which this present Age is too too much addicted... Thus have I broken the Nut of Herbarisme, do thou take out the Kernel and eate it and much good may it do thee. (William Coles)

It cannot be assumed that all of the materials in a compound remedy were expected to have antimalarial activity of their own - some might have been intended to treat various symptoms or to improve the flavor and appearance of the remedy. It must be suspected that at times, rare or expensive ingredients such as ground pearls, myrrh, saffron, or 
crab's eyes were added for no other reason than to increase the perceived value of the remedy (e.g. Salmon, 1696). A medicinal chemistry approach to the compound medicines might be to test the components individually, and then as the compound, to determine whether the components act synergistically; however, this would be quite laborious.

\section{5: Conclusions}

It may be seen from the results of this project, and those of other workers, that cinchona bark was far from being the only remedy for malaria used in Europe prior to the advent of modern antimalarial chemotherapy. The results of antiplasmodial testing by other workers (Table 4.3) have shown that at least some of the treatments used may have been effective. However, the majority of the phytotherapies for malaria identified in this project have not yet been tested against Plasmodium species. Despite the cautions above, the results obtained by other workers indicate that this approach may provide valuable leads for medicinal chemists. Moreover, this project has examined only a fraction of the surviving historical literature on the treatment of malaria. A more comprehensive project might be of great historical value. The following are the words of the historian Theodor Puschmann, writing in 1878:

The history of a science is that science itself. The knowledge of its past gives understanding of its present. The doctor who neglects historical studies becomes an empiricist; he will fall into many errors, undertake many fruitless studies, because he has not learned to avoid the mistakes of 
his predecessors, and because he has become used to measuring facts by the narrow measuring stick of the time period to which he belongs.

Theodor Puschmann, 1878 (Vorwort, Alexander of Tralles: Original-Text und Übersetzung. $)^{17}$

But, as Bartholomæus Anglicus has said, "be this ynowe at this tyme". ${ }^{18}$

${ }^{17}$ Die Geschichte einer Wissenschaft ist diese Wissenschaft selbst. Die Kenntniss ihrer Vergangenheit gibt das Verständniss ihrer Gegenwart. Der Arzt, welcher die historischen Studien vernachlässigt, wird zum Empiriker; er wird manchen Irrweg einschlagen, manche fruchtlose Arbeit unternehmen, weil eir nicht gelernt hat, die Fehler seiner Vorgänger zu vermeiden, und weil er sich gewöhnt hat, die Thatsachen mit dem Massstab des engen Zeitraumes zu messen, dem er angehört. (Historical spelling preserved. English translation mine.)

${ }_{18}$ Bartholomæus Anglicus, in On the Properties of Things. (Translation into English by John Trevisa, 1398, reprinted in 1975; p. 984.) 


\section{CHAPTER 5:}

\section{Experimental Methods}

\section{1.: General synthetic methods}

Described below are the general synthetic methods used to make the compounds described in this work. For specific synthetic details for each compound, including characterization data, see Appendix A: Specific synthetic methods and characterization data. For in vitro antiplasmodial activity and cytotoxicity data, see Appendix B: Tables of in vitro antiplasmodial activity and cytotoxicity. For sample NMR data (for PL241), see Appendix C: Sample NMR spectra: PL241.

\subsection{1.: Synthesis of drug candidates and intermediates: Quinoline-ring modified reversed chloroquine-type compounds}

Substituted 4-chloroquinolines with hydrogen in the 2-position were made by the GouldJacobs reaction, followed by chlorination with phosphorus oxychloride (Figure 62;

Claisen, 1897; Gould, 1939; Price, 1946): 


\section{Gould-Jacobs Reaction:}

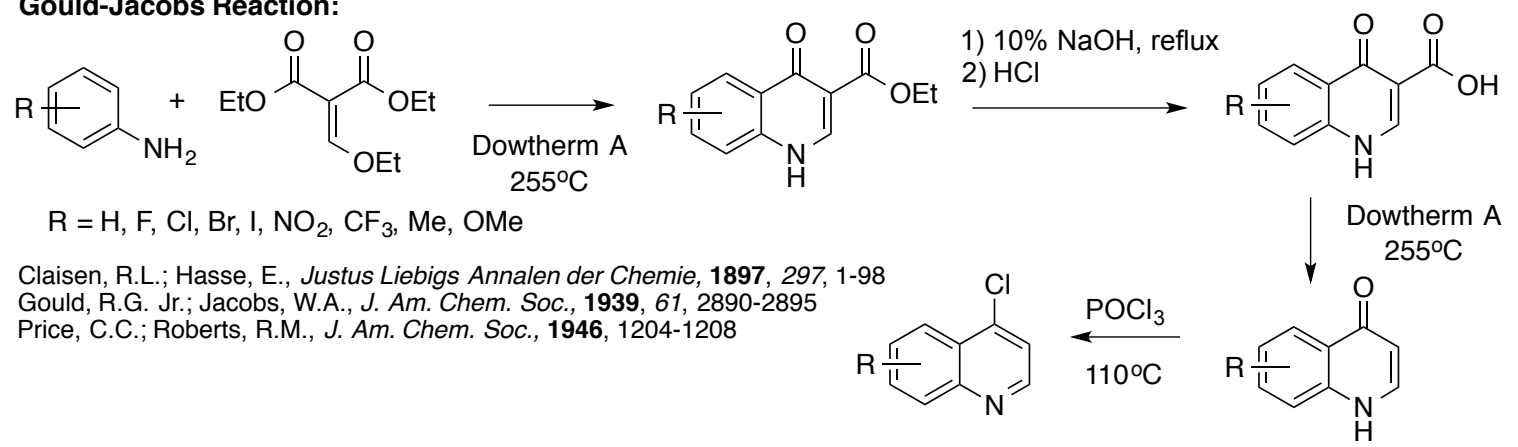

Figure 62: Synthesis of 4-chloroquinolines by the Gould-Jacobs reaction, followed by chlorination with phosphorus oxychloride.

4-chloroquinolines containing a trifluoromethyl group in the 2-position were made by the Conrad-Limpach reaction, followed by phosphorus oxychloride chlorination (Figure 63; Conrad, 1887; Reynolds, 1955):

\section{Conrad-Limpach Reaction:}

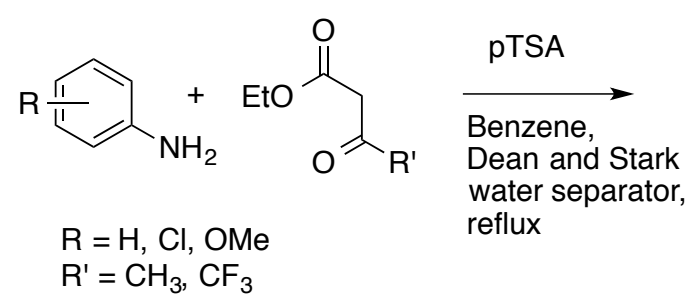<smiles>[R]c1[nH]c2c(c(=O)c1C(=O)O)C=C[R]C=C2</smiles>

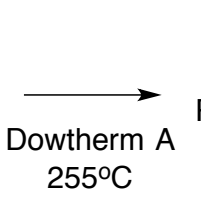<smiles></smiles>

Conrad, M.; Limpach, L., Ber., 1887, 20, 944-98; 1891, 24, 2990-2; Reynolds, G.A.; Hauser, C.R., Organic Syntheses Collective Vol 3., 1955, 374-5 and 593-4

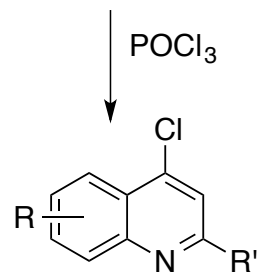

Figure 63: Synthesis of 2-trifluoromethyl-4-chloroquinolines by the Conrad-Limpach reaction, followed by phosphorus oxychloride chlorination.

In most cases the resulting substituted 4-chloroquinolines were then allowed to undergo solvolysis with 3-amino-1-propanol to give 4-amino alcohols, and the hydroxyl group was then converted to a methanesulfonyl group (Figure 64; Burgess, 2006; Burgess, 
2008; Burgess, 2010):

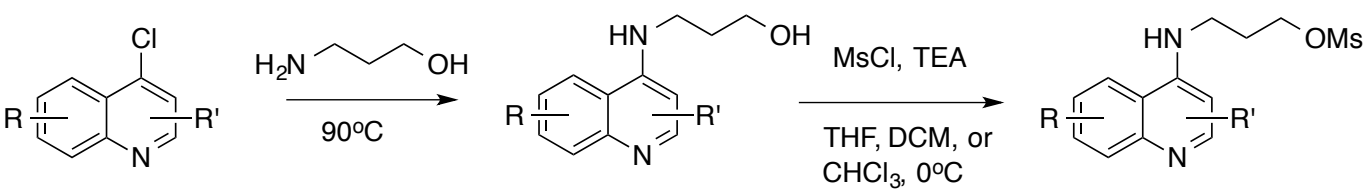

$\mathrm{R}=\mathrm{H}, \mathrm{F}, \mathrm{Cl}, \mathrm{Br}, \mathrm{I}, \mathrm{NO}_{2}, \mathrm{CF}_{3}, \mathrm{Me}, \mathrm{OMe}$

$\mathrm{R}^{\prime}=\mathrm{H}, \mathrm{CH}_{3}, \mathrm{CF}_{3}$

Burgess, S. J., Kelly, J.A., Shomloo, S., Wittlin, S., Brun, R., Liebmann, K., Peyton, D.H., J. Med. Chem., 2010, 53, 6477-6489

Figure 64: Reaction of 4-chloroquinolines with 3-amino-1-propanol, followed by activation of the resulting alcohol by methanesulfonyl chloride.

Finally, the resulting compounds were allowed to react with an appropriate secondary amine to yield either the final products (Group 1, Figure 65, below) or an imine that was then reduced with sodium borohydride to yield the final product (Group 2, Figure 65, below). The secondary amines required to produce the compounds in Figure 65, Group 1 , were purchased, but in the case of the secondary amine required to produce compounds shown in Figure 65, Group 2, the secondary amine was first synthesized as shown below (Figure 65; Burgess, 2006; Burgess, 2010; Gunsaru, 2010): 
Group 1:

(n)

Group 2:

Deane, $\begin{gathered}\text { Dean and Stark } \\ \text { Water separator, } \\ \text { reflux }\end{gathered}$

Burgess, S. J., Kelly, J.A., Shomloo, S., Wittlin, S., Brun, R., Liebmann, K., Peyton, D.H., J. Med. Chem., 2010, 53, 6477-6489
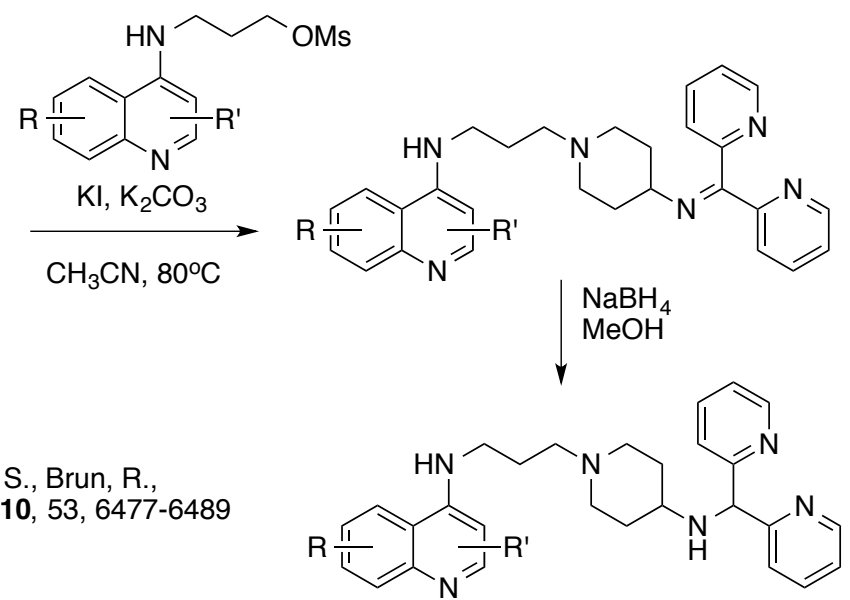

Figure 65: Reaction of mesyl alcohols with secondary amines to produce the final products.

In one case, a different method was used to produce a final product starting from the 4chloroquinoline; this is detailed below (PL142, Method 2, Appendix A, p. 257). In most cases, final products were purifiable by recrystallization, though column chromatography was sometimes necessary. 


\subsection{2: Synthesis of asymmetrical bis-quinoline type compounds}

The synthesis of the asymmetrical bis-quinoline compounds required the synthesis of two different quinoline starting materials. One quinoline starting material was identical to that shown above (Figure 64, far right). The other was produced by reaction of the appropriate 4-chloroquinoline with 3-carbethoxy-4-aminopiperidine in phenol (Andersag, 1948; Surrey, 1951; De, 1998), followed by removal of the carbethoxy group by heating with aqueous sodium hydroxide in ethanol (Figure 66; Iwasaki, 1994):

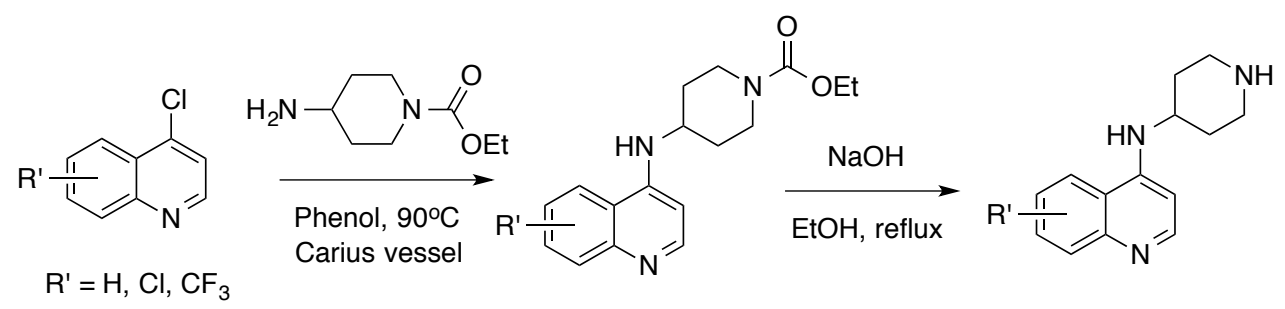

Figure 66: Synthesis of one starting material for asymmetrical bis-quinoline compounds.

Reaction of the two quinoline starting materials under the same conditions shown above then provided the desired bis-quinoline (Figure 67; Burgess, 2006; Burgess, 2010):

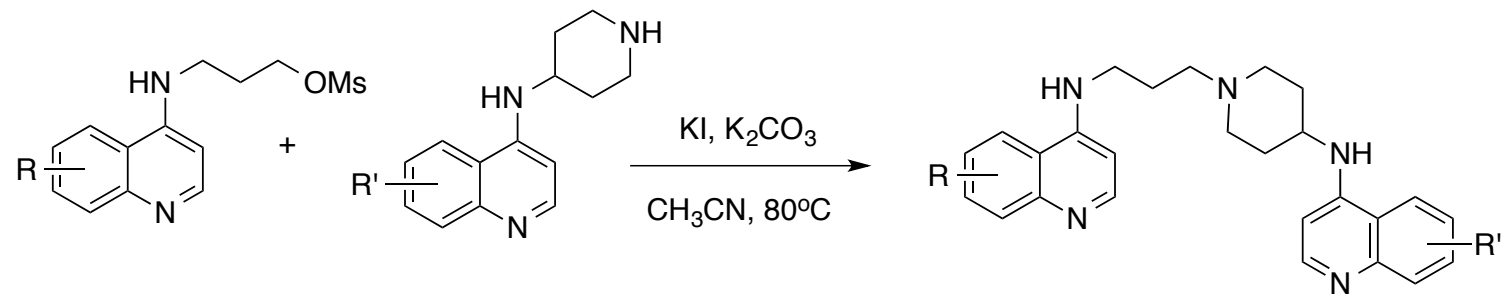

Figure 67: Synthesis of asymmetrical bis-quinoline compounds.

A different, less satisfactory synthetic method was initially used to produce PL241. This is detailed below (Appendix A, p. 323). 
As with the reversed chloroquine-type compounds in section 5.1.1, the bisquinolines could in most cases be purified by recrystallization. However, column chromatography was necessary in a few cases.

\subsection{3: Characterization of products}

Final products were characterized by NMR $\left({ }^{1} \mathrm{H},{ }^{13} \mathrm{C}\right.$, COSY, HSQC, NOESY, and ${ }^{19} \mathrm{~F}$ if applicable), melting point, HPLC, and LC/MS (details of methods used below). Intermediates not previously reported in the literature were characterized by ${ }^{1} \mathrm{H} \mathrm{NMR}$, melting point (for purified products), and occasionally HPLC and LC/MS. For sample NMR spectral interpretations for final products, see pages $187,193,213,220,256,262-3$ and 316. For example NMR spectra, see Appendix C: Sample NMR data: PL241. Nearly all 4-chloroquinoline starting materials were synthesized from the corresponding aniline in several steps (only 4-chloro-2,8-(ditrifluoromethyl)quinoline and 4,7dichloroquinaldine were purchased). The intermediates in these syntheses are reported as individual steps below, but the products generally were not characterized (NMR was sometimes used, and in most cases this spectral data is reported below). As these reactions are well understood and ample characterization data exists in the literature for the 4-quinolones and 4-chloroquinolines produced, it was found convenient to limit characterization by NMR and melting point to the 4-chloroquinoline, which is the starting point for the novel compounds. Of the 4-chloroquinoline intermediates, only two had not previously been characterized in the literature. These were 4,5-dichloro-2- 
(trifluoromethyl)quinoline and 4,7-dichloro(2-trifluoromethyl)quinoline. These were characterized by ${ }^{1} \mathrm{H},{ }^{13} \mathrm{C},{ }^{19} \mathrm{~F}$, and 2D NMR, melting point, and GC/MS.

${ }^{1} \mathrm{H},{ }^{13} \mathrm{C}$, COSY, HSQC, HMBC, and ${ }^{19} \mathrm{~F}$, NMR experiments were run on a Bruker $400 \mathrm{MHz}$ or $600 \mathrm{MHz}$ spectrometer. HPLC was performed using UV detection at 254 and $325 \mathrm{~nm}$, using a Varian ProStar 325 UV/vis dual wavelength detector. Two HPLC methods were used. For HPLC Method A, a SUPELCO Ascentis RP-Amide 5 $\mu \mathrm{m}, 4.6$ $\mathrm{mm} \times 150 \mathrm{~mm}$ column was used, eluting with a gradient of $95: 5$ to $30: 70$ water with $0.1 \%$ formic acid (v/v)/acetonitrile. For HPLC method C, a SUPELCO Ascentis C18 $5 \mu \mathrm{m}, 4.6 \times 150 \mathrm{~mm}$ column was used, eluting with a gradient from 95:5 to 5:95 water with $0.1 \%$ formic acid $(\mathrm{v} / \mathrm{v}) /$ acetonitrile. High resolution mass spectrometry was performed on a Bruker micrOTOF-Q instrument. Results were obtained using electrospray ionization (ESI) in the positive mode, at a flow rate of $0.4 \mathrm{~mL} / \mathrm{min}$. with 1:1 methanol-water. Gas chromatography-mass spectrometry (GC-MS) was performed using a Hewlett Packard HP5890 Series II gas chromatograph with a 30-m DB5 column. The oven temperature was set at $130^{\circ}$ for 2 minutes, and then increased to $300^{\circ} \mathrm{C}$ at the rate of $30^{\circ} \mathrm{C}$ per minute. This instrument was used with the kind permission of Dr. Michael Riscoe of the Portland Veterans Affairs Medical Center.

\section{2: In vitro studies on inhibition of $P$. falciparum parasite growth}

The antiplasmodial activities of the compounds in this study were determined by Dr. Jane Xu Kelly and Dr. Yuexin Li of the Portland Veteran's Affairs Medical Center by 
methods described previously (e.g. Burgess, 2010; Pou, 2012). The following three strains of $P$. falciparum were used: 1) a chloroquine-sensitive strain, D6, 2) a chloroquine resistant strain, Dd2, originally isolated from southeast Asia 3) a second chloroquine resistant strain, 7G8, originally isolated from Brazil. The parasites were maintained continueously in culture, and asynchronous cultures were used for testing. Samples of the cultures were diluted to $0.2 \%$ parasitemia and $0.2 \%$ hemocrit using uninfected red blood cells and complete cell growth medium (RPMI-1640 with 0.5\% Albumax II). Chloroquine was used as a positive control. Solutions of chloroquine and the test compounds were made at $10 \mathrm{mM}$ in DMSO. These solutions were diluted into complete cell growth medium. In 96-well microplate, the stock solutions were diluted with complete cell growth medium to provide triplicate wells at concentrations between 0 to $10^{-4} \mathrm{M}$, each having a final volume of $100 \mu \mathrm{L}$. A given assay was performed using concentrations either in the range of $0.025 \mathrm{nM}$ to $250 \mathrm{nM}$, or $2.5 \mathrm{nM}$ to $2500 \mathrm{nM}$. The plates were then incubated under standard culture conditions for 72 hours before harvesting. The SYBR Green-I fluorescence-based method (Smilkstein, 2004) was used to read the plates, using a 96-well plate fluorescence reader (Gemini-EM, Molecular devices) with respective excitation and emission wavelengths of 497 and $520 \mathrm{~nm}$. Fluorescence was plotted against the logarithm of drug concentration. $\mathrm{IC}_{50}$ values were then obtained by curve fitting by nonlinear regression analysis, using Prism (Graph Pad) software. The $\mathrm{IC}_{50}$ obtained for the chloroquine positive control was then used to "normalize" the $\mathrm{IC}_{50}$ values obtained for the test compounds to the following chloroquine IC 50 values: $6.9 \mathrm{nM}^{\mathrm{D} 6}, 102 \mathrm{nM}^{\mathrm{Dd} 2}$, and $108 \mathrm{nM}^{7 \mathrm{G} 8}$ (Burgess, 2010). An example of the 
formula used to obtain the normalized value for the $\mathrm{IC}_{50}$ of a given test compound is shown here for the case of strain D6, using $6.9 \mathrm{nM}$ as the control value for chloroquine's $\mathrm{IC}_{50}$ against strain $\mathrm{D} 6$ :

Normalized $I C_{50}$ of test compound against $D 6=\left(6.9 / I C_{50}\right.$ of chloroquine against D6) $\times$ $I C_{50}$ of test compound against D6.

From the variability in $\mathrm{IC}_{50}$ values obtained in different tests on the same compounds over a period of several years, the uncertainty in the obtained values is estimated to be $\pm 30 \%$ (based on results for three randomly chosen compounds).

Happy the Man, who, studying Nature's Laws, Thro' known Effects can trace the secret Cause.

Virgil, Georgics II, line 490 ${ }^{19}$, rendered by John Dryden (1697).

\footnotetext{
${ }^{19}$ Note: Line 698 in Dryden's text. Latin text reads as follows: Felix, qui potuit rerum cognoscere causas, atque metus omnis et inexorabile fatum subiecit pedibus strepitumque Acherontis avari. See Virgil (1999), Virgil: Eclogues, Georgics, Aenid, with an English translation by H. Rushton Fairclough, revised by G.P. Goold. Cambridge, MA: Harvard University Press.
} 


\section{References}

Adams, M., Alther, W., Kessler, M., Kluge, M., Hamburger, M. (2011). Malaria in the Renaissance: Remedies from European herbals from the $16^{\text {th }}$ and $17^{\text {th }}$ century. Journal of Ethnopharmacology, 133, 278-288.

Abdel-Magid, A.F., Carson, K.G., Harris, B.D., Maryanoff, C.A., Shah, R.D. (1996). Reductive amination of aldehydes and ketones with sodium triacetoxyborohydride. Studies on direct and indirect reductive amination procedures. Journal of Organic Chemistry 61(11), 3849-3862.

Alexander von Tralles (1963). Alexander von Tralles, Original-Text und Übersetzung. 2 vols. Translated by T. Puschmann. Amsterdam: Verlag Adolf M. Hakkert.

Alumasa, J.N., Gorka, A.P., Casabianca, L.B., Comstock, E., deDios, A.C., Roepe, P.D. (2011). The hydroxyl functionality and a rigid proximal $\mathrm{N}$ are required for forming a novel non-covalent quinine-heme complex. Journal of Inorganic Biochemistry, 105, 467-475.

Alvarez-Suarez, J., Giampieri, F., Battino, M. (2013). Honey as a source of dietary antioxidants: Structures, bioavailability and evidence of protective effects against human chronic diseases. Current Medicinal Chemistry, 20(5), 621-638

Andrews, S. (2006). Design, Synthesis, and in Vitro Effectiveness of Reversed Chloroquines, a Novel Class of Antimalarial Drugs. Dissertation. Portland State University: Portland, Oregon.

Andrews, S., Burgess, S.J., Skaalrud, D., Kelly, J.X., Peyton, D.H. (2010). Reversal agent and linker variants of reversed chloroquines: Activities against Plasmodium falciparum. Journal of Medicinal Chemistry, 53, 916-919.

Akoachere, M., Buchholz, K., Fischer, E., Burhenne, J., Haefeli, W.E., Schirmer, R.H., Becker, K. (2005). In vitro assessment of methylene blue on chloroquine-sensitive and resistant Plasmodium falciparum strains reveals synergistic action with artemisinins. Antimicrobial Agents and Chemotherapy, 49(11), 4592-4597.

Allais, A., Meier, J. (1969). Neue Chinolinderivate und Verfahren zu ihrer Herstellung. German Patent, DE1815467.

Andersag, H., Breitner, S. (1941). N-Basically substituted compounds of the heterocyclic series. U.S. Patent, US2231444. 
Andersag, H., Breitner, S., Jung, H. (1939). Verfahren zur Darstellung von in 4-Stellung bäsisch substituierte Aminogruppen enthaltenden Chinolinverbindungen. German Patent, DE683692C.

Andersag, H., Breitner, S. (1956). Zur Entwicklung des Malaria-Heilmittels Resochin. Medizin und Chemie 1956, 5, 168-173.

Andersag, H. (1948). Antimalariamittel aus der Gruppe halogensubstitutierter Chinolinverbindungen. Chemische Berichte 81, 499-507.

Ayad, F., Tilley, L., Deady L.W. (2001). Synthesis, antimalarial activity and inhibition of haem detoxification of novel bisquinolines. Bioorganic \& Medicinal Chemistry Letters, 11, 2075-2077.

Baker, R.H., Lappin, G.R., Albisetti, C.J., Jr., Riegel, B. (1946). Decarboxylation of nitro substituted 3-carboxy-4-quinolinols by pyrolysis of their silver salts. Journal of the American Chemical Society, 68, 1267.

Bahar, M., Deng, Y., Zhu, X., He, S., Pandharkar, T., Drew, M.E., Navarro-Vázquez, A., Anlkin, C., Gil, R.R., Doskoch, R.W., Werbovetz, K.A., Kinghorn, A.D. (2013). Potent antiprotozoal activity of a novel semi-synthetic berberine derivative. Bioorganic and Medicinal Chemistry Letters, 21(9), 2606-2610.

Baird, J.K. (2014). Pernicious and threatening Plasmodium vivax as reality. American Journal of Tropical Medicine and Hygiene, 91(1), 1-2.

Bamunuarachchi, G.S., Ratnasooriya, W.D., Premakumara, S., and Udagama, P.V. (2013). Antimalarial properties of Artemisia vulgaris L. ethanolic leaf extract in a Plasmodium berghei murine malaria model. Journal of Vector Borne Diseases, 50, 278284.

Baranger, P., Filer, M.K. (1948). Contribution a l'étude des mélanges d'alcaloïdes du quinquina. Annales de l'Institut Pasteur, 75, 329-337.

Bartolomæus Anglicus, 1975. On the properties of things: John Trevisa's translation of Bartolomoeus Anglicus De Proprietatibus Rerum. M.C. Seymour (Ed.)., translated by John Trevisa (1398). Oxford: Clarendon Press.

Basco, L.K. (2003). In vitro activities of piperaquine and other 4-aminoquinolines against clinical isolates of Plasmodium falciparum in Cameroon. Antimicrobial Agents and Chemotherapy, 47(4), 1391-1394.

Bégué, J.P., Bonnet-Delpon, D. (2008). Bioorganic and Medicinal Chemistry of Fluorine. Julien Legros (translator). Hoboken, New Jersey: John Wiley \& Sons. 
Bennet, B.C. (2007). Doctrine of signatures: an explanation of medicinal plant discovery or dissemination of knowledge? Economic Botany, 61(3), 246-255.

J. Bolte, C. Demuynck, J. Lhomme, M.C. Fournié-Zaluski, B.P. Roques (1979). Synthetic models of deoxyribonucleic acid complexes with antimalarial compounds. Biochemistry, 18(22), 4928-4935.

Bock, H. (1572). Kreutterbůch. Straßburg: Josiam Rihel. Available online from Digitalna knjižnica Slovenije, http://www.dlib.si/rokopsi/farmakopeja/farmakopeja.html.

Bray, P.G., Martin, R.E., Tilley, L., Ward, S.A., Kirk, K., Fidock, D.A. (2005). Defining the role of PfCRT in Plasmodium falciparum chloroquine resistance. Molecular Microbiology, 56(2), 323-333.

Bray, P.G., Mungthin, M., Ridley, R.G., Ward, S.A. (1998). Access to hematin: The basis of chloroquine resistance. Molecular Pharmacology, 54, 170-179.

Bray, P.G., Janneh, O., Raynes, K.J., Mungthin, M., Ginsburg, H., Ward, S.A. (1999). Cellular uptake of chloroquine is dependent on binding to ferriprotoporphyrin IX and is independent of NHE activity in Plasmodium falciparum. The Journal of Cell Biology, 145, 363-376.

Breverton, T. (Translator), (2012). The physicians of Myddfai: Cures and Remedies of the Medieval World. Carmarthenshire, Wales: Llyfrau Cambria.

Briolant, S., Henry, M., Oeuvray, C., Amalvict, R., Baret, E., Didillon, E., Rogier, C., Pradines, B. (2010). Absence of association between piperaquine in vitro responses and polymorphisms in the $p f c r t, p f m d r l, p f m r p$, and $p f n h e$ genes in Plasmodium falciparum. Antimicrobial Agents and Chemotherapy, 54, 3537-3544.

Brocard, J., Lebibi, J., Maciejewski, L. (1995). Complexes organometalliques du fer antipaludiques. French patent, FR 2733985.

Brunfels, O., 1964. Contrafayt Kreüterbůch nach rechter volkommener art und Beschreibungen der Alten/ besst/ berümpten ärtzt/ vormals in Teutscher sprach/ der masßen nye gesehen/ noch im Truck außgangen. 1532. Munich: Kölbl.

Burckhalter, J.H., Tendick, F.H., Jones, E.M., Jones, P.A., Holcomb, W.F., Rawlins, A.L. (1948). Aminoalkylphenols as antimalarials. II. (Heterocyclic-amino)- $\alpha$-amino-ocresols. The synthesis of camoquin. Journal of the American Chemical Society, 70, 1363-1373. 
Burgess, S.J. (2008). Design and Synthesis of Antimalarial Drugs Based on a Chloroquine Scaffold. Dissertation, Portland State University: Portland, Oregon.

Burgess, S.J., Selzer, A., Kelly, J.X., Smilkstein, M.J., Riscoe, M.K., Peyton, D.H. (2006). A chloroquine-like molecule designed to reverse resistance in Plasmodium falciparum. Journal of Medicinal Chemistry, 49, 5623-5625.

Burgess, S.J., Kelly, J.X., Shomloo, S., Wittlin, S., Brun, R., Liebmann, K., Peyton, D.H. (2010). Synthesis, structure-activity relationship, and mode-of-action studies of antimalarial reversed chloroquine compounds. Journal of Medicinal Chemistry, 52, 6477-6489.

Burrows, J.N., Chibale, K., Wells, T.N.C. (2011). The state of the art in anti-malarial drug discovery and development. Current Topics in Medicinal Chemistry, 11, 12261254 .

Cameron, M.L. (2006). Anglo Saxon Medicine. Cambridge: Cambridge University Press.

Celsus, A.C. (1960). Celsus: De medicina, 3 vols. W.G. Spencer (translator).

Cambridge, Massachusetts: Harvard University Press.

Chen, C. (2014). Development of antimalarial drugs and their application in China: a historical review. Infectious Diseases of Poverty, 3(9).

Chernin, E. (1984). The malariatherapy of neurosyphilis. Journal of Parasitology 70(5), 611-17.

Cibulskis, R.E., Aregawi, M., Williams, R., Otten, M., Dye, C. (2011). Worldwide incidence of malaria in 2009: Estimates, time trends, and a critique of methods. PloS Medicine, 8(12), 1-12.

Chopra, R. N. (1938). Anti-malarial Remedies: Natural and Synthetic. Calcutta Medical Journal 34, 183-193.

Claisen, R.L. (1897). Untersuchungen über die Oxymethylenverbindungen. Justus Liebigs Annalen der Chemie 297, 1-98 (the relevant synthesis is on pages 77-8).

Coatney, G.R., Cooper, W.C., Eddy, N.B., Greenberg, J. (1953). Survey of Antimalarial Agents: chemotherapy of Plasmodium gallinaceum infections; toxicity; correlation of structure and action. Washington, D.C., Federal Security Agency, Public Health Service.

Cockayne, O. (1864). Leechdoms, wortcunning, and starcraft of early England, Vol. I. London: Longman, Green, Longman, Roberts, and Green. 
Cockayne, T.O. (1961). Leechdoms, wortcunning, and starcraft of early England, Vols. II and III. London: The Holland Press.

Cole, W. (1657). Adam in Eden, or nature's paradise. The history of plants, fruits, herbs, and flowers. London: Printed by J. Streater for Nathaniel Brooke at the Angel in Cornhil, near the Royal Exchange.

Collins, M. (2000). Medieval herbals: The illustrative traditions. London: The British Library.

Conrad, M., Limpach, L. (1887). Synthesen von Chinolinderivaten mittelst Acetessigester. Berichte der deutschen chemischen Gesellschaft 20(1), 944-948.

Conrad, M., Limpach, L. (1891). Synthese von Chinolinderivaten mittelst Acetessigester. Berichte der deutschen chemischen Gesellschaft 24(2), 2990-2992.

Conroy, A.E., Mosher, H.S., Whitmore, F.C., 1949. Heterocyclic basic compounds. XII. 7-Bromo- and 7-iodo-quinolines. Journal of the American Chemical Society, 71, 3236-7.

Covell, G., Nicol W.D. (1951). Clinical, chemotherapeutic, and immunological studies on induced malaria. British Medical Bulletin 8(1), 51-5.

Crespo, M.P., Tilley, L., Klonis, N. (2010). Solution behavior of hematin under aqueous conditions and implications for its interactions with chloroquine. Journal of Biological Inorganic Chemistry, 15(7), 1009-1022.

Culpepper, N. (1677). Blagrave's supplement; or, enlargement, to Mr. Nich. Culpepper's English Physician. Containing a description of the form, names, place, time, celestial government, and virtues, of all such medicinal plants as grow in England, and are omitted in his book, called the English Physician. And supplying the additional virtues of such plants wherein he is defective. Also with the virtues of all drugs as are found in any part of the world, and brought to be sold in our druggists and apothecaries shops, with their dangers and corrections. London: Obadiah Blagrave, at the Sign of the Bear in St. Paul's Church Yard, near the Little North Door.

Danzel, L. (1948). La centaurelle, un bon antimalarique naturel. Revue du paludisme et de medecine tropicale, 6(48), 133-45.

Davis, T.M.E., Hung, T.Y., Sim, I.K., Karunajeewa, H.A., Ilett, K.F. (2005).

Piperaquine: A resurgent antimalarial drug. Drugs, 65(1), 75-87. 
de Castro, M.C., Singer, B.H. (2005). Was malaria present in the Amazon before the European conquest? Available evidence and future research agenda. Journal of Archaeological Science, 32(3), 337-340.

De Vos, P. (2010). European materia medica in historical texts: Longevity of a tradition and implications for future use. Journal of Ethnopharmacology, 132, 28-47.

De, D., Krogstad, F.M., Cogswell, F.B., Krogstad, D.J. (1996). Aminoquinolines that circumvent resistance in Plasmodium falciparum in vitro. American Journal of Tropical Medicine and Hygeine 55(6), 579-583.

De, D., Krogstad, F.M., Byers, L.B., Krogstad, D.J. (1998). Structure activity relationships for antiplasmodial activity among 7-substituted 4-aminoquinolines. Journal of Medicinal Chemistry 41(25), 4918-4926.

Dioscorides, P. (1968). The Greek Herbal of Dioscorides, Illustrated by a Byzantine, A.D. 512, Englished by John Goodyer, A.D. 1655, Edited and First Printed A.D. 1933 (vix). New York: Hafner Publishing Company.

Dharani, N., Rukunga, G., Mbora, A., Mwaura, L., Dawson, I., Jamnadass, R. (2010). Common Antimalarial Trees and Shrubs of East Africa: A description of species and a guide to cultivation and conservation through use. Nairobi, Kenya: World Agroforestry Center.

Dive, D., Biot, C. (2008). Ferrocene conjugates of chloroquine and other antimalarials: the development of ferroquine, a new antimalarial. ChemMedChem, 3, 383-391.

Dondorp, A.M., Desakorn, V., Pongtavornpinyo, W., Sahassananda, D., Silamut, K., Chotivanich, K., Newton, P.N., Pitisuttithum, P., Smithyman, A.M., White, N.J. (2005). Estimation of the total parasite biomass in acute falciparum malaria from plasma PfHRP2. PloS Med, 2(8), 788-797.

Dorn, A., Vippagunta, S.R., Matile, H., Jaquet, C., Vennerstrom, J.L., Ridley, R.G. (1998). An assessment of drug-haematin binding as a mechanism for inhibition of haematin polymerisation by quinoline antimalarials, Biochemical Pharmacology, 55, 727-736.

Druilhe, P., Brandicourt, O., Chongsuphajaisiddhi, T., Berthe, J. (1988). Activity of a combination of three cinchona bark alkaloids against Plasmodium falciparum in vitro. Antimicrobial Agents and Chemotheraphy, 32(2), 250-254.

Duke, J.A. Handbook of medicinal herbs. Boca Raton, Florida: CRC Press. 
Eastman, R.T., Dharia, N.V., Winzeler, E.A., Fidock, D.A. (2011). Piperaquine resistance is associated with a copy number variation on chromosome 5 in drug-pressured Plasmodium falciparum parasites. Antimicrobial Agents and Chemotherapy, 55(8), 3908-3916.

Egan, T.J. (2008). Hemozoin formation. Molecular \& Biochemical Parasitology, 157, $127-136$.

Egan, T., Ncokazi, K.K. (2005). Quinoline antimalarials decrease the rate of $\beta$-hematin formation. Journal of Inorganic Biochemistry, 99, 1532-1539.

Elderfield, R.C., Gensler, W.J., Head, J.D., Hageman, H.A., Kremer, C.B., Wright, J.B., Holley, A.D., Williamson, B., Galbreath, J., Wiederhold, L., Frohardt, R., Kupchan, S.M., Williamson, T.A., Birnstein, O. (1946). Alkylaminoalkyl derivatives of 8aminoquinoline. Journal of the American Chemical Society 68(8), 1524-1529.

Elfawal, M., Towler, M.J., Reich, N.G., Golenbock, D., Weathers, P.J., Rich., S.M. (2012). Dried whole plant Artemisia annua as an antimalarial therapy. PloS One, 7(12), e52746.

Elford, B.C., Roberts, M.F., Phillipson, J.D., Wilson, R.J. (1987). Potentiation of the antimalarial activity of qinghaosu by methoxylated flavones. Transactions of the Royal Society of Tropical Medicine and Hygiene, 81, 434-436.

Elslager, E.F., Tendick, F.H., Werbel, L.M., Worth, D.F. (1969). Antimalarial and antischistosomal effects of proximal hydraxine and hydroxylamine analogs of chloroquine and quinacrine. Journal of Medicinal Chemistry, 12, 970-974.

Erujuwa, O.O., Sulaiman, S.A., Ab Wahab, M.S. (2014). Effects of honey and its mechanisms of action on the development and progression of cancer. Molecules, 19, 2497-2522.

Fidock, D.A., Nomura, T., Talley, A.K., Cooper, R.A., Dzekunov, S.M., Ferdig, M.T., Ursos, L.M.B., Sidhu, A.B.S., Naudé, B., Deitsch, K.W., Su, X.Z., Wootton, J.C., Roepe, P.D., Wellems, T.E. (2000). Mutations in the $P$. falciparum digestive vacuole transmembrane protein PfCRT and evidence for their role in chloroquine resistance, Molecular Cell, 6, 861-871.

Fitch, C.D., Kanjananggulpan, P. (1987). The state of ferriprotoporphyrin IX in malaria pigment. The Journal of Biological Chemistry, 262(32), 15552-15555.

Flückiger, F.A., Hanbury, D. (1874). Pharmacographia: A History of the Principle Drugs of Vegetable Origin, Met With in Great Britain and British India. London: MacMillan and Co., 302-331. 
Foley, M., Tilley, L. (1997). Quinoline antimalarials: Mechanisms of action and resistance. International Journal for Parasitology, 27(2), 231-240.

Fornaciari, G., Giuffra, V., Ferroglio, E., Gino, S., Bianucci, R. (2010). Plasmodium falciparum immunodetection in bone remains of members of the Renaissance Medici family (Florence, Italy, sixteenth century). Transactions of the Royal Society of Tropical Medicine and Hygiene, 104, 583-587.

Forrester, J.M. and Henry, J. (2005). Jean Fernel's On the hidden causes of things: Forms, souls, and occult diseases in Renaissance medicine, with an edition and translation of Fernel's De Abditis Rerum Causis. Leiden, the Netherlands: Koninklijke Brill.

Francis, S.E., Sullivan, D.J., Jr., Goldberg, D.E. (1997). Hemoglobin metabolism in the malaria parasite Plasmodium falciparum. Annual Review of Microbiology 51, 97-123.

Freitas, D.R.C., Santos, J.B., Castro, C.N. (2014). Healing with malaria: a brief historical review of malariotherapy for neurosyphilis, mental disorders and other infectious diseases. Revista da Sociedade Brasileira de Medicina Tropical, 47(2), 260-261.

Frohne, D., Pfänder H.J. (2005). Poisonous plants: A handbook for doctors, pharmacists, toxicologists, biologists, and veterinarians. $2^{\text {nd }}$ Ed. I. Alford (translator). Portland, Oregon: Timber Press.

Fujioka, H., Nishiyama, Y., Furukawa, H., Kumada, N. (1989). In vitro and in vivo activities of atalaphillinine and related acridone alkaloids against rodent malaria. Antimicrobial Agents and Chemotherapy, 33(1), 6-9.

Funk, E., Potter, S.L. (1917). Potter's Therapeutics, Materia Medica, and Pharmacy. Philadelphia, P. Blakiston's Son \& Co., 733.

Gabriel, S. (1887). Über eine Darstellungsweise primärer Amine aus den entsprechenden Halogenverbindungen. Berichte der deutschen chemischen Gesellschaft, 20, 2224-2236.

Geerlings, A., Hallard, D., Martinez Caballero, A., Lopes Cardoso, I., van der Heijden, R., Verpoorte, R. (1999). Alkaloid production by a Cinchona officinalis 'Ledgeriana' hairy root culture containiing constitutive expression constructs of tryptophan decarboxylase and strictosidine synthase cDNAs from Catharanthus roseus. Plant Cell Reports 19, 191-196.

Gerard, J. (1597). The herball or generall historie of plants. Gathered by John Gerarde of London master in chirurgerie. London: John Norton. 
Gerard, J. and Johnson, T. (1633). The herball or general historie of plants. Gathered by John Gerarde of London master in chirurgerie, very much enlarged and amended by Thomas Johnson, citizen and apothecarye of London. London: Adam Norton and Richard Whitakers.

Gilles, H.M. (2002). Historical outline. In Essential Malariology, 4th Ed., Warrell, D.A., Gilles, H.M. (ed.s), London: Arnold, 1-7.

Gottfried, R.S. (1986). Doctors and medicine in medieval England, 1340-1530.

Princeton, New Jersey: Princeton University Press.

Grant, M. (1970). Nero: Emperor in revolt. New York: American Heritage Press.

Greenwood, B.M., Bojang, K., Whitty, C.J.M., Targett, G.A. (2005). Malaria. The Lancet, 365, 1487-1498.

Greenwood, D. (1995). Conflicts of interest: the genesis of synthetic antimalarial agents in peace and war. Journal of Antimicrobial Chemistry, 36, 857-872.

Greenwood, D. (1992). The quinine connection. The Journal of Antimicrobial Chemotherapy 30(4), 417-27.

Goodman Gilman, A., Goodman, L.S., Rall, T.W., Murad, F. (1985). Goodman and Gilman's The Pharmacological Basis of Therapeutics. 7th Ed. New York: MacMillan, 1041-1044.

Gould, R.G., Jr., Jacobs, W.A. (1939). The synthesis of certain substituted quinolines and 5,6-benzoquinolines. Journal of the American Chemical Society, 61, 2890-2895.

Francisco Guerra (1977). The introduction of cinchona in the treatment of malaria, parts 1 and 2. Journal of Tropical Medicine and Hygiene 80, 112-118; 135-140.

Bornface Gunsaru (2010). Simplified Reversed Chloroquines to Overcome Malaria Resistance to Quinoline-based Drugs. Dissertation. Portland, Oregon: Portland State University.

Gunther, R.T. (1968). Preface. In R.T. Gunther (Ed.)., The Greek Herbal of Dioscorides, Illustrated by a Byzantine, A.D. 512, Englished by John Goodyer, A.D. 1655, Edited and First Printed A.D. 1933. New York: Hafner Publishing Company.

Guttmann, P., Ehrlich, P. (1891). Über die Wirkung des Methylenblau bei Malaria. Berliner klinische Wochenschrift, 28, 953-6. 
Kurtzhals, J.A.L. (2005). Ineffective change of antimalaria prophylaxis to Artemisia vulgaris in a group traveling to West Africa (Chemical Abstracts summary). Ugeskrift for Laeger, 167(43), 4082-3.

Hahn, F.E., O’Brien, R.L., Ciak, J., Allison, J.L., Olenick, J.G. (1966). Military Medicine, 131(9), 1071-1089.

Hänscheid, T., Egan, T.J., Grobusch, M.P. (2007). Haemozoin: from melatonin pigment to drug target, diagnostic tool, and immune modulator. The Lancet, 7, 675-685.

Hao, M., Jia, D., Li, Q., He Y., Yuan, L., Xu, S., Chen, K., Wu, J., Shen, L., Sun, L., Zhao, H., Yang, Z., Cui, L. (2013). In vitro sensistivities of Plasmodium falciparum isolates from the China-Myanmar border to piperaquine and association with polymorphisms in candidate genes. Antimicrobial Agents and Chemotherapy, 57(4), 1723-1729.

Hauser, C.R., Reynolds, G.A. (1950). Relative ease of cyclization of 2-, 3-, and 4aminopyridine derivatives. Synthesis of naphthyridines. Journal of Organic Chemistry, 15, 1224-1232.

Hawass, Z., Gad, Y.Z., Ismail, S., Khairat, R., Fathalla, D., Hasan, N., Ahmed, A., Elleithy, H., Ball, M., Gaballah, F., Wasef, S., Fateen, M., Amer, H., Gostner, P., Selim, Ashraf, Zink., A., Pusch, C. (2010). Ancestry and pathology in King Tutankhamun's family. Journal of the American Medical Association, 303(7), 638-647.

Hay, S.I., Guerra, C.A., Tatem, A.J., Noor, A.M., Snow, R.W. (2004). The global distribution and population at risk of malaria: past, present, and future. The Lancet Infectious Diseases, 4, 327-336.

Henderson, H., 1994. The physicians of Myddfai: The Welsh herbal tradition. The Botanical Journal of Scotland, 46(4), 623-627.

Hippocrates (1957-1994). Hippocrates, 5 vols. W.H.S. Jones, P. Potter, W.D. Smith (translators). Cambridge, Massachusetts: Harvard University Press.

Hoeppli, R. (1959). Parasites and Parasitic Infections in Early Medicine and Science. University of Malaya Press: Singapore.

F. Hoffmann-LaRoche \& Co. Verfahren zur Darstellung von 4-Oxychinolin-2carbonsäure. German patent. DE575534, 1933.

Hückel, W. (1962). Vorlesungen über Pharmazeutische Chemie und Arzneimittelsynthese, II. Band, Organische Teil. Stuttgart: Enke. 
Hutchens, A.R. (1991). Indian herbology of North America. Boston: Shambhala.

Ing, H.R., Manske, R.H.F. (1926). A modification of the Gabriel synthesis of amines. Journal of the Chemical Society, 2348-51.

Iwasaki, N., Sakaguchi, J., Ohashi, T., Takahara, E., Ogawa, N., Yasuda, S., Koshinaka, E., Kato, H., Ito, Y., Sawanishi, H. (1994). Amphoteric Drugs. I. Synthesis and antiallergic activity of [4-(diphenylmethoxy)piperidino)alkanoic acid derivatives. Chemical and Pharmaceutical Bulletin, 42(11), 2276-2284.

Jackson, B.D., (1950). Gerard, John (1545-1612), in The Dictionary of National Biography, L. Stephen and S. Lee (Ed.), vol. VII, 1100-1101. London: Oxford University Press.

Jackson, K.E., Klonis, N., Ferguson, D.J.P., Adisa, A., Dogovski, C., Tilley, L. (2004). Food vacuole-associated lipid bodies and heterogeneous lipid environments in the malaria parasite, Plasmodium falciparum. Molecular Microbiology, 54(1), 109-122.

Jarcho, S. (1993). Quinine's Predecessor: Francesco Torti and the Early History of Cinchona. Baltimore, Maryland: Johns Hopkins University Press.

Jones, W. (1909). Malaria and Greek History, England: Manchester University Press, reprinted in 1977.

Kamal, H. (1967). A Dictionary of Pharaonic Medicine. Cairo, Egypt: National Publication House.

Kamaraj C., Kaushik N.K., Rahuman A.A., Mohanakrishnan, D., Bagavan A., Elango G., Zahir A.A., Santhoshkumar T., Marimuthu S., Jayaseelan C., Kirthi A.V., Rajakumar G., Velayutham K., Sahal D. (2012). Antimalarial activities of medicinal plants traditionally used in the villages of Dharmapuri regions of South India. Journal of Ethnopharmacology, 141, 796-802.

Kaschula, C.H., Egan, T.J., Hunter, R., Basilico, N., Parapini, S., Taramelli, D., Pasini, E., Monti, D. (2002). Structure-activity relationships in 4-aminoquinoline antiplasmodials. The role of the group at the 7-position. Journal of Medicinal Chemistry 45(16), 3531-3539.

Kaufman, T.S., Rúveda, E.A. (2005). The quest for quinine: those who won the battles and those who won the war. Angewandte Chemie International Edition 44, 854-885.

Keen, E. (2007). A peopled landscape: Bartholemew the Englishman on the properties of daily life. Parergon, 24(2), 7-22. 
Kelly, J.X., Winter, R.W., Cornea, A., Peyton, D.H., Hinrichs, D.J., Riscoe, M. (2002). The kinetics of uptake and accumulation of 3,6-bis- $\omega$-diethylaminoamyloxyxanthone by the human malaria parasite Plasmodium falciparum. Molecular and Biochemical Parasitology, 123, 47-54.

Khan, M.O.F., Levi, M.S., Tekwani, B.L., Khan, S.I., Kimura, E., Borne, R.F. (2009). Synthesis and antimalarial activities of cyclen 4-aminoquinoline analogs. Antimicrobial Agents and Chemotherapy, 53(4), 1320-1324.

Kikuth, W. (1942). Zur Frage der Malaria Prophylaxe. Hoppe-Seyler's Zeitschrift für physiologische Chemie, 274, 9-18.

Kirsch, P., Röschenthaler, G.V. (2007). Functional compounds based on hypervalent sulfur fluorides. Current Fluoroorganic Chemistry, ACS Symposium Series, 949, 221243.

Koch, A. Tamez, P. Pezzuto, J. Soejarto, D. (2005). Evaluation of plants used for antimalarial treatment by the Masai of Kenya. Ethnopharmacology 101, 95-99.

Krogstad, D.J., Gluzman, I.Y., Kyle, D.E., Odoula, A.M.J., Martin, S.K., Milhous, W.K., Schlesinger, P.H. (1987). Efflux of chloroquine from Plasmodium falciparum: mechanism of chloroquine resistance. Science, 238, 1283-1285.

Lakshmanan, V., Bray, P.G., Verdier-Pinard, D., Johnson, D.J., Horrocks, P., Muhle, R.A., Alakpa, G.E., Hughes, R.H., Ward, S.A., Krogstad, D.J., Bir Singh Sidhu, A., Fidock D.A. (2005). A critical role for PfCRT K76T in Plasmodium falciparum verapamil-reversible chloroquine resistance. The EMBO Journal, 24, 2294-2305.

Lalremruata, A., Ball, M., Banucci, R., Welte, B., Nerlich, A.G., Kun, J.F.J., Pusch, C.M. (2013). Molecular identification of falciparum malaria and human tuberculosis coinfections in mummies from the Fayum Depression (Lower Egypt). PloS 1, 8(4), doi:10.1371/journal.pone.0060307.

Lauer, W.M., Arnold, R.T., Tiffany, B., Tinker, J. (1946). The synthesis of some chloromethoxyquinolines. Journal of the American Chemical Society, 68, 1268-9.

Lee, S. (1950). Culpepper, Nicholas (1616-1664). In The Dictionary of National Biography, vol. V, L. Stephen and S. Lee (Eds.), 286-287. London: Oxford University Press.

Leed, A., DuBay, K., Ursos, L.M.B., Sears, D., de Dios, A.C., Roepe, P.D. (2002). Solution structures of antimalarial drug-heme complexes. Biochemistry, 41, 1024510255. 
Leonardi, A., Barlocco, D., Montesano, F., Cignarella, G., Motta, G., Testa, R., Poggesi, E., Seeber, M., De Benedetti, P.G., Fanelli, F. (2004). Synthesis, screening, and molecular modeling of new potent and selective antagonists at the $\alpha_{1 \mathrm{D}}$ adrenergic receptor. Journal of Medicinal Chemistry, 47, 1900-1918.

Liu, K.S., Yang, S.L., Roberts, M., Elford, B., Phillipson, J. (1992). Antimalarial activity of Artemisia annua flavonoids from whole plants and cell cultures. Plant Cell Reports, 11(12), 637-640.

Lin, A.J., Loo, T.L., (1978). Synthesis and antitumor activity of halogen-substituted 4(3,3-dimethyl-1-triazeno)quinolines. Journal of Medicinal Chemistry, 21(3), 268-272.

Madrid, P.B., Sherrill, J., Liou, A.P., Weisman, J.L., DeRisi, J.L., Guy, R.K. (2005). Synthesis of ring-substituted 4-aminoquinolines and evaluation of their antimalarial activities. Bioorganic and Medicinal Chemistry Letters 15, 1015-1018

Madrid, P.B., Liou A.P., DeRisi, J.L., Guy, R.K. (2006). Incorporation of an intramolecular hydrogen-bonding motif in the side chain of 4-aminoquinolines enhances activity aginst drug-resistant $P$. falciparum. Journal of Medicinal Chemistry, 49, 45354543.

Major, R.H. (1954). A history of medicine. 2 vols. Springfield, Illinois: Charles C. Thomas.

Makler, M.T. (1990). Dequalinium salts for the treatment of malaria (Flow Inc., USA). U.S. Patent 4,946,849, 7 August 1990.

Martin, R.E., Marchetti, R.V., Cowan, A.I., Howitt, S.M., Bröer, S., Kirk, K. (2009). Chloroquine transport via the malaria parasite's chloroquine resistance transporter.

Science 325, 1680-1682.

Mauss, H., Mietzsch, F. (1933). Atebrin, ein neues Heilmittel gegen Malaria. Klinische Wochenschrift, 12(33), 1276-1278.

Meissner, P.E., Mandi, G., Coulibaly, B., Witte, S., Tapsoba, T., Mansmann, U., Rengelshausen, J., Schiek, W., Jahn, A., Walter-Sack, I., Mikus, G., Burhenne, J., Riedel, K.D., Shirmer, R.H, Kouyaté, B., Müller, O. (2006). Methylene blue for malaria in Africa: results from a dose-finding study in combination with chloroquine. Malaria Journal, 5:84. doi:10.1186/1475-2875-5-84. 
Micheli, F., Andreotti, D., Braggio, S., Checchia, A. (2010). A specific and direct comparison of the trifluoromethyl and pentafluorosulfanyl groups on the selective dopamine D3 antagonist 3-(3-\{[4-methyl-5-(4-methyl-1,3-oxazol-5-yl)-4H-1,2,4-triazol3-yl]thio\}propyl)-1-phenyl-3-azabicyclo[3.1.0]-hexane template. Bioorganic and Medicinal Chemistry Letters 20, 4566-4568.

Mietzsch, F. (1951). Entwicklungslinien der Chemotherapie (vom chemischen Standpunkt gesehen). Klinische Wochenschrift 29(7-8), 125-35.

Mo, T., Mi, X., Milner, E.E., Dow, G.S., Wipf, P. (2010). Synthesis of an 8pentafluorosulfanyl analog of the antimalarial agent mefloquine. Tetrahedron Letters 51(39), 5137-5140.

Moore, N. (1950). Salmon, William (1644-1713). In Stephen, L. and Lee, S. (Ed.s), The Dictionary of National Biography, vol. XVII, L., London: Oxford University Press, 698699.

Muangnoicharoen, S., Johnson, D.J., Looareesuwan, S., Krudsood, S., Ward, S.A. (2009). Role of known molecular markers of resistance in the antimalarial potency of piperaquine and dihydroartemisinin in vitro. Antimicrobial Agents and Chemotherapy, 53, 1362-1366.

Mühlens, P. (1937). Chinin-Nebenwirkungen. Archiv für Schiffs- und Tropenhygeine 41(12), 710-15.

Nishikawa, Y., Shindo, T., Ishii, K., Nakamura, H., Kon, T., Uno, H. (1989). Acrylamide derivatives as antiallergenic agents. I. Synthesis and structure-activity relationships of $N$-[(4-substituted 1-piperazinyl)alkyl]-3-(aryl and heteroaryl)acrylamides. Chemical and Pharmaceutical Bulletin, 37(1), 100-105.

Nuttall, G.H.F., Cobbett, L., Strangeways-Pigg, T. (1901). Studies in relation to malaria. I. The geographical distribution of anopheles in relation to the former distribution of ague in England. The Journal of Hygiene, 1(1), 4-44.

Oliveira, M.F., Kycia, S.W., Gomez, A., Kosar, A.J., Bohle, D.S., Hempelmann, E., Menezes, D., Vannier-Santos, M.A., Oliveira, P.L., Ferreira, S.T. (2005). Structural and morphological characterization of hemozoin produced by Schistosoma mansoni and Rhodnius prolixus. FEBS Letters, 579, 6010-6016.

Oreagba, A.I., Aina, O.O., Awodele, O., Olayemi, S.O., Mabadeje, A.F.B., Ashorobi, R.B. (2008). Prophylactic effect of grapefruit juice against Plasmodium berghei infection in mice. International Journal of Parasitology, 4(1), 60-63. 
O’Neill, P.M., Posner, G.H. (2004). A medicinal chemistry perspective on artemisinin and related endoperoxides. Journal of Medicinal Chemistry 47(12), 2945-2964.

O’Neill, P.M., Willock, D.J., Hawley, S.R., Bray, P.G., Storr, R.C., Ward, S.A., Park, B.K. (1997). Synthesis, antimalarial activity, and molecular modeling of tebuquine analogues. Journal of Medicinal Chemistry, 40, 437-448.

The Oxford English Dictionary (1971). The Compact Edition of the Oxford English Dictionary: Complete text reproduced micrographically. 2 vols. New York: Oxford University Press.

Ozbilgin, A., Durmuskahya, C., Kayalar, H., Ostan, I. (2014). Assessment of in vivo antimalarial activities of some selected medicinal plants from Turkey. Parasitology Research 113, 165-173.

Packard, R.M. (2014). The origins of antimalarial-drug resistance. The New England Journal of Medicine, 371(5), 397-399.

Pascual, A., Madamet, M., Bertaux, L., Amalvict, R., Benoit, N., Travers, D., Cren, J., Taudon, N., Rogier, C., Parzy, D., Pradines, B. (2013). In vitro piperaquine susceptibility is not associated with the Plasmodium falciparum chloroquine resistance transporter gene. Malaria Journal, 12, 431/1-431/6.

Pascual, A., Parola, P., Benoit-Vical, F., Simon, F., Malvy, D., Picot, S., Delaunay, P., Basset, D., Maubon, D., Faugere, B., Menard, G., Bourgeois, N., Ouevray, C., Didillon, E., Rogier, C., Pradines, B. (2012). Ex vivo activity of the ACT new components pyronaridine and piperaquine in comparison with conventional ACT drugs against isolates of Plasmodium falciparum. Malaria Journal, 11, 45.

Pelletier, P., Caventou, J.B. (1820). Recherches chimiques sur les Quinquinas. Annales de Chimie et de Physique 15, 289-318.

Pelletier, P., Caventou, J.B. (1820). Suite des Recherches chimiques sur les Quinquinas. Annales de Chimie et de Physique 15, 337-65.

Peyton, D.H. (2012). Reversed chloroquine antimalarials as a strategy to overcome resistance in malaria. Current Topics in Medicinal Chemistry 12, 400-407.

Phillips, E.D. (1973). Greek Medicine. London: Thames and Hudson.

The Plant List (2013). Version 1.1. Published on the Internet; http://www.theplantlist.org/ (accessed 15 August).

Pliny the Elder (1956-1962). Natural History, 10 vols. H. Rackham, W.H.S. Jones., and D.E. Eichholz (translators). Cambridge, MA: Harvard University Press. 
Pou, S., Winter, R.W., Nilson, A., Kelly, J.X., Li, Y., Dogget, S., Riscoe, E.W., Wegmann, K.W., Hinrichs, D.J., Riscoe, M.K. (2012). Sontochin as a guide to the development of drugs against chloroquine-resistant malaria. Antimicrobial Agents and Chemotherapy, 56(7), 3475-3480.

Price, C.C., Roberts, R.M. (1946). The synthesis of 4-hydroxyquinolines. I. Through ethoxymethylenemalonic ester. Journal of the American Chemical Society, 68, 1204-8.

Price, R.N., Nosten, F. (2014). Single-dose radical cure of Plasmodium vivax: a step closer. The Lancet, 383, 1020-1021.

Prugnolle, F., Durand, P., Ollomo, B., Duval, L., Ariey, F., Arnathau, C., Gonzalez, J.P., Leroy, E., Renaud, F., 2011. A fresh look at the origin of Plasmodium falciparum, the most malignant malaria agent. PLOS Pathogens, 7(2), e1001283.

Quispe, A.M., Pozo, E., Guerrero, E., Durand, S., Baldeviano, G.C., Edgel, K.A., Graf, P.C.F., Lescano, A.G. (2014). Plasmodium vivax hospitalizations in a monoendemic malaria region: severe vivax malaria? American Journal of Tropical Medicine and Hygiene, 91(1), 11-17.

Rackham, H. (1958). Introduction. In Pliny the Elder, Natural History, Vol. I, translated by H. Rackham (vii-xiv). Cambridge, MA: Harvard University Press.

Ramsey, V.G., Cretcher, L.H. (1947). Quinoline series. VIII. Some 6-(2hydroxyethoxy)-4-aminoquinolines. Journal of the American Chemical Society, 69, 1659-1662.

Rasoanaivo, P., Wright, C.W., Willcox, M.L., Gilbert, B. (2011). Whoe plant extracts versus single compounds for the treatment of malaria: synergy and positive interactions. Malaria Journal, 10(Suppl. 1), S4.

Rathore, D., McCutchan, T.F., Sullivan, M., Kumar, S. (2005). Antimalarial drugs: current status and new developments. Expert Opinion on Investigational Drugs, 14(7), $871-883$.

Raynes, K., Foley, M., Tilley, L., Deady, L.W. (1996). Novel bisquinoline antimalarials: Synthesis, antimalarial activity, and inhibitin of haem polymerization. Biochemical Pharmacology, 52, 551-559. 
Ressurreição, A.S., Gonçalves, D., Sitoe, A.R., Albuquerque, I.S., Gut, J., Góis, A, Gonçalves, L.M., Bronze, M.R., Hanscheid, T., Biagini, G.A., Rosenthal, P.J., Prudêncio, M., O’Neill, P., Mota, M.M., Lopes, F., Moreira, R., 2013. Structural optimization of quinolon-4(1H)-imines as dual-stage antimalarials: toward increased potency and metabolic stability. Journal of Medicinal Chemistry, 56, 7679-7690.

Reynolds, G.A., Hauser, C.R. (1955). Ethyl $\beta$-anilinocrotonate. Organic Syntheses Collective Volume 3, 374-375.

Reynolds, G.A., Hauser, C.R. (1955). 2-Methyl-4-hydroxyquinoline. Organic Syntheses Collective Volume 3, 593-594.

Rhône-Poulenc (1962). Nouveaux dérivés de la quinoléine et leur préparation. Belgian Patent 612207, July 1962.

Rhône-Poulenc (1965). Nouveaux dérivés de la quinoléine et leur préparation. French Patent 84092, May 1965.

Rhône-Poulenc (1963). Nouveaux dérivés de la quinoléine et leur préparation. Belgian Patent 633453, December 1963.

Ribeiro, C.J.A., Kumar, S.P., Gut, J., Gonçalves, L.M., Rosenthal, P.J., Moreira, R., Santos, M.M.M. (2013). Squaric acid/4-aminoquinoline conjugates: novel potent antiplasmodial agents. European Journal of Medicinal Chemistry, 69, 365-372.

Riegel, B., Lappin, G.R., Adelson, B.H., Jackson, R.I., Albisetti, C.J. Jr., Dodson, R.M., Baker, R.H., 1946. Synthesis of some 4-quinolinols and 4-chloroquinolines by the ethoxymethylenemalonic ester method. Journal of the American Chemical Society, 68, 1264-6.

Riscoe, M., Kelly, J.X., Winter, R. (2005). Xanthones as antimalarial agents: discovery, mode of action, and optimization. Current Medicinal Chemistry, 12, 2539-2549.

Roepe, P.D. (2011). PfCRT-mediated drug transport in malarial parasites, Biochemistry, 50, 163-171.

Salmon, W. (1696). A family dictionary, or, household companion. $2^{\text {nd }}$ edition. London: Printed for H. Rhodes, at the Star, the corner of Bride Lane, in Fleet Street.

Sangian, H., Faramarzi, H., Yazdinezhad, A., Mousavi, S.J., Zamani Z., Noubarani, M., Ramazani, A. (2013). Antiplasmodial activity of ethanolic extracts of some selected medicinal plants from the northwest of Iran. Parisitology Research, 112, 3697-3701.

Saunders, D.L., Vanachayangkul, P., Lon, C. (2014). Dihydroartemisinin-piperaquine failure in Cambodia. The New England Journal of Medicine, 371, 484-485. 
Saunders, W. (1783). Observations on the superior efficacy of the red Peruvian bark, in the cure of agues and other fevers. Boston: Printed by Robert Hodge, for William Green.

Schlesigner, P.H., Krogstad, D.J., Herwaldt, B.L. (1988). Antimicrobial Agents and Chemotherapy, 32, 793-8.

Schönhöfer, F. (1965). 40 Jahre Plasmochin. Arzneimittelforschung, 15, 1256-8.

Schönhöfer, F. (1942). Über die Bedeutung der chinoidin Bindung in Chinolinverbindungen für die Malariawirkung. Hoppe-Seyler's Zeitschrift für physiologische Chemie 274, 1-8.

Schuleman, W. (1932). Synthetic anti-malarial preparations: a discussion of the various steps which led to the synthesis and discovery of "plasmoquine," and a brief account of its use in tropical medicine. Proceedings of the Royal Society of Medicine 25, 897-905.

Schulemann, W., Schönhöfer, F., Wingler, A. (1929). Verfahren zur Darstellung Nsubstitutierter Aminochinoline. German patent, DE486079.

Schulemann, W., Schönhöfer, F., Wingler, A. (1930). Manufacture of new pharmaceutical products. US patent, US1747531.

Schlitzer, M. (2007). Malaria chemotherapeutics part I: History of antimalarial drug development, currently used therapeutics, and drugs in clinical development. ChemMedChem 2, 944-86.

Sharpe, W.D. and Isidore of Seville (1964). Isidore of Seville: The medical writings: An English translation with an introduction and commentary. Transactions of the American Philosophical Society, 54(2), 1-75.

Singer, C. (1961). Introduction. In Leechdoms, wortcunning, and starcraft of early England, Vol. I. London: The Holland Press.

Singh, V., Banyal, H.S. (2011). Antimalarial effect of Tinospora cordifolia (Willd.) Hook.f. \& Thoms. and Cissampelos pareira L. on Plasmodium berghei. Current Science, 101(10) 1356-1358.

Slater, A.F.G., Swiggard, W.J., Orton, B.R., Flitter, W.D., Goldberg, D.E., Cerami, A., Henderson, G. B. (1991). An iron-carboxylate bond links the heme units of malaria pigment. Proceedings of the National Academy of Sciences, USA, 88, 325-329.

Slater, L.B. (2004). Malaria chemotherapy and the "kaleidoscopic" organisation of biomedical research during World War II. Ambix, 51(2), 107-134 
Slater, L.B. (2009). War and Disease: Biomedical Research on Malaria in the Twentieth Century. New Brunswick, New Jersey: Rutgers University Press.

Smilkstein, M., Sriwilaijaroen, N., Kelly, J.X., Wilairat, P., Riscoe, M. (2004). Simple and inexpensive fluoroescence-based technique for high-throughput antimalarial drug screening. Antimicrobial Agents and Chemotherapy, 48(5), 1803-6.

Smith, A.C., Williams, R.M. (2008). Rabe rest in peace: confirmation of the RabeKindler conversion of $d$-quinotoxine into quinine: experimental affirmation of the Woodward-Doering formal total synthesis of quinine. Angewandte Chemie International Edition 47(9), 1736-1740.

Snyder, H.R., Freier, H.E., Kovacic, P., Van Heyningen, E.M., 1947. Synthesis of 4hydroxyquinolines. VIII. Some halogen-containing 4-aminoquinoline derivatives. Journal of the American Chemical Society, 69, 371-374.

Soejarto, D. D.; Gyllenhaal, C.; Kadushin, M. R.; Southavong, B.; Sydara, K.; Bouamanivong, S.; Xaiveu, M.; Zhang, H.-J.; Franzblau, S. G.; Tan, Ghee T.; Pezzuto, J. M.; Riley, M. C.; Elkington, B. G.; Waller, D. P., An ethnobotanical survey of medicinal plants of Laos toward the discovery of bioactive compounds as potential candidates for pharmaceutical development, Pharmaceutical Biology, 2012, 50(1), 42-60.

Stahl, P.H. (2003a). Drug solubilization with organic solvents, surfactants, and lipids. In C.G. Wermuth (Ed.), The Practice of Medicinal Chemistry, $2^{\text {nd }}$ ed., London:Elsevier Academic Press, 631-648.

Stahl, P.H. (2003b). Preparation of water-soluble compounds through salt formation. In C.G. Wermuth (Ed.), The Practice of Medicinal Chemistry, $2^{\text {nd }}$ ed., London:Elsevier Academic Press, 601-615.

Steinacker Dey, A., Joullié, M.M. (1965). Synthesis and properties of fluorinecontaining heterocyclic compounds. I. Trifluoromethyl quinolines (1). Journal of Heterocyclic Chemistry, 2(2), 113-119.

Stork, G., Niu, D., Fujimoto, A., Koft, E.R., Balkovec, J.M., Tata, J.R., Dake, G.R. (2001). The first stereoselective total synthesis of quinine. Journal of the American Chemical Society 123(14), 3239-3242.

Strecker, A (1854). Untersuchungen über die Constitution des Chinins. Justus Liebigs Annalen der Chemie 1, 155-70.

Strydom, K.A., Ismail, F., Frean, J. (2014). Plasmodium ovale: a case of not-so-benign tertian malaria. Malaria Journal, 13:85. 
Stump, B., Eberle, C., Schweizer, W.B., Kaiser, M., Brun, R., Krauth-Siegel, R.L., Lentz, D., Diederich, F. (2009). Pentafluorosulfanyl as a novel building block for enzyme inhibitors: trypanothione reductase inhibition and antiprotozoal activities of diarylamines. ChemBioChem 10(1), 79-83.

Sullivan, D.J. (2002). Theories on malarial pigment formation and quinoline action. International Journal for Parasitology, 32, 1645-1653.

Sullivan, D.J. Jr., Gluzman, I.Y., Russell, D.G., Goldberg, D.E. (1996). On the molecular mechanism of chloroquine's antimalarial action. Proceedings of the National Academy of Sciences, USA, 93, 11865-11870.

Supplement to the British Medical Journal (1891). An epitome of current medical literature. Supplement to the British Medical Journal, December 19, 198.

Supplement to the British Medical Journal (1892). An epitome of current medical literature. Supplement to the British Medical Journal, March 19, 47.

Surrey, A.R., Cutler, R.A. (1951). The role of phenol in the reaction of 4,7dichloroquinoline with novol diamine. Journal of the American Chemical Society, 73, 2623-6.

Surrey, A.R., Hammer, H.F. (1946). Preparation of bz-dichloro-4-aminoquinoline derivatives. Journal of the American Chemical Society, 68, 1244-6.

Ta, T.H., Hisam, S., Lanza, M., Jiram, A.I., Ismail, N., Rubio, J.M. (2014). First case of a naturally acquired human infection with Plasmodium cynomolgi. The Malaria Journal, 13:68, doi:10.1186/1475-2875-13-68.

Tanabe, K., Mita, T., Jombart, T., Eriksson, A., Horibe, S., Palacpac, N., RanfordCartwright, L., Sawai, H., Sakihama, N., Ohmae, H., Nakamura, M., Ferreira, M.U., Escalante, A.A., Prugnolle, F., Björkman, A., Färnert, A., Kaneko, A., Horii, T., Manica, A., Kishino, H., Balloux, F., 2010. Plasmodium falciparum accompanied the human expansion out of Africa. Current Biology, 20, 1283-1289.

Tarbell, D.S., 1946. Synthesis of 4,6- and 4,8-dichloroquinoline. Journal of the American Chemical Society, 68, 1277-8.

Taylor, N. (1945). Cinchona in Java: The Story of Quinine. New York: Greenburg.

Theophrastus (1949). Enquiry into plants. 3 vols. A. Hort (translator). Cambridge, Massachusetts: Harvard University Press. 
Thera, M.A., Plowe, C.V. (2012). Vaccines for malaria: how close are we? Annual Reviews in Medicine, 63, 345-357.

Thornton, R.J. (1814). A family herbal: or, familiar account of the medical properties of British and foreign plants. 2nd edition. London: R. and R. Crosby and Co., Stationer's Court, Ludgates Street.

Tomar, N., Jain, C.L., Tyagi, P. (2013). Synthesis, spectral analysis and characterization of substituted bisquinolines and their antimalarial activity. Acta Ciencia Indica,

Chemistry, 39(3), 81-84: Chemical Abstracts summary (reference could not be obtained).

University of Cambridge (2009-2011). Entry on Robert John Thornton. A Cambridge Alumni Database. http://venn.lib.cam.ac.uk, accessed 15 August 2014.

Vaughan, W. (1795). The evidence of the superior efficacy of the Cinchona flava, or yellow Peruvian bark. London: T. Cox, No. 30, St. Thomas's-Street, Borough.

Vehling, J.D. (1977). Apicius: Cookery and Dining in Imperial Rome. Mineola, NY: Dover Publications.

Veith, I. (1972). Huang Ti Nei Ching Su Wên: The Yellow Emperor's Classic of Internal Medicine. I. Veith (translator). Berkely and Los Angeles, California: University of California Press.

Vennerstrom, J.L. Ager, A.L. Andersen, S.L. Gerena, L. Ridley, R.G. Milhous, W.K. (1998). Antimalarial N,N-bis(7-chloroquinolin-4-yl)heteroalkanediamines. Journal of Medicinal Chemistry, 41, 4360-4364.

Vennerstrom, J.L., Ellis, W.Y., Ager, A.L., Andersen, S.L., Gerena, L., Milhous, W.K. (1992). Bisquinolines. 1. N,N-Bis(7-chloroquinolin-4-yl)alkanediamines with potential against chloroquine-resistant malaria. Journal of Medicinal Chemistry, 35, 2129-2134.

Virgil (1697). The Work of Virgil, Containing his Pastoral, Georgic, and Aeneis. Translated into English Verse; by Mr. Dryden. John Dryden (translator). London: Printed for Jacob Tonson, at the Judge's-Head in Fleetstreet, near the Inner-Temple-Gate.

Warhurst, D.C., Craig, J.C., Adagu, S.I., Guy, R.K., Madrid, P.B., Fivelman, Q.L. (2007). Activity of piperaquine and other 4-aminoquinoline antiplasmodial drugs against chloroquine sensitive and resistant blood-stages of Plasmodium falciparum: Role of $\beta$ haematin inhibition and drug concentration in vacuolar water- and lipid-phases. Biochemical Pharmacology 73, 1910-1926. 
Warhurst, D., Craig, J.C., Adagu, I.S., Meyer, D.J., Lee, S.Y. (2003). The relationship of physico-chemical properties and structure to the differential antiplasmodial activity of the cinchona alkaloids. Malaria Journal 2, 26.

Warrell, D.A. (2002). Clinical features of malaria. In Warrell, D.A. and Gilles, H.M. (Ed.s), Essential Malariology, 4th Ed., London: Arnold, 191-205.

Weathers, P.J., Arsenault, P.R., Covello, P.S., McMickle, A., Teoh, K.H., Reed, D.W. (2011). Artemisinin production in Artemisia annua: studies in planta and results of a novel delivery method for treating malaria and other neglected diseases. Phytochemical Reviews, 10, 173-183.

Welch, J.T., Lim, D. (2007). The synthesis and biological activity of pentafluorosulfanyl analogs of fluoxetine, fenfluramine, and norfenfluramine. Bioorganic and Medicinal Chemistry 15, 6659-6666.

Wermuth, C.G. (2003). Preparation of water-soluble compounds by covalent attachment of solubilizing moieties. In C.G. Wermuth (Ed.), The Practice of Medicinal Chemistry, $2^{\text {nd }}$ ed., London:Elsevier Academic Press, 617-630.

Wesche D.L., Black, J. (1990). A comparison of the antimalarial activity of the cinchona alkaloids against $P$. falciparum in vitro. Journal of Tropical Medicine and Hygiene 93, 153-159.

White, N.J. (2007). Cardiotoxicity of antimalarial drugs. The Lancet Infectious Diseases 7, 549-558.

Willcox, M.L., Bodeker, G. (2004). Traditional herbal medicines for malaria. Biomedical Journal 329, 1156-9.

Wipf, P., Mo, T., Geib, S.J., Caridha, D., Dow, G.S., Gerena, L., Roncal, N., Milner, E.E. (2009). Synthesis and biological evaluation of the first pentafluorosulfanyl analogs of mefloquine. Organic and Biomolecular Chemistry 7, 4163-4165.

Wiselogle, F.Y. (1946). A Survey of Antimalarial Drugs, 1941-1945. Ann Arbor, Michigan: J.W. Edwards.

Wislicenus, W., Spiro, K. (1889). Über die Einwirkung von Anilin auf Oxalessigester und Methyloxalessigester. Berichte der deutschen chemischen Gesellschaft 22, 33483352.

World Health Organization, WHO Global Malaria Programme World Malaria Report 2013. 2013, WHO Press, Geneva, Switzerland. 
Woodward, R.B., Doering, W.E (1944). The total synthesis of quinine. Journal of the American Chemical Society 66(5), 849.

Woodward, R.B., Doering, W.E (1945). The total synthesis of quinine. Journal of the American Chemical Society 67(5), 860-874.

Yalcindag, E., Elguero, E., Arnathau, C., Durand, P., Akiana, J., Anderson, T.J., Aubouy, A., Balloux, F., Besnard, P., Bogreau, H., Carnevale, P., D’Alessandro, U., Fontenille, D., Gamboa, D., Jombart, T., Le Mire, J., Leroy, E., Maestre, A., Mayxay, M., Ménard, D., Musset, L., Newton, P.N., Nkoghé, D., Noya, O., Ollomo, B., Rogier, C., Veron, V., Wide, A., Zakeri, S., Carme, B., Legrand, E., Chevillon, C., Ayala, F.J., Renaud, F., Prugnolle, F., 2012. Multiple independed introductions of Plasmodium falciparum in South America. PNAS, 109(2), 511-516.

Yang, J., Wen, X., Jia B., Mao, Q., Wang, Q., Lai, M. (2010). Quality evaluation of Potentilla discolor by high-performance liquid chromatography coupled with diode array detection and electrospray ionisation tandem mass spectrometry. Phytochemical Analysis, 22, 547-554.

Yayon, A., Cabantchik, Z.I., Ginsburg, H. (1985). Susceptibility of human malaria parasites to chloroquine is $\mathrm{pH}$ dependent. Proceedings of the National Academy of Sciences, USA, 82, 2784-2788.

Young, M.D., Moore, D.V. (1961). Chloroquine resistance in Plasmodium falciparum. The American Journal of Tropical Medicine and Hygeine, 10, 317-20.

Zhu, S., Chandrashekar, G., Meng, L., Robinson, K., Chatterji, D. (2012). Febrifugine analogue compounds: synthesis and antimalarial evaluation. Bioorganic and Medicinal Chemistry 20(2), 927-932.

Zimmerman, S., Thomi, S., Kaiser, M., Hamburger, M., Adams, M. (2012). Screening and HPLC-based activity profiling for new antiprotozoal leads from European plants. Scientia Pharmaceutica, 80, 205-213. 


\section{APPENDIX A: Specific synthetic methods and characterization data}

The following synthetic methods are organized by quinoline ring substitution pattern (for the monoquinolines), followed by a separate section for bis-quinolines and their starting materials. For an overview of the compounds included, see the Table of Contents, page vii. For an overview of the synthetic methods used to make the compounds described herein, and a description of the methods used to obtain the characterization data, see Chapter 5, sections 5.1-2. Again, note that characterization data has often been omitted for those quinolone intermediates that have been previously well characterized in the literature. To find the synthetic method for a final product by its code number (PL number), see Table A1, below.

Table A1: Compounds listed by code number (PL number)

\begin{tabular}{|l|l|l|}
\hline PL number & $\begin{array}{l}\text { Page on which } \\
\text { synthetic method } \\
\text { appears }\end{array}$ \\
\hline PL16 & 309 \\
\hline PL67 & 2410 \\
\hline PL147/301 & 2423 \\
\hline
\end{tabular}




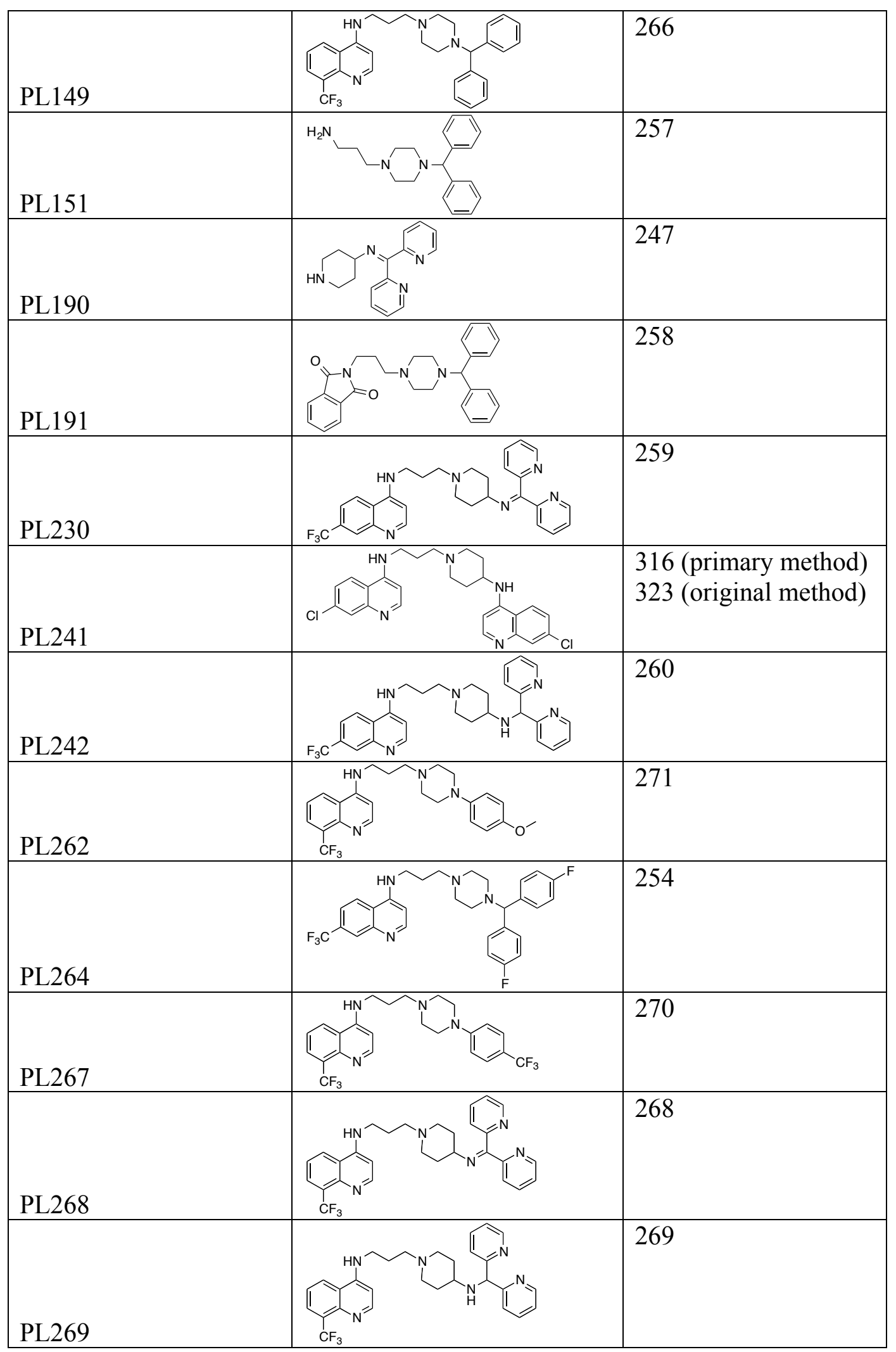




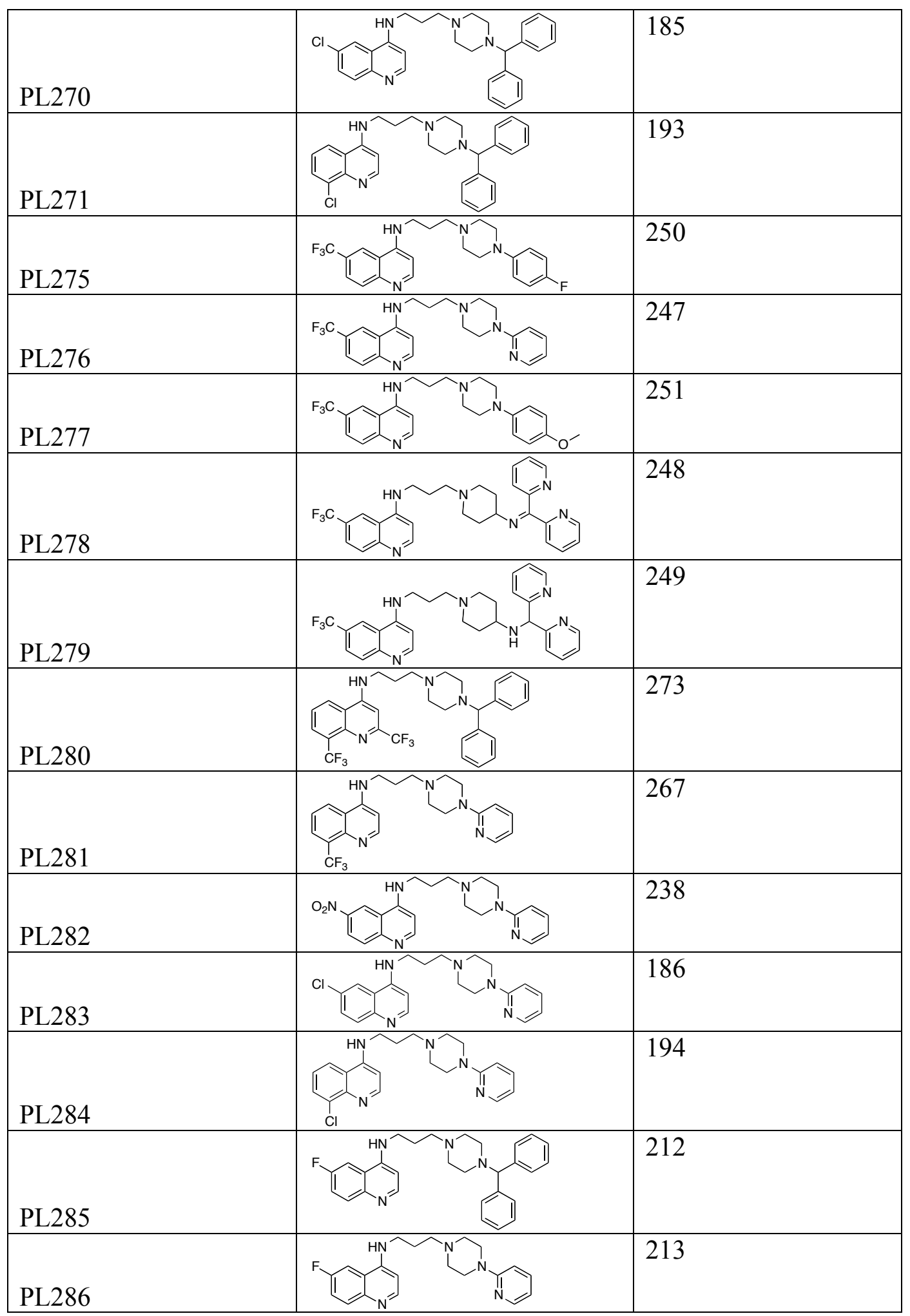




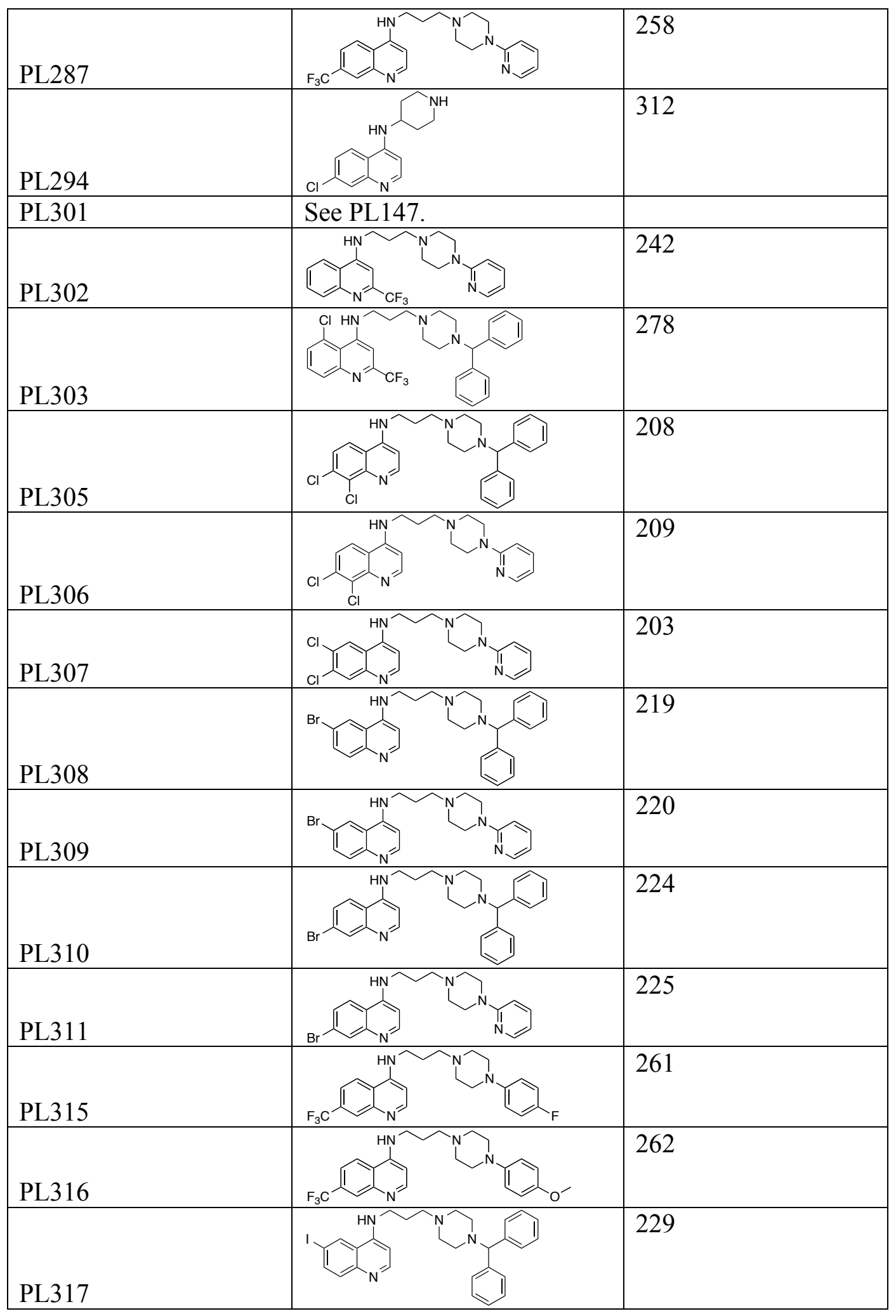




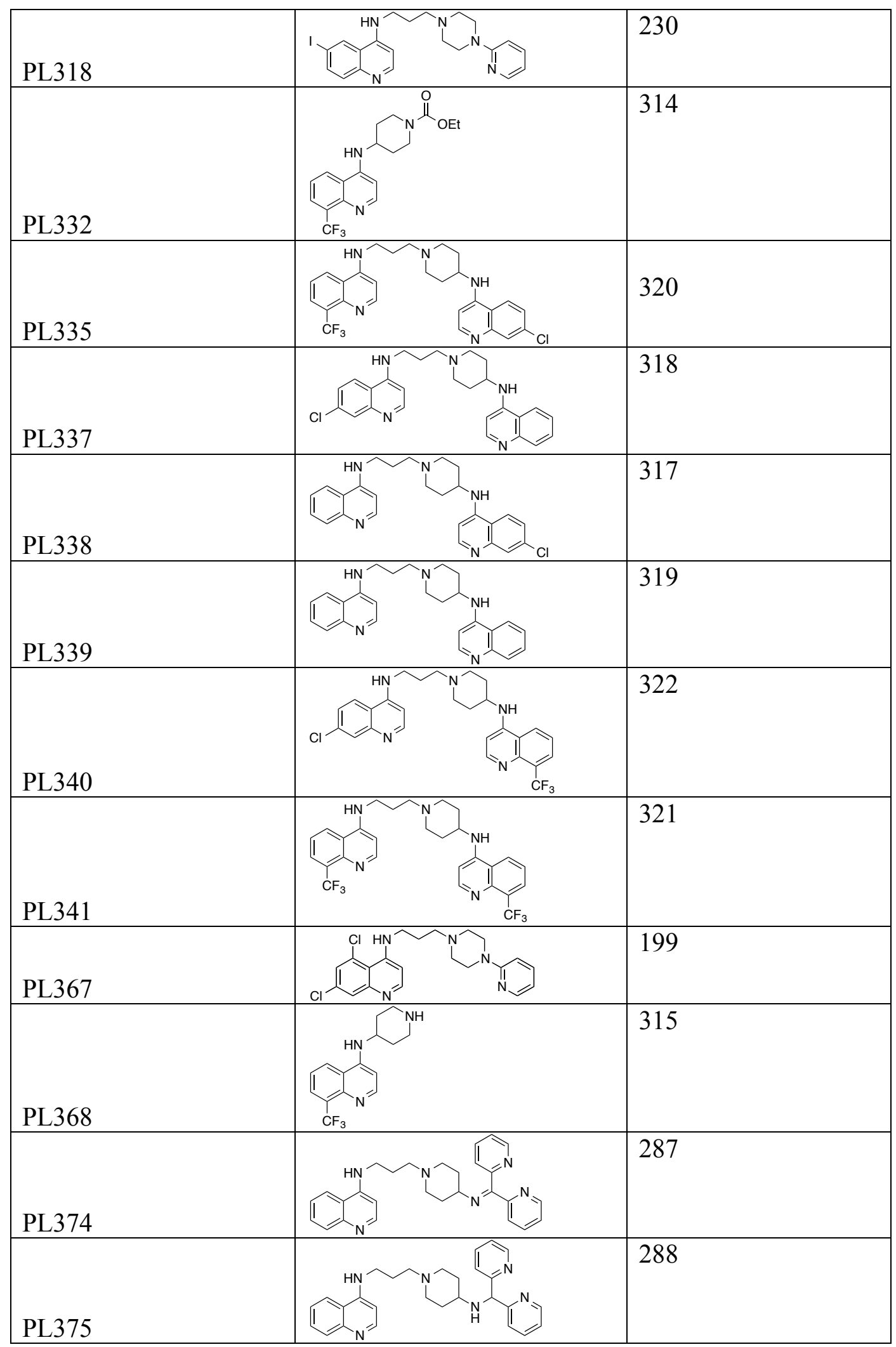

181 


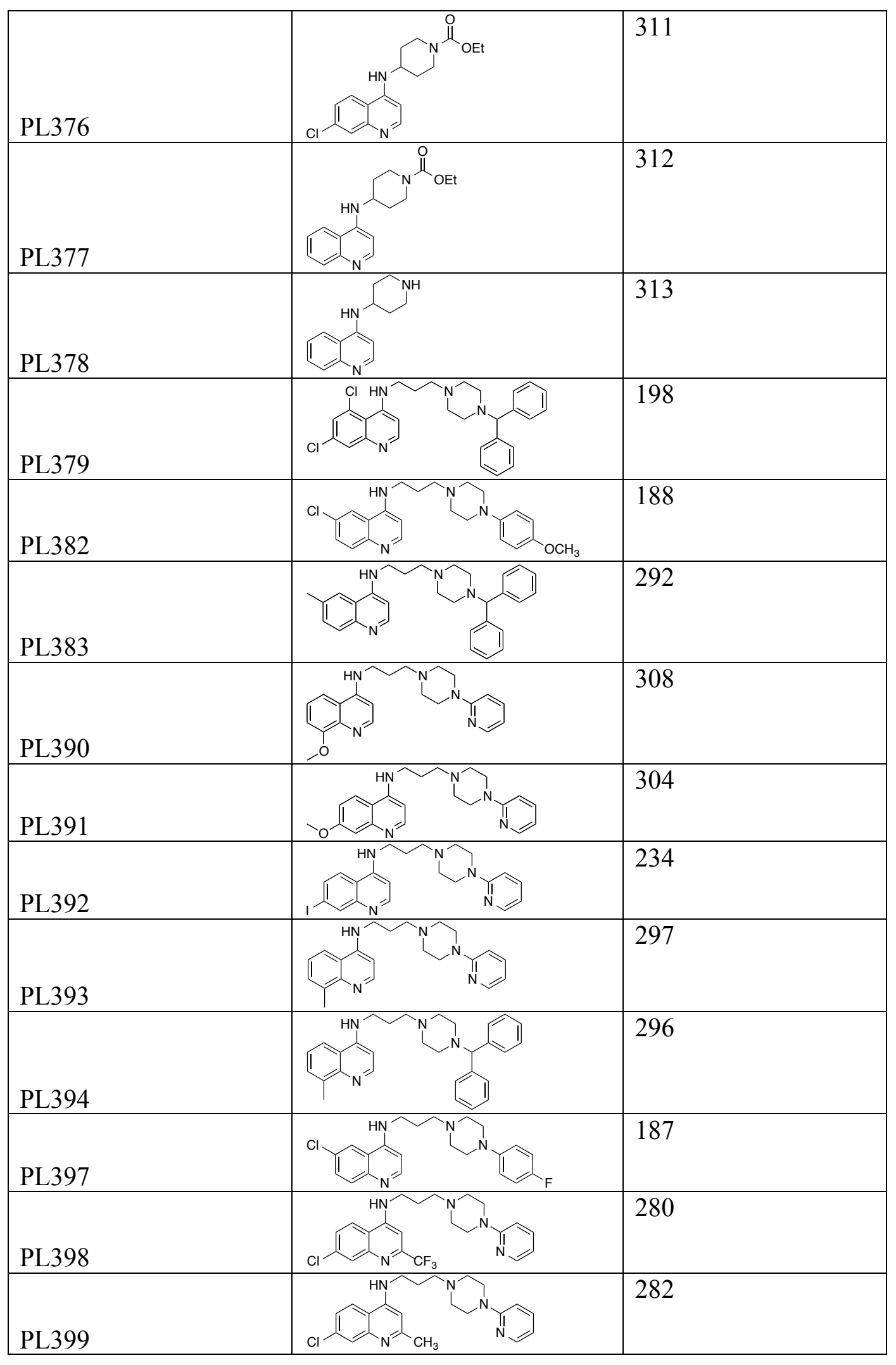




\section{A.1. Chloroquinolines}

\section{A.1.1: 6-chloroquinolines}

3-carbethoxy-6-chloro-4-quinolone (Price, 1946; Riegel, 1946)<smiles>CCOC(=O)c1c[nH]c2ccc(Cl)cc2c1=O</smiles>

para-Chloroaniline $(10.05 \mathrm{~g}, 78.8 \mathrm{mmol})$ and diethyl ethoxymethylene malonate $(17.03$ $\mathrm{g}, 78.8 \mathrm{mmol})$ were heated in refluxing Dowtherm A $(70 \mathrm{~mL})$ for 25 minutes. After cooling, the reaction mixture was diluted with hexanes $(150 \mathrm{~mL})$ and vacuum filtered, rinsing well with additional hexanes, to recover the product as an off-white, crystalline solid (18.32 g, 92\%).

3-carboxy-6-chloro-4-quinolone (Price, 1946; Riegel, 1946)<smiles>O=C(O)c1c[nH]c2ccc(Cl)cc2c1=O</smiles>

3-carbethoxy-6-chloro-4-quinolone (18.32 g, $72.8 \mathrm{mmol})$ in $200 \mathrm{~mL}$ of $10 \%$ caustic soda was allowed to reflux, stirring, for 3 hours. The hot reaction mixture was poured into 500 $\mathrm{mL}$ water and acidified with concentrated muriatic acid. After cooling, vacuum filtration yielded a white solid. This was allowed to air dry, and was used without further purification or drying.

6-chloro-4-quinolone (Price, 1946; Riegel, 1946)<smiles>O=c1cc[nH]c2ccc(Cl)cc12</smiles> 
3-carboxy-6-chloro-4-quinolone from the above reaction (presumed to contain residual water) was heated in Dowtherm A $(100 \mathrm{~mL})$ at reflux for 40 minutes. After cooling, the reaction mixture was diluted with $100 \mathrm{~mL}$ hexanes and vacuum filtered to yield a sawdust-colored solid. NMR indicated that reaction was not complete. The solid was again suspended in Dowtherm $(100 \mathrm{~mL})$ and returned to reflux for a further 15 minutes. Upon cooling, the reaction mixture was diluted with hexanes $(150 \mathrm{~mL})$ and vacuum filtered, rinsing well with additional hexanes, to recover the product as a greenish-tan, crystalline solid (13.93 g, used without further purification).

4,6-dichloroquinoline (Price, 1946; Riegel, 1946; Tarbell, 1946)<smiles>Clc1ccc2nccc(Cl)c2c1</smiles>

6-chloro-4-quinolone from the above reaction (13.93 $\mathrm{g}$ of crude material) and phosphorus oxychloride $(40 \mathrm{~mL})$ were heated at a gentle reflux for 5 hours. After cooling, the reaction mixture was poured gradually onto ice and then cautiously basified with $50 \%$ caustic soda. This was diluted to $3.3 \mathrm{~L}$ with water and divided into three equal portions, each of which was extracted with chloroform ( $100 \mathrm{~mL}$, followed by $3 \times 30 \mathrm{~mL})$. The pooled chloroform layers from all extractions were dried $\left(\mathrm{MgSO}_{4}\right)$ and evaporated under reduced pressure with warming to yield a pale tan solid (13.48 g, 86\% from parachloroaniline, $\mathrm{mp}=102.3-103 \cdot 6^{\circ} \mathrm{C}$ (lit. $104^{\circ} \mathrm{C}$ (Tarbell, 1946)).

${ }^{1} \mathrm{H}$ NMR $\delta(\mathrm{ppm})\left(\mathrm{CHCl}_{3}-\mathrm{d}\right): 8.78(1 \mathrm{H}, \mathrm{d}, \mathrm{J}=4.71 \mathrm{~Hz}), 8.23(1 \mathrm{H}, \mathrm{d}, \mathrm{J}=2.34 \mathrm{~Hz}), 8.07$ $(1 \mathrm{H}, \mathrm{d}, \mathrm{J}=8.98 \mathrm{~Hz}), 7.72(1 \mathrm{H}, \mathrm{dd}, \mathrm{J}=8.98,2.33 \mathrm{~Hz}), 7.52(1 \mathrm{H}, \mathrm{d}, \mathrm{J}=4.70 \mathrm{~Hz})$.

\section{3-(6-chloroquinolin-4-ylamino)propanol}<smiles>OCCCNc1ccnc2ccc(Cl)cc12</smiles>

4,6-dichloroquinoline (5.00 g, $25.2 \mathrm{mmol})$ and 3-amino-1-propanol (12.0 mL, $157 \mathrm{mmol})$ were heated at $85^{\circ} \mathrm{C}$ for 2 days, whereupon TLC indicated that reaction was complete. The hot reaction mixture was then poured into water $(150 \mathrm{~mL})$, while stirring vigorously. After resting 20 minutes, the resulting precipitate was recovered by vacuum filtration, followed by air drying and partial recrystallization from ethyl acetate to provide the desired product as fine, tan, crystalline solid $\left(5.20 \mathrm{~g}, 87 \%, \mathrm{mp}=165.4-166.8^{\circ} \mathrm{C}\right)$. 
${ }^{1} \mathrm{H}$ NMR $\delta(\mathrm{ppm})\left(\mathrm{DMSO}-\mathrm{d}_{6}\right): 8.40(1 \mathrm{H}, \mathrm{d}, \mathrm{J}=5.37 \mathrm{~Hz}), 8.38(1 \mathrm{H}, \mathrm{d}, \mathrm{J}=2.38 \mathrm{~Hz}), 7.78$ $(1 \mathrm{H}, \mathrm{d}, \mathrm{J}=8.95 \mathrm{~Hz}), 7.60(1 \mathrm{H}, \mathrm{dd}, \mathrm{J}=8.95,2.30 \mathrm{~Hz}), 7.23(1 \mathrm{H}, \mathrm{br} \mathrm{t}, \mathrm{J}=5.31 \mathrm{~Hz}), 6.49$ $(1 \mathrm{H}, \mathrm{d}, \mathrm{J}=5.42 \mathrm{~Hz}), 4.60(1 \mathrm{H}, \mathrm{t}, \mathrm{J}=5.06 \mathrm{~Hz}), 3.55(2 \mathrm{H}, \mathrm{m}), 3.28-3.35$ (water signal overlaps $\mathrm{m}, \sim 2 \mathrm{H}), 1.79-1.87(2 \mathrm{H}, \mathrm{m})$.

${ }^{1} \mathrm{H}$ NMR $\delta(\mathrm{ppm})\left(\mathrm{CHCl}_{3}-\mathrm{d}\right): 8.52(1 \mathrm{H}, \mathrm{d}, \mathrm{J}=5.34 \mathrm{~Hz}), 7.90(1 \mathrm{H}, \mathrm{d}, \mathrm{J}=8.96 \mathrm{~Hz}), 7.68$ $(1 \mathrm{H}, \mathrm{d}, \mathrm{J}=2.26 \mathrm{~Hz}), 7.55(1 \mathrm{H}, \mathrm{dd}, \mathrm{J}=8.96,2.24 \mathrm{~Hz}), 6.42(1 \mathrm{H}, \mathrm{d}, \mathrm{J}=5.36 \mathrm{~Hz}), 5.80(1$ $\mathrm{H}, \mathrm{br} \mathrm{s}), 3.97(2 \mathrm{H}, \mathrm{t}, \mathrm{J}=5.45 \mathrm{~Hz}), 3.47-3.48(2 \mathrm{H}, \mathrm{m}), 2.00-2.08(2 \mathrm{H}, \mathrm{m})$.

\section{3-(6-chloroquinolin-4-ylamino)propyl methanesulfonate}<smiles>COCCCNc1ccnc2ccc(Cl)cc12</smiles>

3-(6-chloroquinolin-4-ylamino)propanol $(4.20 \mathrm{~g}, 17.7 \mathrm{mmol})$ and triethylamine $(3.71 \mathrm{~mL}$, $26.6 \mathrm{mmol})$ in dry THF $(100 \mathrm{~mL})$ were cooled to below $0^{\circ} \mathrm{C}$ on ice/salt. Methanesulfonyl chloride ( $1.58 \mathrm{~mL}, 20.3 \mathrm{mmol})$ was added dropwise. After stirring for 30 minutes on ice, there remained some undissolved solid that had the appearance of starting material. An additional $50 \mathrm{~mL}$ THF were added, followed by additional triethylamine $(1.2 \mathrm{~mL}, 8.6$ $\mathrm{mmol})$ and methanesulfonyl chloride $(0.50 \mathrm{~mL}, 6.4 \mathrm{mmol})$, and stirring was continued for a further 40 minutes, whereupon TLC indicated that reaction was not complete (a sample of the reaction mixture indicated completion, but a sample incorporating the undissolved solid indicated the presence of unreacted starting material). The reaction mixture was filtered to remove the solid material. The filtrate was diluted with ethyl acetate $(25 \mathrm{~mL})$ and washed with $35 \mathrm{~mL}$ saturated sodium bicarbonate; after separating, the aqueous layer was extracted with ethyl acetate $(3 \times 10 \mathrm{~mL})$. The pooled organic layers were dried $\left(\mathrm{MgSO}_{4}\right)$ and evaporated under reduced pressure with warming to give the desired product as a yellow solid $(4.16 \mathrm{~g}, 75 \%)$.

\section{PL270: N-(3-(4-benzhydrylpiperazin-1-yl)propyl)-6-chloroquinolin-4-amine)}<smiles>Clc1ccc2nccc(NCCCN3CCN(C(c4ccccc4)c4ccccc4)CC3)c2c1</smiles> 
3-(6-chloroquinolin-4-ylamino)propyl methanesulfonate (2.03 g, $6.45 \mathrm{mmol}), \mathrm{N}$ (diphenylmethyl)piperazine $(1.67 \mathrm{~g}, 6.62 \mathrm{mmol})$, and triethylamine $(1.32 \mathrm{~mL}, 9.57$ $\mathrm{mmol})$ were heated at reflux in acetonitrile $(22 \mathrm{~mL})$ for 22 hours. TLC then indicated that reaction was complete. The solvent was removed by evaporation under reduced pressure with warming. The residue was partitioned between $100 \mathrm{~mL}$ chloroform and 35 $\mathrm{mL}$ water; after separation, the aqueous layer was extracted with chloroform $(3 \times 15 \mathrm{~mL})$. The pooled organic layers were dried $\left(\mathrm{MgSO}_{4}\right)$ and evaporated under reduced pressure with warming. The residue was partially recrystallized from $95 \%$ ethanol, and then fully recrystallized from chloroform to yield the desired product as a white, crystalline solid $\left(0.21 \mathrm{~g}, 0.4 \%, \mathrm{mp}=212-214^{\circ} \mathrm{C}\right)$.

${ }^{1} \mathrm{H}$ NMR $\delta(\mathrm{ppm})\left(\mathrm{CHCl}_{3}-\mathrm{d}\right): 8.49(1 \mathrm{H}, \mathrm{d}, \mathrm{J}=5.28 \mathrm{~Hz}), 8.01(1 \mathrm{H}, \mathrm{d}, \mathrm{J}=2.30 \mathrm{~Hz}), 7.90$ $(1 \mathrm{H}, \mathrm{d}, \mathrm{J}=8.98 \mathrm{~Hz}), 7.75(1 \mathrm{H}$, br t, J $=3.94 \mathrm{~Hz}), 7.58(1 \mathrm{H}, \mathrm{dd}, \mathrm{J}=8.98,2.25 \mathrm{~Hz}), 7.45-$ $7.49(4 \mathrm{H}, \mathrm{m}), 7.27-7.28(4 \mathrm{H}, \mathrm{m}), 7.16-7.18(2 \mathrm{H}, \mathrm{m}), 6.31(1 \mathrm{H}, \mathrm{d}, \mathrm{J}=5.32 \mathrm{~Hz}), 4.48(1$ $\mathrm{H}, \mathrm{s}), 3.34(2 \mathrm{H}, \mathrm{td}, \mathrm{J}=5.39,0.00 \mathrm{~Hz}), 2.64(10 \mathrm{H}$, br s overlaps $\mathrm{t}, \mathrm{J}=5.16 \mathrm{~Hz}), 1.92(2$ $\mathrm{H}$, apparent $\mathrm{p}, \mathrm{J}=5.27 \mathrm{~Hz}$ ).

${ }^{13} \mathrm{C} \mathrm{NMR} \delta(\mathrm{ppm})\left(\mathrm{CHCl}_{3}-\mathrm{d}\right): 151.5,150.0,147.0,143.1,131.6,129.7,128.6,127.9$, $127.0,120.1,120.0,119.9,98.8,76.1,59.3,54.1,52.1,45.0,23.2$.

HPLC (method C) $t_{\mathrm{R}}=11.33 \min (95 \%$ pure). MS (ESI): $m / z 471.2301 \mathrm{M}+\mathrm{H}$ (calculated 471.2310).

\section{PL283: 6-chloro- $N$-(3-(4-(pyridin-2-yl)piperazin-1-yl)propyl)quinolin-4-amine}<smiles>O=[R16]c1ccc2nccc(NCCCN3CCN(c4ccccn4)CC3)c2c1</smiles>

3-(6-chloroquinolin-4-ylamino)propyl methanesulfonate (1.00 g, $3.2 \mathrm{mmol}), 1-(2-$ pyridyl)piperazine ( $0.65 \mathrm{~g}, 4.0 \mathrm{mmol})$, potassium carbonate $(0.66 \mathrm{~g}, 4.8 \mathrm{mmol})$, and a catalytic amount of potassium iodide were heated at $75^{\circ} \mathrm{C}$ in acetonitrile $(15 \mathrm{~mL})$ for 28 hours. TLC then indicated that reaction was complete. The solvent was removed under reduced pressure with warming, and the residue was shaken with ethyl acetate $(30 \mathrm{~mL})$ and water $(20 \mathrm{~mL})$. Some material remained insoluble, and was removed by vacuum filtration. The filtrate was separated, and the aqueous layer was extracted with ethyl acetate $(3 \times 10 \mathrm{~mL})$. The pooled ethyl acetate layers were dried over $\mathrm{MgSO}_{4}$ and evaporated under reduced pressure with warming to yield a solid. This was combined with the solid material that had been removed from the extraction by filtration. This material was recrystallized from a mixture of ethyl acetate and $95 \%$ ethanol $(6: 1,15 \mathrm{~mL})$ 
to provide the desired product as large, golden crystals $(0.66 \mathrm{~g}, 54 \%, \mathrm{mp}=175.6-$ $\left.177.5^{\circ} \mathrm{C}\right)$.

${ }^{1} \mathrm{H}$ NMR $\delta(\mathrm{ppm})\left(\mathrm{CHCl}_{3}-\mathrm{d}\right): 8.51(1 \mathrm{H}, \mathrm{d}, \mathrm{J}=5.31 \mathrm{~Hz}, \mathrm{Q}-\mathrm{C} 2-\mathrm{H}), 8.23-8.23(1 \mathrm{H}, \mathrm{m}$, Py$\mathrm{H} 6$ (from N, counterclockwise)), $7.94(1 \mathrm{H}, \mathrm{d}, \mathrm{J}=2.31 \mathrm{~Hz}, \mathrm{Q}-\mathrm{C} 5-\mathrm{H}), 7.86(1 \mathrm{H}, \mathrm{d}, \mathrm{J}=$ $8.93 \mathrm{~Hz}, \mathrm{Q}-\mathrm{C} 8-\mathrm{H}), 7.62(1 \mathrm{H}, \mathrm{t}, \mathrm{J}=4.05 \mathrm{~Hz}, \mathrm{Q}-\mathrm{NH}), 7.51(1 \mathrm{H}, \mathrm{ddd}, \mathrm{J}=8.54,7.15,2.02$ Hz, Py-H4), 7.46 (1 H, dd, J = 8.93, 2.27 Hz, Q-H7), 6.70 (1 H, d, J = 8.54 Hz, Py-H3), $6.67(1 \mathrm{H}, \mathrm{dd}, \mathrm{J}=7.16,4.93 \mathrm{~Hz}, \mathrm{Py}-\mathrm{H} 5), 6.35(1 \mathrm{H}, \mathrm{d}, \mathrm{J}=5.35 \mathrm{~Hz}, \mathrm{Q}-\mathrm{C} 3-\mathrm{H}), 3.78(4 \mathrm{H}$, m, Pip $\left.\mathrm{CH}_{2} \mathrm{CH}_{2}-\mathrm{Py}\right), 3.41\left(2 \mathrm{H}, \mathrm{td}, \mathrm{J}=5.37,0.00 \mathrm{~Hz}, \mathrm{QNHCH}_{2}\right), 2.70-2.71(6 \mathrm{H}, \mathrm{m}$, Pip $\mathrm{CH}_{2} \mathrm{CH}_{2}-\mathrm{Py}, \sim 2.71$; $\left.\mathrm{QNHCH}_{2} \mathrm{CH}_{2} \mathrm{CH}_{2}, \sim 2.70\right), 2.01(2 \mathrm{H}$, apparent $\mathrm{p}, \mathrm{J}=5.28 \mathrm{~Hz}$, $\mathrm{CH}_{2} \mathrm{CH}_{2} \mathrm{CH}_{2}$ ).

${ }^{13} \mathrm{C}$ NMR $\delta(\mathrm{ppm})\left(\mathrm{CHCl}_{3}\right.$-d): 159.7, 151.5 (Q-C2), 149.8, 148.0 (Py-C6 from N, counterclockwise), 146.9, 137.5 (Py-C4), 131.5 (Q-C8), 130.0, 129.5 (Q-C7), 119.9, 119.8 (either 119.9 or 119.8 is Q-C5), 115.4, 113.7 (Py-C5), 107.2 (Py-C3), 98.7 (Q-C3), $59.1\left(\mathrm{QNHCH}_{2} \mathrm{CH}_{2} \mathrm{CH}_{2} \mathrm{Pip}\right.$ ), 53.6 ( $\mathrm{Pip} \mathrm{CH}_{2} \mathrm{CH}_{2}$-Py), 45.2 ( $\left.\mathrm{Pip} \mathrm{CH}_{2} \mathrm{CH}_{2}-\mathrm{Py}\right), 44.6$ $\left(\mathrm{QNHCH} \mathrm{CH}_{2} \mathrm{CH}_{2}\right), 23.4\left(\mathrm{QNHCH} \mathrm{CH}_{2} \mathrm{CH}_{2}\right)$.

MS (ESI): $m / z 382.17990 \mathrm{M}+\mathrm{H}$ (calculated 382.17930)

$\operatorname{HPLC}\left(\right.$ method A) $t_{\mathrm{R}}=5.09 \min (98 \%$ pure $)$.

\section{PL397: 6-chloro- $N$-(3-(4-(4-fluorophenyl)piperazin-1-yl)propyl)quinolin-4-amine}

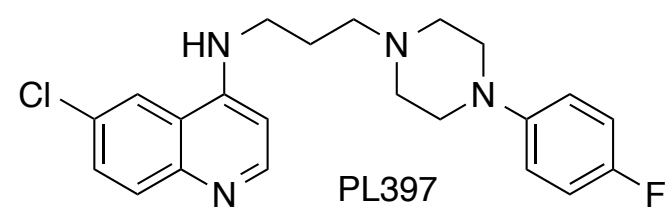

3-(6-chloroquinolin-4-ylamino)propyl methanesulfonate (1.00 g, $3.2 \mathrm{mmol})$, 1-(4fluorophenyl)piperazine $(0.60 \mathrm{~g}, 3.3 \mathrm{mmol})$, potassium carbonate $(0.66 \mathrm{~g}, 4.8 \mathrm{mmol})$, and a catalytic amount of potassium iodide were heated at $75^{\circ} \mathrm{C}$ in acetonitrile $(15 \mathrm{~mL})$ for 28 hours. TLC then indicated that reaction was complete. The solvent was removed under reduced pressure with warming, and the residue was shaken with ethyl acetate $(30 \mathrm{~mL})$ and water $(20 \mathrm{~mL})$. A yellow solid remained insoluble, and was removed by vacuum filtration. The filtrate was separated, and the aqueous layer was extracted with ethyl acetate $(3 \times 10 \mathrm{~mL})$. The pooled ethyl acetate layers were dried over $\mathrm{MgSO}_{4}$ and evaporated under reduced pressure with warming to yield a golden, crystalline solid. The solid material removed from the extraction by filtration was recrystallized from a mixture 
of ethyl acetate and $95 \%$ ethanol $(6: 1,20 \mathrm{~mL})$ to yield a golden, crystalline solid $(0.51 \mathrm{~g}$, $\left.40 \%, \mathrm{mp}=183.4-184.8^{\circ} \mathrm{C}\right)$.

${ }^{1} \mathrm{H} \mathrm{NMR} \delta(\mathrm{ppm})\left(\mathrm{CHCl}_{3}-\mathrm{d}\right): 8.51(1 \mathrm{H}, \mathrm{d}, \mathrm{J}=5.31 \mathrm{~Hz}), 7.93(1 \mathrm{H}, \mathrm{d}, \mathrm{J}=2.24 \mathrm{~Hz}), 7.87$ $(1 \mathrm{H}, \mathrm{d}, \mathrm{J}=8.93 \mathrm{~Hz}), 7.57(1 \mathrm{H}$, br t, J $=3.95 \mathrm{~Hz}), 7.48(1 \mathrm{H}, \mathrm{dd}, \mathrm{J}=8.94,2.24 \mathrm{~Hz}), 6.94-$ $6.99(4 \mathrm{H}, \mathrm{m}), 6.34(1 \mathrm{H}, \mathrm{d}, \mathrm{J}=5.35 \mathrm{~Hz}), 3.40(2 \mathrm{H}, \mathrm{td}, \mathrm{J}=5.77,4.06 \mathrm{~Hz}), 3.36(4 \mathrm{H}, \mathrm{m})$, $2.77(4 \mathrm{H}, \mathrm{m}), 2.72(2 \mathrm{H}, \mathrm{t}, \mathrm{J}=5.15 \mathrm{~Hz}), 2.00(2 \mathrm{H}$, apparent $\mathrm{p}, \mathrm{J}=5.36 \mathrm{~Hz})$.

${ }^{19} \mathrm{~F} \mathrm{NMR} \delta(\mathrm{ppm})\left(\mathrm{CHCl}_{3}-\mathrm{d}\right):-124.7(\mathrm{~m})$.

${ }^{13} \mathrm{C} \mathrm{NMR} \delta(\mathrm{ppm})\left(\mathrm{CHCl}_{3}-\mathrm{d}\right): 158.2,156.6,151.4,149.8,147.7\left(\mathrm{~d}, \mathrm{~J}_{\mathrm{F}}=2.05 \mathrm{~Hz}\right.$ ?), 146.9, $131.5,129.9,129.5,119.8\left(\mathrm{~d}, \mathrm{~J}_{\mathrm{F}}=6.08 \mathrm{~Hz}\right.$ ?), $118.3\left(\mathrm{~d}, \mathrm{~J}_{\mathrm{F}}=8.49 \mathrm{~Hz}\right.$ ) $), 115.5\left(\mathrm{~d}, \mathrm{~J}_{\mathrm{F}}=\right.$ 22.01 Hz?) 98.7, 59.1, 53.9, 50.2, 44.7, 23.4.

MS (ESI): $m / z$ 399.17560 M + H (calculated NUMBER)

HPLC (method A) $t_{\mathrm{R}}=8.41 \min (>99 \%$ pure).

\section{PL382: 6-chloro- $N$-(3-(4-(4-methoxyphenyl)piperazin-1-yl)propyl)quinolin-4-amine}<smiles>COc1ccc(N2CCN(CCCNc3ccnc4ccc(Cl)cc34)CC2)cc1</smiles>

3-(6-chloroquinolin-4-ylamino)propyl methanesulfonate (1.00 g, $3.2 \mathrm{mmol}), 1-(4-$ methoxyphenyl)piperazine $(0.64 \mathrm{~g}, 3.3 \mathrm{mmol})$, potassium carbonate $(0.66 \mathrm{~g}, 4.8 \mathrm{mmol})$, and a catalytic amount of potassium iodide were heated at $75^{\circ} \mathrm{C}$ in acetonitrile $(15 \mathrm{~mL})$ for 28 hours. TLC then indicated that reaction was complete. The solvent was removed under reduced pressure with warming, and the residue was partitioned between chloroform $(20 \mathrm{~mL})$ and water $(20 \mathrm{~mL})$. After separation, the aqueous layer was extracted with further chloroform $(3 \times 7 \mathrm{~mL})$, and the pooled organic layers were dried over $\mathrm{MgSO}_{4}$ and evaporated under reduced pressure with warming. The residue was recrystallized by boiling in excess $95 \%$ ethanol, followed by slow concentration to $3 \mathrm{~mL}$ at room temperature. This afforded the desired product as tan crystals $(0.40 \mathrm{~g}, 26 \%, \mathrm{mp}$ $\left.=198 \cdot 5-199 \cdot 0^{\circ} \mathrm{C}\right)$.

${ }^{1} \mathrm{H}$ NMR $\delta(\mathrm{ppm})\left(\mathrm{CHCl}_{3}-\mathrm{d}\right): 8.51(1 \mathrm{H}, \mathrm{d}, \mathrm{J}=5.31 \mathrm{~Hz}), 7.95(1 \mathrm{H}, \mathrm{d}, \mathrm{J}=2.30 \mathrm{~Hz}), 7.87$ $(1 \mathrm{H}, \mathrm{d}, \mathrm{J}=8.94 \mathrm{~Hz}), 7.57(1 \mathrm{H}, \mathrm{t}, \mathrm{J}=3.99 \mathrm{~Hz}), 7.48(1 \mathrm{H}, \mathrm{dd}, \mathrm{J}=8.93,2.26 \mathrm{~Hz}), 6.97-$ 
$6.98(2 \mathrm{H}, \mathrm{m}), 6.85-6.86(2 \mathrm{H}, \mathrm{m}), 6.34(1 \mathrm{H}, \mathrm{d}, \mathrm{J}=5.35 \mathrm{~Hz}), 3.79(3 \mathrm{H}, \mathrm{s}), 3.39(2 \mathrm{H}, \mathrm{td}$, $\mathrm{J}=5.79,4.06 \mathrm{~Hz}), 3.33(4 \mathrm{H}, \mathrm{m}), 2.76(4 \mathrm{H}, \mathrm{m}), 2.71(2 \mathrm{H}, \mathrm{t}, \mathrm{J}=5.20 \mathrm{~Hz}), 1.99(2 \mathrm{H}$, apparent $\mathrm{p}, \mathrm{J}=5.39 \mathrm{~Hz}$ ).

${ }^{13} \mathrm{C} \mathrm{NMR} \delta(\mathrm{ppm})\left(\mathrm{CHCl}_{3}-\mathrm{d}\right): 154.1,151.4,149.9,146.9,145.5,131.5,130.0,129.6$, $119.9,119.8,118.8,114.4,98.7,59.2,55.6,54.0,50.7,44.7,23.4$.

MS (ESI): $m / z$ 411.19454 M + H (calculated 411.19462)

HPLC (method A) $t_{\mathrm{R}}=8.51 \min (69 \%$ pure $)$.

\section{A.1.2: 8-chloroquinolines}

3-carbethoxy-8-chloro-4-quinolone (Price, 1946; Tarbell, 1946)<smiles>CCOC(=O)c1c[nH]c2c(Cl)cccc2c1=O</smiles>

ortho-Chloroaniline $(5.35 \mathrm{~mL}, 51.2 \mathrm{mmol})$ and diethyl ethoxymethylene malonate $(10.1$ $\mathrm{mL}, 50.3 \mathrm{mmol})$ were heated in refluxing Dowtherm A $(70 \mathrm{~mL})$ for 30 minutes. After cooling, the reaction mixture was diluted with hexanes $(150 \mathrm{~mL})$ and vacuum filtered, rinsing with further hexanes $(200 \mathrm{~mL})$, followed by acetone $(100 \mathrm{~mL})$. The product was obtained as a beige, powdery solid (11.32 g, 89\%).

${ }^{1} \mathrm{H}$ NMR $\delta(\mathrm{ppm})\left(\mathrm{DMSO}_{\mathrm{d}}\right): 11.91(1 \mathrm{H}, \mathrm{br} \mathrm{s}), 8.43(1 \mathrm{H}, \mathrm{s}), 8.14(1 \mathrm{H}, \mathrm{dd}, \mathrm{J}=8.10$, $1.38 \mathrm{~Hz}), 7.91(1 \mathrm{H}, \mathrm{dd}, \mathrm{J}=7.72,1.38 \mathrm{~Hz}), 7.43(1 \mathrm{H}, \mathrm{t}, \mathrm{J}=7.92 \mathrm{~Hz}), 4.24(2 \mathrm{H}, \mathrm{q}, \mathrm{J}=$ $7.10 \mathrm{~Hz}), 1.29(3 \mathrm{H}, \mathrm{t}, \mathrm{J}=7.10 \mathrm{~Hz})$ 
<smiles>O=C(O)c1c[nH]c2c(Cl)cccc2c1=O</smiles>

3-carbethoxy-8-chloro-4-quinolone (11.32 g, $45.0 \mathrm{mmol})$ was heated at reflux in $200 \mathrm{~mL}$ of $10 \%$ caustic soda for 1 hour. The hot reaction mixture was poured into $300 \mathrm{~mL}$ water, then made acidic by the addition of concentrated muriatic acid. After cooling, vacuum filtration yielded a white solid. This was allowed to air dry for 48 hours followed by drying in a vacuum oven at $50^{\circ} \mathrm{C}$ for 5 hours. The resulting cream-colored solid $(10.40$ $\mathrm{g}$, containing residual water) was used without further drying in the ensuing reaction.

${ }^{1} \mathrm{H}$ NMR $\delta(\mathrm{ppm})\left(\mathrm{DMSO}_{\mathrm{d}}\right): 14.88$ (1 H, br s), 13.00 (1 H, br s), 8.67 (1 H, s), 8.28 (1 $\mathrm{H}, \mathrm{dd}, \mathrm{J}=8.18,1.34 \mathrm{~Hz}), 8.10(1 \mathrm{H}, \mathrm{dd}, \mathrm{J}=7.74,1.35 \mathrm{~Hz}), 7.61(1 \mathrm{H}, \mathrm{dd}, \mathrm{J}=8.17,7.74$ $\mathrm{Hz}$.

8-chloro-4-quinolone (Price, 1946; Tarbell, 1946):<smiles>O=c1cc[nH]c2c(Cl)cccc12</smiles>

3-carboxy-8-chloro-4-quinolone from the above reaction (10.40 g, containing residual water) was heated in Dowtherm A $(50 \mathrm{~mL})$ at reflux for 40 minutes. After cooling, the reaction mixture was diluted with $100 \mathrm{~mL}$ hexanes and allowed to sit for 48 hours, followed by vacuum filtration, rinsing with further hexanes $(200 \mathrm{~mL})$ followed by a mixture of acetone and hexanes $(1: 1,50 \mathrm{~mL})$. This gave a beige solid $(8.27 \mathrm{~g}$, used without further purification in the following reaction).

${ }^{1} \mathrm{H}$ NMR $\delta(\mathrm{ppm})\left(\mathrm{DMSO}_{\mathrm{d}}\right): 11.39(1 \mathrm{H}, \mathrm{s}), 8.07(1 \mathrm{H}, \mathrm{dd}, \mathrm{J}=8.10,1.39 \mathrm{~Hz}), 7.85-7.85$ $(2 \mathrm{H}, \mathrm{m}), 7.33(1 \mathrm{H}, \mathrm{t}, \mathrm{J}=7.88 \mathrm{~Hz}), 6.13(1 \mathrm{H}, \mathrm{dd}, \mathrm{J}=7.49,1.00 \mathrm{~Hz})$. 
4,8-dichloroquinoline (Price, 1946; Tarbell, 1946; Riegel, 1946):<smiles>Clc1ccnc2c(Cl)cccc12</smiles>

8-chloro-4-quinolone from the above reaction $(7.27 \mathrm{~g}$, no more than $40 \mathrm{mmol})$ and 20.0 $\mathrm{mL}$ phosphorus oxychloride $(220 \mathrm{mmol})$ were heated at $70^{\circ} \mathrm{C}$ for 2.5 hours, followed by heating at $110^{\circ} \mathrm{C}$ for 1 hour. After cooling, the reaction mixture was poured cautiously into ice water $(300 \mathrm{~mL})$, stirring vigorously. After 30 minutes, the aqueous mixture was made basic to litmus by the addition of concentrated sodium hydroxide. After cooling, this mixture was diluted to $2 \mathrm{~L}$ and divided into two portions. Each portion was extracted with chloroform ( $100 \mathrm{~mL}$ followed by $3 \times 15 \mathrm{~mL})$, and the pooled organic layers from both extractions were dried $\left(\mathrm{MgSO}_{4}\right)$ and evaporated under reduced pressure with warming to yield a pale beige solid $(6.83 \mathrm{~g}, 67 \%$ from ortho-chloroaniline, $\mathrm{mp}=159.1$ $160.1^{\circ} \mathrm{C}$ (lit. $155-6^{\circ} \mathrm{C}$ (Tarbell, 1946)).

\section{3-(8-chloroquinolin-4-ylamino)propanol}<smiles>OCCCNc1ccnc2c(Cl)cccc12</smiles>

4,8-dichloroquinoline (3.00 g, $15 \mathrm{mmol})$ and 3-amino-1-propanol (5.95 mL, $7.8 \mathrm{mmol})$ were heated in a $10 \mathrm{~mL}$ Biotage microwave vial at $130^{\circ} \mathrm{C}$ for 15 minutes, whereupon TLC indicated that some starting material remained; heating at $130^{\circ} \mathrm{C}$ was continued for an additional 15 minutes. The hot reaction mixture was then poured into water $(100 \mathrm{~mL})$ with good stirring. After standing 18 hours, the solid product was recovered by vacuum filtration, followed by recrystallization from a mixture of ethyl acetate and $95 \%$ ethanol (55 mL, approximately 10:1). The desired product was isolated as gleaming, beige, crystalline flakes $\left(2.35 \mathrm{~g}, 66 \%, \mathrm{mp}=155.0-155.7^{\circ} \mathrm{C}\right)$.

${ }^{1} \mathrm{H}$ NMR $\delta(\mathrm{ppm})\left(\right.$ DMSO-d $\left._{6}\right): 8.47(1 \mathrm{H}, \mathrm{d}, \mathrm{J}=5.35 \mathrm{~Hz}), 8.19(1 \mathrm{H}, \mathrm{dd}, \mathrm{J}=8.51,1.28$ $\mathrm{Hz}), 7.79(1 \mathrm{H}, \mathrm{dd}, \mathrm{J}=7.44,1.20 \mathrm{~Hz}), 7.37(1 \mathrm{H}, \mathrm{dd}, \mathrm{J}=8.45,7.44 \mathrm{~Hz}), 7.32(1 \mathrm{H}, \mathrm{br} \mathrm{t}, \mathrm{J}$ $=5.38 \mathrm{~Hz}), 6.55(1 \mathrm{H}, \mathrm{d}, \mathrm{J}=5.41 \mathrm{~Hz}), 4.61(1 \mathrm{H}, \mathrm{t}, \mathrm{J}=5.07 \mathrm{~Hz}), 3.55(2 \mathrm{H}, \mathrm{m}), 3.34-3.35$ (water signal overlaps $\mathrm{m}, \sim 2 \mathrm{H}), 1.80-1.85(2 \mathrm{H}, \mathrm{m})$. 
${ }^{1} \mathrm{H}$ NMR $\delta(\mathrm{ppm})\left(\mathrm{CHCl}_{3}\right.$-d): $8.65(1 \mathrm{H}, \mathrm{d}, \mathrm{J}=5.34 \mathrm{~Hz}), 7.75(1 \mathrm{H}, \mathrm{dd}, \mathrm{J}=7.47,1.24 \mathrm{~Hz})$, $7.65(1 \mathrm{H}, \mathrm{dd}, \mathrm{J}=8.46,1.25 \mathrm{~Hz}), 7.30(1 \mathrm{H}, \mathrm{dd}, \mathrm{J}=8.44,7.48 \mathrm{~Hz}), 6.45(1 \mathrm{H}, \mathrm{d}, \mathrm{J}=5.37$ $\mathrm{Hz}), 6.03(1 \mathrm{H}$, br t, J = 4.71 Hz), 3.97 (2 H, t, J = 5.41 Hz), 3.48 (2 H, m), 2.04-2.06 (2 $\mathrm{H}, \mathrm{m})$.

\section{3-(8-chloroquinolin-4-ylamino)propyl methanesulfonate}<smiles>COCCCNc1ccnc2c(Cl)cccc12</smiles>

3-(8-chloroquinolin-4-ylamino)propanol (1.00 g, $42 \mathrm{mmol})$ and triethylamine $(0.88 \mathrm{~mL}$, $63 \mathrm{mmol})$ in dry THF $(100 \mathrm{~mL})$ were cooled to below $0^{\circ} \mathrm{C}$ on ice/salt. Methanesulfonyl chloride $(0.38 \mathrm{~mL}, 49 \mathrm{mmol})$ was added dropwise. After stirring for 1 hour on ice, reaction appeared complete by TLC; however, additional methanesulfonyl chloride $(0.11$ $\mathrm{mL}, 0.65 \mathrm{mmol}$ ) was added and stirring was continued for a further 30 minutes. The reaction mixture was then diluted with ethyl acetate $(30 \mathrm{~mL})$ and washed with saturated sodium bicarbonate $(25 \mathrm{~mL})$; after separating, the aqueous layer was extracted with ethyl acetate $(3 \times 7 \mathrm{~mL})$. The pooled organic layers were rinsed with brine $(10 \mathrm{~mL})$, dried $\left(\mathrm{MgSO}_{4}\right)$ and evaporated under reduced pressure with warming to give the desired product as a pale yellow, waxy solid (0.72 $\mathrm{g}, 54 \%)$.

${ }^{1} \mathrm{H}$ NMR $\delta(\mathrm{ppm})\left(\mathrm{CHCl}_{3}-\mathrm{d}\right): 8.66(1 \mathrm{H}, \mathrm{d}, \mathrm{J}=5.20 \mathrm{~Hz}), 7.73-7.80(1 \mathrm{H}, \mathrm{m}), 7.36(1 \mathrm{H}, \mathrm{t}$, $\mathrm{J}=8.01 \mathrm{~Hz}), 6.49(1 \mathrm{H}, \mathrm{d}, \mathrm{J}=5.12 \mathrm{~Hz}), 4.42(2 \mathrm{H}, \mathrm{t}, \mathrm{J}=5.64 \mathrm{~Hz}), 3.59(2 \mathrm{H}, \mathrm{m}), 3.06$ (3 $\mathrm{H}, \mathrm{s}), 2.19-2.20$ (2 H, m).

${ }^{1} \mathrm{H}$ NMR $\delta(\mathrm{ppm})\left(\mathrm{DMSO}_{-} \mathrm{d}_{6}\right): 8.48(1 \mathrm{H}, \mathrm{d}, \mathrm{J}=5.78 \mathrm{~Hz}), 8.29(1 \mathrm{H}, \mathrm{d}, \mathrm{J}=8.52 \mathrm{~Hz}), 7.87-$ $7.90(2 \mathrm{H}, \mathrm{m}), 7.47(1 \mathrm{H}, \mathrm{t}, \mathrm{J}=8.00 \mathrm{~Hz}), 6.68(1 \mathrm{H}, \mathrm{d}, \mathrm{J}=5.85 \mathrm{~Hz}), 4.36(2 \mathrm{H}, \mathrm{t}, \mathrm{J}=6.16$ $\mathrm{Hz}), 3.47$ (3 H, m), 2.10-2.11 (2 H, m). 


\section{PL271: N-(3-(4-benzhydrylpiperazin-1-yl)propyl)-8-chloroquinolin-4-amine}

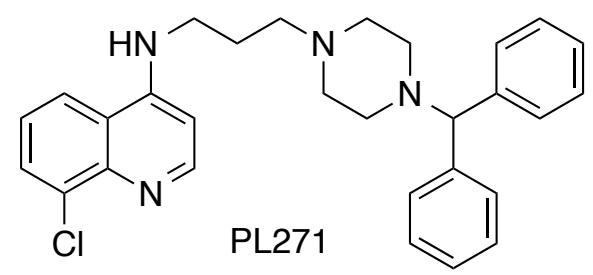

3-(8-chloroquinolin-4-ylamino)propyl methanesulfonate (0.68 g, $2.2 \mathrm{mmol}), \mathrm{N}$ (diphenylmethyl)piperazine $(0.56 \mathrm{~g}, 2.2 \mathrm{mmol})$, potassium carbonate $(0.47 \mathrm{~g}, 3.4 \mathrm{mmol})$, and a catalytic amount of potassium iodide were heated at reflux in acetonitrile $(50 \mathrm{~mL})$ for 20 hours. TLC then indicated that reaction was complete. The reaction mixture was diluted with $5 \mathrm{~mL}$ water, and the solvent was removed by evaporation under reduced pressure with warming. The residue thus obtained was partitioned between chloroform $(35 \mathrm{~mL})$ and water $(50 \mathrm{~mL})$. After separation, the aqueous layer was extracted with chloroform $(3 \times 7 \mathrm{~mL})$. The pooled organic layers were dried $\left(\mathrm{MgSO}_{4}\right)$ and concentrated under reduced pressure with warming, and the resulting pale yellow solid was boiled in $50 \mathrm{~mL} \mathrm{95 \%} \mathrm{ethanol;} \mathrm{the} \mathrm{clear,} \mathrm{yellow} \mathrm{supernatent} \mathrm{was} \mathrm{decanted} \mathrm{from} \mathrm{a} \mathrm{small} \mathrm{amount} \mathrm{of}$ insoluble material. After cooling and crystallization, the desired product was isolated by vacuum filtration (a shimmering, white, crystalline solid, $0.43 \mathrm{~g}, 42 \%, \mathrm{mp}=206-208^{\circ} \mathrm{C}$ ).

${ }^{1} \mathrm{H}$ NMR $\delta(\mathrm{ppm})\left(\mathrm{CHCl}_{3}-\mathrm{d}\right): 8.62(1 \mathrm{H}, \mathrm{d}, \mathrm{J}=5.30 \mathrm{~Hz}, \mathrm{Q}-\mathrm{C} 2-\mathrm{H}), 7.83(1 \mathrm{H}, \mathrm{dd}, \mathrm{J}=8.42$, $1.29 \mathrm{~Hz}, \mathrm{Q}-\mathrm{C} 7-\mathrm{H}$ or Q-C5-H, probably C7), $7.76(1 \mathrm{H}, \mathrm{dd}, \mathrm{J}=7.40,1.21 \mathrm{~Hz}$, Q-C5-H or Q-C7-H, probably C5), $7.64(1 \mathrm{H}$, br t, J = 4.00 Hz, Q-N-H), 7.42-7.46 (4 H, m, Ph-H x 4, ortho), 7.27-7.33 (4 H, m, Ph-H x 4, meta), 7.21-7.22 (2 H, m, Ph-H x 2, para), 7.17 (1 H, dd, 8.40, 7.40 Hz, Q-C6-H), 6.36 (1 H, d, J = 5.34 Hz, Q-C3-H), 4.36 (1 H, s, $\left.\mathrm{CH}(\mathrm{Ph})_{2}\right), 3.36\left(2 \mathrm{H}, \mathrm{td}, \mathrm{J}=5.80,4.01 \mathrm{~Hz}, \mathrm{Q}-\mathrm{NHCH}_{2} \mathrm{CH}_{2} \mathrm{CH}_{2}\right), 2.64(10 \mathrm{H}$, br s overlaps $\mathrm{t}, \mathrm{J}=5.41 \mathrm{~Hz}, \mathrm{CH}_{2} \times 4$ (piperazine) and Q- $\left.\mathrm{NHCH}_{2} \mathrm{CH}_{2} \mathrm{CH}_{2}\right), 1.93$ (2 H, apparent p, J = $\left.5.41 \mathrm{~Hz}, \mathrm{Q}-\mathrm{NHCH}_{2} \mathrm{CH}_{2} \mathrm{CH}_{2}\right)$.

${ }^{13} \mathrm{C}$ NMR $\delta(\mathrm{ppm})\left(\mathrm{CHCl}_{3}-\mathrm{d}\right): 151.7$ (Q-C2), 150.9 (Q-C, possibly Q-C4 (HMBC to $\left.\mathrm{QNHCH}_{2}\right)$ ), 144.9 (Q-C), 142.2 (Ph-C, ipso), 133.7 (Q-C), 129.1 (Q-C5 or possibly C7, 7.76), 128.6 (Ph-C, meta), 128.1 (Ph-C, ortho), 127.1 (Ph-C, para), 123.5 (Q-C6), 120.4 (Q-C7 or possibly C5, 7.83), $120.1(\mathrm{Q}-\mathrm{C}), 98.9(\mathrm{Q}-\mathrm{C} 3), 76.4\left(\mathrm{CH}(\mathrm{Ph})_{2}\right), 58.8(\mathrm{Q}-$ $\left.\mathrm{NHCH}_{2} \mathrm{CH}_{2} \mathrm{CH}_{2}\right), 53.9\left(\mathrm{CH}_{2} \times 2\right.$, piperazine), $51.8\left(\mathrm{CH}_{2} \times 2\right.$, piperazine), $44.6(\mathrm{Q}-$ $\mathrm{NHCH}_{2} \mathrm{CH}_{2} \mathrm{CH}_{2}$ ), 23.4 (Q- $\mathrm{NHCH}_{2} \mathrm{CH}_{2} \mathrm{CH}_{2}$ ).

MS (ESI): $m / z 471.2300 \mathrm{M}+\mathrm{H}$ (calculated 471.2310).

HPLC (method C) $t_{\mathrm{R}}=10.93 \min (98 \%$ pure $)$. 


\section{PL284: 8-chloro-N-(3-(4-(pyridin-2-yl)piperazin-1-yl)propyl)quinolin-4-amine}<smiles>CC(C)(C)OC(=O)c1cccc(NCCCN2CCN(c3ccccn3)CC2)c1</smiles>

3-(8-chloroquinolin-4-ylamino)propyl methanesulfonate (1.65 g, $5.2 \mathrm{mmol}), 1$-(2pyridyl)piperazine $(0.85 \mathrm{~g}, 5.2 \mathrm{mmol})$, and potassium carbonate $(1.09 \mathrm{~g}, 7.9 \mathrm{mmol})$ in acetonitrile $(15 \mathrm{~mL})$ were allowed to reflux for 3 days. Precipitation was evident, and so the reaction mixture was vacuum filtered, rinsing extensively with water, and then with 1 $\mathrm{mL} 95 \%$ ethanol. The resulting cream-colored, sparkling solid proved to be the desired product $\left(0.49 \mathrm{~g}, 25 \%, \mathrm{mp}=164.5-165.7^{\circ} \mathrm{C}\right)$.

${ }^{1} \mathrm{H}$ NMR $\delta(\mathrm{ppm})\left(\mathrm{CHCl}_{3}-\mathrm{d}\right): 8.65(1 \mathrm{H}, \mathrm{d}, \mathrm{J}=5.34 \mathrm{~Hz}), 8.23-8.25(1 \mathrm{H}, \mathrm{m}), 7.80(1 \mathrm{H}$, $\mathrm{dd}, \mathrm{J}=8.44,1.30 \mathrm{~Hz}), 7.69(1 \mathrm{H}, \mathrm{dd}, \mathrm{J}=7.46,1.25 \mathrm{~Hz}), 7.51-7.55(1 \mathrm{H}, \mathrm{m}), 7.39(1 \mathrm{H}, \mathrm{br}$ $\mathrm{t}, \mathrm{J}=4.22 \mathrm{~Hz}), 7.17(1 \mathrm{H}, \mathrm{dd}, \mathrm{J}=8.42,7.46 \mathrm{~Hz}), 6.67-6.68(2 \mathrm{H}, \mathrm{m}), 6.41(1 \mathrm{H}, \mathrm{d}, \mathrm{J}=$ $5.38 \mathrm{~Hz}), 3.65-3.70(4 \mathrm{H}, \mathrm{m}), 3.41(2 \mathrm{H}, \mathrm{td}, \mathrm{J}=5.95,4.20 \mathrm{~Hz}), 2.65-2.70(6 \mathrm{H}, \mathrm{m}), 2.00$ $(2 \mathrm{H}$, apparent $\mathrm{p}, \mathrm{J}=5.59 \mathrm{~Hz})$.

${ }^{13} \mathrm{C} \mathrm{NMR} \delta(\mathrm{ppm})\left(\mathrm{CHCl}_{3}-\mathrm{d}\right): 159.4,151.7,150.8,148.1,145.0,137.7,133.8,129.2$, 123.7, 120.4, 119.5, 113.8, 107.1, 99.1, 58.7, 53.5, 45.3, 44.4, 23.7.

MS (ESI): $m / z$ 382.18024 M + H (calculated 382.17930)

HPLC (method A) $t_{\mathrm{R}}=3.68 \min (97 \%$ pure $)$.

\section{A.1.3: 5,7-dichloroquinolines}

3-carbethoxy-5,7-dichloro-4-quinolone (Price, 1946; Surrey, 1946)<smiles>CCOC(=O)c1c[nH]c2cc(Cl)cc(Cl)c2c1=O</smiles> 
3,5-dichloroaniline $(8.11 \mathrm{~g}, 50.1 \mathrm{mmol})$ and diethyl ethoxymethylene malonate (10.04 $\mathrm{mL}, 50.1 \mathrm{mmol})$ were heated in refluxing Dowtherm A $(65 \mathrm{~mL})$ for 30 minutes. After cooling, the reaction mixture was diluted with hexanes $(100 \mathrm{~mL})$ and vacuum filtered, rinsing with hexanes $(300 \mathrm{~mL})$ and acetone $(75 \mathrm{~mL})$, to recover the product as a sparkling, pearly white solid (11.42 g, 80\% yield).

3-carboxy-5,7-dichloro-4-quinolone (Price, 1946; Surrey, 1946)<smiles>O=C(O)c1c[nH]c2cc(Cl)cc(Cl)c2c1=O</smiles>

3-carbethoxy-5,7-dichloro-4-quinolone (11.37 g, $39.7 \mathrm{mmol})$ in $500 \mathrm{~mL}$ of $10 \%$ caustic soda was allowed to reflux, stirring, for 6 days, at which point solid was still present. The orange reaction mixture was decanted from the reaction solids and made acidic by the addition of concentrated muriatic acid. Further $10 \%$ caustic soda was added to the reaction flask and reflux was continued for an additional 24 hours, whereupon it was found that all solid material had dissolved; this too was poured into $100 \mathrm{~mL}$ water and made acidic by the addition of concentrated muriatic acid. The two acidified reaction mixtures were combined and filtered. The resulting pale pink solid was allowed to air dry, and was used in the ensuing reaction without further purification $(21.23 \mathrm{~g}$, containing residual water). NMR indicated that this contained some decarboxylated material, approximately $13 \%$ of the total quinolone content.

${ }^{1} \mathrm{H}$ NMR $\delta(\mathrm{ppm})($ DMSO-d 6$)$ : Major peaks: $15.06(1 \mathrm{H}, \mathrm{s}), 8.93(1 \mathrm{H}, \mathrm{s}), 7.80(1 \mathrm{H}, \mathrm{d}, \mathrm{J}=$ $2.06 \mathrm{~Hz}), 7.74(1 \mathrm{H}, \mathrm{d}, \mathrm{J}=2.04 \mathrm{~Hz})$.

5,7-dichloro-4-quinolone (Price, 1946; Surrey, 1946)<smiles>O=c1cc[nH]c2cc(Cl)cc(Cl)c12</smiles>

3-carboxy-5,7-dichloro-4-quinolone from the above reaction (containing residual water as well as some decarboxylated material) was heated in Dowtherm $\mathrm{A}(80 \mathrm{~mL})$ at $255^{\circ} \mathrm{C}$ 
for 40 minutes. After cooling, the reaction mixture was diluted with $75 \mathrm{~mL}$ hexanes and vacuum filtered, rinsing with $150 \mathrm{~mL}$ additional hexanes; the resulting solid was then boiled in $50 \mathrm{~mL}$ hexanes for 1 hour. After standing overnight, vacuum filtration of this mixture afforded the desired product as a faintly pink, powdery solid $(8.01 \mathrm{~g})$.

${ }^{1} \mathrm{H}$ NMR $\delta(\mathrm{ppm})\left(\right.$ DMSO-d $\left._{6}\right): 7.85(1 \mathrm{H}, \mathrm{dd}, \mathrm{J}=7.50,5.67 \mathrm{~Hz}), 7.52(1 \mathrm{H}, \mathrm{d}, \mathrm{J}=2.07$ $\mathrm{Hz}), 7.36(1 \mathrm{H}, \mathrm{d}, \mathrm{J}=2.06 \mathrm{~Hz}), 6.01(1 \mathrm{H}, \mathrm{d}, \mathrm{J}=7.44 \mathrm{~Hz})$.

4,5,7-trichloroquinoline (Price, 1946; Surrey, 1946)<smiles>Clc1cc(Cl)c2c(Cl)ccnc2c1</smiles>

Phosphorous oxychloride ( $20.6 \mathrm{~mL}, 221 \mathrm{mmol}$ ) was cautiously added to 5,7-dichloro-4quinolone from the above reaction $(8.01 \mathrm{~g}, 37.4 \mathrm{mmol})$, followed by heating at reflux for 21 hours. After cooling, the reaction mixture was poured gradually onto ice, then gradually made basic to litmus with solid caustic potash. This was diluted with water to $1 \mathrm{~L}$ and combined with $50 \mathrm{~mL}$ chloroform. Some material remained undissolved, and was recovered by vacuum filtration; the filtrate was separated, and the aqueous layer was extracted with chloroform $(5 \times 15 \mathrm{~mL})$. The pooled chloroform layers from all extractions were combined, dried $\left(\mathrm{MgSO}_{4}\right)$ and evaporated under reduced pressure with warming to yield a caramel-colored, crystalline solid. NMR indicated that this was the desired 4,5,7-trichloroquinoline $\left(1.26 \mathrm{~g}, 15 \%, \mathrm{mp}=107.0-109.0^{\circ} \mathrm{C}\right.$ (lit. $105-6^{\circ} \mathrm{C}$ (Surrey, 1946)). NMR indicated that the solid recovered from filtration (7.59 g) also contained the desired quinoline, together with approximately $10 \%$ of unreacted 5,7-dichloro-4quinolone starting material.

${ }^{1} \mathrm{H} \mathrm{NMR} \delta(\mathrm{ppm})\left(\mathrm{CHCl}_{3}-\mathrm{d}\right): 8.72(1 \mathrm{H}, \mathrm{d}, \mathrm{J}=4.69 \mathrm{~Hz}), 8.06(1 \mathrm{H}, \mathrm{d}, \mathrm{J}=2.21 \mathrm{~Hz}), 7.66$ $(1 \mathrm{H}, \mathrm{d}, \mathrm{J}=2.21 \mathrm{~Hz}), 7.51(1 \mathrm{H}, \mathrm{d}, \mathrm{J}=4.68 \mathrm{~Hz})$.

${ }^{1} \mathrm{H}$ NMR $\delta(\mathrm{ppm})\left(\mathrm{DMSO}-\mathrm{d}_{6}\right): 8.87(1 \mathrm{H}, \mathrm{d}, \mathrm{J}=4.71 \mathrm{~Hz}), 8.19(1 \mathrm{H}, \mathrm{d}, \mathrm{J}=2.23 \mathrm{~Hz}), 7.99$ $(1 \mathrm{H}, \mathrm{d}, \mathrm{J}=2.23 \mathrm{~Hz}), 7.83(1 \mathrm{H}, \mathrm{d}, \mathrm{J}=4.72 \mathrm{~Hz})$. 


\section{3-(5,7-dichloroquinolin-4-ylamino)propanol}<smiles>OCCCNc1ccnc2cc(Cl)cc(Cl)c12</smiles>

4,5,7-trichloroquinoline (3.01 g, $12.9 \mathrm{mmol})$ and 3-amino-1-propanol (5.93 mL, 77.5 mmol) were heated in a Carius vessel at $90^{\circ} \mathrm{C}$ for 3 hours. TLC then indicated that reaction was complete. The hot reaction mixture was poured into $100 \mathrm{~mL}$ water, with vigorous stirring. After standing overnight, the resulting solid was recovered by vacuum filtration, followed by air-drying $\left(2.01 \mathrm{~g}, 59 \%, \mathrm{mp}=119.3-120.1^{\circ} \mathrm{C}\right)$.

${ }^{1} \mathrm{H}$ NMR $\delta(\mathrm{ppm})\left(\mathrm{DMSO}_{-}\right): 8.41(1 \mathrm{H}, \mathrm{d}, \mathrm{J}=5.53 \mathrm{~Hz}), 7.78(1 \mathrm{H}, \mathrm{d}, \mathrm{J}=2.30 \mathrm{~Hz}), 7.56$ $(1 \mathrm{H}$, br t, J = 2.32 Hz), $6.56(1 \mathrm{H}, \mathrm{d}, \mathrm{J}=5.59 \mathrm{~Hz}), 4.77(1 \mathrm{H}, \mathrm{t}, \mathrm{J}=4.91 \mathrm{~Hz}), 3.59(2 \mathrm{H}$, $\mathrm{m}$ ), 3.32-3.37 (water signal overlaps $\mathrm{m}, \sim 2 \mathrm{H}), 1.80-1.87(2 \mathrm{H}, \mathrm{m})$.

\section{3-(5,7-dichloroquinolin-4-ylamino)propyl methanesulfonate}<smiles>COCCCNc1ccnc2cc(Cl)cc(Cl)c12</smiles>

3-(5,7-dichloroquinolin-4-ylamino)propanol (2.00 g, $7.41 \mathrm{mmol})$ and triethylamine (1.5 $\mathrm{mL}, 11 \mathrm{mmol})$ in dry THF $(100 \mathrm{~mL})$ were cooled to below $0^{\circ} \mathrm{C}$ on ice/salt.

Methanesulfonyl chloride $(0.66 \mathrm{~mL}, 8.5 \mathrm{mmol})$ was added dropwise. After stirring for 30 minutes, TLC indicated that reaction was complete. The reaction mixture was diluted with ethyl acetate $(30 \mathrm{~mL})$ and washed with $100 \mathrm{~mL}$ saturated sodium bicarbonate. The aqueous layer was extracted with ethyl acetate $(3 \times 10 \mathrm{~mL})$, and the pooled organic layers were dried $\left(\mathrm{MgSO}_{4}\right)$ and evaporated under reduced pressure with warming to give the desired product as a pale yellow solid $(2.65 \mathrm{~g}$, containing residual solvent and triethylamine). This material was used without purification in the ensuing reactions. 
PL379: N-(3-(4-benzhydrylpiperazin-1-yl)propyl)-5,7-dichloroquinolin-4-amine<smiles>Clc1cc(Cl)c2c(NCCCN3CCN(C(c4ccccc4)c4ccccc4)CC3)ccnc2c1</smiles>

3-(5,7-dichloroquinolin-4-ylamino)propyl methanesulfonate ( $0.52 \mathrm{~g}$ crude material from the above reaction, no more than $1.5 \mathrm{mmol}), \mathrm{N}$-(diphenylmethyl)piperazine $(0.39 \mathrm{~g}, 1.5$ $\mathrm{mmol})$, potassium carbonate $(0.31 \mathrm{~g}, 2.2 \mathrm{mmol})$, and a catalytic amount of potassium iodide were heated at reflux in acetonitrile $(24 \mathrm{~mL})$ for 24 hours, whereupon TLC indicated that reaction was complete. The solvent was removed under reduced pressure with warming, and the residue was partitioned between chloroform $(60 \mathrm{~mL})$ and water $(40 \mathrm{~mL})$. After separation, the aqueous layer was extracted with chloroform $(3 \times 15 \mathrm{~mL})$, dried $\left(\mathrm{MgSO}_{4}\right)$ and evaporated under reduced pressure with warming. The residue was recrystallized from $15 \mathrm{~mL}$ ethyl acetate to yield the desired product as pale golden crystals $(0.25 \mathrm{~g}, 34 \%$ from 3-(5,7-dichloroquinolin-4-ylamino)propanol, $\mathrm{mp}=125.4$ $\left.128.1^{\circ} \mathrm{C}\right)$.

${ }^{1} \mathrm{H}$ NMR $\delta(\mathrm{ppm})\left(\mathrm{CHCl}_{3}-\mathrm{d}\right): 8.41(1 \mathrm{H}, \mathrm{d}, \mathrm{J}=5.51 \mathrm{~Hz}), 7.83(1 \mathrm{H}, \mathrm{d}, \mathrm{J}=2.26 \mathrm{~Hz}), 7.39$ $7.43(5 \mathrm{H}, \mathrm{m}), 7.32(1 \mathrm{H}, \mathrm{d}, \mathrm{J}=2.26 \mathrm{~Hz}), 7.25-7.27$ (solvent signal overlaps $\mathrm{m}, \sim 4 \mathrm{H}$ ), 7.17-7.19 (2 H, m), $6.37(1 \mathrm{H}, \mathrm{d}, \mathrm{J}=5.56 \mathrm{~Hz}), 4.23(1 \mathrm{H}, \mathrm{s}), 3.29(2 \mathrm{H}, \mathrm{td}, \mathrm{J}=6.70,4.93$ $\mathrm{Hz}), 2.49(10 \mathrm{H}, \mathrm{m}), 1.90(2 \mathrm{H}$, apparent p, $\mathrm{J}=6.82 \mathrm{~Hz})$.

${ }^{13} \mathrm{C} \mathrm{NMR} \delta(\mathrm{ppm})\left(\mathrm{CHCl}_{3}\right.$-d): 151.8, 151.3, 151.0, 142.7, 133.4, 129.1, 128.8, 128.5, $128.0,127.1,127.0,114.9,100.1,76.3,56.2,53.7,51.9,42.1,25.5$.

MS (ESI): $m / z$ 505.19286 M + H (calculated 505.19203)

$\operatorname{HPLC}(\operatorname{method} \mathrm{A}) t_{\mathrm{R}}=10.75 \min (>99 \%$ pure $)$. 


\section{PL367: 5,7-dichloro- $N$-(3-(4-(pyridin-2-yl)piperazin-1-yl)propyl)quinolin-4-amine}<smiles>Clc1cc(Cl)c2c(NCCCN3CCN(c4ccccn4)CC3)ccnc2c1</smiles>

3-(5,7-dichloroquinolin-4-ylamino)propyl methanesulfonate (1.62 g, $4.64 \mathrm{mmol}), 1$-(2pyridyl)piperazine $(0.79 \mathrm{~g}, 4.8 \mathrm{mmol})$, potassium carbonate $(0.96 \mathrm{~g}, 6.9 \mathrm{mmol})$, and a catalytic amount of potassium iodide were heated at reflux in acetonitrile $(48 \mathrm{~mL})$ for 5 days. The solvent was then removed under reduced pressure with warming, and the residue was partitioned between chloroform $(60 \mathrm{~mL})$ and water $(40 \mathrm{~mL})$. After separation, the aqueous layer was extracted with chloroform $(3 \times 15 \mathrm{~mL})$, dried $\left(\mathrm{MgSO}_{4}\right)$ and evaporated under reduced pressure with warming. The residue was recrystallized by dissolution in excess boiling ethyl acetate, followed by concentration to $10 \mathrm{~mL}$ at room temperature. Filtration afforded the desired product as a cream colored solid. The mother liquor was further concentrated to yield a second crop of the same material (total yield $1.19 \mathrm{~g}$, 63\% from 3-(5,7-dichloroquinolin-4-ylamino)propanol, $\mathrm{mp}=101.5$ $\left.103.3^{\circ} \mathrm{C}\right)$.

${ }^{1} \mathrm{H}$ NMR $\delta(\mathrm{ppm})\left(\mathrm{CHCl}_{3}-\mathrm{d}\right): 8.44(1 \mathrm{H}, \mathrm{d}, \mathrm{J}=5.50 \mathrm{~Hz}), 8.20-8.20(1 \mathrm{H}, \mathrm{m}), 7.84(1 \mathrm{H}, \mathrm{d}$, $\mathrm{J}=2.25 \mathrm{~Hz}), 7.48(1 \mathrm{H}, \mathrm{ddd}, \mathrm{J}=8.57,7.12,2.01 \mathrm{~Hz}), 7.33(2 \mathrm{H}, \mathrm{br} \mathrm{d}, \mathrm{J}=2.30 \mathrm{~Hz}), 6.63-$ $6.65(2 \mathrm{H}, \mathrm{m}), 6.42(1 \mathrm{H}, \mathrm{d}, \mathrm{J}=5.55 \mathrm{~Hz}), 3.57(4 \mathrm{H}, \mathrm{m}), 3.31-3.41(2 \mathrm{H}, \mathrm{m}), 2.59(4 \mathrm{H}$, $\mathrm{m}), 2.56(2 \mathrm{H}, \mathrm{t}, \mathrm{J}=6.82 \mathrm{~Hz}), 1.98(2 \mathrm{H}$, apparent $\mathrm{p}, \mathrm{J}=6.79 \mathrm{~Hz})$.

${ }^{13} \mathrm{C} \mathrm{NMR} \delta(\mathrm{ppm})\left(\mathrm{CHCl}_{3}-\mathrm{d}\right): 159.5,151.9,151.3,151.0,148.0,137.5,133.5,129.1$, $128.8,127.2$, 114.9, 113.4, 107.1, 100.2, 56.2, 53.3, 45.2, 42.0, 25.5.

MS (ESI): $m / z$ 416.14101 M + H (calculated 416.14033)

$\operatorname{HPLC}(\operatorname{method} \mathrm{A}) t_{\mathrm{R}}=6.50 \min (99 \%$ pure $)$. 


\section{A.1.4: 6,7-dichloroquinolines}

3-carbethoxy-6,7-dichloro-4-quinolone (Price, 1946; Surrey, 1946)<smiles>CCOC(=O)c1c[nH]c2cc(Cl)c(Cl)cc2c1=O</smiles>

3,4-dichloroaniline $(6.00 \mathrm{~g}, 37.0 \mathrm{mmol})$ and diethyl ethoxymethylene malonate $(7.42 \mathrm{~mL}$, $37.0 \mathrm{mmol})$ were heated in refluxing Dowtherm A $(100 \mathrm{~mL})$ for 30 minutes. After cooling, the reaction mixture was diluted with hexanes $(200 \mathrm{~mL})$ and vacuum filtered to recover the solid product $(9.11 \mathrm{~g}, 86 \%$ yield $)$.

3-carboxy-6,7-dichloro-4-quinolone (Price, 1946; Surrey, 1946)<smiles>O=C(O)c1c[nH]c2cc(Cl)c(Cl)cc2c1=O</smiles>

3-carbethoxy-6,7-dichloro-4-quinolone $(9.11 \mathrm{~g}, 31.8 \mathrm{mmol})$ in $100 \mathrm{~mL}$ of $10 \%$ caustic soda was allowed to reflux, stirring, for 20 hours. Solid was still present, and additional $10 \%$ caustic soda $(400 \mathrm{~mL})$ was added. Reflux was continued for a further 20 hours, after which no solid remained in the reaction. The hot reaction mixture was poured into water $(200 \mathrm{~mL})$ and made acidic by the addition of concentrated $\mathrm{HCl}$. After resting overnight, the white precipitate was recovered by vacuum filtration and allowed to air dry. The resulting off-white powder appeared by NMR to contain the 6,7- and 5,6dichloro regioismers in a proportion of approximately 95:5. This material was used without further purification in the following reaction $(9.11 \mathrm{~g}$, also containing residual water).

${ }^{1} \mathrm{H}$ NMR $\delta(\mathrm{ppm})\left(\mathrm{DMSO}_{-} \mathrm{d}_{6}\right)$ : Major peaks: $8.76(1 \mathrm{H}, \mathrm{s}), 8.26(1 \mathrm{H}, \mathrm{s}), 7.90(1 \mathrm{H}, \mathrm{s})$. 
6,7-dichloro-4-quinolone (Price, 1946; Surrey, 1946)<smiles>O=c1cc[nH]c2cc(Cl)c(Cl)cc12</smiles>

3-carboxy-6,7-dichloro-4-quinolone from the above reaction $(9.11 \mathrm{~g}$, containing residual water) was heated in Dowtherm A $(100 \mathrm{~mL})$ at $255^{\circ} \mathrm{C}$ for 50 minutes. After cooling, the reaction mixture was diluted with $100 \mathrm{~mL}$ hexanes and vacuum filtered to yield a sawdust-colored solid $(8.16 \mathrm{~g})$. This material was used without further purification in the following reaction.

${ }^{1} \mathrm{H}$ NMR $\delta(\mathrm{ppm})\left(\right.$ DMSO-d $\left._{6}\right): 8.11(1 \mathrm{H}, \mathrm{s}), 7.90(1 \mathrm{H}, \mathrm{d}, \mathrm{J}=5.94 \mathrm{~Hz}), 7.60(1 \mathrm{H}, \mathrm{s}), 5.86$ $(1 \mathrm{H}, \mathrm{d}, \mathrm{J}=5.95 \mathrm{~Hz})$.

4,6,7-trichloroquinoline (Price, 1946; Surrey, 1946)<smiles>Clc1cc2nccc(Cl)c2cc1Cl</smiles>

Phosphorus oxychloride $(50 \mathrm{~mL}, 536 \mathrm{mmol})$ was added cautiously to 6,7-dichloro-4quinolone from the above reaction (12.43 $\mathrm{g}$ of crude material). This was equipped with stacked air condensers and allowed to heat, stirring, at $105^{\circ} \mathrm{C}$ for 24 hours. After cooling, the reaction mixture was poured gradually into $700 \mathrm{~mL}$ ice water and then cautiously basified with solid caustic soda. This was diluted to $2.3 \mathrm{~L}$ and combined with $400 \mathrm{~mL}$ chloroform. Some material remained undissolved, and was recovered by vacuum filtration; the remaining material was separated into three equal portions, each of which was treated in the following manner: after separation of the layers, the aqueous layer was extracted with chloroform $(3 \times 20 \mathrm{~mL})$. The pooled chloroform layers from all extractions were combined, dried $\left(\mathrm{MgSO}_{4}\right)$ and evaporated under reduced pressure with warming to yield a cream-colored solid. NMR indicated that this was the primarily the desired 4,6,7-trichloroquinoline, containing 5,6,7-trichloroquinoline in a proportion of approximately 1:6 (see below for spectrum). The desired compound was obtained by recrystallization from 1:1 chloroform:hexanes (4.48 g including 4 crops, $52 \%$ from 3,4dichloroaniline, beige crystals, $\mathrm{mp}=155.5-158.2^{\circ} \mathrm{C}$ (lit. $154-155^{\circ} \mathrm{C}$ (Surrey, 1946)). 
${ }^{1} \mathrm{H}$ NMR $\delta(\mathrm{ppm})\left(\mathrm{CHCl}_{3}-\mathrm{d}\right)$, prior to recrystallization, containing both regioisomers in a proportion of approximately 6:1: $8.79(6 \mathrm{H}, \mathrm{d}, \mathrm{J}=4.72 \mathrm{~Hz}), 8.72(1 \mathrm{H}, \mathrm{d}, \mathrm{J}=4.67 \mathrm{~Hz})$, $8.35(6 \mathrm{H}, \mathrm{s}), 8.26(6 \mathrm{H}, \mathrm{s}), 8.01(1 \mathrm{H}, \mathrm{d}, \mathrm{J}=9.06 \mathrm{~Hz}), 7.80(1 \mathrm{H}, \mathrm{d}, \mathrm{J}=9.06 \mathrm{~Hz}), 7.58$ (1 $\mathrm{H}, \mathrm{d}, \mathrm{J}=4.68 \mathrm{~Hz}), 7.51(6 \mathrm{H}, \mathrm{d}, \mathrm{J}=4.71 \mathrm{~Hz})$.

${ }^{1} \mathrm{H}$ NMR $\delta(\mathrm{ppm})\left(\mathrm{CHCl}_{3}-\mathrm{d}\right)$, after recrystallization: $8.78(1 \mathrm{H}, \mathrm{d}, \mathrm{J}=4.72 \mathrm{~Hz}), 8.34(1 \mathrm{H}$, s), $8.26(1 \mathrm{H}, \mathrm{s}), 7.51(1 \mathrm{H}, \mathrm{d}, \mathrm{J}=4.72 \mathrm{~Hz})$.

\section{3-(6,7-dichloroquinolin-4-ylamino)propanol (Method 1)}<smiles>NCCCO</smiles>

4,6,7-trichloroquinoline $(0.91 \mathrm{~g}, 3.9 \mathrm{mmol})$ and 3-amino-1-propanol (1.79 $\mathrm{mL}, 23.4$ mmol) were heated at $90^{\circ} \mathrm{C}$ for 3 days. The hot reaction mixture was then poured into $250 \mathrm{~mL}$ water, while stirring vigorously. After standing overnight, the resulting precipitate was recovered by vacuum filtration, followed by air drying and partial recrystallization from ethyl acetate $\left(0.62 \mathrm{~g}\right.$ of a beige solid, $\left.59 \%, \mathrm{mp}=220-222^{\circ} \mathrm{C}\right)$.

${ }^{1} \mathrm{H}$ NMR $\delta(\mathrm{ppm})\left(\mathrm{DMSO}_{-} \mathrm{d}_{6}\right): 8.61(1 \mathrm{H}, \mathrm{s}), 8.41(1 \mathrm{H}, \mathrm{d}, \mathrm{J}=5.44 \mathrm{~Hz}), 7.98(1 \mathrm{H}, \mathrm{s}), 7.36$ $(1 \mathrm{H}, \mathrm{s}), 6.51(1 \mathrm{H}, \mathrm{d}, \mathrm{J}=5.50 \mathrm{~Hz}), 4.57(1 \mathrm{H}, \mathrm{t}, \mathrm{J}=5.08 \mathrm{~Hz}), 3.54(2 \mathrm{H}, \mathrm{m}), 3.32$ (water signal overlaps $\mathrm{m}, \sim 2 \mathrm{H}), 1.81-1.82(2 \mathrm{H}, \mathrm{m})$.

${ }^{1} \mathrm{H}$ NMR $\delta(\mathrm{ppm})\left(\mathrm{CHCl}_{3}-\mathrm{d}\right): 8.52(1 \mathrm{H}, \mathrm{d}, \mathrm{J}=5.36 \mathrm{~Hz}), 8.07(1 \mathrm{H}, \mathrm{s}), 7.80(1 \mathrm{H}, \mathrm{s}), 6.41$ $(1 \mathrm{H}, \mathrm{d}, \mathrm{J}=5.39 \mathrm{~Hz}), 5.86(1 \mathrm{H}$, br s$), 3.98(2 \mathrm{H}, \mathrm{t}, \mathrm{J}=5.41 \mathrm{~Hz}), 3.48(2 \mathrm{H}, \mathrm{td}, \mathrm{J}=6.23$, $4.78 \mathrm{~Hz}), 2.06(2 \mathrm{H}$, apparent $\mathrm{p}, \mathrm{J}=2.98 \mathrm{~Hz})$.

\section{3-(6,7-dichloroquinolin-4-ylamino)propanol (Method 2)}<smiles>Clc1cc2nccc(Cl)c2cc1Cl</smiles><smiles>C[13CH3]</smiles><smiles>OCCCNc1ccnc2cc(Cl)c(Cl)cc12</smiles>

4,6,7-trichloroquinoline ( $0.25 \mathrm{~g}, 1.1 \mathrm{mmol})$ and 3-amino-1-propanol (1.00 mL, $13 \mathrm{mmol})$ were combined in a $0.5-2 \mathrm{~mL}$ Biotage microwave vial and heated at $130^{\circ} \mathrm{C}$ for 15 
minutes, whereupon TLC indicated that reaction was complete. The hot reaction mixture was poured into $50 \mathrm{~mL}$ water, while stirring vigorously. After standing 20 minutes, the resulting precipitate was recovered by vacuum filtration, followed by air drying to provide the desired product as a beige, powdery solid ( $0.26 \mathrm{~g}$ of a beige solid, $87 \%)$.

\section{3-(6,7-dichloroquinolin-4-ylamino)propyl methanesulfonate}<smiles>COCCCNc1ccnc2cc(Cl)c(Cl)cc12</smiles>

3-(6,7-dichloroquinolin-4-ylamino)propanol (0.62 g, $2.3 \mathrm{mmol})$ and triethylamine $(0.48$ $\mathrm{mL}, 3.4 \mathrm{mmol})$ in dry THF $(50 \mathrm{~mL})$ were cooled to below $0^{\circ} \mathrm{C}$ on ice/salt.

Methanesulfonyl chloride $(0.21 \mathrm{~mL}, 2.7 \mathrm{mmol})$ was added dropwise. After stirring for 1 hour on ice, TLC indicated that reaction was complete; nevertheless, additional methanesulfonyl chloride $(0.02 \mathrm{~mL}, 0.3 \mathrm{mmol})$ was added and stirring was continued for a further 15 hours. The reaction mixture was then washed with $100 \mathrm{~mL}$ saturated sodium bicarbonate. The aqueous layer was extracted with ethyl acetate $(3 \times 10 \mathrm{~mL})$, and the pooled organic layers were rinsed with $10 \mathrm{~mL}$ brine, then dried $\left(\mathrm{MgSO}_{4}\right)$ and evaporated under reduced pressure with warming to give the desired product as a tan solid $(0.71 \mathrm{~g}$, $87 \%)$.

${ }^{1} \mathrm{H}$ NMR $\delta(\mathrm{ppm})\left(\mathrm{DMSO}_{\mathrm{d}}\right): 8.61(1 \mathrm{H}, \mathrm{s}), 8.44(1 \mathrm{H}, \mathrm{d}, \mathrm{J}=5.45 \mathrm{~Hz}), 8.01(1 \mathrm{H}, \mathrm{s}), 7.43$ $(1 \mathrm{H}, \mathrm{s}), 6.55(1 \mathrm{H}, \mathrm{d}, \mathrm{J}=5.51 \mathrm{~Hz}), 4.35(2 \mathrm{H}, \mathrm{t}, \mathrm{J}=6.18 \mathrm{~Hz}), 3.41(2 \mathrm{H}, \mathrm{m}), 3.20(3 \mathrm{H}$, s), 2.07-2.08 (2 H, m).

\section{PL307: 6,7-dichloro- $N$-(3-(4-(pyridin-2-yl)piperazin-1-yl)propyl)quinolin-4-amine}<smiles>Clc1cc2nccc(NCCCN3CCN(c4ccccn4)CC3)c2cc1Br</smiles>

3-(6,7-dichloroquinolin-4-ylamino)propyl methanesulfonate (0.71 g, $2.0 \mathrm{mmol})$, 1-(2pyridyl)piperazine $(0.35 \mathrm{~g}, 2.1 \mathrm{mmol})$, potassium carbonate $(0.41 \mathrm{~g}, 3.0 \mathrm{mmol})$, and a catalytic amount of potassium iodide were heated in refluxing acetonitrile $(21 \mathrm{~mL})$ for 3 days. The solvent was removed under reduced pressure with warming, and the residue 
was partitioned between chloroform $(30 \mathrm{~mL})$ and water $(30 \mathrm{~mL})$. After separation, the aqueous layer was extracted with further chloroform $(3 \times 7 \mathrm{~mL})$, and the pooled organic layers were dried $\left(\mathrm{MgSO}_{4}\right)$ and evaporated under reduced pressure with warming to yield a brown solid. This was taken up in excess boiling 95\% ethanol and allowed to concentrate slowly at room temperature. The resulting amber crystals proved to be the desired product $\left(0.27 \mathrm{~g}, 33 \%, \mathrm{mp}=221-223^{\circ} \mathrm{C}\right)$.

${ }^{1} \mathrm{H}$ NMR $\delta(\mathrm{ppm})\left(\mathrm{CHCl}_{3}-\mathrm{d}\right): 8.49(1 \mathrm{H}, \mathrm{d}, \mathrm{J}=5.36 \mathrm{~Hz}), 8.23-8.23(1 \mathrm{H}, \mathrm{m}), 8.02(2 \mathrm{H}, \mathrm{d}$, $\mathrm{J}=11.61 \mathrm{~Hz}), 7.80(1 \mathrm{H}, \mathrm{t}, \mathrm{J}=3.94 \mathrm{~Hz}), 7.52(1 \mathrm{H}, \mathrm{ddd}, \mathrm{J}=8.53,7.17,2.02 \mathrm{~Hz}), 6.71(1$ $\mathrm{H}, \mathrm{d}, \mathrm{J}=8.54 \mathrm{~Hz}), 6.68(1 \mathrm{H}, \mathrm{dd}, \mathrm{J}=7.17,4.93 \mathrm{~Hz}), 6.31(1 \mathrm{H}, \mathrm{d}, \mathrm{J}=5.40 \mathrm{~Hz}), 3.77(4 \mathrm{H}$, $\mathrm{m}), 3.40(2 \mathrm{H}, \mathrm{td}, \mathrm{J}=5.36,0.01 \mathrm{~Hz}), 2.71-2.72(6 \mathrm{H}, \mathrm{m}), 1.96-2.01(2 \mathrm{H}, \mathrm{m})$.

${ }^{13} \mathrm{C} \mathrm{NMR} \delta(\mathrm{ppm})\left(\mathrm{CHCl}_{3}\right.$-d): 159.7, 152.4, 149.7, 148.0, 147.5, 137.6, 133.0, 133.0, $130.8,128.3,121.9,118.4,113.9,107.3,98.7,59.2,53.6,45.3,44.7,23.2$.

MS (ESI): $m / z$ 416.14087 M + H (calculated 416.14033)

$\operatorname{HPLC}(\operatorname{method} \mathrm{A}) t_{\mathrm{R}}=6.86 \min (>99 \%$ pure $)$.

\section{A.1.5: 7,8-dichloroquinolines}

3-carbethoxy-7,8-dichloro-4-quinolone (Price, 1946; Surrey, 1946)<smiles>CCOC(=O)c1c[nH]c2c(Cl)c(Cl)ccc2c1=O</smiles>

2,3-dichloroaniline $(25.85 \mathrm{~g}, 160 \mathrm{mmol})$ and diethyl ethoxymethylene malonate $(31.65$ $\mathrm{mL}, 160 \mathrm{mmol})$ were heated in refluxing Dowtherm A $(100 \mathrm{~mL})$ for 40 minutes. After cooling, the reaction mixture was diluted with $30-60^{\circ}$ petroleum æther $(150 \mathrm{~mL})$ and vacuum filtered, rinsing well with additional petroleum æether, to recover the product as an off-white solid (37.10 g, 81\% yield).

3-carboxy-7,8-dichloro-4-quinolone (Price, 1946; Surrey, 1946) 
<smiles>O=C(O)c1c[nH]c2c(Cl)c(Cl)ccc2c1=O</smiles>

3-carbethoxy-7.8-dichloro-4-quinolone (37.10 g, $130 \mathrm{mmol}$ ) in $400 \mathrm{~mL}$ of $10 \%$ caustic soda was allowed to reflux, stirring, for 20 hours. Solid was still present, and therefore $40 \mathrm{~mL} \mathrm{50 \%} \mathrm{caustic} \mathrm{soda} \mathrm{was} \mathrm{added} \mathrm{to} \mathrm{the} \mathrm{reaction,} \mathrm{followed} \mathrm{by} 200 \mathrm{~mL}$ water. Note: upon cooling somewhat, the reaction mixture solidified; upon returning to reflux, much of the solid again dissolved. Reflux was continued for a further 1.5 hours. Since a small amount of solid still remained, the reaction was vacuum filtered while hot, rinsing with hot water. The filtrate was brought to a simmer (to dissolve material that had solidified upon cooling), and acidified with concentrated hydrochloric acid while hot. After cooling, vacuum filtration yielded a white solid, product A. Meanwhile, the solid from filtration of the basic reaction mixture returned to the reaction vessel and again heated at reflux in a further $400 \mathrm{~mL} \mathrm{10 \%} \mathrm{caustic} \mathrm{soda.} \mathrm{After} 1.5$ hours, all material had dissolved, and so the reaction mixture was acidified while hot by the addition of concentrated hydrochloric acid. Upon cooling, filtration again yielded an off-white solid (product B). Product A appeared to contain a large amount of salt (by taste and flame test) and residual water. Only product $B$, which appeared to be the desired material by NMR, was used in the next reaction $(15.75 \mathrm{~g}, 47 \%)$.

${ }^{1} \mathrm{H}$ NMR $\delta(\mathrm{ppm})\left(\mathrm{DMSO}_{\mathrm{d}}\right): 13.08(1 \mathrm{H}, \mathrm{br} \mathrm{s}), 8.66(1 \mathrm{H}, \mathrm{s}), 8.24(1 \mathrm{H}, \mathrm{d}, \mathrm{J}=8.80 \mathrm{~Hz})$, $7.81(1 \mathrm{H}, \mathrm{d}, \mathrm{J}=8.80 \mathrm{~Hz})$.

7,8-dichloro-4-quinolone (Price, 1946; Surrey, 1946)<smiles>O=c1cc[nH]c2c(Cl)c(Cl)ccc12</smiles>

3-carboxy-7,8-dichloro-4-quinolone (15.75 g, $61.0 \mathrm{mmol})$ was decarboxyated in two portions (I and II). Portion I was heated in Dowtherm A $(100 \mathrm{~mL})$ at reflux for 1 hour. Upon cooling, the reaction mixture was diluted with $30-60^{\circ}$ petroleum æther $(150 \mathrm{~mL})$ and vacuum filtered, rinsing well with additional petroleum æther. Portion II was heated in Dowtherm A (100 mL) at reflux for 40 minutes; upon cooling, NMR indicated that decarboxylation was not complete. The reaction was returned to reflux and inadvertently heated for 4 hours. After cooling, the reaction mixture was diluted with $30-60^{\circ}$ 
petroleum æther $(150 \mathrm{~mL})$ and vacuum filtered, rinsing well with further petroleum æther. The products from decarboxylation of portions I and II were combined (a tan crystalline solid, $12.31 \mathrm{~g}, 94 \%$ ).

${ }^{1} \mathrm{H}$ NMR $\delta(\mathrm{ppm})\left(\mathrm{DMSO}_{\mathrm{d}}\right)$ : $11.51(1 \mathrm{H}, \mathrm{br} \mathrm{s}), 8.06(1 \mathrm{H}, \mathrm{d}, \mathrm{J}=8.73 \mathrm{~Hz}), 7.88(1 \mathrm{H}, \mathrm{dd}$, $\mathrm{J}=7.56,6.02 \mathrm{~Hz}), 7.55(1 \mathrm{H}, \mathrm{d}, \mathrm{J}=8.73 \mathrm{~Hz}), 6.15(1 \mathrm{H}, \mathrm{dd}, \mathrm{J}=7.54,1.10 \mathrm{~Hz})$.

${ }^{1} \mathrm{H}$ NMR $\delta(\mathrm{ppm})\left(\mathrm{DMSO}_{\mathrm{d}}\right): 11.51(1 \mathrm{H}, \mathrm{br} \mathrm{d}, \mathrm{J}=5.93 \mathrm{~Hz}), 8.06(1 \mathrm{H}, \mathrm{d}, \mathrm{J}=8.73 \mathrm{~Hz})$, $7.88(1 \mathrm{H}, \mathrm{dd}, \mathrm{J}=7.55,6.02 \mathrm{~Hz}), 7.55(1 \mathrm{H}, \mathrm{d}, \mathrm{J}=8.73 \mathrm{~Hz}), 6.15(1 \mathrm{H}, \mathrm{dd}, \mathrm{J}=7.54,1.10$ $\mathrm{Hz})$.

4,7,8-trichloroquinoline (Price, 1946; Surrey, 1946)<smiles>Clc1ccc2c(Cl)ccnc2c1Cl</smiles>

7,8-dichloro-4-quinolone (12.31 g, $57.5 \mathrm{mmol})$ was allowed to heat, stirring, in phosphorus oxychloride ( $41 \mathrm{~mL}, 440 \mathrm{mmol}$ ) at a gentle reflux for 24 hours. After cooling, the reaction mixture was poured gradually onto ice (with good stirring) and then made basic with $10 \%$ caustic soda (final volume $900 \mathrm{~mL}$ ). This was extracted with chloroform $(4 \times 75 \mathrm{~mL})$. The combined chloroform extracts were dried $\left(\mathrm{MgSO}_{4}\right)$ and evaporated under reduced pressure with warming to yield a cream-colored solid $(9.18 \mathrm{~g}$, $69 \%, \mathrm{mp}=126.0-126.8^{\circ} \mathrm{C}$ (lit. $\left.125-126^{\circ} \mathrm{C}\right)$.

${ }^{1} \mathrm{H}$ NMR $\delta(\mathrm{ppm})\left(\mathrm{CHCl}_{3}-\mathrm{d}\right): 8.93(1 \mathrm{H}, \mathrm{d}, \mathrm{J}=4.70 \mathrm{~Hz}), 8.14(1 \mathrm{H}, \mathrm{d}, \mathrm{J}=9.09 \mathrm{~Hz}), 7.71$ $(1 \mathrm{H}, \mathrm{d}, \mathrm{J}=9.09 \mathrm{~Hz}), 7.58(1 \mathrm{H}, \mathrm{d}, \mathrm{J}=4.71 \mathrm{~Hz})$.

\section{3-(5,7-dichloroquinolin-4-ylamino)propanol}<smiles>OCCCNc1ccnc2c(Cl)c(Cl)ccc12</smiles> 
4,7,8-trichloroquinoline (4.50 g, $19.4 \mathrm{mmol})$ and 3-amino-1-propanol ( $8.80 \mathrm{~mL}, 115$ mmol) were heated at $110^{\circ} \mathrm{C}$ for 24 hours. The hot reaction mixture was then poured into $250 \mathrm{~mL}$ water, while stirring vigorously. The resulting precipitate was recovered by vacuum filtration, followed by air drying and partial recrystallization from ethyl acetate. NMR indicated that a small amount of 3-amino-1-propanol remained, and so the product was ground finely and again partially recrystallized from ethyl acetate to yield the desired product as a tan solid $(4.42 \mathrm{~g}, 84 \%)$.

${ }^{1} \mathrm{H}$ NMR $\delta(\mathrm{ppm})\left(\mathrm{DMSO}-\mathrm{d}_{6}\right): 8.49(1 \mathrm{H}, \mathrm{d}, \mathrm{J}=5.44 \mathrm{~Hz}), 8.23(1 \mathrm{H}, \mathrm{d}, \mathrm{J}=9.15 \mathrm{~Hz}), 7.60$ $(1 \mathrm{H}, \mathrm{d}, \mathrm{J}=9.08 \mathrm{~Hz}), 7.46(1 \mathrm{H}, \mathrm{t}, \mathrm{J}=5.32 \mathrm{~Hz}), 6.58(1 \mathrm{H}, \mathrm{d}, \mathrm{J}=5.50 \mathrm{~Hz}), 4.60(1 \mathrm{H}, \mathrm{t}, \mathrm{J}$ $=5.03 \mathrm{~Hz}), 3.54(2 \mathrm{H}, \mathrm{m}), 3.34$ (water signal overlaps $\mathrm{m}, \sim 2 \mathrm{H}), 1.82(2 \mathrm{H}, \mathrm{m})$.

\section{3-(7,8-dichloroquinolin-4-ylamino)propyl methanesulfonate}<smiles>COCCCNc1ccnc2c(Cl)c(Cl)ccc12</smiles>

3-(7,8-dichloroquinolin-4-ylamino)propanol $(4.42 \mathrm{~g}, 16.3 \mathrm{mmol})$ and triethylamine (3.35 $\mathrm{mL}, 24.0 \mathrm{mmol})$ in dry dichloromethane $(100 \mathrm{~mL})$ were cooled to below $0^{\circ} \mathrm{C}$ on ice/salt. Methanesulfonyl chloride $(1.60 \mathrm{~mL}, 20.6 \mathrm{mmol})$ was added dropwise. After stirring for 1 hour on ice, additional triethylamine $(1.0 \mathrm{~mL}, 7.2 \mathrm{mmol})$ and methanesulfonyl chloride $(0.50 \mathrm{~mL}, 6.4 \mathrm{mmol})$ were added and stirring was continued for a further 30 minutes, whereupon TLC indicated that reaction was complete. The reaction mixture was washed with $120 \mathrm{~mL}$ saturated sodium bicarbonate; after separating, the aqueous layer was extracted with dichloromethane $(3 \times 15 \mathrm{~mL})$. The pooled organic layers were dried $\left(\mathrm{MgSO}_{4}\right)$ and evaporated under reduced pressure with warming to give the desired product as a yellowish tan solid $(4.63 \mathrm{~g}, 82 \%$,).

${ }^{1} \mathrm{H}$ NMR $\delta(\mathrm{ppm})\left(\mathrm{DMSO}-\mathrm{d}_{6}\right): 8.51(1 \mathrm{H}, \mathrm{d}, \mathrm{J}=5.42 \mathrm{~Hz}), 8.24(1 \mathrm{H}, \mathrm{d}, \mathrm{J}=9.17 \mathrm{~Hz}), 7.63$ $(1 \mathrm{H}, \mathrm{d}, \mathrm{J}=9.09 \mathrm{~Hz}), 7.49(1 \mathrm{H}, \mathrm{t}, \mathrm{J}=5.36 \mathrm{~Hz}), 6.62(1 \mathrm{H}, \mathrm{d}, \mathrm{J}=5.49 \mathrm{~Hz}), 4.35(2 \mathrm{H}, \mathrm{t}, \mathrm{J}$ $=6.18 \mathrm{~Hz}), 3.40(2 \mathrm{H}, \mathrm{m}), 3.20(3 \mathrm{H}, \mathrm{s}), 2.04-2.11(2 \mathrm{H}, \mathrm{m})$. 


\section{PL305: $N$-(3-(4-benzhydrylpiperazin-1-yl)propyl)-7,8-dichloroquinolin-4-amine}<smiles>Clc1ccc2c(NCCCN3CCN(C(c4ccccc4)c4ccccc4)CC3)ccnc2c1Cl</smiles>

3-(7,8-dichloroquinolin-4-ylamino)propyl methanesulfonate (1.80 g, $5.15 \mathrm{mmol}), \mathrm{N}$ (diphenylmethyl)piperazine $(1.38 \mathrm{~g}, 5.47 \mathrm{mmol})$, and potassium carbonate $(0.74 \mathrm{~g}, 5.4$ mmol were heated at $75^{\circ} \mathrm{C}$ in acetonitrile $(15 \mathrm{~mL})$ for 9 days. TLC then indicated that reaction was complete. The solvent was removed by evaporation under reduced pressure with warming. The residue was partitioned between chloroform $(40 \mathrm{~mL})$ and water $(35$ $\mathrm{mL})$; after separation, the aqueous layer was extracted with additional chloroform $(3 \times 10$ $\mathrm{mL}$ ). The aqueous layer contained a tan precipitate that remained undissolved during extraction; this was recovered by vacuum filtration. NMR indicated that this was predominantly the desired product. The pooled organic layers were dried $\left(\mathrm{MgSO}_{4}\right)$ and evaporated under reduced pressure with warming to yield a miniscule quantity of unpromising yellow oil; this was subsequently discarded. The solid material recovered from extraction was recrystallized by dissolution in excess boiling ethyl acetate, followed by slow concentration at room temperature to yield the desired product as a tan, crystalline solid $\left(1.72 \mathrm{~g}, 66 \%, \mathrm{mp}=171.5-173.2^{\circ} \mathrm{C}\right)$.

${ }^{1} \mathrm{H} \mathrm{NMR} \delta(\mathrm{ppm})\left(\mathrm{CHCl}_{3}-\mathrm{d}\right): 8.60(1 \mathrm{H}, \mathrm{d}, \mathrm{J}=5.34 \mathrm{~Hz}), 7.79(1 \mathrm{H}$, br t, J = 3.96 Hz), 7.68 $(1 \mathrm{H}, \mathrm{d}, \mathrm{J}=9.03 \mathrm{~Hz}), 7.41-7.45$ (4 H, m), 7.30-7.36 (4 H, m), 7.24-7.29 (solvent peak overlaps m, 2 H), $7.15(1 \mathrm{H}, \mathrm{d}, \mathrm{J}=8.99 \mathrm{~Hz}), 6.34(1 \mathrm{H}, \mathrm{d}, \mathrm{J}=5.39 \mathrm{~Hz}), 4.46(1 \mathrm{H}, \mathrm{s})$, $3.35(2 \mathrm{H}, \mathrm{td}, \mathrm{J}=5.78,3.94 \mathrm{~Hz}), 2.65(10 \mathrm{H}$, br s overlaps t, $\mathrm{J}=5.31 \mathrm{~Hz}), 1.93(2 \mathrm{H}$, apparent $\mathrm{p}, \mathrm{J}=5.33 \mathrm{~Hz}$ ).

${ }^{13} \mathrm{C} \mathrm{NMR} \delta(\mathrm{ppm})\left(\mathrm{CHCl}_{3}\right.$-d): 152.4, 151.0, 146.1, 141.7, 133.5, 131.6, 128.5, 128.3, $127.3,124.8,120.3,118.4,99.1,75.8,59.0,54.0,51.5,44.8,23.1$.

MS (ESI): $m / z$ 505.19271 M + H (calculated 505.19203)

$\operatorname{HPLC}(\operatorname{method} \mathrm{A}) t_{\mathrm{R}}=10.82 \min (99 \%$ pure $)$. 


\section{PL306: 7,8-dichloro- $N$-(3-(4-(pyridin-2-yl)piperazin-1-yl)propyl)quinolin-4-amine}<smiles>O=[R6]c1cnc2c(NCCCN3CCN(c4ccccn4)CC3)ccc(Cl)c2c1Cl</smiles>

3-(7,8-dichloroquinolin-4-ylamino)propyl methanesulfonate (1.80 g, $5.15 \mathrm{mmol}), 1$-(2pyridyl)piperazine $(0.90 \mathrm{~mL}, 5.5 \mathrm{mmol})$, and potassium carbonate $(0.71 \mathrm{~g}, 7.8 \mathrm{mmol})$ were heated at $75^{\circ} \mathrm{C}$ in acetonitrile $(15 \mathrm{~mL})$ for 3 days. TLC then indicated that reaction was complete. The solvent was removed under reduced pressure with warming, and the residue was boiled in $100 \mathrm{~mL}$ water for 20 minutes. Upon cooling, the solid was recovered by vacuum filtration and partially recrystallized from ethyl acetate, followed by full recrystallization from $95 \%$ ethanol to provide the desired product as a sparkling, beige solid $(0.53 \mathrm{~g}, 25 \%)$.

${ }^{1} \mathrm{H}$ NMR $\delta(\mathrm{ppm})\left(\mathrm{CHCl}_{3}-\mathrm{d}\right): 8.64(1 \mathrm{H}, \mathrm{d}, \mathrm{J}=5.38 \mathrm{~Hz}), 8.24-8.24(1 \mathrm{H}, \mathrm{m}), 7.73(1 \mathrm{H}, \mathrm{d}$, $\mathrm{J}=9.04 \mathrm{~Hz}), 7.54-7.54(1 \mathrm{H}, \mathrm{m}), 7.50(1 \mathrm{H}, \mathrm{s}), 7.31(1 \mathrm{H}, \mathrm{d}, \mathrm{J}=9.00 \mathrm{~Hz}), 6.69-6.70(2 \mathrm{H}$, m), $6.42(1 \mathrm{H}, \mathrm{d}, \mathrm{J}=5.42 \mathrm{~Hz}), 3.68(4 \mathrm{H}, \mathrm{m}), 3.43$ (2 H, td, J = 5.93, 4.14 Hz), 2.69-2.70 $(6 \mathrm{H}, \mathrm{m}), 2.01(2 \mathrm{H}$, apparent $\mathrm{p}, \mathrm{J}=5.52 \mathrm{~Hz})$.

${ }^{13} \mathrm{C} \mathrm{NMR} \delta(\mathrm{ppm})\left(\mathrm{CHCl}_{3}-\mathrm{d}\right): 159.3,152.4,150.9,148.1,146.1,137.7,133.6,131.9$, $125.1,119.8,118.4,113.9,107.2$, 99.3, 58.8, 53.5, 45.4, 44.5, 23.5.

MS (ESI): $m / z$ 416.14033 M + H (calculated 416.14061)

$\operatorname{HPLC}(\operatorname{method} \mathrm{A}) t_{\mathrm{R}}=6.52 \min (96 \%$ pure $)$. 


\section{A.2. Haloquinolines other than chlorine}

\section{A.2.1: 6-fluoroquinolines}

3-carbethoxy-6-fluoro-4-quinolone (Price, 1946; Snyder, 1947)<smiles>CCOC(=O)c1c[nH]c2ccc(F)cc2c1=O</smiles>

para-Fluoroaniline $(26.39 \mathrm{~g}, 0.237 \mathrm{~mol})$ and diethyl ethoxymethylene malonate $(48.0$ $\mathrm{mL}, 0.238 \mathrm{~mol})$ in Dowtherm A $(100 \mathrm{~mL})$ were allowed to heat gradually, stirring, to $255^{\circ} \mathrm{C}$, at which temperature the reaction was allowed to remain for 35 minutes. After cooling, the reaction mixture was diluted with $35-60^{\circ}$ petroleum æther $(200 \mathrm{~mL})$ and vacuum filtered to obtain the product as a tan, powdery solid $(45.83 \mathrm{~g}, 82 \%)$.

6-fluoro-4-quinolone (Price, 1946; Snyder, 1947)<smiles>CCOC(=O)c1c[nH]c2ccc(F)cc2c1=O</smiles>

The above product $(45.83 \mathrm{~g}, 0.195 \mathrm{~mol})$ in $400 \mathrm{~mL}$ of $10 \%$ caustic soda was allowed to reflux, stirring, for 2 hours, at which point all solid material had dissolved. After partial cooling, the reaction was poured gradually and with good stirring into $300 \mathrm{~mL} \mathrm{6M}$ muriatic acid. The resulting off-white precipitate was recovered by vacuum filtration. After air-drying, the above product was heated in Dowtherm A $(100 \mathrm{~mL})$ at $255^{\circ} \mathrm{C}$ for 40 minutes. After cooling, the reaction mixture was diluted with $100 \mathrm{~mL} 35-60^{\circ}$ petroleum æther and vacuum filtered. The product was obtained as a tan, powdery solid $(30.11 \mathrm{~g}$, $95 \%)$.

${ }^{1} \mathrm{H}$ NMR $\delta(\mathrm{ppm})\left(\mathrm{DMSO}_{\mathrm{d}}\right)$ : $11.98(1 \mathrm{H}, \mathrm{br} \mathrm{s}), 7.93(1 \mathrm{H}, \mathrm{dd}, \mathrm{J}=7.35,5.92 \mathrm{~Hz}), 7.72(1$ $\mathrm{H}, \mathrm{dd}, \mathrm{J}=9.43,2.99 \mathrm{~Hz}), 7.65(1 \mathrm{H}, \mathrm{dd}, \mathrm{J}=9.00,4.71 \mathrm{~Hz}), 7.56(1 \mathrm{H}, \mathrm{ddd}, \mathrm{J}=9.09,8.22$, $3.00 \mathrm{~Hz})$.

${ }^{19}$ F NMR $\delta(p p m)\left(D_{M S O}-d_{6}\right):-118.1(\mathrm{~m})$. 
4-chloro-6-fluoroquinoline (Price, 1946; Snyder, 1947)<smiles>Fc1ccc2nccc(Cl)c2c1</smiles>

Phosphorus oxychloride ( $80 \mathrm{~mL}, 860 \mathrm{mmol}$ ) was cautiously added to 6-fluoro-4quinolone $(30.11 \mathrm{~g}, 185 \mathrm{mmol})$. The reaction was allowed to heat, stirring, at $110^{\circ} \mathrm{C}$ for 18 hours. After cooling, the reaction mixture was poured gradually onto ice and then made basic ( $\mathrm{pH} \mathrm{10)}$ with solid caustic potash. This resulted in formation of white precipitate, which was recovered by filtration and allowed to air dry $(19.16 \mathrm{~g}, 57 \% \mathrm{mp}=$ 60.7-65. $3^{\circ} \mathrm{C}$ (lit. $\left.76.5-77^{\circ} \mathrm{C}\right)$. Note: Four years elapsed between synthesis of this product and determination of melting point. The product had been stored in a sealed bottle in a dark drawer during this time.

${ }^{1} \mathrm{H}$ NMR $\delta(\mathrm{ppm})\left(\mathrm{CHCl}_{3}-\mathrm{d}\right): 8.76(1 \mathrm{H}, \mathrm{d}, \mathrm{J}=4.71 \mathrm{~Hz}), 8.14(1 \mathrm{H}, \mathrm{dd}, \mathrm{J}=9.24,5.33 \mathrm{~Hz})$, $7.86(1 \mathrm{H}, \mathrm{dd}, \mathrm{J}=9.41,2.83 \mathrm{~Hz}), 7.54-7.55(2 \mathrm{H}, \mathrm{m})$.

${ }^{19} \mathrm{~F}$ NMR $\delta(\mathrm{ppm})\left(\mathrm{CHCl}_{3}-\mathrm{d}\right):-110.6(\mathrm{~m})$.

\section{3-(6-fluoroquinolin-4-ylamino)propanol}<smiles>OCCCNc1ccnc2ccc(F)cc12</smiles>

4-chloro-6-fluoroquinoline (10.01 g, $55.1 \mathrm{mmol})$ and 3-amino-1-propanol (25.29 mL, 331 $\mathrm{mmol}$ ) were heated at $110^{\circ} \mathrm{C}$ for 24 hours. The hot reaction mixture was poured into 750 $\mathrm{mL}$ water, gradually and with good stirring. The resulting precipitate was isolated by vacuum filtration, and then partially recrystallized from ethyl acetate. Filtration afforded the desired product as a tan solid $\left(9.74 \mathrm{~g}, 80 \%, \mathrm{mp}=159.1-160.1^{\circ} \mathrm{C}\right)$.

${ }^{1} \mathrm{H}$ NMR $\delta(\mathrm{ppm})\left(\mathrm{DMSO}_{\mathrm{d}}\right): 8.38(1 \mathrm{H}, \mathrm{d}, \mathrm{J}=5.32 \mathrm{~Hz}), 8.04(1 \mathrm{H}, \mathrm{dd}, \mathrm{J}=11.15,2.85$ $\mathrm{Hz}), 7.83$ (1 H, dd, J = 9.21, $5.84 \mathrm{~Hz}), 7.49-7.50(1 \mathrm{H}, \mathrm{m}), 7.04(1 \mathrm{H}, \mathrm{br} \mathrm{t}, \mathrm{J}=5.28 \mathrm{~Hz})$, $6.47(1 \mathrm{H}, \mathrm{d}, \mathrm{J}=5.37 \mathrm{~Hz}), 4.58(1 \mathrm{H}, \mathrm{t}, \mathrm{J}=5.07 \mathrm{~Hz}), 3.55(2 \mathrm{H}, \mathrm{td}, \mathrm{J}=6.13,5.03 \mathrm{~Hz})$, 3.33 (water signal overlaps $\mathrm{m}, \sim 2 \mathrm{H}), 1.82(2 \mathrm{H}$, apparent $\mathrm{p}, \mathrm{J}=6.65 \mathrm{~Hz}$ ).

${ }^{19}$ F NMR $\delta(p p m)\left(D_{M S O}-d_{6}\right):-116.6(\mathrm{~m})$. 
${ }^{1} \mathrm{H}$ NMR $\delta(\mathrm{ppm})\left(\mathrm{CHCl}_{3}\right.$-d): $8.52(1 \mathrm{H}, \mathrm{d}, \mathrm{J}=5.30 \mathrm{~Hz}), 7.96(1 \mathrm{H}, \mathrm{dd}, \mathrm{J}=9.19,5.61 \mathrm{~Hz})$, 7.35-7.36 (2 H, m), $6.42(1 \mathrm{H}, \mathrm{d}, \mathrm{J}=5.32 \mathrm{~Hz}), 5.70(1 \mathrm{H}, \mathrm{s}), 3.97(2 \mathrm{H}, \mathrm{t}, \mathrm{J}=5.44 \mathrm{~Hz})$, $3.48(2 \mathrm{H}, \mathrm{m}), 2.04-2.06(2 \mathrm{H}, \mathrm{m})$.

MS (ESI): $m / z$ 221.10864 M + H (calculated 221.10847)

HPLC (method A) $t_{\mathrm{R}}=6.98 \mathrm{~min}\left(86 \%\right.$ pure). Second peak $t_{\mathrm{R}}=7.77 \mathrm{~min}(13 \%)$. Note: Four years elapsed between synthesis of this product and testing by HPLC. The product had been stored in a sealed bottle in a dark drawer during this time.

\section{3-(6-fluoroquinolin-4-ylamino)propyl methanesulfonate}<smiles>COCCCNc1ccnc2ccc(F)cc12</smiles>

3-(6-fluoroquinolin-4-ylamino)propanol (3.00 g, $13.6 \mathrm{mmol})$ and triethylamine $(3.00 \mathrm{~mL}$, $21.5 \mathrm{mmol})$ in dry chloroform $(125 \mathrm{~mL})$ were cooled to below $0^{\circ} \mathrm{C}$ on ice/salt. Methanesulfonyl chloride $(1.22 \mathrm{~mL}, 15.7 \mathrm{mmol})$ was added dropwise. After stirring for an hour on ice, TLC indicated that reaction was complete. The reaction mixture was shaken with $25 \mathrm{~mL}$ saturated sodium bicarbonate, followed by extraction of the aqueous layer with three $10 \mathrm{~mL}$ portions of chloroform. The pooled organic layers were washed with $10 \mathrm{~mL}$ water, dried over anhydrous magnesium sulfate, and evaporated under reduced pressure with warming. This afforded the desired product as a pale yellow, powdery solid (3.78 g, 93\%).

\section{PL285: N-(3-(4-benzhydrylpiperazin-1-yl)propyl)-6-fluoroquinolin-4-amine}<smiles>Fc1ccc2nccc(NCCCN3CCN(C(c4ccccc4)c4ccccc4)CC3)c2c1</smiles> 
3-(6-fluoro quinolin-4-ylamino)propyl methanesulfonate (1.81 g, $6.07 \mathrm{mmol}), \mathrm{N}$ (diphenylmethyl)piperazine (1.62 g, $6.42 \mathrm{mmol})$, and potassium carbonate (1.26 g, 9.12 $\mathrm{mmol}$ ) were heated in refluxing acetonitrile $(22 \mathrm{~mL})$ for 5 hours. The reaction mixture was vacuum filtered, rinsing extensively with water, and then with $1 \mathrm{~mL} 95 \%$ ethanol. This afforded the desired product as a sparkling, cream-colored solid $(2.12 \mathrm{~g}, 77 \%, \mathrm{mp}=$ $\left.201-203^{\circ} \mathrm{C}\right)$.

${ }^{1} \mathrm{H} \mathrm{NMR} \delta(\mathrm{ppm})\left(\mathrm{CHCl}_{3}-\mathrm{d}\right): 8.49\left(1 \mathrm{H}, \mathrm{d}, \mathrm{J}_{3,2}=5.26 \mathrm{~Hz}, \mathrm{Q}-\mathrm{C} 2-\mathrm{H}\right), 7.96\left(1 \mathrm{H}, \mathrm{dd}, \mathrm{J}_{7,8}=\right.$ 9.23, $\left.\mathrm{J}_{\mathrm{F}}=5.61 \mathrm{~Hz}, \mathrm{Q}-\mathrm{C} 8-\mathrm{H}\right), 7.71\left(1 \mathrm{H}, \mathrm{dd}, \mathrm{J}_{\mathrm{F}}=10.02, \mathrm{~J}_{7,5}=2.79 \mathrm{~Hz}, \mathrm{Q}-\mathrm{C} 5-\mathrm{H}\right), 7.62(1$ $\mathrm{H}$, br t, $\left.\mathrm{J}_{\mathrm{CH} 2, \mathrm{NH}}=3.94 \mathrm{~Hz}, \mathrm{Q}-\mathrm{C} 4-\mathrm{NH}\right)$, 7.47-7.49 $(4 \mathrm{H}, \mathrm{m}, \mathrm{Ph}-\mathrm{H}$, ortho $), 7.43(1 \mathrm{H}$, ddd, $\mathrm{J}_{8,7}=9.23, \mathrm{~J}_{\mathrm{F}}=8.02, \mathrm{~J}_{5,7}=2.75 \mathrm{~Hz}, \mathrm{Q}-\mathrm{C} 7-\mathrm{H}$ ), 7.24-7.31 (solvent signal overlaps $\mathrm{m}, \sim 4$ $\mathrm{H}, \mathrm{Ph}-\mathrm{H}$, meta $), 7.15-7.22(2 \mathrm{H}, \mathrm{m}, \mathrm{Ph}-\mathrm{H}$, para $), 6.31\left(1 \mathrm{H}, \mathrm{d}, \mathrm{J}_{2,3}=5.31 \mathrm{~Hz}, \mathrm{Q}-\mathrm{C} 3-\mathrm{H}\right)$, $4.36\left(1 \mathrm{H}, \mathrm{s}, \mathrm{CH}(\mathrm{Ph})_{2}\right), 3.35\left(2 \mathrm{H}, \mathrm{td}, \mathrm{J}_{\mathrm{CH} 2, \mathrm{CH} 2}=5.71, \mathrm{~J}_{\mathrm{NH}, \mathrm{CH} 2}=3.98 \mathrm{~Hz}, \mathrm{Q}-\mathrm{C} 1-\right.$

$\left.\mathrm{NHCH}_{2} \mathrm{CH}_{2} \mathrm{CH}_{2}\right), 2.58\left(10 \mathrm{H}\right.$, br s overlaps t, center at $2.64 \mathrm{ppm}, \mathrm{J}_{\mathrm{CH} 2, \mathrm{CH} 2}=8.82 \mathrm{~Hz}$, Pip$\mathrm{CH}_{2} \times 4$ and Q-C1- $\left.\mathrm{NHCH}_{2} \mathrm{CH}_{2} \mathrm{CH}_{2}\right), 1.92\left(2 \mathrm{H}\right.$, apparent $\mathrm{p}, \mathrm{J}_{\mathrm{CH} 2 \times 2, \mathrm{CH} 2}=5.31 \mathrm{~Hz}, \mathrm{Q}-\mathrm{Cl}$ $\mathrm{NHCH}_{2} \mathrm{CH}_{2} \mathrm{CH}_{2}$ ).

${ }^{19} \mathrm{~F} \mathrm{NMR} \delta(\mathrm{ppm})\left(\mathrm{CHCl}_{3}-\mathrm{d}\right):-117.1(\mathrm{~m})$.

${ }^{13} \mathrm{C} \mathrm{NMR} \delta(\mathrm{ppm})\left(\mathrm{CHCl}_{3}-\mathrm{d}\right): 160.8,158.3\left(\mathrm{~d}, \mathrm{~J}_{\mathrm{F}}=244.47 \mathrm{~Hz}, \mathrm{Q}-\mathrm{C} 6\right), 150.6\left(\mathrm{~d}, \mathrm{~J}_{\mathrm{F}}=1.95\right.$ $\mathrm{Hz}, \mathrm{Q}-\mathrm{C} 2), 150.2\left(\mathrm{~d}, \mathrm{~J}_{\mathrm{F}}=4.19 \mathrm{~Hz}, \mathrm{Q}\right), 145.4(\mathrm{Q}), 142.9$ (Ph-C, ipso), 132.1 (d, J $\mathrm{J}_{\mathrm{F}}=8.91$ Hz, Q-C8), 128.6 (Ph-C, meta), 127.9 (Ph-C, ortho), 127.0 (Ph-C, para), 119.6 (d, $\mathrm{J}_{\mathrm{F}}=$ $8.64 \mathrm{~Hz}, \mathrm{Q}), 118.5\left(\mathrm{~d}, \mathrm{~J}_{\mathrm{F}}=24.30 \mathrm{~Hz}, \mathrm{Q}-\mathrm{C} 7\right), 105.3\left(\mathrm{~d}, \mathrm{~J}_{\mathrm{F}}=21.88 \mathrm{~Hz}, \mathrm{Q}-\mathrm{C} 5\right), 98.3$ (QC3), $76.7\left(\mathrm{CH}(\mathrm{Ph})_{2}\right), 59.0\left(\mathrm{Q}-\mathrm{C} 1-\mathrm{NHCH}_{2} \mathrm{CH}_{2} \mathrm{CH}_{2}\right), 53.9$ (Pip- $\mathrm{C} \times 2$, adjacent to $\mathrm{NHCH}_{2} \mathrm{CH}_{2} \mathrm{CH}_{2}$ ), 52.1 (Pip- $\mathrm{C}$ x 2, adjacent to $\left.\mathrm{CH}(\mathrm{Ph})_{2}\right), 44.8\left(\mathrm{Q}-\mathrm{C} 1-\mathrm{NHCH}_{2} \mathrm{CH}_{2} \mathrm{CH}_{2}\right.$ ), 23.3 (Q-C1- $\mathrm{NHCH}_{2} \mathrm{CH}_{2} \mathrm{CH}_{2}$ ).

MS (ESI): $m / z 455.26087 \mathrm{M}+\mathrm{H}$ (calculated 455.26055)

$\operatorname{HPLC}(\operatorname{method} \mathrm{A}) t_{\mathrm{R}}=10.21 \min (98 \%$ pure $)$.

\section{PL286: 6-fluoro- $N$-(3-(4-(pyridin-2-yl)piperazin-1-yl)propyl)quinolin-4-amine}<smiles>Fc1ccc2nccc(NCCCN3CCN(c4ccccn4)CC3)c2c1</smiles>

3-(6-fluoroquinolin-4-ylamino)propyl methanesulfonate (1.97 g, $6.60 \mathrm{mmol}), 1-(2-$ pyridyl)piperazine $(1.34 \mathrm{~g}, 8.21 \mathrm{mmol})$, and potassium carbonate $(1.26 \mathrm{~g}, 9.12 \mathrm{mmol})$ were heated in refluxing acetonitrile $(16 \mathrm{~mL})$ for 4 days. The solvent was removed under 
reduced pressure with warming, and the residue was partitioned between water $(25 \mathrm{~mL})$ and ethyl acetate $(35 \mathrm{~mL})$. After separation the aqueous layer was extracted with additional ethyl acetate $(3 \times 10 \mathrm{~mL})$, and the pooled organic layers were dried $\left(\mathrm{MgSO}_{4}\right)$ and evaporated under reduced pressure with warming. The residue was dissolved in excess boiling ethyl acetate. This was then allowed to concentrate slowly at room temperature. Filtration afforded the desired product as pale yellow needles $(0.40 \mathrm{~g}, 17 \%$, $\left.\mathrm{mp}=145.3-146.6^{\circ} \mathrm{C}\right)$.

${ }^{1} \mathrm{H}$ NMR $\delta(\mathrm{ppm})\left(\mathrm{CHCl}_{3}-\mathrm{d}\right): 8.51(1 \mathrm{H}, \mathrm{d}, \mathrm{J}=5.30 \mathrm{~Hz}), 8.23(1 \mathrm{H}, \mathrm{dd}, \mathrm{J}=4.96,1.87 \mathrm{~Hz})$, $7.94(1 \mathrm{H}, \mathrm{dd}, \mathrm{J}=9.22,5.58 \mathrm{~Hz}), 7.51-7.52(2 \mathrm{H}, \mathrm{m}), 7.33(1 \mathrm{H}, \mathrm{ddd}, \mathrm{J}=9.20,7.93,2.75$ $\mathrm{Hz}), 7.09(1 \mathrm{H}, \mathrm{br} \mathrm{t}, \mathrm{J}=4.20 \mathrm{~Hz}), 6.67-6.69(2 \mathrm{H}, \mathrm{m}), 6.38(1 \mathrm{H}, \mathrm{d}, \mathrm{J}=5.32 \mathrm{~Hz}), 3.72(4$ $\mathrm{H}, \mathrm{m}), 3.42(2 \mathrm{H}, \mathrm{td}, \mathrm{J}=5.94,4.30 \mathrm{~Hz}), 2.68-2.70(6 \mathrm{H}, \mathrm{m}), 2.01-2.03(2 \mathrm{H}, \mathrm{m})$.

${ }^{19} \mathrm{~F}$ NMR $\delta(\mathrm{ppm})\left(\mathrm{CHCl}_{3}-\mathrm{d}\right):-116.0(\mathrm{~m})$.

MS (ESI): $m / z$ 366.20932 M + H (calculated 366.20885)

HPLC (method A) $t_{\mathrm{R}}=2.66 \mathrm{~min}(81 \%$ pure). (Additional peaks elute at $1.64 \mathrm{~min}, 13 \%$, and $7.68 \mathrm{~min}, 5 \%$.)

\section{A.2.2: 7-fluoroquinolines}

3-carbethoxy-5- and 7-fluoro-4-quinolone (Price, 1946; Snyder, 1947)<smiles>CCOC(=O)c1c[nH]c2cc(F)ccc2c1=O</smiles>

meta-Fluoroaniline (11.64 g, $105 \mathrm{mmol})$ and diethyl ethoxymethylene malonate (21.04 $\mathrm{mL}, 105 \mathrm{mmol})$ in Dowtherm A $(100 \mathrm{~mL})$ were allowed to heat gradually, stirring, to $255^{\circ} \mathrm{C}$, at which temperature the reaction was allowed to remain for 30 minutes. After cooling, the reaction mixture was diluted with $35-60^{\circ}$ petroleum æther $(200 \mathrm{~mL})$ and vacuum filtered to obtain a cream-colored, powdery solid $(21.19 \mathrm{~g}, 86 \%)$. 
5- and 7- fluoro-3-carboxy-4-quinolone (Price, 1946; Snyder, 1947)<smiles>O=C(O)c1c[nH]c2cc(F)ccc2c1=O</smiles>

A portion of the above product $(11.80 \mathrm{~g}, 50.2 \mathrm{mmol})$ in $250 \mathrm{~mL}$ of $10 \%$ caustic soda was allowed to reflux, stirring, for 1.75 hours, at which point all solid material had dissolved. After cooling to room temperature, the reaction was poured into $300 \mathrm{~mL}$ deionized water and triturated with concentrated muriatic acid until no more precipitate formed. The resulting off-white precipitate was recovered by vacuum filtration. The off-white solid obtained after air-drying (11.12 g, presumed to contain residual water) was used without further drying or purification in the ensuing reaction.

5- and 7-fluoro-4-quinolone (Price, 1946; Snyder, 1947)<smiles>CNc1cccc(F)c1C(C)=O</smiles><smiles>O=c1cc[nH]c2cc(F)ccc12</smiles>

The above product ( $10.39 \mathrm{~g}$, presumed to contain residual water) was heated in Dowtherm A $(60 \mathrm{~mL})$ at $255^{\circ} \mathrm{C}$ for 1.5 hours. After cooling, the reaction mixture was diluted with $35-60^{\circ}$ petroleum æther $(100 \mathrm{~mL})$ and vacuum filtered. The product was a beige solid (7.92 g, 97\% from 3-carbethoxy-5- and 7-fluoro-4-quinolone).

4-chloro-5- and 7-fluoroquinoline (Price, 1946; Snyder, 1947)<smiles>Fc1ccc2c(Cl)ccnc2c1</smiles>

Phosphorus oxychloride (40 mL, $430 \mathrm{mmol}$ ) was cautiously added to 5- and 7-fluoro-4quinolone (7.92 g, $45 \mathrm{mmol})$. This mixture was allowed to heat, stirring, at $100^{\circ} \mathrm{C}$ for 1 
hour and 45 minutes. After cooling, the reaction mixture was poured gradually onto ice and then made basic $(\mathrm{pH}>10)$ with solid caustic potash. The resulting white precipitate was recovered by filtration and allowed to air dry. NMR indicated that this product was a mixture of 4-chloro-5-fluoroquinoline and 4-chloro-7-fluoroquinoline, as expected. Separation of the 7- and 5-fluoro regioisomers by recrystallization from hexanes was not successful. The regioisomers were therefore separated by chromatography on alumina, eluting with 98:2 hexanes:ethyl acetate followed by 93:7 hexanes:ethyl acetate. The desired 4-chloro-7-fluoroquinoline was recovered as a white, crystalline solid with a flowery odor, similar to that of 4,7-dichloroquinoline $\left(4.99 \mathrm{~g}, 57 \%, \mathrm{mp}=74.9-75.6^{\circ} \mathrm{C}\right.$ (lit. $73.5-74^{\circ} \mathrm{C}$ (Snyder, 1947)), $\mathrm{R}_{\mathrm{f}}=0.1$ (basic alumina, hexanes)).

${ }^{1} \mathrm{H} \mathrm{NMR} \delta(\mathrm{ppm})\left(\mathrm{CHCl}_{3}-\mathrm{d}\right): 8.79(1 \mathrm{H}, \mathrm{d}, \mathrm{J}=4.74 \mathrm{~Hz}), 8.26(1 \mathrm{H}, \mathrm{dd}, \mathrm{J}=9.27,5.91 \mathrm{~Hz})$, $7.77(1 \mathrm{H}, \mathrm{dd}, \mathrm{J}=9.77,2.57 \mathrm{~Hz}), 7.48(1 \mathrm{H}, \mathrm{d}, \mathrm{J}=4.65 \mathrm{~Hz}), 7.44-7.44(1 \mathrm{H}, \mathrm{m})$.

${ }^{19} \mathrm{~F}$ NMR $\delta(\mathrm{ppm})\left(\mathrm{CHCl}_{3}\right.$-d), ${ }^{1} \mathrm{H}$-decoupled: -108.30.

Note: Reaction of the above material with 3-amino-1-propanol gave a mixture of products due to replacement of the 7-fluoro substituent with 3-amino-1-propanol in addition to the expected substitution of the 4-chloro substituent. Replacement of the 7fluoro substituent of 4-chloro-7-fluoroquinoline by amines has been observed previously (Snyder, 1947). In the case of the above compound, the 7-substituted product was removed by chromatography. Once purified, mesylation of the 4-substituted product resulted in partial substitution of the 7-fluoro substituent by the triethylamine base used in the reaction. Due to the small yield of both products, the project was placed on hold. The easy replacement of the 7-fluoro substituent by amines, even tertiary amines, suggested possible avenues for the synthesis of 4,7-diamino-substituted quinolines, but these have not yet been pursued.

\section{A.2.3: 6-bromoquinolines}

3-carbethoxy-6-bromo-4-quinolone (Price, 1946; Lin, 1978)<smiles>CCOC(=O)c1c[nH]c2ccc(Br)cc2c1=O</smiles>

para-Bromoaniline (13.53 g, $78.7 \mathrm{mmol})$ and diethyl ethoxymethylene malonate (15.9 $\mathrm{mL}, 78.7 \mathrm{mmol})$ in Dowtherm A $(60 \mathrm{~mL})$ were allowed to heat gradually, stirring, to 
$255^{\circ} \mathrm{C}$, at which temperature the reaction was allowed to remain for 1.25 hours. After cooling, the reaction mixture was diluted with $30-60^{\circ}$ petroleum æether and vacuum filtered, rinsing with additional petroleum æther, then with acetone. This afforded a sparkling, cream-colored solid (17.56 g, 75\%).

3-carboxy-6-bromo-4-quinolone (Price, 1946; Lin, 1978)<smiles>O=C(O)c1c[nH]c2ccc(Br)cc2c1=O</smiles>

3-carbethoxy-6-bromo-4-quinolone (17.56 g, $59.3 \mathrm{mmol}$ ) in $250 \mathrm{~mL}$ of $10 \%$ caustic soda was heated at reflux, stirring, for 1.5 hours, at which point all solid material had dissolved. The hot reaction mixture was poured into $500 \mathrm{~mL}$ water and acidified by addition of concentrated muriatic acid. The resulting white precipitate was isolated by vacuum filtration. After air-drying, mass of product obtained was $16.38 \mathrm{~g}$ (product presumed to contain water; yield not calculated). The product was used without further drying or purification in the next step.

6-bromo-4-quinolone (Price, 1946; Lin, 1978)<smiles>O=c1cc[nH]c2ccc(Br)cc12</smiles>

The above product (16.38 g, presumed to contain water) was decarboxylated in two portions. Each portion was heated in Dowtherm A $(50 \mathrm{~mL})$ at $255^{\circ} \mathrm{C}$ for 1.25 hours. After cooling, the reaction mixture was diluted with $35-60^{\circ}$ petroleum æther and vacuum filtered to recover the solid product as a pearlescent, pale beige solid. In both cases, NMR indicated that this material was the decarboxylated product $(13.40 \mathrm{~g})$.

${ }^{1} \mathrm{H}$ NMR $\delta(\mathrm{ppm})\left(\mathrm{DMSO}_{\mathrm{d}}\right): 11.94(1 \mathrm{H}, \mathrm{d}, \mathrm{J}=5.86 \mathrm{~Hz}, \mathrm{Q}-\mathrm{N} 1-\mathrm{H}), 8.16(1 \mathrm{H}, \mathrm{d}, \mathrm{J}=2.43$ $\mathrm{Hz}, \mathrm{Q}-\mathrm{C} 5-\mathrm{H}), 7.95$ (1 H, dd, J = 7.37, 5.19 Hz, Q-C2-H), 7.79 (1 H, dd, J = 8.79, $2.48 \mathrm{~Hz}$, Q-C7-H), 7.53 (1 H, d, J = 8.82 Hz, Q-C8-H), 6.08 (1 H, d, J = 7.38 Hz, Q-C3-H). 
4-chloro-6-bromoquinoline (Price, 1946; Lin, 1978)<smiles>Clc1ccnc2ccc(Br)cc12</smiles>

The above product (13.40 g, no more than $59.3 \mathrm{mmol}$ ) was heated at reflux in $42 \mathrm{~mL}$ phosphorus oxychloride for 2 hours. TLC indicated that the reaction was complete, and the reaction was therefore poured gradually into ice water, followed by basification with solid caustic potash (final volume $500 \mathrm{~mL}$ ). After cooling, the resulting precipitate was collected by vacuum filtration and allowed to air dry $(10.82 \mathrm{~g}, \sim 75 \%, \mathrm{mp}=113.3$ $114.8^{\circ} \mathrm{C}$ (lit. $111-112^{\circ} \mathrm{C}$ ).

${ }^{1} \mathrm{H}$ NMR $\delta(\mathrm{ppm})\left(\mathrm{CHCl}_{3}-\mathrm{d}\right): 8.80(1 \mathrm{H}, \mathrm{d}, \mathrm{J}=4.73 \mathrm{~Hz} . \mathrm{Q}-\mathrm{C} 2-\mathrm{H}), 8.41(1 \mathrm{H}, \mathrm{d}, \mathrm{J}=2.19$ Hz, Q-C5-H), 8.02 (1 H, d, J = 8.96 Hz, Q-C8-H), 7.86 (1 H, dd, J = 8.96, 2.18 Hz, QC7-H), 7.53 (1 H, d, J = 4.73 Hz, Q-C3-H).

\section{3-(6-bromoquinolin-4-ylamino)propanol}<smiles>OCCCNc1ccnc2ccc(Br)cc12</smiles>

4-chloro-6-bromoquinoline (5.00 g, $20.6 \mathrm{mmol})$ and 3-amino-1-propanol (15.50 mL, 203 $\mathrm{mmol}$ ) were heated at $100^{\circ} \mathrm{C}$ in a Carius vessel for 3 hours, whereupon TLC indicated that the reaction was complete. The hot reaction mixture was then poured into $200 \mathrm{~mL}$ water, while stirring vigorously. After standing overnight, the resulting precipitate was recovered by vacuum filtration, followed by air drying and partial recrystallization from $25 \mathrm{~mL}$ ethyl acetate $\left(3.46 \mathrm{~g}\right.$ of a beige solid, $\left.60 \%, \mathrm{mp}=176.3-177.8^{\circ} \mathrm{C}\right)$.

${ }^{1} \mathrm{H}$ NMR $\delta(\mathrm{ppm})\left(\right.$ DMSO-d $\left._{6}\right): 8.51(1 \mathrm{H}, \mathrm{s}), 8.40(1 \mathrm{H}, \mathrm{d}, \mathrm{J}=5.38 \mathrm{~Hz}), 7.71(2 \mathrm{H}, \mathrm{d}, \mathrm{J}=$ $1.24 \mathrm{~Hz}), 7.24(1 \mathrm{H}$, br t, J = 5.27 Hz), $6.49(1 \mathrm{H}, \mathrm{d}, \mathrm{J}=5.43 \mathrm{~Hz}), 4.58(1 \mathrm{H}, \mathrm{t}, \mathrm{J}=5.08$ $\mathrm{Hz}$ ), $3.55(2 \mathrm{H}, \mathrm{m}), 3.30-3.32$ (water signal overlaps $\mathrm{m}, \sim 2 \mathrm{H}), 1.82(2 \mathrm{H}$, apparent $\mathrm{p}, \mathrm{J}=$ $6.68 \mathrm{~Hz})$. 
${ }^{1} \mathrm{H}$ NMR $\delta(\mathrm{ppm})\left(\mathrm{CHCl}_{3}-\mathrm{d}\right): 8.54(1 \mathrm{H}, \mathrm{d}, \mathrm{J}=5.38 \mathrm{~Hz}), 7.85-7.85(2 \mathrm{H}, \mathrm{m}), 7.68(1 \mathrm{H}$, dd, $\mathrm{J}=8.95,2.12 \mathrm{~Hz}$ ), 7.27 (solvent signal overlaps $\mathrm{m}, \sim 1 \mathrm{H}), 6.44(1 \mathrm{H}, \mathrm{d}, \mathrm{J}=5.40 \mathrm{~Hz}$ ), $3.97(2 \mathrm{H}, \mathrm{t}, \mathrm{J}=5.46 \mathrm{~Hz}), 3.48(2 \mathrm{H}, \mathrm{m}), 2.05(2 \mathrm{H}, \mathrm{m})$.

\section{3-(6-bromoquinolin-4-ylamino)propyl methanesulfonate}<smiles>COCCCNc1ccnc2ccc(Br)cc12</smiles>

3-(6-bromoquinolin-4-ylamino)propanol (3.16 g, $11.2 \mathrm{mmol})$ and triethylamine $(2.35$ $\mathrm{mL}, 16.8 \mathrm{mmol})$ in dry THF $(100 \mathrm{~mL})$ were cooled to below $0^{\circ} \mathrm{C}$ on ice/salt. Methanesulfonyl chloride $(1.00 \mathrm{~mL}, 12.9 \mathrm{mmol})$ was added dropwise. After stirring for 1 hour on ice, TLC indicated that reaction was not complete; additional methanesulfonyl chloride $(0.15 \mathrm{~mL}, 1.9 \mathrm{mmol})$ were therefore added. After a further hour of stirring, TLC indicated that reaction was complete. The reaction mixture was diluted with ethyl acetate $(10 \mathrm{~mL})$ and washed with saturated sodium bicarbonate $(100 \mathrm{~mL})$. The aqueous layer was then extracted with additional ethyl acetate $(3 \times 10 \mathrm{~mL})$, and the pooled organic layers were rinsed with water $(10 \mathrm{~mL})$, dried $\left(\mathrm{MgSO}_{4}\right)$, and evaporated under reduced pressure with warming to give the desired product as a pale yellow solid $(3.32 \mathrm{~g}, 83 \%)$.

${ }^{1} \mathrm{H}$ NMR $\delta(\mathrm{ppm})\left(\mathrm{DMSO}_{-} \mathrm{d}_{6}\right): 8.52(1 \mathrm{H}, \mathrm{s}), 8.43(1 \mathrm{H}, \mathrm{d}, \mathrm{J}=5.41 \mathrm{~Hz}), 7.73(2 \mathrm{H}, \mathrm{m})$, 7.29-7.41 (1 H, m), $6.54(1 \mathrm{H}, \mathrm{d}, \mathrm{J}=5.47 \mathrm{~Hz}), 4.35(2 \mathrm{H}, \mathrm{t}, \mathrm{J}=6.21 \mathrm{~Hz}), 3.37-3.38$ (water signal overlaps m, 2 H), $3.20(3 \mathrm{H}, \mathrm{s}), 2.08(2 \mathrm{H}, \mathrm{m})$.

\section{PL308: $N$-(3-(4-benzhydrylpiperazin-1-yl)propyl)-6-bromoquinolin-4-amine}<smiles>Brc1ccc2nccc(NCCCN3CCN(C(c4ccccc4)c4ccccc4)CC3)c2c1</smiles>

3-(6-bromoquinolin-4-ylamino)propyl methanesulfonate (1.59 g, $4.43 \mathrm{mmol}), \mathrm{N}$ (diphenylmethyl)piperazine $(1.17 \mathrm{~g}, 4.65 \mathrm{mmol})$, potassium carbonate $(0.91 \mathrm{~g}, 6.7$ $\mathrm{mmol}$ ), and a catalytic amount of potassium iodide were heated in refluxing acetonitrile 
$(15 \mathrm{~mL})$ for 24 hours, whereupon substantial precipitate was noted to have formed. A further $20 \mathrm{~mL}$ acetonitrile was added (to improve stirring), and reflux was continued for a further 4 days. TLC then indicated that reaction was complete. The solvent was then removed under reduced pressure with warming, and the residue was partitioned between chloroform $(30 \mathrm{~mL})$ and water $(40 \mathrm{~mL})$. After separation, the aqueous layer was extracted with further chloroform $(3 \times 7 \mathrm{~mL})$, and the pooled organic layers were rinsed with brine $(10 \mathrm{~mL})$, dried $\left(\mathrm{MgSO}_{4}\right)$ and evaporated under reduced pressure with warming to yield a pale brownish yellow solid. This material was partially recrystallized from 20 $\mathrm{mL} 95 \%$ ethanol to provide the desired product as fine, white crystals $(1.58 \mathrm{~g}, 69 \%, \mathrm{mp}=$ $\left.209-210^{\circ} \mathrm{C}\right)$.

${ }^{1} \mathrm{H}$ NMR $\delta(\mathrm{ppm})\left(\mathrm{CHCl}_{3}-\mathrm{d}\right): 8.50(1 \mathrm{H}, \mathrm{d}, \mathrm{J}=5.32 \mathrm{~Hz}, \mathrm{Q}-\mathrm{C} 2-\mathrm{H}), 8.13(1 \mathrm{H}, \mathrm{d}, \mathrm{J}=2.15$ $\mathrm{Hz}, \mathrm{Q}-\mathrm{C} 5-\mathrm{H}), 7.83(1 \mathrm{H}, \mathrm{d}, \mathrm{J}=8.97 \mathrm{~Hz}, \mathrm{Q}-\mathrm{C} 8-\mathrm{H}), 7.70(2 \mathrm{H}, \mathrm{br} \mathrm{dd}, \mathrm{J}=8.78,2.31 \mathrm{~Hz}$, QC7-H overlaps Q-C4-NH), 7.46-7.48 (4 H, m, Ph-CH ortho), 7.25-7.32 (solvent signal overlaps $\mathrm{m}, \sim 4 \mathrm{H}, \mathrm{Ph}-\mathrm{CH}-$ meta $), 7.17(2 \mathrm{H}, \mathrm{m}, \mathrm{Ph}-\mathrm{CH}$ para $), 6.32(1 \mathrm{H}, \mathrm{d}, \mathrm{J}=5.37 \mathrm{~Hz}$, Q-C3-H), $4.56\left(1 \mathrm{H}, \mathrm{s}, \mathrm{CH}(\mathrm{Ph})_{2}\right), 3.34\left(2 \mathrm{H}, \mathrm{td}, \mathrm{J}=5.67,3.95 \mathrm{~Hz}, \mathrm{Q}-\mathrm{NH}-\mathrm{CH}_{2} \mathrm{CH}_{2} \mathrm{CH}_{2}\right)$, 2.63-2.65 (10 H, br s overlaps t, J $=5.23 \mathrm{~Hz}$, Pip- $\mathrm{CH}_{2} \times 4$ and Q-NH- $\left.\mathrm{CH}_{2} \mathrm{CH}_{2} \mathrm{CH}_{2}\right), 1.92$ (2 H, apparent p, J $=5.26 \mathrm{~Hz}$, Q-NH- $\mathrm{CH}_{2} \mathrm{CH}_{2} \mathrm{CH}_{2}$ ).

${ }^{13} \mathrm{C}$ NMR $\delta(\mathrm{ppm})\left(\mathrm{CHCl}_{3}\right.$-d): $151.6(\mathrm{Q}-\mathrm{C} 2), 149.9(\mathrm{Q}), 147.2(\mathrm{Q}), 143.1$ (Ph-C ipso), 132.2 (Q-C7), 131.7 (Q-C8), 128.6 (Ph-C meta), 127.9 (Ph-C ortho), 127.0 (Ph-C para), 123.2 (Q-C5), $\left.120.5(\mathrm{Q}), 117.8(\mathrm{Q}), 98.8(\mathrm{Q}-\mathrm{C} 3), 75.9(\mathrm{CH}(\mathrm{Ph}))_{2}\right), 59.4(\mathrm{Q}-\mathrm{NH}-$ $\mathrm{CH}_{2} \mathrm{CH}_{2} \mathrm{CH}_{2}$ ), 54.2 (Pip-C-C-NCH(Ph) $)$, 52.0 (Pip-C-C-NCH(Ph) $)$, 45.1 (Q-NH$\left.\mathrm{CH}_{2} \mathrm{CH}_{2} \mathrm{CH}_{2}\right), 23.2\left(\mathrm{Q}-\mathrm{NH}-\mathrm{CH}_{2} \mathrm{CH}_{2} \mathrm{CH}_{2}\right)$.

MS (ESI): $m / z$ 515.18091 M + H (calculated 515.18049)

HPLC (method A, $15 \min ) t_{\mathrm{R}}=11.02 \min (84 \%$ pure $)$.

\section{PL309: 6-bromo- $N$-(3-(4-(pyridin-2-yl)piperazin-1-yl)propyl)quinolin-4-amine}<smiles>Brc1ccc2nccc(NCCCN3CCN(c4ccccn4)CC3)c2c1</smiles>

3-(6-bromoquinolin-4-ylamino)propyl methanesulfonate (1.66 g, $4.62 \mathrm{mmol}), 1-(2-$ pyridyl)piperazine $(0.78 \mathrm{~g}, 4.85 \mathrm{mmol})$, potassium carbonate $(0.95 \mathrm{~g}, 6.93 \mathrm{mmol})$, and a catalytic amount of potassium iodide were heated in refluxing acetonitrile $(15 \mathrm{~mL})$ for 24 hours. Due to the formation of a precipitate, stirring was poor, and a further $20 \mathrm{~mL}$ of 
acetonitrile was therefore added. Reflux was continued for a further 4 days. The solvent was then removed under reduced pressure with warming, and the residue was partitioned between chloroform $(30 \mathrm{~mL})$ and water $(40 \mathrm{~mL})$. After separation, the aqueous layer was extracted with further chloroform $(3 \times 7 \mathrm{~mL})$, and the pooled organic layers were rinsed with brine $(10 \mathrm{~mL})$, dried $\left(\mathrm{MgSO}_{4}\right)$ and evaporated under reduced pressure with warming to yield a yellowish tan solid. This material was taken up in excess boiling $95 \%$ ethanol and allowed to concentrate gradually at room temperature; the resulting pale golden crystals were recovered by vacuum filtration $\left(1.17 \mathrm{~g}, 57 \%, \mathrm{mp}=186.1-187.9^{\circ} \mathrm{C}\right)$.

${ }^{1} \mathrm{H}$ NMR $\delta(\mathrm{ppm})\left(\mathrm{CHCl}_{3}-\mathrm{d}\right): 8.52(1 \mathrm{H}, \mathrm{d}, \mathrm{J}=5.33 \mathrm{~Hz}), 8.22-8.22(1 \mathrm{H}, \mathrm{m}), 8.10(1 \mathrm{H}, \mathrm{d}$, $\mathrm{J}=2.18 \mathrm{~Hz}), 7.79(1 \mathrm{H}, \mathrm{d}, \mathrm{J}=8.93 \mathrm{~Hz}), 7.71(1 \mathrm{H}$, br t, $\mathrm{J}=4.09 \mathrm{~Hz}), 7.59(1 \mathrm{H}, \mathrm{dd}, \mathrm{J}=$ 8.92, $2.14 \mathrm{~Hz}), 7.51(1 \mathrm{H}, \mathrm{ddd}, \mathrm{J}=8.53,7.15,2.04 \mathrm{~Hz}), 6.71(1 \mathrm{H}, \mathrm{d}, \mathrm{J}=8.55 \mathrm{~Hz}), 6.66$ $(1 \mathrm{H}, \mathrm{ddd}, \mathrm{J}=7.17,4.89,0.84 \mathrm{~Hz}), 6.34(1 \mathrm{H}, \mathrm{d}, \mathrm{J}=5.36 \mathrm{~Hz}), 3.81(4 \mathrm{H}, \mathrm{m}), 3.41(2 \mathrm{H}$, $\mathrm{td}, \mathrm{J}=5.38,0.01 \mathrm{~Hz}), 2.71-2.72(6 \mathrm{H}, \mathrm{m}), 2.01(2 \mathrm{H}$, apparent $\mathrm{p}, \mathrm{J}=5.40 \mathrm{~Hz})$.

${ }^{13} \mathrm{C} \mathrm{NMR} \delta(\mathrm{ppm})\left(\mathrm{CHCl}_{3}\right.$-d): 159.7, 151.6, 149.7, 148.0, 147.1, 137.5, 132.1, 131.6, $123.1,120.4,117.8,113.7,107.3,98.7,59.3,53.6,45.2,44.7,23.4$.

MS (ESI): $m / z 426.12947 \mathrm{M}+\mathrm{H}$ (calculated 426.12878)

HPLC (method A) $t_{\mathrm{R}}=5.97 \min (99 \%$ pure $)$.

\section{A.2.4: 7-bromoquinolines}

3-carbethoxy-7-bromo-4-quinolone (Price, 1946)<smiles>CCOC(=O)c1c[nH]c2cc(Br)ccc2c1=O</smiles>

meta-Bromoaniline (11.92 g, $69.3 \mathrm{mmol})$ and diethyl ethoxymethylene malonate (14.00 $\mathrm{mL}, 69.3 \mathrm{mmol})$ in Dowtherm A $(60 \mathrm{~mL})$ were allowed to heat gradually, stirring, to $255^{\circ} \mathrm{C}$, at which temperature the reaction was allowed to remain for 60 minutes. After cooling, the reaction mixture was diluted with $30-60^{\circ}$ petroleum æther, then vacuum filtered, rinsing with additional petroleum æther, followed by acetone to give an offwhite, powdery solid (13.67 g, 67\%). 
3-carboxy-7-bromo-4-quinolone (Price, 1946)<smiles>O=C(O)c1c[nH]c2cc(Br)ccc2c1=O</smiles>

3-carbethoxy-7-bromo-4-quinolone (13.67 g, $46.2 \mathrm{mmol}$ ) in $130 \mathrm{~mL}$ of $10 \%$ caustic soda was heated at reflux, stirring, for 1 hour, at which point all solid material had dissolved. The hot reaction mixture was poured into $1.2 \mathrm{M}$ muriatic acid $(400 \mathrm{~mL})$. The resulting white precipitate was isolated by vacuum filtration. After air-drying, $13.00 \mathrm{~g}$ of a white solid was obtained (containing residual water). The product was used without further drying or purification in the next step.

7-bromo-4-quinolone (Price, 1946; Conroy, 1949)<smiles>O=c1cc[nH]c2cc(Br)ccc12</smiles>

The above product (13.00 g, containing residual water) was heated in refluxing Dowtherm A $(200 \mathrm{~mL})$ for 1 hour. After cooling, the reaction mixture was diluted with $35-60^{\circ}$ petroleum æther and vacuum filtered to recover the solid product as a pearlescent, tan solid (10.94 g, containing residual solvent; yield not calculated).

4-chloro-7-bromoquinoline (Price, 1946; Conroy, 1949)<smiles>Clc1ccnc2cc(Br)ccc12</smiles>

The above product (10.94 g, no more than $46.2 \mathrm{mmol}$ ) was heated at reflux in phosphorus oxychloride $(45 \mathrm{~mL})$ for 2 hours. TLC indicated that the reaction was complete, and the reaction was therefore poured gradually onto ice, followed by basification with solid 
caustic potash (final volume $500 \mathrm{~mL}$ ). After cooling, the resulting precipitate was collected by vacuum filtration and allowed to air dry. NMR indicated that this material was 4-chloro-7-bromoquinoline containing approximately $10 \% 4$-chloro-5bromoquinoline. The pure 7-bromo regioisomer was obtained by recrystallization from $95 \%$ ethanol $\left(7.02 \mathrm{~g}, 42 \%\right.$ from $m$-bromoaniline, $\mathrm{mp}=107.3-108.9^{\circ} \mathrm{C}$ (lit. $105-106^{\circ} \mathrm{C}$ (Conroy, 1949)).

${ }^{1} \mathrm{H}$ NMR $\delta(\mathrm{ppm})\left(\mathrm{CHCl}_{3}-\mathrm{d}\right): 8.78(1 \mathrm{H}, \mathrm{d}, \mathrm{J}=4.72 \mathrm{~Hz}), 8.32(1 \mathrm{H}, \mathrm{d}, \mathrm{J}=1.96 \mathrm{~Hz}), 8.11$ $(1 \mathrm{H}, \mathrm{d}, \mathrm{J}=8.95 \mathrm{~Hz}), 7.74(1 \mathrm{H}, \mathrm{dd}, \mathrm{J}=8.96,1.96 \mathrm{~Hz}), 7.51(1 \mathrm{H}, \mathrm{d}, \mathrm{J}=4.71 \mathrm{~Hz})$.

\section{3-(7-bromoquinolin-4-ylamino)propanol}<smiles>OCCCNc1ccnc2cc(Br)ccc12</smiles>

4-chloro-6-bromoquinoline (3.00 g, $12.4 \mathrm{mmol})$ and 3-amino-1-propanol (5.98 mL, 78.2 $\mathrm{mmol}$ ) were heated at $100^{\circ} \mathrm{C}$ for 4.5 hours, whereupon TLC indicated that the reaction was complete. The hot reaction mixture was poured into water $(200 \mathrm{~mL})$, while stirring vigorously. After standing overnight, the resulting precipitate was recovered by vacuum filtration, followed by air drying and partial recrystallization from $20 \mathrm{~mL}$ ethyl acetate $\left(2.29 \mathrm{~g}\right.$ of a tan, crystalline solid, $\left.66 \%, \mathrm{mp}=162.3-163.2^{\circ} \mathrm{C}\right)$.

${ }^{1} \mathrm{H}$ NMR $\delta(\mathrm{ppm})\left(\mathrm{DMSO}-\mathrm{d}_{6}\right): 8.39(1 \mathrm{H}, \mathrm{d}, \mathrm{J}=5.40 \mathrm{~Hz}), 8.18(1 \mathrm{H}, \mathrm{d}, \mathrm{J}=9.01 \mathrm{~Hz}), 7.94$ $(1 \mathrm{H}, \mathrm{d}, \mathrm{J}=2.11 \mathrm{~Hz}), 7.55(1 \mathrm{H}, \mathrm{dd}, \mathrm{J}=8.95,2.14 \mathrm{~Hz}), 7.30(1 \mathrm{H}, \mathrm{t}, \mathrm{J}=5.33 \mathrm{~Hz}), 6.48(1$ $\mathrm{H}, \mathrm{d}, \mathrm{J}=5.46 \mathrm{~Hz}), 4.59(1 \mathrm{H}, \mathrm{t}, \mathrm{J}=5.01 \mathrm{~Hz}), 3.55(2 \mathrm{H}, \mathrm{m}), 3.30-3.32(2 \mathrm{H}, \mathrm{m}), 1.82(2$ $\mathrm{H}$, apparent $\mathrm{p}, \mathrm{J}=6.68 \mathrm{~Hz}$ ).

${ }^{1} \mathrm{H}$ NMR $\delta(\mathrm{ppm})\left(\mathrm{CHCl}_{3}-\mathrm{d}\right): 8.51(1 \mathrm{H}, \mathrm{d}, \mathrm{J}=5.36 \mathrm{~Hz}), 8.12(1 \mathrm{H}, \mathrm{d}, \mathrm{J}=2.02 \mathrm{~Hz}), 7.56$ $(1 \mathrm{H}, \mathrm{d}, \mathrm{J}=8.91 \mathrm{~Hz}), 7.46(1 \mathrm{H}, \mathrm{dd}, \mathrm{J}=8.90,2.03 \mathrm{~Hz}), 6.40(1 \mathrm{H}, \mathrm{d}, \mathrm{J}=5.38 \mathrm{~Hz}), 5.92(1$ $\mathrm{H}, \mathrm{s}), 3.97(2 \mathrm{H}, \mathrm{t}, \mathrm{J}=5.42 \mathrm{~Hz}), 3.46-3.47(2 \mathrm{H}, \mathrm{m}), 2.01-2.08(2 \mathrm{H}, \mathrm{m})$. 


\section{3-(7-bromoquinolin-4-ylamino)propyl methanesulfonate}<smiles>COCCCNc1ccnc2cc(Br)ccc12</smiles>

3-(7-bromoquinolin-4-ylamino)propanol (0.58 g, $2.06 \mathrm{mmol})$ and triethylamine $(0.44$ $\mathrm{mL}, 3.16 \mathrm{mmol})$ in dry tetrahydrofuran $(70 \mathrm{~mL})$ were cooled to below $0{ }^{\circ} \mathrm{C}$ on ice/salt. Methanesulfonyl chloride $(0.18 \mathrm{~mL}, 2.32 \mathrm{mmol})$ was added dropwise. After stirring for 1.5 hours on ice, TLC indicated that reaction was not complete; additional methanesulfonyl chloride $(0.03 \mathrm{~mL}, 0.4 \mathrm{mmol})$ were therefore added. After a further 18 hours of stirring at room temperature, TLC indicated that reaction was complete. The reaction mixture was washed with saturated sodium bicarbonate $(100 \mathrm{~mL})$, and the aqueous layer was extracted with ethyl acetate $(3 \times 10 \mathrm{~mL})$. The pooled organic layers were rinsed with brine $(15 \mathrm{~mL})$, dried over $\mathrm{MgSO}_{4}$, and evaporated under reduced pressure with warming to give the desired product as a cream-colored solid $(0.68 \mathrm{~g}$, $92 \%)$.

${ }^{1} \mathrm{H}$ NMR $\delta(\mathrm{ppm})\left(\mathrm{DMSO}_{\mathrm{d}}\right): 8.41(1 \mathrm{H}, \mathrm{d}, \mathrm{J}=5.40 \mathrm{~Hz}), 8.20(1 \mathrm{H}, \mathrm{d}, \mathrm{J}=8.99 \mathrm{~Hz}), 7.96$ $(1 \mathrm{H}, \mathrm{d}, \mathrm{J}=2.10 \mathrm{~Hz}), 7.59(1 \mathrm{H}, \mathrm{dd}, \mathrm{J}=8.94,2.13 \mathrm{~Hz}), 7.38(1 \mathrm{H}, \mathrm{t}, \mathrm{J}=5.38 \mathrm{~Hz}), 6.53(1$ $\mathrm{H}, \mathrm{d}, \mathrm{J}=5.46 \mathrm{~Hz}$ ), $4.35(2 \mathrm{H}, \mathrm{t}, \mathrm{J}=6.19 \mathrm{~Hz}$ ), 3.37-3.38 (water overlaps m, 2 H), 3.20 (3 $\mathrm{H}, \mathrm{s}), 2.08(2 \mathrm{H}$, apparent $\mathrm{p}, \mathrm{J}=6.61 \mathrm{~Hz})$.

\section{PL310: $N$-(3-(4-benzhydrylpiperazin-1-yl)propyl)-7-bromoquinolin-4-amine}<smiles>Brc1ccc2c(NCCCN3CCN(C(c4ccccc4)c4ccccc4)CC3)ccnc2c1</smiles>

3-(7-bromoquinolin-4-ylamino)propyl methanesulfonate (0.68 g, $1.89 \mathrm{mmol}), \mathrm{N}$ (diphenylmethyl)piperazine $(0.50 \mathrm{~g}, 1.98 \mathrm{mmol})$, potassium carbonate $(0.39 \mathrm{~g}, 2.82$ $\mathrm{mmol}$ ), and a catalytic amount of potassium iodide were heated in refluxing acetonitrile $(25 \mathrm{~mL})$ for 24 hours, whereupon TLC indicated that reaction was complete. The solvent was removed under reduced pressure with warming, and the residue was partitioned between chloroform $(30 \mathrm{~mL})$ and water $(30 \mathrm{~mL})$. After separation, the aqueous layer was 
extracted with further chloroform $(3 \times 7 \mathrm{~mL})$, and the pooled organic layers were rinsed with brine $(10 \mathrm{~mL})$, dried $\left(\mathrm{MgSO}_{4}\right)$ and evaporated under reduced pressure with warming to yield a tan, crystalline solid. Recrystallization from $95 \%$ ethanol provided the desired product as lustrous, pale yellow crystals $\left(0.29 \mathrm{~g}, 30 \%, \mathrm{mp}=185.5-187.3^{\circ} \mathrm{C}\right)$.

${ }^{1} \mathrm{H}$ NMR $\delta(\mathrm{ppm})\left(\mathrm{CHCl}_{3}-\mathrm{d}\right): 8.48(1 \mathrm{H}, \mathrm{d}, \mathrm{J}=5.34 \mathrm{~Hz}), 8.10(1 \mathrm{H}, \mathrm{d}, \mathrm{J}=2.03 \mathrm{~Hz}), 7.70$ $(1 \mathrm{H}, \mathrm{d}, \mathrm{J}=8.93 \mathrm{~Hz}), 7.60(1 \mathrm{H}, \mathrm{br} \mathrm{t}, \mathrm{J}=4.05 \mathrm{~Hz}), 7.44(4 \mathrm{H}, \mathrm{d}, \mathrm{J}=7.55 \mathrm{~Hz}), 7.29-7.37$ $(4 \mathrm{H}, \mathrm{m}), 7.26$ (solvent signal overlaps $\mathrm{m}, \sim 3 \mathrm{H}), 6.29(1 \mathrm{H}, \mathrm{d}, \mathrm{J}=5.39 \mathrm{~Hz}), 4.44(1 \mathrm{H}, \mathrm{s})$, $3.34(2 \mathrm{H}, \mathrm{td}, \mathrm{J}=5.79,4.03 \mathrm{~Hz}), 2.64(10 \mathrm{H}$, br s overlaps t $\mathrm{J}=5.58 \mathrm{~Hz}), 1.92(2 \mathrm{H}, \mathrm{m}, \mathrm{J}$ $=5.37 \mathrm{~Hz})$.

${ }^{13} \mathrm{C}$ NMR $\delta(\mathrm{ppm})\left(\mathrm{CHCl}_{3}\right.$-d): 152.1, 150.6, 149.4, 141.8, 132.0, 128.5, 128.2, 127.2, $127.1,122.8,122.5,117.8,98.5,75.8,59.0,54.0,51.5,44.5,23.2$.

MS (ESI): $m / z 515.18133 \mathrm{M}+\mathrm{H}$ (calculated 515.18049)

$\operatorname{HPLC}\left(\right.$ method A) $t_{\mathrm{R}}=10.54 \min (99 \%$ pure $)$

\section{PL311: 7-bromo- $N$-(3-(4-(pyridin-2-yl)piperazin-1-yl)propyl)quinolin-4-amine}<smiles>Brc1ccc2c(NCCCN3CCN(c4ccccn4)CC3)ccnc2c1</smiles>

3-(6-bromoquinolin-4-ylamino)propyl methanesulfonate (1.42 g, $3.95 \mathrm{mmol}), 1-(2-$ pyridyl)piperazine $(0.84 \mathrm{~g}, 5.15 \mathrm{mmol})$, potassium carbonate $(0.81 \mathrm{~g}, 5.86 \mathrm{mmol})$, and acetonitrile $(16 \mathrm{~mL})$ were heated at reflux for 5 days, whereupon substantial precipitate was noted to have formed. The precipitate was recovered from the reaction mixture by vacuum filtration, rinsing with $60 \mathrm{~mL}$ water; this precipitate was recrystallized from $95 \%$ ethanol to yield the desired product as golden crystals $(0.37 \mathrm{~g}, 22 \%, \mathrm{mp}=169.7-$ $\left.171.4^{\circ} \mathrm{C}\right)$.

${ }^{1} \mathrm{H}$ NMR $\delta(\mathrm{ppm})\left(\mathrm{CHCl}_{3}-\mathrm{d}\right): 8.51(1 \mathrm{H}, \mathrm{d}, \mathrm{J}=5.35 \mathrm{~Hz}), 8.24-8.24(1 \mathrm{H}, \mathrm{m}), 8.11(1 \mathrm{H}, \mathrm{d}$, $\mathrm{J}=2.03 \mathrm{~Hz}), 7.72(1 \mathrm{H}, \mathrm{d}, \mathrm{J}=8.91 \mathrm{~Hz}), 7.54-7.54(1 \mathrm{H}, \mathrm{m}), 7.36(1 \mathrm{H}, \mathrm{dd}, \mathrm{J}=8.87,2.04$ $\mathrm{Hz}), 7.30(1 \mathrm{H}, \mathrm{br} \mathrm{t}, \mathrm{J}=4.21 \mathrm{~Hz}), 6.68-6.69(2 \mathrm{H}, \mathrm{m}), 6.36(1 \mathrm{H}, \mathrm{d}, \mathrm{J}=5.39 \mathrm{~Hz}), 3.67(4$ $\mathrm{H}, \mathrm{m}), 3.42(2 \mathrm{H}, \mathrm{td}, \mathrm{J}=5.46,0.02 \mathrm{~Hz}), 2.65-2.70(6 \mathrm{H}, \mathrm{m}), 2.00(2 \mathrm{H}$, apparent $\mathrm{p}, \mathrm{J}=$ $5.60 \mathrm{~Hz}), 1.93(1 \mathrm{H}, \mathrm{s})$. 
${ }^{13} \mathrm{C}$ NMR $\delta(\mathrm{ppm})\left(\mathrm{CHCl}_{3}\right.$-d): 159.3, 152.1, 150.5, 149.4, 148.1, 137.7, 132.1, 127.4, $122.9,121.9,117.8,113.8,107.1,98.7,58.6,53.5,45.4,44.2,23.7$.

MS (ESI): $m / z 426.12955 \mathrm{M}+\mathrm{H}$ (calculated 426.12878)

$\operatorname{HPLC}(\operatorname{method~A}) t_{\mathrm{R}}=5.78 \min (>99 \%$ pure $)$.

\section{A.2.5: 6-iodoquinolines}

3-carbethoxy-6-iodo-4-quinolone (Price, 1946; Lin, 1978)<smiles>CCOC(=O)c1c[nH]c2ccc(I)cc2c1=O</smiles>

para-Iodoaniline $(13.24 \mathrm{~g}, 60.5 \mathrm{mmol})$ and diethyl ethoxymethylene malonate $(13.05 \mathrm{~g}$, $60.4 \mathrm{mmol})$ in Dowtherm A $(100 \mathrm{~mL})$ were allowed to heat gradually, stirring, to $255^{\circ} \mathrm{C}$, at which temperature the reaction was allowed to remain for 25 minutes. After cooling, the reaction mixture was diluted with $150 \mathrm{~mL}$ hexanes, then vacuum filtered, rinsing with hexanes $(200 \mathrm{~mL})$ followed by acetone $(70 \mathrm{~mL})$ to give a lustrous, pearl-gray solid $(19.37$ g, $93 \%)$.

3-carboxy-6-iodo-4-quinolone (Price, 1946; Lin, 1978)<smiles>O=C(O)c1c[nH]c2ccc(I)cc2c1=O</smiles>

3-carbethoxy-6-iodo-4-quinolone (19.37 g, $56.5 \mathrm{mmol}$ ) in $250 \mathrm{~mL}$ of $10 \%$ caustic soda was heated just under reflux, stirring, for 24 hours. At the end of this time, a small amount of undissolved solid was removed by vacuum filtration $(0.53 \mathrm{~g}$ after drying, this was presumed to be unsaponified starting material). The filtrate was made acidic by addition of concentrated muriatic acid. The resulting pure white precipitate was recovered from the pale yellow filtrate by vacuum filtration. After air-drying, $18.80 \mathrm{~g}$ of product 
was obtained (containing residual water). This material was used without further drying or purification in the next step.

${ }^{1} \mathrm{H}$ NMR $\delta(\mathrm{ppm})\left(\mathrm{DMSO}_{\mathrm{d}}\right)$ : $15.04(1 \mathrm{H}, \mathrm{br} \mathrm{s}), 13.58(1 \mathrm{H}, \mathrm{s}), 8.92(1 \mathrm{H}, \mathrm{s}), 8.57(1 \mathrm{H}, \mathrm{d}$, $\mathrm{J}=2.00 \mathrm{~Hz}), 8.18(1 \mathrm{H}, \mathrm{dd}, \mathrm{J}=8.73,2.03 \mathrm{~Hz}), 7.65(1 \mathrm{H}, \mathrm{d}, \mathrm{J}=8.73 \mathrm{~Hz})$.

6-iodo-4-quinolone (Price, 1946; Lin, 1948)<smiles>O=c1cc[nH]c2ccc(I)cc12</smiles>

The above product (18.80 g, containing residual water) was heated in Dowtherm A (125 $\mathrm{mL})$ at $255^{\circ} \mathrm{C}$ for 25 minutes. After cooling, NMR indicated that the reaction had not gone to completion; it was therefore heated for an additional 25 minutes at $255^{\circ} \mathrm{C}$. After cooling, the reaction mixture was diluted with $100 \mathrm{~mL} 35-60^{\circ}$ petroleum æther and vacuum filtered to recover the solid product $(15.70 \mathrm{~g}$, presumed to contain residual solvent; yield not calculated). This was used without purification in the next step.

4-chloro-6-iodoquinoline (Price, 1946; Lin, 1978)<smiles>Clc1ccnc2ccc(I)cc12</smiles>

The above product (15.62 g, presumed to contain residual solvent) was heated in phosphorus oxychloride $(60 \mathrm{~mL}, 640 \mathrm{mmol})$ for 1 hour at $100^{\circ} \mathrm{C}$, followed by 20 hours at $70^{\circ} \mathrm{C}$, and finally 2 hours at $100^{\circ} \mathrm{C}$. TLC indicated that the reaction was complete, and the dark reaction mixture was therefore poured gradually onto ice, followed by basification with concentrated caustic soda. After cooling, the aqueous mixture (diluted to $2.7 \mathrm{~L}$ ) was divided into three portions. Each portion was extracted with chloroform $(50 \mathrm{~mL}$, then $5 \times 15 \mathrm{~mL})$, and the pooled organic layers were dried $\left(\mathrm{MgSO}_{4}\right)$ and evaporated under reduced pressure with warming to yield an off-white, powdery solid (14.24 g, 81\% from starting aniline, mp $137-139^{\circ} \mathrm{C}$ (lit. $138-139.5^{\circ} \mathrm{C}$ (Lin, 1978)). 
${ }^{1} \mathrm{H} \mathrm{NMR} \delta(\mathrm{ppm})\left(\mathrm{CHCl}_{3}-\mathrm{d}\right): 8.78(1 \mathrm{H}, \mathrm{d}, \mathrm{J}=4.69 \mathrm{~Hz}, \mathrm{Q}-\mathrm{C} 2-\mathrm{H}), 8.62(1 \mathrm{H}, \mathrm{d}, \mathrm{J}=1.96$ $\mathrm{Hz}, \mathrm{Q}-\mathrm{C} 5-\mathrm{H}), 8.02(1 \mathrm{H}, \mathrm{dd}, \mathrm{J}=8.83,1.94 \mathrm{~Hz}, \mathrm{Q}-\mathrm{C} 7-\mathrm{H}), 7.84(1 \mathrm{H}, \mathrm{d}, \mathrm{J}=8.83 \mathrm{~Hz}$, QC8-H), $7.50(1 \mathrm{H}, \mathrm{d}, \mathrm{J}=4.69 \mathrm{~Hz}, \mathrm{Q}-\mathrm{C} 3-\mathrm{H})$.

\section{3-(6-iodoquinolin-4-ylamino)propanol}<smiles>OCCCNc1ccnc2ccc(I)cc12</smiles>

4-chloro-6-iodoquinoline (7.00 g, $24.2 \mathrm{mmol}$ ) and 3-amino-1-propanol (10.90 g, 145 $\mathrm{mmol}$ ) were heated at $95^{\circ} \mathrm{C}$ in a Carius vessel for 24 hours. The reaction mixture still contained solid material. Temperature was increased to $140^{\circ} \mathrm{C}$ for 1 hour, with no visible change, and then to $160^{\circ} \mathrm{C}$. After a further hour, no solid was visible, and TLC indicated that the reaction was complete. The reaction was allowed to cool to $110^{\circ} \mathrm{C}$, and the hot reaction mixture was then poured into $200 \mathrm{~mL}$ water. After standing 1 hour, the resulting precipitate was recovered by vacuum filtration, followed by air-drying ( $7.55 \mathrm{~g}$ of a yellow solid, $95 \%, \mathrm{mp}=177.0-179 \cdot 4^{\circ} \mathrm{C}$ ).

${ }^{1} \mathrm{H}$ NMR $\delta(\mathrm{ppm})\left(\mathrm{DMSO}-\mathrm{d}_{6}\right): 8.65(1 \mathrm{H}, \mathrm{d}, \mathrm{J}=1.91 \mathrm{~Hz}), 8.38(1 \mathrm{H}, \mathrm{d}, \mathrm{J}=5.37 \mathrm{~Hz}), 7.84$ $(1 \mathrm{H}, \mathrm{dd}, \mathrm{J}=8.80,1.87 \mathrm{~Hz}), 7.54(1 \mathrm{H}, \mathrm{d}, \mathrm{J}=8.80 \mathrm{~Hz}), 7.24(1 \mathrm{H}, \mathrm{br} \mathrm{t}, \mathrm{J}=5.27 \mathrm{~Hz}), 6.47$ $(1 \mathrm{H}, \mathrm{d}, \mathrm{J}=5.43 \mathrm{~Hz}), 4.58(1 \mathrm{H}, \mathrm{t}, \mathrm{J}=5.07 \mathrm{~Hz}), 3.54(2 \mathrm{H}, \mathrm{m}), 3.26-3.33(2 \mathrm{H}, \mathrm{m}), 1.82$ $(2 \mathrm{H}, \mathrm{m})$.

\section{3-(6-iodoquinolin-4-ylamino)propyl methanesulfonate}<smiles>COCCCNc1ccnc2ccc(I)cc12</smiles>

3-(6-iodoquinolin-4-ylamino)propanol (3.50 g, $10.7 \mathrm{mmol})$ and triethylamine $(2.23 \mathrm{~mL}$, $16.1 \mathrm{mmol}$ ) in $100 \mathrm{~mL}$ dry tetrahydrofuran were cooled to below $0^{\circ} \mathrm{C}$ on ice/salt. Methanesulfonyl chloride $(0.96 \mathrm{~mL}, 12.3 \mathrm{mmol})$ was added dropwise. After stirring for 3 hours on ice, TLC indicated that reaction was not complete. Additional methanesulfonyl chloride $(0.15 \mathrm{~mL}, 1.9 \mathrm{mmol})$ was added. After a further 30 minutes, the reaction was 
sealed and refrigerated for 18 hours. TLC then indicated that no quinoline starting material remained. The reaction mixture was diluted with ethyl acetate $(30 \mathrm{~mL})$ and shaken with saturated $\mathrm{NaHCO}_{3}(45 \mathrm{~mL})$. After separation, the organic layer was washed with water $(3 \times 10 \mathrm{~mL})$, then dried $\left(\mathrm{MgSO}_{4}\right)$ and evaporated under reduced pressure with warming (extract A). The initial aqueous layer was extracted with further ethyl acetate (3 x $15 \mathrm{~mL})$, and this ethyl acetate was pooled, dried $\left(\mathrm{MgSO}_{4}\right)$, and also evaporated under reduced pressure with warming (extract B). Comparison of extracts A and B indicated that neither contained a significant amount of triethylamine, and that extract B contained $6 \%$ of the total yield (i.e. additional extractions of the aqueous layer increase yield without increasing the amount of triethylamine contamination of the product, and it is not worthwhile to rinse the organic layers with water to remove residual triethylamine).

Extracts A and B were combined (a yellow solid, $3.92 \mathrm{~g}, 90 \%$ ).

${ }^{1} \mathrm{H}$ NMR $\delta(\mathrm{ppm})\left(\mathrm{DMSO}_{\mathrm{d}}\right): 8.65(1 \mathrm{H}, \mathrm{d}, \mathrm{J}=1.91 \mathrm{~Hz}), 8.41(1 \mathrm{H}, \mathrm{d}, \mathrm{J}=5.36 \mathrm{~Hz}), 7.86$ $(1 \mathrm{H}, \mathrm{dd}, \mathrm{J}=8.80,1.86 \mathrm{~Hz}), 7.55(1 \mathrm{H}, \mathrm{d}, \mathrm{J}=8.80 \mathrm{~Hz}), 7.29(1 \mathrm{H}, \mathrm{s}), 6.51(1 \mathrm{H}, \mathrm{d}, \mathrm{J}=$ $5.42 \mathrm{~Hz}$ ), $4.35(2 \mathrm{H}, \mathrm{t}, \mathrm{J}=6.21 \mathrm{~Hz}), 3.33$ (water overlaps m, 2 H), $3.20(3 \mathrm{H}, \mathrm{s}), 2.08(2$ $\mathrm{H}$, apparent $\mathrm{p}, \mathrm{J}=6.61 \mathrm{~Hz}$ ).

\section{PL317: N-(3-(4-benzhydrylpiperazin-1-yl)propyl)-6-iodoquinolin-4-amine}

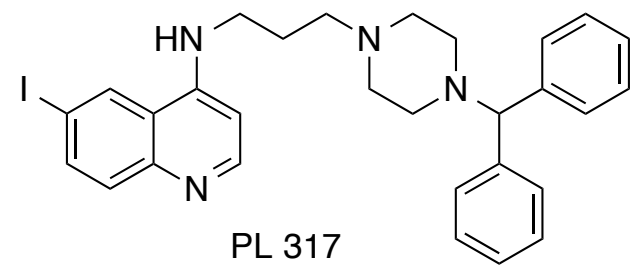

3-(6-iodo quinolin-4-ylamino)propyl methanesulfonate (1.96 g, $4.82 \mathrm{mmol}), \mathrm{N}-$ (diphenylmethyl)piperazine $(1.28 \mathrm{~g}, 5.07 \mathrm{mmol})$, potassium carbonate $(1.00 \mathrm{~g}, 7.23$ $\mathrm{mmol}$ ), and a catalytic amount of potassium iodide were heated in refluxing acetonitrile $(50 \mathrm{~mL})$ for 24 hours. TLC then indicated that reaction was complete. The solvent was removed by evaporation under reduced pressure with warming, diluting with $35 \mathrm{~mL}$ water at the end. This material was then extracted with ethyl acetate $(25 \mathrm{~mL})$. Some material remained insoluble, and so the aqueous layer was extracted with dichloromethane $(25 \mathrm{~mL})$; residual undissolved material was removed by vacuum filtration. The aqueous layer was then extracted with a further ethyl acetate $(3 \times 10 \mathrm{~mL})$, and the pooled organic layers were dried $\left(\mathrm{MgSO}_{4}\right)$ and evaporated under reduced pressure with warming to yield an ochre solid. The insoluble material from extraction was dissolved in excess boiling 95\% ethanol and allowed to evaporate gradually to 200 $\mathrm{mL}$ (at room temperature); filtration afforded the desired product as large, lustrous, 
golden crystals. The mother liquor was further concentrated to yield a second crop of crystals $\left(1.37 \mathrm{~g}\right.$ in total, $\left.51 \%, \mathrm{mp}=208-210^{\circ} \mathrm{C}\right)$.

${ }^{1} \mathrm{H}$ NMR $\delta(\mathrm{ppm})\left(\mathrm{CHCl}_{3}-\mathrm{d}\right): 8.50(1 \mathrm{H}, \mathrm{d}, \mathrm{J}=5.34 \mathrm{~Hz}), 8.25(1 \mathrm{H}, \mathrm{d}, \mathrm{J}=1.89 \mathrm{~Hz}), 7.87$ $(1 \mathrm{H}, \mathrm{dd}, \mathrm{J}=8.87,1.85 \mathrm{~Hz}), 7.68(1 \mathrm{H}, \mathrm{d}, \mathrm{J}=8.87 \mathrm{~Hz}), 7.51(1 \mathrm{H}$, br t, J = 4.04 Hz), 7.46$7.48(4 \mathrm{H}, \mathrm{m}), 7.27-7.27$ (solvent peak overlaps $\mathrm{m}, \sim 4 \mathrm{H}), 7.14-7.21(2 \mathrm{H}, \mathrm{m}), 6.32(1 \mathrm{H}$, d, $\mathrm{J}=5.39 \mathrm{~Hz}), 4.68(1 \mathrm{H}, \mathrm{s}), 3.34(2 \mathrm{H}, \mathrm{td}, \mathrm{J}=5.68,4.01 \mathrm{~Hz}), 2.63(10 \mathrm{H}$, br s overlaps t, $\mathrm{J}=5.25 \mathrm{~Hz}), 1.92(2 \mathrm{H}$, apparent $\mathrm{p}, \mathrm{J}=5.29 \mathrm{~Hz})$.

${ }^{13} \mathrm{C} \mathrm{NMR} \delta(\mathrm{ppm})\left(\mathrm{CHCl}_{3}-\mathrm{d}\right): 151.7,149.6,147.6,143.1,137.7,131.8,129.2,128.6$, $127.9,127.0,121.2,99.0,89.1,75.5,59.4,54.3,52.0,45.1,23.3$.

MS (ESI): $m / z 563.16755 \mathrm{M}+\mathrm{H}$ (calculated 563.16662)

HPLC (method A) $t_{\mathrm{R}}=10.91 \min (99 \%$ pure $)$.

\section{PL318: 6-iodo- $N$-(3-(4-(pyridin-2-yl)piperazin-1-yl)propyl)quinolin-4-amine}

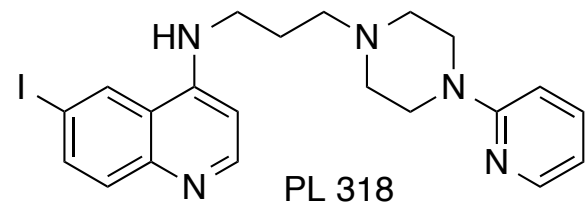

3-(6-iodoquinolin-4-ylamino)propyl methanesulfonate (1.96 g, $4.82 \mathrm{mmol}), 1$-(2pyridyl)piperazine $(0.87 \mathrm{~g}, 5.33 \mathrm{mmol})$, and potassium carbonate $(1.00 \mathrm{~g}, 7.23 \mathrm{mmol})$ were heated in refluxing acetonitrile $(50 \mathrm{~mL})$ for 28 hours. The solvent was removed under reduced pressure with warming, and the residue was diluted with water $(35 \mathrm{~mL})$ and filtered. The solid material was dissolved in excess boiling solvent ( $25 \%$ ethanol, $75 \%$ ethyl acetate) and allowed to concentrate slowly at room temperature to $22 \mathrm{~mL}$.

Filtration afforded the desired product as small, amber crystals $(1.25 \mathrm{~g}, 55 \%, \mathrm{mp}=193.5$ $\left.194.5^{\circ} \mathrm{C}\right)$.

${ }^{1} \mathrm{H}$ NMR $\delta(\mathrm{ppm})\left(\mathrm{CHCl}_{3}-\mathrm{d}\right): 8.51(1 \mathrm{H}, \mathrm{d}, \mathrm{J}=5.34 \mathrm{~Hz}), 8.27(1 \mathrm{H}, \mathrm{d}, \mathrm{J}=1.91 \mathrm{~Hz}), 8.20-$ $8.22(1 \mathrm{H}, \mathrm{m}), 7.75(1 \mathrm{H}, \mathrm{dd}, \mathrm{J}=8.85,1.88 \mathrm{~Hz}), 7.71(1 \mathrm{H}, \mathrm{t}, \mathrm{J}=4.02 \mathrm{~Hz}), 7.65(1 \mathrm{H}, \mathrm{d}, \mathrm{J}$ $=8.84 \mathrm{~Hz}), 7.49(1 \mathrm{H}, \mathrm{ddd}, \mathrm{J}=8.56,7.14,2.02 \mathrm{~Hz}), 6.73(1 \mathrm{H}, \mathrm{d}, \mathrm{J}=8.57 \mathrm{~Hz}), 6.64(1 \mathrm{H}$, $\mathrm{dd}, \mathrm{J}=7.14,4.92 \mathrm{~Hz}), 6.33(1 \mathrm{H}, \mathrm{d}, \mathrm{J}=5.38 \mathrm{~Hz}), 3.84(4 \mathrm{H}, \mathrm{m}), 3.40(2 \mathrm{H}, \mathrm{td}, \mathrm{J}=5.73$, $4.03 \mathrm{~Hz}), 2.70-2.71(6 \mathrm{H}, \mathrm{m}), 2.00(2 \mathrm{H}$, apparent $\mathrm{p}, \mathrm{J}=5.35 \mathrm{~Hz})$.

${ }^{13} \mathrm{C} \mathrm{NMR} \delta(\mathrm{ppm})\left(\mathrm{CHCl}_{3}-\mathrm{d}\right): 159.6,151.7,149.5,147.9,147.5,137.5,137.4,131.6$, 129.3, 121.0, 113.6, 107.4, 98.7, 88.8, 59.4, 53.7, 45.2, 44.8, 23.3. 
MS (ESI): $m / z$ 474.11508 M + H (calculated 474.11492)

HPLC (method A) $t_{\mathrm{R}}=6.55 \min (>99 \%$ pure).

\section{A.2.6: 7-iodoquinolines}

3-carbethoxy-5- and 7-iodo-4-quinolone (Price, 1946; Conroy, 1949)<smiles>CCOC(=O)c1c[nH]c2cc(I)ccc2c1=O</smiles>

meta-Iodoaniline (11.14 g, $52.1 \mathrm{mmol})$ and diethyl ethoxymethylene malonate (10.28 $\mathrm{mL}, 51.3 \mathrm{mmol})$ in Dowtherm A $(125 \mathrm{~mL})$ were allowed to heat gradually, stirring, to $255^{\circ} \mathrm{C}$, at which temperature the reaction was allowed to remain for 30 minutes. After cooling, the reaction mixture was vacuum filtered (without dilution), rinsing with $10 \mathrm{~mL}$ Dowtherm A, then with $35-60^{\circ}$ petroleum æther $(200 \mathrm{~mL})$, and finally with acetone (70 $\mathrm{mL})$ to give an off-white, powdery solid (19.25 g). NMR indicated that the 7- and 5iodo regioisomers were present in a proportion of approximately $9: 1$. This material was used without purification in the ensuing reactions.

5- and 7- iodo-3-carboxy-4-quinolone (Price, 1946; Conroy, 1949)<smiles>CCOC(=O)c1c[nH]c2cc(I)ccc2c1=O</smiles>

The above product $(19.25 \mathrm{~g}, \leq 52.1 \mathrm{mmol})$ in $450 \mathrm{~mL}$ of $10 \%$ caustic soda was allowed to reflux, stirring, for 3 hours, at which point all solid material had dissolved. After cooling to room temperature, some solid appeared, and so the reaction was reheated before being poured into $450 \mathrm{~mL}$ deionized water and acidified with concentrated muriatic acid. After cooling, the resulting white precipitate was recovered by vacuum filtration $(14.41 \mathrm{~g}$, used without analysis in the ensuing reaction). 
5- and 7-iodo-4-quinolone (Price, 1946; Conroy, 1949)<smiles>O=c1cc[nH]c2cc(I)ccc12</smiles>

Without further drying, the above product $(14.41 \mathrm{~g})$ was heated in Dowtherm A $(75 \mathrm{~mL})$ at $255^{\circ} \mathrm{C}$ for 50 minutes. After cooling, the reaction mixture was diluted with $100 \mathrm{~mL}$ $35-60^{\circ}$ petroleum æther and vacuum filtered. The solid product was used without analysis in the next reaction.

4-chloro-7-iodoquinoline (Price, 1946; Conroy, 1949)<smiles>Clc1ccnc2cc(I)ccc12</smiles>

Phosphorus oxychloride $(30 \mathrm{~mL}, 320 \mathrm{mmol})$ was cautiously added to the product from the above reaction $(12.43 \mathrm{~g})$. The mixture was heated at $105^{\circ} \mathrm{C}$ for 4 hours, followed by heating at $70^{\circ} \mathrm{C}$ for 14 hours. After cooling, the reaction mixture was poured gradually into ice water $(700 \mathrm{~mL})$ and then made basic $(\mathrm{pH} \mathrm{10})$ with solid caustic soda. The resulting inhomogeneous mixture was diluted with water to $1.1 \mathrm{~L}$ and extracted in three equal portions. Each was extracted with chloroform ( $100 \mathrm{~mL}$, followed by $3 \times 30 \mathrm{~mL})$, and the combined organic layers were dried $\left(\mathrm{MgSO}_{4}\right)$ and evaporated under reduced pressure with warming to yield a pale brown solid $(9.60 \mathrm{~g}, 64 \%$ from the aniline, $\mathrm{mp}=$ 100.4-102. ${ }^{\circ} \mathrm{C}$ (lit. $101-102^{\circ} \mathrm{C}$ (Conroy, 1949)). NMR indicated that none of the 5-iodo regioisomer was present.

\section{3-(7-iodoquinolin-4-ylamino)propanol}<smiles>OCCCNc1ccnc2cc(I)ccc12</smiles> 
4-chloro-7-iodoquinoline (3.00 g, $10.4 \mathrm{mmol}$ ) and 3-amino-1-propanol (4.76 mL, 62.2 $\mathrm{mmol}$ ) were heated at $85^{\circ} \mathrm{C}$ in a Carius vessel for 20 hours. TLC indicated that the reaction was complete, and so the hot reaction mixture was poured into $100 \mathrm{~mL}$ water (stirring well). After standing 1 hour, the resulting precipitate was recovered by vacuum filtration, followed by air drying $\left(3.28 \mathrm{~g}\right.$ of an ochre solid, $\left.96 \%, \mathrm{mp}=172.1-173.9^{\circ} \mathrm{C}\right)$.

${ }^{1} \mathrm{H}$ NMR $\delta(\mathrm{ppm})\left(\mathrm{DMSO}_{-} \mathrm{d}_{6}\right): 8.36(1 \mathrm{H}, \mathrm{d}, \mathrm{J}=5.38 \mathrm{~Hz}), 8.15(1 \mathrm{H}, \mathrm{d}, \mathrm{J}=1.83 \mathrm{~Hz}), 8.00$ $(1 \mathrm{H}, \mathrm{d}, \mathrm{J}=8.86 \mathrm{~Hz}), 7.68(1 \mathrm{H}, \mathrm{dd}, \mathrm{J}=8.78,1.88 \mathrm{~Hz}), 7.26(1 \mathrm{H}, \mathrm{br} \mathrm{t}, \mathrm{J}=5.37 \mathrm{~Hz}), 6.48$ $(1 \mathrm{H}, \mathrm{d}, \mathrm{J}=5.44 \mathrm{~Hz}), 4.59(1 \mathrm{H}, \mathrm{t}, \mathrm{J}=5.04 \mathrm{~Hz}), 3.54(2 \mathrm{H}, \mathrm{m}), 3.27-3.32$ (water signal overlaps $\mathrm{m}, \sim 2 \mathrm{H}, \mathrm{m}), 1.81(2 \mathrm{H}$, apparent $\mathrm{p}, \mathrm{J}=6.66 \mathrm{~Hz})$.

${ }^{1} \mathrm{H} \mathrm{NMR} \delta(\mathrm{ppm})\left(\mathrm{CHCl}_{3}-\mathrm{d}\right): 8.50(1 \mathrm{H}, \mathrm{d}, \mathrm{J}=5.35 \mathrm{~Hz}), 8.36(1 \mathrm{H}, \mathrm{d}, \mathrm{J}=1.79 \mathrm{~Hz}), 7.64$ $(1 \mathrm{H}, \mathrm{dd}, \mathrm{J}=8.78,1.81 \mathrm{~Hz}), 7.41(1 \mathrm{H}, \mathrm{d}, \mathrm{J}=8.81 \mathrm{~Hz}), 6.40(1 \mathrm{H}, \mathrm{d}, \mathrm{J}=5.37 \mathrm{~Hz}), 3.96(2$ $\mathrm{H}, \mathrm{t}, \mathrm{J}=5.43 \mathrm{~Hz}), 3.47(2 \mathrm{H}, \mathrm{m}), 2.04-2.04(2 \mathrm{H}, \mathrm{m})$.

MS (ESI): $m / z 329.01435 \mathrm{M}+\mathrm{H}$ (calculated 329.01496)

HPLC (method A) $t_{\mathrm{R}}=8.66 \min (98 \%$ pure $)$.

\section{3-(7-iodoquinolin-4-ylamino)propyl methanesulfonate}<smiles>COCCCNc1ccnc2cc(I)ccc12</smiles>

3-(7-iodoquinolin-4-ylamino)propanol $(1.00 \mathrm{~g}, 3.05 \mathrm{mmol})$ and triethylamine $(0.64 \mathrm{~mL}$, $4.6 \mathrm{mmol}$ ) in $100 \mathrm{~mL}$ dry tetrahydrofuran were cooled to $5^{\circ} \mathrm{C}$ in an ice bath. Methanesulfonyl chloride $(0.26 \mathrm{~mL}, 3.4 \mathrm{mmol})$ was added dropwise. After stirring for 30 minutes, TLC indicated that reaction was not complete. Additional triethylamine $(0.27$ $\mathrm{mL}, 1.9 \mathrm{mmol})$ and methanesulfonyl chloride $(0.07 \mathrm{~mL}, 0.9 \mathrm{mmol})$ were added. After a further 45 minutes, TLC indicated that reaction was complete. The reaction mixture was diluted with $25 \mathrm{~mL}$ ethyl acetate and shaken with $30 \mathrm{~mL}$ saturated $\mathrm{NaHCO}_{3}$. The aqueous layer was diluted with $15 \mathrm{~mL}$ water to dissolve a small amount of precipitate that formed. After separation of the layers, the aqueous layer was extracted with $3 \times 10 \mathrm{~mL}$ ethyl acetate, and the pooled organic layers were dried $\left(\mathrm{MgSO}_{4}\right)$ and evaporated under reduced pressure with warming to yield a grayish yellow solid, containing residual ethyl acetate and triethylamine. This material was used without purification in the ensuing reaction. 
${ }^{1} \mathrm{H}$ NMR $\delta(\mathrm{ppm})\left(\mathrm{CHCl}_{3}-\mathrm{d}\right): 8.50(1 \mathrm{H}, \mathrm{d}, \mathrm{J}=5.36 \mathrm{~Hz}), 8.38(1 \mathrm{H}, \mathrm{d}, \mathrm{J}=1.79 \mathrm{~Hz}), 7.69$ $(1 \mathrm{H}, \mathrm{dd}, \mathrm{J}=8.80,1.80 \mathrm{~Hz}), 7.50(1 \mathrm{H}, \mathrm{d}, \mathrm{J}=8.84 \mathrm{~Hz}), 6.44(1 \mathrm{H}, \mathrm{d}, \mathrm{J}=5.40 \mathrm{~Hz}), 5.56(1$ $\mathrm{H}, \mathrm{s}), 4.41(2 \mathrm{H}, \mathrm{t}, \mathrm{J}=5.66 \mathrm{~Hz}), 3.57(2 \mathrm{H}, \mathrm{m}), 3.06(3 \mathrm{H}, \mathrm{s}), 2.16-2.18(2 \mathrm{H}, \mathrm{m})$. Minor peaks due to triethylamine and ethyl acetate were also present.

\section{PL392: 7-iodo- $N$-(3-(4-(pyridin-2-yl)piperazin-1-yl)propyl)quinolin-4-amine}<smiles>CCCCCCCCNc1ccnc2cc(I)ccc12</smiles>

3-(7-iodoquinolin-4-ylamino)propyl methanesulfonate (no more than $2.2 \mathrm{mmol}$, containing residual triethylamine and ethyl acetate), 1-(2-pyridyl)piperazine ( $0.38 \mathrm{~g}, 2.3$ $\mathrm{mmol})$, and potassium carbonate $(0.45 \mathrm{~g}, 2.2 \mathrm{mmol})$ were heated in refluxing acetonitrile $(25 \mathrm{~mL})$ for 13 hours. The reaction mixture was diluted with $5 \mathrm{~mL}$ water, and the solvent was removed under reduced pressure with warming; the residue was partitioned between chloroform $(150 \mathrm{~mL})$ and water $(125 \mathrm{~mL})$. After separation, the aqueous layer was extracted with additional chloroform $(3 \times 10 \mathrm{~mL})$, and the pooled organic layers were dried $\left(\mathrm{MgSO}_{4}\right)$ and evaporated under reduced pressure with warming to yield a golden oil. This was recrystallized from $20 \mathrm{~mL}$ ethyl acetate $/ 95 \%$ ethanol (9:1) to yield the desired product as yellow crystals $(0.58 \mathrm{~g}, 56 \%$ from 3-(7-iodoquinolin-4ylamino)propanol, $\mathrm{mp}=176.5-177 \cdot 1^{\circ} \mathrm{C}$ ).

${ }^{1} \mathrm{H}$ NMR $\delta(\mathrm{ppm})\left(\mathrm{CHCl}_{3}-\mathrm{d}\right): 8.50(1 \mathrm{H}, \mathrm{d}, \mathrm{J}=5.34 \mathrm{~Hz}), 8.35(1 \mathrm{H}, \mathrm{d}, \mathrm{J}=1.74 \mathrm{~Hz}), 8.23-$ $8.25(1 \mathrm{H}, \mathrm{m}), 7.57(1 \mathrm{H}, \mathrm{d}, \mathrm{J}=8.80 \mathrm{~Hz}), 7.54-7.54(2 \mathrm{H}, \mathrm{m}), 7.28(1 \mathrm{H}, \mathrm{br} \mathrm{t}, \mathrm{J}=4.42$ $\mathrm{Hz}), 6.67-6.71(2 \mathrm{H}, \mathrm{m}), 6.36(1 \mathrm{H}, \mathrm{d}, \mathrm{J}=5.38 \mathrm{~Hz}), 3.67(4 \mathrm{H}, \mathrm{m}), 3.41(2 \mathrm{H}, \mathrm{td}, \mathrm{J}=5.97$, $4.24 \mathrm{~Hz}), 2.67-2.68(6 \mathrm{H}, \mathrm{m}), 2.00(2 \mathrm{H}$, apparent $\mathrm{p}, \mathrm{J}=5.61 \mathrm{~Hz})$.

${ }^{13} \mathrm{C} \mathrm{NMR} \delta(\mathrm{ppm})\left(\mathrm{CHCl}_{3}-\mathrm{d}\right): 159.3,151.9,150.5,149.5,148.1,138.8,137.7,132.7$, 121.8, 118.3, 113.8, 107.2, 107.1, 98.8, 94.8, 58.7, 53.5, 45.4, 44.3, 23.7.

MS (ESI): $m / z$ 474.11539 M + H (calculated 474.11492)

HPLC (method A) $t_{\mathrm{R}}=6.43 \min (97 \%$ pure). 


\section{A.3.: Nitroquinolines, trifluoromethyl quinolines, and 7-chloro-2-methylquinolines}

\section{A.3.1: 6-nitroquinolines}

3-carbethoxy-6-nitro-4-quinolone (Price, 1946; Riegel, 1946)<smiles>CCOC(=O)c1c[nH]c2ccc([N+](=O)[O-])cc2c1=O</smiles>

para-Nitroaniline $(5.00 \mathrm{~g}, 36.2 \mathrm{mmol})$ and diethyl ethoxymethylene malonate $(7.25 \mathrm{~mL}$, $36.2 \mathrm{mmol}$ ) were heated on a boiling water bath for 40 minutes. Crystallization of the crude reaction mixture from methanol afforded the condensation product as greenish-gray crystals. This material was heated in refluxing Dowtherm A $(125 \mathrm{~mL})$ for 30 minutes. After cooling, the reaction mixture was diluted with $35-60^{\circ}$ petroleum æather $(200 \mathrm{~mL})$ and vacuum filtered to recover the solid product (6.96 g, 74\% yield).

3-carboxy-6-nitro-4-quinolone (Price, 1946; Riegel, 1946)<smiles>O=C(O)c1c[nH]c2ccc([N+](=O)[O-])cc2c1=O</smiles>

3-carbethoxy-6-nitro-4-quinolone (6.96 g, $26.5 \mathrm{mmol})$ in $55 \mathrm{~mL}$ of $10 \%$ caustic soda was allowed to reflux, stirring, for 30 minutes, at which point all solid material had dissolved. After partial cooling, the brilliant orange, semisolid reaction mixture was poured into water $(200 \mathrm{~mL})$; after heating to $60^{\circ} \mathrm{C}$ to dissolve the solid, the mixture was acidified with $10 \%$ muriatic acid. The resulting tan precipitate was isolated by vacuum filtration (the filtrate was now colorless). After air-drying, the product was used without further purification in the ensuing reaction.

${ }^{1} \mathrm{H}$ NMR $\delta(\mathrm{ppm})\left(\mathrm{DMSO}_{\mathrm{d}}\right): 14.59(1 \mathrm{H}$, br s, COOH$), 13.78(1 \mathrm{H}$, br s, Q-N1-H), 9.05 (1 H, s, Q-C2-H), 8.98 (1 H, d, J = 2.64 Hz, Q-C5-H), $8.63(1 \mathrm{H}, \mathrm{dd}, \mathrm{J}=9.16,2.66 \mathrm{~Hz}$, Q-C7-H), 8.02 (1 H, d, J = 9.16 Hz, Q-C8-H). 
6-nitro-4-quinolone (Price, 1946; Baker, 1946)<smiles>O=c1cc[nH]c2ccc([N+](=O)[O-])cc12</smiles>

3-carboxy-6-nitro-4-quinolone from the above reaction was decarboxylated in two portions as follows. Approximately half of the above product was heated in Dowtherm A $(100 \mathrm{~mL})$ at $255^{\circ} \mathrm{C}$ for 30 minutes. After cooling, the reaction mixture was diluted with

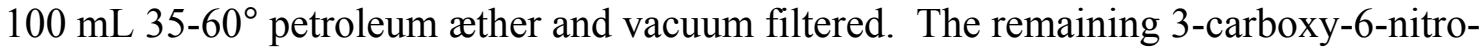
4-quinolone was treated in the same manner and the products from the two reactions were combined (4.77 g, 95\% from 3-carbethoxy-6-nitro-4-quinolone).

${ }^{1} \mathrm{H}$ NMR $\delta(\mathrm{ppm})\left(\mathrm{DMSO}_{6}\right): 12.28(1 \mathrm{H}, \mathrm{br} \mathrm{d}, \mathrm{J}=5.26 \mathrm{~Hz}, \mathrm{Q}-\mathrm{N} 1-\mathrm{H}), 8.84(1 \mathrm{H}, \mathrm{d}, \mathrm{J}=$ $2.71 \mathrm{~Hz}, \mathrm{Q}-\mathrm{C} 5-\mathrm{H}), 8.42(1 \mathrm{H}, \mathrm{dd}, \mathrm{J}=9.15,2.73 \mathrm{~Hz}, \mathrm{Q}-\mathrm{C} 7-\mathrm{H}), 8.05(1 \mathrm{H}, \mathrm{dd}, \mathrm{J}=7.52$, 5.24 Hz, Q-C2-H), 7.73 (1 H, d, J = 9.16 Hz, Q-C8-H), 6.19 (1 H, d, J = 7.53 Hz, Q-C3$\mathrm{H})$.

4-chloro-6-nitroquinoline (Price, 1946; Baker, 1946)<smiles>O=[N+]([O-])c1ccc2nccc(Cl)c2c1</smiles>

6-nitro-4-quinolone (4.77 g, $25.1 \mathrm{mmol}$ ) was heated in $25 \mathrm{~mL}$ phosphorus oxychloride for 1.5 hours at reflux. Upon cooling to room temperature, the reaction mixture was poured gradually onto ice (stirring vigorously). The aqueous mixture $(400 \mathrm{~mL})$ was then extracted (without basifying) with four $50 \mathrm{~mL}$ portions of DCM, and the pooled organic layers were rinsed with $50 \mathrm{~mL}$ brine. The yellow organic layers contained a black precipitate. This was removed by vacuum filtration, followed by drying of the filtrate over $\mathrm{MgSO}_{4}$ and evaporation under reduced pressure with warming to yield a cream colored powder with an odor resembling that of 4,7-dichloroquinoline $(3.35 \mathrm{~g}, 64 \%$, mp $=138.5-144.5^{\circ} \mathrm{C}$ (lit. 141-141.5 ${ }^{\circ} \mathrm{C}$ (Baker, 1946)). Note: It is probably that the yield could have been improved if the aqueous mixture had been basified before extraction. 
${ }^{1} \mathrm{H}$ NMR $\delta(\mathrm{ppm})\left(\mathrm{CHCl}_{3}-\mathrm{d}\right): 9.21(1 \mathrm{H}, \mathrm{d}, \mathrm{J}=2.52 \mathrm{~Hz}, \mathrm{Q}-\mathrm{C} 5-\mathrm{H}), 8.97(1 \mathrm{H}, \mathrm{d}, \mathrm{J}=4.72$ $\mathrm{Hz}, \mathrm{Q}-\mathrm{C} 2-\mathrm{H}), 8.55$ (1 H, dd, J = 9.23, $2.51 \mathrm{~Hz}, \mathrm{Q}-\mathrm{C} 7-\mathrm{H}), 8.29(1 \mathrm{H}, \mathrm{d}, \mathrm{J}=9.22 \mathrm{~Hz}, \mathrm{Q}-$ C8-H), 7.67 (1 H, d, J = 4.71 Hz, Q-C3-H).

\section{3-(6-nitroquinolin-4-ylamino)propanol}<smiles>O=[N+]([O-])c1ccc2nccc(NCCCO)c2c1</smiles>

4-chloro-6-nitroquinoline (2.82 g, $13.5 \mathrm{mmol})$ and 3-amino-1-propanol (15.0 mL, 196 $\mathrm{mmol}$ ) were heated at $90^{\circ} \mathrm{C}$ for 1.5 hours, followed by further heating at $130^{\circ} \mathrm{C}$ for 20 minutes. TLC then indicated that the reaction was complete. The hot reaction mixture was poured into $200 \mathrm{~mL}$ water, gradually and with good stirring. Vacuum filtration, followed by air-drying, afforded the desired product as a sparkling, ochre solid (2.76 g, $83 \%)$.

${ }^{1} \mathrm{H}$ NMR $\delta(\mathrm{ppm})\left(\mathrm{DMSO}_{6}\right): 9.37(1 \mathrm{H}, \mathrm{d}, \mathrm{J}=2.52 \mathrm{~Hz}, \mathrm{Q}-\mathrm{C} 5-\mathrm{H}), 8.51(1 \mathrm{H}, \mathrm{d}, \mathrm{J}=5.56$ $\mathrm{Hz}, \mathrm{Q}-\mathrm{C} 2-\mathrm{H}), 8.31$ (1 H, dd, J = 9.25, $2.48 \mathrm{~Hz}, \mathrm{Q}-\mathrm{C} 7-\mathrm{H}), 7.95$ (1 H, br t, J = 5.25 Hz, QC4-NH), 7.90 (1 H, d, J = 9.25 Hz, Q-C8-H), 6.61 (1 H, d, J = 5.61 Hz, Q-C3-H), 4.59 (1 $\mathrm{H}, \mathrm{t}, \mathrm{J}=5.07 \mathrm{~Hz}, \mathrm{OH}), 3.55\left(2 \mathrm{H}, \mathrm{td}, \mathrm{J}=6.13,5.06 \mathrm{~Hz}, \mathrm{Q}-\mathrm{NHCH}_{2} \mathrm{CH}_{2} \mathrm{CH}_{2}\right), 3.38(2 \mathrm{H}$, $\left.\mathrm{td}, \mathrm{J}=7.04,5.39 \mathrm{~Hz}, \mathrm{Q}-\mathrm{NHCH}_{2} \mathrm{CH}_{2} \mathrm{CH}_{2}\right), 1.84(2 \mathrm{H}$, apparent p, J = 6.64 Hz, Q$\mathrm{NHCH}_{2} \mathrm{CH}_{2} \mathrm{CH}_{2}$ ).

\section{3-(6-nitroquinolin-4-ylamino)propyl methanesulfonate}<smiles>COCCCNc1ccnc2ccc([N+](=O)[O-])cc12</smiles>

3-(6-nitroquinolin-4-ylamino)propanol $(2.76 \mathrm{~g}, 11.2 \mathrm{mmol})$ and triethylamine $(2.36 \mathrm{~mL}$, $16.9 \mathrm{mmol}$ ) in $100 \mathrm{~mL}$ dry chloroform were cooled to below $0^{\circ} \mathrm{C}$ on ice/salt.

Methanesulfonyl chloride $(1.01 \mathrm{~mL}, 13.0 \mathrm{mmol})$ was added dropwise. After stirring for an hour on ice, additional methanesulfonyl chloride $(0.5 \mathrm{~mL}, 6.43 \mathrm{mmol})$ was added. After a further 30 minutes, TLC indicated that no quinoline starting material remained. The reaction was vacuum filtered to remove a precipitate, and the filtrate was shaken 
with $45 \mathrm{~mL}$ saturated $\mathrm{NaHCO}_{3}$. After separation, the aqueous layer was extracted with further chloroform $(3 \times 10 \mathrm{~mL})$, and the pooled organic layers were washed with $10 \mathrm{~mL}$ brine, dried $\left(\mathrm{MgSO}_{4}\right)$, and evaporated under reduced pressure with warming. This afforded a bright yellow semisolid with the odor of triethylamine (approximately $3 \mathrm{~g}$, yield not calculated). This material was used without further purification.

${ }^{1} \mathrm{H}$ NMR $\delta(\mathrm{ppm})\left(\mathrm{DMSO}_{\mathrm{d}}\right)$ : $9.38(1 \mathrm{H}, \mathrm{d}, \mathrm{J}=2.53 \mathrm{~Hz}, \mathrm{Q}-\mathrm{C} 5-\mathrm{H}), 8.55(1 \mathrm{H}, \mathrm{d}, \mathrm{J}=5.55$ Hz, Q-C2-H), 8.33 (1 H, dd, J = 9.24, $2.48 \mathrm{~Hz}, \mathrm{Q}-\mathrm{C} 7-\mathrm{H}), 7.97$ (1 H, t, J = 5.25 Hz, Q-C4$\mathrm{NH}), 7.92$ (1 H, d, J = 9.24 Hz, Q-C8-H), 6.65 (1 H, d, J = 5.61 Hz, Q-C5-H), 4.37 (2 H, $\left.\mathrm{t}, \mathrm{J}=6.20 \mathrm{~Hz}, \mathrm{CH}_{2} \mathrm{CH}_{2} \mathrm{CH}_{2} \mathrm{OMs}\right), 3.44\left(2 \mathrm{H}, \mathrm{td}, \mathrm{J}=6.90,5.34 \mathrm{~Hz}, \mathrm{CH}_{2} \mathrm{CH}_{2} \mathrm{CH}_{2} \mathrm{OMs}\right)$, $3.21\left(3 \mathrm{H}, \mathrm{s}, \mathrm{CH}_{3}\right), 2.11\left(2 \mathrm{H}\right.$, apparent $\left.\mathrm{p}, \mathrm{J}=6.58 \mathrm{~Hz}, \mathrm{CH}_{2} \mathrm{CH}_{2} \mathrm{CH}_{2} \mathrm{OMs}\right)$. Minor peaks due to the presence of residual triethylamine were also present.

\section{PL282: 6-nitro- $N$-(3-(4-(pyridin-2-yl)piperazin-1-yl)propyl)quinolin-4-amine}

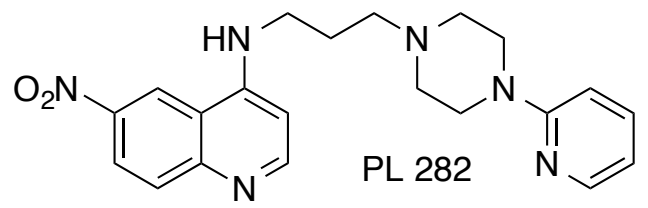

3-(6-nitroquinolin-4-ylamino)propyl methanesulfonate (0.36 g, $1.1 \mathrm{mmol}), 1$-(2pyridyl)piperazine $(0.23 \mathrm{~g}, 1.4 \mathrm{mmol})$, and potassium carbonate $(0.23 \mathrm{~g}, 1.7 \mathrm{mmol})$ in acetonitrile $(15 \mathrm{~mL})$ were allowed to reflux for 3 days. The reaction mixture was vacuum filtered, rinsing extensively with water, and then with $1 \mathrm{~mL} 95 \%$ ethanol. The canaryyellow, crystalline solid thus obtained proved to be the desired product $(0.24 \mathrm{~g}, 55 \%, \mathrm{mp}$ $\left.=175.5-177.4^{\circ} \mathrm{C}\right)$.

${ }^{1} \mathrm{H}$ NMR $\delta(\mathrm{ppm})\left(\mathrm{CHCl}_{3}-\mathrm{d}\right): 8.88(1 \mathrm{H}, \mathrm{d}, \mathrm{J}=2.48 \mathrm{~Hz}), 8.63(1 \mathrm{H}, \mathrm{d}, \mathrm{J}=5.50 \mathrm{~Hz}), 8.21-$ $8.21(1 \mathrm{H}, \mathrm{m}), 8.00(1 \mathrm{H}, \mathrm{d}, \mathrm{J}=9.25 \mathrm{~Hz}), 7.92(1 \mathrm{H}$, br t, J = 3.99 Hz), $7.52(1 \mathrm{H}, \mathrm{ddd}, \mathrm{J}=$ 8.56, 7.15, 2.01 Hz), $6.70(1 \mathrm{H}, \mathrm{d}, \mathrm{J}=8.56 \mathrm{~Hz}), 6.66(1 \mathrm{H}, \mathrm{dd}, \mathrm{J}=7.13,4.94 \mathrm{~Hz}), 6.46$ (1 $\mathrm{H}, \mathrm{d}, \mathrm{J}=5.54 \mathrm{~Hz}), 3.80(4 \mathrm{H}, \mathrm{m}), 3.47(2 \mathrm{H}, \mathrm{td}, \mathrm{J}=5.83,4.10 \mathrm{~Hz}), 2.72(6 \mathrm{H}, \mathrm{m}), 2.05$ (2 $\mathrm{H}$, apparent $\mathrm{p}, \mathrm{J}=5.44 \mathrm{~Hz}$ ).

${ }^{13} \mathrm{C} \mathrm{NMR} \delta(\mathrm{ppm})\left(\mathrm{CHCl}_{3}-\mathrm{d}\right): 159.5,154.2,152.0,151.4,147.9,143.5,137.6,131.3$, 122.6, 118.0, 117.9, 113.6, 107.2, 99.7, 59.1, 53.8, 45.0, 44.9, 23.3.

MS (ESI): $m / z$ 393.20411M + H (calculated 393.20335)

HPLC $\left(\operatorname{method~A)~} t_{\mathrm{R}}=2.97 \mathrm{~min}(89 \%\right.$ pure $)$. Additional peaks elute at $1.66 \mathrm{~min}, 7 \%$, and $2.20 \mathrm{~min}, 3 \%$. 


\section{A.3.2: 2-trifluoromethylquinolines}

2-trifluoromethyl-4-quinolone (Conrad, 1887; Conrad, 1891; Reynolds, 1955;

Steinacker Dey, 1965)<smiles>O=c1cc(C(F)(F)F)[nH]c2ccccc12</smiles>

Ethyl-4,4,4-trifluoroacetoacetate $(13.0 \mathrm{~g}, 70.6 \mathrm{mmol})$ and aniline $(6.44 \mathrm{~mL}, 70.7 \mathrm{mmol})$ were allowed to heat at $125^{\circ} \mathrm{C}$ in a retort for 1.5 hours. TLC and NMR indicated that reaction was not complete. The reaction mixture was combined with benzene $(100 \mathrm{~mL})$ and a catalytic amount of para-toluenesulfonic acid and allowed to heat for 2 hours at reflux in a flask equipped with a Dean and Stark water separator topped with a watercooled Liebig condenser. TLC then indicated that reaction was complete. The solvent was therefore removed by evaporation under reduced pressure with warming. The residue was allowed to heat in Dowtherm A $(110 \mathrm{~mL})$ to $255^{\circ} \mathrm{C}$, and allowed to remain at this temperature for 70 minutes. The cooled reaction mixture was diluted with $35-60^{\circ}$ petroleum æther $(150 \mathrm{~mL})$, and the solid product was recovered by vacuum filtration (6.28 $\mathrm{g}$ of a cream-colored solid, $42 \%$ ).

4-chloro-2-(trifluoromethyl)quinoline (Steinacker Dey, 1965)<smiles>FC(F)(F)c1cc(Cl)c2ccccc2n1</smiles>

2-trifluoromethyl-4-quinolone $(6.00 \mathrm{~g}, 22.2 \mathrm{mmol})$ and phosphorus oxychloride (45.0 $\mathrm{mL}, 483 \mathrm{mmol}$ ) were allowed to heat at $110^{\circ} \mathrm{C}$ for 75 minutes. After cooling, the reaction mixture was gradually poured into ice water $(200 \mathrm{~mL}$, adding additional ice as needed to control the resulting exothermic reaction) with vigorous stirring. After resting 18 hours, the aqueous mixture was made basic by the addition of solid caustic potash. Upon cooling, the solid product was recovered by vacuum filtration $(5.53 \mathrm{~g})$. This material was recrystallized from $95 \%$ ethanol $(17 \mathrm{~mL})$ to provide the desired product as tan crystals with a flowery scent $\left(5.13 \mathrm{~g}, 79 \%, \mathrm{mp}=32.9-34.1{ }^{\circ} \mathrm{C}\right.$ (lit. $38-40^{\circ} \mathrm{C}$ (Steinacker Dey, 1965)). 
${ }^{1} \mathrm{H}$ NMR $\delta(\mathrm{ppm})\left(\mathrm{CHCl}_{3}-\mathrm{d}\right): 8.31(1 \mathrm{H}, \mathrm{dd}, \mathrm{J}=8.45,1.36 \mathrm{~Hz}), 8.26(1 \mathrm{H}, \mathrm{d}, \mathrm{J}=8.51 \mathrm{~Hz})$, 7.89 (1 H, ddd, $\mathrm{J}=8.51,6.91,1.44 \mathrm{~Hz}), 7.84$ (1 H, s), 7.79 (1 H, ddd, J = 8.44, 6.92, 1.22 $\mathrm{Hz})$.

${ }^{19} \mathrm{~F}$ NMR $\delta(\mathrm{ppm})\left(\mathrm{CHCl}_{3}-\mathrm{d}\right):-67.6$.

\section{3-(2-(trifluoromethyl)quinolin-4-ylamino)propanol}<smiles>OCCCNc1cc(C(F)(F)F)nc2ccccc12</smiles>

4-chloro-2-(trifluoromethyl)quinoline (2.65 g, $11.4 \mathrm{mmol})$ and 3-amino-1-propanol (7.00 $\mathrm{mL}, 91.5 \mathrm{mmol}$ ) were allowed to heat at $90^{\circ} \mathrm{C}$ for 1 hour. The hot reaction mixture was then poured into $100 \mathrm{~mL}$ water, stirring vigorously. After standing 1 hour, the resulting precipitate was recovered by vacuum filtration, followed by air-drying ( $2.99 \mathrm{~g}$ of a white powder, $97 \%, \mathrm{mp}=162.3-163.7^{\circ} \mathrm{C}$ ).

${ }^{1} \mathrm{H}$ NMR $\delta(\mathrm{ppm})\left(\mathrm{DMSO}_{-} \mathrm{d}_{6}\right): 8.31(1 \mathrm{H}, \mathrm{d}, \mathrm{J}=8.47 \mathrm{~Hz}), 7.89(1 \mathrm{H}, \mathrm{d}, \mathrm{J}=8.42 \mathrm{~Hz}), 7.69$ $7.77(2 \mathrm{H}, \mathrm{m}), 7.56(1 \mathrm{H}, \mathrm{t}, \mathrm{J}=7.64 \mathrm{~Hz}), 6.76(1 \mathrm{H}, \mathrm{s}), 4.62(1 \mathrm{H}, \mathrm{t}, \mathrm{J}=5.07 \mathrm{~Hz}), 3.55$ (2 $\mathrm{H}, \mathrm{m}), 3.42(2 \mathrm{H}, \mathrm{m}), 1.80-1.88(2 \mathrm{H}, \mathrm{m})$.

${ }^{19} \mathrm{~F}$ NMR $\delta(\mathrm{ppm})\left(\mathrm{DMSO}_{\mathrm{d}}\right):-66.6$.

\section{3-(5-chloro-2-trifluoromethylquinolin-4-ylamino)propyl methanesulfonate}<smiles>COCCCNc1cc(C(F)(F)F)nc2ccccc12</smiles>

3-(2-trifluoromethylquinolin-4-ylamino)propanol (2.58 g, $9.5 \mathrm{mmol})$ and triethylamine $(1.99 \mathrm{~mL}, 14 \mathrm{mmol})$ in anhydrous tetrahydrofuran $(100 \mathrm{~mL})$ were cooled to below $0^{\circ} \mathrm{C}$ on ice/salt. Methanesulfonyl chloride $(0.85 \mathrm{~mL}, 11 \mathrm{mmol})$ was added dropwise. After stirring for 90 minutes on ice, TLC indicated that the reaction was complete. The reaction mixture was diluted with ethyl acetate $(20 \mathrm{~mL})$ and washed with saturated 
sodium bicarbonate $(30 \mathrm{~mL})$. The aqueous layer was extracted with ethyl acetate $(3 \times 7$ $\mathrm{mL})$, and the pooled organic layers were rinsed with brine $(10 \mathrm{~mL})$, dried $\left(\mathrm{MgSO}_{4}\right)$, and evaporated under reduced pressure with warming to give a tan solid $(2.73 \mathrm{~g}, 82 \%)$.

${ }^{1} \mathrm{H}$ NMR $\delta(\mathrm{ppm})\left(\right.$ DMSO-d $\left._{6}\right): 8.32(1 \mathrm{H}, \mathrm{d}, \mathrm{J}=1.63 \mathrm{~Hz}), 7.90(1 \mathrm{H}, \mathrm{d}, \mathrm{J}=8.43 \mathrm{~Hz}), 7.73-$ $7.75(2 \mathrm{H}, \mathrm{m}), 7.57-7.58(1 \mathrm{H}, \mathrm{m}), 6.79(1 \mathrm{H}, \mathrm{s}), 4.36(2 \mathrm{H}, \mathrm{t}, \mathrm{J}=6.16 \mathrm{~Hz}), 3.48(2 \mathrm{H}, \mathrm{m})$, $3.20(2 \mathrm{H}, \mathrm{s}), 2.06-2.16(2 \mathrm{H}, \mathrm{m})$.

\section{PL147 (PL301): N-(3-(4-benzhydrylpiperazin-1-yl)propyl)-2- trifluoromethylquinolin-4-amine}

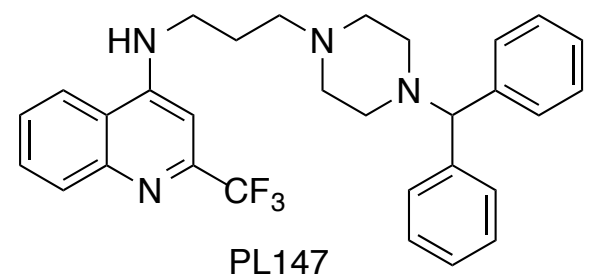

3-(2-trifluoromethylquinolin-4-ylamino)propyl methanesulfonate (1.36 g, $3.9 \mathrm{mmol})$, 1(diphenylmethyl)piperazine $(1.03 \mathrm{~g}, 4.1 \mathrm{mmol})$, and potassium carbonate $(0.81 \mathrm{~g}, 5.9$ $\mathrm{mmol})$ were heated at reflux in anhydrous acetonitrile $(22 \mathrm{~mL})$ for 18 hours. TLC then indicated that reaction was complete. The solvent was removed under reduced pressure with warming, and the residue was partitioned between chloroform $(25 \mathrm{~mL})$ and water $(25 \mathrm{~mL})$. After separation, the aqueous layer was extracted with further chloroform $(3 \mathrm{x}$ $10 \mathrm{~mL})$, and the pooled organic layers were dried $\left(\mathrm{MgSO}_{4}\right)$ and evaporated under reduced pressure with warming to yield a beige solid. This material was recrrystallized from $95 \%$ ethanol to provide the desired product as pale beige crystals $(0.91 \mathrm{~g}, 46 \%, \mathrm{mp}=191.8$ $\left.193.7^{\circ} \mathrm{C}\right)$.

${ }^{1} \mathrm{H}$ NMR $\delta(\mathrm{ppm})\left(\mathrm{CHCl}_{3}-\mathrm{d}\right): 8.06(1 \mathrm{H}, \mathrm{dd}, \mathrm{J}=8.50,1.15 \mathrm{~Hz}), 7.99(1 \mathrm{H}, \mathrm{br} \mathrm{t}, \mathrm{J}=3.96$ $\mathrm{Hz}), 7.95(1 \mathrm{H}, \mathrm{dd}, \mathrm{J}=8.45,1.30 \mathrm{~Hz}), 7.71(1 \mathrm{H}, \mathrm{ddd}, \mathrm{J}=8.52,6.82,1.29 \mathrm{~Hz}), 7.45-7.45$ (4 H, m), 7.39 (1 H, ddd, J = 8.42, 6.82, 1.25 Hz), 7.30-7.32 (4 H, m), 7.19-7.27 (2 H, m), $6.61(1 \mathrm{H}, \mathrm{s}), 4.36(1 \mathrm{H}, \mathrm{s}), 3.42(2 \mathrm{H}, \mathrm{td}, \mathrm{J}=5.78,3.98 \mathrm{~Hz}), 2.62-2.63(10 \mathrm{H}, \mathrm{br} \mathrm{s}$ overlaps $\mathrm{t}, \mathrm{J}=5.45 \mathrm{~Hz}), 1.95(2 \mathrm{H}$, apparent $\mathrm{p}, \mathrm{J}=5.34 \mathrm{~Hz})$.

${ }^{19} \mathrm{~F} \mathrm{NMR} \delta(\mathrm{ppm})\left(\mathrm{CHCl}_{3}-\mathrm{d}\right): 0.5,-68.1$. 
${ }^{13} \mathrm{C} \mathrm{NMR} \delta(\mathrm{ppm})\left(\mathrm{CHCl}_{3}-\mathrm{d}\right): 152.1,149.1\left(\mathrm{q}, \mathrm{J}_{\mathrm{F}}=33.1 \mathrm{~Hz}, \mathrm{Q}-\mathrm{C} 2-\mathrm{CF}_{3}\right), 147.5,142.2$, $130.5,129.8,128.6,128.0,127.1,125.6,120.9,120.7,119.1,93.6,76.5,58.9,53.9,51.8$, 44.7, 23.1.

MS (ESI): $m / z$ 505.25791 M + H (calculated 505.25736)

$\operatorname{HPLC}(\operatorname{method} \mathrm{A}) t_{\mathrm{R}}=14.42 \min (91 \%$ pure $)$.

\section{PL302: 2-trifluoromethyl-N-(3-(4-(pyridin-2-yl)piperazin-1-yl)propyl)quinolin-4- amine}

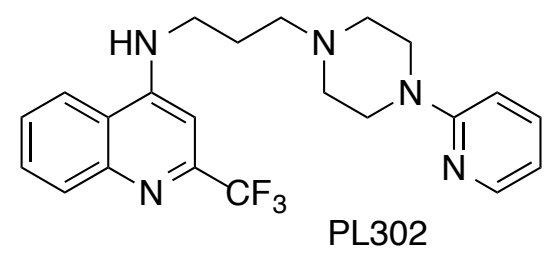

3-(2-trifluoromethylquinolin-4-ylamino)propyl methanesulfonate (1.36 g, $3.9 \mathrm{mmol}), 1$ (2-pyridyl)piperazine $(0.75 \mathrm{~g}, 4.1 \mathrm{mmol})$, and potassium carbonate $(0.81 \mathrm{~g}, 5.9 \mathrm{mmol})$ were heated at reflux in anhydrous acetonitrile $(23 \mathrm{~mL})$ for 42 hours. The solvent was then removed under reduced pressure with warming to provide a thick, yellow oil that solidified upon standing. This material was recrystallized from $95 \%$ ethanol to provide the desired product as fine, off-white crystals $\left(0.54 \mathrm{~g}, 33 \%, \mathrm{mp}=146.2-146.8^{\circ} \mathrm{C}\right)$.

${ }^{1} \mathrm{H}$ NMR $\delta(\mathrm{ppm})\left(\mathrm{CHCl}_{3}-\mathrm{d}\right): 8.24-8.24(1 \mathrm{H}, \mathrm{m}), 8.06(1 \mathrm{H}, \mathrm{d}, \mathrm{J}=8.47 \mathrm{~Hz}), 7.91(1 \mathrm{H}, \mathrm{d}$, $\mathrm{J}=8.42 \mathrm{~Hz}), 7.72(1 \mathrm{H}$, br $\mathrm{t}, \mathrm{J}=4.19 \mathrm{~Hz}), 7.64(1 \mathrm{H}, \mathrm{ddd}, \mathrm{J}=8.49,6.84,1.35 \mathrm{~Hz}), 7.54$ $(1 \mathrm{H}, \mathrm{ddd}, \mathrm{J}=8.52,7.17,2.02 \mathrm{~Hz}), 7.38-7.38(1 \mathrm{H}, \mathrm{m}), 6.68-6.72(2 \mathrm{H}, \mathrm{m}), 6.67(1 \mathrm{H}, \mathrm{s})$, $3.71(4 \mathrm{H}, \mathrm{m}), 3.50(2 \mathrm{H}, \mathrm{td}, \mathrm{J}=5.44,0.01 \mathrm{~Hz}), 2.70-2.71(6 \mathrm{H}, \mathrm{m}), 2.04(2 \mathrm{H}$, apparent p, $\mathrm{J}=5.51 \mathrm{~Hz})$.

${ }^{13} \mathrm{C} \mathrm{NMR} \delta(\mathrm{ppm})\left(\mathrm{CHCl}_{3}-\mathrm{d}\right): 159.4,152.0,148.1,147.5,137.7,130.6,129.9,125.9$, 120.4, 119.1, 113.8, 107.1, 93.8, 58.8, 53.5, 45.3, 44.5, 23.5.

${ }^{19} \mathrm{~F} \mathrm{NMR} \delta(\mathrm{ppm})\left(\mathrm{CHCl}_{3}-\mathrm{d}\right):-68.6$.

MS (ESI): $m / z$ 416.20605 M + H (calculated 416.20566)

$\operatorname{HPLC}(\operatorname{method} \mathrm{A}) t_{\mathrm{R}}=8.07 \min (97 \%$ pure $)$. 


\section{A.3.3: 6-trifluoromethylquinolines}

3-carbethoxy-6-trifluoromethyl-4-quinolone (Ressurreição, 2013)<smiles>CCOC(=O)c1c[nH]c2ccc(C(F)(F)F)cc2c1=O</smiles>

meta-Trifluoromethyl aniline $(25.48 \mathrm{~g}, 160 \mathrm{mmol})$ and diethyl ethoxymethylene malonate $(32 \mathrm{~mL}, 160 \mathrm{mmol})$ in Dowtherm A $(150 \mathrm{~mL})$ were allowed to heat gradually, stirring, to $255^{\circ} \mathrm{C}$, at which temperature the reaction was allowed to remain for 30 minutes. After cooling, the reaction mixture was diluted with $35-60^{\circ}$ petroleum æther $(200 \mathrm{~mL})$ and vacuum filtered, giving $38.94 \mathrm{~g}$ of a cream-colored, fine, crystalline solid (38.94 g, 86\%).

${ }^{1} \mathrm{H}$ NMR $\delta(\mathrm{ppm})($ DMSO-d 6 ): $12.62(1 \mathrm{H}, \mathrm{d}, \mathrm{J}=6.25 \mathrm{~Hz}), 8.66(1 \mathrm{H}, \mathrm{d}, \mathrm{J}=6.47 \mathrm{~Hz})$, $8.41(1 \mathrm{H}, \mathrm{d}, \mathrm{J}=2.02 \mathrm{~Hz}), 8.03(1 \mathrm{H}, \mathrm{dd}, \mathrm{J}=8.68,2.20 \mathrm{~Hz}), 7.83(1 \mathrm{H}, \mathrm{d}, \mathrm{J}=8.66 \mathrm{~Hz})$, $4.24(2 \mathrm{H}, \mathrm{q}, \mathrm{J}=7.10 \mathrm{~Hz}), 1.29(3 \mathrm{H}, \mathrm{t}, \mathrm{J}=7.10 \mathrm{~Hz})$.

${ }^{19}$ F NMR $\delta(\mathrm{ppm})\left(\mathrm{DMSO}-\mathrm{d}_{6}\right):-60.7$.

3-carboxy-6-trifluoromethyl-4-quinolone (Price, 1946; Ressurreição, 2013)<smiles>O=C(O)c1c[nH]c2ccc(C(F)(F)F)cc2c1=O</smiles>

3-carbethoxy-6-trifluoromethyl-4-quinolone (38.94 g, $0.136 \mathrm{~mol}$ ) in $400 \mathrm{~mL}$ of 10\% caustic soda was allowed to reflux, stirring, for 1.5 hours, at which point all solid material had dissolved. After cooling partially, the reaction was poured into $5 \mathrm{M} \mathrm{HCl}(350 \mathrm{~mL})$ with good stirring. The resulting off-white precipitate was recovered by vacuum filtration, followed by air-drying (34.72 g, containing residual water).

${ }^{1} \mathrm{H}$ NMR $\delta(\mathrm{ppm})\left(\right.$ DMSO-d $\left._{6}\right): 8.10(1 \mathrm{H}, \mathrm{s}), 7.88(1 \mathrm{H}, \mathrm{s}), 7.31(1 \mathrm{H}, \mathrm{dd}, \mathrm{J}=8.76,2.06$ $\mathrm{Hz}), 7.10(1 \mathrm{H}, \mathrm{d}, \mathrm{J}=8.77 \mathrm{~Hz})$. 
6-trifluoromethyl-4-quinolone (Price, 1946; Ressurreição, 2013)<smiles>O=c1cc[nH]c2ccc(C(F)(F)F)cc12</smiles>

3-carboxy-6-trifluoromethyl-4-quinolone (34.72 g, containing residual water) was heated in Dowtherm A $(200 \mathrm{~mL})$ at $255^{\circ} \mathrm{C}$ for 1.5 hours. After cooling, the reaction mixture was diluted with $200 \mathrm{~mL} 35-60^{\circ}$ petroleum æther and vacuum filtered. The product was a tan, fine, crystalline solid, $27.01 \mathrm{~g}(94 \%)$.

${ }^{19} \mathrm{~F}$ NMR $\delta(\mathrm{ppm})(\mathrm{CHCl} 3-\mathrm{d}):-63.0$.

4-chloro-6-(trifluoromethyl)quinoline (Price, 1946; Ressurreição, 2013)<smiles>FC(F)(F)c1ccc2nccc(Cl)c2c1</smiles>

Phosphorus oxychloride (40 $\mathrm{mL}, 430 \mathrm{mmol}$ ) was cautiously added to 6-trifluoromethyl4-quinolone $(27.01 \mathrm{~g}, 127 \mathrm{mmol})$, followed by heating at $110^{\circ} \mathrm{C}$ for $1.5 \mathrm{~h}$. At the end of this time TLC indicated that the reaction had gone to completion. After cooling, the reaction mixture was gradually added to $300 \mathrm{~mL}$ ice water. Without basifying, this aqueous solution was extracted with chloroform $(200 \mathrm{~mL}$, then $3 \times 50 \mathrm{~mL})$. Upon drying over $\mathrm{MgSO}_{4}$ and evaporation under reduced pressure with warming, yield from this was $8.72 \mathrm{~g}$. Further extraction with dichloromethane (3 times $75 \mathrm{~mL}$ ) followed by drying over $\mathrm{MgSO}_{4}$ and evaporation under reduced pressure with warming gave an additional $4.40 \mathrm{~g}$ of the product, a tan, crystalline material with a sweet and pleasing aroma, similar to that of 4,7-dichloroquinoline. Total yield is $13.12 \mathrm{~g}$ ( $0.057 \mathrm{~mol}, 45 \%$ yield $)$.

${ }^{1} \mathrm{H}$ NMR $\delta(\mathrm{ppm})\left(\mathrm{CHCl}_{3}-\mathrm{d}\right): 8.94(1 \mathrm{H}, \mathrm{d}, \mathrm{J}=4.83 \mathrm{~Hz}), 8.59(1 \mathrm{H}, \mathrm{s}), 8.38(1 \mathrm{H}, \mathrm{d}, \mathrm{J}=$ $8.85 \mathrm{~Hz}), 8.00(1 \mathrm{H}, \mathrm{dd}, \mathrm{J}=8.84,1.98 \mathrm{~Hz}), 7.68(1 \mathrm{H}, \mathrm{d}, \mathrm{J}=4.83 \mathrm{~Hz})$.

${ }^{19} \mathrm{~F}$ NMR $\delta(\mathrm{ppm})(\mathrm{CHCl3}-\mathrm{d}):-63.3$. 


\section{3-(6-(trifluoromethyl)quinolin-4-ylamino)propanol}<smiles>OCCCNc1ccnc2ccc(C(F)(F)F)cc12</smiles>

4-chloro-6-(trifluoromethyl)quinoline $(8.58 \mathrm{~g}, 37 \mathrm{mmol})$ and 3-amino-1-propanol (17.0 $\mathrm{mL}, 222 \mathrm{mmol}$ ) were heated at $90^{\circ} \mathrm{C}$ for 2 hours, at the end of which time TLC indicated that the reaction had gone to completion. The reaction mixture was poured into water $(500 \mathrm{~mL})$, and the resulting precipitate was recovered by vacuum filtration, followed by air-drying and partial recrystallization from ethyl acetate to provide the desired compound as an off-white powder $\left(5.85 \mathrm{~g}, 0.0216 \mathrm{~mol}, 59 \%\right.$ yield, $\left.\mathrm{mp}=165.1-167.0^{\circ} \mathrm{C}\right)$.

${ }^{1} \mathrm{H}$ NMR $\delta(\mathrm{ppm})\left(\mathrm{DMSO}_{\mathrm{d}}\right): 8.73(1 \mathrm{H}, \mathrm{d}, \mathrm{J}=2.03 \mathrm{~Hz}), 8.49(1 \mathrm{H}, \mathrm{d}, \mathrm{J}=5.45 \mathrm{~Hz}), 7.93$ $(1 \mathrm{H}, \mathrm{d}, \mathrm{J}=8.80 \mathrm{~Hz}), 7.83(1 \mathrm{H}, \mathrm{dd}, \mathrm{J}=8.83,2.00 \mathrm{~Hz}), 7.59(1 \mathrm{H}, \mathrm{br} \mathrm{t}, \mathrm{J}=5.36 \mathrm{~Hz}), 6.57$ $(1 \mathrm{H}, \mathrm{d}, \mathrm{J}=5.50 \mathrm{~Hz}), 4.59(1 \mathrm{H}, \mathrm{t}, \mathrm{J}=5.05 \mathrm{~Hz}), 3.56(2 \mathrm{H}, \mathrm{td}, \mathrm{J}=6.10,5.07 \mathrm{~Hz}), 3.34-$ 3.37 (solvent signal overlaps $\mathrm{m}, \sim 2 \mathrm{H}), 1.84(2 \mathrm{H}$, apparent $\mathrm{p}, \mathrm{J}=6.62 \mathrm{~Hz}$ ).

${ }^{19} \mathrm{~F}$ NMR $\delta(\mathrm{ppm})\left(\mathrm{DMSO}-\mathrm{d}_{6}\right):-60.3$.

\section{3-(6-(trifluoromethyl)quinolin-4-ylamino)propyl methanesulfonate}<smiles>COCCCNc1ccnc2ccc(C(F)(F)F)cc12</smiles>

3-(6-(trifluoromethyl)quinolin-4-ylamino)propanol (5.85 g, $21.6 \mathrm{mmol})$ and triethylamine $(9.1 \mathrm{~mL}, 6.5 \mathrm{mmol})$ were taken up in dry chloroform $(250 \mathrm{~mL})$ and cooled to below $0{ }^{\circ} \mathrm{C}$ on ice/salt, and methanesulfonyl chloride $(1.93 \mathrm{~mL}, 24.8 \mathrm{mmol})$ was gradually added. After stirring for 2 hours on ice, TLC indicated that the reaction had gone to completion. It was therefore rinsed with saturated sodium bicarbonate $(150 \mathrm{~mL})$, and the aqueous layer was extracted 3 times with $15 \mathrm{~mL}$ portions of chloroform. The pooled organic extracts were dried over $\mathrm{MgSO}_{4}$ and evaporated under reduced pressure with warming to yield an off-white solid $(7.57 \mathrm{~g}, \sim 100 \%)$.

${ }^{1} \mathrm{H}$ NMR $\delta(\mathrm{ppm})\left(\mathrm{DMSO}_{\mathrm{d}}\right): 8.73(1 \mathrm{H}, \mathrm{d}, \mathrm{J}=1.83 \mathrm{~Hz}), 8.52(1 \mathrm{H}, \mathrm{d}, \mathrm{J}=5.44 \mathrm{~Hz}), 7.95$ $(1 \mathrm{H}, \mathrm{d}, \mathrm{J}=8.81 \mathrm{~Hz}), 7.85(1 \mathrm{H}, \mathrm{dd}, \mathrm{J}=8.84,1.93 \mathrm{~Hz}), 7.61(1 \mathrm{H}$, br t, J = 5.35 Hz), 6.61 
$(1 \mathrm{H}, \mathrm{d}, \mathrm{J}=5.50 \mathrm{~Hz}), 4.36(2 \mathrm{H}, \mathrm{t}, \mathrm{J}=6.19 \mathrm{~Hz}), 3.42(2 \mathrm{H}, \mathrm{td}, \mathrm{J}=6.93,5.34 \mathrm{~Hz}), 3.20(3$ $\mathrm{H}, \mathrm{s}), 2.12(2 \mathrm{H}$, apparent $\mathrm{p}, \mathrm{J}=7.03 \mathrm{~Hz})$.

${ }^{19} \mathrm{~F}$ NMR $\delta(\mathrm{ppm})\left(\mathrm{DMSO}-\mathrm{d}_{6}\right):-59.4$.

\section{PL148: N-(3-(4-benzhydrylpiperazin-1-yl)propyl)-6-(trifluoromethyl)quinolin-4- amine}<smiles>FC(F)(F)c1ccc2nccc(NCCCN3CCN(C(c4ccccc4)c4ccccc4)CC3)c2c1</smiles>

3-(6-(trifluoromethyl)quinolin-4-ylamino)propyl methanesulfonate (0.98 g, $2.8 \mathrm{mmol})$, 1benzhydrylpiperazine $(0.78 \mathrm{~g}, 3.1 \mathrm{mmol})$, and potassium carbonate $(0.60 \mathrm{~g}, 4.3 \mathrm{mmol})$ were heated at reflux in anhydrous acetonitrile $(15 \mathrm{~mL})$ for 24 hours, whereupon TLC indicated that reaction was complete. Substantial precipitate had formed in the reaction mixture. This was recovered by vacuum filtration, rinsing with water, and the resulting solid was partially recrystallized from a mixture of $95 \%$ ethanol and ethyl acetate (approximately 4:1, total volume $20 \mathrm{~mL}$ ) to give the desired product as a white, crystalline solid $\left(1.07 \mathrm{~g}, 76 \%, \mathrm{mp}=213-218^{\circ} \mathrm{C}\right)$.

${ }^{1} \mathrm{H} \mathrm{NMR} \delta(\mathrm{ppm})\left(\mathrm{CHCl}_{3}-\mathrm{d}\right): 8.59(1 \mathrm{H}, \mathrm{d}, \mathrm{J}=5.36 \mathrm{~Hz}), 8.20(1 \mathrm{H}, \mathrm{s}), 8.05(1 \mathrm{H}, \mathrm{d}, \mathrm{J}=$ $8.84 \mathrm{~Hz}), 7.83(1 \mathrm{H}, \mathrm{dd}, \mathrm{J}=8.85,1.91 \mathrm{~Hz}), 7.62(1 \mathrm{H}, \mathrm{br} \mathrm{t}, \mathrm{J}=3.97 \mathrm{~Hz}), 7.47-7.48(4 \mathrm{H}$, m), 7.24-7.29 (4 H, m), 7.16-7.18 (2 H, m), $6.39(1 \mathrm{H}, \mathrm{d}, \mathrm{J}=5.41 \mathrm{~Hz}), 4.36(1 \mathrm{H}, \mathrm{s}), 3.37$ $(2 \mathrm{H}, \mathrm{td}, \mathrm{J}=5.69,4.03 \mathrm{~Hz}), 2.64(10 \mathrm{H}$, br s overlaps $\mathrm{t}, \mathrm{J}=5.17 \mathrm{~Hz}), 1.94(2 \mathrm{H}$, apparent $\mathrm{p}, \mathrm{J}=5.32 \mathrm{~Hz}$ ).

${ }^{19} \mathrm{~F}$ NMR $\delta(\mathrm{ppm})\left(\mathrm{CHCl}_{3}-\mathrm{d}\right): 0.5,-59.5$.

${ }^{13} \mathrm{C} \mathrm{NMR} \delta(\mathrm{ppm})\left(\mathrm{CHCl}_{3}-\mathrm{d}\right): 153.1,151.2,149.9,143.1,130.9,128.6,127.9,127.0$, $125.6\left(\mathrm{q}, \mathrm{J}_{\mathrm{F}}=9.96 \mathrm{~Hz}\right), 124.7\left(\mathrm{q}, \mathrm{J}_{\mathrm{F}}=3.02 \mathrm{~Hz}\right), 119.2\left(\mathrm{q}, \mathrm{J}_{\mathrm{F}}=3.02 \mathrm{~Hz}\right), 118.4,99.4,75.7$, $59.4,54.3,51.8,45.3,23.3$.

HPLC (method C) $t_{\mathrm{R}}=11.80 \min (98 \%$ pure). MS (ESI): $m / z 505.2566 \mathrm{M}+\mathrm{H}$ (calculated 505.2574).

${ }^{19} \mathrm{~F} \mathrm{NMR} \delta(\mathrm{ppm})\left(\mathrm{CHCl}_{3}-\mathrm{d}\right):-59.5$. 
PL276: 6-trifluoromethyl- $N$-(3-(4-(pyridin-2-yl)piperazin-1-yl)propyl)quinolin-4amine<smiles>FC(F)(F)c1ccc2nccc(NCCCN3CCN(c4ccccn4)CC3)c2c1</smiles>

3-(6-(trifluoromethyl)quinolin-4-ylamino)propyl methanesulfonate (1.53 g, $4.39 \mathrm{mmol})$, $\mathrm{N}$-(2-pyridyl)piperazine $(0.79 \mathrm{~g}, 4.8 \mathrm{mmol})$, and potassium carbonate $(0.95 \mathrm{~g}, 6.87 \mathrm{mmol})$ were heated at reflux in anhydrous acetonitrile $(15 \mathrm{~mL})$ for 24 hours. TLC then indicated that reaction was complete. Substantial precipitate had formed in the reaction mixture. This was recovered by vacuum filtration, rinsing with acetonitrile $(30 \mathrm{~mL})$, followed by water $(40 \mathrm{~mL})$. The resulting solid was recrystallized from $5 \mathrm{~mL} \mathrm{95 \%} \mathrm{ethanol} \mathrm{to} \mathrm{give} \mathrm{the}$ desired product as a white, crystalline solid $\left(0.82 \mathrm{~g}, 45 \%, \mathrm{mp}=168.8-171.0^{\circ} \mathrm{C}\right)$.

${ }^{1} \mathrm{H}$ NMR $\delta(\mathrm{ppm})\left(\mathrm{CHCl}_{3}-\mathrm{d}\right): 8.61(1 \mathrm{H}, \mathrm{d}, \mathrm{J}=5.39 \mathrm{~Hz}), 8.22-8.24(1 \mathrm{H}, \mathrm{m}), 8.15(1 \mathrm{H}, \mathrm{s})$, $8.03(1 \mathrm{H}, \mathrm{d}, \mathrm{J}=8.79 \mathrm{~Hz}), 7.74(1 \mathrm{H}, \mathrm{dd}, \mathrm{J}=8.80,1.95 \mathrm{~Hz}), 7.52-7.52(2 \mathrm{H}, \mathrm{m}), 6.66-$ $6.67(2 \mathrm{H}, \mathrm{m}), 6.44(1 \mathrm{H}, \mathrm{d}, \mathrm{J}=5.44 \mathrm{~Hz}), 3.69(4 \mathrm{H}, \mathrm{m}), 3.44(2 \mathrm{H}, \mathrm{td}, \mathrm{J}=5.87,4.17 \mathrm{~Hz})$, $2.69(6 \mathrm{H}, \mathrm{m}), 2.02(2 \mathrm{H}$, apparent p, J = 5.51 Hz).

${ }^{19} \mathrm{~F} \mathrm{NMR} \delta(\mathrm{ppm})\left(\mathrm{CHCl}_{3}-\mathrm{d}\right):-61.7$.

${ }^{13} \mathrm{C} \mathrm{NMR} \delta(\mathrm{ppm})\left(\mathrm{CHCl}_{3}-\mathrm{d}\right): 159.5,153.1,151.0,149.9,148.0,147.9,137.6,130.9$, $126.0,125.8\left(\mathrm{q}, \mathrm{J}_{\mathrm{F}}=32.5 \mathrm{~Hz}, \mathrm{Q}-\mathrm{C} 6-\mathrm{CF}_{3}\right), 124.7,118.7,118.3,113.6,107.0,99.3,59.0$, $53.7,45.0,44.7,23.6$.

MS (ESI): $m / z$ 416.2050 M + H (calculated 416.2057).

HPLC (method C) $t_{\mathrm{R}}=6.64 \min (99 \%$ pure).

PL190: $N$-(dipyridin-2-methylene)piperidin-4-amine (Burgess, 2008; Burgess, 2010)<smiles>O=[Pt]c1ccccn1</smiles> 
In a round bottomed flask equipped with a Dean and Stark water separator, 4-aminopiperidine $(16.82 \mathrm{~g}, 0.168 \mathrm{~mol})$, di-2-pyridyl ketone $(25.67 \mathrm{~g}, 0.139 \mathrm{~mol})$, and a catalytic amount of paratoluenesulfonic acid were allowed to reflux for 20 hours. TLC then indicated that the reaction had gone to completion, and the solvent was therefore evaporated under reduced pressure. The resulting rust-colored solid (41.45 g) was used without further purification.

\section{PL278: 6-trifluoromethyl- $N$-(3-(4-(dipyridin-2-ylmethyleneamino)piperidin-1- yl)propyl)quinolin-4-amine}

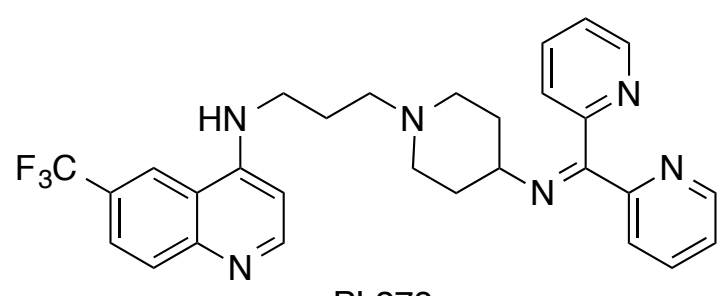

PL278

3-(6-(trifluoromethyl)quinolin-4-ylamino)propyl methanesulfonate $(2.00 \mathrm{~g}, 5.74 \mathrm{mmol})$, PL190 (1.76 g, $6.61 \mathrm{mmol}$; see above), and potassium carbonate $(1.19 \mathrm{~g}, 8.61 \mathrm{mmol})$ were heated at reflux in anhydrous acetonitrile $(24 \mathrm{~mL})$ for 24 hours. TLC indicated that reaction was complete, and so the solvent was removed under reduced pressure with warming, and the residue partitioned between chloroform $(50 \mathrm{~mL})$ and water $(50 \mathrm{~mL})$. After separation, the aqueous layer was extracted with further chloroform $(3 \times 15 \mathrm{~mL})$ and the pooled organic layers were dried $\left(\mathrm{MgSO}_{4}\right)$ and evaporated under reduced pressure with warming. The resulting brown solid was dissolved in a mixture of dichloromethane and methanol and allowed to evaporate at room temperature; the resulting crystals were washed with ethyl acetate, followed by $95 \%$ ethanol to provide the desired product as pale yellow, sparkling crystals $\left(0.74 \mathrm{~g}, 26 \%, \mathrm{mp}=224-225^{\circ} \mathrm{C}\right)$.

${ }^{1} \mathrm{H}$ NMR $\delta(\mathrm{ppm})\left(\mathrm{CHCl}_{3}-\mathrm{d}\right): 8.73(1 \mathrm{H}, \mathrm{d}, \mathrm{J}=4.93 \mathrm{~Hz}), 8.60(1 \mathrm{H}, \mathrm{d}, \mathrm{J}=5.39 \mathrm{~Hz}), 8.49$ $(1 \mathrm{H}, \mathrm{d}, \mathrm{J}=4.85 \mathrm{~Hz}), 8.40(1 \mathrm{H}, \mathrm{d}, \mathrm{J}=8.01 \mathrm{~Hz}), 8.18(1 \mathrm{H}, \mathrm{s}), 8.05(1 \mathrm{H}, \mathrm{d}, \mathrm{J}=8.82 \mathrm{~Hz})$, 7.77-7.82 $(2 \mathrm{H}, \mathrm{m}), 7.58(1 \mathrm{H}, \mathrm{s}), 7.31-7.37(1 \mathrm{H}, \mathrm{m}), 7.24-7.27$ (solvent signal overlaps $\mathrm{m}, \sim 2 \mathrm{H}), 6.42(1 \mathrm{H}, \mathrm{d}, \mathrm{J}=5.45 \mathrm{~Hz}), 3.37-3.43(3 \mathrm{H}, \mathrm{m}), 2.99-3.04(2 \mathrm{H}, \mathrm{m}), 2.60(2 \mathrm{H}$, td, J = 5.10, 1.54 Hz), $2.14(2 \mathrm{H}, \mathrm{m}), 1.97-1.99(4 \mathrm{H}, \mathrm{m}), 1.81-1.83(2 \mathrm{H}, \mathrm{m})$.

${ }^{19} \mathrm{~F} \mathrm{NMR} \delta(\mathrm{ppm})\left(\mathrm{CHCl}_{3}-\mathrm{d}\right):-61.5$.

${ }^{13} \mathrm{C}$ NMR $\delta(\mathrm{ppm})\left(\mathrm{CHCl}_{3}-\mathrm{d}\right): 165.1,157.3,155.8,153.0,151.2,149.9,149.7,148.6$, $136.3,135.9,130.8,125.9$ (q, J $\left.\mathrm{J}_{\mathrm{F}}=32.1 \mathrm{~Hz}, \mathrm{Q}-\mathrm{C} 6-\mathrm{CF}_{3}\right), 124.6,124.0,123.4,123.1$, $123.0,122.3,118.8,118.4,99.3,59.0,58.4,52.1,44.8,32.6,23.9$. 
MS (ESI): $m / z$ 519.24868 M + H (calculated 519.24786)

HPLC $\left(\right.$ method A) $t_{\mathrm{R}}=1.58 \mathrm{~min}(54 \%$ pure). (Additional peaks elute at $2.01 \mathrm{~min}, 6 \%$, and $9.18 \mathrm{~min}, 39 \%$ ).

\section{PL279: 6-trifluoromethyl- $N$-(3-(4-(dipyridin-2-ylmethylamino)piperidin-1- yl)propyl)quinolin-4-amine}

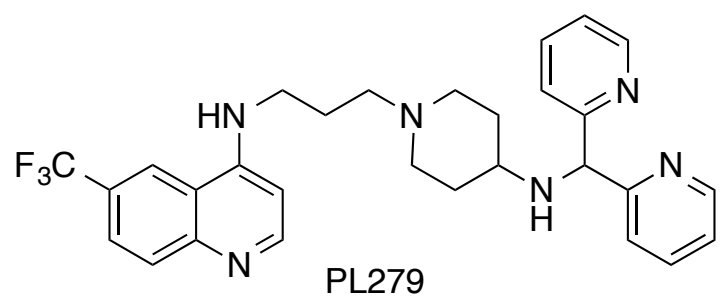

PL278 (0.74 g, $1.4 \mathrm{mmol})$ was taken up in anhydrous methanol $(25 \mathrm{~mL})$, and sodium borohydride $(0.16 \mathrm{~g}, 4.2 \mathrm{mmol})$ was cautiously added. After stirring 2 hours, additional sodium borohydride $(0.06 \mathrm{~g}, 2 \mathrm{mmol})$ was added. After 30 minutes, the solvent was removed by evaporation under reduced pressure and the resulting solid was allowed to stir for 1 hour with $15 \mathrm{~mL}$ water. This was then extracted with methylene chloride (15 $\mathrm{mL}$ followed by $3 \times 10 \mathrm{~mL}$ ), and the pooled organic extracts were dried over $\mathrm{MgSO}_{4}$ and evaporated under reduced pressure. Recrystallization of the residue from $95 \%$ ethanol $(10 \mathrm{~mL})$ gave the product as a golden brown solid $\left(0.34 \mathrm{~g}, 49 \%, \mathrm{mp}=128.2-129.8^{\circ} \mathrm{C}\right)$.

${ }^{1} \mathrm{H}$ NMR $\delta(\mathrm{ppm})\left(\mathrm{CHCl}_{3}-\mathrm{d}\right): 8.58(1 \mathrm{H}, \mathrm{d}, \mathrm{J}=5.40 \mathrm{~Hz}), 8.56-8.56(2 \mathrm{H}, \mathrm{m}), 8.10(1 \mathrm{H}, \mathrm{s})$, $8.03(1 \mathrm{H}, \mathrm{d}, \mathrm{J}=8.82 \mathrm{~Hz}), 7.77(1 \mathrm{H}, \mathrm{dd}, \mathrm{J}=8.82,1.97 \mathrm{~Hz}), 7.63(2 \mathrm{H}, \mathrm{td}, \mathrm{J}=7.66,1.88$ $\mathrm{Hz}), 7.51(3 \mathrm{H}, \mathrm{d}, \mathrm{J}=7.80 \mathrm{~Hz}), 7.14(2 \mathrm{H}, \mathrm{ddd}, \mathrm{J}=7.48,4.84,1.23 \mathrm{~Hz}), 6.40(1 \mathrm{H}, \mathrm{d}, \mathrm{J}=$ $5.43 \mathrm{~Hz}), 5.25(1 \mathrm{H}, \mathrm{s}), 3.38(2 \mathrm{H}, \mathrm{td}, \mathrm{J}=5.87,4.06 \mathrm{~Hz}), 2.96(2 \mathrm{H}, \mathrm{d}, \mathrm{J}=11.07 \mathrm{~Hz})$, 2.55-2.58 (3 H, m), 2.08 (2 H, br s), 1.96-2.03 (2 H, m), $1.93(2 \mathrm{H}$, apparent p, J = 5.52 $\mathrm{Hz}), 1.61(2 \mathrm{H}, \mathrm{m})$.

${ }^{19} \mathrm{~F}$ NMR $\delta(\mathrm{ppm})\left(\mathrm{CHCl}_{3}-\mathrm{d}\right):-61.4$.

${ }^{13} \mathrm{C} \mathrm{NMR} \delta(\mathrm{ppm})\left(\mathrm{CHCl}_{3}-\mathrm{d}\right): 162.3,153.0,151.1,149.9,149.1,149.1,136.6,130.8$, $125.7\left(\mathrm{q}, \mathrm{J}_{\mathrm{F}}=32.5 \mathrm{~Hz}, \mathrm{Q}-\mathrm{C}_{6}-\mathrm{CF}_{3}\right), 124.6,122.3,122.1,118.8,118.3,99.3,66.7,58.7$, $52.9,52.7,44.7,32.5,23.9$.

HPLC (method A) $t_{\mathrm{R}}=6.38 \min (95 \%$ pure $)$. 
PL275: 6-trifluoromethyl- $N$-(3-(4-(4-fluorophenyl)piperazin-1-yl)propyl)quinolin-4amine

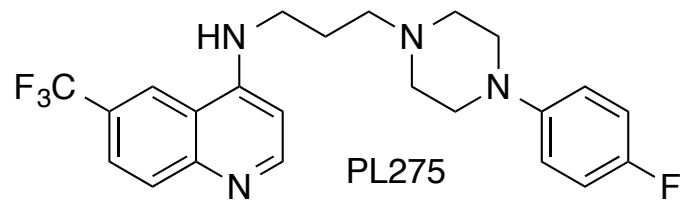

3-(6-(trifluoromethyl)quinolin-4-ylamino)propyl methanesulfonate (1.53 g, $4.4 \mathrm{mmol})$, $\mathrm{N}$-(4-fluorophenyl)piperazine ( $0.87 \mathrm{~g}, 4.8 \mathrm{mmol})$, and potassium carbonate $(0.95 \mathrm{~g}, 6.9$ $\mathrm{mmol})$ were heated at reflux in anhydrous acetonitrile $(15 \mathrm{~mL})$ for 24 hours, at which time TLC indicated that reaction was complete. A large amount of precipitate had formed in the reaction mixture. This was recovered by vacuum filtration, rinsing with acetonitrile $(30 \mathrm{~mL})$, followed by water $(40 \mathrm{~mL})$. The solid thus obtained was recrystallized from $8 \mathrm{~mL} 95 \%$ ethanol to give the desired product as a white, crystalline solid $\left(1.04 \mathrm{~g}, 55 \%, \mathrm{mp}=181.6-183.2^{\circ} \mathrm{C}\right)$.

${ }^{1} \mathrm{H}$ NMR $\delta(\mathrm{ppm})\left(\mathrm{CHCl}_{3}-\mathrm{d}\right): 8.61(1 \mathrm{H}, \mathrm{d}, \mathrm{J}=5.39 \mathrm{~Hz}), 8.13(1 \mathrm{H}, \mathrm{s}), 8.03(1 \mathrm{H}, \mathrm{d}, \mathrm{J}=$ $8.79 \mathrm{~Hz}), 7.75(1 \mathrm{H}, \mathrm{dd}, \mathrm{J}=8.80,1.93 \mathrm{~Hz}), 7.38(1 \mathrm{H}, \mathrm{t}, \mathrm{J}=4.11 \mathrm{~Hz}), 6.97-7.01(2 \mathrm{H}, \mathrm{m})$, 6.89-6.90 (2 H, m), $6.43(1 \mathrm{H}, \mathrm{d}, \mathrm{J}=5.43 \mathrm{~Hz}), 3.43(2 \mathrm{H}, \mathrm{td}, \mathrm{J}=5.84,4.20 \mathrm{~Hz}), 3.25(4$ $\mathrm{H}, \mathrm{m}), 2.73(4 \mathrm{H}, \mathrm{m}), 2.70(2 \mathrm{H}, \mathrm{t}, \mathrm{J}=5.34 \mathrm{~Hz}), 2.01(2 \mathrm{H}$, apparent p, J = 5.48 Hz).

${ }^{19} \mathrm{~F} \mathrm{NMR} \delta(\mathrm{ppm})\left(\mathrm{CHCl}_{3}-\mathrm{d}\right): 0.5,-60.8,-124.5(\mathrm{~m})$.

${ }^{13} \mathrm{C} \mathrm{NMR} \delta(\mathrm{ppm})\left(\mathrm{CHCl}_{3}-\mathrm{d}\right): 158.1,156.5,153.0,151.0,149.9,147.6\left(\mathrm{~d}, \mathrm{~J}_{\mathrm{F}}=2.05 \mathrm{~Hz}\right.$ ?), $130.9,127.0,125.9\left(\mathrm{q}, \mathrm{J}_{\mathrm{F}}=32.1 \mathrm{~Hz}\right), 125.2,124.6,123.4,118.7,118.3,118.1\left(\mathrm{~d}, \mathrm{~J}_{\mathrm{F}}=\right.$ 7.66 Hz?),, 115.5 (d, $\mathrm{J}_{\mathrm{F}}=21.43 \mathrm{~Hz}$ ?), 99.4, 59.0, 54.0, 50.0, 44.7, 23.6.

MS (ESI): $m / z$ 433.2001 M + H (calculated 433.2010).

HPLC (method C) $t_{\mathrm{R}}=9.54 \min (>99 \%$ pure $)$. 


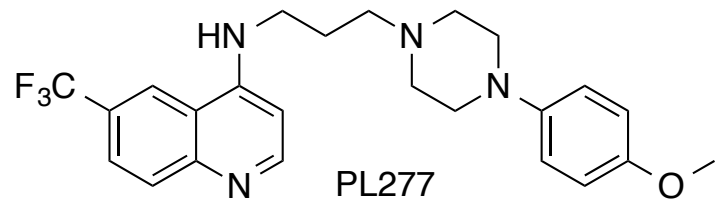

3-(6-(trifluoromethyl)quinolin-4-ylamino)propyl methanesulfonate (1.53 g, $4.39 \mathrm{mmol})$, 1-(4-methoxyphenyl)piperazine $(0.92 \mathrm{~g}, 4.8 \mathrm{mmol})$, and potassium carbonate $(0.95 \mathrm{~g}, 6.9$ $\mathrm{mmol})$ were heated at reflux in anhydrous acetonitrile $(16 \mathrm{~mL})$ for 24 hours, whereupon TLC indicated that reaction was complete. Substantial precipitate had formed in the reaction mixture. This was recovered by vacuum filtration, rinsing with acetonitrile (30 $\mathrm{mL})$, followed by water $(40 \mathrm{~mL})$. The resulting solid was recrystallized from $5 \mathrm{~mL} 95 \%$ ethanol to give the desired product as a white, crystalline solid $(0.27 \mathrm{~g}, 14 \%, \mathrm{mp}=173.7-$ $\left.175.0^{\circ} \mathrm{C}\right)$.

${ }^{1} \mathrm{H} \mathrm{NMR} \delta(\mathrm{ppm})\left(\mathrm{CHCl}_{3}-\mathrm{d}\right): 8.61(1 \mathrm{H}, \mathrm{d}, \mathrm{J}=5.40 \mathrm{~Hz}), 8.14(1 \mathrm{H}, \mathrm{s}), 8.04(1 \mathrm{H}, \mathrm{d}, \mathrm{J}=$ $8.81 \mathrm{~Hz}), 7.76(1 \mathrm{H}, \mathrm{dd}, \mathrm{J}=8.83,1.92 \mathrm{~Hz}), 7.34(1 \mathrm{H}, \mathrm{t}, \mathrm{J}=4.16 \mathrm{~Hz}), 6.92-6.93(2 \mathrm{H}, \mathrm{m})$, 6.84-6.89 (2 H, m), $6.45(1 \mathrm{H}, \mathrm{d}, \mathrm{J}=5.45 \mathrm{~Hz}), 3.80(3 \mathrm{H}, \mathrm{s}), 3.44(2 \mathrm{H}, \mathrm{td}, \mathrm{J}=5.85,4.21$ $\mathrm{Hz}), 3.23(4 \mathrm{H}, \mathrm{m}), 2.74(4 \mathrm{H}, \mathrm{m}), 2.70(2 \mathrm{H}, \mathrm{t}, \mathrm{J}=5.35 \mathrm{~Hz}), 2.02(2 \mathrm{H}$, apparent $\mathrm{p}, \mathrm{J}=$ $5.47 \mathrm{~Hz})$.

${ }^{13} \mathrm{C}$ NMR $\delta(\mathrm{ppm})\left(\mathrm{CHCl}_{3}-\mathrm{d}\right): 153.9,153.0,151.0,149.9,145.3,130.9,125.9,124.6$, $123.0,118.7,118.5,118.3,114.4,99.4,59.0,55.6,54.1,50.5,44.7,29.7,23.6$.

${ }^{19} \mathrm{~F} \mathrm{NMR} \delta(\mathrm{ppm})\left(\mathrm{CHCl}_{3}-\mathrm{d}\right):-61.3$.

HPLC (method C) $t_{\mathrm{R}}=9.22 \min (>99 \%$ pure). MS (ESI): $m / z 445.2200 \mathrm{M}+\mathrm{H}$ (calculated 445.2210). 


\section{A.3.4: 7-trifluoromethylquinolines}

7-trifluoromethyl-4-quinolone (Price, 1946; Snyder, 1947)

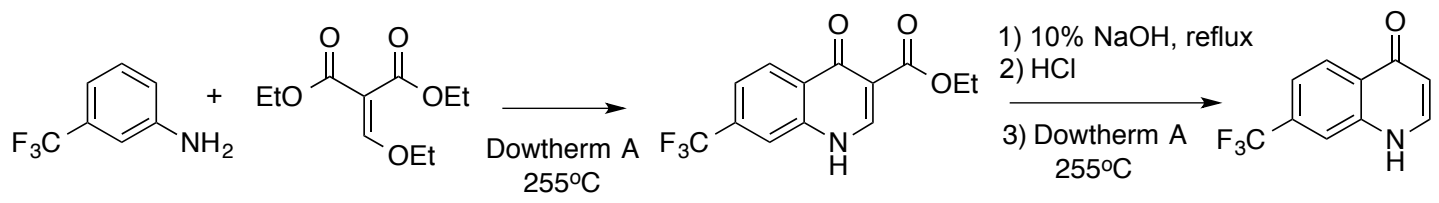

meta-Trifluoromethyl aniline $(4.5 \mathrm{~g}, 27.9 \mathrm{mmol})$ and diethyl ethoxymethylene malonate $(6.00 \mathrm{~mL}, 27.9 \mathrm{mmol})$ in Dowtherm A $(100 \mathrm{~mL})$ were allowed to heat gradually, stirring, to $255^{\circ} \mathrm{C}$, at which temperature the reaction was allowed to remain for 1 hour. After cooling, the reaction mixture was diluted with $30-60^{\circ}$ petroleum æther $(100 \mathrm{~mL})$ and vacuum filtered, rinsing with additional $30-60^{\circ}$ petroleum æther $(250 \mathrm{~mL})$. The resulting solid $(6.64 \mathrm{~g})$ was allowed to reflux in $10 \%$ caustic soda $(50 \mathrm{~mL})$ for 1 day. After cooling, the reaction was made acidic by addition of $10 \%$ muriatic acid. The resulting off-white precipitate was recovered by vacuum filtration, followed by drying in a vacuum dessicator for 1 hour. Without further drying, this material was combined with $20 \mathrm{~mL}$ Dowtherm A and gradually heated to $255^{\circ} \mathrm{C}$, at which temperature it was allowed to remain for 60 minutes. Upon cooling, the reaction mixture was diluted with $30-60^{\circ}$ petroleum æther $(50 \mathrm{~mL})$, and the product was recovered by vacuum filtration (rinsing with additional $30-60^{\circ}$ petroleum æther). The product was a cream-colored, crystalline solid (4.65 g, 78\% from starting aniline). NMR indicated that the product was primarily the desired 7-trifluoromethyl-4-quinolone, containing approximately $3 \% 5$ trifluoromethyl-4-quionolone.

${ }^{1} \mathrm{H}$ NMR $\delta(\mathrm{ppm})($ DMSO-d 6 ): Major peaks: $12.01(1 \mathrm{H}, \mathrm{s}), 8.28(1 \mathrm{H}, \mathrm{d}, \mathrm{J}=8.47 \mathrm{~Hz})$, $8.05(1 \mathrm{H}, \mathrm{s}), 7.92(1 \mathrm{H}, \mathrm{s}), 7.59(1 \mathrm{H}, \mathrm{dd}, \mathrm{J}=8.47,1.70 \mathrm{~Hz}), 6.14(1 \mathrm{H}, \mathrm{d}, \mathrm{J}=7.47 \mathrm{~Hz})$. Minor peaks due to the 5 -trifluoromethyl regioisomer are also present.

${ }^{19}$ F NMR $\delta(\mathrm{ppm})($ DMSO-d 6 ): -61.6 (major peak), -55.9 (minor peak).

4-chloro-7-(trifluoromethyl)quinoline (Price, 1946; Snyder, 1947)<smiles>FC(F)(F)c1ccc2c(Cl)ccnc2c1</smiles> 
Phosphorus oxychloride $(25 \mathrm{~mL}, 270 \mathrm{mmol})$ was cautiously added to 7-trifluoromethyl4-quinolone ( $4.65 \mathrm{~g}, 21.8 \mathrm{mmol}$ ), followed by heating at $110^{\circ} \mathrm{C}$ for $1 \mathrm{~h}$. After cooling, the reaction mixture was gradually added to $300 \mathrm{~mL}$ ice water. This was allowed to sit for 16 hours. Without basifying, the aqueous solution was extracted with dichloromethane $(100 \mathrm{~mL}$, then $3 \times 75 \mathrm{~mL})$. Drying of the pooled organic layers over $\mathrm{MgSO}_{4}$ followed by evaporation under reduced pressure with warming gave the desired product as a pale pink solid $\left(1.50 \mathrm{~g}, 30 \%, \mathrm{mp}=70.9-72.3^{\circ} \mathrm{C}\right.$ (lit. $71-72^{\circ} \mathrm{C}$ (Snyder, 1947)). NMR indicated that the product contained less than $2 \%$ of 4 -chloro-5trifluoromethylquinoline; this was not removed.

${ }^{1} \mathrm{H}$ NMR $\delta(\mathrm{ppm})\left(\mathrm{CHCl}_{3}-\mathrm{d}\right): 8.91(1 \mathrm{H}, \mathrm{d}, \mathrm{J}=4.75 \mathrm{~Hz}), 8.50(1 \mathrm{H}, \mathrm{s}), 8.40(1 \mathrm{H}, \mathrm{d}, \mathrm{J}=$ $8.82 \mathrm{~Hz}), 7.86(1 \mathrm{H}, \mathrm{dd}, \mathrm{J}=8.82,1.75 \mathrm{~Hz}), 7.65(1 \mathrm{H}, \mathrm{d}, \mathrm{J}=4.74 \mathrm{~Hz})$.

${ }^{19} \mathrm{~F} \mathrm{NMR} \delta(\mathrm{ppm})\left(\mathrm{CHCl}_{3}-\mathrm{d}\right):-62.9$.

\section{3-(7-(trifluoromethyl)quinolin-4-ylamino)propanol}<smiles>OCCCNc1ccnc2cc(C(F)(F)F)ccc12</smiles>

4-chloro-7-(trifluoromethyl)quinoline (1.5 g, $6.9 \mathrm{mmol})$ and 3-amino-1-propanol (8.0 $\mathrm{mL}, 105 \mathrm{mmol}$ ) were heated at $90^{\circ} \mathrm{C}$ for 18 hours. The reaction mixture was then poured into water $(50 \mathrm{~mL})$, and the resulting precipitate was recovered by vacuum filtration, followed by air-drying to provide the desired compound $(1.59 \mathrm{~g}, 85 \%, \mathrm{mp}=137.2-$ $\left.137.9^{\circ} \mathrm{C}\right)$.

${ }^{1} \mathrm{H}$ NMR $\delta(\mathrm{ppm})\left(\mathrm{DMSO}-\mathrm{d}_{6}\right): 8.51(1 \mathrm{H}, \mathrm{d}, \mathrm{J}=5.41 \mathrm{~Hz}), 8.46(1 \mathrm{H}, \mathrm{d}, \mathrm{J}=8.82 \mathrm{~Hz}), 8.08$ $(1 \mathrm{H}, \mathrm{s}), 7.68(1 \mathrm{H}, \mathrm{dd}, \mathrm{J}=8.79,1.95 \mathrm{~Hz}), 7.45(1 \mathrm{H}, \mathrm{br} \mathrm{t}, \mathrm{J}=5.36 \mathrm{~Hz}), 6.59(1 \mathrm{H}, \mathrm{d}, \mathrm{J}=$ $5.47 \mathrm{~Hz}$ ), $4.61(1 \mathrm{H}, \mathrm{t}, \mathrm{J}=5.05 \mathrm{~Hz}), 3.56(2 \mathrm{H}, \mathrm{m}), 3.35$ (water signal overlaps $\mathrm{m}, \sim 2 \mathrm{H}$ ), $1.84(2 \mathrm{H}, \mathrm{m})$.

${ }^{19} \mathrm{~F}$ NMR $\delta(\mathrm{ppm})\left(\mathrm{DMSO}-\mathrm{d}_{6}\right):-61.1$.

${ }^{1} \mathrm{H} \mathrm{NMR} \delta(\mathrm{ppm})\left(\mathrm{CHCl}_{3}-\mathrm{d}\right): 8.57(1 \mathrm{H}, \mathrm{d}, \mathrm{J}=5.36 \mathrm{~Hz}), 8.23(1 \mathrm{H}, \mathrm{s}), 7.78(1 \mathrm{H}, \mathrm{d}, \mathrm{J}=$ $8.77 \mathrm{~Hz}), 7.52(1 \mathrm{H}, \mathrm{dd}, \mathrm{J}=8.75,1.85 \mathrm{~Hz}), 6.44(1 \mathrm{H}, \mathrm{d}, \mathrm{J}=5.38 \mathrm{~Hz}), 6.09(1 \mathrm{H}, \mathrm{br} \mathrm{t}, \mathrm{J}=$ $4.63 \mathrm{~Hz}), 4.00(2 \mathrm{H}, \mathrm{t}, \mathrm{J}=5.38 \mathrm{~Hz}), 3.48(2 \mathrm{H}, \mathrm{td}, \mathrm{J}=6.14,4.73 \mathrm{~Hz}), 2.07(2 \mathrm{H}$, apparent $\mathrm{p}, \mathrm{J}=5.75 \mathrm{~Hz})$.

${ }^{19} \mathrm{~F} \mathrm{NMR} \delta(\mathrm{ppm})\left(\mathrm{CHCl}_{3}-\mathrm{d}\right):-62.7$. 


\section{3-(7-(trifluoromethyl)quinolin-4-ylamino)propyl methanesulfonate}<smiles>COCCCNc1ccnc2cc(C(F)(F)F)ccc12</smiles>

3-(7-(trifluoromethyl)quinolin-4-ylamino)propanol (1.59 g, $5.9 \mathrm{mmol})$ and triethylamine $(1.23 \mathrm{~mL}, 8.8 \mathrm{mmol})$ in dry dichloromethane $(50 \mathrm{~mL})$ were cooled to below $0^{\circ} \mathrm{C}$ on ice/salt, and methanesulfonyl chloride $(0.53 \mathrm{~mL}, 6.8 \mathrm{mmol})$ was gradually added. After stirring for 17 hours, TLC indicated that the reaction was not complete. Therefore, the reaction was again cooled to $0^{\circ} \mathrm{C}$ and additional triethylamine $(1.2 \mathrm{~mL}, 8.6 \mathrm{mmol})$ and methanesulfonyl chloride $(0.38 \mathrm{~mL}, 4.9 \mathrm{mmol})$ were added. After stirring an additional 18 hours, TLC indicated that reaction was complete. The reaction mixture was rinsed with saturated sodium bicarbonate $(35 \mathrm{~mL})$, and the aqueous layer was extracted 3 times with $10 \mathrm{~mL}$ portions of dichloromethane. The pooled organic extracts were dried over $\mathrm{MgSO}_{4}$ and evaporated under reduced pressure with warming to yield a yellow solid (1.96 g, 95\%, containing traces of residual triethylamine). This was used without further purification in the ensuing reactions.

${ }^{1} \mathrm{H}$ NMR $\delta(\mathrm{ppm})\left(\mathrm{DMSO}_{-} \mathrm{d}_{6}\right): 8.53(1 \mathrm{H}, \mathrm{d}, \mathrm{J}=5.43 \mathrm{~Hz}), 8.47(1 \mathrm{H}, \mathrm{d}, \mathrm{J}=8.82 \mathrm{~Hz}), 8.09$

$(1 \mathrm{H}, \mathrm{s}), 7.72(1 \mathrm{H}, \mathrm{dd}, \mathrm{J}=8.79,1.96 \mathrm{~Hz}), 7.53(1 \mathrm{H}, \mathrm{s}), 6.64(1 \mathrm{H}, \mathrm{d}, \mathrm{J}=5.49 \mathrm{~Hz}), 4.36$

$(2 \mathrm{H}, \mathrm{t}, \mathrm{J}=6.19 \mathrm{~Hz}), 3.42(2 \mathrm{H}, \mathrm{m}), 3.20(3 \mathrm{H}, \mathrm{s}), 2.08-2.10(2 \mathrm{H}, \mathrm{m})$.

${ }^{19}$ F NMR $\delta(p p m)\left(D M S O-d_{6}\right):-61.3$.

\section{PL264: N-(3-(4-(bis(4-fluorophenyl)methyl)piperazin-1-yl)propyl)-7-} (trifluoromethyl)quinolin-4-amine<smiles>CC(C)(O)OC(=O)Oc1ccccc1</smiles>

3-(7-(trifluoromethyl)quinolin-4-ylamino)propyl methanesulfonate (0.67 g, $1.9 \mathrm{mmol}), 1$ bis-(4-fluorophenyl)methyl piperazine $(0.55 \mathrm{~g}, 1.9 \mathrm{mmol})$, and triethylamine $(0.50 \mathrm{~mL}$, 
$3.6 \mathrm{mmol})$ were heated at reflux in anhydrous acetonitrile $(25 \mathrm{~mL})$ for 18 hours, whereupon TLC indicated that reaction was complete. The solvent was evaporated under reduced pressure with warming, and the residue was partitioned between chloroform ( 35 $\mathrm{mL})$ and water $(35 \mathrm{~mL})$. After separation, the aqueous layer was extracted with further chloroform $(3 \times 10 \mathrm{~mL})$, and the pooled organic layers were dried $\left(\mathrm{MgSO}_{4}\right)$ followed by evaporation under reduced pressure with warming. The resulting brown oil was purified by chromatography on alumina, eluting with $3: 2$ hexanes:ethyl acetate. This provided the desired product as a white, crystalline solid $\left(0.48 \mathrm{~g}, 47 \%, \mathrm{mp}=154.8-155.8^{\circ} \mathrm{C}, \mathrm{R}_{\mathrm{f}}=0.8\right.$ (basic alumina, 95/5 EA/MeOH v/v)).

${ }^{1} \mathrm{H} \mathrm{NMR} \delta(\mathrm{ppm})\left(\mathrm{CHCl}_{3}-\mathrm{d}\right): 8.58(1 \mathrm{H}, \mathrm{d}, \mathrm{J}=5.29 \mathrm{~Hz}), 8.24(1 \mathrm{H}, \mathrm{s}), 7.95(1 \mathrm{H}, \mathrm{d}, \mathrm{J}=$ $8.73 \mathrm{~Hz}), 7.56(1 \mathrm{H}, \mathrm{br} \mathrm{t}, \mathrm{J}=4.02 \mathrm{~Hz}), 7.42(1 \mathrm{H}, \mathrm{dd}, \mathrm{J}=8.71,1.84 \mathrm{~Hz}), 7.37-7.38(4 \mathrm{H}$, $\mathrm{m}), 6.98-7.04(4 \mathrm{H}, \mathrm{m}), 6.39(1 \mathrm{H}, \mathrm{d}, \mathrm{J}=5.36 \mathrm{~Hz}), 4.38(1 \mathrm{H}, \mathrm{s}), 3.38(2 \mathrm{H}, \mathrm{td}, \mathrm{J}=5.82$, $4.07 \mathrm{~Hz}), 2.65(10 \mathrm{H}$, br s overlaps t, J $=5.28 \mathrm{~Hz}), 1.95(2 \mathrm{H}$, apparent $\mathrm{p}, \mathrm{J}=5.41 \mathrm{~Hz})$.

${ }^{19} \mathrm{~F} \mathrm{NMR} \delta(\mathrm{ppm})\left(\mathrm{CHCl}_{3}-\mathrm{d}\right):-63.1,-115.8$.

${ }^{13} \mathrm{C} \mathrm{NMR} \delta(\mathrm{ppm})\left(\mathrm{CHCl}_{3}-\mathrm{d}\right): 162.8,161.1,152.5,150.4,147.7,137.5,129.5,129.4$, $115.6,115.4,99.5,74.4,58.8,53.9,51.6,44.5,23.3$.

HPLC (method C) $t_{\mathrm{R}}=12.39 \min (99 \%$ pure). MS (ESI): $m / z 541.2376 \mathrm{M}+\mathrm{H}$ (calculated 541.2385).

\section{PL142: N-(3-(4-benzhydrylpiperazin-1-yl)propyl)-7-(trifluoromethyl)quinolin-4- amine}<smiles>FC(F)(F)c1ccc2c(NCCCN3CCN(C(c4ccccc4)c4ccccc4)CC3)ccnc2c1</smiles>

\section{Method 1}<smiles>COCCCNc1ccnc2cc(C(F)(F)F)ccc12</smiles> 
3-(7-(trifluoromethyl)quinolin-4-ylamino)propyl methanesulfonate (1.09 g, $3.1 \mathrm{mmol}), 1$ benzyhydrylpiperazine $(0.83 \mathrm{~g}, 3.3 \mathrm{mmol})$, potassium carbonate $(0.65 \mathrm{~g}, 4.7 \mathrm{mmol})$, and a catalytic amount of potassium iodide were heated at reflux in anhydrous acetonitrile (30 $\mathrm{mL}$ ) for 5 days, whereupon TLC indicated that reaction was complete. The reaction mixture was diluted with $5 \mathrm{~mL}$ water and the solvent was removed by evaporation under reduced pressure with warming. The residue was partitioned between ethyl acetate ( 25 $\mathrm{mL})$ and water $(25 \mathrm{~mL})$. After separation, the aqueous layer was extracted with further ethyl acetate $(3 \times 7 \mathrm{~mL})$, and the pooled organic layers were dried over magnesium sulfate, followed by evaporation and recrystallization of the residue from $95 \%$ ethanol; the desired product was recovered as a white, crystalline solid $(0.47 \mathrm{~g}, 30 \%, \mathrm{mp}=162.0$ $\left.163.8^{\circ} \mathrm{C}\right)$.

${ }^{1} \mathrm{H}$ NMR $\delta(\mathrm{ppm})\left(\mathrm{CHCl}_{3}-\mathrm{d}\right): 8.56(1 \mathrm{H}, \mathrm{d}, \mathrm{J}=5.30 \mathrm{~Hz}, \mathrm{Q}-\mathrm{C} 2-\mathrm{H}), 8.23(1 \mathrm{H}, \mathrm{s}, \mathrm{Q}-\mathrm{C} 8-\mathrm{H}$ ?), $7.92(1 \mathrm{H}, \mathrm{d}, \mathrm{J}=8.74 \mathrm{~Hz}, \mathrm{Q}-\mathrm{C} 5-\mathrm{H}), 7.72(1 \mathrm{H}, \mathrm{br} \mathrm{t}, \mathrm{J}=3.96 \mathrm{~Hz}, \mathrm{Q}-\mathrm{C} 4-\mathrm{NH}), 7.42-7.43$ (4 $\mathrm{H}, \mathrm{m}, \mathrm{Ph}-\mathrm{H}$ ortho), 7.32-7.34 (5 H, m, Ph-H meta overlaps Q-C6-H), 7.23-7.27 (solvent signal overlaps $\mathrm{m}, \sim 2 \mathrm{H}, \mathrm{Ph}-\mathrm{H}$ para $), 6.36(1 \mathrm{H}, \mathrm{d}, \mathrm{J}=5.35 \mathrm{~Hz}, \mathrm{Q}-\mathrm{C} 3-\mathrm{H}), 4.48(1 \mathrm{H}, \mathrm{s}$, $\left.\mathrm{CH}(\mathrm{Ph})_{2}\right), 3.36\left(2 \mathrm{H}, \mathrm{td}, \mathrm{J}=5.78,4.02 \mathrm{~Hz}\right.$, Q-NH- $\left.\mathrm{CH}_{2} \mathrm{CH}_{2} \mathrm{CH}_{2}\right), 2.65(10 \mathrm{H}$, br s overlaps $\mathrm{t}, \mathrm{J}=5.34 \mathrm{~Hz}$, Pip- $\mathrm{CH}_{2} \mathrm{x} 4$ and Q-NH- $\left.\mathrm{CH}_{2} \mathrm{CH}_{2} \mathrm{CH}_{2}\right), 1.92-1.96(2 \mathrm{H}$, apparent $\mathrm{p}, \mathrm{J}=5.38$ $\mathrm{Hz}, \mathrm{Q}-\mathrm{NH}-\mathrm{CH}_{2} \mathrm{CH}_{2} \mathrm{CH}_{2}$ ).

${ }^{19} \mathrm{~F}$ NMR $\delta(\mathrm{ppm})\left(\mathrm{CHCl}_{3}-\mathrm{d}\right):-62.9$.

${ }^{13} \mathrm{C}$ NMR $\delta(\mathrm{ppm})\left(\mathrm{CHCl}_{3}\right.$-d): 152.4 (Q-C2), 150.4, 147.6, 141.6 (Ph-C ipso), 130.5 (q, J $=32.57 \mathrm{~Hz}, \mathrm{Q}-\underline{\mathrm{C}} 7), 128.5\left(\mathrm{Ph}-\mathrm{C}\right.$ meta) $, 128.2(\mathrm{Ph}-\mathrm{C}$ ortho $), 127.4\left(\mathrm{q}, \mathrm{J}_{\mathrm{F}}=4.25 \mathrm{~Hz}, \mathrm{Q}-\right.$ C8), $127.2\left(\mathrm{Ph}-\mathrm{C}\right.$ para) $124.2\left(\mathrm{q}, \mathrm{J}_{\mathrm{F}}=271.81 \mathrm{~Hz}, \mathrm{CF}_{3}\right), 122.3,120.8,119.5\left(\mathrm{q}, \mathrm{J}_{\mathrm{F}}=3.26\right.$ $\mathrm{Hz}, \mathrm{Q}-\mathrm{C6}$ ), 99.4 (Q-C3), $75.6\left(\mathrm{CH}(\mathrm{Ph})_{2}\right), 59.0$ (Q-NH- $\mathrm{CH}_{2} \mathrm{CH}_{2} \mathrm{CH}_{2}$ ), 54.0 (Pip-C-C$\left.\mathrm{NCH}(\mathrm{Ph})_{2}\right), 51.4\left(\mathrm{Pip}-\mathrm{C}-\mathrm{C}-\mathrm{NCH}(\mathrm{Ph})_{2}\right), 44.6\left(\mathrm{Q}-\mathrm{NH}-\mathrm{CH}_{2} \mathrm{CH}_{2} \mathrm{CH}_{2}\right), 23.1(\mathrm{Q}-\mathrm{NH}-$ $\mathrm{CH}_{2} \mathrm{CH}_{2} \mathrm{CH}_{2}$ ).

MS (ESI): $m / z 505.2563 \mathrm{M}+\mathrm{H}$ (calculated 505.2574).

HPLC (method C) $t_{\mathrm{R}}=11.60 \min (98 \%$ pure $)$. 
PL142, Method 2 (Based upon Gabriel, 1887; Ing, 1926; Leonardi, 2004; Nishikawa, 1989; Andersag, 1948; Surrey, 1951)<smiles></smiles>

4-chloro-7-(trifluoromethyl)quinoline ( $0.37 \mathrm{~g}, 1.6 \mathrm{mmol})$ and phenol (2.11 g, $22 \mathrm{mmol})$ were allowed to heat at $105^{\circ} \mathrm{C}$ for 1.5 hours. PL151 (0.80 g, $2.6 \mathrm{mmol}$; see below) was then added, and the mixture was allowed to heat at $120^{\circ} \mathrm{C}$ for 28 hours. The cooled reaction mixture was diluted with dichloromethane $(20 \mathrm{~mL})$ and washed with $1 \mathrm{M}$ caustic soda $(6 \times 10 \mathrm{~mL})$, followed by brine $(10 \mathrm{~mL})$. The pooled organic layers were dried $\left(\mathrm{MgSO}_{4}\right)$ and concentrated under reduced pressure with warming to provide a reddish brown glass. This material was purified by chromatography on alumina, eluting with 30:70 hexanes:ethyl acetate, followed by 100\% ethyl acetate and finally, 95:5 ethyl acetate:methanol. The desired product was obtained as a tan solid $\left(0.15 \mathrm{~g}, 19 \%, \mathrm{R}_{\mathrm{f}}=0.8\right.$ (basic alumina, 95/5 EA/MeOH v/v)).

PL151: 3-(4-benzhydrylpiperazin-1-yl)propan-1-amine (Gabriel, 1887; Ing, 1926; Leonardi, 2004; Nishikawa, 1989)

PL191 (1.47 g, 3.3 mmol; see below) and hydrazine monohydrate (0.48 mL, 9.9 mmol) were heated in refluxing $95 \%$ ethanol $(50 \mathrm{~mL})$ for 3 hours, at which time TLC indicated that the reaction was complete. Upon cooling, crystallization occurred; the reaction was further chilled in an ice bath, followed by filtration. The white solid obtained was rinsed with chilled $95 \%$ ethanol $(3 \times 10 \mathrm{~mL})$, followed by chilled diethyl æther $(2 \times 10 \mathrm{~mL})$. The filtrate was basified to $\mathrm{pH} 9$ by the addition of $2 \mathrm{M} \mathrm{NaOH}$ and concentrated under reduced pressure with warming. The residue was diluted with water $(20 \mathrm{~mL})$ and extracted with dichloromethane $(3 \times 10 \mathrm{~mL})$. The pooled organic layers were dried 
$\left(\mathrm{MgSO}_{4}\right)$ and concentrated under reduced pressure with warming to yield a yellow oil, which became a waxy solid upon standing. This proved to be the desired product $(0.80 \mathrm{~g}$, $79 \%)$.

${ }^{1} \mathrm{H}$ NMR $\delta(\mathrm{ppm})\left(\mathrm{CHCl}_{3}-\mathrm{d}\right):$ 7.40-7.42 $(4 \mathrm{H}, \mathrm{m}), 7.22-7.30$ (solvent signal overlaps $\mathrm{m}, \sim 4$ H), 7.14-7.19 $(2 \mathrm{H}, \mathrm{m}), 4.21(1 \mathrm{H}, \mathrm{s}), 2.73(2 \mathrm{H}, \mathrm{t}, \mathrm{J}=6.83 \mathrm{~Hz}), 2.41-2.42(10 \mathrm{H}, \mathrm{br} \mathrm{s}$ overlaps $\mathrm{t}, \mathrm{J}=7.55 \mathrm{~Hz}), 1.62(2 \mathrm{H}$, apparent $\mathrm{p}, \mathrm{J}=7.23 \mathrm{~Hz})$.

PL191: 2-(3-(4-benzhydrylpiperazin-1-yl)propyl)phthalimide (Gabriel, 1887; Ing, 1926; Leonardi, 2004; Nishikawa, 1989)

1-(Diphenylmethyl)piperazine (11.00 g, $44 \mathrm{mmol}), \mathrm{N}$-3-(bromopropyl)phthalimide (12.84 $\mathrm{g}, 48 \mathrm{mmol})$, and potassium carbonate $(16.07 \mathrm{~g}, 120 \mathrm{mmol})$ were allowed to heat in anhydrous acetonitrile $(210 \mathrm{~mL})$ at reflux under a nitrogen atmosphere for 18 hours, at which time TLC indicated that reaction was complete. The reaction mixture was concentrated under reduced pressure with warming, and the residue was diluted with ethyl acetate $(125 \mathrm{~mL})$ and washed with water $(75 \mathrm{~mL}$, then $4 \times 50 \mathrm{~mL})$, then dried over magnesium sulfate and concentrated under reduced pressure with warming. The amber oil thus obtained was divided into two equal portions, each of which was purified by column chromatography on alumina, eluting with $100 \%$ ethyl acetate followed by $95: 5$ ethyl acetate:methanol. The off-white solid thus obtained contained the residual $N-3$ (bromopropyl)phthalimide in addition to the desired product. This material was recrystallized from ethyl acetate to obtain the desired product as an off-white, crystalline solid $\left(7.73 \mathrm{~g}, 56 \%, \mathrm{R}_{\mathrm{f}}=0.6\right.$ (silica, $95 / 5$ chloroform $/$ methanol $\mathrm{v} / \mathrm{v}$ )). Note: It was also possible to perform the ensuing reactions without chromatographic purification of this material, with comparable results.

${ }^{1} \mathrm{H}$ NMR $\delta(\mathrm{ppm})\left(\mathrm{CHCl}_{3}-\mathrm{d}\right): 7.82(2 \mathrm{H}, \mathrm{dd}, \mathrm{J}=5.44,3.05 \mathrm{~Hz}), 7.71(2 \mathrm{H}, \mathrm{dd}, \mathrm{J}=5.46$, 3.04 Hz), 7.35-7.37 (4 H, m), 7.12-7.20 (2 H, m), $4.07(1 \mathrm{H}, \mathrm{s}), 3.74(2 \mathrm{H}, \mathrm{t}, \mathrm{J}=6.94 \mathrm{~Hz})$, $2.41(10 \mathrm{H}$, br s overlaps $\mathrm{t}, \mathrm{J}=7.19 \mathrm{~Hz}), 1.79-1.87(2 \mathrm{H}, \mathrm{m})$.

\section{PL287: 7-trifluoromethyl- $\mathrm{N}$-(3-(4-(pyridin-2-yl)piperazin-1-yl)propyl)quinolin-4- amine}<smiles>FC(F)(F)c1ccc2c(NCCCN3CCN(c4ccccn4)CC3)ccnc2c1</smiles> 
3-(7-(trifluoromethyl)quinolin-4-ylamino)propyl methanesulfonate $(3.10 \mathrm{~g}, 8.9 \mathrm{mmol}), 1$ (2-pyridyl)piperazine ( $0.92 \mathrm{~g}, 5.6 \mathrm{mmol})$, and potassium carbonate $(1.85 \mathrm{~g}, 13 \mathrm{mmol})$ were heated at reflux in anhydrous acetonitrile $(24 \mathrm{~mL})$ for 5 days. The solvent was removed by evaporation under reduced pressure with warming, and the residue was partitioned between dichloromethane $(50 \mathrm{~mL})$ and water $(25 \mathrm{~mL})$. After separation, the aqueous layer was extracted with further dichloromethane $(3 \times 10 \mathrm{~mL})$, and the pooled organic layers were dried over magnesium sulfate, followed by evaporation under reduced pressure with warming and recrystallization of the residue from ethyl acetate to obtain the desired product as beige crystals $\left(0.72 \mathrm{~g}, 19 \%, \mathrm{mp}=172.3-173.9^{\circ} \mathrm{C}\right)$.

${ }^{1} \mathrm{H} \mathrm{NMR} \delta(\mathrm{ppm})\left(\mathrm{CHCl}_{3}-\mathrm{d}\right): 8.60(1 \mathrm{H}, \mathrm{d}, \mathrm{J}=5.34 \mathrm{~Hz}), 8.22-8.25(2 \mathrm{H}, \mathrm{m}), 7.97(1 \mathrm{H}, \mathrm{d}$, $\mathrm{J}=8.75 \mathrm{~Hz}), 7.54(1 \mathrm{H}, \mathrm{ddd}, \mathrm{J}=8.53,7.17,2.02 \mathrm{~Hz}), 7.45(1 \mathrm{H}, \mathrm{dd}, \mathrm{J}=8.75,1.88 \mathrm{~Hz})$, $7.42(1 \mathrm{H}, \mathrm{t}, \mathrm{J}=4.03 \mathrm{~Hz}), 6.69-6.70(2 \mathrm{H}, \mathrm{m}), 6.44(1 \mathrm{H}, \mathrm{d}, \mathrm{J}=5.38 \mathrm{~Hz}), 3.70(4 \mathrm{H}, \mathrm{m})$, $3.43(2 \mathrm{H}, \mathrm{td}, \mathrm{J}=5.96,4.23 \mathrm{~Hz}), 2.69-2.70(6 \mathrm{H}, \mathrm{m}), 2.02(2 \mathrm{H}$, apparent p, J = 5.49 Hz).

${ }^{13} \mathrm{C} \mathrm{NMR} \delta(\mathrm{ppm})\left(\mathrm{CHCl}_{3}-\mathrm{d}\right): 159.3,152.5,150.3,148.1,147.7,137.7,130.7\left(\mathrm{q}, \mathrm{J}_{\mathrm{F}}=32.5\right.$ $\left.\mathrm{Hz}, \mathrm{Q}-\mathrm{C} 7-\mathrm{CF}_{3}\right), 127.7,121.7,120.8,119.7,113.8,107.2$, 99.6, 58.7, 53.5, 45.4, 44.3, 23.6 .

MS (ESI): $m / z$ 416.20603 M + H (calculated 416.20566)

$\operatorname{HPLC}\left(\right.$ method A) $t_{\mathrm{R}}=6.41 \min (>99 \%$ pure $)$.

\section{PL230: 7-trifluoromethyl- $\mathrm{N}$-(3-(4-(dipyridin-2-ylmethyleneamino)piperidin-1- yl)propyl)quinolin-4-amine}<smiles>O=C(O[PH](=O)(=O)O)c1ccnc2cc(C(F)(F)F)ccc12</smiles>

3-(7-trifluoromethyl-4-ylamino)propyl methanesulfonate ( $0.32 \mathrm{~g}, 0.92 \mathrm{mmol}), \mathrm{N}$ (dipyridin-2-methylene)piperidin-4-amine $(0.36 \mathrm{~g}, 1.4 \mathrm{mmol})$, and potassium carbonate $(0.18 \mathrm{~g}, 1.3 \mathrm{mmol})$ were allowed to heat at $70^{\circ} \mathrm{C}$ in anhydrous acetonitrile $(12 \mathrm{~mL})$ for 6 days. TLC then indicated that the reaction was complete. The reaction mixture was diluted with water $(30 \mathrm{~mL})$ and partially evaporated under reduced pressure with warming, followed by filtration to yield a sticky, light brown solid. This was allowed to 
air dry, then purified by chromatography on basic alumina, eluting with $100 \%$ ethyl acetate. This provided the desired product as a white powder $(0.14 \mathrm{~g}, 29 \%, \mathrm{mp}=191-$ $199^{\circ} \mathrm{C}, \mathrm{R}_{\mathrm{f}}=0.1$ (basic alumina, ethyl acetate)).

${ }^{1} \mathrm{H}$ NMR $\delta(\mathrm{ppm})\left(\mathrm{CHCl}_{3}-\mathrm{d}\right): 8.75-8.75(1 \mathrm{H}, \mathrm{m}), 8.59(1 \mathrm{H}, \mathrm{d}, \mathrm{J}=5.34 \mathrm{~Hz}), 8.52-8.52(1$ $\mathrm{H}, \mathrm{m}), 8.34-8.41(1 \mathrm{H}, \mathrm{m}), 8.26(1 \mathrm{H}, \mathrm{s}), 8.22(1 \mathrm{H}, \mathrm{d}, \mathrm{J}=8.73 \mathrm{~Hz}), 8.15(1 \mathrm{H}, \mathrm{t}, \mathrm{J}=4.03$ $\mathrm{Hz}), 7.82-7.83(2 \mathrm{H}, \mathrm{m}), 7.76(1 \mathrm{H}, \mathrm{dd}, \mathrm{J}=8.70,1.88 \mathrm{~Hz}), 7.36(1 \mathrm{H}, \mathrm{ddd}, \mathrm{J}=7.67,4.91$, $1.21 \mathrm{~Hz}), 7.29-7.29(2 \mathrm{H}, \mathrm{m}), 6.40(1 \mathrm{H}, \mathrm{d}, \mathrm{J}=5.38 \mathrm{~Hz}), 3.41-3.42(3 \mathrm{H}, \mathrm{m}), 3.06-3.10(2$ $\mathrm{H}, \mathrm{m}), 2.63(2 \mathrm{H}, \mathrm{td}, \mathrm{J}=4.98,1.35 \mathrm{~Hz}), 2.05-2.09(4 \mathrm{H}, \mathrm{m}), 1.96(2 \mathrm{H}$, apparent $\mathrm{p}, \mathrm{J}=$ $5.32 \mathrm{~Hz}), 1.73-1.98(2 \mathrm{H}, \mathrm{m})$.

${ }^{13} \mathrm{C} \mathrm{NMR} \delta(\mathrm{ppm})\left(\mathrm{CHCl}_{3}-\mathrm{d}\right): 165.5,157.0,155.6,152.5,150.5,149.7,148.7,147.7$, $136.5,136.0,130.7\left(\mathrm{q}, \mathrm{J}_{\mathrm{F}}=32.1 \mathrm{~Hz}, \mathrm{Q}-\mathrm{C} 7-\mathrm{CF}_{3}\right), 127.4,124.2,123.4,123.1,122.6$, $122.2,121.0,119.7,115.6,99.2,59.0,58.5,52.1,44.7,32.9,23.6$.

${ }^{19} \mathrm{~F}$ NMR $\delta(\mathrm{ppm})\left(\mathrm{CHCl}_{3}-\mathrm{d}\right):-63.1$. (corrected to Freon 11)

MS (ESI): $m / z 519.24828 \mathrm{M}+\mathrm{H}$ (calculated 519.24786)

$\operatorname{HPLC}\left(\right.$ method A) $t_{\mathrm{R}}=1.59 \min (79 \%$ pure). (Additional peak elutes at $2.02 \mathrm{~min}, 19 \%$.)

\section{PL242: 7-trifluoromethyl- $N$-(3-(4-(dipyridin-2-ylmethylamino)piperidin-1- yl)propyl)quinolin-4-amine}

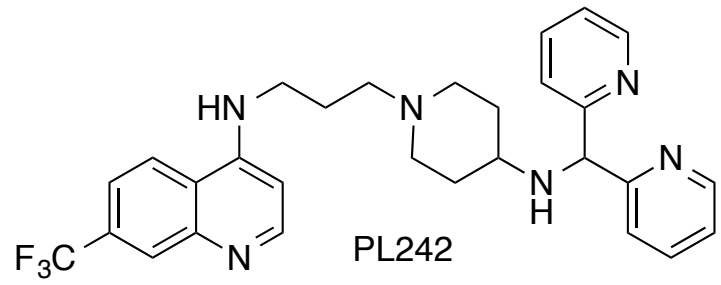

PL 230 (0.11 g, $0.21 \mathrm{mmol})$ was dissolved in anhydrous methanol $(10 \mathrm{~mL})$, followed by the addition of sodium borohydride $(0.03 \mathrm{~g}, 0.79 \mathrm{mmol})$. After stirring at room temperature for one hour, equipped with an alumina drying tube, additional sodium borohydride $(0.01 \mathrm{~g}, 0.26 \mathrm{mmol})$ was added. After a further 30 minutes, the solvent was removed by evaporation under reduced pressure with warming. The residue was combined with water $(10 \mathrm{~mL})$ and allowed to stir for 1.5 hours at room temperature, followed by extraction with dichloromethane $(8 \times 5 \mathrm{~mL})$. The pooled organic layers were dried $\left(\mathrm{MgSO}_{4}\right)$ and evaporated under reduced pressure with warming to yield the desired product as a pale brown solid $\left(0.11 \mathrm{~g}, \sim 100 \%, \mathrm{mp}=140.5-145.0^{\circ} \mathrm{C}\right)$. 
${ }^{1} \mathrm{H}$ NMR $\delta(\mathrm{ppm})\left(\mathrm{CHCl}_{3}-\mathrm{d}\right): 8.56-8.59(3 \mathrm{H}, \mathrm{m}), 8.23(1 \mathrm{H}, \mathrm{s}), 8.03(1 \mathrm{H}, \mathrm{d}, \mathrm{J}=8.76 \mathrm{~Hz})$, $7.94(1 \mathrm{H}, \mathrm{t}, \mathrm{J}=3.93 \mathrm{~Hz}), 7.63-7.64(3 \mathrm{H}, \mathrm{m}), 7.48(2 \mathrm{H}, \mathrm{d}, \mathrm{J}=7.88 \mathrm{~Hz}), 7.16-7.16(2 \mathrm{H}$, $\mathrm{m}), 6.38(1 \mathrm{H}, \mathrm{d}, \mathrm{J}=5.40 \mathrm{~Hz}), 5.25(1 \mathrm{H}, \mathrm{s}), 3.37(2 \mathrm{H}, \mathrm{td}, \mathrm{J}=5.74,3.89 \mathrm{~Hz}), 3.00-3.04$ (2 H, m), 2.62-2.72 (1 H, m), 2.56-2.61 (2 H, m), 2.00-2.04 (4 H, m), 1.93 (2 H, apparent $\mathrm{p}, \mathrm{J}=5.34 \mathrm{~Hz}), 1.67(2 \mathrm{H}, \mathrm{m})$.

${ }^{19} \mathrm{~F} \mathrm{NMR} \delta(\mathrm{ppm})\left(\mathrm{CHCl}_{3}-\mathrm{d}\right):-63.3$.

${ }^{13} \mathrm{C} \mathrm{NMR} \delta(\mathrm{ppm})\left(\mathrm{CHCl}_{3}-\mathrm{d}\right): 162.2,152.4,150.5,149.1,147.7,136.6,130.7\left(\mathrm{q}, \mathrm{J}_{\mathrm{F}}=32.8\right.$ $\left.\mathrm{Hz}, \mathrm{Q}-\underline{\mathrm{C}} 7-\mathrm{CF}_{3}\right), 127.4,122.4,122.3,122.2,120.9,119.7,99.3,66.5,58.7,53.1,52.8$, 44.6, 33.1, 23.6.

MS (ESI): $m / z$ 521.2627 M + H (calculated 521.2635).

HPLC (method C) $t_{\mathrm{R}}=6.37 \min (98 \%$ pure $)$.

\section{PL315: 7-trifluoromethyl- $N$-(3-(4-(4-fluorophenyl)piperazin-1-yl)propyl)quinolin-4- amine}

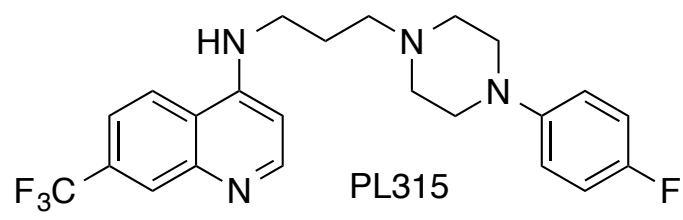

3-(7-(trifluoromethyl)quinolin-4-ylamino)propyl methanesulfonate (1.33 g, $3.8 \mathrm{mmol})$, $\mathrm{N}$-(4-fluorophenyl)piperazine $(0.72 \mathrm{~g}, 4.0 \mathrm{mmol})$, and potassium carbonate $(0.79 \mathrm{~g}, 5.7$ $\mathrm{mmol})$ were heated at $75^{\circ} \mathrm{C}$ in anhydrous acetonitrile $(15 \mathrm{~mL})$ for 18 hours, whereupon TLC indicated that reaction was complete. The reaction mixture was diluted with $5 \mathrm{~mL}$ water, followed by removal of the solvent under reduced pressure with warming. The residue was partitioned between chloroform $(20 \mathrm{~mL})$ and water $(20 \mathrm{~mL})$. After separation, the aqueous layer was extracted with additional chloroform $(3 \times 10 \mathrm{~mL})$, and the pooled organic layers were dried $\left(\mathrm{MgSO}_{4}\right)$ and evaporated under reduced pressure with warming. The resulting brown semisolid was crystallized from chloroform, followed by recrystallization from ethyl acetate $(5 \mathrm{~mL})$ to provide the desired product as a cream-colored solid $\left(0.17 \mathrm{~g}, 10 \%, \mathrm{mp}=182.1-183.3^{\circ} \mathrm{C}\right)$.

${ }^{1} \mathrm{H}$ NMR $\delta(\mathrm{ppm})\left(\mathrm{CHCl}_{3}-\mathrm{d}\right): 8.60(1 \mathrm{H}, \mathrm{d}, \mathrm{J}=5.35 \mathrm{~Hz}), 8.24(1 \mathrm{H}, \mathrm{s}), 7.98(1 \mathrm{H}, \mathrm{d}, \mathrm{J}=$ 8.75 Hz), 7.40-7.46 (2 H, m), 7.02-7.03 (2 H, m), 6.93-6.95 (2 H, m), 6.44 (1 H, d, J = $5.38 \mathrm{~Hz}), 3.43(2 \mathrm{H}, \mathrm{td}, \mathrm{J}=5.47,0.01 \mathrm{~Hz}), 3.27(4 \mathrm{H}, \mathrm{m}), 2.76(4 \mathrm{H}, \mathrm{m}), 2.72(2 \mathrm{H}, \mathrm{t}, \mathrm{J}=$ $5.39 \mathrm{~Hz}), 2.02(2 \mathrm{H}$, apparent $\mathrm{p}, \mathrm{J}=5.54 \mathrm{~Hz})$. 


\footnotetext{
${ }^{19} \mathrm{~F} \mathrm{NMR} \delta(\mathrm{ppm})\left(\mathrm{CHCl}_{3}-\mathrm{d}\right):-63.2,-124.3(\mathrm{~m})$.

${ }^{13} \mathrm{C} \mathrm{NMR} \delta(\mathrm{ppm})\left(\mathrm{CHCl}_{3}-\mathrm{d}\right): 158.3,156.7,152.5,147.7,130.9,127.6,121.8,120.7$, $119.5,117.9,115.8,115.6,99.6,58.5,53.6,50.3,44.3,23.5$.
}

MS (ESI): $m / z 433.20099 \mathrm{M}+\mathrm{H}$ (calculated 433.20122)

HPLC (method A) $t_{\mathrm{R}}=8.94 \min (99 \%$ pure $)$.

\section{PL316: 7-trifluoromethyl- $N$-(3-(4-(4-methoxyphenyl)piperazin-1-yl)propyl)quinolin- 4-amine}

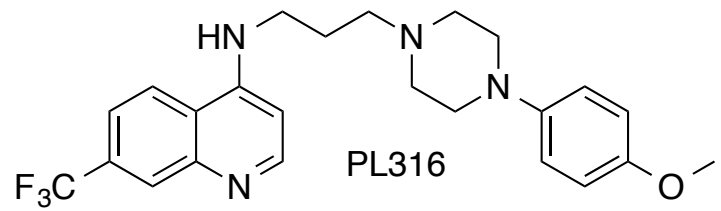

3-(7-(trifluoromethyl)quinolin-4-ylamino)propyl methanesulfonate $(1.04 \mathrm{~g}, 3.0 \mathrm{mmol})$, $\mathrm{N}$-(p-methoxyphenyl)piperazine $(0.29 \mathrm{~g}, 1.5 \mathrm{mmol}), \mathrm{N}$-(p-methoxyphenyl)piperazine dihydrochloride $(0.44 \mathrm{~g}, 1.7 \mathrm{mmol})$, potassium carbonate $(1.08 \mathrm{~g}, 7.8 \mathrm{mmol})$, and a catalytic amount of potassium iodide were heated at reflux in anhydrous acetonitrile (25 $\mathrm{mL}$ ) for 5 days, whereupon TLC indicated that reaction was complete. The solvent was removed by evaporation under reduced pressure with warming, and the resulting golden brown, thick oil was partitioned between ethyl acetate $(25 \mathrm{~mL})$ and water $(25 \mathrm{~mL})$. After separation, the aqueous layer was extracted with further ethyl acetate $(3 \times 7 \mathrm{~mL})$, and the pooled organic layers were dried over magnesium sulfate, followed by evaporation and recrystallization of the residue from $95 \%$ ethanol; the desired product was recovered as large, colorless crystals $\left(0.52 \mathrm{~g}, 39 \%, \mathrm{mp}=155.9-157.2^{\circ} \mathrm{C}\right)$.

${ }^{1} \mathrm{H} \mathrm{NMR} \delta(\mathrm{ppm})\left(\mathrm{CHCl}_{3}-\mathrm{d}\right): 8.60(1 \mathrm{H}, \mathrm{d}, \mathrm{J}=5.33 \mathrm{~Hz}, \mathrm{Q}-\mathrm{C} 2-\mathrm{H}), 8.24(1 \mathrm{H}, \mathrm{d}, \mathrm{J}=1.70$ $\mathrm{Hz}, \mathrm{Q}-\mathrm{C} 8-\mathrm{H}), 8.01(1 \mathrm{H}, \mathrm{d}, \mathrm{J}=8.73 \mathrm{~Hz}, \mathrm{Q}-\mathrm{C} 5-\mathrm{H}), 7.54(1 \mathrm{H}, \mathrm{brt}$ t, J = $4.19 \mathrm{~Hz}), 7.43(1 \mathrm{H}$, dd, J = 8.70, $1.88 \mathrm{~Hz}, \mathrm{Q}-\mathrm{C} 6-\mathrm{H}), 6.94-6.97\left(2 \mathrm{H}, \mathrm{m}, \mathrm{Ph}-\mathrm{H}\right.$, ortho to $\left.-\mathrm{OCH}_{3}\right), 6.89-6.92$ (2 $\mathrm{H}, \mathrm{m}, \mathrm{Ph}-\underline{\mathrm{H}}$, meta to $\left.\mathrm{OCH}_{3}\right), 6.43(1 \mathrm{H}, \mathrm{d}, \mathrm{J}=5.37 \mathrm{~Hz}, \mathrm{Q}-\mathrm{C} 3-\mathrm{H}), 3.81\left(3 \mathrm{H}, \mathrm{s}, \mathrm{OCH}_{3}\right)$, $3.43\left(2 \mathrm{H}, \mathrm{td}, \mathrm{J}=5.89,4.15 \mathrm{~Hz}, \mathrm{Q}-\mathrm{NH}-\mathrm{CH}_{2} \mathrm{CH}_{2} \mathrm{CH}_{2}\right), 3.24\left(4 \mathrm{H}, \mathrm{m}, \mathrm{Pip}^{-\mathrm{CH}_{2}} \times 2\right.$, adjacent to $\mathrm{Ph}$ ), $2.76\left(4 \mathrm{H}, \mathrm{m}\right.$, Pip- $\mathrm{CH}_{2} \times 2$, not adjacent to $\left.\mathrm{Ph}\right), 2.71(2 \mathrm{H}, \mathrm{t}, \mathrm{J}=5.34 \mathrm{~Hz}$, Q-NH- $\left.\mathrm{CH}_{2} \mathrm{CH}_{2} \mathrm{CH}_{2}\right), 2.01\left(2 \mathrm{H}\right.$, apparent p, J $=5.51 \mathrm{~Hz}, \mathrm{Q}-\mathrm{NH}-\mathrm{CH}_{2} \mathrm{CH}_{2} \mathrm{CH}_{2}$ ).

${ }^{19} \mathrm{~F} \mathrm{NMR} \delta(\mathrm{ppm})\left(\mathrm{CHCl}_{3}-\mathrm{d}\right):-63.1$. 
${ }^{13} \mathrm{C}$ NMR $\delta$ (ppm) $\left(\mathrm{CHCl}_{3}\right.$-d): 154.2 (Ph-C ipso to $\left.\mathrm{OCH}_{3}\right), 152.5$ (Q-C2), 150.3 (Q-C4), 147.8 (Q-C), 145.5 (Ph-C, para to $\left.\mathrm{OCH}_{3}\right), 130.7$ (q, J $\left.\mathrm{J}_{\mathrm{F}}=31.9 \mathrm{~Hz}, \mathrm{Q}-\mathrm{C} 7\right), 127.6\left(\mathrm{q}, \mathrm{J}_{\mathrm{F}}=\right.$ $4.5 \mathrm{~Hz}, \mathrm{Q}-\mathrm{C} 8), 124.1$ (q, J $\mathrm{J}_{\mathrm{F}}=175.1 \mathrm{~Hz}, \mathrm{CF}_{3}$ ), 122.0 (Q-C5), 120.8 (Q-C), 119.6 (q, $\mathrm{J}_{\mathrm{F}}=$ $2.7 \mathrm{~Hz}, \mathrm{Q}-\mathrm{C} 6), 118.4$ (Ph-C, ortho to $\left.\mathrm{OCH}_{3}\right), 114.7$ (Ph-C, meta to $\left.\mathrm{OCH}_{3}\right), 99.6$ (Q-C3), $58.7\left(\mathrm{Q}-\mathrm{NH}-\mathrm{CH}_{2} \mathrm{CH}_{2} \mathrm{CH}_{2}\right), 55.6\left(\mathrm{OCH}_{3}\right), 53.8\left(\mathrm{Pip}-\underline{\mathrm{CH}}_{2} \mathrm{x}\right.$ 2, not adjacent to $\left.\mathrm{Ph}\right), 50.9$

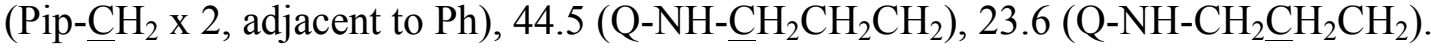

MS (ESI): $m / z$ 445.22082 M + H (calculated 445.22097)

HPLC $\left(\operatorname{method~A)~} t_{\mathrm{R}}=8.60 \min (>99 \%\right.$ pure $)$.

\section{A.3.5: 8-trifluoromethylquinolines}

3-carboxy-8-trifluoromethyl-4-quinolone (Price, 1946; Allais, 1969)<smiles>[NH3+]c1ccccc1C(F)(F)F</smiles><smiles>CCOC=C(C(=O)OCC)C(=O)OCC</smiles><smiles>[2H]O[13CH3]</smiles><smiles>CCOC(=O)c1c[nH]c2c(C(F)(F)F)cccc2c1=O</smiles><smiles>O=C(O)c1c[nH]c2c(C(F)(F)F)cccc2c1=O</smiles>

ortho-Trifluoromethyl aniline $(7.19 \mathrm{~mL}, 58.0 \mathrm{mmol})$ and diethyl ethoxymethylene malonate $(11.63 \mathrm{~mL}, 58.0 \mathrm{mmol})$ in Dowtherm A $(80 \mathrm{~mL})$ were allowed to heat gradually, stirring, to $255^{\circ} \mathrm{C}$, at which temperature the reaction was allowed to remain for 20 minutes. After cooling, the reaction mixture was diluted with hexanes $(100 \mathrm{~mL})$ and vacuum filtered, rinsing with additional hexanes $(250 \mathrm{~mL})$ followed by acetone $(150$ $\mathrm{mL})$. The resulting solid was allowed to reflux in $10 \%$ caustic soda $(200 \mathrm{~mL})$ for 20 hours. After cooling partially, the reaction was made acidic by addition of $3 \mathrm{M}$ muriatic acid. The resulting off-white precipitate was recovered by vacuum filtration. After air drying, yield was $7.31 \mathrm{~g}$ (49\%, possibly containing residual water).

${ }^{1} \mathrm{H}$ NMR $\delta(\mathrm{ppm})\left(\mathrm{CH}_{3} \mathrm{OH}-\mathrm{d}_{4}\right): 8.68(1 \mathrm{H}, \mathrm{s}), 8.58(1 \mathrm{H}, \mathrm{d}, \mathrm{J}=8.16 \mathrm{~Hz}), 8.14(1 \mathrm{H}, \mathrm{d}, \mathrm{J}=$ $7.50 \mathrm{~Hz}), 7.62(1 \mathrm{H}, \mathrm{t}$ (presumably dd), J=7.85 Hz). 
<smiles>O=c1cc[nH]c2c(C(F)(F)F)cccc12</smiles>

3-carboxy-8-trifluoromethyl-4-quinolone $(7.31 \mathrm{~g}, 28.4 \mathrm{mmol})$ was heated in Dowtherm A $(100 \mathrm{~mL})$ at $255^{\circ} \mathrm{C}$ for 30 minutes. After cooling, NMR indicated that reaction was not complete; the reaction was therefore returned to reflux for an additional 30 minutes. After cooling, the reaction mixture was diluted with hexanes $(100 \mathrm{~mL})$ and vacuum filtered, rinsing with additional hexanes $(250 \mathrm{~mL})$ to yield the desired product $(5.33 \mathrm{~g}$, $88 \%)$.

4-chloro-8-(trifluoromethyl)quinoline (Price, 1946; Allais, 1969)<smiles>FC(F)(F)c1cccc2c(Cl)ccnc12</smiles>

Phosphorus oxychloride (25 mL, $268 \mathrm{mmol})$ was cautiously added to 8-trifluoromethyl4-quinolone $(3.76 \mathrm{~g}, 17.6 \mathrm{mmol})$, followed by heating at $110^{\circ} \mathrm{C}$ for $2.5 \mathrm{~h}$. After cooling, the reaction mixture was gradually poured into ice water with vigorous stirring. After resting, and without basifying, the aqueous mixture $(800 \mathrm{~mL})$ was extracted with dichloromethane $(500 \mathrm{~mL}$, then $5 \times 100 \mathrm{~mL})$ to provide the desired product as a tan, crystalline solid $\left(3.80 \mathrm{~g}, 93 \%, \mathrm{mp}=79.5-81.2^{\circ} \mathrm{C}\right.$ (lit. $78^{\circ} \mathrm{C}$ (Allais, 1969)).

${ }^{1} \mathrm{H}$ NMR $\delta(\mathrm{ppm})\left(\mathrm{CHCl}_{3}-\mathrm{d}\right): 8.95(1 \mathrm{H}, \mathrm{d}, \mathrm{J}=4.71 \mathrm{~Hz}), 8.48(1 \mathrm{H}, \mathrm{d}, \mathrm{J}=8.55 \mathrm{~Hz}), 8.15$ $(1 \mathrm{H}, \mathrm{d}, \mathrm{J}=7.33 \mathrm{~Hz}), 7.71(1 \mathrm{H}, \mathrm{t}, \mathrm{J}=7.93 \mathrm{~Hz}), 7.61(1 \mathrm{H}, \mathrm{d}, \mathrm{J}=4.71 \mathrm{~Hz})$.

${ }^{19} \mathrm{~F}$ NMR $\delta(\mathrm{ppm})\left(\mathrm{CHCl}_{3}-\mathrm{d}\right):-60.1$. 


\section{3-(8-(trifluoromethyl)quinolin-4-ylamino)propanol}<smiles>OCCCNc1ccnc2c(C(F)(F)F)cccc12</smiles>

4-chloro-8-(trifluoromethyl)quinoline $(20.49 \mathrm{~g}, 88.5 \mathrm{mmol})$ and 3-amino-1-propanol $(43.0 \mathrm{~mL}, 562 \mathrm{mmol})$ were allowed to heat at $110^{\circ} \mathrm{C}$ for 1.5 hours, at the end of which time TLC indicated that reaction was complete. The hot reaction mixture was therefore poured into $500 \mathrm{~mL}$ deionized water, with vigorous agititation. The resulting precipitate was recovered by vacuum filtration. Upon drying, the product was an off-white powder $\left(21.53 \mathrm{~g}, 90 \%, \mathrm{mp}=162.6-163.7^{\circ} \mathrm{C}\right)$.

${ }^{1} \mathrm{H}$ NMR $\delta(\mathrm{ppm})\left(\mathrm{DMSO}_{\mathrm{d}}\right): 8.52(1 \mathrm{H}, \mathrm{d}, \mathrm{J}=8.53 \mathrm{~Hz}), 8.49(1 \mathrm{H}, \mathrm{d}, \mathrm{J}=5.43 \mathrm{~Hz}), 8.01$ $(1 \mathrm{H}, \mathrm{d}, \mathrm{J}=7.29 \mathrm{~Hz}), 7.52(1 \mathrm{H}, \mathrm{t}, \mathrm{J}=7.88 \mathrm{~Hz}), 7.42(1 \mathrm{H}, \mathrm{t}, \mathrm{J}=5.37 \mathrm{~Hz}), 6.58(1 \mathrm{H}, \mathrm{d}, \mathrm{J}$ $=5.49 \mathrm{~Hz}), 4.60(1 \mathrm{H}, \mathrm{t}, \mathrm{J}=5.06 \mathrm{~Hz}), 3.55(2 \mathrm{H}, \mathrm{m}), 3.36-3.38$ (water signal overlaps $\mathrm{m}$, $\sim 2 \mathrm{H}), 1.79-1.87$ (2 H, m).

${ }^{1} \mathrm{H} \mathrm{NMR} \delta(\mathrm{ppm})\left(\mathrm{CHCl}_{3}-\mathrm{d}\right): 8.69(1 \mathrm{H}, \mathrm{d}, \mathrm{J}=5.37 \mathrm{~Hz}), 7.96(2 \mathrm{H}, \mathrm{m}), 7.43(1 \mathrm{H}, \mathrm{t}, \mathrm{J}=$ $7.89 \mathrm{~Hz}), 6.50(1 \mathrm{H}, \mathrm{d}, \mathrm{J}=5.40 \mathrm{~Hz}), 6.05(1 \mathrm{H}, \mathrm{br} \mathrm{s}), 3.98(2 \mathrm{H}, \mathrm{t}, \mathrm{J}=5.39 \mathrm{~Hz}), 3.49(2 \mathrm{H}$, $\mathrm{m}), 2.06(2 \mathrm{H}, \mathrm{m})$.

${ }^{19} \mathrm{~F}$ NMR $\delta(\mathrm{ppm})\left(\mathrm{DMSO}-\mathrm{d}_{6}\right):-58.6$.

MS (ESI): $m / z 271.10583 \mathrm{M}+\mathrm{H}$ (calculated 271.10527)

HPLC (method A) $t_{\mathrm{R}}=7.98 \min (>99 \%$ pure $)$.

\section{3-(8-trifluoromethyl-quinolin-4-ylamino)propyl methanesulfonate}<smiles>COCCCNc1ccnc2c(C(F)(F)F)cccc12</smiles> 
3-(8-(trifluoromethyl)quinolin-4-ylamino)propanol (21.53 g, $79.7 \mathrm{mmol})$ and triethylamine $(20.0 \mathrm{~mL}, 140 \mathrm{mmol})$ in anhydrous chloroform $(500 \mathrm{~mL})$ were cooled to below $0^{\circ} \mathrm{C}$ on ice/salt, and methanesulfonyl chloride $(12.0 \mathrm{~mL}, 154 \mathrm{mmol})$ was gradually added. After stirring 1.5 hours on ice, TLC indicated that reaction was not complete. Additional methanesulfonyl chloride $(1.70 \mathrm{~mL}, 2.19 \mathrm{mmol})$ was added; after an additional hour of stirring, TLC indicated that reaction was complete. The reaction mixture was shaken with saturated sodium bicarbonate $(150 \mathrm{~mL})$, and the aqueous layer was then extracted with $3 \times 20 \mathrm{~mL}$ chloroform. Upon standing, a fine, needlelike precipitate appeared in the pooled organic layers; this was recovered by filtration. NMR indicated that this material was the desired product (a white, crystalline solid, $5.87 \mathrm{~g}, \mathrm{mp}$ $=141.6-142.8^{\circ} \mathrm{C}$ ). The filtrate was dried over magnesium sulfate and evaporated under reduced pressure with warming to yield a tan solid. NMR indicated that this, too, was the desired product (20.97 g; total yield $26.84 \mathrm{~g}, 97 \%$ ).

${ }^{1} \mathrm{H}$ NMR $\delta(\mathrm{ppm})\left(\mathrm{DMSO}-\mathrm{d}_{6}\right): 8.50-8.51(2 \mathrm{H}, \mathrm{m}), 8.03(1 \mathrm{H}, \mathrm{d}, \mathrm{J}=7.28 \mathrm{~Hz}), 7.54(1 \mathrm{H}, \mathrm{t}$, $\mathrm{J}=7.88 \mathrm{~Hz}), 7.46(1 \mathrm{H}, \mathrm{t}, \mathrm{J}=5.41 \mathrm{~Hz}), 6.62(1 \mathrm{H}, \mathrm{d}, \mathrm{J}=5.47 \mathrm{~Hz}), 4.36(2 \mathrm{H}, \mathrm{t}, \mathrm{J}=6.18$ $\mathrm{Hz}), 3.42(2 \mathrm{H}, \mathrm{m}), 3.20(3 \mathrm{H}, \mathrm{s}), 2.05-2.13(2 \mathrm{H}, \mathrm{m})$.

${ }^{19}$ F NMR $\delta(\mathrm{ppm})($ DMSO-d 6$):-58.6$.

MS (ESI): $m / z 349.08340 \mathrm{M}+\mathrm{H}$ (calculated 349.08282)

$\mathrm{HPLC}\left(\right.$ method A) $t_{\mathrm{R}}=9.28 \min (99 \%$ pure $)$

Note: HPLC and MS data are of the precipitate, which is presumed to be of atypically high purity for a 3-(quinoline-4-ylamino)propyl methanesulfonate produced by this method.

\section{PL149: N-(3-(4-benzhydrylpiperazin-1-yl)propyl)-8-(trifluoromethyl)quinolin-4- amine}<smiles>[R17]c1cccc(C(c2ccccc2)N2CCN(CCCNc3ccnc4c(C(F)(F)F)cccc34)CC2)c1</smiles>

3-(8-(trifluoromethyl)quinolin-4-ylamino)propyl methanesulfonate $(1.67 \mathrm{~g}, 4.79 \mathrm{mmol})$, 1-benzyhydrylpiperazine $(1.26 \mathrm{~g}, 4.99 \mathrm{mmol})$, and potassium carbonate $(0.82 \mathrm{~g}, 5.9$ $\mathrm{mmol})$ were heated at reflux in anhydrous acetonitrile $(22 \mathrm{~mL})$ for 24 hours, whereupon TLC indicated that reaction was complete. The solvent was removed by evaporation 
under reduced pressure with warming, and the residue was partitioned between dichloromethane $(35 \mathrm{~mL})$ and water $(35 \mathrm{~mL})$. After separation, the aqueous layer was extracted with further dichloromethane $(3 \times 10 \mathrm{~mL})$, and the pooled organic layers were dried over magnesium sulfate followed by evaporation under reduced pressure with warming. Recrystallization of the residue from $95 \%$ ethanol provided the desired product as a cream-colored solid $\left(0.44 \mathrm{~g}, 18 \%, \mathrm{mp}=205-208^{\circ} \mathrm{C}\right)$.

${ }^{1} \mathrm{H}$ NMR $\delta(\mathrm{ppm})\left(\mathrm{CHCl}_{3}-\mathrm{d}\right): 8.65(1 \mathrm{H}, \mathrm{d}, \mathrm{J}=5.36 \mathrm{~Hz}), 8.10(1 \mathrm{H}, \mathrm{d}, \mathrm{J}=8.46 \mathrm{~Hz}), 7.99$ $(1 \mathrm{H}, \mathrm{d}, \mathrm{J}=7.27 \mathrm{~Hz}), 7.71(1 \mathrm{H}$, br t, J = 3.97 Hz), 7.41-7.47 (4 H, m), 7.31 (4 H, m), 7.22-7.27 (solvent signal overlaps $\mathrm{m}, \sim 3 \mathrm{H}), 6.39(1 \mathrm{H}, \mathrm{d}, \mathrm{J}=5.41 \mathrm{~Hz}), 4.38(1 \mathrm{H}, \mathrm{s}), 3.37$ $(2 \mathrm{H}, \mathrm{td}, \mathrm{J}=5.78,4.02 \mathrm{~Hz}), 2.65(10 \mathrm{H}$, br s overlaps t, J = 5.43 Hz), $1.94(2 \mathrm{H}$, apparent $\mathrm{p}, \mathrm{J}=5.37 \mathrm{~Hz})$.

${ }^{19} \mathrm{~F} \mathrm{NMR} \delta(\mathrm{ppm})\left(\mathrm{CHCl}_{3}-\mathrm{d}\right): 0.5,-60.3$.

${ }^{13} \mathrm{C} \mathrm{NMR} \delta(\mathrm{ppm})\left(\mathrm{CHCl}_{3}-\mathrm{d}\right): 152.0,150.7,145.4,142.1,130.5,128.6,128.1,127.1$, $125.5,122.2,119.8,118.4,116.2,98.9,76.3,58.9,54.0,51.8,44.5,23.3$.

MS (ESI): $m / z$ 505.25751 M + H (calculated 505.25736)

$\operatorname{HPLC}(\operatorname{method} \mathrm{A}) t_{\mathrm{R}}=10.70 \min (94 \%$ pure $)$.

\section{PL281: 8-trifluoromethyl- $N$-(3-(4-(pyridin-2-yl)piperazin-1-yl)propyl)quinolin-4- amine}

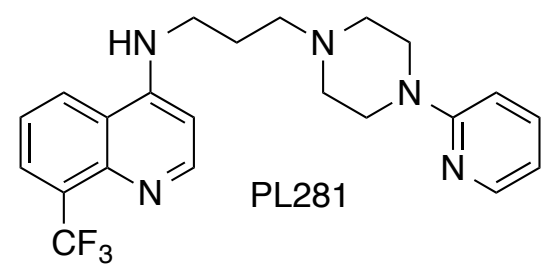

3-(8-(trifluoromethyl)quinolin-4-ylamino)propyl methanesulfonate $(1.67 \mathrm{~g}, 4.79 \mathrm{mmol})$, 1-(2-pyridyl)piperazine $(0.92 \mathrm{~g}, 5.6 \mathrm{mmol})$, and potassium carbonate $(0.98 \mathrm{~g}, 7.1 \mathrm{mmol})$ were heated at reflux in anhydrous acetonitrile $(24 \mathrm{~mL})$ for 2 days. By analogy to other reactions of this type, the reaction was vacuum filtered to remove precipitated product; however, after water rinsing, no solid was collected. After allowing the filtrate to stand overnight, crystallization was noted. These crystals were recovered by filtration, rinsing with a few drops of $95 \%$ ethanol and acetone. NMR indicated that this material was the desired product ( $\tan$ crystals, $0.53 \mathrm{~g}, 27 \%, \mathrm{mp}=122.8-127.1^{\circ} \mathrm{C}$ ). 
${ }^{1} \mathrm{H}$ NMR $\delta(\mathrm{ppm})\left(\mathrm{CHCl}_{3}-\mathrm{d}\right): 8.67(1 \mathrm{H}, \mathrm{d}, \mathrm{J}=5.37 \mathrm{~Hz}), 8.24-8.24(1 \mathrm{H}, \mathrm{m}), 8.09(1 \mathrm{H}, \mathrm{d}$, $\mathrm{J}=8.46 \mathrm{~Hz}), 7.93(1 \mathrm{H}, \mathrm{d}, \mathrm{J}=7.29 \mathrm{~Hz}), 7.53-7.53(1 \mathrm{H}, \mathrm{m}), 7.43(1 \mathrm{H}, \mathrm{br} \mathrm{t}, \mathrm{J}=4.14 \mathrm{~Hz})$, $7.30(1 \mathrm{H}, \mathrm{dd}, \mathrm{J}=8.42,7.28 \mathrm{~Hz}), 6.68-6.69(2 \mathrm{H}, \mathrm{m}), 6.45(1 \mathrm{H}, \mathrm{d}, \mathrm{J}=5.41 \mathrm{~Hz}), 3.69$ (4 $\mathrm{H}, \mathrm{m}), 3.43(2 \mathrm{H}, \mathrm{td}, \mathrm{J}=5.93,4.19 \mathrm{~Hz}), 2.69-2.70(6 \mathrm{H}, \mathrm{m}), 2.02(2 \mathrm{H}$, apparent $\mathrm{p}, \mathrm{J}=$ $5.59 \mathrm{~Hz})$.

${ }^{13} \mathrm{C} \mathrm{NMR} \delta(\mathrm{ppm})\left(\mathrm{CHCl}_{3}\right.$-d): 159.4, 152.0, 150.5, 148.1, 145.4, 137.7, 127.6, 127.5, $124.9,122.5,119.8,113.8,107.2,99.1,58.7,53.5,45.4,44.3,23.6$.

MS (ESI): $m / z 416.20568 \mathrm{M}+\mathrm{H}$ (calculated 416.20566)

HPLC (method A) $t_{\mathrm{R}}=5.31 \min (99 \%$ pure).

\section{PL268: 8-trifluoromethyl- $N$-(3-(4-(dipyridin-2-ylmethyleneamino)piperidin-1- yl)propyl)quinolin-4-amine}

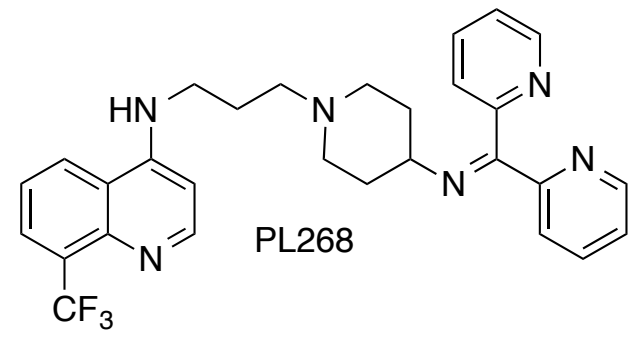

3-(8-trifluoromethyl-4-ylamino)propyl methanesulfonate (9.50 g, $27 \mathrm{mmol}), \mathrm{N}$ (dipyridin-2-methylene)piperidin-4-amine $(7.60 \mathrm{~g}, 29 \mathrm{mmol})$, and triethylamine $(5.70$ $\mathrm{mL}, 41 \mathrm{mmol})$ were heated in anhydrous acetonitrile $(50 \mathrm{~mL})$ at reflux for 2 days, at the end of which time TLC indicated that the reaction had gone to completion. The solvent was then removed under reduced pressure with warming and the resulting inhomogeneous brown solid was then partitioned between chloroform $(250 \mathrm{~mL})$ and saturated sodium bicarbonate $(50 \mathrm{~mL})$. The aqueous layer was extracted with additional chloroform $(3 \times 50 \mathrm{~mL})$, and the pooled chloroform layers were dried over $\mathrm{MgSO}_{4}$ and evaporated under reduced pressure with warming. The resulting heterogeneous semisolid was twice recrystallized from 95\% ethanol, yielding a sparkling off-white solid (3.52 g, $\left.25 \%, \mathrm{mp}=185.5-186.6^{\circ} \mathrm{C}\right)$.

${ }^{1} \mathrm{H}$ NMR $\delta(\mathrm{ppm})\left(\mathrm{CHCl}_{3}-\mathrm{d}\right): 8.74-8.74(1 \mathrm{H}, \mathrm{m}), 8.67(1 \mathrm{H}, \mathrm{d}, \mathrm{J}=5.33 \mathrm{~Hz}), 8.51-8.53$ (1 $\mathrm{H}, \mathrm{m}), 8.31-8.33(1 \mathrm{H}, \mathrm{m}), 8.25(1 \mathrm{H}, \mathrm{d}, \mathrm{J}=8.44 \mathrm{~Hz}), 8.01(1 \mathrm{H}, \mathrm{d}, \mathrm{J}=7.24 \mathrm{~Hz}), 7.95$ (1 $\mathrm{H}$, br t, J = 4.00 Hz), 7.80-7.84 (2 H, m), $7.55(1 \mathrm{H}, \mathrm{t}, \mathrm{J}=7.81 \mathrm{~Hz}), 7.36(1 \mathrm{H}, \mathrm{ddd}, \mathrm{J}=$ 
7.69, 4.93, $1.20 \mathrm{~Hz}), 7.29-7.29(2 \mathrm{H}, \mathrm{m}), 6.41(1 \mathrm{H}, \mathrm{d}, \mathrm{J}=5.39 \mathrm{~Hz}), 3.38-3.39(3 \mathrm{H}, \mathrm{m})$, 3.05-3.08 (2 H, m), $2.60(2 \mathrm{H}, \mathrm{t}, \mathrm{J}=5.05 \mathrm{~Hz}), 2.01-2.13(4 \mathrm{H}, \mathrm{m}), 1.95(2 \mathrm{H}$, apparent p, J $=5.35 \mathrm{~Hz}), 1.77-1.93(2 \mathrm{H}, \mathrm{m})$.

${ }^{19} \mathrm{~F}$ NMR $\delta(\mathrm{ppm})\left(\mathrm{CHCl}_{3}-\mathrm{d}\right):-60.7$.

${ }^{13} \mathrm{C}$ NMR $\delta(\mathrm{ppm})\left(\mathrm{CHCl}_{3}-\mathrm{d}\right): 165.5,157.1,155.7,152.0,150.8,149.8,148.8,145.4$, $136.4,136.0,127.5,125.6,124.2,123.4,123.1,122.5,122.2,120.0,118.4,116.2$, 98.9, $59.0,55.8,52.2,44.7,33.0,23.6$.

MS (ESI): $m / z$ 519.24853 M + H (calculated 519.24786)

HPLC (method A) $t_{\mathrm{R}}=1.49 \min (>99 \%$ pure $)$.

\section{PL269: 8-trifluoromethyl- $N$-(3-(4-(dipyridin-2-ylmethylamino)piperidin-1- yl)propyl)quinolin-4-amine}

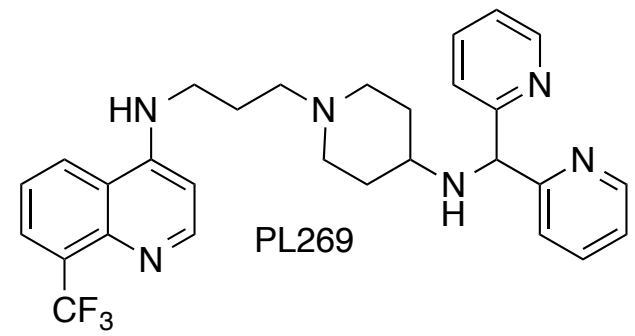

PL 268 (3.44g, $6.63 \mathrm{mmol})$ was dissolved in anhydrous methanol (40 mL) to which sodium borohydride $(0.70 \mathrm{~g}, 19 \mathrm{mmol})$ was then cautiously added. After stirring at room temperature for one hour, TLC indicated that the reaction had not gone to completion, and so additional sodium borohydride was added in several portions (in total an additional $0.70 \mathrm{~g}, 19 \mathrm{mmol}$ ) until TLC indicated that the reaction had gone to completion (after a further hour). After removal of methanol by evaporation under reduced pressure with warming, $25 \mathrm{~mL}$ water was added and stirring was continued 1 hour. The aqueous mixture was then extracted with chloroform $(20 \mathrm{~mL}$ followed by three additional $10 \mathrm{~mL}$ portions), and the chloroform layers were dried $\left(\mathrm{MgSO}_{4}\right)$ and evaporated under reduced pressure to yield a pale yellow glass $\left(2.88 \mathrm{~g}, 83 \%, \mathrm{mp}=157.5-159.7^{\circ} \mathrm{C}\right)$.

${ }^{1} \mathrm{H}$ NMR $\delta(\mathrm{ppm})\left(\mathrm{CHCl}_{3}-\mathrm{d}\right): 8.64(1 \mathrm{H}, \mathrm{d}, \mathrm{J}=5.38 \mathrm{~Hz}), 8.56-8.59(2 \mathrm{H}, \mathrm{m}), 8.12(1 \mathrm{H}, \mathrm{d}$, $\mathrm{J}=8.49 \mathrm{~Hz}), 7.97(1 \mathrm{H}, \mathrm{d}, \mathrm{J}=7.29 \mathrm{~Hz}), 7.80(1 \mathrm{H}, \mathrm{br} \mathrm{t}, \mathrm{J}=3.93 \mathrm{~Hz}), 7.63(2 \mathrm{H}, \mathrm{td}, \mathrm{J}=$ 7.68, 1.77 Hz), 7.44-7.50 (3 H, m), 7.15-7.16 (2 H, m), $6.38(1 \mathrm{H}, \mathrm{d}, \mathrm{J}=5.42 \mathrm{~Hz}), 5.25$ (1 
$\mathrm{H}, \mathrm{s}), 3.35-3.36(2 \mathrm{H}, \mathrm{m}), 2.98-3.01(2 \mathrm{H}, \mathrm{m}), 2.62-2.62(1 \mathrm{H}, \mathrm{m}), 2.53-2.60(2 \mathrm{H}, \mathrm{m})$, 1.98-2.01 (4 H, m), 1.91 (2 H, apparent p, J = 5.37 Hz), 1.63-1.64 (2 H, m).

${ }^{13} \mathrm{C} \mathrm{NMR} \delta(\mathrm{ppm})\left(\mathrm{CHCl}_{3}-\mathrm{d}\right): 162.1,151.9,150.7,149.1,145.4,136.7,127.4\left(\mathrm{q}, \mathrm{J}_{\mathrm{F}}=30.3\right.$ $\left.\mathrm{Hz}, \mathrm{Q}-\mathrm{C} 8-\mathrm{CF}_{3}\right), 125.4,123.6,122.5,122.4,122.2,119.9,98.8,66.6,62.5,58.6,52.8$, $44.5,33.0,23.7,23.7$.

${ }^{19} \mathrm{~F}$ NMR $\delta(\mathrm{ppm})\left(\mathrm{CHCl}_{3}-\mathrm{d}\right):-60.7$.

HPLC (method C) $t_{\mathrm{R}}=5.68 \mathrm{~min}(95 \%$ pure). MS (ESI): $\mathrm{m} / z 521.2626 \mathrm{M}+\mathrm{H}$ (calculated 521.2635).

\section{PL267: 8-trifluoromethyl- $N$-(3-(4-(4-(trifluoromethyl)phenyl)piperazin-1- yl)propyl)quinolin-4-amine}

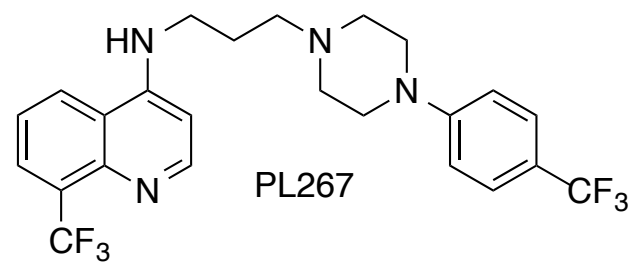

3-(8-trifluoromethyl-4-ylamino)propyl methanesulfonate (4.81 g, $13.8 \mathrm{mmol}) 1$-(4trifluoromethylphenylpiperazine $(3.19 \mathrm{~g}, 1.4 \mathrm{mmol})$, and triethylamine $(3 \mathrm{~mL}, 2.2 \mathrm{mmol})$ were heated in refluxing acetonitrile $(24 \mathrm{~mL})$ for 2 days. TLC indicated that reaction was complete. The solvent was removed under reduced pressure with warming, and the residue was partitioned between chloroform $(100 \mathrm{~mL})$ and saturated $\mathrm{NaHCO}_{3}(100 \mathrm{~mL})$. After separation of the organic layer, the aqueous layer was extracted with further chloroform $(3 \times 50 \mathrm{~mL})$, and the pooled organic layers were dried $\left(\mathrm{MgSO}_{4}\right)$ and evaporated under reduced pressure with warming to yield a brown oil. Partial recrystallization from $95 \%$ ethanol followed by recrystallization from chloroform yielded the desired product as a white, crystalline solid $\left(0.70 \mathrm{~g}, 11 \%, \mathrm{mp}=168.8-170.3^{\circ} \mathrm{C}\right)$.

${ }^{1} \mathrm{H}$ NMR $\delta(\mathrm{ppm})\left(\mathrm{CHCl}_{3}-\mathrm{d}\right): 8.67(1 \mathrm{H}, \mathrm{d}, \mathrm{J}=5.36 \mathrm{~Hz}), 8.04(1 \mathrm{H}, \mathrm{d}, \mathrm{J}=8.46 \mathrm{~Hz}), 7.93$ $(1 \mathrm{H}, \mathrm{d}, \mathrm{J}=7.30 \mathrm{~Hz}), 7.53(2 \mathrm{H}, \mathrm{d}, \mathrm{J}=8.57 \mathrm{~Hz}), 7.29(1 \mathrm{H}, \mathrm{t}, \mathrm{J}=4.21 \mathrm{~Hz}), 7.26(1 \mathrm{H}, \mathrm{t}, \mathrm{J}$ $=7.90 \mathrm{~Hz}), 6.97(2 \mathrm{H}, \mathrm{d}, \mathrm{J}=8.57 \mathrm{~Hz}), 6.44(1 \mathrm{H}, \mathrm{d}, \mathrm{J}=5.41 \mathrm{~Hz}), 3.38-3.43(6 \mathrm{H}, \mathrm{m})$, $2.74(4 \mathrm{H}, \mathrm{m}), 2.70(2 \mathrm{H}, \mathrm{t}, \mathrm{J}=5.45 \mathrm{~Hz}), 2.01(2 \mathrm{H}$, apparent $\mathrm{p}, \mathrm{J}=5.60 \mathrm{~Hz})$.

${ }^{19} \mathrm{~F} \mathrm{NMR} \delta(\mathrm{ppm})\left(\mathrm{CHCl}_{3}-\mathrm{d}\right):-60.8,-61.9$. 
${ }^{13} \mathrm{C} \mathrm{NMR} \delta(\mathrm{ppm})\left(\mathrm{CHCl}_{3}-\mathrm{d}\right): 153.1,152.0,150.4,145.4,127.7\left(\mathrm{q}, \mathrm{J}_{\mathrm{F}}=30.6 \mathrm{~Hz}, \underline{\mathrm{C}-\mathrm{CF}_{3}}\right)$, 126.6, 124.8, 122.4, 121.1 (q, $\left.\mathrm{J}_{\mathrm{F}}=32.9 \mathrm{~Hz}, \underline{\mathrm{C}}-\mathrm{CF}_{3}\right), 119.7,114.7,114.7,99.1,58.5,53.3$, $48.2,44.2,23.7$.

MS (ESI): $m / z$ 483.1976 M + H (calculated 483.1978).

HPLC (method C) $t_{\mathrm{R}}=10.63 \min (97 \%$ pure).

\section{PL262: 8-trifluoromethyl- $N$-(3-(4-(4-methoxyphenyl)piperazin-1-yl)propyl)quinolin- 4-amine}

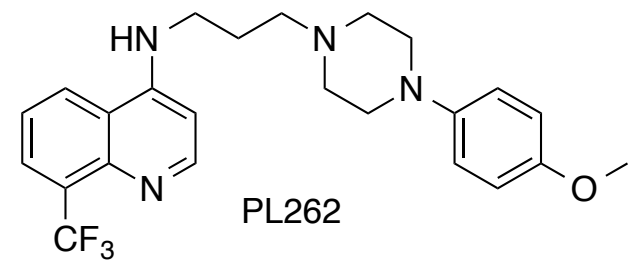

3-(8-(trifluoromethyl)quinolin-4-ylamino)propyl methanesulfonate (1.29 g, $3.70 \mathrm{mmol}$ ), $\mathrm{N}$-(p-methoxyphenyl)piperazine dihydrochloride $(1.04 \mathrm{~g}, 3.92 \mathrm{mmol})$, and potassium carbonate $(1.29 \mathrm{~g}, 11.5 \mathrm{mmol})$ were heated at reflux in anhydrous acetonitrile $(25 \mathrm{~mL})$ for 5 days, whereupon TLC indicated that reaction was complete. The solvent was removed by evaporation under reduced pressure with warming, and the residue was partitioned between water $(35 \mathrm{~mL})$ and dichloromethane $(30 \mathrm{~mL})$. After separation, the aqueous layer was extracted with further dichloromethane $(3 \times 10 \mathrm{~mL})$, and the pooled organic layers were rinsed with brine $(10 \mathrm{~mL})$, then dried over magnesium sulfate and evaporated under reduced pressure with warming. The residue was purified by column chromatography on basic alumina, eluting with 3:2 hexanes:ethyl acetate, followed by recrystallization from ethyl acetate to give the desired product as a cream-colored solid $\left(0.42 \mathrm{~g}, 26 \%, \mathrm{mp}=123-125^{\circ} \mathrm{C}, \mathrm{R}_{\mathrm{f}}=0.7\right.$ (basic alumina, 95/5 EA/MeOH v/v)).

${ }^{1} \mathrm{H}$ NMR $\delta(\mathrm{ppm})\left(\mathrm{CHCl}_{3}-\mathrm{d}\right): 8.67(1 \mathrm{H}, \mathrm{d}, \mathrm{J}=5.36 \mathrm{~Hz}), 8.13(1 \mathrm{H}, \mathrm{d}, \mathrm{J}=8.45 \mathrm{~Hz}), 7.93$ $(1 \mathrm{H}, \mathrm{d}, \mathrm{J}=7.28 \mathrm{~Hz}), 7.60(1 \mathrm{H}, \mathrm{t}, \mathrm{J}=4.08 \mathrm{~Hz}), 7.28(1 \mathrm{H}, \mathrm{t}, \mathrm{J}=7.86 \mathrm{~Hz}), 6.95-6.96(2 \mathrm{H}$, m), 6.88-6.91 (2 H, m), $6.43(1 \mathrm{H}, \mathrm{d}, \mathrm{J}=5.41 \mathrm{~Hz}), 3.81(3 \mathrm{H}, \mathrm{s}), 3.42(2 \mathrm{H}, \mathrm{td}, \mathrm{J}=5.84$, $4.10 \mathrm{~Hz}), 3.24(4 \mathrm{H}, \mathrm{m}), 2.76(4 \mathrm{H}, \mathrm{m}), 2.71(2 \mathrm{H}, \mathrm{t}, \mathrm{J}=5.29 \mathrm{~Hz}), 2.00(2 \mathrm{H}$, apparent p, J $=5.47 \mathrm{~Hz}$ ).

${ }^{19} \mathrm{~F} \mathrm{NMR} \delta(\mathrm{ppm})\left(\mathrm{CHCl}_{3}-\mathrm{d}\right):-60.8$. 
${ }^{13} \mathrm{C}$ NMR $\delta(\mathrm{ppm})\left(\mathrm{CHCl}_{3}-\mathrm{d}\right): 154.2,152.0,150.6,145.5,145.4,127.5,125.3,122.4$, $119.8,118.3,114.6,99.0,58.8,55.6,53.8,50.9,44.5,23.5,23.5$.

MS (ESI): $m / z$ 445.22102 M + H (calculated 445.22097)

$\operatorname{HPLC}(\operatorname{method~A}) t_{\mathrm{R}}=8.21 \min (>99 \%$ pure $)$.

\section{A.3.6: 2,8-ditrifluoromethylquinolines}

\section{3-(2,8-bis(trifluoromethyl)quinolin-4-ylamino)propanol}<smiles>OCCCNc1cc(C(F)(F)F)nc2c(C(F)(F)F)cccc12</smiles>

4-chloro-2,8-bis(trifluoromethyl)quinoline $(0.96 \mathrm{~g}, 3.2 \mathrm{mmol}$, purchased from Oakwood Chemical Company) and 3-amino-1-propanol $(2.0 \mathrm{~mL}, 2.6 \mathrm{mmol})$ were allowed to heat at $70^{\circ} \mathrm{C}$ for 1.5 hours, followed by heating at $100^{\circ} \mathrm{C}$ for 1 hour. TLC then indicated that reaction was complete. The hot reaction mixture was partitioned between water $(50 \mathrm{~mL})$ and ethyl acetate $(15 \mathrm{~mL}$, then $3 \times 10 \mathrm{~mL})$. The pooled organic layers were dried $\left(\mathrm{MgSO}_{4}\right)$ and evaporated under reduced pressure with warming to yield the desired product as a creamy white solid $\left(0.97 \mathrm{~g}, 91 \%, \mathrm{mp}=130.5-131.2^{\circ} \mathrm{C}\right)$.

${ }^{1} \mathrm{H}$ NMR $\delta(\mathrm{ppm})\left(\mathrm{DMSO}_{\mathrm{d}}\right): 8.63(1 \mathrm{H}, \mathrm{d}, \mathrm{J}=8.57 \mathrm{~Hz}), 8.15(1 \mathrm{H}, \mathrm{d}, \mathrm{J}=7.30 \mathrm{~Hz}), 8.00$ $(1 \mathrm{H}, \mathrm{t}, \mathrm{J}=5.41 \mathrm{~Hz}), 7.68(1 \mathrm{H}, \mathrm{t}, \mathrm{J}=7.92 \mathrm{~Hz}), 6.90(1 \mathrm{H}, \mathrm{s}), 4.63(1 \mathrm{H}, \mathrm{t}, \mathrm{J}=5.07 \mathrm{~Hz})$, $3.55(2 \mathrm{H}, \mathrm{m}), 3.46(2 \mathrm{H}, \mathrm{m}), 1.79-1.89(2 \mathrm{H}, \mathrm{m})$.

${ }^{19}$ F NMR $\delta(\mathrm{ppm})($ DMSO-d 6$):-58.9,-67.1$. 


\section{3-(2,8-bis(trifluoromethyl)quinolin-4-ylamino)propyl methanesulfonate}<smiles>COCCCNc1cc(C(F)(F)F)nc2c(C(F)(F)F)cccc12</smiles>

3-(2,8-bis(trifluoromethyl)quinolin-4-ylamino)propanol (1.13 g, $3.71 \mathrm{mmol})$ and triethylamine $(0.78 \mathrm{~mL}, 5.6 \mathrm{mmol})$ in dry THF $(50 \mathrm{~mL})$ were cooled to below $0^{\circ} \mathrm{C}$ on ice/salt. Methanesulfonyl chloride $(0.33 \mathrm{~mL}, 4.3 \mathrm{mmol})$ was added dropwise. After stirring for 1 hour on ice, TLC indicated that reaction was not complete; therefore, additional methanesulfonyl chloride $(0.02 \mathrm{~mL}, 0.3 \mathrm{mmol})$ was added and stirring was continued for a further 15 hours. The reaction mixture was then washed with $100 \mathrm{~mL}$ saturated sodium bicarbonate. The aqueous layer was extracted with ethyl acetate $(3 \times 10$ $\mathrm{mL}$ ), and the pooled organic layers were rinsed with $10 \mathrm{~mL}$ brine, then dried $\left(\mathrm{MgSO}_{4}\right)$ and evaporated under reduced pressure with warming to give the desired product as a cream-colored solid (1.19 g, 84\%).

${ }^{1} \mathrm{H}$ NMR $\delta(\mathrm{ppm})\left(\mathrm{DMSO}_{-} \mathrm{d}_{6}\right): 8.63(1 \mathrm{H}, \mathrm{d}, \mathrm{J}=8.58 \mathrm{~Hz}), 8.17(1 \mathrm{H}, \mathrm{d}, \mathrm{J}=7.31 \mathrm{~Hz}), 8.01$ $(1 \mathrm{H}, \mathrm{t}, \mathrm{J}=5.44 \mathrm{~Hz}), 7.70(1 \mathrm{H}, \mathrm{t}, \mathrm{J}=7.92 \mathrm{~Hz}), 6.93(1 \mathrm{H}, \mathrm{s}), 4.36(2 \mathrm{H}, \mathrm{t}, \mathrm{J}=6.14 \mathrm{~Hz})$, $3.52(2 \mathrm{H}, \mathrm{m}), 3.20(3 \mathrm{H}, \mathrm{s}), 2.09(2 \mathrm{H}, \mathrm{m})$.

${ }^{19} \mathrm{~F}$ NMR $\delta(\mathrm{ppm})\left(\mathrm{DMSO}-\mathrm{d}_{6}\right):-58.9,-67.0$.

\section{PL280: $N$-(3-(4-benzhydrylpiperazin-1-yl)propyl)-2,8-di(trifluoromethyl)quinolin-4- amine}<smiles>FC(F)(F)c1cc(NCCCN2CCN(C(c3ccccc3)c3ccccc3)CC2)c2cccc(C(F)(F)F)c2n1</smiles>

3-(2,8-di(trifluoromethyl)quinolin-4-ylamino)propyl methanesulfonate $(1.21 \mathrm{~g}, 2.91$ $\mathrm{mmol}), 1$-benzyhydrylpiperazine $(0.79 \mathrm{~g}, 3.1 \mathrm{mmol})$, and potassium carbonate $(0.62 \mathrm{~g}$, $4.5 \mathrm{mmol})$ were heated at reflux in anhydrous acetonitrile $(25 \mathrm{~mL})$ for 24 hours. TLC indicated that reaction was complete, and so the solvent was removed under reduced pressure with warming, and the residue partitioned between chloroform $(50 \mathrm{~mL})$ and 
water $(50 \mathrm{~mL})$. After separation, the aqueous layer was extracted with further chloroform $(3 \times 15 \mathrm{~mL})$ and the pooled organic layers were dried $\left(\mathrm{MgSO}_{4}\right)$ and evaporated under reduced pressure with warming. The resulting tan solid was recrystallized from ethyl acetate $(>20 \mathrm{~mL})$ to provide the desired product as a white, crystalline solid $(0.50 \mathrm{~g}, 30 \%$, $\left.\mathrm{mp}=227-229^{\circ} \mathrm{C}\right)$.

${ }^{1} \mathrm{H} \mathrm{NMR} \delta(\mathrm{ppm})\left(\mathrm{CHCl}_{3}-\mathrm{d}\right): 8.19(1 \mathrm{H}, \mathrm{br} \mathrm{t}, \mathrm{J}=3.90 \mathrm{~Hz}), 8.12(1 \mathrm{H}, \mathrm{d}, \mathrm{J}=8.51 \mathrm{~Hz}), 8.04$ $(1 \mathrm{H}, \mathrm{d}, \mathrm{J}=7.27 \mathrm{~Hz}), 7.41-7.47(4 \mathrm{H}, \mathrm{m}), 7.30-7.33(5 \mathrm{H}, \mathrm{m}), 7.23(2 \mathrm{H}, \mathrm{m}), 6.65(1 \mathrm{H}, \mathrm{s})$, $4.40(1 \mathrm{H}, \mathrm{s}), 3.40(2 \mathrm{H}, \mathrm{td}, \mathrm{J}=5.26,-0.00 \mathrm{~Hz}), 2.68(10 \mathrm{H}$, br s overlaps t, $\mathrm{J}=30.53 \mathrm{~Hz})$, $1.96(2 \mathrm{H}$, apparent $\mathrm{p}, \mathrm{J}=5.26 \mathrm{~Hz})$.

${ }^{19} \mathrm{~F}$ NMR $\delta(\mathrm{ppm})\left(\mathrm{CHCl}_{3}-\mathrm{d}\right):-59.4,-67.6$.

${ }^{13} \mathrm{C}$ NMR $\delta$ (ppm)(DMSO-d 6 ): 152.4, 143.8, 142.9, 129.0, 128.5, 127.5, 126.8, 124.4, $119.4,94.0,75.2,55.4,53.0,51.5,41.0,24.8$.

MS (ESI): $m / z 573.24611 \mathrm{M}+\mathrm{H}$ (calculated 573.24474)

\section{A.3.7: 5- and 7-chloro-2-(trifluoromethyl)-quinolines}

5- and 7-chloro-2-trifluoromethyl-4-quinolone (based upon Conrad, 1887; Conrad, 1891; Reynolds, 1955)<smiles>O=c1cc(C(F)(F)F)[nH]c2cc(Cl)ccc12</smiles>

Ethyl-4,4,4-trifluoroacetoacetate $(11.99 \mathrm{~g}, 65.1 \mathrm{mmol})$, meta-chloroaniline $(8.40 \mathrm{~g}, 65.8$ $\mathrm{mmol}$ ), and a catalytic amount of para-toluenesulfonic acid were allowed to heat in refluxing benzene $(75 \mathrm{~mL})$ in a flask equipped with a Dean and Stark water separator topped with stacked Vigreux condensers. After 18 hours, the solvent was removed by evaporation under reduced pressure with warming to provide a pale yellow, viscous liquid. This residue was allowed to heat in Dowtherm A $(100 \mathrm{~mL})$ to $230^{\circ} \mathrm{C}$, followed by cooling to room temperature; after standing 18 hours, the reaction was heated to $255^{\circ} \mathrm{C}$ and allowed to remain at this temperature for 45 minutes. The cooled reaction mixture was filtered without dilution, rinsing with Dowtherm A followed by $35-60^{\circ}$ petroleum æther. This provided a beige powder that was used without further purification $(6.61 \mathrm{~g}$, presumed to contain a mixture of 5- and 7-chloro regioisomers). 
${ }^{19} \mathrm{~F}$ NMR $\delta(\mathrm{ppm})\left(\mathrm{DMSO}_{-}\right)$: $-66.7,-67.0$.

\section{4,5-dichloro-2-(trifluoromethyl)quinoline and 4,7-dichloro-2- (trifluoromethyl)quinoline (based upon Steinacker Dey, 1965):}

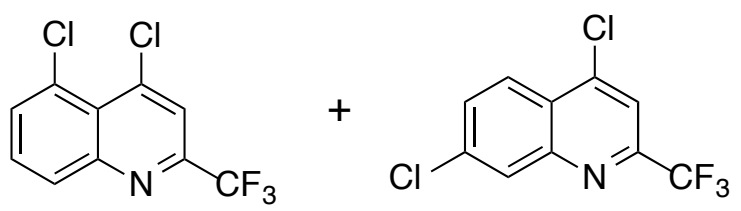

Phosphorus oxychloride (39 mL, $418 \mathrm{mmol}$ ) was cautiously added to 5- and 7-chloro-2trifluoromethyl-4-quinolone $(6.61 \mathrm{~g}, 26.7 \mathrm{mmol})$, and the mixture was heated at $110^{\circ} \mathrm{C}$ for 1 hour. After cooling, the reaction mixture was gradually poured into ice water with vigorous stirring. After resting, the aqueous mixture was basified with solid caustic potash and diluted with water to $1 \mathrm{~L}$. This mixture was extracted with chloroform $(200$ $\mathrm{mL}$, then $3 \times 20 \mathrm{~mL})$, dried $\left(\mathrm{MgSO}_{4}\right)$, and concentrated under reduced pressure with warming to yield a dark, olive green liquid. NMR indicated that this contained both 4,5dichloro-2-(trifluoromethyl)quinoline and 4,7-dichloro-2-(trifluoromethyl)quinoline in a ratio of approximately $2: 3$. Crystallization from hexanes afforded 4,5-dichloro-2(trifluoromethyl)quinoline alone. Concentration of the mother liquor yielded a second crop of the same material (1.09 $\mathrm{g}$ from both crystallizations, a white, crystalline solid having a strong odor similar to that of 4,7-dichloroquinoline, $15 \%, \mathrm{mp}=95.1-97.1^{\circ} \mathrm{C}$ ). The mother liquor was further concentrated to yield an additional three crops of 4,5dichloro-2-(trifluoromethyl)quinoline. The remaining mother liquor was then allowed to evaporate to a brown solid. Upon recrystallizing a portion of this material from hexanes, a mixture of regioiosomers crystallized (approximately 1:9 4,7-dichloro:4,5-dichloro-2(trifluoromethyl)quinoline). A similar result was obtained by crystallizing a second portion from ethyl acetate. Automated flash chromatography on alumina, eluting with $100 \%$ hexanes, achieved only partial separation. The fractions containing more than $50 \%$ of the 4,7-dichloro-2-(trifluoromethyl)quinoline were further purified by automated flash chromatography on silica, eluting with $100 \%$ hexanes. 4,7-dichloro-2-

(trifluoromethyl)quinoline was obtained as a viscous, colorless liquid; this was allowed to stand for several days. After disturbance of the liquid by removal of a sample, abrupt crystallization occurred. The product, a white, crystalline solid $(2.00 \mathrm{~g}, 28 \%, \mathrm{mp}=40.9$ $41.9^{\circ} \mathrm{C}$ ), had a faint odor like that of 4,7-dichloroquinoline, but this was far less pronounced than that of the 4,5-dichloro regioisomer.

Characterization data for 4,5-dichloro-2-(trifluoromethyl)quinoline: 


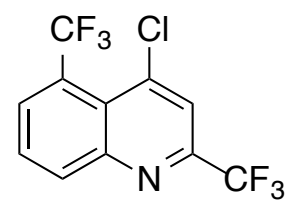

White crystals, $\mathrm{mp}=95 \cdot 1-97.1^{\circ} \mathrm{C}$

$\mathrm{R}_{\mathrm{f}}=0.2$ (silica, hexanes), 0.3 (basic alumina, hexanes)

${ }^{1} \mathrm{H}$ NMR $\delta(\mathrm{ppm})\left(\mathrm{CHCl}_{3}-\mathrm{d}\right): 8.17(1 \mathrm{H}, \mathrm{dd}, \mathrm{J}=8.43,1.34 \mathrm{~Hz}$, Q-C6-H or Q-C8-H), 7.83 $(1 \mathrm{H}, \mathrm{s}, \mathrm{Q}-\mathrm{C} 3-\mathrm{H}), 7.78(1 \mathrm{H}, \mathrm{dd}, \mathrm{J}=7.58,1.35 \mathrm{~Hz}, \mathrm{Q}-\mathrm{C} 8-\mathrm{H}$ or Q-C6-H), $7.71(1 \mathrm{H}, \mathrm{dd}, \mathrm{J}$ $=8.44,7.58 \mathrm{~Hz}, \mathrm{Q}-\mathrm{C} 7-\mathrm{H})$.

${ }^{19} \mathrm{~F} \mathrm{NMR} \delta(\mathrm{ppm})\left(\mathrm{CHCl}_{3}-\mathrm{d}\right):-68.5$.

${ }^{13} \mathrm{C}$ NMR $\delta(\mathrm{ppm})\left(\mathrm{CHCl}_{3}-\mathrm{d}\right): 150.1,147.81\left(\mathrm{q}, \mathrm{J}_{\mathrm{F}}=23.14 \mathrm{~Hz}\right), 144.0,132.8(\mathrm{Q}-\mathrm{C} 8 ?)$ 130.8 (Q-C6?), 130.7 (Q-C7), 130.3, 124.6, 120.8 (q, $\left.\mathrm{J}_{\mathrm{F}}=1.01 \mathrm{~Hz}\right), 120.7$ (q, $\mathrm{J}_{\mathrm{F}}=183.82$ $\mathrm{Hz}$ ?), 118.5, 116.2 (if these last two weak peaks are the center of a quartet, 117.4, $J=$ $231 \mathrm{~Hz})$.

GC/MS: $\mathrm{t}_{\mathrm{R}}=5.32 \mathrm{~min}, 265 \mathrm{M}^{+}\left({ }^{35} \mathrm{Cl}_{2}\right), 100 \%, 196\left(\mathrm{M}^{-\mathrm{CF}_{3}}\right)^{+}, 42 \%, 161\left(\mathrm{M}-\mathrm{CF}_{3}-\mathrm{Cl}\right)^{+}$, $28 \%, 99\left(\mathrm{C}_{8} \mathrm{H}_{3}\right)^{+}, 31 \%, 69\left(\mathrm{CF}_{3}\right)^{+}, 11 \%$.

Characterization data for 4,7-dichloro-2-(trifluoromethyl)quinoline:<smiles>FC(F)(F)c1cc(Cl)c2ccc(Cl)cc2n1</smiles>

White crystals, $\mathrm{mp}=40.9-41.9^{\circ} \mathrm{C}$

$\mathrm{R}_{\mathrm{f}}=0.3$ (silica, hexanes), 0.5 (alumina, hexanes)

${ }^{1} \mathrm{H} \mathrm{NMR} \delta(\mathrm{ppm})\left(\mathrm{CHCl}_{3}-\mathrm{d}\right): 8.26\left(1 \mathrm{H}, \mathrm{d}, \mathrm{J}_{6,8} \sim 1.62 \mathrm{~Hz}, \mathrm{Q} \mathrm{C} 8-\mathrm{H}\right) 8.24\left(1 \mathrm{H}, \mathrm{d}, \mathrm{J}_{6,5} \sim\right.$ $8.71 \mathrm{~Hz}$, Q C5-H), $7.82\left(1 \mathrm{H}, \mathrm{s}, \mathrm{Q}\right.$ C3-H), $7.73\left(1 \mathrm{H}, \mathrm{dd}, \mathrm{J}_{5,6}=8.99, \mathrm{~J}_{8,6}=2.10 \mathrm{~Hz}\right.$, Q C6H). Note: Peaks at 8.26 and 8.24 overlap. The estimated peak positions and coupling constants are provided.

${ }^{19} \mathrm{~F} \mathrm{NMR} \delta(\mathrm{ppm})\left(\mathrm{CHCl}_{3}-\mathrm{d}\right):-68.3$. 
${ }^{13} \mathrm{C}$ NMR $\delta(\mathrm{ppm})\left(\mathrm{CHCl}_{3}-\mathrm{d}\right): 148.92\left(\mathrm{q}, \mathrm{J}_{\mathrm{F}}=35.2 \mathrm{~Hz}\right), 148.3,144.8,138.1,130.8,129.5$, 125.6, 125.6, $120.79\left(\mathrm{q}, \mathrm{J}_{\mathrm{F}}=275.73 \mathrm{~Hz}\right.$ ), 119.0, $117.5\left(\mathrm{q}, \mathrm{J}_{\mathrm{F}}=2.37 \mathrm{~Hz}\right), 115.7$ (if the last two weak peaks, 117.5 and 119.0, are part of a quartet, $J$ would be $337.11 \mathrm{~Hz}$ ).

GC/MS: $\mathrm{t}_{\mathrm{R}}=5.08 \mathrm{~min}, 265 \mathrm{M}^{+}\left({ }^{35} \mathrm{Cl}_{2}\right), 100 \%, 196\left(\mathrm{M}_{-}-\mathrm{CF}_{3}\right)^{+}, 42 \%, 161\left(\mathrm{M}-\mathrm{CF}_{3}-\mathrm{Cl}\right)^{+}$, $28 \%, 99\left(\mathrm{C}_{8} \mathrm{H}_{3}\right)^{+}, 31 \%, 69\left(\mathrm{CF}_{3}\right)^{+}, 11 \%$.

\section{3-(5-chloro-2-(trifluoromethyl)quinolin-4-ylamino)propanol}<smiles>OCCCNc1cc(C(F)(F)F)nc2cccc(Cl)c12</smiles>

4,5-dichloro-2-(trifluoromethyl)quinoline (1.09 g, $4.08 \mathrm{mmol}$ ) and 3-amino-1-propanol $(1.87 \mathrm{~mL}, 24.4 \mathrm{mmol})$ were allowed to heat at $80^{\circ} \mathrm{C}$ for 17 hours, at the end of which time TLC indicated that reaction was complete. The hot reaction mixture was therefore poured into $100 \mathrm{~mL}$ water, stirring vigorously. After standing 45 minutes, the resulting precipitate was recovered by vacuum filtration. Upon drying, the product was an offwhite powder $(1.13 \mathrm{~g}, 91 \%)$.

${ }^{1} \mathrm{H}$ NMR $\delta(\mathrm{ppm})\left(\right.$ DMSO-d $\left._{6}\right): 8.01(1 \mathrm{H}, \mathrm{br} \mathrm{t}, \mathrm{J}=4.87 \mathrm{~Hz}), 7.87(1 \mathrm{H}, \mathrm{dd}, \mathrm{J}=8.28,1.48$ $\mathrm{Hz}), 7.66(1 \mathrm{H}, \mathrm{dd}, \mathrm{J}=8.25,7.68 \mathrm{~Hz}), 7.60(1 \mathrm{H}, \mathrm{dd}, \mathrm{J}=7.55,1.48 \mathrm{~Hz}), 6.82(1 \mathrm{H}, \mathrm{s})$, $4.84(1 \mathrm{H}, \mathrm{t}, \mathrm{J}=4.87 \mathrm{~Hz}), 3.61(2 \mathrm{H}, \mathrm{td}, \mathrm{J}=5.74,4.77 \mathrm{~Hz}), 3.43(2 \mathrm{H}, \mathrm{td}, \mathrm{J}=6.57,4.92$ $\mathrm{Hz}), 1.87(2 \mathrm{H}$, apparent $\mathrm{p}, \mathrm{J}=6.13 \mathrm{~Hz})$.

${ }^{19} \mathrm{~F}$ NMR $\delta(\mathrm{ppm})\left(\mathrm{DMSO}-\mathrm{d}_{6}\right):-67.0$.

\section{3-(5-chloro-2-(trifluoromethyl)quinolin-4-ylamino)propyl methanesulfonate}<smiles>COCCCNc1cc(C(F)(F)F)nc2cccc(Cl)c12</smiles>

3-(5-chloro-2-trifluoromethylquinolin-4-ylamino)propanol (1.13 g, $3.71 \mathrm{mmol})$ and triethylamine $(0.78 \mathrm{~mL}, 5.6 \mathrm{mmol})$ in dry THF $(50 \mathrm{~mL})$ were cooled to below $0^{\circ} \mathrm{C}$ on 
ice/salt. Methanesulfonyl chloride $(0.33 \mathrm{~mL}, 4.3 \mathrm{mmol})$ was added dropwise. After stirring for 1 hour on ice, TLC indicated that reaction was not complete; therefore, additional methanesulfonyl chloride $(0.02 \mathrm{~mL}, 0.3 \mathrm{mmol})$ was added and stirring was continued for a further 15 hours. The reaction mixture was then washed with $100 \mathrm{~mL}$ saturated sodium bicarbonate. The aqueous layer was extracted with ethyl acetate $(3 \times 10$ $\mathrm{mL}$ ), and the pooled organic layers were rinsed with $10 \mathrm{~mL}$ brine, then dried $\left(\mathrm{MgSO}_{4}\right)$ and evaporated under reduced pressure with warming to give the desired product as a cream-colored solid (1.19 g, 84\%).

${ }^{1} \mathrm{H}$ NMR $\delta(\mathrm{ppm})\left(\right.$ DMSO-d $\left._{6}\right): 7.89(2 \mathrm{H}$, br t overlaps dd, $\mathrm{J}=8.29,1.65 \mathrm{~Hz}), 7.68(1 \mathrm{H}$, dd, J = 8.21, $7.70 \mathrm{~Hz}), 7.63(1 \mathrm{H}, \mathrm{dd}, \mathrm{J}=7.55,1.51 \mathrm{~Hz}), 6.88(1 \mathrm{H}, \mathrm{s}), 4.37(2 \mathrm{H}, \mathrm{t}, \mathrm{J}=$ $6.00 \mathrm{~Hz}), 3.54(2 \mathrm{H}, \mathrm{td}, \mathrm{J}=6.76,5.23 \mathrm{~Hz}), 3.20(3 \mathrm{H}, \mathrm{s}), 2.12(2 \mathrm{H}$, apparent p, J = 6.49 $\mathrm{Hz})$.

\section{PL303: N-(3-(4-benzhydrylpiperazin-1-yl)propyl)-5-chloro-2- (trifluoromethyl)quinolin-4-amine}

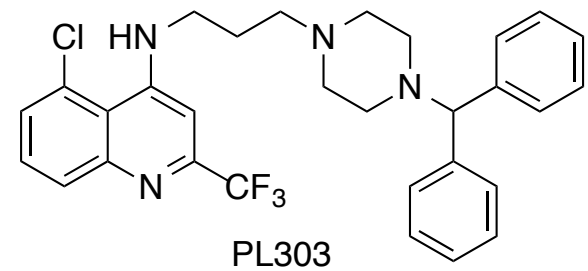

3-(5-chloro-2-trifluoromethylquinolin-4-ylamino)propyl methanesulfonate $(1.19 \mathrm{~g}, 3.1$ $\mathrm{mmol})$, potassium carbonate $(0.64 \mathrm{~g}, 4.6 \mathrm{mmol}), 1$-(diphenylmethyl)piperazine $(0.82 \mathrm{~g}$, $3.2 \mathrm{mmol}$ ), and a catalytic amount of potassium iodide were allowed to reflux in anhydrous acetonitrile $(22 \mathrm{~mL})$ for 3 days. TLC then indicated that reaction was complete. The solvent was removed under reduced pressure with warming, and the residue was partitioned between chloroform $(30 \mathrm{~mL})$ and water $(30 \mathrm{~mL})$. After separation, the aqueous layer was extracted with further chloroform $(3 \times 7 \mathrm{~mL})$, and the pooled organic layers were dried $\left(\mathrm{MgSO}_{4}\right)$ and evaporated under reduced pressure with warming to yield an amber oil. This material was crystallized from $95 \%$ ethanol to yield the desired product as a white, crystalline solid $\left(1.06 \mathrm{~g}, 65 \%, \mathrm{mp}=146.5-147.9^{\circ} \mathrm{C}\right)$.

${ }^{1} \mathrm{H} \mathrm{NMR} \delta(\mathrm{ppm})\left(\mathrm{CHCl}_{3}-\mathrm{d}\right): 7.96(1 \mathrm{H}, \mathrm{dd}, \mathrm{J}=8.40,1.39 \mathrm{~Hz}), 7.65(1 \mathrm{H}, \mathrm{br} \mathrm{t}, \mathrm{J}=4.80$ $\mathrm{Hz}$ ), 7.51 (1 H, t, J = 8.02 Hz), 7.40-7.44 $(5 \mathrm{H}, \mathrm{m}), 7.25-7.26$ (solvent signal overlaps $\mathrm{m}$, $\sim 4 \mathrm{H}), 7.13-7.20(2 \mathrm{H}, \mathrm{m}), 6.68(1 \mathrm{H}, \mathrm{s}), 4.23(1 \mathrm{H}, \mathrm{s}), 3.36(2 \mathrm{H}, \mathrm{m}), 2.52(10 \mathrm{H}, \mathrm{br} \mathrm{s}$ overlaps $\mathrm{t}, \mathrm{J}=7.15 \mathrm{~Hz}), 1.94(2 \mathrm{H}$, apparent $\mathrm{p}, \mathrm{J}=6.78 \mathrm{~Hz})$. 
${ }^{19} \mathrm{~F} \mathrm{NMR} \delta(\mathrm{ppm})\left(\mathrm{CHCl}_{3}-\mathrm{d}\right): 0.5,-68.5$.

${ }^{13} \mathrm{C}$ NMR $\delta(\mathrm{ppm})\left(\mathrm{CHCl}_{3}\right.$-d): 152.7, 150.3, 142.7, 130.5, 129.3, 128.7, 128.5, 128.0, 127.0, 126.9, 121.2, 116.4, 116.2, 95.3, 76.3, 56.1, 53.7, 51.8, 42.2, 25.4 .

MS (ESI): $m / z$ 539.22023 M + H (calculated 539.21839)

$\operatorname{HPLC}(\operatorname{method} \mathrm{A}) t_{\mathrm{R}}=20.93 \min (95 \%$ pure $)$.

\section{3-(7-chloro-2-(trifluoromethyl)-quinolin-4-ylamino)propanol}<smiles>OCCCNc1cc(C(F)(F)F)nc2cc(Cl)ccc12</smiles>

4,7-dichloro(2-trifluoromethyl)quinoline (1.00 g, $3.8 \mathrm{mmol}$ ) and 3-amino-1-propanol $(1.72 \mathrm{~mL}, 23 \mathrm{mmol})$ were combined in a $2-5 \mathrm{~mL}$ Biotage microwave vial and heated at $130^{\circ} \mathrm{C}$ for 20 minutes, whereupon TLC indicated that reaction was complete. The colorless, semi-solid reaction mixture was stirred vigorously in water $(100 \mathrm{~mL})$, followed by standing for 30 minutes. Filtration yielded a white, crystalline solid, which was partially recrystallized from a mixture of $95 \%$ ethanol and ethyl acetate $(\sim 2: 3,30 \mathrm{~mL})$ to provide the desired product (a white, crystalline solid, 0.91g, 79\% ).

${ }^{1} \mathrm{H}$ NMR $\delta(\mathrm{ppm})\left(\right.$ DMSO-d $\left._{6}\right): 8.37(1 \mathrm{H}, \mathrm{d}, \mathrm{J}=9.07 \mathrm{~Hz}), 7.93(1 \mathrm{H}, \mathrm{d}, \mathrm{J}=2.22 \mathrm{~Hz}), 7.88$ $(1 \mathrm{H}, \mathrm{br} \mathrm{t}, \mathrm{J}=5.39 \mathrm{~Hz}, \mathrm{NH}), 7.61(1 \mathrm{H}, \mathrm{dd}, \mathrm{J}=9.00,2.28 \mathrm{~Hz}), 6.79(1 \mathrm{H}, \mathrm{s}), 4.63(1 \mathrm{H}, \mathrm{t}$, $\mathrm{J}=5.06 \mathrm{~Hz}, \mathrm{OH}), 3.55(2 \mathrm{H}, \mathrm{td}, \mathrm{J}=6.01,5.09 \mathrm{~Hz}), 3.42(2 \mathrm{H}, \mathrm{td}, \mathrm{J}=7.06,5.41 \mathrm{~Hz}), 1.83$ $(2 \mathrm{H}$, apparent $\mathrm{p}, \mathrm{J}=6.58 \mathrm{~Hz}$ ).

${ }^{19}$ F NMR $\delta(\mathrm{ppm})($ DMSO-d 6$):-66.3$.

\section{3-(7-chloro-2-(trifluoromethyl)quinolin-4-ylamino)propyl methanesulfonate}<smiles>COCCCNc1cc(C(F)(F)F)nc2cc(Cl)ccc12</smiles> 
3-(7-chloro-2-trifluoromethylquinolin-4-ylamino)propanol $(0.50 \mathrm{~g}, 1.6 \mathrm{mmol})$ and triethylamine $(0.33 \mathrm{~mL}, 2.4 \mathrm{mmol})$ in dry THF $(100 \mathrm{~mL})$ were cooled to $5^{\circ} \mathrm{C}$ in an ice bath. Methanesulfonyl chloride $(0.15 \mathrm{~mL}, 1.9 \mathrm{mmol})$ was added dropwise. After stirring for 45 minutes on ice, additional methanesulfonyl chloride $(0.05 \mathrm{~mL}, 0.6 \mathrm{mmol})$ was added. After a further 20 minutes, TLC indicated that reaction was not complete; therefore, additional triethylamine $(0.20 \mathrm{~mL}, 1.4 \mathrm{mmol})$ and methanesulfonyl chloride $(0.03 \mathrm{~mL}, 0.4 \mathrm{mmol})$ were added and stirring was continued for a further 20 minutes. The reaction mixture was then washed with $35 \mathrm{~mL}$ saturated sodium bicarbonate. The aqueous layer was extracted with ethyl acetate $(3 \times 10 \mathrm{~mL})$, and the pooled organic layers were rinsed with $15 \mathrm{~mL}$ brine, then dried $\left(\mathrm{MgSO}_{4}\right)$ and evaporated under reduced pressure with warming to give the desired product as a white solid $(0.63 \mathrm{~g}, \sim 100 \%)$.

${ }^{1} \mathrm{H}$ NMR $\delta(\mathrm{ppm})\left(\mathrm{DMSO}-\mathrm{d}_{6}\right): 8.38(1 \mathrm{H}, \mathrm{d}, \mathrm{J}=9.07 \mathrm{~Hz}), 7.95(1 \mathrm{H}, \mathrm{d}, \mathrm{J}=2.22 \mathrm{~Hz}), 7.90$ $(1 \mathrm{H}, \mathrm{t}, \mathrm{J}=5.40 \mathrm{~Hz}), 7.64(1 \mathrm{H}, \mathrm{dd}, \mathrm{J}=8.99,2.26 \mathrm{~Hz}), 6.82(1 \mathrm{H}, \mathrm{s}), 4.36(2 \mathrm{H}, \mathrm{t}, \mathrm{J}=6.12$ $\mathrm{Hz}), 3.48(2 \mathrm{H}, \mathrm{td}, \mathrm{J}=7.02,5.42 \mathrm{~Hz}), 3.19(3 \mathrm{H}, \mathrm{s}), 2.09(2 \mathrm{H}$, apparent p, J = 6.54 Hz).

${ }^{19} \mathrm{~F}$ NMR $\delta(\mathrm{ppm})\left(\mathrm{DMSO}_{-} \mathrm{d}_{6}\right):-66.2$.

\section{PL398: 7-chloro-2-(trifluoromethyl)- $N$-(3-(4-(pyridin-2-yl)piperazin-1- yl)propyl)quinolin-4-amine}

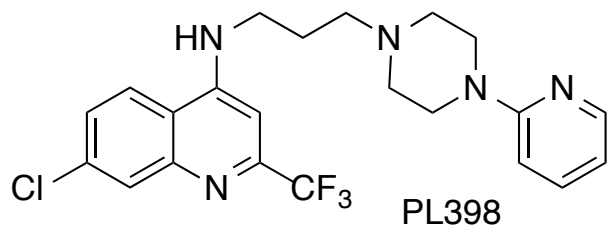

3-(7-chloro-2-trifluoromethylquinolin-4-ylamino)propyl methanesulfonate $(0.61 \mathrm{~g}, 1.6$ $\mathrm{mmol}), 1$-(2-pyridyl)piperazine $(0.27 \mathrm{~g}, 1.6 \mathrm{mmol})$, potassium carbonate $(0.33 \mathrm{~g}, 2.4$ $\mathrm{mmol}$ ), and a catalytic amount of potassium iodide were heated at reflux in anhydrous acetonitrile $(24 \mathrm{~mL})$ for 18 hours. The reaction mixture was diluted with water $(5 \mathrm{~mL})$, and the solvent was removed under reduced pressure with warming. The residue was partitioned between chloroform $(35 \mathrm{~mL})$ and water $(30 \mathrm{~mL})$. After separation, the aqueous layer was extracted with chloroform $(3 \times 5 \mathrm{~mL})$, and the pooled organic layers were dried over magnesium sulfate and evaporated under reduced pressure with warming. The resulting beige solid was recrystallized from $3 \mathrm{~mL}$ ethyl acetate to provide the desired product as glittering, white crystals $(0.34 \mathrm{~g}, 47 \%)$. 
${ }^{1} \mathrm{H}$ NMR $\delta(\mathrm{ppm})\left(\mathrm{CHCl}_{3}-\mathrm{d}\right): 8.24(1 \mathrm{H}, \mathrm{m}), 8.03(1 \mathrm{H}, \mathrm{d}, \mathrm{J}=2.14 \mathrm{~Hz}), 7.86(1 \mathrm{H}, \mathrm{t}, \mathrm{J}=$ $4.11 \mathrm{~Hz}), 7.82(1 \mathrm{H}, \mathrm{d}, \mathrm{J}=8.97 \mathrm{~Hz}), 7.55(1 \mathrm{H}, \mathrm{ddd}, \mathrm{J}=8.47,7.25,2.02 \mathrm{~Hz}), 7.29(1 \mathrm{H}$, dd, J = 8.94, 2.16 Hz), 6.70-6.70 (2 H, m), 6.63 (1 H, s), 3.68-3.69 (4 H, m), 3.47 (2 H, $\mathrm{td}, \mathrm{J}=5.87,4.08 \mathrm{~Hz}), 2.70-2.71(6 \mathrm{H}, \mathrm{m}), 1.97-2.06(2 \mathrm{H}, \mathrm{m})$.

${ }^{13} \mathrm{C}$ NMR $\delta(\mathrm{ppm})\left(\mathrm{CHCl}_{3}-\mathrm{d}\right): 159.3,152.0,150.0\left(\mathrm{q}, \mathrm{J}_{\mathrm{F}}=33.1 \mathrm{~Hz}\right), 148.2,148.1,137.7$, $135.9,129.4,126.5,121.9,121.8\left(\mathrm{q}, \mathrm{J}_{\mathrm{F}}=275 \mathrm{~Hz}\right), 117.4,113.9,107.2,94.1\left(\mathrm{q}, \mathrm{J}_{\mathrm{F}}=2.2\right.$ $\mathrm{Hz}), 58.8,53.5,45.3,44.6,23.2$.

${ }^{19} \mathrm{~F}$ NMR $\delta(\mathrm{ppm})\left(\mathrm{CHCl}_{3}-\mathrm{d}\right):-68.8$.

$\operatorname{HPLC}(\operatorname{method~A}) t_{\mathrm{R}}=11.81 \min (>99 \%$ pure $)$.

\section{A.3.8: 7-chloro-2-methylquinolines}

\section{3-(2-methyl-7-chloroquinolin-4-ylamino)propanol}<smiles>Cc1cc(NCCCO)c2ccc(Cl)cc2n1</smiles>

4,7-dichloro(2-methyl)quinoline (0.50 g, $2.4 \mathrm{mmol}$, purchased from Sigma Aldrich) and 3-amino-1-propanol (1.7 mL, $22 \mathrm{mmol})$ were combined in a 2-5 $\mathrm{mL}$ Biotage microwave vial and heated at $130^{\circ} \mathrm{C}$ for 20 minutes, whereupon TLC indicated that reaction was complete. The strawberry-colored reaction mixture was poured into water $(100 \mathrm{~mL})$ with vigorous stirring, followed by standing for 20 minutes. Filtration yielded a pale pink solid, which was partially recrystallized from a mixture of $95 \%$ ethanol and ethyl acetate $(\sim 1: 9,5 \mathrm{~mL})$ to provide the desired product (a pinkish mauve, granular solid, $0.32 \mathrm{~g}$, $53 \%)$.

${ }^{1} \mathrm{H}$ NMR $\delta(\mathrm{ppm})\left(\mathrm{DMSO}_{\mathrm{d}}\right): 8.18(1 \mathrm{H}, \mathrm{d}, \mathrm{J}=8.98 \mathrm{~Hz}), 7.68(1 \mathrm{H}, \mathrm{d}, \mathrm{J}=2.24 \mathrm{~Hz}), 7.36$ $(1 \mathrm{H}, \mathrm{dd}, \mathrm{J}=8.92,2.27 \mathrm{~Hz}), 7.14(1 \mathrm{H}$, br t, J = 5.30 Hz), $6.38(1 \mathrm{H}, \mathrm{s}), 4.58(1 \mathrm{H}, \mathrm{t}, \mathrm{J}=$ $5.06 \mathrm{~Hz}$ ), $3.54(2 \mathrm{H}, \mathrm{td}, \mathrm{J}=6.12,5.04 \mathrm{~Hz}$ ), 3.31 (water signal overlaps $\mathrm{m}, \sim 2 \mathrm{H}), 2.45$ (3 $\mathrm{H}, \mathrm{s}), 1.82$ (2 H, apparent p, J = 6.65 Hz). 


\section{3-(7-chloro-2-methylquinolin-4-ylamino)propyl methanesulfonate}<smiles>COCCCNc1cc(C)nc2cc(Cl)ccc12</smiles>

3-(7-chloro-2-methylquinolin-4-ylamino)propanol $(0.27 \mathrm{~g}, 1.1 \mathrm{mmol})$ and triethylamine $(0.23 \mathrm{~mL}, 1.6 \mathrm{mmol})$ in dry THF $(100 \mathrm{~mL})$ were cooled to $5^{\circ} \mathrm{C}$ in an ice bath.

Methanesulfonyl chloride $(0.10 \mathrm{~mL}, 1.3 \mathrm{mmol})$ was added dropwise. After stirring for 45 minutes on ice, additional methanesulfonyl chloride $(0.03 \mathrm{~mL}, 0.4 \mathrm{mmol})$ was added. After a further 20 minutes, TLC indicated that reaction was complete. The reaction mixture was washed with $35 \mathrm{~mL}$ saturated sodium bicarbonate. The aqueous layer was extracted with ethyl acetate $(3 \times 10 \mathrm{~mL})$, and the pooled organic layers were dried $\left(\mathrm{MgSO}_{4}\right)$ and evaporated under reduced pressure with warming to give the desired product as a white solid $(0.24 \mathrm{~g}, 72 \%)$.

${ }^{1} \mathrm{H}$ NMR $\delta(\mathrm{ppm})\left(\mathrm{DMSO}_{6}\right): 9.17(1 \mathrm{H}, \mathrm{br} \mathrm{t}, \mathrm{J}=5.52 \mathrm{~Hz}), 8.52(1 \mathrm{H}, \mathrm{d}, \mathrm{J}=9.09 \mathrm{~Hz})$, $7.91(1 \mathrm{H}, \mathrm{d}, \mathrm{J}=2.12 \mathrm{~Hz}), 7.75(1 \mathrm{H}, \mathrm{dd}, \mathrm{J}=9.01,2.12 \mathrm{~Hz}), 6.83(1 \mathrm{H}, \mathrm{s}), 4.35(2 \mathrm{H}, \mathrm{t}, \mathrm{J}$ $=6.08 \mathrm{~Hz}), 3.60(2 \mathrm{H}, \mathrm{td}, \mathrm{J}=6.98,5.48 \mathrm{~Hz}), 3.21(3 \mathrm{H}, \mathrm{s}), 2.65(3 \mathrm{H}, \mathrm{s}), 2.12(2 \mathrm{H}$, apparent $\mathrm{p}, \mathrm{J}=6.55 \mathrm{~Hz}$ ).

\section{PL399: 7-chloro-2-methyl- $N$-(3-(4-(pyridin-2-yl)piperazin-1-yl)propyl)quinolin-4- amine}<smiles>Cc1cc(NCCCN2CCN(c3ccccn3)CC2)c2ccc(Cl)cc2n1</smiles>

3-(7-chloro-2-methylquinolin-4-ylamino)propyl methanesulfonate $(0.24 \mathrm{~g}, 0.73 \mathrm{mmol})$, 1-(2-pyridyl)piperazine $(0.12 \mathrm{~g}, 0.73 \mathrm{mmol})$, potassium carbonate $(0.15 \mathrm{~g}, 1.1 \mathrm{mmol})$, and a catalytic amount of potassium iodide were heated at reflux in anhydrous acetonitrile $(24 \mathrm{~mL})$ for 18 hours. After dilution of the reaction mixture with water (5 $\mathrm{mL})$, the solvent was removed under reduced pressure with warming; the residue was partitioned between chloroform $(25 \mathrm{~mL})$ and water $(20 \mathrm{~mL})$ and separated. The aqueous layer was then extracted with chloroform $(3 \times 5 \mathrm{~mL})$, and the pooled organic layers were dried over magnesium sulfate and evaporated under reduced pressure with warming. The resulting pale amber oil was taken up in $1 \mathrm{~mL}$ ethyl acetate. Upon standing, 
crystallization occurred; vacuum filtration provided the desired product as white crystals $(0.07 \mathrm{~g}, 24 \%)$.

${ }^{1} \mathrm{H}$ NMR $\delta(\mathrm{ppm})\left(\mathrm{CHCl}_{3}-\mathrm{d}\right): 8.24(1 \mathrm{H}, \mathrm{m}), 7.86(1 \mathrm{H}, \mathrm{d}, \mathrm{J}=2.14 \mathrm{~Hz}), 7.73(1 \mathrm{H}, \mathrm{d}, \mathrm{J}=$ $8.89 \mathrm{~Hz}), 7.52-7.53(1 \mathrm{H}, \mathrm{m}), 7.18(1 \mathrm{H}, \mathrm{dd}, \mathrm{J}=8.86,2.16 \mathrm{~Hz}), 7.11(1 \mathrm{H}, \mathrm{t}, \mathrm{J}=4.21 \mathrm{~Hz})$, $6.69(2 \mathrm{H}, \mathrm{m}), 6.26(1 \mathrm{H}, \mathrm{s}), 3.67(4 \mathrm{H}, \mathrm{m}), 3.41(2 \mathrm{H}, \mathrm{td}, \mathrm{J}=5.96,4.30 \mathrm{~Hz}), 2.65-2.70(6$ $\mathrm{H}, \mathrm{m}), 2.59(3 \mathrm{H}, \mathrm{s}), 1.99(2 \mathrm{H}$, apparent $\mathrm{p}, \mathrm{J}=5.64 \mathrm{~Hz})$.

${ }^{13} \mathrm{C} \mathrm{NMR} \delta(\mathrm{ppm})\left(\mathrm{CHCl}_{3}-\mathrm{d}\right): 160.9,159.4,150.4,149.0,148.1,137.7,134.7,128.0$, 124.1, 121.6, 116.1, 113.8, 107.1, 98.8, 58.6, 53.5, 45.3, 44.2, 25.8, 23.8.

$\operatorname{HPLC}(\operatorname{method} \mathrm{A}) t_{\mathrm{R}}=2.01 \min (85 \%), 1.54 \min (14 \%)$.

\section{A.4: 7-hydroquinolines}

3-carbethoxy-4-quinolone (Price, 1946; Hauser, 1950)<smiles>CCOC(=O)c1c[nH]c2ccccc2c1=O</smiles>

Aniline (10.0 mL, $110 \mathrm{mmol})$ and diethyl ethoxymethylene malonate $(21.99 \mathrm{~mL}, 110$ $\mathrm{mmol})$ were heated in refluxing Dowtherm A $(100 \mathrm{~mL})$ for 30 minutes. After cooling, the reaction mixture was diluted with hexanes $(150 \mathrm{~mL})$ and vacuum filtered, rinsing with further hexanes $(200 \mathrm{~mL})$, followed by acetone $(100 \mathrm{~mL})$. The product was obtained as grayish beige, powdery solid $(13.87 \mathrm{~g}, 58 \%)$.

${ }^{1} \mathrm{H}$ NMR $\delta(\mathrm{ppm})\left(\mathrm{DMSO}_{6} \mathrm{~d}_{6}\right): 12.31(1 \mathrm{H}, \mathrm{s}), 8.54(1 \mathrm{H}, \mathrm{s}), 8.16(1 \mathrm{H}, \mathrm{dd}, \mathrm{J}=8.09,1.47$ $\mathrm{Hz}), 7.71(1 \mathrm{H}, \mathrm{ddd}, \mathrm{J}=8.27,6.99,1.54 \mathrm{~Hz}), 7.62(1 \mathrm{H}, \mathrm{dd}, \mathrm{J}=8.24,1.07 \mathrm{~Hz}), 7.42(1 \mathrm{H}$, ddd, J = 8.08, 6.99, $1.17 \mathrm{~Hz}), 4.22(2 \mathrm{H}, \mathrm{q}, \mathrm{J}=7.10 \mathrm{~Hz}), 1.28(3 \mathrm{H}, \mathrm{t}, \mathrm{J}=7.10 \mathrm{~Hz})$. 
<smiles>O=C(O)c1c[nH]c2ccccc2c1=O</smiles>

3-carbethoxy-4-quinolone (13.87 g, $63.9 \mathrm{mmol})$ was heated at reflux in $200 \mathrm{~mL}$ of $10 \%$ caustic soda for 18 hours. The hot reaction mixture was poured into $300 \mathrm{~mL}$ water, then made acidic by the addition of concentrated muriatic acid. After cooling, vacuum filtration followed by air-drying provided the desired product as a white solid (12.20 g, containing residual water). This material was used without further drying in the ensuing reaction.

${ }^{1} \mathrm{H}$ NMR $\delta(\mathrm{ppm})\left(\mathrm{DMSO}_{6}\right): 15.36$ (1 H, br s), 13.48 (1 H, br s), 8.90 (1 H, s), 8.31 (1 $\mathrm{H}, \mathrm{d}, \mathrm{J}=8.15 \mathrm{~Hz}), 7.90(1 \mathrm{H}, \mathrm{m}), 7.84(1 \mathrm{H}, \mathrm{d}, \mathrm{J}=8.35 \mathrm{~Hz}), 7.62(1 \mathrm{H}, \mathrm{m})$.

4-quinolone (Price, 1946; Hauser, 1950)<smiles>O=c1cc[nH]c2ccccc12</smiles>

3-carboxy-4-quinolone from the above reaction (12.06 g, containing residual water) was heated in Dowtherm A $(100 \mathrm{~mL})$ at reflux for 40 minutes. After cooling, the reaction mixture was diluted with $100 \mathrm{~mL}$ hexanes and allowed to sit for 48 hours, followed by vacuum filtration, rinsing with further hexanes $(300 \mathrm{~mL})$ to provide the product as an offwhite, powdery solid (9.28 g, 100\% from 3-carbethoxy-4-quinolone).

${ }^{1} \mathrm{H}$ NMR $\delta(\mathrm{ppm})\left(\mathrm{DMSO}_{-} \mathrm{d}_{6}\right): 11.74(1 \mathrm{H}, \mathrm{s}), 8.09$ (1 H, dd, J = 8.08, $\left.1.47 \mathrm{~Hz}\right), 7.89(1 \mathrm{H}$, $\mathrm{dd}, \mathrm{J}=7.39,5.89 \mathrm{~Hz}), 7.64(1 \mathrm{H}, \mathrm{ddd}, \mathrm{J}=8.34,6.94,1.56 \mathrm{~Hz}), 7.54(1 \mathrm{H}, \mathrm{d}, \mathrm{J}=8.31 \mathrm{~Hz})$, 7.31 (1 H, ddd, J = 8.09, 6.94, $1.12 \mathrm{~Hz}), 6.03$ (1 H, dd, J = 7.38, $1.22 \mathrm{~Hz}$ ). 
4-chloroquinoline (Price, 1946; Hauser, 1950)<smiles>Clc1ccnc2ccccc12</smiles>

4-quinolone ( $9.28 \mathrm{~g}, 63.9 \mathrm{mmol}$ ) and phosphorus oxychloride ( $35 \mathrm{~mL}, 375 \mathrm{mmol})$ were heated at $110^{\circ} \mathrm{C}$ for 2.5 hours, whereupon TLC indicated that the reaction was complete. After cooling, the reaction mixture was poured cautiously onto ice, stirring vigorously. After resting, the aqueous mixture was made basic to litmus by the addition of solid caustic potash (final volume $800 \mathrm{~mL}$ ). After cooling, this mixture was extracted with chloroform ( $200 \mathrm{~mL}$ followed by $3 \times 20 \mathrm{~mL}$ ), and the pooled organic layers were dried $\left(\mathrm{MgSO}_{4}\right)$ and evaporated under reduced pressure with warming to yield the desired product as a viscous, aromatic liquid. After offgassing for several days, followed by storage for several years in a closed vial, this became a beige solid $(9.42 \mathrm{~g}, 90 \%, \mathrm{mp}=$ 25.9-28. $1^{\circ} \mathrm{C}$ (lit. $34-35^{\circ} \mathrm{C}$; Hauser, 1950)).

${ }^{1} \mathrm{H}$ NMR $\delta(\mathrm{ppm})\left(\mathrm{CHCl}_{3}-\mathrm{d}\right): 8.80(1 \mathrm{H}, \mathrm{d}, \mathrm{J}=4.70 \mathrm{~Hz}), 8.25(1 \mathrm{H}, \mathrm{dd}, \mathrm{J}=8.42,1.38 \mathrm{~Hz})$, $8.14(1 \mathrm{H}, \mathrm{dd}, \mathrm{J}=8.48,1.11 \mathrm{~Hz}), 7.79(1 \mathrm{H}, \mathrm{ddd}, \mathrm{J}=8.49,6.89,1.44 \mathrm{~Hz}), 7.66(1 \mathrm{H}, \mathrm{ddd}$, $\mathrm{J}=8.42,6.90,1.23 \mathrm{~Hz}), 7.51(1 \mathrm{H}, \mathrm{d}, \mathrm{J}=4.70 \mathrm{~Hz})$.

\section{3-(quinolin-4-ylamino)propanol}<smiles>OCCCNc1ccnc2ccccc12</smiles>

4-chloroquinoline (3.00 g, $18.3 \mathrm{mmol})$ and 3-amino-1-propanol ( $8.42 \mathrm{~mL}, 110 \mathrm{mmol})$ were heated at $70^{\circ} \mathrm{C}$ in a Carius vessel for 24 hours. TLC indicated that the reaction was not complete. The temperature was increased to $90^{\circ} \mathrm{C}$, and heating was continued for a further 6 days. Reaction was found to be complete by TLC, and the thick reaction mixture was poured without cooling into water $(300 \mathrm{~mL})$. After resting for 20 minutes, the resulting precipitate was recovered by vacuum filtration to give the desired product as a creamy white, sparkling solid $\left(3.60 \mathrm{~g}, 97 \%, \mathrm{mp}=148.7-149.7^{\circ} \mathrm{C}\right)$.

${ }^{1} \mathrm{H}$ NMR $\delta(\mathrm{ppm})\left(\right.$ DMSO-d $\left._{6}\right): 8.38(1 \mathrm{H}, \mathrm{d}, \mathrm{J}=5.30 \mathrm{~Hz}), 8.18(1 \mathrm{H}, \mathrm{dd}, \mathrm{J}=8.42,1.33$ $\mathrm{Hz}), 7.76(1 \mathrm{H}, \mathrm{dd}, \mathrm{J}=8.37,1.26 \mathrm{~Hz}), 7.59(1 \mathrm{H}, \mathrm{ddd}, \mathrm{J}=8.39,6.77,1.37 \mathrm{~Hz}), 7.40(1 \mathrm{H}$, ddd, $\mathrm{J}=8.40,6.77,1.35 \mathrm{~Hz}), 7.13(1 \mathrm{H}, \mathrm{t}, \mathrm{J}=5.39 \mathrm{~Hz}), 6.44(1 \mathrm{H}, \mathrm{d}, \mathrm{J}=5.35 \mathrm{~Hz}), 4.59$ 
$(1 \mathrm{H}, \mathrm{t}, \mathrm{J}=5.06 \mathrm{~Hz}), 3.55(2 \mathrm{H}, \mathrm{m}), 3.32-3.36$ (water signal overlaps $\mathrm{m}, \sim 2 \mathrm{H}), 1.83(2 \mathrm{H}$, apparent $\mathrm{p}, \mathrm{J}=6.65 \mathrm{~Hz}$ ).

MS (ESI): $m / z$ 203.11814 M + H (calculated 203.11789)

HPLC (method A) $t_{\mathrm{R}}=6.47 \min (99 \%$ pure $)$.

\section{3-(quinolin-4-ylamino)propyl methanesulfonate}

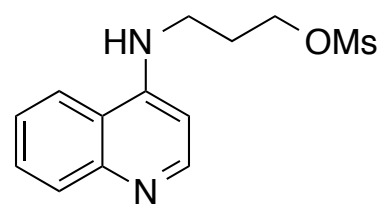

3-(quinolin-4-ylamino)propanol ( $0.50 \mathrm{~g}, 2.5 \mathrm{~mol})$ and triethylamine $(0.52 \mathrm{~mL}, 3.7 \mathrm{mmol})$ were taken up in $50 \mathrm{~mL}$ anhydrous dichloromethane and chilled to below $0^{\circ} \mathrm{C}$ in an icesalt bath. Methanesulfonyl chloride $(0.22 \mathrm{~mL}, 2.8 \mathrm{mmol})$ was gradually added and stirring on ice was continued for 1 hour. TLC indicated that the reaction was not complete. The flask was sealed and stored at $5^{\circ} \mathrm{C}$ for 18 hours. Further triethylamine $(1.00 \mathrm{~mL}, 7.2 \mathrm{mmol})$ and methanesulfonyl chloride $(0.12 \mathrm{~mL}, 1.5 \mathrm{mmol})$ were then added. After thirty minutes, TLC indicated that reaction was complete. The reaction mixture was washed with saturated $\mathrm{NaHCO}_{3}(25 \mathrm{~mL})$, and the aqueous layer was then extracted with dichloromethane $(3 \times 7 \mathrm{~mL})$. The pooled organic layers were dried over magnesium sulfate and evaporated under reduced pressure with warming to yield a cream colored solid (0.61 g, 88\%).

${ }^{1} \mathrm{H}$ NMR $\delta(\mathrm{ppm})\left(\right.$ DMSO-d $\left._{6}\right): 8.40(1 \mathrm{H}, \mathrm{d}, \mathrm{J}=5.31 \mathrm{~Hz}), 8.20(1 \mathrm{H}, \mathrm{dd}, \mathrm{J}=8.45,1.31$ $\mathrm{Hz}), 7.78(1 \mathrm{H}, \mathrm{dd}, \mathrm{J}=8.39,1.25 \mathrm{~Hz}), 7.61(1 \mathrm{H}, \mathrm{ddd}, \mathrm{J}=8.42,6.78,1.31 \mathrm{~Hz}), 7.42(1 \mathrm{H}$, ddd, J = 8.42, 6.78, $1.33 \mathrm{~Hz}), 7.17(1 \mathrm{H}, \mathrm{br} \mathrm{t}, \mathrm{J}=5.45 \mathrm{~Hz}), 6.48(1 \mathrm{H}, \mathrm{d}, \mathrm{J}=5.36 \mathrm{~Hz})$, $4.35(2 \mathrm{H}, \mathrm{t}, \mathrm{J}=6.21 \mathrm{~Hz}), 3.39(2 \mathrm{H}, \mathrm{m}), 3.20(3 \mathrm{H}, \mathrm{s}), 2.08(2 \mathrm{H}$, apparent $\mathrm{p}, \mathrm{J}=6.61$ $\mathrm{Hz})$. 


\section{PL374: N-(3-(4-(dipyridin-2-ylmethyleneamino)piperidin-1-yl)propyl)quinolin-4- amine}

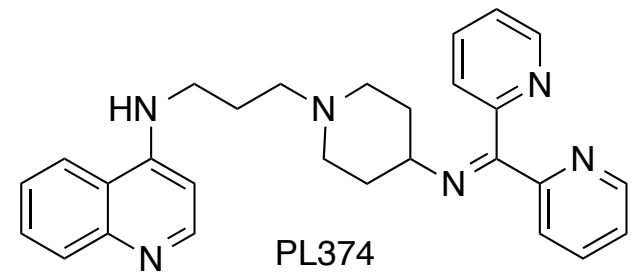

3-(quinolin-4-ylamino)propyl methanesulfonate (1.17 g, $4.2 \mathrm{mmol}$ ), PL190 (1.28 g, 4.8 $\mathrm{mmol})$, potassium carbonate $(0.87 \mathrm{~g}, 6.3 \mathrm{~mol})$, and a catalytic amount of potassium iodide were allowed to reflux in anhydrous acetonitrile $(50 \mathrm{~mL})$ for 24 hours, at which time TLC indicated that reaction was complete. The reaction mixture was diluted with water ( 5 $\mathrm{mL}$ ) and evaporated under reduced pressure with warming. The residue was partitioned between water $(25 \mathrm{~mL})$ and chloroform $(50 \mathrm{~mL})$. After separation, the aqueous layer was further extracted with chloroform $(3 \times 10 \mathrm{~mL})$. The pooled organic layers were dried $\left(\mathrm{MgSO}_{4}\right)$ and evaporated under reduced pressure with warming. The resulting thick, amber oil was purified by flash chromatography on basic alumina, eluting with a gradient of $100 \%$ hexanes to $3 / 2$ hexanes/ethyl acetate $(\mathrm{v} / \mathrm{v})$. The resulting tan solid was taken up in boiling ethyl acetate $(40 \mathrm{~mL})$ and the solution was allowed to evaporate at room temperature to $10 \mathrm{~mL}$. Filtration afforded the desired product as tan crystals $(0.63 \mathrm{~g}$, $\left.34 \%, \mathrm{mp}=171.0-172.5^{\circ} \mathrm{C}\right)$.

${ }^{1} \mathrm{H}$ NMR $\delta(\mathrm{ppm})\left(\mathrm{CHCl}_{3}-\mathrm{d}\right): 8.73-8.75(1 \mathrm{H}, \mathrm{m}), 8.54(1 \mathrm{H}, \mathrm{d}, \mathrm{J}=5.26 \mathrm{~Hz}), 8.51(1 \mathrm{H}$, m), $8.34(1 \mathrm{H}, \mathrm{m}), 8.01(1 \mathrm{H}, \mathrm{d}, \mathrm{J}=8.37 \mathrm{~Hz}), 7.97(1 \mathrm{H}, \mathrm{m}), 7.81(2 \mathrm{H}, \mathrm{m}), 7.63(1 \mathrm{H}, \mathrm{m})$, $7.57(1 \mathrm{H}, \mathrm{t}, \mathrm{J}=4.11 \mathrm{~Hz}), 7.52(1 \mathrm{H}, \mathrm{m}), 7.35(1 \mathrm{H}, \mathrm{m}), 7.28(2 \mathrm{H}, \mathrm{m}), 6.35(1 \mathrm{H}, \mathrm{d}, \mathrm{J}=$ $5.31 \mathrm{~Hz}), 3.39(3 \mathrm{H}, \mathrm{m}), 3.06(2 \mathrm{H}, \mathrm{m}), 2.58(2 \mathrm{H}, \mathrm{td}, \mathrm{J}=5.25,1.20 \mathrm{~Hz}), 2.13(2 \mathrm{H}, \mathrm{m})$, $2.03(2 \mathrm{H}$, br m), $1.94(2 \mathrm{H}$, apparent p, J = 5.39 Hz), $1.83(2 \mathrm{H}, \mathrm{m})$.

${ }^{13} \mathrm{C} \mathrm{NMR} \delta(\mathrm{ppm})\left(\mathrm{CHCl}_{3}\right.$-d): 165.4, 157.2, 155.8, 151.3, 150.6, 149.7, 148.7, 148.5, $136.4,136.0,129.8,128.9,124.2,124.1,123.4,123.0,122.2,120.8,119.2,98.2,59.0$, $58.8,52.2,44.4,33.0,24.0$.

MS (ESI): $m / z$ 451.26047 M + H (calculated 451.26102)

HPLC (method A) $t_{\mathrm{R}}=1.15 \min (49 \%), 2.26 \min (1 \%), 9.20 \min (50 \%)$. 


\section{PL375: $N$-(3-(4-(dipyridin-2-ylmethylamino)piperidin-1-yl)propyl)quinolin-4-amine}<smiles>[R5]c1cnc2ccccc2c1NCCCN1CCC(NC(c2ccccn2)c2ccccn2)CC1</smiles>

PL374 (0.58 g, $1.3 \mathrm{~mol})$ was dissolved in anhydrous methanol (40 mL). Sodium borohydride $(0.18 \mathrm{~g}, 4.8 \mathrm{mmol})$ was added and the reaction was allowed to stir at room temperature, equipped with a calcium chloride drying tube, for 1 hour. Additional sodium borohydride was then added $(0.09 \mathrm{~g}, 2.4 \mathrm{mmol})$, and stirring was continued for 14 hours, whereupon TLC indicated that the reaction was complete. After removal of the solvent under reduced pressure with warming, the residue was stirred with water (35 $\mathrm{mL}$ ), then shaken with $35 \mathrm{~mL}$ dichloromethane. After separation, the aqueous layer was extracted with further dichloromethane $(3 \times 10 \mathrm{~mL})$, dried $\left(\mathrm{MgSO}_{4}\right)$, and evaporated under reduced pressure with warming to yield a pale yellow glass. This material was allowed to stand overnight, followed by heating at $50^{\circ} \mathrm{C}$ in the vacuum oven for 1 hour to remove residual solvent. The desired product was obtained as a pale yellow glass $(0.57$ g, $\left.96 \%, \mathrm{mp}=93.0-98.8^{\circ} \mathrm{C}\right)$.

${ }^{1} \mathrm{H}$ NMR $\delta(\mathrm{ppm})\left(\mathrm{CHCl}_{3}-\mathrm{d}\right): 8.57-8.57(2 \mathrm{H}, \mathrm{m}), 8.52(1 \mathrm{H}, \mathrm{d}, \mathrm{J}=5.32 \mathrm{~Hz}), 7.95(1 \mathrm{H}$, $\mathrm{dd}, \mathrm{J}=8.43,1.20 \mathrm{~Hz}), 7.89(1 \mathrm{H}, \mathrm{dd}, \mathrm{J}=8.40,1.32 \mathrm{~Hz}), 7.63-7.63(3 \mathrm{H}, \mathrm{m}), 7.46-7.48$ (4 $\mathrm{H}, \mathrm{m}), 7.15(2 \mathrm{H}, \mathrm{ddd}, \mathrm{J}=7.46,4.88,1.19 \mathrm{~Hz}), 6.33(1 \mathrm{H}, \mathrm{d}, \mathrm{J}=5.37 \mathrm{~Hz}), 5.25(1 \mathrm{H}, \mathrm{s})$, $3.37(2 \mathrm{H}, \mathrm{td}, \mathrm{J}=5.88,4.16 \mathrm{~Hz}), 2.93-3.05(2 \mathrm{H}, \mathrm{m}), 2.54-2.59(3 \mathrm{H}, \mathrm{m}), 1.94-1.96(6 \mathrm{H}$, $\mathrm{m}), 1.66-1.68(2 \mathrm{H}, \mathrm{m})$.

${ }^{13} \mathrm{C} \mathrm{NMR} \delta(\mathrm{ppm})\left(\mathrm{CHCl}_{3}-\mathrm{d}\right): 162.1,151.1,150.6,149.1,148.3,136.6,129.6,128.9$, $124.3,122.4,122.2,120.6,119.1,98.1,66.6,60.4,58.6,52.8,44.3,33.0,24.0$.

MS (ESI): $m / z$ 453.27612 M + H (calculated 453.27655)

HPLC (method A) $t_{\mathrm{R}}=2.41 \mathrm{~min}(81 \%$ pure). (An additional major peak elutes at 1.57 minutes, $16 \%$.) 


\section{A.5: Methylquinolines}

\section{A.5.1: 6-Methylquinolines}

3-carbethoxy-6-methyl-4-quinolone (Price, 1946; Burckhalter, 1948)<smiles>CCOC(=O)c1c[nH]c2ccc(C)cc2c1=O</smiles>

para-Toluidine (4.97 g, $46 \mathrm{mmol})$ and diethyl ethoxymethylene malonate (10.04 g, 46 mmol) were allowed to heat in Dowtherm A $(80 \mathrm{~mL})$ to $255^{\circ} \mathrm{C}$. After 20 minutes at this temperature, the reaction was removed from the heat. Upon cooling, the reaction mixture was diluted with hexanes $(100 \mathrm{~mL})$, and the solid was recovered by vacuum filtration, rinsing with hexanes $(200 \mathrm{~mL})$ followed by acetone $(100 \mathrm{~mL})$ to provide the product as a pinkish tan, powdery solid (5.79 g, 54\%).

3-carbethoxy-6-methyl-4-quinolone (Price, 1946; Burckhalter, 1948<smiles>Cc1ccc2[nH]cc(C(=O)O)c(=O)c2c1</smiles>

3-carbethoxy-6-methyl-4-quinolone from the above reaction $(5.79 \mathrm{~g}, 25 \mathrm{mmol})$ was allowed to heat in $10 \%$ sodium hydroxide $(200 \mathrm{~mL})$ at reflux for 46 hours. After cooling, the reaction mixture was diluted to $500 \mathrm{~mL}$ and made acidic by the addition of concentrated muriatic acid. The resulting precipitate was recovered by vacuum filtration and allowed to air dry (7.25 g, presumed to contain residual water). 
6-methyl-4-quinolone (Price, 1946; Burckhalter, 1948)<smiles>Cc1ccc2[nH]ccc(=O)c2c1</smiles>

3-carboxy-6-methyl-4-quinolone from the above reaction (7.25 g, presumed to contain residual water) was allowed to heat in Dowtherm $\mathrm{A}(30 \mathrm{~mL})$ to $255^{\circ} \mathrm{C}$, at which temperature it was allowed to remain for 30 minutes. Upon cooling, the reaction mixture was diluted with hexanes and the solid material was recovered by vacuum filtration (an off-white powder, $6.00 \mathrm{~g}$ ). The product was used without purification in the ensuing reaction.

${ }^{1} \mathrm{H}$ NMR $\delta(\mathrm{ppm})\left(\mathrm{DMSO}_{\mathrm{d}}\right): 11.74(1 \mathrm{H}, \mathrm{s}), 7.84-7.90(2 \mathrm{H}, \mathrm{m}), 7.45-7.47(2 \mathrm{H}, \mathrm{m})$, $6.00(1 \mathrm{H}, \mathrm{d}, \mathrm{J}=7.35 \mathrm{~Hz}), 2.40(3 \mathrm{H}, \mathrm{s})$.

4-chloro-6-methylquinoline (Price, 1946; Burckhalter, 1948)<smiles>Cc1ccc2nccc(Cl)c2c1</smiles>

6-methyl-4-quinolone (6.00 g) and phosphorus oxychloride ( $40 \mathrm{~mL}, 430 \mathrm{mmol})$ were allowed to heat at $110^{\circ} \mathrm{C}$ for 3 days. After cooling, the reaction mixture was poured cautiously onto ice (final volume $1.4 \mathrm{~L}$ ). After resting, the mixture was made basic by the addition of solid caustic potash, followed by extraction with chloroform $(100 \mathrm{~mL}$, followed by 3 x $50 \mathrm{~mL}$ ). The pooled chloroform layers were dried over magnesium sulfate and evaporated under reduced pressure with warming to provide the desired product as a golden brown, crystalline solid $(3.90 \mathrm{~g}, 48 \%$ from para-toluidine, $\mathrm{mp}=$ 49.8-53.8 ${ }^{\circ} \mathrm{C}$ (lit. $55^{\circ} \mathrm{C}$; Burckhalter, 1948)). 


\section{3-(6-methylquinolin-4-ylamino)propanol}<smiles>Cc1ccc2nccc(NCCCO)c2c1</smiles>

4-chloro-6-methylquinoline (1.96 g, $11 \mathrm{mmol})$ and 3-amino-1-propanol (5.07 mL, 66 mmol) were heated at $90^{\circ} \mathrm{C}$ for 24 hours in a Carius vessel, at the end of which time TLC indicated that the reaction had gone to completion. The hot reaction mixture was poured into water $(200 \mathrm{~mL})$, and after standing 1 hour the resulting precipitate was recovered by vacuum filtration, followed by air-drying to provide the desired compound $(2.20 \mathrm{~g}, 92 \%)$.

${ }^{1} \mathrm{H}$ NMR $\delta(\mathrm{ppm})\left(\mathrm{DMSO}_{6}\right): 8.32(1 \mathrm{H}, \mathrm{d}, \mathrm{J}=5.27 \mathrm{~Hz}), 7.98(1 \mathrm{H}, \mathrm{s}), 7.66(1 \mathrm{H}, \mathrm{d}, \mathrm{J}=$ $8.49 \mathrm{~Hz}), 7.43(1 \mathrm{H}, \mathrm{dd}, \mathrm{J}=8.50,1.80 \mathrm{~Hz}), 6.99(1 \mathrm{H}$, br t, J = 5.35 Hz), $6.40(1 \mathrm{H}, \mathrm{d}, \mathrm{J}=$ $5.31 \mathrm{~Hz}), 4.59(1 \mathrm{H}$, br t, J = 4.99 Hz), $3.55(2 \mathrm{H}, \mathrm{m}), 2.47(3 \mathrm{H}, \mathrm{s}), 1.80-1.85(2 \mathrm{H}, \mathrm{m})$.

\section{3-(6-methylquinolin-4-ylamino)propyl methanesulfonate}<smiles>COCCCNc1ccnc2ccc(C)cc12</smiles>

3-(6-methylquinolin-4-ylamino)propanol (2.20 g, $10 \mathrm{mmol})$ and triethylamine $(1.54 \mathrm{~g}, 15$ mmol $)$ in dry tetrahydrofuran $(100 \mathrm{~mL})$ were cooled to below $0^{\circ} \mathrm{C}$ on ice/salt, and methanesulfonyl chloride $(0.91 \mathrm{~mL}, 12 \mathrm{mmol})$ was gradually added. After stirring for 2 hours on ice, TLC indicated that the reaction had not gone to completion. Additional triethylamine $(0.51 \mathrm{~g}, 5.0 \mathrm{mmol})$ and methanesulfonyl chloride $(0.39 \mathrm{~mL}, 5.0 \mathrm{mmol})$ were therefore added. The reaction was sealed and stored at $5^{\circ} \mathrm{C}$ for three days, then diluted with ethyl acetate $(50 \mathrm{~mL})$ and rinsed with saturated sodium bicarbonate $(50 \mathrm{~mL})$. The aqueous layer was extracted with further ethyl acetate $(3 \times 10 \mathrm{~mL})$, and the pooled organic extracts were washed with brine $(10 \mathrm{~mL})$, dried over magnesium sulfate, and evaporated under reduced pressure with warming to yield the desired product $(2.08 \mathrm{~g}$, containing residual ethyl acetate and triethylamine). This material was used without further purification in the ensuing reaction. 


\section{PL383: N-(3-(4-benzhydrylpiperazin-1-yl)propyl)-6-methylquinolin-4-amine}<smiles>Cc1ccc2nccc(NCCCN3CCN(C(c4ccccc4)c4ccccc4)CC3)c2c1</smiles>

3-(6-quinolin-4-ylamino)propyl methanesulfonate (1.04 g, $3.5 \mathrm{mmol})$, 1benzhydrylpiperazine $(0.88 \mathrm{~g}, 3.5 \mathrm{mmol})$, potassium carbonate $(0.73 \mathrm{~g}, 5.3 \mathrm{mmol})$, and a catalytic amount of potassium iodide were heated at reflux in anhydrous acetonitrile (50 $\mathrm{mL}$ ) for 4 days, whereupon TLC indicated that reaction was complete. The solvent was removed under reduced pressure with warming, and the residue was partitioned between chloroform $(50 \mathrm{~mL})$ and water $(50 \mathrm{~mL})$, followed by extraction of the aqueous layer with additional chloroform $(3 \times 10 \mathrm{~mL})$. The pooled organic layers were dried over magnesium sulfate and evaporated under reduced pressure with warming. The solid residue was recrystallized from ethyl acetate $/ 95 \%$ ethanol (approximately $9: 1$ ). The desired product was obtained as small, beige crystals $(0.34 \mathrm{~g}, 7.5 \%$ from 3-(6methylquinolin-4-ylamino)propanol, $\mathrm{mp}=168.9-171.3^{\circ} \mathrm{C}$ ).

${ }^{1} \mathrm{H}$ NMR $\delta(\mathrm{ppm})\left(\mathrm{CHCl}_{3}-\mathrm{d}\right): 8.46(1 \mathrm{H}, \mathrm{d}, \mathrm{J}=5.24 \mathrm{~Hz}), 7.87(1 \mathrm{H}, \mathrm{d}, \mathrm{J}=8.55 \mathrm{~Hz}), 7.70$ $(1 \mathrm{H}, \mathrm{s}), 7.47(1 \mathrm{H}, \mathrm{dd}, \mathrm{J}=8.59,1.82 \mathrm{~Hz}), 7.44(4 \mathrm{H}, \mathrm{m}), 7.28(4 \mathrm{H}, \mathrm{m}), 7.18(2 \mathrm{H}, \mathrm{m})$, $7.15(1 \mathrm{H}$, br t, J = 4.15 Hz), $6.30(1 \mathrm{H}, \mathrm{d}, \mathrm{J}=5.29 \mathrm{~Hz}), 4.31(1 \mathrm{H}, \mathrm{s}), 3.35(2 \mathrm{H}, \mathrm{td}, \mathrm{J}=$ 5.43, 0.01 Hz), 2.58-2.69 (13 H, br s overlaps s, $2.69 \mathrm{ppm}$, and t, $2.61 \mathrm{ppm}, \mathrm{J}=5.51 \mathrm{~Hz})$, $1.92(2 \mathrm{H}$, apparent $\mathrm{p}, \mathrm{J}=5.49 \mathrm{~Hz})$.

${ }^{13} \mathrm{C} \mathrm{NMR} \delta(\mathrm{ppm})\left(\mathrm{CHCl}_{3}\right.$-d): 150.4, 150.1, 146.9, 142.8, 133.6, 130.9, 129.6, 128.6, $127.8,127.1,119.5,119.0,98.4,76.7,58.9,54.0,52.2,44.5,23.8,22.1$.

MS (ESI): $m / z 451.28603 \mathrm{M}+\mathrm{H}$ (calculated 451.28562)

HPLC (method A) $t_{\mathrm{R}}=10.40 \mathrm{~min}(89 \%$ pure). (Additional peaks elute at 9.58 minutes, $10 \%$, and 8.03 minutes, $1 \%$.) 


\section{A.5.2: 8-Methylquinolines}

3-carbethoxy-8-methyl-4-quinolone (Price, 1946; Burckhalter, 1948)<smiles>CCOC(=O)c1c[nH]c2c(C)cccc2c1=O</smiles>

ortho-Toluidine $(9.78 \mathrm{~mL}, 92 \mathrm{mmol})$ and diethyl ethoxymethylene malonate $(18.53 \mathrm{~mL}$, $92 \mathrm{mmol})$ were allowed to heat in Dowtherm A $(200 \mathrm{~mL})$ to $255^{\circ} \mathrm{C}$. After 20 minutes at this temperature, the reaction was removed from the heat. Upon cooling, the reaction mixture was diluted with hexanes, and the solid was recovered by vacuum filtration, rinsing with hexanes followed by acetone (an off-white powder, $19.53 \mathrm{~g}, 92 \%$ ).

3-carboxy-8-methoxy-4-quinolone (Price, 1946; Burckhalter, 1948)<smiles>Cc1cccc2c(=O)c(C(=O)O)c[nH]c12</smiles>

3-carbethoxy-8-methyl-4-quinolone from the above reaction (19.53 g) was allowed to heat in $10 \%$ sodium hydroxide $(215 \mathrm{~mL})$ at reflux for 18 hours. After cooling, the reaction mixture was diluted to $600 \mathrm{~mL}$ and made acidic by the addition of concentrated muriatic acid. The resulting precipitate was recovered by vacuum filtration and allowed to air dry (15.77 g, containing residual water). 
<smiles>Cc1cccc2c(=O)cc[nH]c12</smiles>

3-carboxy-8-methyl-4-quinolone from the above reaction $(15.77 \mathrm{~g}$, presumed to contain residual water) was allowed to heat in Dowtherm $\mathrm{A}(175 \mathrm{~mL})$ to $255^{\circ} \mathrm{C}$, at which temperature it was allowed to remain for 25 minutes. Upon cooling, the reaction mixture was diluted with hexanes and the solid material was recovered by vacuum filtration (a gray powder, $13.82 \mathrm{~g}$ ). This material was used without purification in the ensuing reaction.

${ }^{1} \mathrm{H}$ NMR $\delta(\mathrm{ppm})\left(\mathrm{DMSO}_{\mathrm{d}}\right): 11.09(1 \mathrm{H}, \mathrm{s}), 7.96(1 \mathrm{H}, \mathrm{d}, \mathrm{J}=8.12 \mathrm{~Hz}), 7.82(1 \mathrm{H}, \mathrm{dd}, \mathrm{J}$ $=7.41,6.09 \mathrm{~Hz}), 7.49(1 \mathrm{H}, \mathrm{d}, \mathrm{J}=7.13 \mathrm{~Hz}), 7.21(1 \mathrm{H}, \mathrm{t}, \mathrm{J}=7.61 \mathrm{~Hz}), 6.06(1 \mathrm{H}, \mathrm{d}, \mathrm{J}=$ $7.39 \mathrm{~Hz}), 2.48(3 \mathrm{H}, \mathrm{s})$.

4-chloro-8-methylquinoline (Price, 1946; Burckhalter, 1948)<smiles>Cc1cccc2c(Cl)ccnc12</smiles>

8-methyl-4-quinolone (13.82 g, no more than $84 \mathrm{mmol}$ ) and phosphorus oxychloride (40 $\mathrm{mL}, 430 \mathrm{mmol}$ ) were allowed to heat at $110^{\circ} \mathrm{C}$ for 3 hours. After cooling, the reaction mixture was poured cautiously onto ice. After resting, the mixture was made basic by the addition of solid caustic potash (end volume $1.4 \mathrm{~L}$ ), followed by extraction with chloroform $(100 \mathrm{~mL}$, followed by $3 \times 50 \mathrm{~mL})$. The pooled chloroform layers were dried over magnesium sulfate and evaporated under reduced pressure with warming to provide a cream-colored solid $\left(12.35 \mathrm{~g}, 76 \%\right.$ from para-toluidine, $\mathrm{mp}=96.3-97.2^{\circ} \mathrm{C}\left(\right.$ lit. $99^{\circ} \mathrm{C}$; Burckhalter, 1948).

${ }^{1} \mathrm{H}$ NMR $\delta(\mathrm{ppm})\left(\mathrm{CHCl}_{3}-\mathrm{d}\right): 8.80(1 \mathrm{H}, \mathrm{d}, \mathrm{J}=4.66 \mathrm{~Hz}), 8.11(1 \mathrm{H}, \mathrm{dd}, \mathrm{J}=8.43,1.35 \mathrm{~Hz})$, $7.63(1 \mathrm{H}, \mathrm{dd}, \mathrm{J}=7.02,1.33 \mathrm{~Hz}), 7.54(1 \mathrm{H}, \mathrm{dd}, \mathrm{J}=8.40,7.06 \mathrm{~Hz}), 7.50(1 \mathrm{H}, \mathrm{d}, \mathrm{J}=4.66$ $\mathrm{Hz}), 2.82$ (3 H, s). 


\section{3-(8-methylquinolin-4-ylamino)propanol}<smiles>Cc1cccc2c(NCCCO)ccnc12</smiles>

4-chloro-8-methylquinoline (4.00 g, $1.9 \mathrm{mmol})$ and 3-amino-1-propanol (10.33 mL, 140 mmol) were heated at $90^{\circ} \mathrm{C}$ for 9 days in a Carius vessel, at the end of which time TLC indicated that the reaction had gone to completion. The hot reaction mixture was poured into water $(200 \mathrm{~mL})$, and after standing 1 hour the resulting precipitate was recovered by vacuum filtration, followed by air-drying and recrystallization from ethyl acetate to provide the desired compound as golden tan crystals (4.58 g, 92\%).

${ }^{1} \mathrm{H}$ NMR $\delta(\mathrm{ppm})\left(\mathrm{DMSO}_{-} \mathrm{d}_{6}\right): 8.41(1 \mathrm{H}, \mathrm{d}, \mathrm{J}=5.28 \mathrm{~Hz}), 8.01(1 \mathrm{H}, \mathrm{d}, \mathrm{J}=8.46 \mathrm{~Hz}), 7.46$ $(1 \mathrm{H}, \mathrm{d}, \mathrm{J}=6.93 \mathrm{~Hz}), 7.28(1 \mathrm{H}, \mathrm{dd}, \mathrm{J}=8.44,6.93 \mathrm{~Hz}), 7.05(1 \mathrm{H}$, br t, $\mathrm{J}=5.39 \mathrm{~Hz}), 6.46$ $(1 \mathrm{H}, \mathrm{d}, \mathrm{J}=5.34 \mathrm{~Hz}), 4.59(1 \mathrm{H}, \mathrm{t}, \mathrm{J}=5.05 \mathrm{~Hz}), 3.55(2 \mathrm{H}, \mathrm{m}), 3.32$ (water signal overlaps $\mathrm{m}, \sim 2 \mathrm{H}), 2.61(3 \mathrm{H}, \mathrm{s}), 1.78-1.86(2 \mathrm{H}, \mathrm{m})$.

\section{3-(8-methylquinolin-4-ylamino)propyl methanesulfonate}<smiles>COCCCNc1ccnc2c(C)cccc12</smiles>

3-(8-methylquinolin-4-ylamino)propanol (1.00 g, $4.6 \mathrm{mmol})$ and triethylamine $(1.0 \mathrm{~mL}$, $7.2 \mathrm{mmol})$ in dry tetrahydrofuran $(100 \mathrm{~mL})$ were cooled to below $0^{\circ} \mathrm{C}$ on ice/salt, and methanesulfonyl chloride $(0.42 \mathrm{~mL}, 5.4 \mathrm{mmol})$ was gradually added. After stirring for 2 hours on ice, TLC indicated that the reaction had not gone to completion. Additional triethylamine $(0.40 \mathrm{~mL}, 2.9 \mathrm{mmol})$ and methanesulfonyl chloride $(0.20 \mathrm{~mL}, 2.6 \mathrm{mmol})$ were therefore added. After stirring for a further hour, TLC indicated that reaction was complete. The reaction mixture was diluted with ethyl acetate $(50 \mathrm{~mL})$ and rinsed with saturated sodium bicarbonate $(50 \mathrm{~mL})$, followed by extraction of the aqueous layer by further ethyl acetate $(3 \times 10 \mathrm{~mL})$. The pooled organic extracts were washed with brine 
$(10 \mathrm{~mL})$, dried over magnesium sulfate, and evaporated under reduced pressure with warming to yield an off-white, crystalline solid (1.00 g, 74\%).

${ }^{1} \mathrm{H}$ NMR $\delta(\mathrm{ppm})\left(\mathrm{DMSO}_{-} \mathrm{d}_{6}\right): 8.43(1 \mathrm{H}, \mathrm{d}, \mathrm{J}=5.27 \mathrm{~Hz}), 8.03(1 \mathrm{H}, \mathrm{d}, \mathrm{J}=8.49 \mathrm{~Hz}), 7.48$ $(1 \mathrm{H}, \mathrm{d}, \mathrm{J}=6.92 \mathrm{~Hz}), 7.30(1 \mathrm{H}, \mathrm{dd}, \mathrm{J}=8.45,6.93 \mathrm{~Hz}), 7.10(1 \mathrm{H}, \mathrm{br} \mathrm{t}, \mathrm{J}=5.43 \mathrm{~Hz}), 6.50$ $(1 \mathrm{H}, \mathrm{d}, \mathrm{J}=5.32 \mathrm{~Hz}), 4.35(2 \mathrm{H}, \mathrm{t}, \mathrm{J}=6.20 \mathrm{~Hz}$ ), 3.39-3.41 (water signal overlaps $\mathrm{m}, \sim 2$ $\mathrm{H}), 3.19(3 \mathrm{H}, \mathrm{s}), 2.08(2 \mathrm{H}$, apparent p, $\mathrm{J}=6.60 \mathrm{~Hz})$.

\section{PL394: N-(3-(4-benzhydrylpiperazin-1-yl)propyl)-8-methylquinolin-4-amine}<smiles>Cc1cccc2c(NCCCN3CCN(C(c4ccccc4)c4ccccc4)CC3)ccnc12</smiles>

3-(8-quinolin-4-ylamino)propyl methanesulfonate (0.50 g, $1.7 \mathrm{mmol})$, 1-

benzyhydrylpiperazine $(0.44 \mathrm{~g}, 1.7 \mathrm{mmol})$, potassium carbonate $(0.35 \mathrm{~g}, 2.5 \mathrm{mmol})$, and a catalytic amount of potassium iodide were heated at reflux in anhydrous acetonitrile (50 $\mathrm{mL}$ ) for 24 hours, whereupon TLC indicated that reaction was complete. The solvent was removed under reduced pressure with warming, and the residue was partitioned between chloroform $(50 \mathrm{~mL})$ and water $(50 \mathrm{~mL})$, followed by extraction of the aqueous layer with additional chloroform $(3 \times 10 \mathrm{~mL})$. The pooled organic layers were dried over magnesium sulfate and evaporated under reduced pressure with warming. The resulting amber oil was crystallized from ethyl acetate (initially taken up in $20 \mathrm{~mL}$, then allowed to evaporate to $10 \mathrm{~mL}$ at room temperature). The desired product was obtained as glittering, colorless crystals $\left(0.55 \mathrm{~g}, 72 \%, \mathrm{mp}=154.3-156.0^{\circ} \mathrm{C}\right)$.

${ }^{1} \mathrm{H}$ NMR $\delta(\mathrm{ppm})\left(\mathrm{CHCl}_{3}-\mathrm{d}\right): 8.56(1 \mathrm{H}, \mathrm{d}, \mathrm{J}=5.26 \mathrm{~Hz}), 7.76(1 \mathrm{H}, \mathrm{d}, \mathrm{J}=8.44 \mathrm{~Hz}), 7.50$ $(1 \mathrm{H}, \mathrm{d}, \mathrm{J}=6.98 \mathrm{~Hz}), 7.42-7.47$ (4 H, m), 7.26-7.34 (5 H, m), 7.18-7.26 (3 H, m), 6.34 (1 $\mathrm{H}, \mathrm{d}, \mathrm{J}=5.31 \mathrm{~Hz}), 4.33(1 \mathrm{H}, \mathrm{s}), 3.35(2 \mathrm{H}, \mathrm{td}, \mathrm{J}=5.87,4.20 \mathrm{~Hz}), 2.77(3 \mathrm{H}, \mathrm{s}), 2.53-2.62$ $(10 \mathrm{H}$, br s overlaps $\mathrm{t}, \mathrm{J}=5.84 \mathrm{~Hz}), 1.92(2 \mathrm{H}$, apparent $\mathrm{p}, \mathrm{J}=5.55 \mathrm{~Hz})$.

${ }^{13} \mathrm{C} \mathrm{NMR} \delta(\mathrm{ppm})\left(\mathrm{CHCl}_{3}\right.$-d): 150.8, 150.0, 147.4, 142.4, 137.2, 129.1, 128.5, 128.0, $127.0,123.6,118.8,118.8,98.2,76.5,58.7,53.9,51.9,44.4,23.7,18.9$.

MS (ESI): $m / z$ 451.28600 M + H (calculated 451.28562)

HPLC (method A) $t_{\mathrm{R}}=10.45 \min (98 \%$ pure $)$. 


\section{PL393: 8-methyl-N-(3-(4-(pyridin-2-yl)piperazin-1-yl)propyl)quinolin-4-amine}

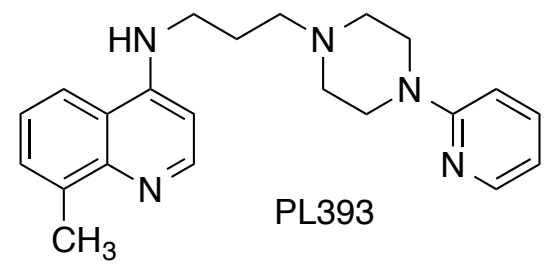

3-(8-quinolin-4-ylamino)propyl methanesulfonate (0.50 g, $1.7 \mathrm{mmol}), \mathrm{N}-(2-$ pyridyl)piperazine $(0.32 \mathrm{~g}, 1.9 \mathrm{mmol})$, potassium carbonate $(0.35 \mathrm{~g}, 2.5 \mathrm{mmol})$, and a catalytic amount of potassium iodide were heated at reflux in anhydrous acetonitrile (50 $\mathrm{mL}$ ) for 5 days. TLC then indicated that reaction was complete. The reaction mixture was diluted with water $(5 \mathrm{~mL})$ followed by evaporation of the solvent under reduced pressure with heating, and the residue was partitioned between chloroform $(50 \mathrm{~mL})$ and water $(50 \mathrm{~mL})$, followed by extraction of the aqueous layer with additional chloroform (3 $\mathrm{x} 10 \mathrm{~mL}$ ). The pooled organic layers were dried over magnesium sulfate and evaporated under reduced pressure with warming. The residue was taken up in boiling ethyl acetate $(30 \mathrm{~mL})$ and allowed to evaporate gradually to $10 \mathrm{~mL}$ at room temperature. Vacuum filtration afforded the desired product as large, colorless crystals $(0.37 \mathrm{~g}, 60 \%, \mathrm{mp}=$ $\left.175.5-177.5^{\circ} \mathrm{C}\right)$.

${ }^{1} \mathrm{H}$ NMR $\delta(\mathrm{ppm})\left(\mathrm{CHCl}_{3}-\mathrm{d}\right): 8.59(1 \mathrm{H}, \mathrm{d}, \mathrm{J}=5.26 \mathrm{~Hz}), 8.23-8.23(1 \mathrm{H}, \mathrm{m}), 7.73(1 \mathrm{H}, \mathrm{d}$, $\mathrm{J}=8.44 \mathrm{~Hz}), 7.52(1 \mathrm{H}, \mathrm{ddd}, \mathrm{J}=8.54,7.16,2.02 \mathrm{~Hz}), 7.44(1 \mathrm{H}, \mathrm{d}, \mathrm{J}=6.98 \mathrm{~Hz}), 7.20(1$ $\mathrm{H}, \mathrm{dd}, \mathrm{J}=8.40,6.97 \mathrm{~Hz}), 7.05(1 \mathrm{H}, \mathrm{t}, \mathrm{J}=4.29 \mathrm{~Hz}), 6.66-6.67(2 \mathrm{H}, \mathrm{m}), 6.39(1 \mathrm{H}, \mathrm{d}, \mathrm{J}=$ $5.30 \mathrm{~Hz}), 3.68(4 \mathrm{H}, \mathrm{m}), 3.41(2 \mathrm{H}, \mathrm{td}, \mathrm{J}=6.01,4.37 \mathrm{~Hz}), 2.75(3 \mathrm{H}, \mathrm{s}), 2.65-2.66(6 \mathrm{H}$, $\mathrm{m}), 1.99(2 \mathrm{H}$, apparent $\mathrm{p}, \mathrm{J}=5.75 \mathrm{~Hz})$.

${ }^{13} \mathrm{C} \mathrm{NMR} \delta(\mathrm{ppm})\left(\mathrm{CHCl}_{3}-\mathrm{d}\right): 159.5,150.7,150.0,148.1,147.5,137.6,137.3,129.2$, $123.9,118.8,118.2,113.6,107.1,98.4,58.6,53.5,45.3,44.1,24.0,18.9$.

MS (ESI): $m / z$ 362.23440 M + H (calculated 362.23392)

HPLC (method A) $t_{\mathrm{R}}=4.42 \min (99 \%$ pure $)$. 


\section{A.6: Methoxyquinolines}

\section{A.6.1: 6-Methoxyquinolines}

3-carbethoxy-6-methoxy-4-quinolone (Price, 1946; Ramsey, 1947)<smiles>CCOC(=O)c1c[nH]c2ccc(OC)cc2c1=O</smiles>

para-Anisidine (12.32 g, $100 \mathrm{mmol})$, diethyl ethoxymethylene malonate (21.68 g, 100 $\mathrm{mmol})$, and Dowtherm A $(100 \mathrm{~mL})$ were heated to reflux, at which temperature the reaction was allowed to remain for 30 minutes. Upon cooling, the reaction mixture was diluted with hexanes and vacuum filtered, rinsing with further hexanes, followed by acetone. This afforded a tan, powdery solid (15.08 g, 61\%).

3-carboxy-6-methoxy-4-quinolone (Price, 1946; Ramsey, 1947)<smiles>COc1ccc2[nH]cc(C(=O)O)c(=O)c2c1</smiles>

3-carboxy-6-methoxy-4-quinolone $(15.08 \mathrm{~g}, 61 \mathrm{mmol})$ was heated for 5 hours in refluxing $10 \%$ caustic soda $(250 \mathrm{~mL})$. The hot reaction mixture was poured into $300 \mathrm{~mL}$ water and made acidic by the addition of concentrated muriatic acid. After standing 20 hours, vacuum filtration afforded 3-carboxy-6-methoxy-4-quinolone as a white, powdery solid (13.30 g, $\sim 100 \%)$.

${ }^{1} \mathrm{H}$ NMR $\delta(\mathrm{ppm})\left(\mathrm{DMSO}_{\mathrm{d}}\right): 15.55(1 \mathrm{H}, \mathrm{s}), 13.43(1 \mathrm{H}, \mathrm{s}), 8.83(1 \mathrm{H}, \mathrm{s}), 7.80(1 \mathrm{H}, \mathrm{d}, \mathrm{J}$ $=9.08 \mathrm{~Hz}), 7.65(1 \mathrm{H}, \mathrm{d}, \mathrm{J}=2.91 \mathrm{~Hz}), 7.54(1 \mathrm{H}, \mathrm{dd}, \mathrm{J}=9.07,2.92 \mathrm{~Hz}), 3.91(3 \mathrm{H}, \mathrm{s})$. 
6-methoxy-4-quinolone (Price, 1946; Ramsey, 1947)<smiles>COc1ccc2[nH]ccc(=O)c2c1</smiles>

3-carbethoxy-6-methoxy-4-quinolone (13.30 g, $61 \mathrm{mmol})$ was heated in $100 \mathrm{~mL}$ refluxing Dowtherm A for 40 minutes. Upon cooling, the reaction mixture was diluted with $100 \mathrm{~mL}$ hexanes and vacuum filtered, rinsing with additional hexanes followed by acetone. This afforded 6-methoxy-4-quinolone as an off-white solid (10.30 g, 97\%).

4-chloro-6-methoxyquinoline (Price, 1946; Ramsey, 1947)<smiles>COc1ccc2nccc(Cl)c2c1</smiles>

6-methoxy-4-quinolone (10.30 g, $59 \mathrm{mmol})$ was heated in phosphorus oxychloride (40 $\mathrm{mL}, 43 \mathrm{mmol}$ ) at $110^{\circ} \mathrm{C}$ for 2.5 hours. After cooling, the dark reaction mixture was poured gradually onto ice with vigorous stirring. After standing overnight, the mixture was made basic by the gradual addition of solid caustic potash. The resulting aqueous mixture was extracted with chloroform $(150 \mathrm{~mL}$, followed by $5 \times 20 \mathrm{~mL})$, and the pooled organic layers were dried $\left(\mathrm{MgSO}_{4}\right)$ and evaporated under reduced pressure with warming to yield a dark brown, crystalline solid with a pronounced odor of Dowtherm A. This was taken up in boiling hexanes and decanted from an insoluble black residue, which was twice rinsed with boiling hexanes; the pooled hexanes were returned to a boil and concentrated to $50 \mathrm{~mL}$. Upon cooling, the product was recovered as gleaming, pale caramel-colored needles $\left(6.93 \mathrm{~g}, 61 \%, \mathrm{mp}=79.1-79.9^{\circ} \mathrm{C}\right.$ (lit. 77-79 ${ }^{\circ} \mathrm{C}$; Ramsey, 1947)). 


\section{3-(6-methoxyquinolin-4-ylamino)propanol}

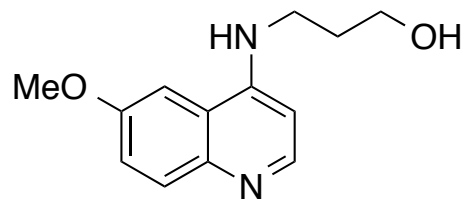

6-methoxy-4-chloroquinoline (2.94 g, $15 \mathrm{mmol})$ and 3-amino-1-propanol (6.97 mL, 91 mmol) were heated at $80^{\circ} \mathrm{C}$ in a Carius vessel for 48 hours. TLC indicated that the reaction was not complete. The temperature was increased to $120^{\circ} \mathrm{C}$ and heating was continued for one hour, following which the reaction was poured without cooling into water $(100 \mathrm{~mL})$, stirring well. An oil separated. After standing 24 hours, the resulting mixture was extracted with dichloromethane $(200 \mathrm{~mL})$. The dichloromethane layer was washed with water $(3 \times 20 \mathrm{~mL})$. After drying over $\mathrm{MgSO}_{4}$ and evaporation under reduced pressure with warming, the resulting yellow oil was taken up in boiling ethyl acetate and allowed to evaporate slowly at room temperature for several days. Filtration afforded the desired product as tan crystals $\left(0.42 \mathrm{~g}, 12 \%, \mathrm{mp}=140.2-141.6^{\circ} \mathrm{C}\right)$.

${ }^{1} \mathrm{H}$ NMR $\delta(\mathrm{ppm})\left(\mathrm{DMSO}_{-} \mathrm{d}_{6}\right): 8.26(1 \mathrm{H}, \mathrm{d}, \mathrm{J}=5.25 \mathrm{~Hz}), 7.69(1 \mathrm{H}, \mathrm{d}, \mathrm{J}=9.11 \mathrm{~Hz}), 7.54$ $(1 \mathrm{H}, \mathrm{d}, \mathrm{J}=2.76 \mathrm{~Hz}), 7.24(1 \mathrm{H}, \mathrm{dd}, \mathrm{J}=9.11,2.71 \mathrm{~Hz}), 6.97(1 \mathrm{H}, \mathrm{t}, \mathrm{J}=5.43 \mathrm{~Hz}), 6.41(1$ $\mathrm{H}, \mathrm{d}, \mathrm{J}=5.32 \mathrm{~Hz}), 4.60(1 \mathrm{H}, \mathrm{t}, \mathrm{J}=5.03 \mathrm{~Hz}), 3.88(3 \mathrm{H}, \mathrm{s}), 3.56(2 \mathrm{H}, \mathrm{q}, \mathrm{J}=5.61 \mathrm{~Hz})$, 3.34 (water overlaps $\mathrm{m}, \sim 2 \mathrm{H}), 1.83(2 \mathrm{H}$, apparent $\mathrm{p}, \mathrm{J}=6.73 \mathrm{~Hz}$ ).

${ }^{1} \mathrm{H}$ NMR $\delta(\mathrm{ppm})\left(\mathrm{CHCl}_{3}-\mathrm{d}\right): 8.43(1 \mathrm{H}, \mathrm{d}, \mathrm{J}=5.25 \mathrm{~Hz}), 7.89(1 \mathrm{H}, \mathrm{d}, \mathrm{J}=9.17 \mathrm{~Hz}), 7.26$ (solvent signal may overlap s, 1 H), $6.94(1 \mathrm{H}, \mathrm{d}, \mathrm{J}=2.71 \mathrm{~Hz}), 6.39(1 \mathrm{H}, \mathrm{d}, \mathrm{J}=5.28$ $\mathrm{Hz}), 5.59(1 \mathrm{H}, \mathrm{s}), 3.96(2 \mathrm{H}, \mathrm{t}, \mathrm{J}=5.50 \mathrm{~Hz}), 3.89(3 \mathrm{H}, \mathrm{s}), 3.48(2 \mathrm{H}, \mathrm{td}, \mathrm{J}=6.26,4.93$ $\mathrm{Hz}), 2.05(2 \mathrm{H}$, apparent $\mathrm{p}, \mathrm{J}=5.84 \mathrm{~Hz})$.

Note: No further compounds were successfully made from this material. For the 3(quinolin-4-ylamino)propanol compounds containing a methoxy substituent, the mesylation reaction that had been used successfully with other compounds of this type did not work well. After many attempts using various solvents, temperatures, and repeated additions of methanesulfonyl chloride and triethylamine, it was discovered that the optimal method was to work up the partially complete reaction and use the crude mixture in the next step. The unreacted 3-(quinolin-4-ylamino)propanol could then be removed by chromatography. Reversed chloroquine type compounds were made from the 7- and 8-methoxy substituted 3-(quinolin-4-ylamino)propanol using this method, but time did not permit a 6-methoxy analogue to be made. 


\section{A.6.2: 7-Methoxyquinolines}

3-carbethoxy-7-methoxy-4-quinolone (Price, 1946; Lauer, 1946)<smiles>CCOC(=O)c1c[nH]c2cc(OC)ccc2c1=O</smiles>

meta-Anisidine (9.05 g, $74 \mathrm{mmol})$, diethyl ethoxymethylene malonate (14.73 mL, 74 $\mathrm{mmol}$ ), and $75 \mathrm{~mL}$ Dowtherm A were heated to $255^{\circ} \mathrm{C}$. After remaining at this temperature for 25 minutes, the reaction was removed from the heat. Upon cooling, the reaction mixture was filtered, rinsing with 3 small portions of Dowtherm A, followed by hexanes and finally, acetone. This afforded the desired product as a tan, powdery solid, with no trace of the 5-methoxy regioisomer $(10.57 \mathrm{~g}, 58 \%)$. The absence of the 5methoxy regioisomer in the product of this reaction has been reported previously (Lauer, 1946).

${ }^{1} \mathrm{H}$ NMR $\delta(\mathrm{ppm})\left(\right.$ DMSO-d $\left._{6}\right): 12.10(1 \mathrm{H}, \mathrm{s}), 8.48(1 \mathrm{H}, \mathrm{s}), 8.05(1 \mathrm{H}, \mathrm{dd}, \mathrm{J}=8.13,1.66$ $\mathrm{Hz}), 6.98-7.03(2 \mathrm{H}, \mathrm{m}), 4.20(2 \mathrm{H}, \mathrm{q}, \mathrm{J}=7.10 \mathrm{~Hz}), 3.87(3 \mathrm{H}, \mathrm{s}), 1.27$ (3 H, t, J = 7.10 $\mathrm{Hz})$.

3-carboxy-7-methoxy-4-quinolone (Price, 1946; Lauer, 1946)<smiles>COc1ccc2c(=O)c(C(=O)O)c[nH]c2c1</smiles>

3-carbethoxy-7-methoxy-4-quinolone $(10.57 \mathrm{~g}, 43 \mathrm{mmol})$ in $20 \%$ caustic soda $(250 \mathrm{~mL})$ was heated at $80^{\circ} \mathrm{C}$ for 18 hours, followed by 1 hour at reflux. Upon cooling to room temperature, the reaction mixture was poured into water $(300 \mathrm{~mL})$ and acidified by the addition of concentrated muriatic acid. After cooling, the resulting white solid was recovered by vacuum filtration, followed by air-drying. This material was used without further drying in the following reaction. 
7-methoxy-4-quinolone (Price, 1946; Lauer, 1946)<smiles>COc1ccc2c(=O)cc[nH]c2c1</smiles>

3-carboxy-7-methoxy-4-quinolone (containing residual water) was heated for 25 minutes at $255^{\circ} \mathrm{C}$ in Dowtherm A. Upon cooling, the reaction mixture was diluted with hexanes $(100 \mathrm{~mL})$ and vacuum filtered, rinsing with further hexanes; the resulting solid was then allowed to reflux in hexanes $(100 \mathrm{~mL})$ for 1 hour. Filtration afforded the desired product as a beige solid $(7.56 \mathrm{~g})$.

${ }^{1} \mathrm{H}$ NMR $\delta(\mathrm{ppm})\left(\mathrm{DMSO}_{\mathrm{d}}\right)$ : $11.60(1 \mathrm{H}, \mathrm{s}), 7.98(1 \mathrm{H}, \mathrm{d}, \mathrm{J}=8.82 \mathrm{~Hz}), 7.80(1 \mathrm{H}, \mathrm{t}, \mathrm{J}=$ $6.33 \mathrm{~Hz}), 6.90-6.91(2 \mathrm{H}, \mathrm{m}), 5.94(1 \mathrm{H}, \mathrm{d}, \mathrm{J}=7.40 \mathrm{~Hz}), 3.85(3 \mathrm{H}, \mathrm{s})$.

4-chloro-7-methoxyquinoline (Price, 1946; Lauer, 1946)<smiles>COc1ccc2c(Cl)ccnc2c1</smiles>

7-methoxy-4-quinolone $(7.56 \mathrm{~g}, 43 \mathrm{mmol})$ was heated at $100^{\circ} \mathrm{C}$ for 2.5 hours in phosphorus oxychloride $(50 \mathrm{~mL}, 540 \mathrm{mmol})$. TLC then indicated that reaction was complete. After cooling, the reaction mixture was poured gradually onto ice with vigorous stirring. After standing, the mixture was basified by the gradual addition of $50 \%$ caustic soda. The resulting aqueous mixture was diluted to $800 \mathrm{~mL}$ with water and divided into three portions, each of which was extracted with chloroform $(100 \mathrm{~mL}$, followed by $5 \times 20 \mathrm{~mL}$ ). The pooled organic layers from all three extractions were dried $\left(\mathrm{MgSO}_{4}\right)$ and evaporated under reduced pressure with warming to yield the desired product as a beige solid $\left(6.58 \mathrm{~g}, 79 \%, \mathrm{mp}=87.1-88.4^{\circ} \mathrm{C}\right.$ (lit. $82-83^{\circ} \mathrm{C}$; Lauer, 1946)).

${ }^{1} \mathrm{H}$ NMR $\delta(\mathrm{ppm})\left(\mathrm{CHCl}_{3}-\mathrm{d}\right): 8.70(1 \mathrm{H}, \mathrm{d}, \mathrm{J}=4.79 \mathrm{~Hz}), 8.12(1 \mathrm{H}, \mathrm{d}, \mathrm{J}=9.22 \mathrm{~Hz}), 7.43$ $(1 \mathrm{H}, \mathrm{d}, \mathrm{J}=2.55 \mathrm{~Hz}), 7.35(1 \mathrm{H}, \mathrm{d}, \mathrm{J}=4.79 \mathrm{~Hz}), 7.29(1 \mathrm{H}, \mathrm{dd}, \mathrm{J}=9.23,2.55 \mathrm{~Hz}), 3.97(3$ $\mathrm{H}, \mathrm{s})$. 


\section{3-(7-methoxyquinolin-4-ylamino)propanol}<smiles>COc1ccc2c(NCCCO)ccnc2c1</smiles>

7-methoxy-4-chloroquinoline (3.25 g, $16.8 \mathrm{mmol})$ and 3-amino-1-propanol (7.73 $\mathrm{mL}$, $101 \mathrm{mmol}$ ) were heated at $90^{\circ} \mathrm{C}$ in a Carius tube for 3 days. TLC indicated that no quinoline starting material remained, and the reaction was therefore poured without cooling into $200 \mathrm{~mL}$ water, stirring well. After standing for 30 minutes, the resulting precipitate was isolated by vacuum filtration as a beige, sparkling solid. This material was recrystallized from 9:1 ethyl acetate:ethanol $(20 \mathrm{~mL})$ to give a beige, crystalline solid $\left(3.32 \mathrm{~g}, 85 \%, \mathrm{mp}=147.8-148.5^{\circ} \mathrm{C}\right)$.

${ }^{1} \mathrm{H}$ NMR $\delta(\mathrm{ppm})\left(\mathrm{CHCl}_{3}-\mathrm{d}\right): 8.45(1 \mathrm{H}, \mathrm{d}, \mathrm{J}=5.39 \mathrm{~Hz}), 7.59(1 \mathrm{H}, \mathrm{d}, \mathrm{J}=9.17 \mathrm{~Hz}), 7.30$ $(1 \mathrm{H}, \mathrm{d}, \mathrm{J}=2.64 \mathrm{~Hz}), 7.03(1 \mathrm{H}, \mathrm{dd}, \mathrm{J}=9.15,2.64 \mathrm{~Hz}), 6.31(1 \mathrm{H}, \mathrm{d}, \mathrm{J}=5.41 \mathrm{~Hz}), 5.74(1$ $\mathrm{H}, \mathrm{s}), 3.95(2 \mathrm{H}, \mathrm{t}, \mathrm{J}=5.50 \mathrm{~Hz}), 3.91(3 \mathrm{H}, \mathrm{s}), 3.46-3.47$ (2 H, m), 1.99-2.07 (2 H, m).

\section{3-(7-methoxyquinolin-4-ylamino)propyl methanesulfonate}<smiles>COCCCNc1ccnc2cc(OC)ccc12</smiles>

3-(7-methoxyquinolin-4-ylamino)propanol (0.60 g, $2.6 \mathrm{mmol})$ was dissolved in anhydrous THF $(100 \mathrm{~mL})$, and triethylamine $(0.36 \mathrm{~mL}, 2.6 \mathrm{mmol})$ was added. The solution was cooled to $10^{\circ} \mathrm{C}$, and methanesulfonyl chloride $(0.20 \mathrm{~mL}, 2.6 \mathrm{mmol})$ was added dropwise. After 50 minutes, the reaction mixture was diluted with ethyl acetate $(50 \mathrm{~mL})$ and washed with saturated sodium bicarbonate $(100 \mathrm{~mL})$. The aqueous layer was extracted with additional ethyl acetate $(3 \times 10 \mathrm{~mL})$, and the pooled organic layers were rinsed with brine $(15 \mathrm{~mL})$, dried over magnesium sulfate, and evaporated under reduced pressure with warming to yield a yellow oil. This material contained approximately $50 \%$ unreacted starting material by NMR, but was used without further purification in the ensuing reaction (for reasons noted previously; see the synthesis of 3(6-methoxyquinolin-4-ylamino)propanol). 


\section{PL391: 7-methoxy- $N$-(3-(4-(pyridin-2-yl)piperazin-1-yl)propyl)quinolin-4-amine}

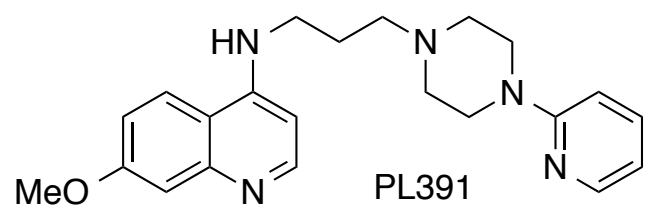

3-(7-methoxyquinolin-4-ylamino)propyl methanesulfonate (impure product from the above reaction, containing no more than $2.6 \mathrm{mmol}$ quinoline material), 1-(2-

pyridyl)piperazine $(0.44 \mathrm{~g}, 2.7 \mathrm{mmol})$, potassium carbonate $(0.53 \mathrm{~g}, 3.9 \mathrm{mmol})$, and a catalytic amount of potassium iodide were heated at reflux in acetonitrile $(22 \mathrm{~mL})$ for 18 hours. The solvent was then removed under reduced pressure with warming, and the residue was partitioned between chloroform $(40 \mathrm{~mL})$ and water $(40 \mathrm{~mL})$. After separation, the aqueous layer was extracted with additional chloroform $(3 \times 10 \mathrm{~mL})$, and the pooled organic layers were rinsed with brine $(10 \mathrm{~mL})$ and dried over magnesium sulfate. The dried solution was partially evaporated under reduced pressure with warming, followed by adsorption onto basic alumina. Flash chromatography was performed with basic alumina as the stationary phase, eluting with a gradient of $100 \%$ hexanes to 35/65 hexanes/ethyl acetate (v/v) over 55 minutes; NMR indicated that the product-containing fractions also contained unreacted 1-(2-pyridyl)piperazine. Flash chromatography on basic alumina was repeated, with a gradient of $100 \%$ hexanes to $80 \%$ hexanes $/ 20 \%$ ethyl acetate $(\mathrm{v} / \mathrm{v})$ over 45 minutes, increasing the proportion of ethyl acetate to $60 \%$ over an additional 55 minutes. The desired product was then obtained as a colorless solid (0.06 g, 6\% yield from 3-(7-methoxyquinolin-4-ylamino)propanol, $\mathrm{mp}=$ 114.5-118.6 ${ }^{\circ} \mathrm{C}, \mathrm{R}_{\mathrm{f}}=0.4$ (basic alumina, 9/1 MeOH/EtOAc v/v)).

${ }^{1} \mathrm{H}$ NMR $\delta(\mathrm{ppm})\left(\mathrm{CHCl}_{3}-\mathrm{d}\right): 8.46(1 \mathrm{H}, \mathrm{d}, \mathrm{J}=5.37 \mathrm{~Hz}), 8.23-8.23(1 \mathrm{H}, \mathrm{m}), 7.75(1 \mathrm{H}, \mathrm{d}$, $\mathrm{J}=9.17 \mathrm{~Hz}), 7.52-7.52(1 \mathrm{H}, \mathrm{m}), 7.30(1 \mathrm{H}, \mathrm{d}, \mathrm{J}=2.62 \mathrm{~Hz}), 7.01(1 \mathrm{H}$, br t, J = 4.36 Hz), $6.94(1 \mathrm{H}, \mathrm{dd}, \mathrm{J}=9.13,2.63 \mathrm{~Hz}), 6.67-6.68(2 \mathrm{H}, \mathrm{m}), 6.29(1 \mathrm{H}, \mathrm{d}, \mathrm{J}=5.41 \mathrm{~Hz}), 3.89$ (3 $\mathrm{H}, \mathrm{s}), 3.67(4 \mathrm{H}, \mathrm{m}), 3.42(2 \mathrm{H}, \mathrm{td}, \mathrm{J}=6.01,4.36 \mathrm{~Hz}), 2.64-2.70(6 \mathrm{H}, \mathrm{m}), 1.96-2.01(2 \mathrm{H}$, $\mathrm{m})$.

${ }^{13} \mathrm{C} \mathrm{NMR} \delta(\mathrm{ppm})\left(\mathrm{CHCl}_{3}-\mathrm{d}\right): 160.2,159.4,151.6,150.5,150.3,148.1,137.7,121.6$, $116.6,113.7,113.5,108.2,107.1,97.4,58.5,55.4,53.5,45.4,44.0,24.0$.

MS (ESI): $m / z$ 378.22946 M + H (calculated 378.22884)

$\operatorname{HPLC}(\operatorname{method} \mathrm{A}) t_{\mathrm{R}}=5.50 \mathrm{~min}(98 \%$ pure $)$. 


\section{A.6.3: 8-Methoxyquinolines}

3-carbethoxy-8-methoxy-4-quinolone (Price, 1946; Lauer, 1946)<smiles>CCOC(=O)c1c[nH]c2c(OC)cccc2c1=O</smiles>

ortho-Anisidine (11.30 g, $92 \mathrm{mmol})$, diethyl ethoxymethylene malonate (18.40 mL, 92 $\mathrm{mmol}$ ), and $75 \mathrm{~mL}$ Dowtherm A were heated to reflux. After remaining at reflux for 20 minutes, the reaction was removed from the heat. Upon cooling, the reaction mixture was diluted with $75 \mathrm{~mL}$ hexanes and filtered, rinsing with further hexanes $(200 \mathrm{~mL})$ and acetone $(75 \mathrm{~mL})$. This afforded the desired product as a creamy white, crystalline solid.

${ }^{1} \mathrm{H}$ NMR $\delta(\mathrm{ppm})\left(\right.$ DMSO-d $\left._{6}\right): 11.92(1 \mathrm{H}, \mathrm{s}), 8.34(1 \mathrm{H}, \mathrm{s}), 7.71(1 \mathrm{H}, \mathrm{dd}, \mathrm{J}=7.36,2.00$ Hz), 7.31-7.37 (2 H, m), 4.21 (2 H, q, J = 7.10 Hz), 4.01 (3 H, s), 1.27 (3 H, t, J = 7.09 $\mathrm{Hz})$.

3-carboxy-8-methoxy-4-quinolone (Price, 1946; Lauer, 1946)<smiles>COc1cccc2c(=O)c(C(=O)O)c[nH]c12</smiles>

The above product was heated for 72 hours in $250 \mathrm{~mL}$ refluxing $10 \%$ caustic soda. The hot reaction mixture was poured into $300 \mathrm{~mL}$ water and acidified by the addition of concentrated hydrochloric acid. Vacuum filtration of the cooled solution afforded the desired product as a creamy white, powdery solid $(11.17 \mathrm{~g}, 0.0510 \mathrm{~mol}, 56 \%$ from two steps). 
8-methoxy-4-quinolone (Price, 1946; Lauer, 1946)<smiles>COc1cccc2c(=O)cc[nH]c12</smiles>

3-carboxy-8-methoxy-4-quinolone (11.17 g, $51 \mathrm{mmol})$ was heated for 1 hour in refluxing Dowtherm A. Upon cooling, a small sample was analyzed by NMR and it was determined that the reaction was no more than $50 \%$ complete. The reaction was therefore heated again at reflux for an additional hour. Upon cooling, dilution with $100 \mathrm{~mL}$ hexanes, and resting for 20 hours, the reaction mixture became a tarry, intractable block. Samples analyzed by NMR and GC/MS indicated that reaction was complete. The reaction mixture was briefly heated to $130^{\circ} \mathrm{C}$, whereupon it became liquid; after cooling to $50^{\circ} \mathrm{C}$, this was poured into a beaker and diluted with additional hexanes. After again resting for 20 hours, filtration afforded the product as a powdery, tan solid $(8.68 \mathrm{~g}, 97 \%)$.

4-chloro-8-methoxyquinoline (Price, 1946; Lauer, 1946)<smiles>COc1cccc2c(Cl)ccnc12</smiles>

8-methoxy-4-quinolone $(8.68 \mathrm{~g}, 50 \mathrm{mmol})$ was heated at $95^{\circ} \mathrm{C}$ for 20 hours in phosphorus oxychloride $(30 \mathrm{~mL}, 320 \mathrm{mmol})$. After cooling, the dark reaction mixture was poured gradually onto ice with vigorous stirring. The mixture was allowed to stand for 30 minutes, then made basic by the gradual addition of solid caustic potash. The resulting aqueous mixture was extracted with chloroform $(150 \mathrm{~mL}$, followed by $5 \times 20 \mathrm{~mL})$, and the pooled organic layers were dried $\left(\mathrm{MgSO}_{4}\right)$ and evaporated under reduced pressure with warming to yield a golden brown liquid that crystallized upon standing. This was recrystallized from a mixture of ethyl acetate and hexanes to yield a tan, crystalline solid (3.30 g, 0.0170 mol, 34\%, $\mathrm{mp}=81.8-82.6^{\circ} \mathrm{C}$ (lit. $79-80^{\circ} \mathrm{C}$; Lauer, 1946)).

${ }^{1} \mathrm{H}$ NMR $\delta(\mathrm{ppm})\left(\mathrm{CHCl}_{3}-\mathrm{d}\right): 8.79(1 \mathrm{H}, \mathrm{d}, \mathrm{J}=4.65 \mathrm{~Hz}), 7.81(1 \mathrm{H}, \mathrm{dd}, \mathrm{J}=8.54,1.13 \mathrm{~Hz})$, $7.57(1 \mathrm{H}, \mathrm{dd}, \mathrm{J}=8.53,7.80 \mathrm{~Hz}), 7.53(1 \mathrm{H}, \mathrm{d}, \mathrm{J}=4.65 \mathrm{~Hz}), 7.12(1 \mathrm{H}, \mathrm{dd}, \mathrm{J}=7.80,1.08$ $\mathrm{Hz}), 4.11(3 \mathrm{H}, \mathrm{s})$. 


\section{3-(8-methoxyquinolin-4-ylamino)propanol}

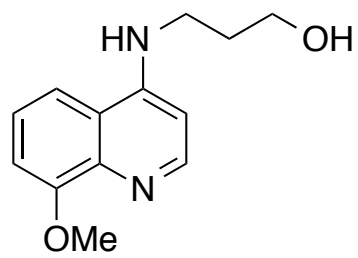

8-methoxy-4-chloroquinoline $(2.03 \mathrm{~g}, 0.0105 \mathrm{~mol})$ and 3-amino-1-propanol $(4.81 \mathrm{~mL}$, $0.0629 \mathrm{~mol}$ ) were heated at $90^{\circ} \mathrm{C}$ in a Carius tube for 48 hours. TLC indicated that no quinoline starting material remained, and the reaction was therefore poured without cooling into $150 \mathrm{~mL}$ water, stirring well. After standing for 24 hours, the resulting precipitate was isolated by vacuum filtration (water rinsing) as a dull yellow, sparkling solid; partial recrystallization from $95 \%$ ethyl acetate, $5 \%$ ethanol yielded the product as a sparkling, ochre solid $\left(1.95 \mathrm{~g}, 78 \%, \mathrm{mp}=170.6-171.4^{\circ} \mathrm{C}\right)$.

${ }^{1} \mathrm{H}$ NMR $\delta(\mathrm{ppm})\left(\mathrm{CHCl}_{3}\right.$-d): $8.57(1 \mathrm{H}, \mathrm{d}, \mathrm{J}=5.25 \mathrm{~Hz}), 7.30-7.33(2 \mathrm{H}, \mathrm{m}), 7.27$ (solvent

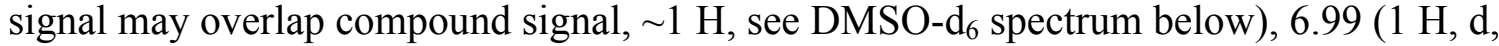
$\mathrm{J}=7.48 \mathrm{~Hz}), 6.46(1 \mathrm{H}, \mathrm{d}, \mathrm{J}=5.27 \mathrm{~Hz}), 5.73(1 \mathrm{H}, \mathrm{t}, \mathrm{J}=4.73 \mathrm{~Hz}), 4.05(3 \mathrm{H}, \mathrm{s}), 3.94$ (2 $\mathrm{H}, \mathrm{t}, \mathrm{J}=5.51 \mathrm{~Hz}), 3.47(2 \mathrm{H}, \mathrm{td}, \mathrm{J}=6.29,4.82 \mathrm{~Hz}), 2.04(2 \mathrm{H}$, apparent $\mathrm{p}, \mathrm{J}=5.87 \mathrm{~Hz})$.

${ }^{1} \mathrm{H}$ NMR $\delta(\mathrm{ppm})\left(\mathrm{DMSO}_{\mathrm{d}}\right): 8.33(1 \mathrm{H}, \mathrm{d}, \mathrm{J}=5.25 \mathrm{~Hz}), 7.69(1 \mathrm{H}, \mathrm{d}, \mathrm{J}=8.52 \mathrm{~Hz}), 7.31$ $(1 \mathrm{H}, \mathrm{t}, \mathrm{J}=8.10 \mathrm{~Hz}), 7.05(1 \mathrm{H}, \mathrm{d}, \mathrm{J}=7.70 \mathrm{~Hz}), 7.00(1 \mathrm{H}, \mathrm{t}, \mathrm{J}=5.37 \mathrm{~Hz}), 6.47(1 \mathrm{H}, \mathrm{d}, \mathrm{J}$ $=5.31 \mathrm{~Hz}), 4.61(1 \mathrm{H}, \mathrm{s}), 3.89(3 \mathrm{H}, \mathrm{s}), 3.55(2 \mathrm{H}, \mathrm{m}), 3.30-3.32$ (water signal overlaps $\mathrm{m}$, $\sim 2 \mathrm{H}), 1.82(2 \mathrm{H}$, apparent $\mathrm{p}, \mathrm{J}=6.64 \mathrm{~Hz})$.

MS (ESI): $m / z 233.12869 \mathrm{M}+\mathrm{H}$ (calculated 233.12845)

HPLC (method A) $t_{\mathrm{R}}=7.67 \min (95 \%$ pure $)$.

\section{3-(8-methoxyquinolin-4-ylamino)propyl methanesulfonate}<smiles>COCCCNc1ccnc2c(OC)cccc12</smiles> 
3-(8-methoxyquinolin-4-ylamino)propanol (0.40 g, $1.7 \mathrm{mmol})$ was dissolved in anhydrous THF $(100 \mathrm{~mL})$ by warming at $50^{\circ} \mathrm{C}$ in a flask equipped with a Vigreux condenser and calcium chloride drying tube. This solution was allowed to cool to room temperature, whereupon precipitation was observed. Triethylamine $(0.24 \mathrm{~mL}, 1.7 \mathrm{mmol})$ was added, followed by cooling to $7^{\circ} \mathrm{C}$ and addition of methanesulfonyl chloride $(0.13$ $\mathrm{mL}, 1.7 \mathrm{mmol})$. After 1 hour, TLC indicated that starting material remained; further methanesulfonyl chloride was added $(0.40 \mathrm{~mL}, 5.1 \mathrm{mmol})$. After a further hour, the reaction was sealed and stored at $8^{\circ} \mathrm{C}$ for 18 hours. The reaction mixture was then washed with saturated sodium bicarbonate $(75 \mathrm{~mL})$, followed by extraction of the aqueous layer with ethyl acetate $(3 \times 15 \mathrm{~mL})$. The pooled organic layers were rinsed with brine $(20 \mathrm{~mL})$, dried over magnesium sulfate, and evaporated under reduced pressure with warming to yield a yellow oil. This contained approximately $20 \%$ unreacted starting material by NMR. This material was used without further purification in the ensuing reaction (for reasons noted previously, see the synthesis of 3-(6-methoxyquinolin-4ylamino)propanol).

\section{PL390: 8-methoxy- $N$-(3-(4-(pyridin-2-yl)piperazin-1-yl)propyl)quinolin-4-amine}

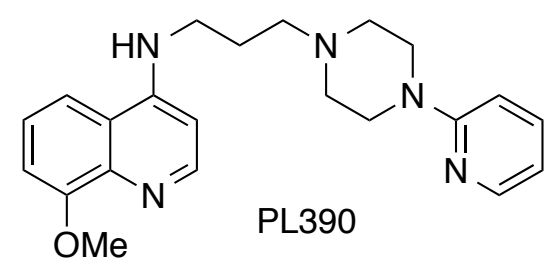

3-(8-methoxyquinolin-4-ylamino)propyl methanesulfonate (impure product from the above reaction, containing no more than $1.7 \mathrm{mmol}$ quinoline material), 1-(2pyridyl)piperazine $(0.30 \mathrm{~g}, 1.8 \mathrm{mmol})$, potassium carbonate $(0.36 \mathrm{~g}, 2.6 \mathrm{mmol})$, and a catalytic amount of potassium iodide were heated at reflux in acetonitrile $(25 \mathrm{~mL})$ for 18 hours. The solvent was then removed under reduced pressure with warming, and an attempt was made to partition the residue between ethyl acetate $(50 \mathrm{~mL})$ and water $(30$ $\mathrm{mL}$ ). Some material remained undissolved and was left in the reaction flask. After separation of the ethyl acetate and water layers, the aqueous layer was extracted with additional ethyl acetate $(3 \times 5 \mathrm{~mL})$, and the pooled organic layers were rinsed with brine $(10 \mathrm{~mL})$ and allowed to dry over magnesium sulfate for 18 hours. The undissolved material from ethyl acetate extraction was now taken up in chloroform $(30 \mathrm{~mL})$, in which it was fully soluble, and washed with the aqueous layer from the ethyl acetate extraction. After separation, the aqueous layer was extracted with additional chloroform $(3 \times 5 \mathrm{~mL})$, and the chloroform layer was dried over magnesium sulfate. The combined dried organic extracts were then partially evaporated under reduced pressure with warming, and 
adsorbed onto $3.5 \mathrm{~g}$ basic alumina. Flash chromatography on basic alumina was performed, eluting with a gradient of $100 \%$ hexanes to $100 \%$ ethyl acetate over 35 minutes; the product-containing fractions from this also contained 1-(2pyridyl)piperazine. Flash chromatography on basic alumina was repeated, with a gradient of $100 \%$ hexanes to $70 \%$ ethyl acetate over 30 minutes, to provide the desired product as a pale yellow solid $(0.13 \mathrm{~g}, 20 \%$ yield from 3-(8-methoxyquinolin-4ylamino)propanol, $\mathrm{mp}=147.9-150.0^{\circ} \mathrm{C}, \mathrm{R}_{\mathrm{f}}=0.4$ (Alumina, $\left.9 / 1 \mathrm{MeOH} / \mathrm{EtOAc} \mathrm{v} / \mathrm{v}\right)$ ).

${ }^{1} \mathrm{H}$ NMR $\delta(\mathrm{ppm})\left(\mathrm{CHCl}_{3}-\mathrm{d}\right): 8.57(1 \mathrm{H}, \mathrm{d}, \mathrm{J}=5.25 \mathrm{~Hz}), 8.23-8.23(1 \mathrm{H}, \mathrm{m}), 7.52(1 \mathrm{H}$, ddd, J = 8.58, 7.13, 2.01 Hz), $7.42(1 \mathrm{H}, \mathrm{d}, \mathrm{J}=8.48 \mathrm{~Hz}), 7.22(1 \mathrm{H}, \mathrm{t}, \mathrm{J}=8.10 \mathrm{~Hz}), 7.06$ $(1 \mathrm{H}, \mathrm{br} \mathrm{t}, \mathrm{J}=4.30 \mathrm{~Hz}), 6.94(1 \mathrm{H}, \mathrm{d}, \mathrm{J}=7.72 \mathrm{~Hz}), 6.67-6.68(2 \mathrm{H}, \mathrm{m}), 6.41(1 \mathrm{H}, \mathrm{d}, \mathrm{J}=$ $5.29 \mathrm{~Hz}), 4.04(3 \mathrm{H}, \mathrm{s}), 3.69(4 \mathrm{H}, \mathrm{m}), 3.42(2 \mathrm{H}, \mathrm{td}, \mathrm{J}=5.95,4.26 \mathrm{~Hz}), 2.66-2.67(6 \mathrm{H}$, m), $2.00(2 \mathrm{H}$, apparent $\mathrm{p}, \mathrm{J}=5.68 \mathrm{~Hz})$.

${ }^{13} \mathrm{C}$ NMR $\delta(\mathrm{ppm})\left(\mathrm{CHCl}_{3}\right.$-d): $159.4,155.9,150.3,150.1,148.1,140.4,137.6,124.2$, $119.9,113.6,112.0,107.1,107.1,99.1,58.6,55.9,53.5,45.3,44.1,23.9$.

MS (ESI): $m / z$ 378.22947 M + H (calculated 378.22884)

$\operatorname{HPLC}\left(\right.$ method A) $t_{\mathrm{R}}=4.64 \min (95 \%$ pure $)$.

\section{A.7: Bis-quinolines}

\section{A.7.1: Bis-quinoline starting materials not described above}

PL16: 3-(7-dichloroquinolin-4-ylamino)propanol (Burgess, 2006; Burgess, 2008; Burgess, 2010)<smiles>OCCCNc1ccnc2cc(Cl)ccc12</smiles>

PL16 was synthesized without deviating from methods previously described by Steven Burgess (a pale tan solid, $\mathrm{mp}=148.5-151.0^{\circ} \mathrm{C}$ ). 
PL29: 3-(7-chloroquinolin-4-ylamino)propyl methanesulfonate (Burgess, 2006; Burgess, 2008; Burgess, 2010):<smiles>COCCCNc1ccnc2cc(Cl)ccc12</smiles>

PL16 (1.88 g, $7.9 \mathrm{mmol})$, triethylamine (1.66 mL, $1.2 \mathrm{mmol})$, and anhydrous THF (100 $\mathrm{mL}$ ) were cooled below $0^{\circ} \mathrm{C}$ on ice/salt, and methanesulfonyl chloride $(0.71 \mathrm{~mL}, 9.1$ $\mathrm{mmol}$ ) was added dropwise. After stirring for an hour on ice, TLC indicated that reaction was not complete, and therefore additional triethylamine $(0.83 \mathrm{~mL}, 6.0 \mathrm{mmol})$ and methanesulfonyl chloride $(0.36 \mathrm{~mL}, 6.0 \mathrm{mmol})$ were added. After a further hour, TLC indicated that no quinoline starting material remained. The reaction mixture was diluted with ethyl acetate $(30 \mathrm{~mL})$ and shaken with saturated sodium bicarbonate $(30 \mathrm{~mL})$, followed by extraction of the aqueous layer with additional ethyl acetate $(3 \times 10 \mathrm{~mL})$. The pooled ethyl acetate layers were washed with brine $(10 \mathrm{~mL})$, dried over magnesium sulfate, and evaporated under reduced pressure with warming to obtain a pale yellow, fluffy solid; this was allowed to stand overnight $(1.86 \mathrm{~g}, 81 \%)$.

${ }^{1} \mathrm{H}$ NMR $\delta(\mathrm{ppm})\left(\mathrm{CHCl}_{3}-\mathrm{d}\right): 8.53(1 \mathrm{H}, \mathrm{d}, \mathrm{J}=5.37 \mathrm{~Hz}, \mathrm{ClQ}-\mathrm{C} 2-\mathrm{H}), 7.95(1 \mathrm{H}, \mathrm{d}, \mathrm{J}=2.18$ $\mathrm{Hz}, \mathrm{ClQ}-\mathrm{C} 8-\mathrm{H}), 7.72(1 \mathrm{H}, \mathrm{d}, \mathrm{J}=8.97 \mathrm{~Hz}, \mathrm{ClQ}-\mathrm{C} 5-\mathrm{H}), 7.38(1 \mathrm{H}, \mathrm{dd}, \mathrm{J}=8.94,2.18 \mathrm{~Hz}$, ClQ-C6-H), $6.42(1 \mathrm{H}, \mathrm{d}, \mathrm{J}=5.40 \mathrm{~Hz}, \mathrm{ClQ}-\mathrm{C} 3-\mathrm{H}), 5.55(1 \mathrm{H}, \mathrm{brt}, \mathrm{J}=5.75 \mathrm{~Hz}, \mathrm{NH}), 4.42$ $\left(2 \mathrm{H}, \mathrm{t}, \mathrm{J}=5.66 \mathrm{~Hz}, \mathrm{CH}_{2} \mathrm{O}\right), 3.58\left(2 \mathrm{H}, \mathrm{td}, \mathrm{J}=6.34,5.77 \mathrm{~Hz}, \mathrm{CH}_{2} \mathrm{~N}\right), 3.06\left(3 \mathrm{H}, \mathrm{s}, \mathrm{CH}_{3}\right)$, $2.18\left(2 \mathrm{H}\right.$, apparent $\left.\mathrm{p}, \mathrm{J}=5.98 \mathrm{~Hz}, \mathrm{CH}_{2}\right)$.

${ }^{1} \mathrm{H}$ NMR $\delta(\mathrm{ppm})\left(\right.$ DMSO-d $\left._{6}\right): 8.42(1 \mathrm{H}, \mathrm{d}, \mathrm{J}=5.39 \mathrm{~Hz}, \mathrm{ClQ}-\mathrm{C} 2-\mathrm{H}), 8.26(1 \mathrm{H}, \mathrm{d}, \mathrm{J}=$ $9.04 \mathrm{~Hz}, \mathrm{ClQ}-\mathrm{C} 5-\mathrm{H}), 7.79(1 \mathrm{H}, \mathrm{d}, \mathrm{J}=2.24 \mathrm{~Hz}, \mathrm{ClQ}-\mathrm{C} 8-\mathrm{H}), 7.47$ (1 H, dd, J = 8.98, 2.27 $\mathrm{Hz}, \mathrm{ClQ}-\mathrm{C6}-\mathrm{H}), 7.33(1 \mathrm{H}, \mathrm{brt} \mathrm{t}, \mathrm{J}=5.39 \mathrm{~Hz}, \mathrm{Q}-\mathrm{C} 4-\mathrm{NH}), 6.51(1 \mathrm{H}, \mathrm{d}, \mathrm{J}=5.45 \mathrm{~Hz}, \mathrm{ClQ}-$ $\mathrm{C} 3-\mathrm{H}$ ), $4.35\left(1 \mathrm{H}, \mathrm{t}, \mathrm{J}=6.19 \mathrm{~Hz}, \mathrm{HNCH}_{2} \mathrm{CH}_{2} \mathrm{CH}_{2}\right.$ ), 3.30-3.45 (water signal overlaps $\mathrm{m}$, $\left.\sim 1 \mathrm{H}, \mathrm{HNCH}_{2} \mathrm{CH}_{2} \mathrm{CH}_{2}\right), 3.19\left(1 \mathrm{H}, \mathrm{s}, \mathrm{CH}_{3}\right), 2.07-2.09(1 \mathrm{H}$, apparent $\mathrm{p}, \mathrm{J}=6.56 \mathrm{~Hz}$, $\mathrm{HNCH}_{2} \mathrm{CH}_{2} \mathrm{CH}_{2}$ ). 


\section{PL376: Ethyl 4-((7-chloroquinolin-4-yl)amino)piperidine-1-carboxylate}<smiles>CCOC(=O)N1CCC(Nc2ccnc3cc(Cl)ccc23)CC1</smiles>

4,7-dichloroquinoline $(2.00 \mathrm{~g}, 10 \mathrm{mmol})$, ethyl-4-amino-1-piperidine carboxylate $(1.83 \mathrm{~g}$, $11 \mathrm{mmol})$, and phenol $(5.70 \mathrm{~g}, 61 \mathrm{~mol})$ were heated at $90^{\circ} \mathrm{C}$ in a sealed Carius vessel for 48 hours. TLC indicated that unreacted 4,7-dichloroquinoline remained, and therefore additional ethyl-4-amino-1-piperidine carboxylate $(0.39 \mathrm{~g}, 2.3 \mathrm{mmol})$ was added. The vessel was again sealed and heated for a further 7 days, whereupon TLC indicated that no unreacted quinoline remained. The reaction mixture was diluted with chloroform (50 $\mathrm{mL})$ and rinsed with $10 \%$ caustic soda $(6 \times 10 \mathrm{~mL})$, followed by further rinsing with brine $(3 \times 10 \mathrm{~mL})$. The organic layer was dried over $\mathrm{MgSO}_{4}$ and concentrated under reduced pressure with warming to yield a thick, tan liquid containing some solid material. After standing 14 hours, this was taken up in boiling solvent (50/50 ethyl acetate/95\% ethanol (v/v)) and allowed to cool and concentrate at room temperature. The crystals thus formed were recovered from the remaining $5 \mathrm{~mL}$ of solvent by vacuum filtration (off-white crystals, $1.18 \mathrm{~g}, 35 \%, \mathrm{mp}=197.3-198.8^{\circ} \mathrm{C}$ ).

${ }^{1} \mathrm{H} \mathrm{NMR} \delta(\mathrm{ppm})\left(\mathrm{CHCl}_{3}-\mathrm{d}\right): 8.54(1 \mathrm{H}, \mathrm{d}, \mathrm{J}=5.36 \mathrm{~Hz}), 7.96(1 \mathrm{H}, \mathrm{d}, \mathrm{J}=2.17 \mathrm{~Hz}), 7.66$ $(1 \mathrm{H}, \mathrm{d}, \mathrm{J}=8.98 \mathrm{~Hz}), 7.37(1 \mathrm{H}, \mathrm{dd}, \mathrm{J}=8.94,2.19 \mathrm{~Hz}), 6.46(1 \mathrm{H}, \mathrm{d}, \mathrm{J}=5.41 \mathrm{~Hz}), 4.92(1$ $\mathrm{H}$, br d, J = 7.25 Hz), 4.16 (4 H, br s overlaps q, J = 7.13 Hz), 3.68-3.69 (1 H, m), 3.04 (2 $\mathrm{H}, \mathrm{td}, \mathrm{J}=12.56,2.82 \mathrm{~Hz}), 2.11-2.20(2 \mathrm{H}, \mathrm{m}), 1.51-1.53(2 \mathrm{H}, \mathrm{m}), 1.28(3 \mathrm{H}, \mathrm{t}, \mathrm{J}=7.11$ $\mathrm{Hz})$.

MS (ESI): $m / z$ 334.13271 M + H (calculated 334.13168)

$\operatorname{HPLC}(\operatorname{method} \mathrm{A}) t_{\mathrm{R}}=10.55 \min (99 \%$ pure $)$. 


\section{PL294: 7-chloro- $N$-(piperidin-4-yl)quinolin-4-amine}<smiles>O=C(O)OCc1ccc(NC2CCNCC2)c2ccc(Cl)cc12</smiles>

PL376 (2.45 g, $7.3 \mathrm{mmol}$, the product of multiple reactions), 95\% ethanol (100 $\mathrm{mL})$, and $10 \%$ caustic soda $(4.5 \mathrm{~mL})$ were allowed to heat, stirring, at reflux for 4 days. As TLC indicated that the reaction was not complete, $50 \%$ caustic soda $(0.5 \mathrm{~mL})$ was added, and reflux was continued for a further 3 days. TLC then indicated that the reaction was complete. The reaction solvent was removed under reduced pressure with warming, and the residue was partitioned between chloroform $(20 \mathrm{~mL})$ and water $(50 \mathrm{~mL})$. After separation, the aqueous layer was extracted with additional chloroform $(3 \times 10 \mathrm{~mL})$, and the pooled organic layers were dried $\left(\mathrm{MgSO}_{4}\right)$ and concentrated under reduced pressure with warming to yield a tan solid $(1.05 \mathrm{~g})$. A cream colored solid was also isolated from the aqueous layer by vacuum filtration $(1.04 \mathrm{~g})$. NMR indicated that both solids obtained were the desired product (total yield $1.83 \mathrm{~g}, 96 \%, \mathrm{mp}=166.3-169.4^{\circ} \mathrm{C}$ ).

${ }^{1} \mathrm{H}$ NMR $\delta(\mathrm{ppm})\left(\mathrm{CHCl}_{3}-\mathrm{d}\right): 8.52(1 \mathrm{H}, \mathrm{d}, \mathrm{J}=5.39 \mathrm{~Hz}), 7.96(1 \mathrm{H}, \mathrm{d}, \mathrm{J}=2.18 \mathrm{~Hz}), 7.65$ $(1 \mathrm{H}, \mathrm{d}, \mathrm{J}=8.96 \mathrm{~Hz}), 7.37(1 \mathrm{H}, \mathrm{dd}, \mathrm{J}=8.93,2.19 \mathrm{~Hz}), 6.45(1 \mathrm{H}, \mathrm{d}, \mathrm{J}=5.42 \mathrm{~Hz}), 4.87(1$ $\mathrm{H}$, br d, J = 7.35 Hz), 3.61-3.62 (1 H, m), 3.19 (2 H, dt, J = 12.68, 3.70 Hz), 2.79-2.81 (2 $\mathrm{H}, \mathrm{m}), 2.15-2.19$ (2 H, m), 1.50-1.50 (2 H, m).

MS (ESI): $m / z 262.11116 \mathrm{M}+\mathrm{H}$ (calculated 262.11065)

HPLC (method A) $t_{\mathrm{R}}=2.74 \min (94 \%$ pure).

\section{PL377: Ethyl 4-(quinolin-4-ylamino)piperidine-1-carboxylate}<smiles>CCOC(=O)N1CCC(Nc2ccnc3ccccc23)CC1</smiles> 
4-chloroquinoline (2.00 g, $12 \mathrm{mmol})$, ethyl-4-amino-1-piperidine carboxylate (3.16 g, 32 $\mathrm{mmol})$, and phenol $(6.90 \mathrm{~g}, 73 \mathrm{mmol})$ were heated at $90^{\circ} \mathrm{C}$ in a sealed Carius vessel for 6 days. TLC indicated that unreacted 4,7-dichloroquinoline remained, and therefore additional ethyl-4-amino-1-piperidine carboxylate (1.00 g, $1.0 \mathrm{mmol})$ was added. The vessel was again sealed and heated for a further 2 days, whereupon TLC indicated that reaction was complete. The reaction mixture was diluted with chloroform $(50 \mathrm{~mL})$ and rinsed with $10 \%$ caustic soda $(5 \times 10 \mathrm{~mL})$, followed by further rinsing with water $(3 \times 10$ $\mathrm{mL}$ ). The organic layer was dried over $\mathrm{MgSO}_{4}$ and concentrated under reduced pressure with warming to yield a brown semisolid. This material was taken up in boiling ethyl acetate $(70 \mathrm{~mL})$ and allowed to cool and concentrate at room temperature (to approximately $15 \mathrm{~mL}$ ). Vacuum filtration provided the desired product as a sparkling, tan, crystalline solid $\left(2.81 \mathrm{~g}, 77 \%, \mathrm{mp}=209-210^{\circ} \mathrm{C}\right)$.

${ }^{1} \mathrm{H}$ NMR $\delta(\mathrm{ppm})\left(\mathrm{CHCl}_{3}-\mathrm{d}\right): 8.56(1 \mathrm{H}, \mathrm{d}, \mathrm{J}=5.31 \mathrm{~Hz}), 7.99(1 \mathrm{H}, \mathrm{dd}, \mathrm{J}=8.44,1.20 \mathrm{~Hz})$, $7.72(1 \mathrm{H}, \mathrm{dd}, \mathrm{J}=8.43,1.25 \mathrm{~Hz}), 7.64(1 \mathrm{H}, \mathrm{ddd}, \mathrm{J}=8.46,6.85,1.31 \mathrm{~Hz}), 7.44(1 \mathrm{H}$, ddd, $\mathrm{J}=8.40,6.86,1.29 \mathrm{~Hz}), 6.47(1 \mathrm{H}, \mathrm{d}, \mathrm{J}=5.35 \mathrm{~Hz}), 4.90(1 \mathrm{H}, \mathrm{br} \mathrm{d}, \mathrm{J}=7.27 \mathrm{~Hz}), 4.17$ (4 $\mathrm{H}$, br s overlaps q, J = 7.11 Hz), 3.70-3.71 (1 H, m), $3.06(2 \mathrm{H}, \mathrm{td}, \mathrm{J}=12.54,2.73 \mathrm{~Hz})$, 2.13-2.22 (2 H, m), 1.52-1.54 (2 H, m), $1.28(3 \mathrm{H}, \mathrm{t}, \mathrm{J}=7.11 \mathrm{~Hz})$.

MS (ESI): $m / z$ 300.17103 M + H (calculated 300.17065)

HPLC (method A) $t_{\mathrm{R}}=9.81 \min (99 \%$ pure $)$.

\section{PL378: $N$-(piperidin-4-yl)quinolin-4-amine}<smiles></smiles>

PL377 (1.77 g, $5.9 \mathrm{mmol}), 95 \%$ ethanol $(40 \mathrm{~mL})$, and 50\% caustic soda $(2.00 \mathrm{~mL})$ were allowed to heat, stirring, at reflux for 20 hours. As TLC indicated that the reaction was not complete, additional $50 \%$ caustic soda $(1.0 \mathrm{~mL})$ was added, and reflux was continued for a further 3 days. TLC then indicated that the reaction was complete. The reaction solvent was removed under reduced pressure with warming, and the residue was partitioned between chloroform $(25 \mathrm{~mL})$ and water $(25 \mathrm{~mL})$. After separation, the aqueous layer was extracted with additional chloroform $(3 \times 7 \mathrm{~mL})$. The pooled organic layers were vacuum filtered to remove solid material, followed by drying $\left(\mathrm{MgSO}_{4}\right)$ and 
concentration under reduced pressure with warming to yield the desired product as a white powder $\left(0.65 \mathrm{~g}, 48 \%, \mathrm{mp}=112.5-124^{\circ} \mathrm{C}\right)$.

${ }^{1} \mathrm{H}$ NMR $\delta(\mathrm{ppm})\left(\mathrm{CHCl}_{3}-\mathrm{d}\right): 8.55(1 \mathrm{H}, \mathrm{d}, \mathrm{J}=5.33 \mathrm{~Hz}), 7.98(1 \mathrm{H}, \mathrm{dd}, \mathrm{J}=8.45,1.22 \mathrm{~Hz})$, $7.72(1 \mathrm{H}, \mathrm{dd}, \mathrm{J}=8.42,1.26 \mathrm{~Hz}), 7.63$ (1 H, ddd, $\mathrm{J}=8.45,6.85,1.33 \mathrm{~Hz}), 7.43$ (1 H, ddd, $\mathrm{J}=8.39,6.85,1.30 \mathrm{~Hz}), 6.47(1 \mathrm{H}, \mathrm{d}, \mathrm{J}=5.36 \mathrm{~Hz}), 4.89(1 \mathrm{H}, \mathrm{br} \mathrm{d}, \mathrm{J}=7.32 \mathrm{~Hz}), 3.63-$ $3.64(1 \mathrm{H}, \mathrm{m}), 3.19(2 \mathrm{H}, \mathrm{dt}, \mathrm{J}=12.67,3.73 \mathrm{~Hz}), 2.80-2.81(2 \mathrm{H}, \mathrm{m}), 2.17-2.20(2 \mathrm{H}, \mathrm{m})$, $1.44-1.56(2 \mathrm{H}, \mathrm{m})$.

MS (ESI): $m / z 228.14987 \mathrm{M}+\mathrm{H}$ (calculated 228.14952)

$\mathrm{HPLC}(\operatorname{method} \mathrm{A}) t_{\mathrm{R}}=1.58 \mathrm{~min}(78 \%$ pure). (Second largest peak elutes at 2.00 minutes, $17 \%$.)

\section{PL332: Ethyl 4-((8-(trifluoromethyl)quinolin-4-yl)amino)piperidine-1-carboxylate}<smiles>CCOC(=O)N1CCC(Nc2ccnc3c(C(F)(F)F)cccc23)CC1</smiles>

4-chloro-(8-trifluoromethyl)quinoline (1.50 g, $6.5 \mathrm{mmol}$ ), ethyl-4-amino-1-piperidine carboxylate $(1.02 \mathrm{~g}, 5.9 \mathrm{mmol})$, and phenol $(3.04 \mathrm{~g}, 32 \mathrm{~mol})$ were heated at $82^{\circ} \mathrm{C}$ in a sealed Carius vessel for 20 hours. Additional ethyl-4-amino-1-piperidine carboxylate $(0.20 \mathrm{~g}, 1.2 \mathrm{mmol})$ was added. The vessel was again sealed and heated for a further 3 days at $100^{\circ} \mathrm{C}$. whereupon TLC indicated that no unreacted quinoline remained. The reaction mixture was diluted with chloroform $(25 \mathrm{~mL})$ and rinsed with $10 \%$ caustic soda $(5 \times 10 \mathrm{~mL})$, followed by further rinsing with brine $(2 \times 10 \mathrm{~mL})$. The organic layer was dried over $\mathrm{MgSO}_{4}$ and concentrated under reduced pressure with warming to yield a thick, brown oil. This was diluted with dichloromethane and adsorbed onto silica, then purified by flash chromatography on silica, eluting with a gradient of $100 \%$ hexanes to $100 \%$ ethyl acetate. The desired product was obtained as a beige solid $\left(0.63 \mathrm{~g}, 27 \%, \mathrm{R}_{\mathrm{f}}=\right.$ 0.4 (silica, ethyl acetate)). The quinoline phenolate was also isolated from chromatography (a sparkling, white, crystalline solid, $0.94 \mathrm{~g}, 50 \%, \mathrm{mp}=175.4-181.0^{\circ} \mathrm{C}$, $\mathrm{Rf}=0.7$ (silica, ethyl acetate)).

${ }^{19} \mathrm{~F}$ NMR $\delta(\mathrm{ppm})\left(\mathrm{CHCl}_{3}-\mathrm{d}\right):-60.8$. 
MS (ESI): $m / z 368.15863 \mathrm{M}+\mathrm{H}$ (calculated 368.15804)

$\operatorname{HPLC}(\operatorname{method} \mathrm{A}) t_{\mathrm{R}}=10.69 \min (96 \%$ pure $)$.

\section{PL368: N-(piperidin-4-yl)-8-(trifluoromethyl)quinolin-4-amine}

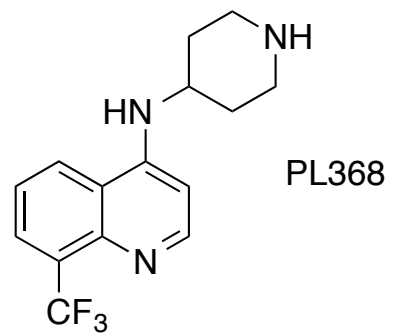

PL332 (0.62 g, $1.7 \mathrm{mmol}), 95 \%$ ethanol $(50 \mathrm{~mL})$, and $10 \%$ caustic soda $(4 \mathrm{~mL})$ were allowed to heat, stirring, at reflux for 18 hours. As TLC indicated that the reaction was not complete, $50 \%$ caustic soda $(0.5 \mathrm{~mL})$ was added, and reflux was continued for a further 24 hours. TLC then indicated that the reaction was complete. After removal of the solvent under reduced pressure with warming, the residue was partitioned between chloroform $(25 \mathrm{~mL})$ and water $(50 \mathrm{~mL})$. After separation, the aqueous layer was extracted with additional chloroform $(3 \times 10 \mathrm{~mL})$, and the pooled organic layers were dried $\left(\mathrm{MgSO}_{4}\right)$ and concentrated under reduced pressure with warming to provide a pale yellow solid $\left(0.18 \mathrm{~g}, 36 \%, \mathrm{mp}=186.8-189.6^{\circ} \mathrm{C}\right)$.

${ }^{1} \mathrm{H}$ NMR $\delta(\mathrm{ppm})\left(\mathrm{CHCl}_{3}-\mathrm{d}\right): 8.69(1 \mathrm{H}, \mathrm{d}, \mathrm{J}=5.40 \mathrm{~Hz}), 8.00(1 \mathrm{H}, \mathrm{d}, \mathrm{J}=7.33 \mathrm{~Hz}), 7.93$ $(1 \mathrm{H}, \mathrm{d}, \mathrm{J}=8.49 \mathrm{~Hz}), 7.46(1 \mathrm{H}, \mathrm{dd}, \mathrm{J}=8.45,7.34 \mathrm{~Hz}), 6.56(1 \mathrm{H}, \mathrm{d}, \mathrm{J}=5.43 \mathrm{~Hz}), 4.93(1$ $\mathrm{H}, \mathrm{br} \mathrm{d}, \mathrm{J}=7.30 \mathrm{~Hz}), 3.63-3.64(1 \mathrm{H}, \mathrm{m}), 3.20(2 \mathrm{H}, \mathrm{m}), 2.79-2.80(2 \mathrm{H}, \mathrm{m}), 2.16-2.20(2$ $\mathrm{H}, \mathrm{m}), 1.49-1.50(2 \mathrm{H}, \mathrm{m})$.

MS (ESI): $m / z$ 296.13763 M + H (calculated 296.13691)

HPLC (method A) $t_{\mathrm{R}}=2.85 \mathrm{~min}(92 \%$ pure). (Additional peaks elute at 1.81 minutes, $2 \%$, and 7.54 minutes, $1 \%$.) 


\section{A.7.2: Bis-quinoline final products}

\section{PL241: 7-chloro- $N$-(3-(4-((7-chloroquinolin-4-yl)amino)piperidin-1- yl)propyl)quinolin-4-amine}

Primary method (for original method, see section A.7.3):

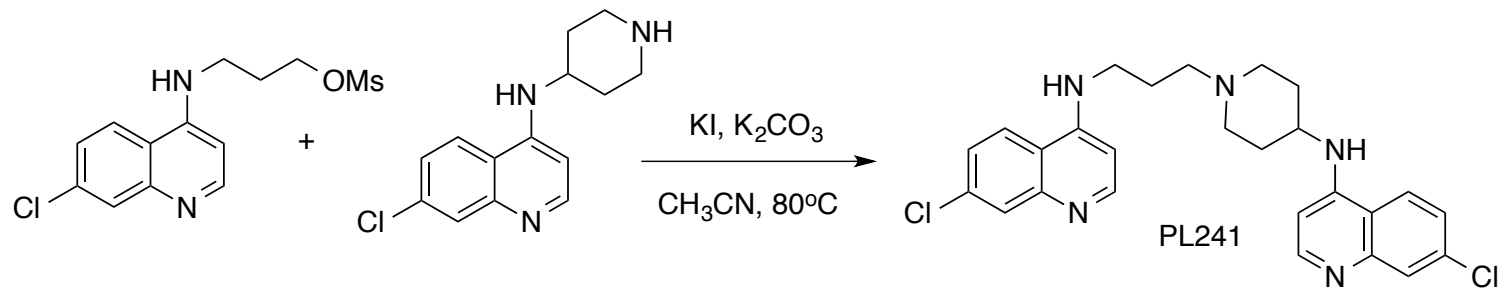

PL29 (1.20 g, $3.8 \mathrm{mmol})$, PL294 (1.05 g, $4.0 \mathrm{mmol})$, potassium carbonate $(5.7 \mathrm{mmol}$, $0.79 \mathrm{~g}$ ), a catalytic amount of potassium iodide, and $50 \mathrm{~mL}$ anhydrous acetonitrile were allowed to heat for 48 hours at reflux, whereupon TLC indicated that the reaction was complete. The reaction mixture was diluted with water $(50 \mathrm{~mL})$ and vacuum filtered. The filtrate was concentrated under reduced pressure with warming, and the reaction mixture was partitioned between 50/50 dichloromethane/chloroform $(20 \mathrm{~mL})$ and $10 \mathrm{~mL}$ saturated sodium bicarbonate, followed by further extraction with three $10 \mathrm{~mL}$ portions dichloromethane. The pooled organic layers were dried over anhydrous magnesium sulfate and concentrated under reduced pressure. The resulting solid was combined with the material filtered from the reaction mixture and recrystallized from $95 \%$ ethanol, which afforded the desired product as a pale yellow, crystalline solid $(1.30 \mathrm{~g})$. Concentration of the mother liquor yielded a further crop of crystals $(0.06 \mathrm{~g}$, total yield $\left.71 \%, \mathrm{mp}=224-227^{\circ} \mathrm{C}(\mathrm{dec})\right)$.

${ }^{1} \mathrm{H}$ NMR $\delta(\mathrm{ppm})\left(\mathrm{CHCl}_{3}-\mathrm{d}\right): 8.56\left(1 \mathrm{H}, \mathrm{d}, \mathrm{J}=5.33 \mathrm{~Hz}, \mathrm{Q}_{1}-\mathrm{C} 2-\mathrm{H}\right), 8.53(1 \mathrm{H}, \mathrm{d}, \mathrm{J}=5.33$ $\left.\mathrm{Hz}, \mathrm{Q}_{2}-\mathrm{C} 2-\mathrm{H}\right), 7.99$ (1 H, d, J = 2.16 Hz, Q $\left.1-\mathrm{C} 5-\mathrm{H}\right), 7.97\left(1 \mathrm{H}, \mathrm{d}, \mathrm{J}=2.14 \mathrm{~Hz}, \mathrm{Q}_{2}-\mathrm{C} 5-\mathrm{H}\right)$, $7.78\left(1 \mathrm{H}, \mathrm{d}, \mathrm{J}=8.90 \mathrm{~Hz}, \mathrm{Q}_{2}-\mathrm{C} 8-\mathrm{H}\right), 7.71\left(1 \mathrm{H}, \mathrm{d}, \mathrm{J}=8.95 \mathrm{~Hz}, \mathrm{Q}_{1}-\mathrm{C} 8-\mathrm{H}\right), 7.43(1 \mathrm{H}, \mathrm{dd}, \mathrm{J}$ $\left.=8.89,2.18 \mathrm{~Hz}, \mathrm{Q}_{1}-\mathrm{C} 6-\mathrm{H}\right), 7.35\left(1 \mathrm{H}, \mathrm{dd}, \mathrm{J}=8.87,2.16 \mathrm{~Hz}, \mathrm{Q}_{2}-\mathrm{C} 6-\mathrm{H}\right), 7.02(1 \mathrm{H}$, br t, J $\left.=4.27 \mathrm{~Hz}, \mathrm{Q}_{1}-\mathrm{C} 4-\mathrm{NH}\right), 6.47\left(1 \mathrm{H}, \mathrm{d}, \mathrm{J}=5.37 \mathrm{~Hz}, \mathrm{Q}_{1}-\mathrm{C} 3-\mathrm{H}\right), 6.38(1 \mathrm{H}, \mathrm{d}, \mathrm{J}=5.37 \mathrm{~Hz}$, $\left.\mathrm{Q}_{2}-\mathrm{C} 3-\mathrm{H}\right), 4.92\left(1 \mathrm{H}, \mathrm{brd}, \mathrm{J}=6.78 \mathrm{~Hz}, \mathrm{Q}_{2}-\mathrm{N} \underline{\mathrm{H}}\right), 3.65$ (1 H, m, Pip-C프), 3.42 (2 H, td, $\left.\mathrm{J}_{\mathrm{CH} 2}=6.01, \mathrm{~J}_{\mathrm{NH}}=4.35 \mathrm{~Hz}, \mathrm{Q}_{1}-\mathrm{NHCH}_{2} \mathrm{CH}_{2} \mathrm{CH}_{2}\right), 3.06(2 \mathrm{H}, \mathrm{m}$, piperidine-CH x 2 adjacent to alkyl chain), $2.67\left(2 \mathrm{H}, \mathrm{t}, \mathrm{J}_{\mathrm{CH} 2}=5.64 \mathrm{~Hz}, \mathrm{Q}_{1}-\mathrm{NHCH}_{2} \mathrm{CH}_{2} \mathrm{CH}_{2}\right), 2.33(2 \mathrm{H}, \mathrm{m}$, piperidine- $\mathrm{CH} \times 2$ adjacent to alkyl chain), $2.28(2 \mathrm{H}, \mathrm{m}$, piperidine $\mathrm{CH} \times 2$ adjacent to $\left.\mathrm{CH}-\mathrm{NH}-\mathrm{Q}_{2}\right), 1.99\left(2 \mathrm{H}\right.$, apparent $\left.\mathrm{p}, \mathrm{J}_{\mathrm{CH} 2 \times 2}=5.75 \mathrm{~Hz}, \mathrm{Q}_{1}-\mathrm{NHCH}_{2} \mathrm{CH}_{2} \mathrm{CH}_{2}\right), 1.75$ (water signal overlaps $\mathrm{m}, \sim 2 \mathrm{H}$, piperidine $\mathrm{CH} \times 2$ adjacent to $\mathrm{CH}-\mathrm{NH}-\mathrm{Q}_{2}$ ).

${ }^{13} \mathrm{C}$ NMR $\delta(\mathrm{ppm})\left(\mathrm{CHCl}_{3}-\mathrm{d}\right): 152.3\left(\mathrm{Q}_{1}-\mathrm{C} 2\right), 152.0\left(\mathrm{Q}_{2}-\mathrm{C} 2\right), 150.4,149.4,149.3,148.4$, 135.1, 134.7, 129.1 (Q-C5), 129.0 (Q-C5), 125.6 (Q $\left.{ }_{1}-\mathrm{C} 6\right), 124.8\left(\mathrm{Q}_{2}-\mathrm{C} 6\right), 121.7$ ( $\left.\mathrm{Q}_{2}-\mathrm{C} 8\right)$, 
$120.7\left(\mathrm{Q}_{1}-\mathrm{C} 8\right), 117.5,117.2,99.6\left(\mathrm{Q}_{1}-\mathrm{C} 3\right), 98.8\left(\mathrm{Q}_{2}-\mathrm{C} 3\right), 58.2\left(\mathrm{Q}_{1}-\mathrm{NHCH}_{2} \mathrm{CH}_{2} \mathrm{CH}_{2}\right)$, 52.5 (piperidine- $\mathrm{C}$ adjacent to alkyl chain), 49.5 (piperidine-CH-NH- $\left.\mathrm{Q}_{2}\right), 43.9\left(\mathrm{Q}_{1}\right.$ $\mathrm{NHCH}_{2} \mathrm{CH}_{2} \mathrm{CH}_{2}$ ), 32.0 (piperidine-C adjacent to $\mathrm{CH}-\mathrm{NH}-\mathrm{Q}_{2}$ ), $24.4\left(\mathrm{Q}_{1}-\mathrm{NHCH}_{2} \mathrm{CH}_{2} \mathrm{CH}_{2}\right)$.

Note: $Q_{1}$ and $Q_{2}$ denote respectively the quinoline ring system on the left and that on the right of the structure as shown above. For the quinoline ring system numbering, see Figure 5, Chapter 1. Spectra are provided in Appendix C (Example spectra: PL241).

MS (ESI): $m / z$ 480.17456 M + H (calculated 480.17163)

HPLC (method A) $t_{\mathrm{R}}=6.93 \min (97 \%$ pure $)$.

\section{PL338: 7-chloro- $N$-(1-(3-(quinolin-4-ylamino)propyl)piperidin-4-yl)quinolin-4- amine}

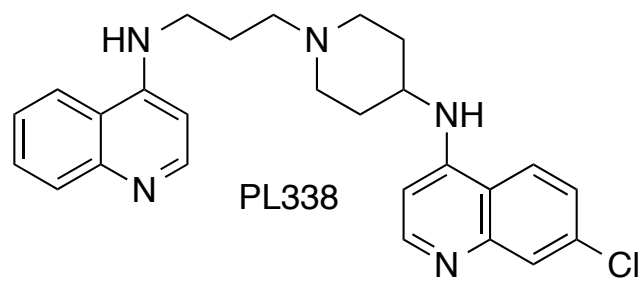

3-(quinolin-4-ylamino)propyl methanesulfonate (0.61 g, $2.2 \mathrm{~mol})$, PL294 (0.60 g, 2.3 $\mathrm{mol}), \mathrm{K}_{2} \mathrm{CO}_{3}(0.45 \mathrm{~g}, 3.3 \mathrm{~mol})$, and a catalytic amount of potassium iodide were heated for 5 days in refluxing acetonitrile $(25 \mathrm{~mL})$, at which point TLC indicated that reaction was complete. The solvent was removed under reduced pressure with warming (after dilution with $10 \mathrm{~mL}$ water), and the residue was combined with water $(50 \mathrm{~mL})$ and chloroform $(80 \mathrm{~mL})$. A large amount of material remained undissolved and was recovered by vacuum filtration (a cream colored solid). The filtrate was placed in a separatory funnel and separated, and the aqueous layer was extracted thrice with $10 \mathrm{~mL}$ portions of chloroform. The pooled chloroform layers were dried $\left(\mathrm{MgSO}_{4}\right)$ and evaporated under reduced pressure with warming to yield a cloudy, pale yellow oil, 0.07 g. NMR indicated that the oil from extraction contained both product and starting material, whereas the solid recovered from filtration was the desired product with very little impurity. The latter was taken up in excess boiling $95 \%$ ethanol, and allowed to evaporate gradually (at room temperature) to $\sim 10 \mathrm{~mL}$. Filtration afforded the desired product as beige crystals $\left(0.79 \mathrm{~g}, 81 \%, \mathrm{mp}=240-250^{\circ} \mathrm{C}(\mathrm{dec})\right)$.

${ }^{1} \mathrm{H}$ NMR $\delta(\mathrm{ppm})\left(\mathrm{DMSO}_{6}\right):$ 8.37-8.41 (3 H, m), 8.19 (1 H, d, J = 8.41 Hz), 7.77-7.79 (2 $\mathrm{H}, \mathrm{m}), 7.61(1 \mathrm{H}, \mathrm{ddd}, \mathrm{J}=8.43,6.73,1.31 \mathrm{~Hz}), 7.42-7.46(2 \mathrm{H}, \mathrm{m}), 7.30(1 \mathrm{H}, \mathrm{br} \mathrm{t}, \mathrm{J}=$ $5.24 \mathrm{~Hz}), 6.99(1 \mathrm{H}$, br d, J = $7.49 \mathrm{~Hz}), 6.55(1 \mathrm{H}, \mathrm{d}, \mathrm{J}=5.54 \mathrm{~Hz}), 6.48(1 \mathrm{H}, \mathrm{d}, \mathrm{J}=5.37$ 
Hz), 3.50-3.53 (1 H, m), 3.41-3.46 (2 H, m), 2.95-2.98 (2 H, m), $2.46(2 \mathrm{H}, \mathrm{t}, \mathrm{J}=6.79$

$\mathrm{Hz}), 2.06-2.12(2 \mathrm{H}, \mathrm{m}), 1.98-2.01(2 \mathrm{H}, \mathrm{m}), 1.85(2 \mathrm{H}$, apparent $\mathrm{p}, \mathrm{J}=6.68 \mathrm{~Hz}), 1.63-$ $1.72(2 \mathrm{H}, \mathrm{m})$.

${ }^{13} \mathrm{C}$ NMR $\delta$ (ppm)(DMSO-d 6 ): 151.8, 150.6, 149.9, 149.2, 149.1, 148.2, 133.3, 128.9, $128.6,127.4,124.4,123.8,123.7,121.5,118.8,117.4,99.1,98.0,55.7,52.3,49.6,40.9$, $30.9,25.3$.

MS (ESI): $m / z$ 446.21096 M + H (calculated 446.21060)

HPLC (method A) $t_{\mathrm{R}}=6.07 \min (99 \%$ pure $)$.

\section{PL337: 7-chloro- $N$-(3-(4-(quinolin-4-ylamino)piperidin-1-yl)propyl)quinolin-4- amine}<smiles>Clc1ccc2c(NCCCN3CCC(Nc4ccnc5ccccc45)CC3)ccnc2c1</smiles>

PL29 (0.83 g, $0.00264 \mathrm{~mol})$, PL378 (0.63 g, $0.00277 \mathrm{~mol}), \mathrm{K}_{2} \mathrm{CO}_{3}(0.55 \mathrm{~g}, 0.00396 \mathrm{~mol})$, and a catalytic amount of potassium iodide were heated for 24 hours in refluxing acetonitrile $(50 \mathrm{~mL})$, at which point TLC indicated that reaction was complete. After dilution with $10 \mathrm{~mL}$ water, the solvent was removed under reduced pressure with warming. The residue was combined with additional water $(30 \mathrm{~mL}$ in total) and chloroform $(30 \mathrm{~mL})$. A cream colored solid remained undissolved, and was recovered by vacuum filtration. The filtrate was separated into two layers, and the aqueous layer was extracted with chloroform $(3 \times 10 \mathrm{~mL})$. The pooled organic layers were dried $\left(\mathrm{MgSO}_{4}\right)$ and evaporated under reduced pressure with warming to yield a waxy, yellow solid. This solid, together with the solid obtained from filtration, was dissolved in excess boiling $95 \%$ ethanol $(100 \mathrm{~mL}$ ) and allowed to evaporate gradually (at room temperature) to $\sim 10$ $\mathrm{mL}$. Filtration afforded the desired product as a beige solid $(0.66 \mathrm{~g}, 56 \%, \mathrm{mp}=224-$ $\left.228^{\circ} \mathrm{C}\right)$.

${ }^{1} \mathrm{H}$ NMR $\delta(\mathrm{ppm})\left(\mathrm{CHCl}_{3}-\mathrm{d}\right): 8.58(1 \mathrm{H}, \mathrm{d}, \mathrm{J}=5.28 \mathrm{~Hz}), 8.54(1 \mathrm{H}, \mathrm{d}, \mathrm{J}=5.34 \mathrm{~Hz}), 8.01$ $(1 \mathrm{H}, \mathrm{dd}, \mathrm{J}=8.43,1.20 \mathrm{~Hz}), 7.97(1 \mathrm{H}, \mathrm{d}, \mathrm{J}=2.14 \mathrm{~Hz}), 7.77-7.81(2 \mathrm{H}, \mathrm{m}), 7.68(1 \mathrm{H}$, ddd, J = 8.46, 6.84, $1.29 \mathrm{~Hz}), 7.51(1 \mathrm{H}, \mathrm{ddd}, \mathrm{J}=8.38,6.84,1.30 \mathrm{~Hz}), 7.37(1 \mathrm{H}, \mathrm{dd}, \mathrm{J}=$ 8.88, $2.16 \mathrm{~Hz}), 7.11(1 \mathrm{H}, \mathrm{br} \mathrm{t}, \mathrm{J}=4.14 \mathrm{~Hz}), 6.49(1 \mathrm{H}, \mathrm{d}, \mathrm{J}=5.35 \mathrm{~Hz}), 6.38(1 \mathrm{H}, \mathrm{d}, \mathrm{J}=$ $5.38 \mathrm{~Hz}), 4.93(1 \mathrm{H}, \mathrm{br} d, \mathrm{~J}=6.80 \mathrm{~Hz}), 3.66-3.69(1 \mathrm{H}, \mathrm{m}), 3.43(2 \mathrm{H}, \mathrm{td}, \mathrm{J}=5.97,4.29$ 
Hz), 3.05-3.08 (2 H, m), $2.68(2 \mathrm{H}, \mathrm{t}, \mathrm{J}=5.61 \mathrm{~Hz}), 2.30(4 \mathrm{H}, \mathrm{d}, \mathrm{J}=14.10 \mathrm{~Hz}), 1.99(2 \mathrm{H}$, apparent p, $\mathrm{J}=5.72 \mathrm{~Hz}), 1.72-1.81(2 \mathrm{H}, \mathrm{m})$.

${ }^{13} \mathrm{C}$ NMR $\delta(\mathrm{ppm})\left(\mathrm{DMSO}_{\mathrm{d}}\right): 151.9,150.7,150.1,149.1,149.0,148.5,133.3,129.0$, $128.7,127.5,124.1,124.0,123.6,122.0,118.9,117.4,98.6,98.6,55.7,52.4,49.5,41.0$, $31.1,25.3$.

MS (ESI): $m / z$ 446.21091 M + H (calculated 446.21060)

HPLC (method A) $t_{\mathrm{R}}=6.35$ min $(93 \%$ pure). (An additional peak elutes at 6.94 minutes, $6 \%$.)

\section{PL339: $N$-(3-(4-(quinolin-4-ylamino)piperidin-1-yl)propyl)quinolin-4-amine}

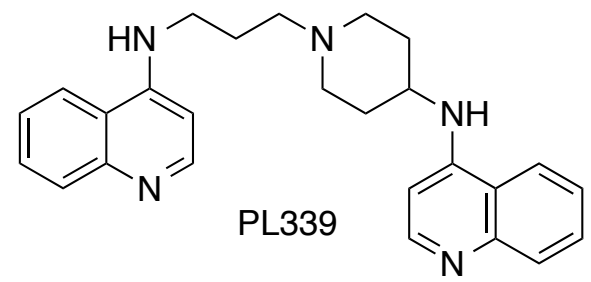

3-(quinolin-4-ylamino)propyl methanesulfonate (0.76 g, $0.00271 \mathrm{~mol})$, PL378 (0.65 g, $0.00285 \mathrm{~mol}), \mathrm{K}_{2} \mathrm{CO}_{3}(0.56 \mathrm{~g}, 0.00407 \mathrm{~mol})$, and a catalytic amount of potassium iodide were heated for 24 hours in refluxing acetonitrile $(40 \mathrm{~mL})$, at which point TLC indicated that reaction was complete. After dilution with $10 \mathrm{~mL}$ water, the acetonitrile was removed by evaporation under reduced pressure with warming, and the residue was combined with dichloromethane $(30 \mathrm{~mL})$ and water $(30 \mathrm{~mL})$. An undissolved tan solid was removed by filtration, rinsing with dichloromethane and water. The dichloromethane and water layers were separated, and the aqueous layer was extracted with dichloromethane $(3 \times 10 \mathrm{~mL})$, followed by drying of the pooled organic layers $\left(\mathrm{MgSO}_{4}\right)$ and evaporation under reduced pressure with warming to yield a yellow solid. NMR indicated that this was primarily starting material, whereas the solid from filtration was primarily the desired product. The latter was dissolved in excess boiling $95 \%$ ethanol, and allowed to evaporate gradually (at room temperature) to approximately 10 $\mathrm{mL}$. Filtration afforded a tan solid $(0.80 \mathrm{~g})$. This material was further purified by automated flash chromatography on alumina, eluting with a gradient of $100 \%$ hexanes to $100 \%$ ethyl acetate. The desired product was obtained as a white solid $(0.29 \mathrm{~g}, 26 \%, \mathrm{mp}$ $=190.2-191.8^{\circ} \mathrm{C}, \mathrm{R}_{\mathrm{f}}=0.14$ (alumina, $\left.10 / 90 \mathrm{MeOH} / \mathrm{EA} \mathrm{v} / \mathrm{v}\right)$ ). 
${ }^{1} \mathrm{H}$ NMR $\delta(\mathrm{ppm})\left(\mathrm{CHCl}_{3}-\mathrm{d}\right): 8.56-8.58(2 \mathrm{H}, \mathrm{m}), 7.95-8.04(2 \mathrm{H}, \mathrm{m}), 7.87(1 \mathrm{H}, \mathrm{dd}, \mathrm{J}=$ 8.38, 1.31 Hz), $7.77(1 \mathrm{H}, \mathrm{dd}, \mathrm{J}=8.41,1.25 \mathrm{~Hz}), 7.65-7.65(2 \mathrm{H}, \mathrm{m}), 7.49-7.49(1 \mathrm{H}, \mathrm{m})$, 7.41-7.41 (1 H, m), $7.01(1 \mathrm{H}$, br t, $\mathrm{J}=4.25 \mathrm{~Hz}), 6.49(1 \mathrm{H}, \mathrm{d}, \mathrm{J}=5.35 \mathrm{~Hz}), 6.40(1 \mathrm{H}, \mathrm{d}$, $\mathrm{J}=5.34 \mathrm{~Hz}), 4.95(1 \mathrm{H}, \mathrm{br} \mathrm{d}, \mathrm{J}=6.91 \mathrm{~Hz}), 3.66-3.66(1 \mathrm{H}, \mathrm{m}), 3.43(2 \mathrm{H}, \mathrm{td}, \mathrm{J}=6.02$, $4.41 \mathrm{~Hz}), 3.04-3.10(2 \mathrm{H}, \mathrm{m}), 2.66-2.68(2 \mathrm{H}, \mathrm{m}), 2.22-2.35$ (4 H, m), 1.99 (2 H, p, J = $5.79 \mathrm{~Hz}), 1.77-1.80(2 \mathrm{H}, \mathrm{m})$.

MS (ESI): $m / z$ 412.25005 M + H (calculated 412.24957)

HPLC (method A) $t_{\mathrm{R}}=4.06 \min (97 \%$ pure $)$.

\section{PL335: 7-chloro- $N$-(1-(3-((8-(trifluoromethyl)quinolin-4-yl)amino)propyl)piperidin- 4-yl)quinolin-4-amine}<smiles>FC(F)(F)c1cccc2c(NCCCN3CCC(Nc4ccnc5cc(Cl)ccc45)CC3)ccnc12</smiles>

3-(8-(trifluoromethyl)quinolin-4-ylamino)propyl methanesulfonate $(0.50 \mathrm{~g}, 0.00144$ $\mathrm{mol})$, PL294 (0.39 g, $0.00151 \mathrm{~mol}), \mathrm{K}_{2} \mathrm{CO}_{3}(0.20 \mathrm{~g}, 0.00145 \mathrm{~mol})$, and a catalytic amount of potassium iodide were heated for 5 days in refluxing acetonitrile $(40 \mathrm{~mL})$, at which point TLC indicated that reaction was complete. After dilution with $10 \mathrm{~mL}$ water, the acetonitrile was removed by evaporation under reduced pressure with warming, and the residue was combined with chloroform $(30 \mathrm{~mL})$ and water $(30 \mathrm{~mL})$. A beige solid remained undissolved and was removed by filtration, rinsing with chloroform and water. After separation of the chloroform and water layers, the aqueous layer was extracted with chloroform $(3 \times 7 \mathrm{~mL})$, and the pooled organic layers were dried $\left(\mathrm{MgSO}_{4}\right)$ and evaporated under reduced pressure with warming to yield a pale yellow, waxy solid, $0.09 \mathrm{~g}$. NMR indicated that the solid from filtration was primarily the desired product. This was dissolved in excess boiling $95 \%$ ethanol, and allowed to evaporate gradually (at room temperature) to approximately $10 \mathrm{~mL}$. Filtration afforded the desired product as sparkling, beige crystals $\left(0.52 \mathrm{~g}, 70 \%, \mathrm{mp}=225-233^{\circ} \mathrm{C}(\mathrm{dec})\right)$.

${ }^{1} \mathrm{H}$ NMR $\delta(\mathrm{ppm})\left(\mathrm{DMSO}_{6}\right): 8.49-8.52(2 \mathrm{H}, \mathrm{m}), 8.36-8.39(2 \mathrm{H}, \mathrm{m}), 8.03(1 \mathrm{H}, \mathrm{d}, \mathrm{J}=$ $7.29 \mathrm{~Hz}), 7.78(1 \mathrm{H}, \mathrm{d}, \mathrm{J}=2.25 \mathrm{~Hz}), 7.53-7.57(2 \mathrm{H}, \mathrm{m}), 7.45(1 \mathrm{H}, \mathrm{dd}, \mathrm{J}=9.01,2.28$ $\mathrm{Hz}), 6.98(1 \mathrm{H}$, br d, J = 7.48 Hz), $6.62(1 \mathrm{H}, \mathrm{d}, \mathrm{J}=5.50 \mathrm{~Hz}), 6.55(1 \mathrm{H}, \mathrm{d}, \mathrm{J}=5.57 \mathrm{~Hz})$, 3.44-3.53 (1 H, m), 3.35-3.36 (2 H, m), $2.96(2 \mathrm{H}, \mathrm{m}), 2.44-2.47(2 \mathrm{H}, \mathrm{m}), 2.09$ (2 H, t, J $=11.56 \mathrm{~Hz}), 1.99(2 \mathrm{H}, \mathrm{m}), 1.86(2 \mathrm{H}$, apparent $\mathrm{p}, \mathrm{J}=6.74 \mathrm{~Hz}), 1.62-1.71(2 \mathrm{H}, \mathrm{m})$. 
${ }^{13} \mathrm{C}$ NMR $\delta$ (ppm)(DMSO-d 6 ): 151.9, 151.4, 150.3, 149.3, 149.1, 144.9, 133.4, 127.4, $126.7,124.4,123.9,123.1,122.4,119.4,117.5,99.1,99.0,55.6,52.3,49.6,40.9,31.0$, 25.3 .

MS (ESI): $m / z$ 514.19866 M + H (calculated 514.19798)

$\operatorname{HPLC}\left(\right.$ method A) $t_{\mathrm{R}}=6.53 \min (99 \%$ pure $)$.

\section{PL341: 8-(trifluoromethyl)- $N$-(3-(4-((8-(trifluoromethyl)quinolin-4- yl)amino)piperidin-1-yl)propyl)quinolin-4-amine}

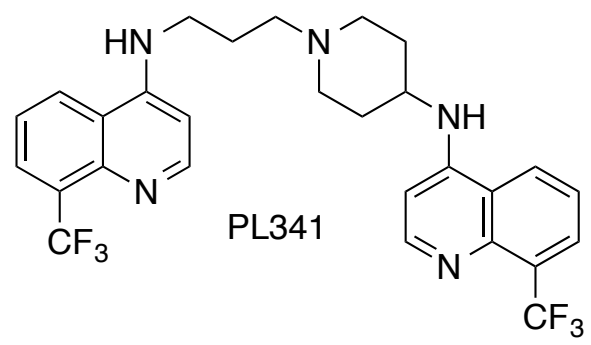

3-(8-(trifluoromethyl)quinolin-4-ylamino)propyl methanesulfonate $(0.66 \mathrm{~g}, 1.9 \mathrm{mmol})$, PL368 (0.59 g, $2.0 \mathrm{mmol}), \mathrm{K}_{2} \mathrm{CO}_{3}(0.39 \mathrm{~g}, 2.8 \mathrm{mmol})$, and a catalytic amount of potassium iodide were heated for 27 hours in refluxing acetonitrile $(50 \mathrm{~mL})$, at which point TLC indicated that reaction was complete; however, heating at reflux was continued for an additional 18 hours. The solvent was removed by evaporation under reduced pressure with warming, and the resulting golden brown solid was combined with chloroform $(30 \mathrm{~mL})$ and water $(30 \mathrm{~mL})$. A large amount of solid material remained undissolved and was removed by filtration, rinsing with chloroform and water (a white solid). This material was dissolved in excess boiling ethyl acetate, followed by gradual evaporation at room temperature to induce crystallization. The fine, off-white crystals thus obtained proved to be the desired product $(0.20 \mathrm{~g}, 19 \%)$.

${ }^{1} \mathrm{H}$ NMR $\delta(\mathrm{ppm})\left(\mathrm{CHCl}_{3}-\mathrm{d}\right): 8.72(1 \mathrm{H}, \mathrm{d}, \mathrm{J}=5.35 \mathrm{~Hz}), 8.69(1 \mathrm{H}, \mathrm{d}, \mathrm{J}=5.35 \mathrm{~Hz}), 8.03-$ $8.07(2 \mathrm{H}, \mathrm{m}), 7.96-8.00(2 \mathrm{H}, \mathrm{m}), 7.52(1 \mathrm{H}, \mathrm{dd}, \mathrm{J}=8.41,7.33 \mathrm{~Hz}), 7.42(1 \mathrm{H}, \mathrm{dd}, \mathrm{J}=$ 8.41, 7.27 Hz), $7.09(1 \mathrm{H}$, br t, J = 4.24 Hz), $6.58(1 \mathrm{H}, \mathrm{d}, \mathrm{J}=5.41 \mathrm{~Hz}), 6.48(1 \mathrm{H}, \mathrm{d}, \mathrm{J}=$ $5.41 \mathrm{~Hz}), 4.97(1 \mathrm{H}, \mathrm{br}$ d, J = 6.71 Hz), 3.66-3.69 $(1 \mathrm{H}, \mathrm{m}), 3.44(2 \mathrm{H}, \mathrm{td}, \mathrm{J}=6.01,4.30$ $\mathrm{Hz}), 3.06-3.09(2 \mathrm{H}, \mathrm{m}), 2.68(2 \mathrm{H}, \mathrm{t}, \mathrm{J}=5.59 \mathrm{~Hz}), 2.28-2.33(4 \mathrm{H}, \mathrm{m}), 1.99-2.05(2 \mathrm{H}$, apparent $\mathrm{p}, \mathrm{J}=5.69 \mathrm{~Hz}), 1.73-1.82(2 \mathrm{H}, \mathrm{m})$.

${ }^{13} \mathrm{C}$ NMR $\delta(\mathrm{ppm})\left(\mathrm{CHCl}_{3}\right.$-d): 152.0, 151.7, 150.4, 148.3, 145.6, 145.5, 127.7, 127.4, 124.6, 123.5, 123.2, 122.3, 119.8, 119.4, 100.1, 99.3, 58.2, 52.5, 43.9, 32.0, 24.3. 
MS (ESI): $m / z 548.22434 \mathrm{M}+\mathrm{H}$ (calculated 548.22519)

HPLC (method A) $t_{\mathrm{R}}=6.93 \min (99 \%$ pure $)$.

\section{PL340: 7-chloro- $N$-(3-(4-((8-(trifluoromethyl)quinolin-4-yl)amino)piperidin-1- yl)propyl)quinolin-4-amine}<smiles></smiles>

PL29 (0.59 g, $1.9 \mathrm{mmol})$, PL368 (0.58 g, $2.0 \mathrm{mmol}), \mathrm{K}_{2} \mathrm{CO}_{3}(0.39 \mathrm{~g}, 2.8 \mathrm{mmol})$, and a catalytic amount of potassium iodide were heated for 24 hours in refluxing acetonitrile $(50 \mathrm{~mL})$, at which point TLC indicated that reaction was complete. The solvent was removed by evaporation under reduced pressure with warming, and the resulting ochre solid was combined with chloroform $(30 \mathrm{~mL})$ and water $(30 \mathrm{~mL})$. A large amount of solid material remained undissolved and was removed by filtration, rinsing with chloroform and water. The chloroform and water layers of the filtrate were separated, and the aqueous layer was extracted with chloroform $(3 \times 10 \mathrm{~mL})$, dried $\left(\mathrm{MgSO}_{4}\right)$, and evaporated under reduced pressure with warming. This material was combined with the insoluble material from extraction (above), and taken up in excess boiling $95 \%$ ethanol. This was allowed to cool and evaporate gradually at room temperature. The crystals that formed were recovered by filtration and further purified by automated flash chromatography on basic alumina, eluting with a gradient of $100 \%$ hexanes to $100 \%$ ethyl acetate. The desired product was obtained as a beige solid $(0.38 \mathrm{~g}, 40 \%, \mathrm{mp}=205$ $207^{\circ} \mathrm{C}, \mathrm{R}_{\mathrm{f}}=0.2$ (alumina, EA)).

${ }^{1} \mathrm{H}$ NMR $\delta(\mathrm{ppm})\left(\mathrm{CHCl}_{3}-\mathrm{d}\right): 8.72(1 \mathrm{H}, \mathrm{d}, \mathrm{J}=5.35 \mathrm{~Hz}), 8.54(1 \mathrm{H}, \mathrm{d}, \mathrm{J}=5.35 \mathrm{~Hz}), 8.04$ $(1 \mathrm{H}, \mathrm{d}, \mathrm{J}=7.31 \mathrm{~Hz}), 7.99(1 \mathrm{H}, \mathrm{d}, \mathrm{J}=8.53 \mathrm{~Hz}), 7.97(1 \mathrm{H}, \mathrm{d}, \mathrm{J}=2.15 \mathrm{~Hz}), 7.78(1 \mathrm{H}, \mathrm{d}, \mathrm{J}$ $=8.92 \mathrm{~Hz}), 7.53(1 \mathrm{H}, \mathrm{dd}, \mathrm{J}=8.44,7.30 \mathrm{~Hz}), 7.35(1 \mathrm{H}, \mathrm{dd}, \mathrm{J}=8.88,2.17 \mathrm{~Hz}), 7.03(1 \mathrm{H}$, br t, J = 4.28 Hz), $6.58(1 \mathrm{H}, \mathrm{d}, \mathrm{J}=5.41 \mathrm{~Hz}), 6.38(1 \mathrm{H}, \mathrm{d}, \mathrm{J}=5.39 \mathrm{~Hz}), 4.98(1 \mathrm{H}, \mathrm{br} \mathrm{d}, \mathrm{J}$ $=6.79 \mathrm{~Hz}), 3.66-3.68(1 \mathrm{H}, \mathrm{m}), 3.43(2 \mathrm{H}, \mathrm{td}, \mathrm{J}=5.99,4.32 \mathrm{~Hz}), 3.06-3.09(2 \mathrm{H}, \mathrm{m}), 2.68$ $(2 \mathrm{H}, \mathrm{t}, \mathrm{J}=5.59 \mathrm{~Hz}), 2.28-2.35(4 \mathrm{H}, \mathrm{m}), 1.99(2 \mathrm{H}$, apparent $\mathrm{p}, \mathrm{J}=5.69 \mathrm{~Hz}), 1.71-1.80(2$ $\mathrm{H}, \mathrm{m})$. 
${ }^{13} \mathrm{C}$ NMR $\delta(\mathrm{ppm})\left(\mathrm{DMSO}_{\mathrm{d}}\right): 151.9,151.3,150.1,149.3,149.0,145.0,133.3,127.4$, 127.1, 125.8, 124.0, 123.9, 122.1, 119.3, 117.4, 99.5, 98.5, 55.6, 52.3, 49.6, 40.9, 30.9, 25.3 .

MS (ESI): $m / z$ 514.19879 M + H (calculated 514.19798)

$\operatorname{HPLC}(\operatorname{method} \mathrm{A}) t_{\mathrm{R}}=6.95 \min (>99 \%$ pure$)$.

\section{A.7.3: Original method used to synthesize PL241 (for primary method, see page} 316)

PL67: N-(3-(4-aminopiperidin-1-yl)propyl)-7-chloroquinolin-4-amine (Burgess, 2008):

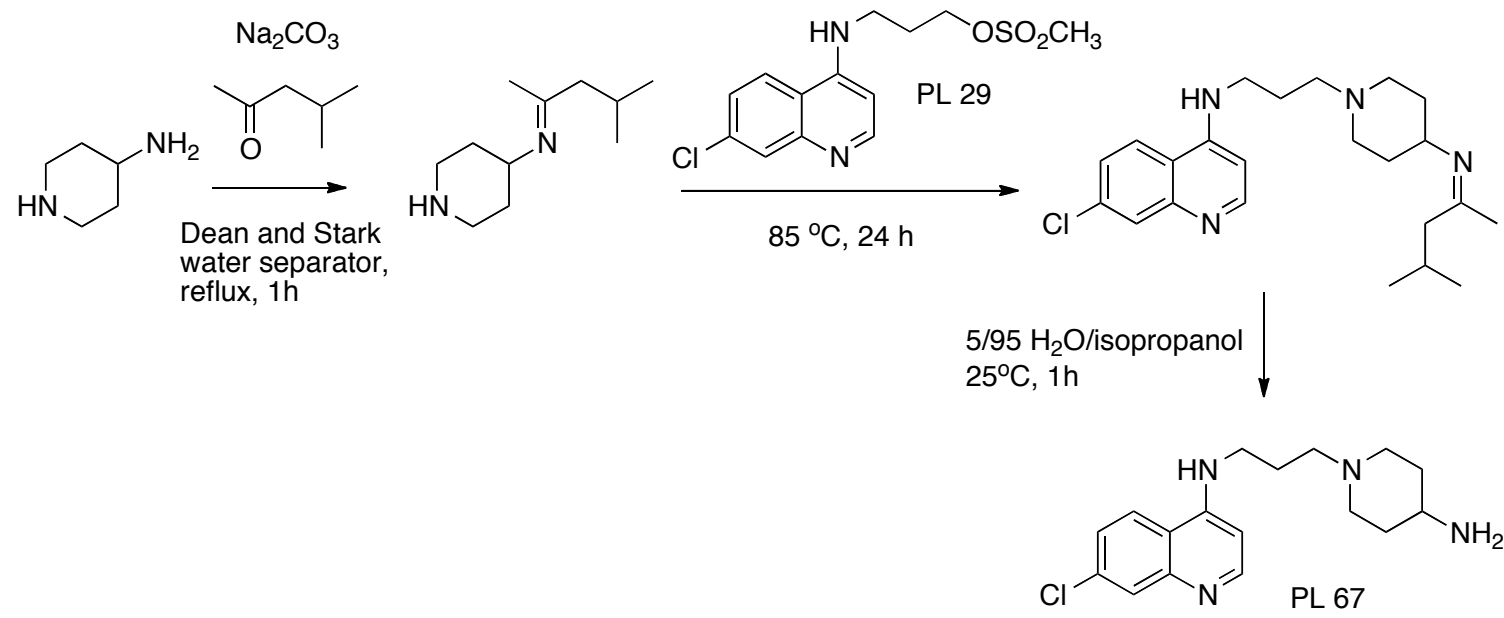

Methyl isobutyl ketone, $125 \mathrm{~mL}$, was allowed to reflux in a round bottom flask equipped with a Dean and Stark water separator. After 30 minutes, sodium carbonate $(0.74 \mathrm{~g}, 7.0$ mmol) and 4-aminopiperidine $(0.580 \mathrm{~mL}, 5.5 \mathrm{mmol})$ were added and reflux was continued for 1 hour, at the end of which time TLC indicated that no more of the amine starting material was present. The reaction was allowed to cool to $85^{\circ} \mathrm{C}$, and PL29 $(1.45$ $\mathrm{g}, 4.6 \mathrm{mmol})$ was added. After 16 hours had elapsed, TLC indicated that no more PL29 was present. The reaction mixture was washed with water $(50 \mathrm{~mL})$ to remove sodium carbonate, and the solvent was then evaporated under reduced pressure. The resulting amber oil was stirred for 1.5 hours in a mixture of $50 \mathrm{~mL}$ isopropanol and $5 \mathrm{~mL}$ water, and the solvent was then evaporated under reduced pressure. The resulting liquid was partitioned between ethyl acetate $(20 \mathrm{~mL})$ and saturated sodium bicarbonate $(25 \mathrm{~mL})$, and the aqueous layer was extracted with additional ethyl acetate $(3 \times 10 \mathrm{~mL})$. During this procedure, a yellow oil remained insoluble; NMR indicated that this was pure product. After removal of water therefrom by heating under reduced pressure, this material was used without further purification. 
PL241, original method (Based upon Andersag, 1948; Surrey, 1951; Burgess, 2008):

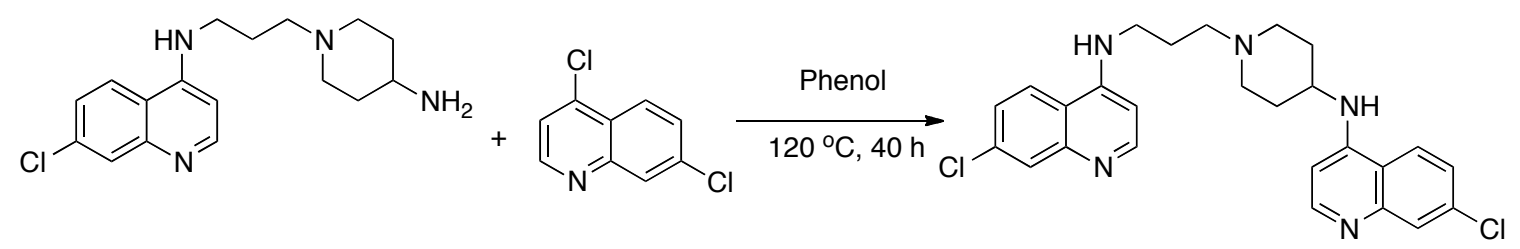

PL 67 (0.30 g, approximately $0.94 \mathrm{mmol})$, 4,7-dichloroquinoline (0.59g, $3.00 \mathrm{mmol})$, and $1.3 \mathrm{~g}$ phenol were heated for 40 hours at $120^{\circ} \mathrm{C}$. The resulting dark brown oil was taken up in dichloromethane $(20 \mathrm{~mL})$ and washed with $1.0 \mathrm{M}$ caustic soda $(6 \times 10 \mathrm{~mL})$, followed by brine $(10 \mathrm{~mL})$. The organic layer was dried over anhydrous magnesium sulfate and evaporated under reduced pressure to yield a brown oil. This was purified by column chromatography on alumina, eluting with ethyl acetate and then with 95/5 ethyl acetate/methanol $(\mathrm{v} / \mathrm{v})$. The resulting solid was recrystallized using a Craig tube from 4:1 ethyl acetate:methanol, which afforded the desired product as a beige solid $(0.034 \mathrm{~g}, 7 \%$, $\mathrm{R}_{\mathrm{f}}=0.6$ (basic alumina, $\left.\mathrm{EA} / \mathrm{MeOH}, 85 / 15, \mathrm{v} / \mathrm{v}\right)$ ). 


\section{APPENDIX B: Tables of antiplasmodial activity and cytotoxicity}

Table B1: Ring-modified Reversed Chloroquine type compounds and their in vitro activity against $\boldsymbol{P}$. falciparum malaria

Note: Organized by reversal agent moiety.

\begin{tabular}{|c|c|c|c|c|c|}
\hline \multirow{2}{*}{$\begin{array}{l}\text { Code } \\
\text { number }\end{array}$} & \multirow{2}{*}{$\begin{array}{l}\text { Quinoline } \\
\text { ring system } \\
\text { substitution }\end{array}$} & \multicolumn{3}{|c|}{$\mathrm{IC}_{50}(\mathrm{nM})$} & \multirow{2}{*}{ Structure } \\
\hline & & D6 & Dd2 & $7 \mathrm{G} 8$ & \\
\hline $\begin{array}{c}\mathrm{CQ} \\
\text { (purchased) }\end{array}$ & 7-Cl & 6.9 & 102 & 106 & \\
\hline $\begin{array}{l}\text { PL127 } \\
\text { (Steven } \\
\text { Burgess) }\end{array}$ & None $(\mathrm{H})$ & 90 & $>250$ & $>250$ & \\
\hline $\begin{array}{c}\text { PL64 } \\
\text { (Steven } \\
\text { Burgess) }\end{array}$ & None $(\mathrm{H})$ & 0.88 & 5.0 & - & \\
\hline $\begin{array}{c}\text { PL06 } \\
\text { (Steven } \\
\text { Burgess) }\end{array}$ & 7-Cl & 1.9 & 2.6 & 11 & \\
\hline PL270 & 6-Cl & 3.4 & 7.9 & 29 & \\
\hline PL271 & $8-\mathrm{Cl}$ & 66 & $>250$ & $>250$ & \\
\hline
\end{tabular}




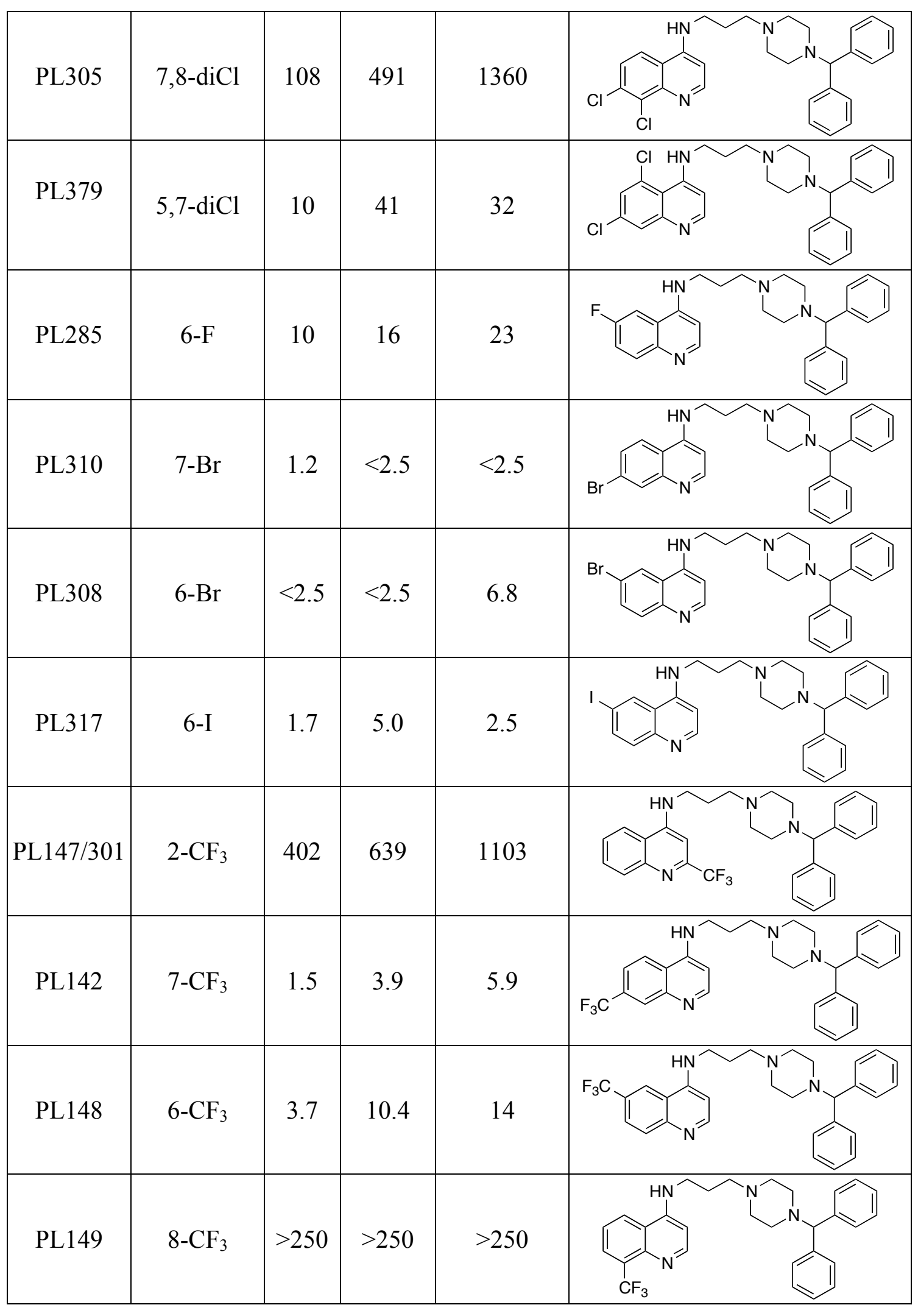




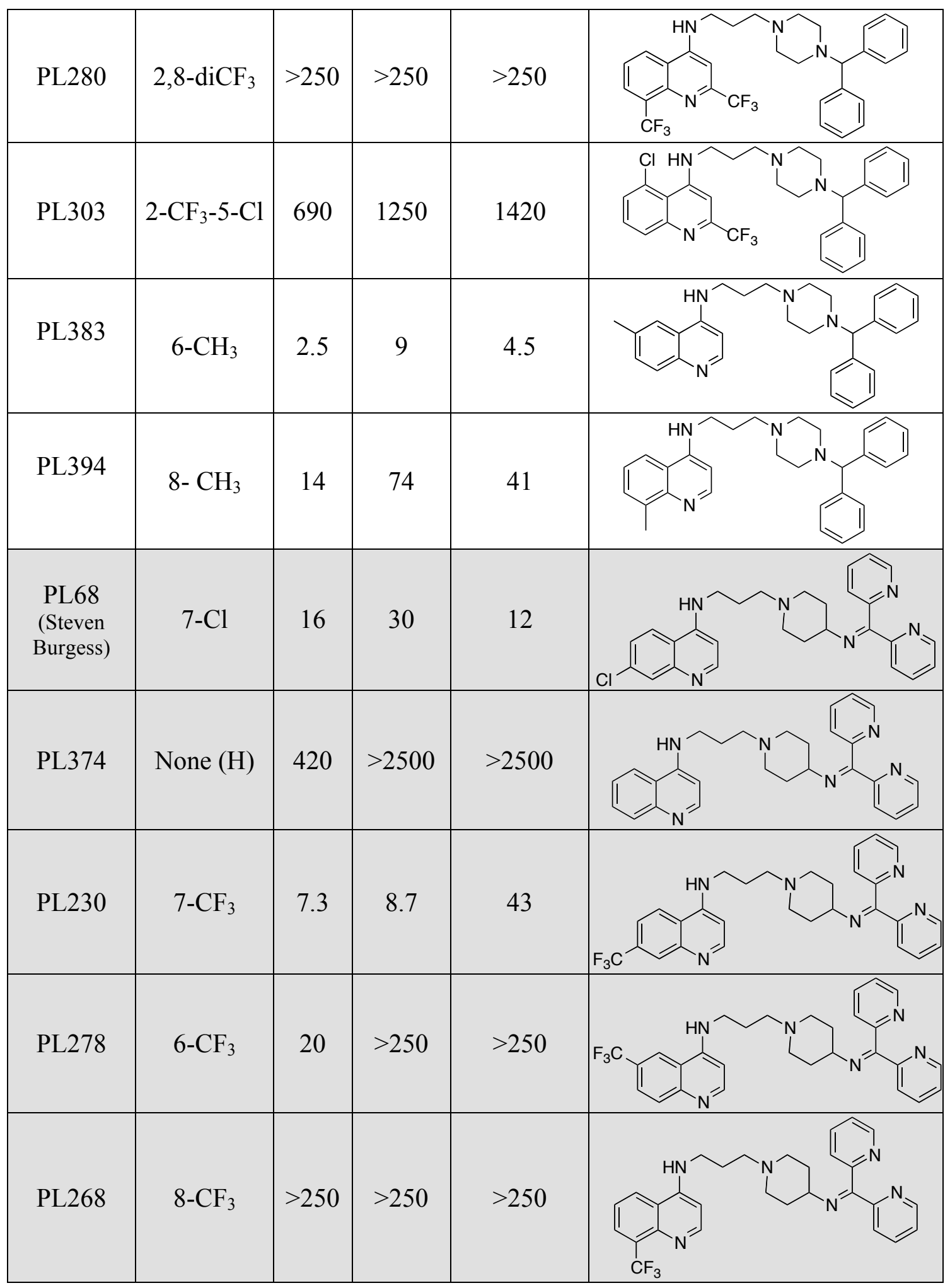




\begin{tabular}{|c|c|c|c|c|c|}
\hline $\begin{array}{c}\text { PL69 } \\
\text { (Steven } \\
\text { Burgess) }\end{array}$ & 7-Cl & 0.9 & 2.2 & 1.8 & \\
\hline PL375 & None $(\mathrm{H})$ & 28 & 789 & 261 & \\
\hline PL242 & $7-\mathrm{CF}_{3}$ & 2.4 & 1.3 & 1.1 & \\
\hline PL279 & $6-\mathrm{CF}_{3}$ & 5.2 & 11 & 7.9 & \\
\hline PL269 & $8-\mathrm{CF}_{3}$ & $>250$ & $>250$ & $>250$ & \\
\hline $\begin{array}{l}\text { PL106 } \\
\text { (Bornface } \\
\text { Gunsaru) }\end{array}$ & 7-Cl & 3.0 & 6.0 & 6.1 & \\
\hline PL283 & $6-\mathrm{Cl}$ & 9.2 & 22 & 25 & \\
\hline PL284 & $8-\mathrm{Cl}$ & 465 & $>2500$ & 1570 & \\
\hline PL367 & 5,7-diCl & 33 & 67 & 83 & \\
\hline PL307 & 6,7-diCl & $<2.5$ & $<2.5$ & 6.8 & \\
\hline
\end{tabular}




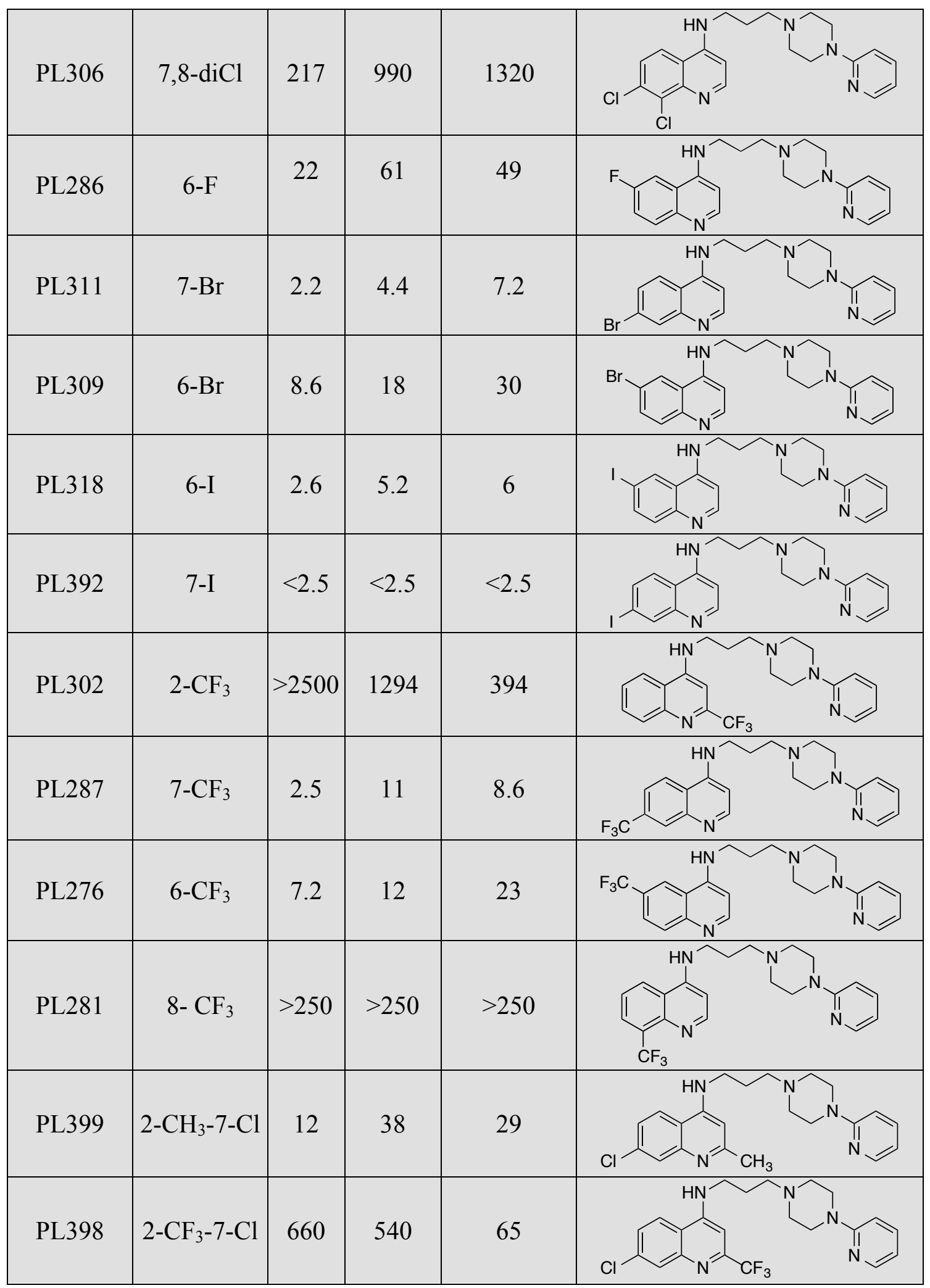




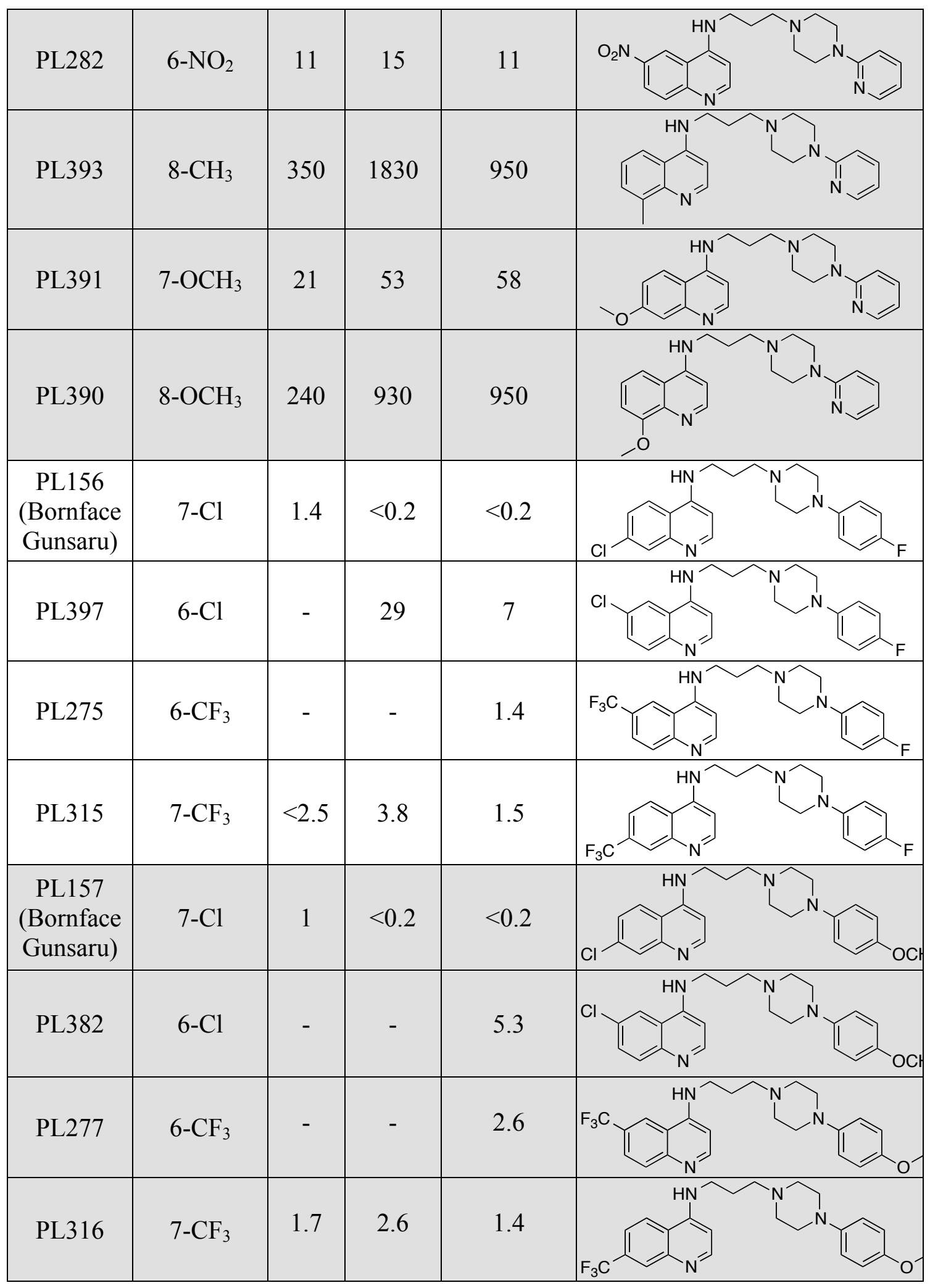




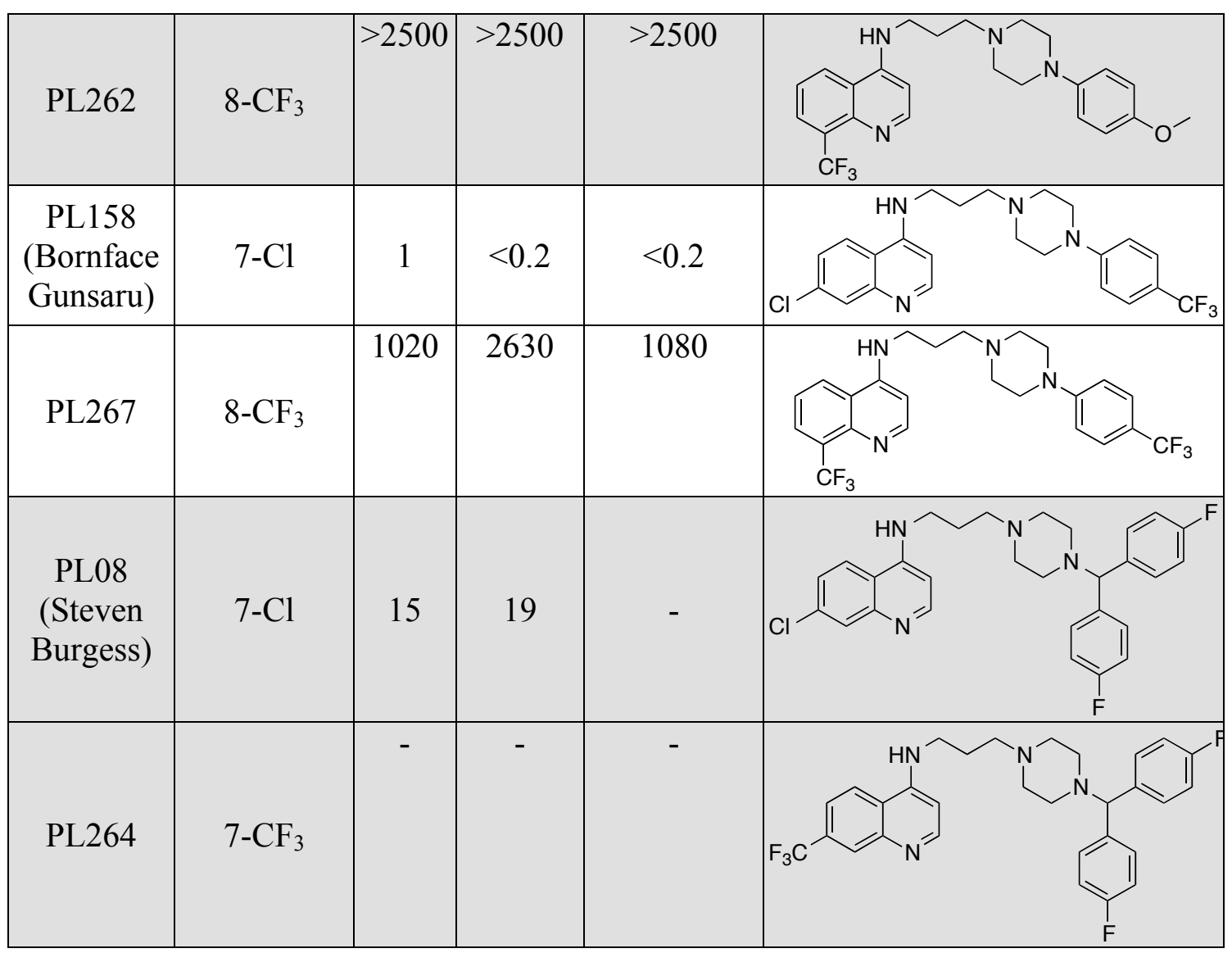


Table B2: Comparison of in vitro activity of 6- and 7- substituted compounds (against $P$. falciparum)

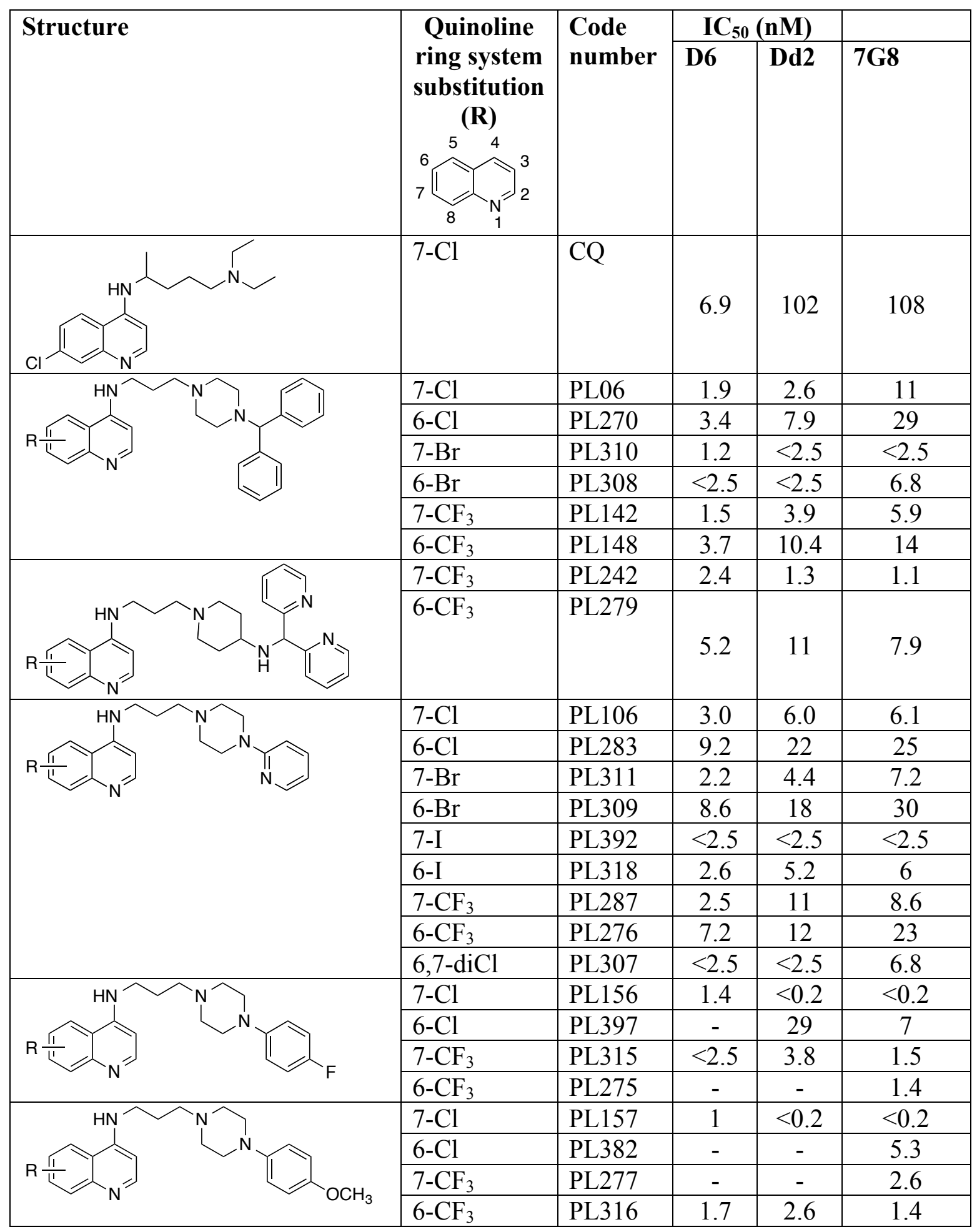


Table B3: Comparison of in vitro activity of chloro-, bromo-, and fluoro- substituted compounds (against $P$. falciparum)

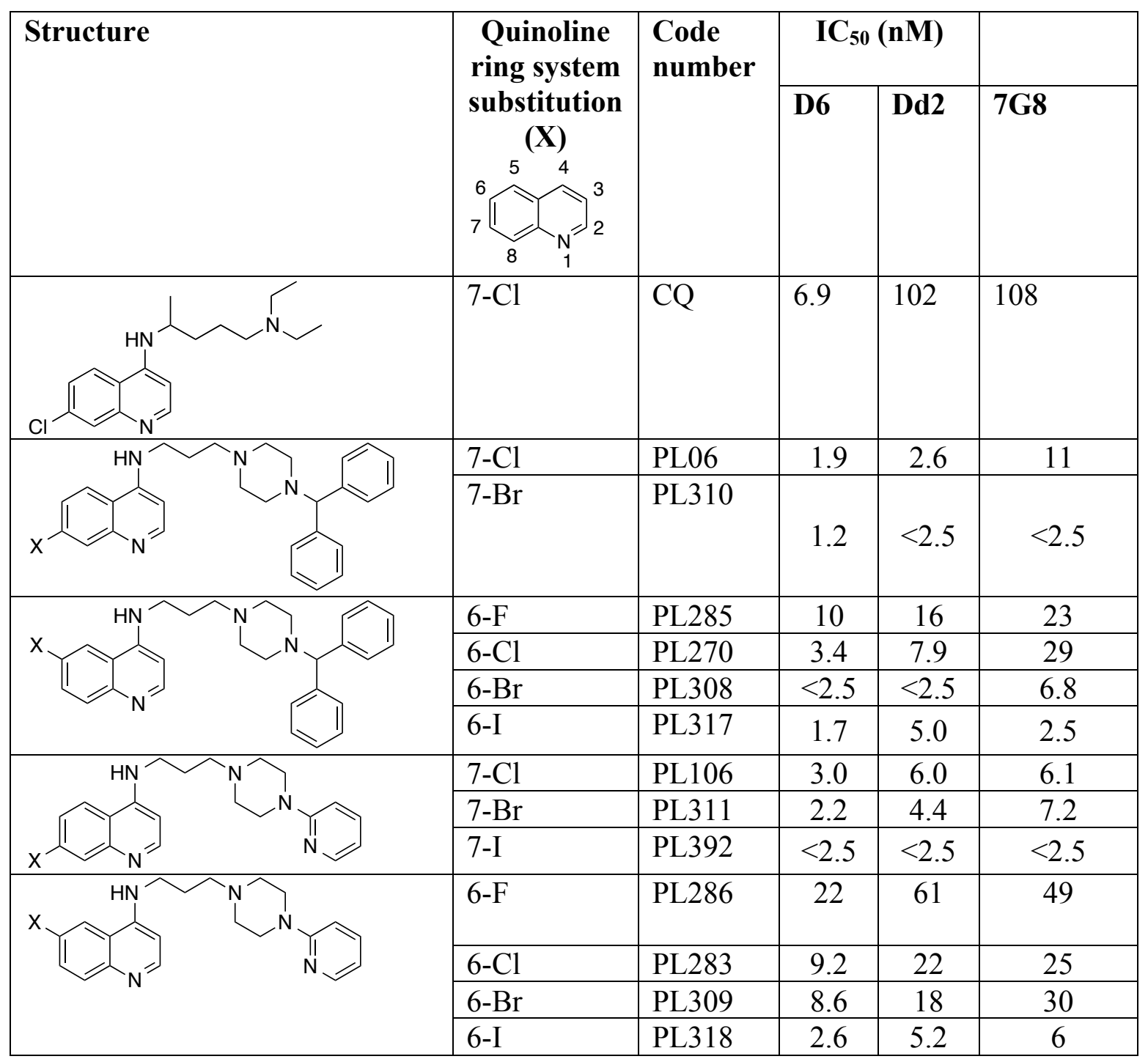


Table B4: Comparison of in vitro activity of chloro-, trifluoromethyl-, and nitrosubstituted compounds (against $P$. falciparum)

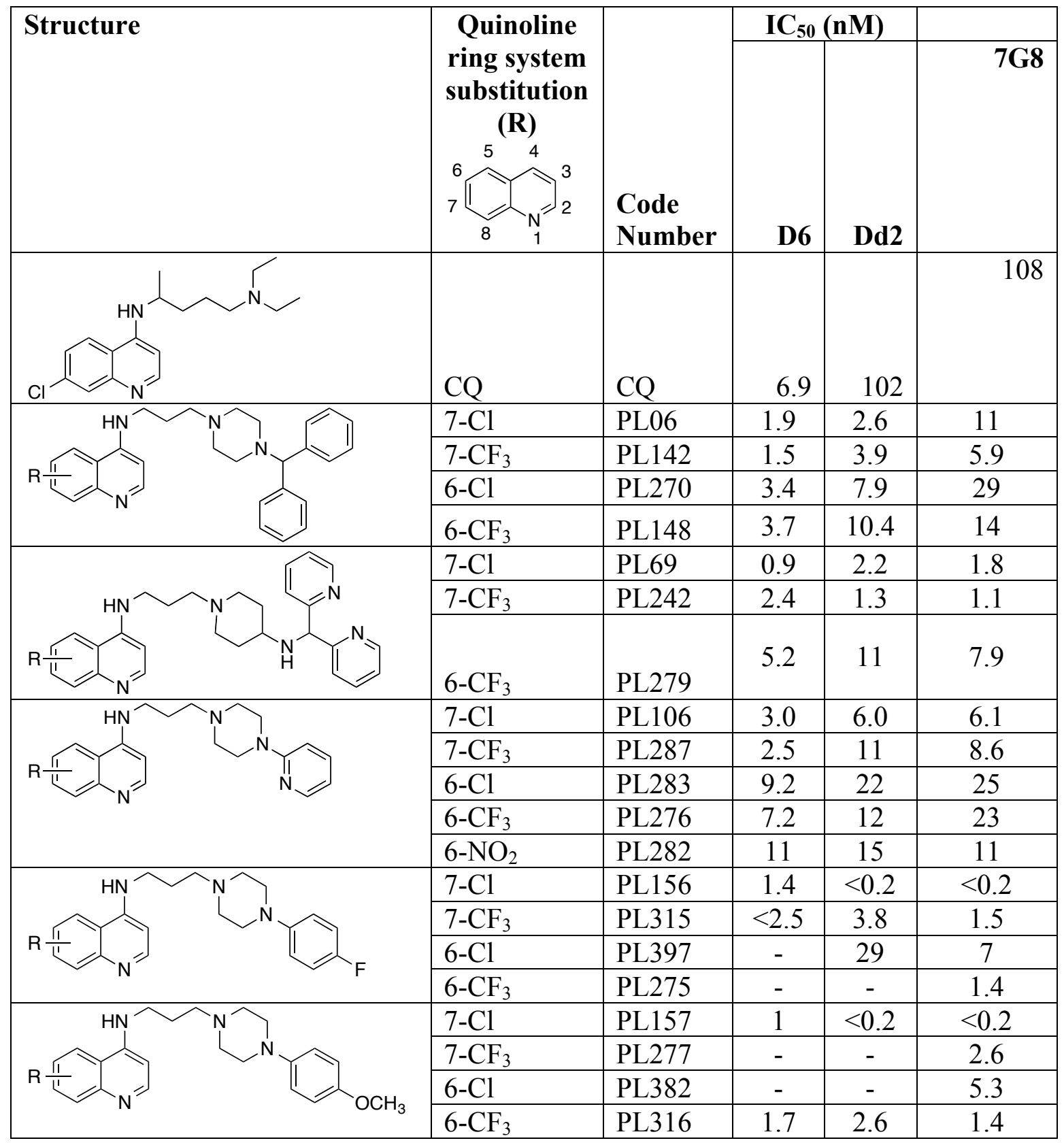


Table B5: Comparison of in vitro activity of chloro-, des-chloro-, methyl, and methoxy- substituted compounds (against $P$. falciparum)

\begin{tabular}{|c|c|c|c|c|c|}
\hline \multirow[t]{2}{*}{ Structure } & \multirow[b]{2}{*}{$\begin{array}{l}\text { Quinoline } \\
\text { ring system } \\
\text { substitution }\end{array}$} & \multirow[b]{2}{*}{$\begin{array}{l}\text { Code } \\
\text { Number }\end{array}$} & \multicolumn{2}{|c|}{$\mathrm{IC}_{50}(\mathrm{nM})$} & \multirow[b]{2}{*}{$7 G 8$} \\
\hline & & & D6 & Dd2 & \\
\hline & $\mathrm{CQ}$ & $\mathrm{CQ}$ & 6.9 & 102 & 108 \\
\hline & None $(\mathrm{H})$ & $\begin{array}{l}\text { PL127 } \\
\text { (Steven } \\
\text { Burgess) }\end{array}$ & 90 & $>250$ & $>250$ \\
\hline & 7-Cl & $\begin{array}{l}\text { PL06 } \\
\text { (Steven } \\
\text { Burgess) }\end{array}$ & 1.9 & 2.6 & 11 \\
\hline & None $(\mathrm{H})$ & $\begin{array}{l}\text { PL64 } \\
\text { (Steven } \\
\text { Burgess) }\end{array}$ & 0.88 & 5.0 & - \\
\hline & $6-\mathrm{Cl}$ & PL270 & 3.4 & 7.9 & 29 \\
\hline & $6-\mathrm{CH}_{3}$ & PL383 & 2.5 & 9 & 4.5 \\
\hline & $8-\mathrm{Cl}$ & PL271 & 66 & $>250$ & $>250$ \\
\hline & $8-\mathrm{CH}_{3}$ & PL394 & 14 & 74 & 41 \\
\hline & $7-\mathrm{Cl}$ & PL106 & 3.0 & 6.0 & 6.1 \\
\hline & $7-\mathrm{OCH}_{3}$ & PL391 & 21 & 53 & 58 \\
\hline & $8-\mathrm{Cl}$ & PL284 & 465 & $>2500$ & 1570 \\
\hline & $8-\mathrm{CH}_{3}$ & PL393 & 350 & 1825 & 951 \\
\hline & $8-\mathrm{OCH}_{3}$ & PL390 & 241 & 930 & 946 \\
\hline
\end{tabular}


Table B6: In vitro activity of bis-quinoline compounds

\begin{tabular}{|c|c|c|c|c|c|}
\hline \multirow{2}{*}{$\begin{array}{l}\text { Code } \\
\text { number }\end{array}$} & \multicolumn{3}{|c|}{$\mathrm{IC}_{50}(\mathrm{nM})$} & \multirow[t]{2}{*}{ Structure } & \\
\hline & D6 & $\mathrm{Dd} 2$ & 7G8 & & \\
\hline PL241 & 0.063 & 0.054 & 0.014 & & \\
\hline PL340 & $<2.5$ & - & $<2.5$ & & \\
\hline PL335 & $<2.5$ & - & $<2.5$ & & \\
\hline PL341 & 35 & - & 259 & & \\
\hline PL337 & $<2.5$ & - & $<2.5$ & & \\
\hline PL338 & $<2.5$ & - & $<2.5$ & & \\
\hline PL339 & 17 & - & 28 & & \\
\hline
\end{tabular}


Table B7: In vitro cytotoxicity data against mouse spleen lymphocytes

\begin{tabular}{|c|c|c|}
\hline Compound & Cytotoxicity ( $\mathrm{LC}_{50}$ in $\mathrm{nM}$ ) & Structure \\
\hline Chloroquine & 12400 & \\
\hline PL06 & 1100 & \\
\hline PL64 & 1600 & \\
\hline PL69 & 6500 & \\
\hline PL106 & 13300 & \\
\hline PL142 & 12500 & \\
\hline PL148 & 4900 & \\
\hline PL149 & 11000 & \\
\hline
\end{tabular}




\begin{tabular}{|l|lll|}
\hline PL242 & 4800 & & \\
\hline PL241 & 190 & &
\end{tabular}




\section{APPENDIX C: Sample NMR spectra: PL241}

The following spectra were run at $600 \mathrm{MHz}$. The solvent used was $\mathrm{CDCl}_{3}$, except where noted (it was necessary to run an additional ${ }^{1} \mathrm{H}$ spectrum in DMSO-d6 to confirm the suspected integration of one peak that was overlapped by the water signal in $\mathrm{CDCl}_{3}$ ). TMS was used as a reference. The one-dimensional spectra shown here were processed using DataChord Spectrum Analyst 4.1.rc39, while the two-dimensional spectra were processed using Bruker Topspin 2.1.

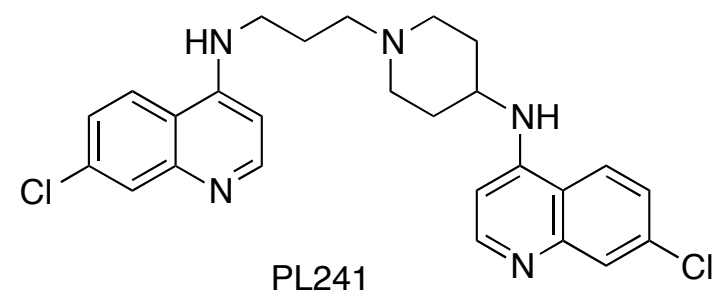

Spectral assignments (see also Appendix A, p. 310):

${ }^{1} \mathrm{H}$ NMR $\delta(\mathrm{ppm})\left(\mathrm{CHCl}_{3}-\mathrm{d}\right): 8.56\left(1 \mathrm{H}, \mathrm{d}, \mathrm{J}=5.33 \mathrm{~Hz}, \mathrm{Q}_{1}-\mathrm{C} 2-\mathrm{H}\right), 8.53(1 \mathrm{H}, \mathrm{d}, \mathrm{J}=5.33$ $\left.\mathrm{Hz}, \mathrm{Q}_{2}-\mathrm{C} 2-\mathrm{H}\right), 7.99\left(1 \mathrm{H}, \mathrm{d}, \mathrm{J}=2.16 \mathrm{~Hz}, \mathrm{Q}_{1}-\mathrm{C} 8-\mathrm{H}\right), 7.97\left(1 \mathrm{H}, \mathrm{d}, \mathrm{J}=2.14 \mathrm{~Hz}, \mathrm{Q}_{2}-\mathrm{C} 8-\mathrm{H}\right)$, $7.78\left(1 \mathrm{H}, \mathrm{d}, \mathrm{J}=8.90 \mathrm{~Hz}, \mathrm{Q}_{2}-\mathrm{C} 5-\mathrm{H}\right), 7.71\left(1 \mathrm{H}, \mathrm{d}, \mathrm{J}=8.95 \mathrm{~Hz}, \mathrm{Q}_{1}-\mathrm{C} 5-\mathrm{H}\right), 7.43(1 \mathrm{H}, \mathrm{dd}, \mathrm{J}$ $\left.=8.89,2.18 \mathrm{~Hz}, \mathrm{Q}_{1}-\mathrm{C} 6-\mathrm{H}\right), 7.35\left(1 \mathrm{H}, \mathrm{dd}, \mathrm{J}=8.87,2.16 \mathrm{~Hz}, \mathrm{Q}_{2}-\mathrm{C} 6-\mathrm{H}\right), 7.02(1 \mathrm{H}, \mathrm{br} \mathrm{t}, \mathrm{J}$ $\left.=4.27 \mathrm{~Hz}, \mathrm{Q}_{1}-\mathrm{C} 4-\mathrm{NH}\right), 6.47\left(1 \mathrm{H}, \mathrm{d}, \mathrm{J}=5.37 \mathrm{~Hz}, \mathrm{Q}_{1}-\mathrm{C} 3-\mathrm{H}\right), 6.38(1 \mathrm{H}, \mathrm{d}, \mathrm{J}=5.37 \mathrm{~Hz}$, $\left.\mathrm{Q}_{2}-\mathrm{C} 3-\mathrm{H}\right), 4.92\left(1 \mathrm{H}, \mathrm{br} \mathrm{d}, \mathrm{J}=6.78 \mathrm{~Hz}, \mathrm{Q}_{2}-\mathrm{NH}\right), 3.65(1 \mathrm{H}, \mathrm{m}, \mathrm{Pip}-\mathrm{CH}), 3.42(2 \mathrm{H}, \mathrm{td}$, $\left.\mathrm{J}_{\mathrm{CH} 2}=6.01, \mathrm{~J}_{\mathrm{NH}}=4.35 \mathrm{~Hz}, \mathrm{Q}_{1}-\mathrm{NHCH}_{2} \mathrm{CH}_{2} \mathrm{CH}_{2}\right), 3.06(2 \mathrm{H}, \mathrm{m}$, piperidine-CH x 2 adjacent to alkyl chain), $2.67\left(2 \mathrm{H}, \mathrm{t}, \mathrm{J}_{\mathrm{CH} 2}=5.64 \mathrm{~Hz}, \mathrm{Q}_{1}-\mathrm{NHCH}_{2} \mathrm{CH}_{2} \mathrm{CH}_{2}\right), 2.33(2 \mathrm{H}, \mathrm{m}$, piperidine- $\mathrm{CH} \times 2$ adjacent to alkyl chain), $2.28(2 \mathrm{H}, \mathrm{m}$, piperidine $\mathrm{CH} \times 2$ adjacent to $\left.\mathrm{CH}-\mathrm{NH}-\mathrm{Q}_{2}\right), 1.99\left(2 \mathrm{H}, \mathrm{p}, \mathrm{J}_{\mathrm{CH} 2 \times 2}=5.75 \mathrm{~Hz}, \mathrm{Q}_{1}-\mathrm{NHCH}_{2} \mathrm{CH}_{2} \mathrm{CH}_{2}\right), 1.75$ (water signal overlaps $\mathrm{m}, \sim 2 \mathrm{H}$, piperidine $\mathrm{CH} \times 2$ adjacent to $\mathrm{CH}-\mathrm{NH}-\mathrm{Q}_{2}$ ).

${ }^{13} \mathrm{C} \mathrm{NMR} \delta(\mathrm{ppm})\left(\mathrm{CHCl}_{3}-\mathrm{d}\right): 152.3\left(\mathrm{Q}_{1}-\mathrm{C} 2\right), 152.0\left(\mathrm{Q}_{2}-\mathrm{C} 2\right), 150.4,149.4,149.3,148.4$, 135.1, 134.7, 129.1 (Q-C8), $129.0(\mathrm{Q}-\mathrm{C} 8), 125.6\left(\mathrm{Q}_{1}-\mathrm{C} 6\right), 124.8\left(\mathrm{Q}_{2}-\mathrm{C} 6\right), 121.7\left(\mathrm{Q}_{2}-\mathrm{C} 5\right)$, $120.7\left(\mathrm{Q}_{1}-\mathrm{C} 5\right), 117.5,117.2,99.6\left(\mathrm{Q}_{1}-\mathrm{C} 3\right), 98.8\left(\mathrm{Q}_{2}-\mathrm{C} 3\right), 58.2\left(\mathrm{Q}_{1}-\mathrm{NHCH}_{2} \mathrm{CH}_{2} \mathrm{CH}_{2}\right)$, 52.5 (piperidine-C adjacent to alkyl chain), 49.5 (piperidine- $\left.\mathrm{CH}-\mathrm{NH}-\mathrm{Q}_{2}\right), 43.9\left(\mathrm{Q}_{1}\right.$ $\mathrm{NHCH}_{2} \mathrm{CH}_{2} \mathrm{CH}_{2}$ ), 32.0 (piperidine-C adjacent to CH-NH-Q ), $24.4\left(\mathrm{Q}_{1}-\mathrm{NHCH}_{2} \mathrm{CH}_{2} \mathrm{CH}_{2}\right)$.

Note: $Q_{1}$ and $Q_{2}$ denote the quinoline ring system on the left and right of the figure, respectively. For quinoline ring numbering system, see Figure 5, Chapter 1. 


\section{List of spectra:}

Figure $\mathrm{C} 1:{ }^{1} \mathrm{H}$ NMR spectrum of PL241 in $\mathrm{CDCl}_{3}$, full view.

Figure $\mathrm{C} 2{ }^{1} \mathrm{H}$ NMR spectrum of PL241 in $\mathrm{CDCl}_{3}$, expansion 1 of 3 (aromatic region, part 1).

Figure C3: ${ }^{1} \mathrm{H}$ NMR spectrum of PL241 in $\mathrm{CDCl}_{3}$, expansion 2 of 3 (aromatic region, part 2).

Figure C4: ${ }^{1} \mathrm{H}$ NMR spectrum of PL241 in $\mathrm{CDCl}_{3}$, expansion 3 of 3 (aliphatic region, part 1).

Figure C5: ${ }^{13} \mathrm{C}$ NMR spectrum of PL241 in $\mathrm{CDCl}_{3}$, full view.

Figure C6: ${ }^{13} \mathrm{C}$ NMR spectrum of PL241 in $\mathrm{CDCl}_{3}$, aliphatic region only.

Figure C7: COSY spectrum of PL241 in $\mathrm{CDCl}_{3}$.

Figure C8: HSQC spectrum of PL241 in $\mathrm{CDCl}_{3}$.

Figure C9: HMBC spectrum of PL241 in $\mathrm{CDCl}_{3}$.

Figure C10: NOESY spectrum of PL241 in $\mathrm{CDCl}_{3}$.

Figure C11: ${ }^{1} \mathrm{H}$ NMR spectrum of PL241 in DMSO-d6.

Figure C12: ${ }^{1} \mathrm{H}$ NMR spectrum of PL241 in DMSO-d6, aliphatic region only. 


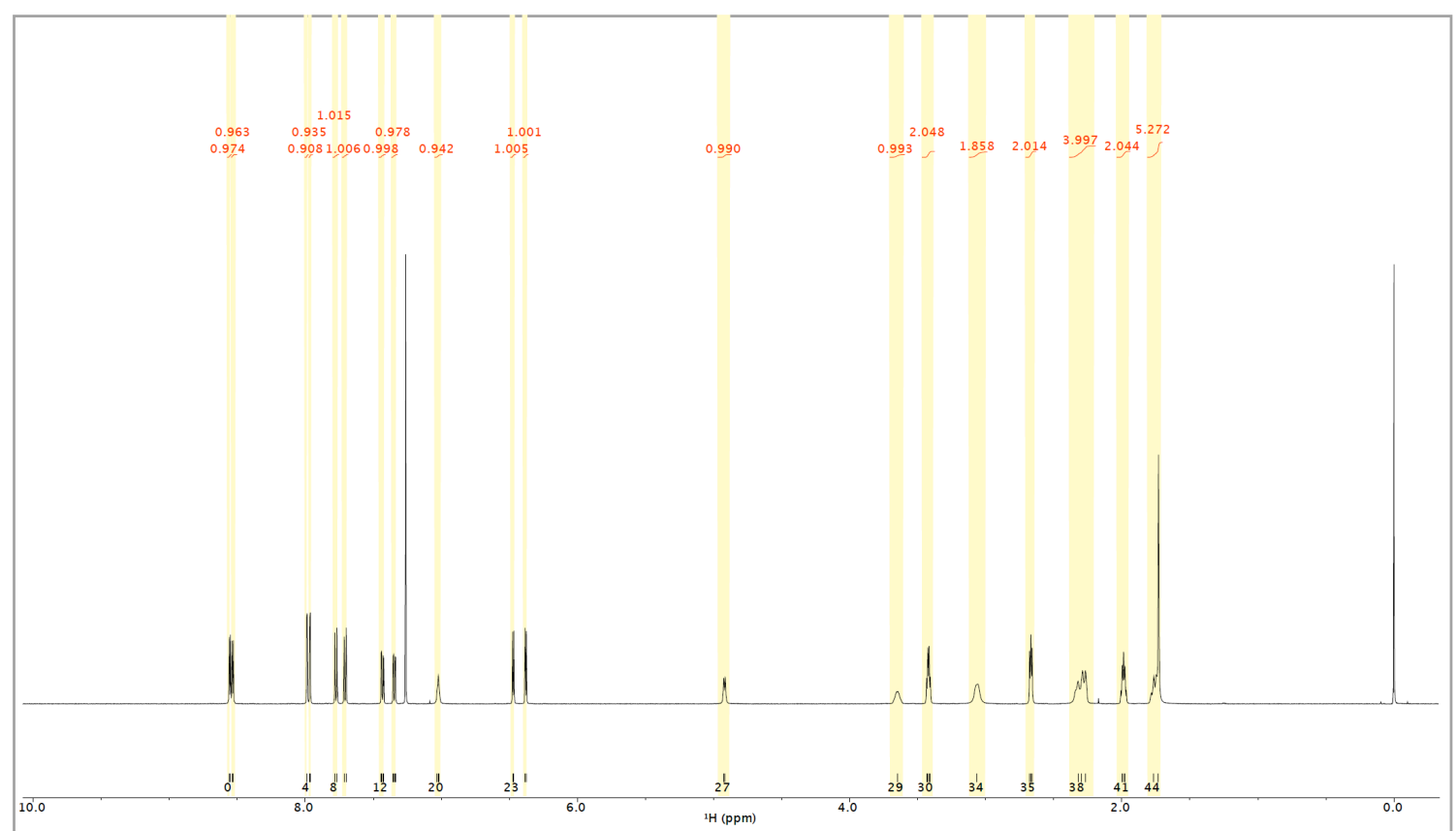

Figure $\mathrm{C} 1:{ }^{1} \mathrm{H} \mathrm{NMR}$ spectrum of PL241 in $\mathrm{CDCl}_{3}$, with integrals (see figures $\mathrm{C} 2, \mathrm{C} 3$, and $\mathrm{C} 4$ for expanded views).

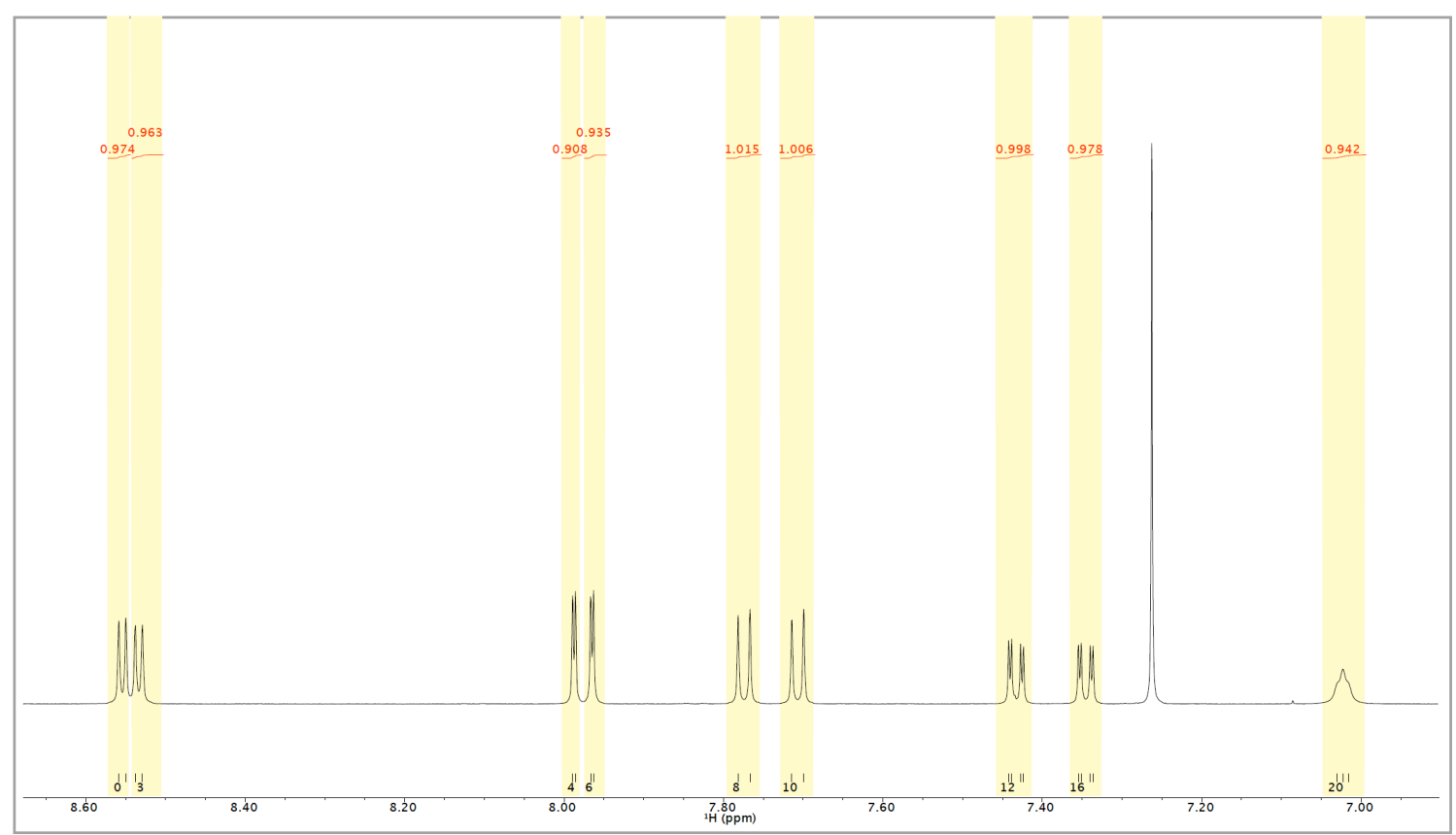

6

Figure C2: ${ }^{1} \mathrm{H}$ NMR spectrum of PL241 in $\mathrm{CDCl}_{3}$, expansion 1 of 3 (aromatic region, part 1). 


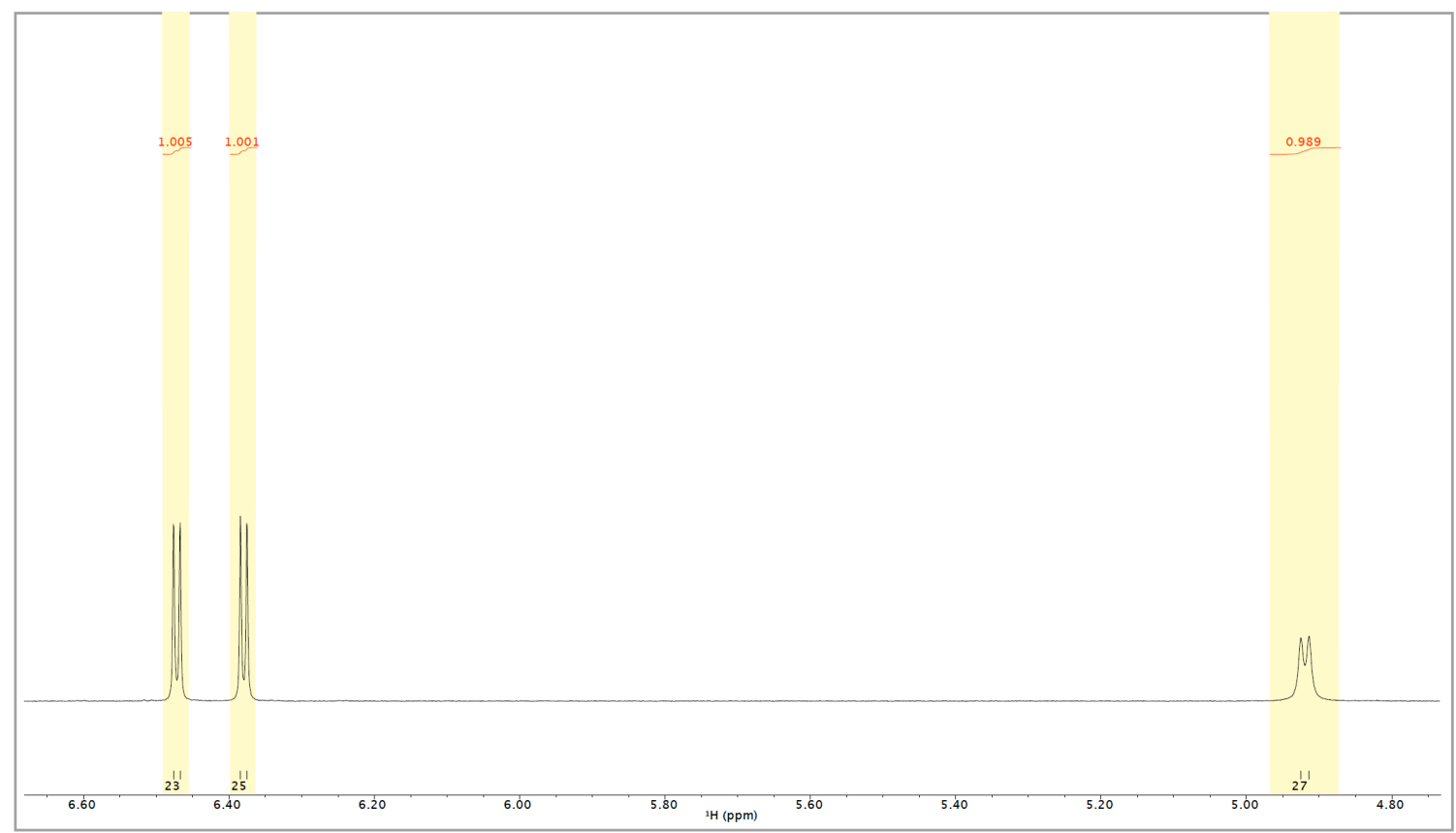

Figure C3: ${ }^{1} \mathrm{H}$ NMR spectrum of PL241 in $\mathrm{CDCl}_{3}$, expansion 2 of 3 (aromatic region, part 2).

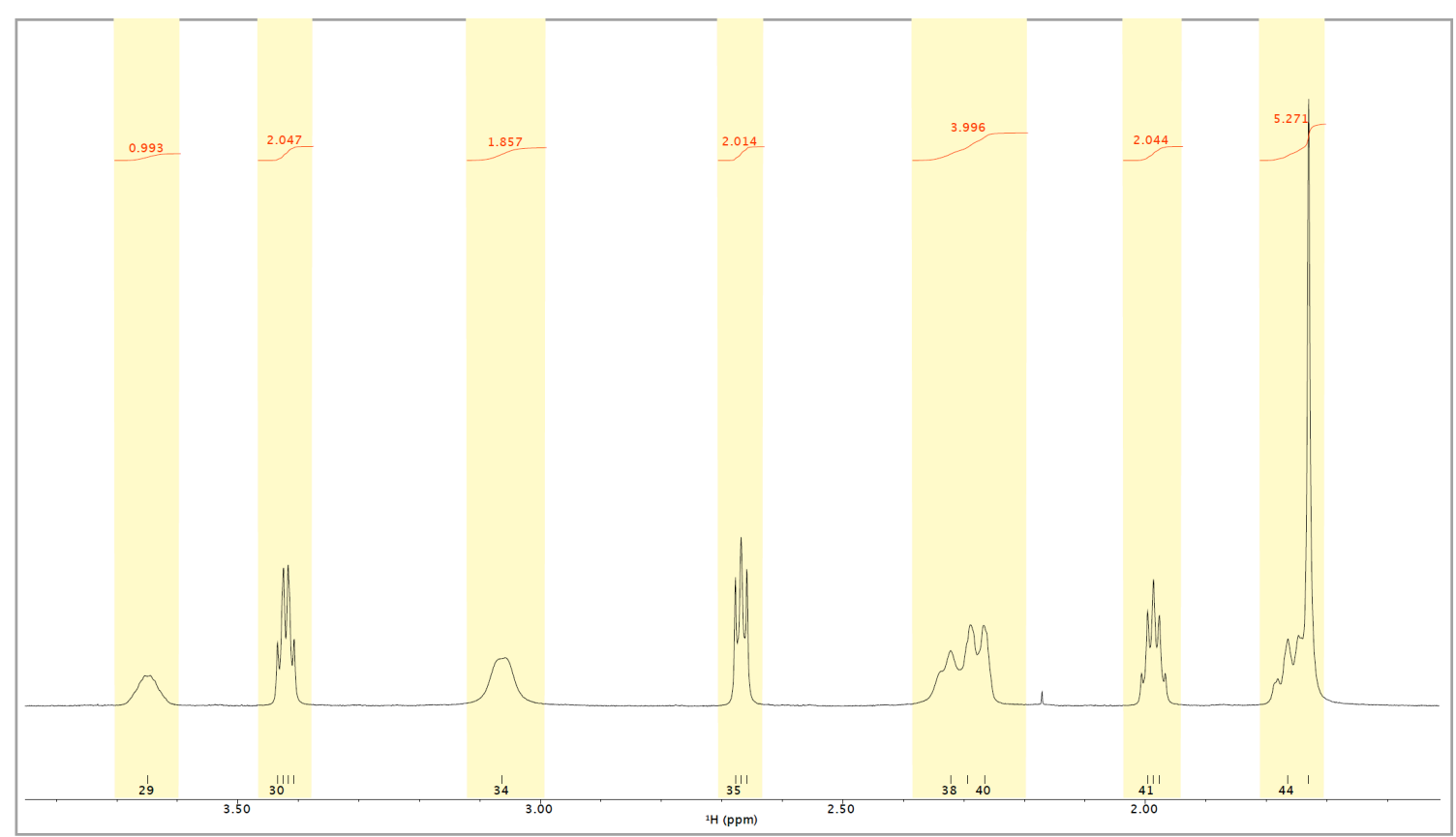

Figure C4: ${ }^{1} \mathrm{H}$ NMR spectrum of PL241 in $\mathrm{CDCl}_{3}$, expansion 3 of 3 (aliphatic region). 


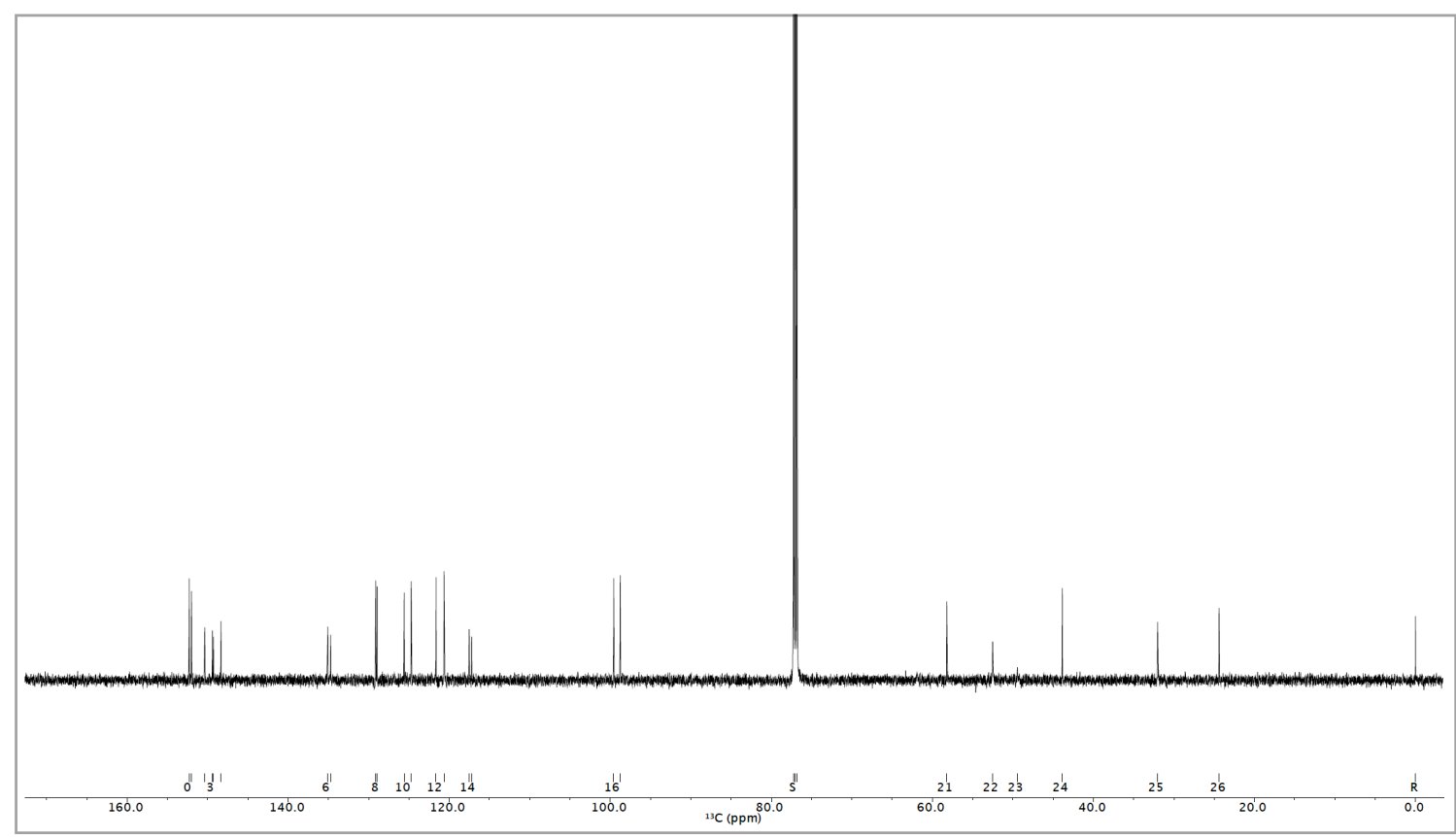

Figure C5: ${ }^{13} \mathrm{C}$ NMR spectrum of PL241 in $\mathrm{CDCl}_{3}$ (see figure $\mathrm{C} 6$ for expanded aromatic region).

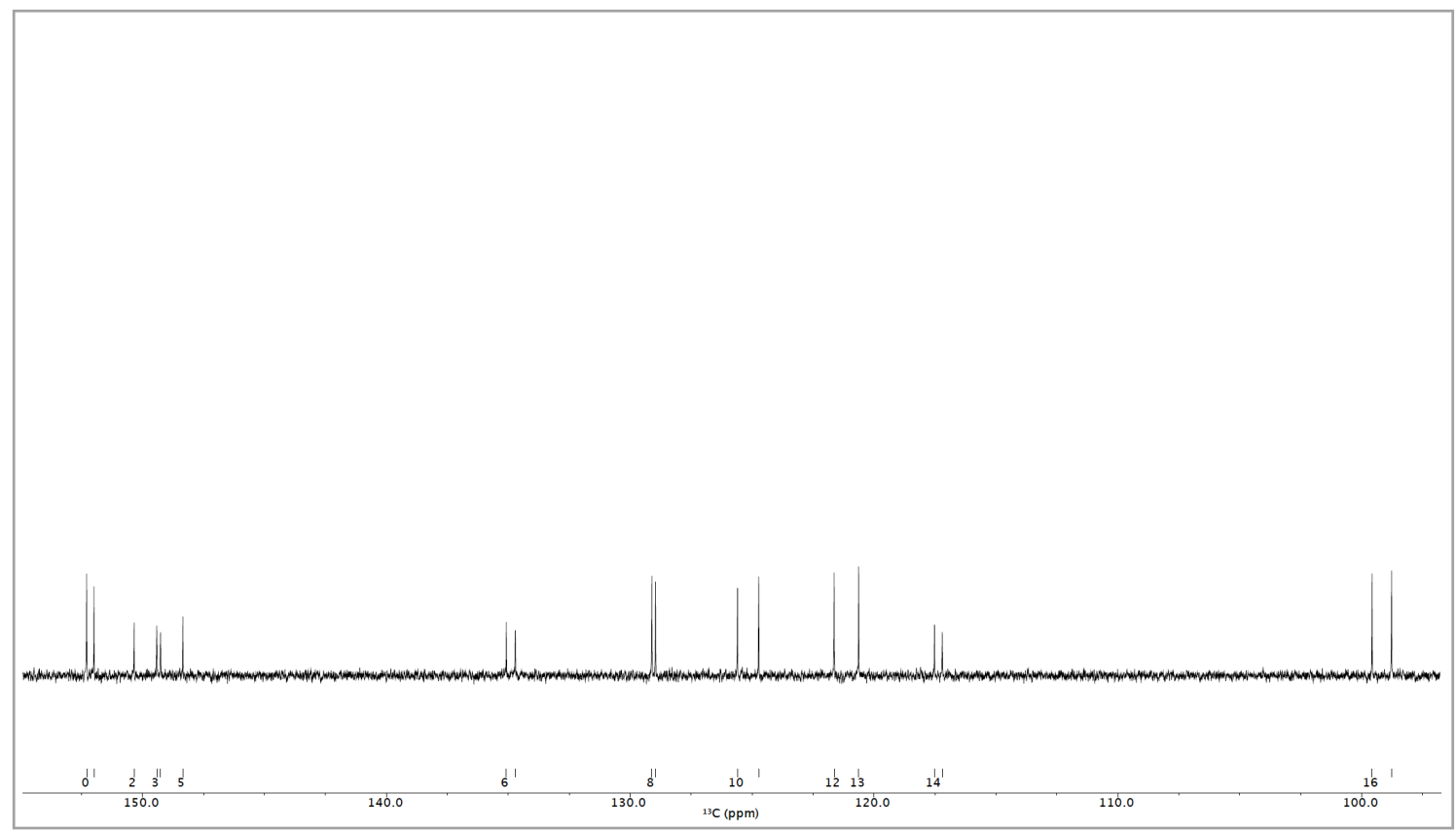

Figure C6: ${ }^{13} \mathrm{C}$ NMR spectrum of PL241 in $\mathrm{CDCl}_{3}$, aromatic region only. 


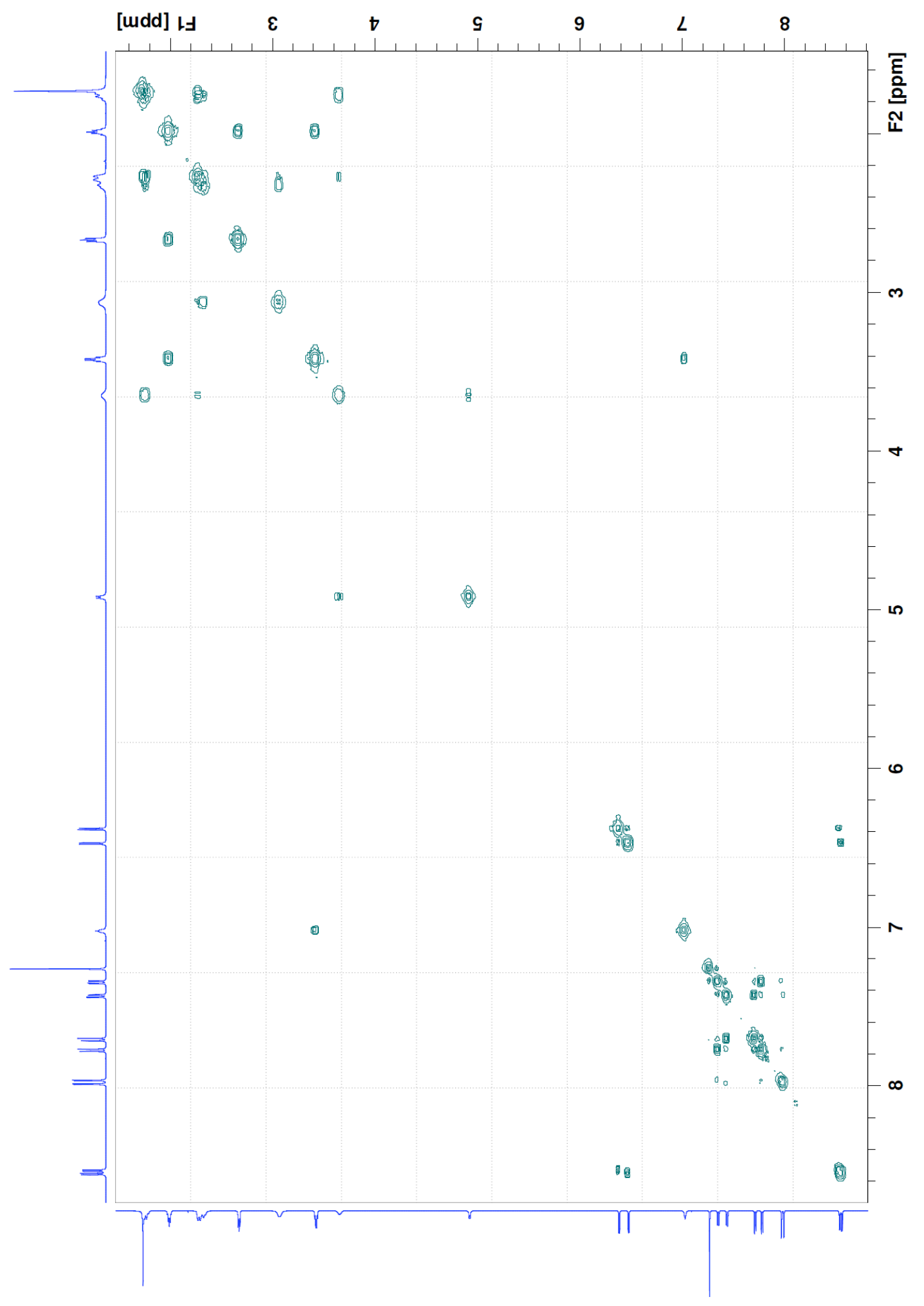

Figure C7: COSY spectrum of PL241 in $\mathrm{CDCl}_{3}$, showing direct proton to proton interactions. 

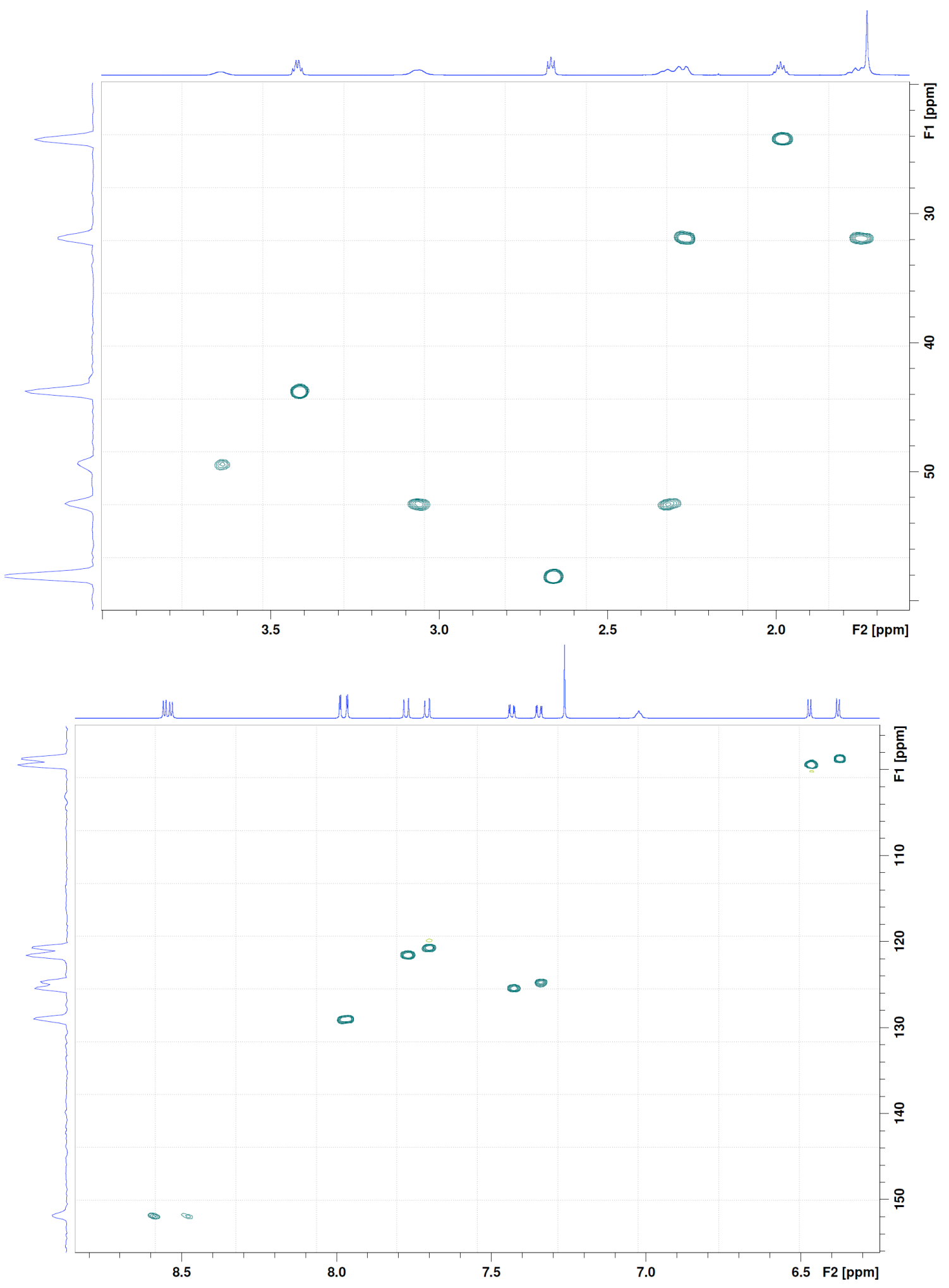

Figure C8: HSQC spectrum of PL241 in $\mathrm{CDCl}_{3}$, showing direct proton to carbon interactions (split into two expanded regions to show detail). 


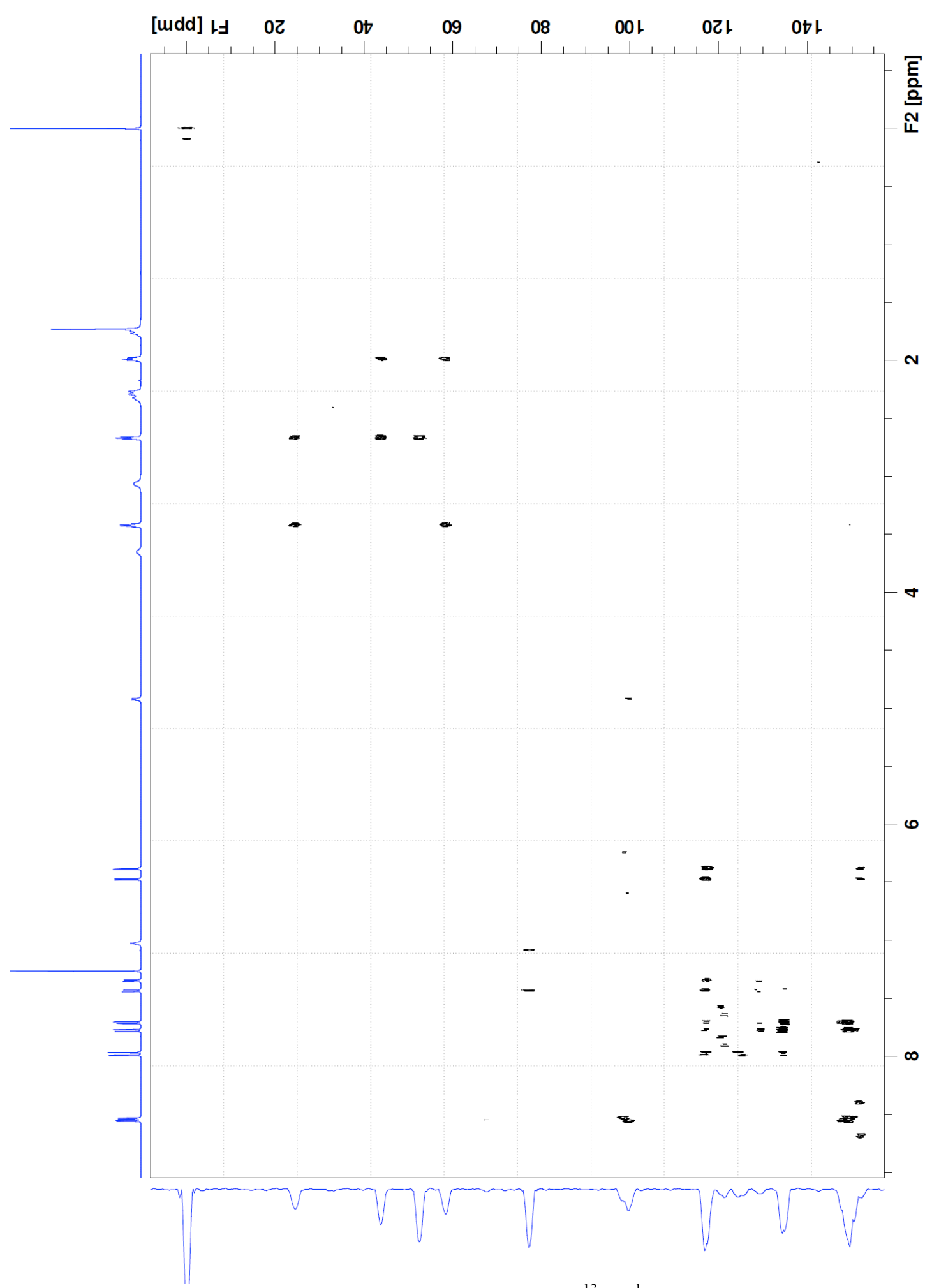

Figure C9: HMBC spectrum of PL241 in $\mathrm{CDCl}_{3}$, showing ${ }^{13} \mathrm{C}-{ }^{1} \mathrm{H}$ multiple bond correlations. 


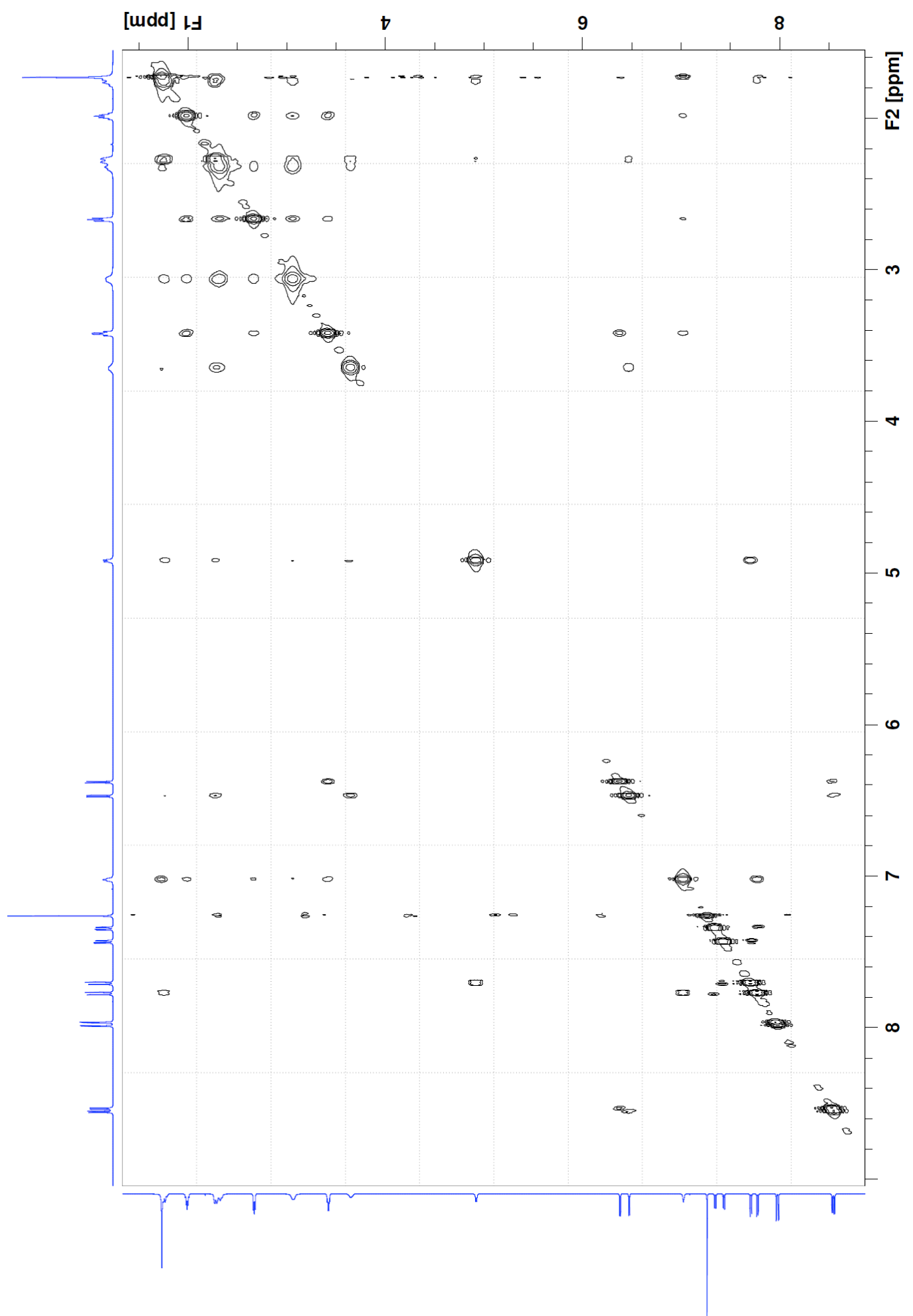

Figure C10: NOESY spectrum of PL241 in $\mathrm{CDCl}_{3}$, showing proton to proton interactions through space. 


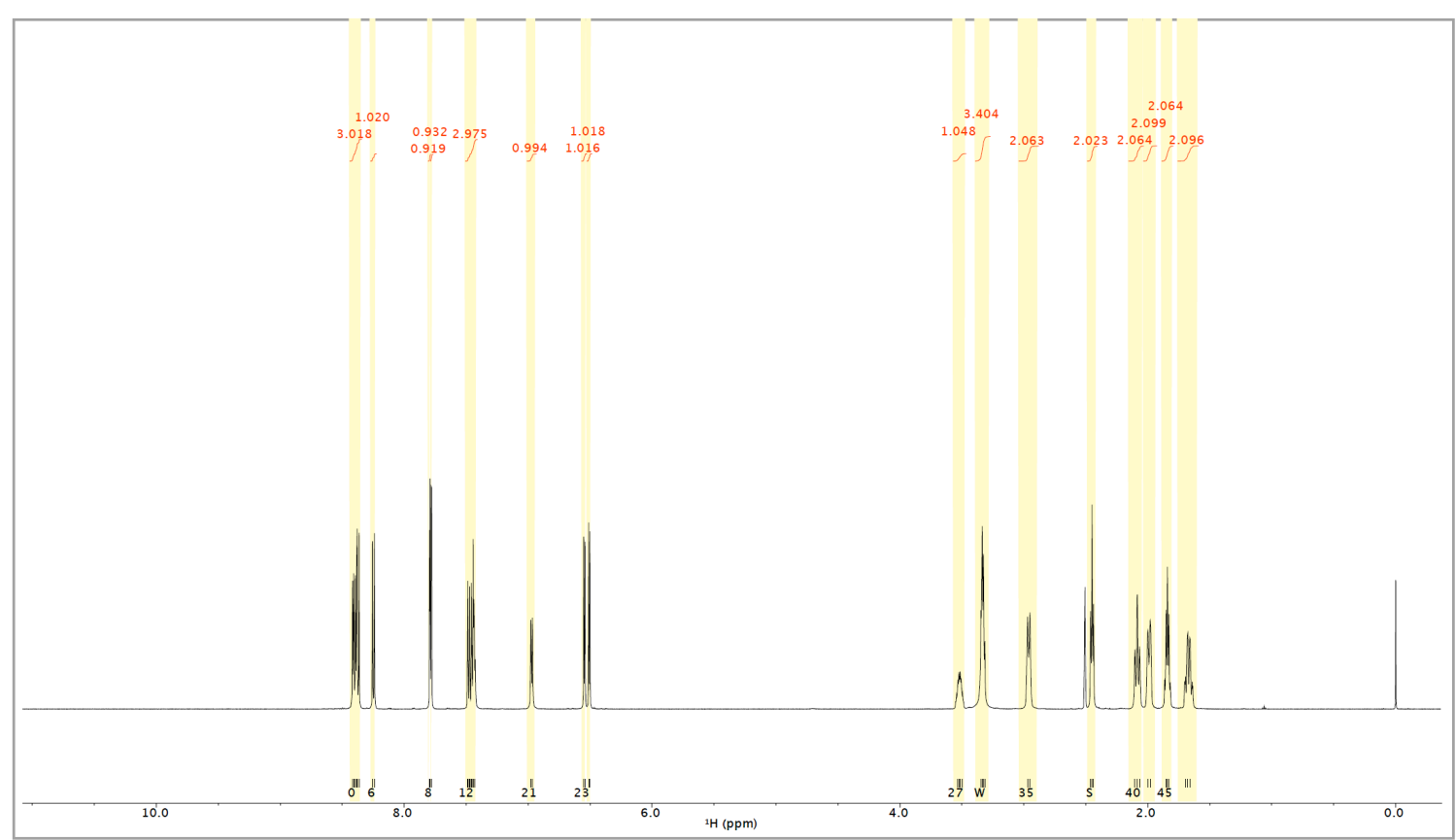

Figure C11: ${ }^{1} \mathrm{H}$ NMR spectrum of PL241 in DMSO-d6, with integrals (see figure C12 for expanded aliphatic region). This spectrum was used to confirm the suspected integration of a peak overlapped by the water signal in the $\mathrm{CDCl}_{3}$ spectrum (here at $1.68 \mathrm{ppm}$ ).

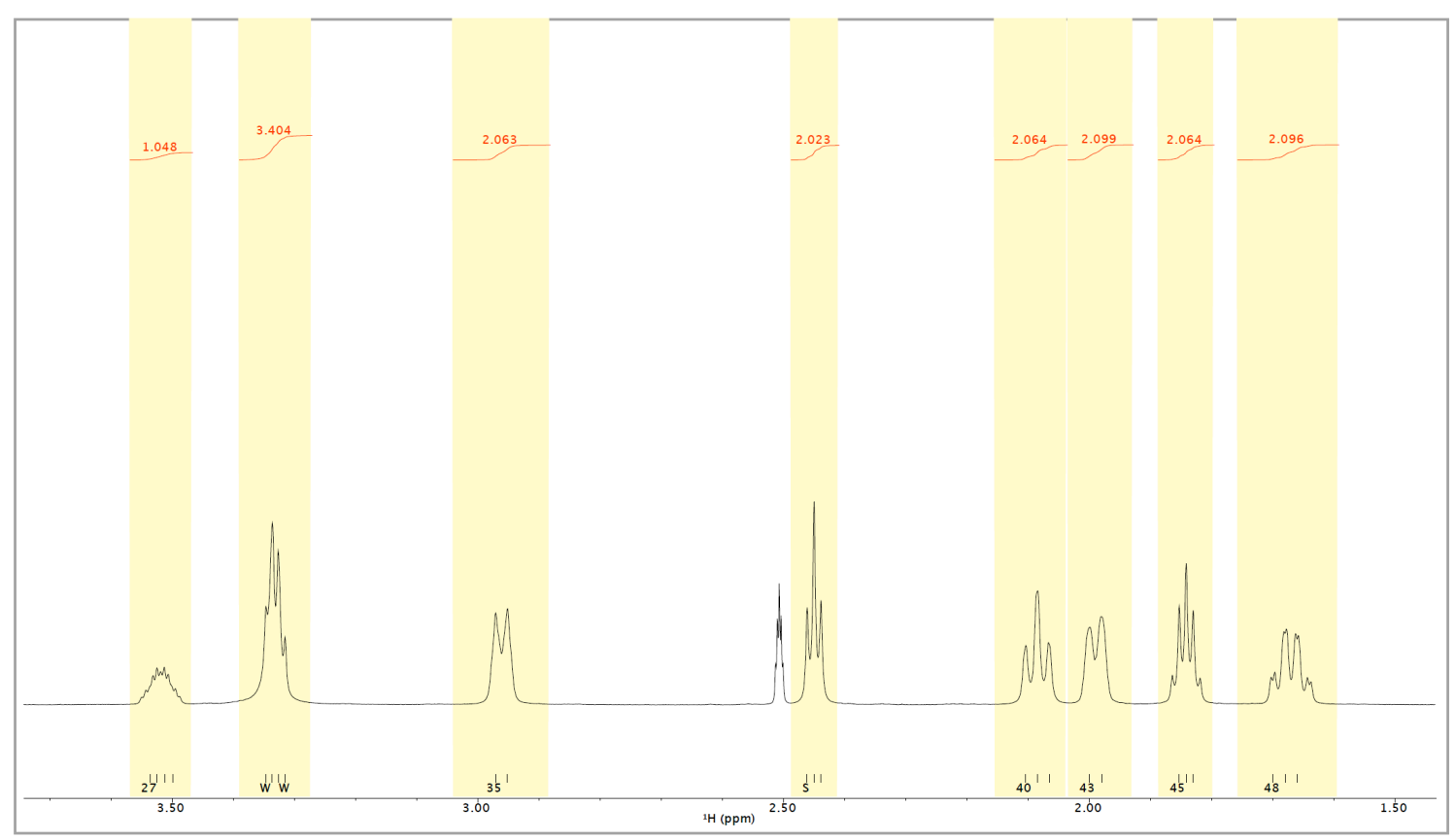

Figure C12: ${ }^{1} \mathrm{H}$ NMR spectrum of PL241 in DMSO-d6, aliphatic region. 